\title{
HORAS FRÍO Y HORAS DE
}

\section{CALOR EN ZONAS CLIMATTICAS}

\section{DE LA ESPAÑA PENINSULLAR}

\section{(2002-2011).}

José Luis García Merayo

Teresa Gallego Abaroa

Lourdes Martínez Núñez 


\section{datos abiertos}

Aviso Legal: los contenidos de esta publicación podrán ser reutilizados, citando la fuente y la fecha, en su caso, de la última actualización

\section{Edita:}

(c) Ministerio de Agricultura, Alimentación y Medio Ambiente Agencia Estatal de Meteorología

Madrid, 2015

Catálogo de Publicaciones de la Administración General del Estado: https://cpage.mpr.gob.es

NIPO: 281-15-029-3

https://doi.org/10.31978/281-15-029-3

Agencia Estatal de Meteorología (AEMET)

C/ Leonardo Prieto Castro, 8

28040 Madrid

http://www.aemet.es/

@Aemet_Esp 


\title{
HORAS FRÍO Y HORAS DE CALOR EN ZONAS CLIMÁTICAS DE LA ESPAÑA PENINSULAR (2002-2011).
}

\author{
José Luis García Merayo \\ Teresa Gallego Abaroa \\ Lourdes Martínez Núñez
}

ÁREA DE CLIMATOLOGÍA Y APLICACIONES OPERATIVAS SERVICIO DE APLICACIONES AGRÍCOLAS E HIDROLÓGICAS

Madrid, 2015 



\section{Índice}

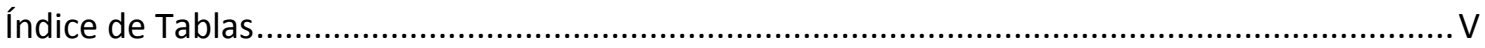

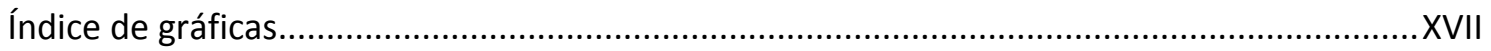

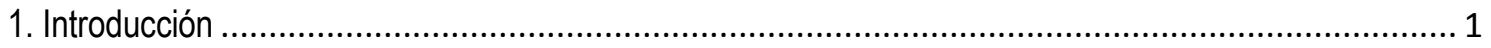

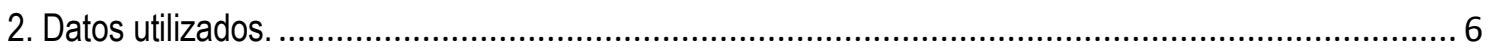

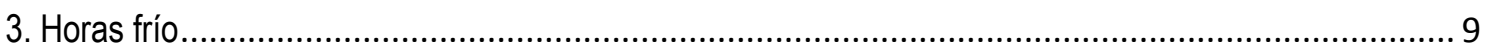

3.1 Horas frío (umbral 7을 C) contadas a partir de datos horarios........................................... 9

3.1.1 Zonas norte y noroeste: a) costa cantábrica ............................................................. 9

3.1.2 Zonas norte y noroeste: b) costa gallega ................................................................. 17

3.1.3 Zonas norte y noroeste: c) interior de Galicia y el valle del Bierzo .............................. 21

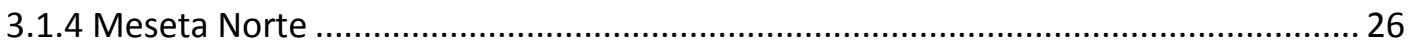

3.1.5 Cuenca del Ebro: a) parte baja y relativamente llana del valle del Ebro .................... 33

3.1.6. Cuenca del Ebro: b) zonas de la parte media de la cuenca: Navarra y La Rioja......... 36

3.1.7 Zona de la franja costera del noreste peninsular: costa catalana...............................39

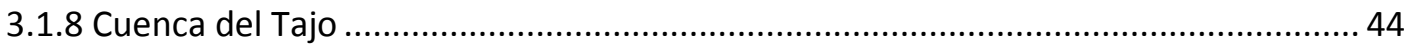

3.1.9 Cuenca del Guadiana: a) parte alta situada en la meseta Sur, principalmente La

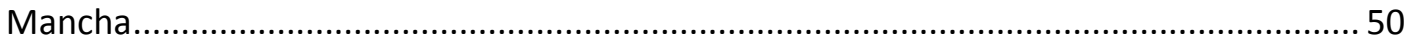

3.1.10 Cuenca del Guadiana: b) parte baja y relativamente llana de la cuenca .................. 53

3.1.11 Cuenca del Guadalquivir: a) parte baja y relativamente llana de la cuenca ............57

3.1.12 Cuenca del Guadalquivir: b) parte media de la cuenca ........................................... 62

3.1.13 Levante: a) franja costera de Levante: huerta levantina ........................................64

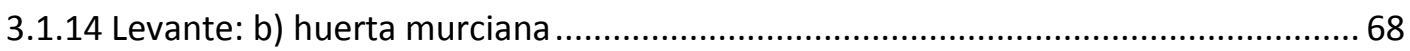

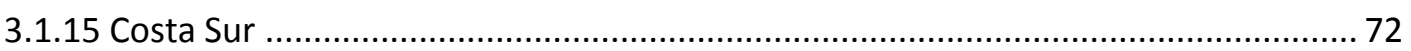

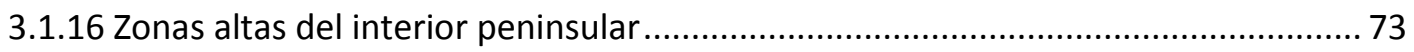

3.2 Comparación de horas frío contadas a partir de datos horarios y horas frío obtenidas a partir de la fórmula de Crossa-Raynaud ........................................................................... 79

3.2.1 Zonas norte y noroeste: a) costa cantábrica .............................................................. 79

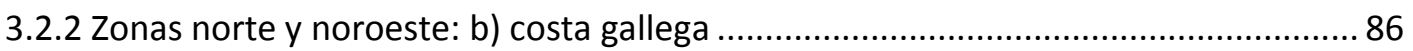

3.2.3 Zonas norte y noroeste: c) interior de Galicia y el valle del Bierzo .............................90

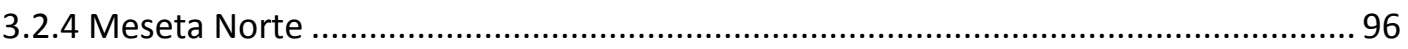

3.2.5 Cuenca del Ebro: a) parte baja y relativamente llana del valle del Ebro .................. 104

3.2.6 Cuenca del Ebro: b) zonas de la parte media de la cuenca: Navarra y La Rioja....... 107

3.2.7 Zona de la franja costera del noreste peninsular: costa catalana........................... 111 
3.2.9 Cuenca del Guadiana: a) parte alta situada en la meseta Sur, principalmente La Mancha.

3.2.10 Cuenca del Guadiana: b) parte baja y relativamente llana de la cuenca................ 128

3.2.11 Cuenca del Guadalquivir: a) parte baja y relativamente llana de la cuenca ........... 131

3.2.12 Cuenca del Guadalquivir: b) parte media de la cuenca ........................................ 134

3.2.13 Levante: a) franja costera de Levante: huerta levantina ........................................ 136

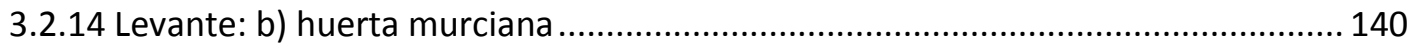

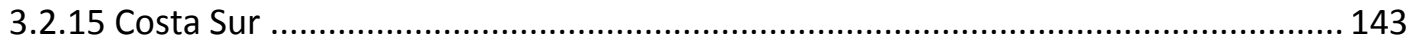

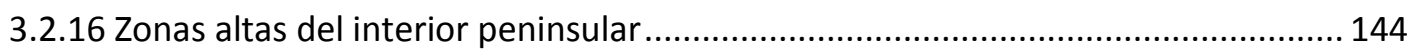

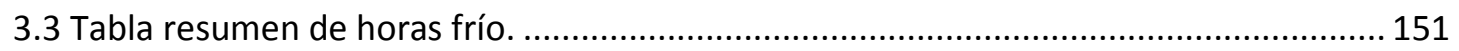

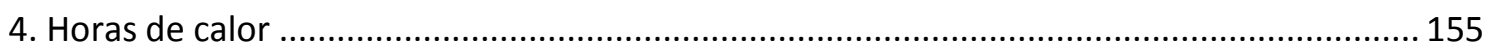

4.1 Horas de calor (umbral 30 C) contadas a partir de datos horarios ............................... 155

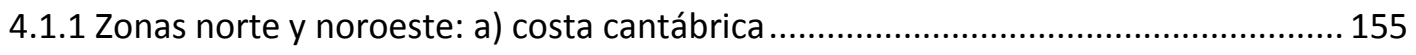

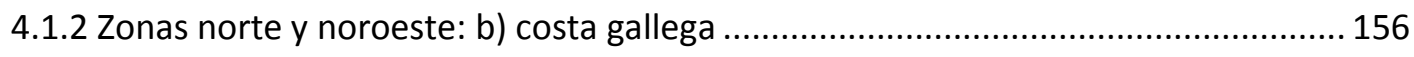

4.1.3 Zonas norte y noroeste: c) interior de Galicia y el valle del Bierzo ............................ 156

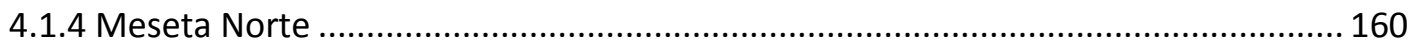

4.1.5 Cuenca del Ebro: a) parte baja y relativamente llana del valle del Ebro .................. 168

4.1.6 Cuenca del Ebro: b) zonas de la parte media de la cuenca: Navarra y la Rioja......... 172

4.1.7 Zona de la franja costera del noreste peninsular: costa catalana........................... 175

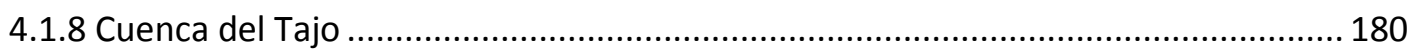

4.1.9 Cuenca del Guadiana: a) parte alta situada en la meseta Sur, principalmente La

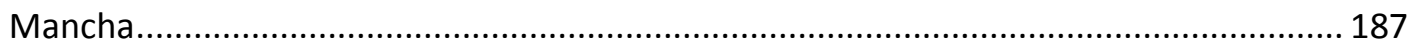

4.1.10 Cuenca del Guadiana: b) parte baja y relativamente llana de la cuenca ................. 191

4.1.11 Cuenca del Guadalquivir: a) parte baja y relativamente llana de la cuenca .......... 194

4.1.12 Cuenca del Guadalquivir: b) parte media de la cuenca: Granada.......................... 197

4.1.13 Levante: a) franja costera de Levante: huerta levantina ...................................... 198

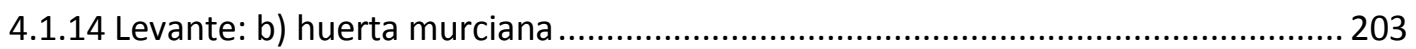

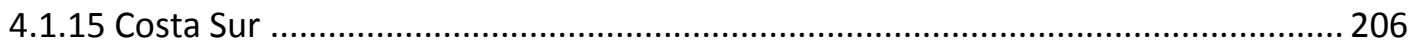

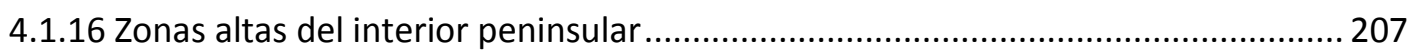

4.2 Comparación de horas de calor contadas a partir de datos horarios y horas de calor obtenidas a partir de la fórmula de Crossa-Raynaud.......................................................... 213

4.2.1 Zonas norte y noroeste: a) costa cantábrica ............................................................ 213

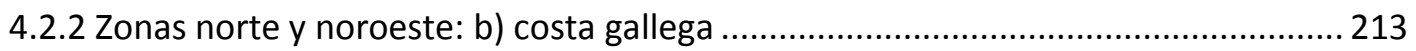

4.2.3 Zonas norte y noroeste: c) interior de Galicia y el valle del Bierzo ........................... 213 
4.2.5 Cuenca del Ebro: a) parte baja y relativamente llana del valle del Ebro

4.2.6 Cuenca del Ebro: b) zonas de la parte media de la cuenca: Navarra y La Rioja....... 227

4.2.7 Zona de la franja costera del noreste peninsular: costa catalana........................ 230

4.2.8 Cuenca del Tajo 236

4.2.9 Cuenca del Guadiana: a) parte alta situada en la meseta Sur, principalmente La Mancha:

4.2.10. Cuenca del Guadiana: b) parte baja y relativamente llana de la cuenca..... 248

4.2.11 Cuenca del Guadalquivir: a) parte baja y relativamente llana de la cuenca......... 250

4.2.12 Cuenca del Guadalquivir: b) parte media de la cuenca .................................. 255

4.2.13 Levante: a) franja costera de Levante: huerta levantina ................................. 256

4.2.14 Levante: a) huerta murciana ............................................................... 260

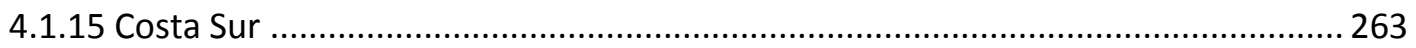

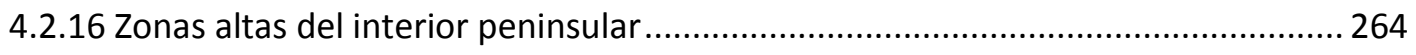

4.3 Tabla resumen de horas de calor .................................................................... 271

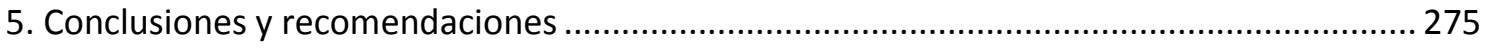

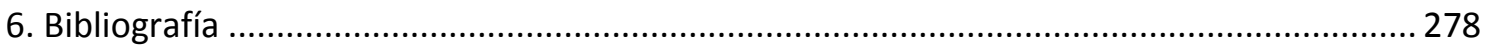





\section{Índice de Tablas}

Tabla 1. Datos descriptivos de los observatorios meteorológicos de la zona norte, noroeste y meseta Norte.

Tabla 2. Datos descriptivos de los observatorios meteorológicos de la zona de la cuenca del Ebro, Tajo, Guadiana, Guadalquivir, Levante y la franja costera catalana.

Tabla 3. Datos descriptivos de los observatorios meteorológicos de la costa Sur y las zonas altas del interior peninsular.

Tabla 4. Comparación de horas frío anuales contadas a partir de datos horarios en los siete observatorios de la zona norte y noroeste: costa cantábrica.

Tabla 5. Horas frío contadas en datos horarios en el observatorio de San Sebastián Igueldo. 9

Tabla 6. Horas frío contadas en datos horarios en el observatorio de Bilbao Sondica. 11

Tabla 7. Horas frío contadas en datos horarios en el observatorio de Santander.

Tabla 8. Horas frío contadas en datos horarios en el observatorio de Santander-Parayas.___ 13

Tabla 9. Horas frío contadas en datos horarios en el observatorio de Gijón.

Tabla 10. Horas frío contadas en datos horarios en el observatorio de Oviedo.__ 14

Tabla 11. . Horas frío contadas en datos horarios en el observatorio de Vitoria. 15

Tabla 12. Comparación de horas frío anuales contadas a partir de datos horarios en los cuatro observatorios de la zona norte y noroeste: costa gallega.

Tabla 13. Horas frío contadas en datos horarios en el observatorio de La Coruña.

Tabla 14. Horas frío contadas en datos horarios en el observatorio de La Coruña Alvedro. _ـ 19

Tabla 15. Horas frío contadas en datos horarios en el observatorio de Pontevedra. _ 19

Tabla 16. Horas frío contadas en datos horarios en el observatorio de Vigo-Peinador. _ 20

Tabla 17. Comparación de horas frío anuales contadas a partir de datos horarios en los cinco

observatorios de la zona norte y noroeste: interior de Galicia y el valle del Bierzo.

Tabla 18. Horas frío contadas en datos horarios en el observatorio de Santiago.

Tabla 19. Horas frío contadas en datos horarios en el observatorio de Lugo Rozas. 23

Tabla 20. Horas frío contadas en datos horarios en el observatorio de Orense.__ 24

Tabla 21. Horas frío contadas en datos horarios en el observatorio de Ponferrada. _ 24

Tabla 22. Horas frío contadas en datos horarios en el observatorio de Almázcara.

Tabla 23. Comparación de horas frío anuales contadas a partir de datos horarios en los ocho

observatorios de la meseta Norte.

Tabla 24. Horas frío contadas en datos horarios en el observatorio de Soria. _ 27

Tabla 25. Horas frío contadas en datos horarios en el observatorio de Burgos Villafría. _ 28

Tabla 26. Horas frío contadas en datos horarios en el observatorio de León Virgen del Camino. __ 28

Tabla 27. Horas frío contadas en datos horarios en el observatorio de Villanubla Valladolid.___ 29

Tabla 28. Horas frío contadas en datos horarios en el observatorio de Valladolid CMT. __ 30

Tabla 29. Horas frío contadas en datos horarios en el observatorio de Segovia. _ 30

Tabla 30. Horas frío contadas en datos horarios en el observatorio de Zamora. _ 31

Tabla 31. Horas frío contadas en datos horarios en el observatorio de Salamanca Matacán. ___ 32

Tabla 32. Comparación de horas frío anuales contadas a partir de datos horarios en los tres

observatorios del valle del Ebro.

Tabla 33. Horas frío contadas en datos horarios en el observatorio de Huesca. __ 34

Tabla 34. Horas frío contadas en datos horarios en el observatorio de Zaragoza aeropuerto. __ 35

Tabla 35. Horas frío contadas en datos horarios en el observatorio de Lérida. __ 35

Tabla 36. Comparación de horas frío anuales contadas a partir de datos horarios en los tres

observatorios de la parte media de la cuenca del Ebro: Navarra y La Rioja.

Tabla 37. Horas frío contadas en datos horarios en el observatorio de Pamplona-Noáin.__ 37

Tabla 38. Horas frío contadas en datos horarios en el observatorio de Haro. 38

Tabla 39. Horas frío contadas en datos horarios en el observatorio de Logroño-Agoncillo. ___ 38

Tabla 40. Comparación de horas frío anuales contadas a partir de datos horarios en los cinco

observatorios de la franja costera del noreste peninsular: costa catalana.

Tabla 41. Horas frío contadas en datos horarios en el observatorio de Barcelona. 
Tabla 42. Horas frío contadas en datos horarios en el observatorio de Gerona.

Tabla 43. Horas frío contadas en datos horarios en el observatorio de Reus.

Tabla 44. Horas frío contadas en datos horarios en el observatorio de Tarragona

Tabla 45. Horas frío contadas en datos horarios en el observatorio de Tortosa.

Tabla 46. Comparación de horas frío anuales contadas a partir de datos horarios en los ocho observatorios de la cuenca del Tajo.

Tabla 47. Horas frío contadas en datos horarios en el observatorio de Madrid Barajas.

Tabla 48. Horas frío contadas en datos horarios en el observatorio de Guadalajara.

Tabla 49. Horas frío contadas en datos horarios en el observatorio de Madrid-Getafe. ___ 46

Tabla 50. Horas frío contadas en datos horarios en el observatorio de Navalmoral. _ـ 47

Tabla 51. Horas frío contadas en datos horarios en el observatorio de Cáceres. —_ 48

Tabla 52. Horas frío contadas en datos horarios en el observatorio de Plasencia. _ 48

Tabla 53. Horas frío contadas en datos horarios en el observatorio de Toledo. 49

Tabla 54. Horas frío contadas en datos horarios en el observatorio de Trujillo. __ 49

Tabla 55. Comparación de horas frío anuales contadas a partir de datos horarios en los cuatro

observatorios de la parte alta de la Cuenca del Guadiana.

Tabla 56. Horas frío contadas en datos horarios en el observatorio de Ciudad Real.

Tabla 57. Horas frío contadas en datos horarios en el observatorio de Alcazar de San Juan. _ـ 52

Tabla 58. Horas frío contadas en datos horarios en el observatorio de Almagro. _ _ 52

Tabla 59. Horas frío contadas en datos horarios en el observatorio de Hinojosa del Duque.___ 53

Tabla 60. Comparación de horas frío anuales contadas a partir de datos horarios en los tres

observatorios de la parte baja de la cuenca del Guadiana.

Tabla 61. Horas frío contadas en datos horarios en el observatorio de Talavera la Real. __ 55

Tabla 62. Horas frío contadas en datos horarios en el observatorio de Badajoz CMT. 55

Tabla 63. Horas frío contadas en datos horarios en el observatorio de Mérida. —— 56

Tabla 64. Comparación de horas frío anuales contadas a partir de datos horarios en los cinco

observatorios de la parte baja de la cuenca del Guadalquivir.

Tabla 65. Horas frío contadas en datos horarios en el observatorio de Sevilla San Pablo. 59

Tabla 66. Horas frío contadas en datos horarios en el observatorio de Sevilla Tablada. 59

Tabla 67. Horas frío contadas en datos horarios en el observatorio de Écija. _ 60

Tabla 68. Horas frío contadas en datos horarios en el observatorio de Morón de la Frontera. ___ 61

Tabla 69. Horas frío contadas en datos horarios en el observatorio del aeropuerto de Córdoba. __ 61

Tabla 70. Comparación de horas frío anuales contadas a partir de datos horarios en los dos observatorios

de la parte media de la cuenca del Guadalquivir.

Tabla 71. Horas frío contadas en datos horarios en el observatorio de Granada. __ 63

Tabla 72. Horas frío contadas en datos horarios en el observatorio de Linares VOR._ 63

Tabla 73. Comparación de horas frío anuales contadas a partir de datos horarios en los cinco

observatorios de la franja costera de Levante: huerta levantina.

Tabla 74. Horas frío contadas en datos horarios en el observatorio de Castellón. _ 66

Tabla 75. Horas frío contadas en datos horarios en el observatorio de Valencia. _ 66

Tabla 76. Horas frío contadas en datos horarios en el observatorio de Valencia Manises.___ 67

Tabla 77. Horas frío contadas en datos horarios en el observatorio de Alicante.___ 67

Tabla 78. Horas frío contadas en datos horarios en el observatorio de Alicante El Altet.___ 68

Tabla 79. Comparación de horas frío anuales contadas a partir de datos horarios en los tres

observatorios de la huerta murciana.

Tabla 80. Horas frío contadas en datos horarios en el observatorio de Alcantarilla.

Tabla 81. Horas frío contadas en datos horarios en el observatorio de San Javier. — 71

Tabla 82. Horas frío contadas en datos horarios en el observatorio de Totana.___ 71

Tabla 83. Horas frío contadas en datos horarios en el observatorio de Málaga aeropuerto. __ 72

Tabla 84. Comparación de horas frío anuales contadas a partir de datos horarios en los seis observatorios de las zonas altas del interior peninsular.

Tabla 85. Horas frío contadas en datos horarios en el observatorio de Albacete. 74

Tabla 86. Horas frío contadas en datos horarios en el observatorio de Cuenca. — 75

Tabla 87. Horas frío contadas en datos horarios en el observatorio de Teruel. —— 75

Tabla 88. Horas frío contadas en datos horarios en el observatorio de Daroca.__ 76

Tabla 89. Horas frío contadas en datos horarios en el observatorio de Molina de Aragón.___ 77

Tabla 90. Horas frío contadas en datos horarios en el observatorio de Soria. __ 77 
Tabla 91. Comparación de horas frío anuales contadas y obtenidas a partir de la fórmula para el observatorio de San Sebastián-Igueldo.

Tabla 92. Comparación de los promedios mensuales de las horas frío para el observatorio de San Sebastián-Igueldo.

Tabla 93.Comparación de horas frío anuales contadas y obtenidas a partir de la fórmula para el observatorio de Bilbao Sondica.

Tabla 94. Comparación de los promedios mensuales de las horas frío para el observatorio de Bilbao Sondica.

Tabla 95. .Comparación de horas frío anuales contadas y obtenidas a partir de la fórmula para el observatorio de Santander Parayas. 80

Tabla 96. Comparación de los promedios mensuales de las horas frío para el observatorio de Santander Parayas.

Tabla 97. Comparación de horas frío anuales contadas y obtenidas a partir de la fórmula para el observatorio de Santander.

Tabla 98. Comparación de los promedios mensuales de las horas frío para el observatorio de Santander.

Tabla 99. Comparación de horas frío anuales contadas y obtenidas a partir de la fórmula para el observatorio de Gijón Musel.

Tabla 100. Comparación de los promedios mensuales de las horas frío para el observatorio de Gijón

Musel.

Tabla 101. Comparación de horas frío anuales contadas y obtenidas a partir de la fórmula para el observatorio de Oviedo.

Tabla 102. Comparación de los promedios mensuales de las horas frío para el observatorio de Oviedo. 84 Tabla 103. Comparación de horas frío anuales contadas y obtenidas a partir de la fórmula para el observatorio de Vitoria.

Tabla 104. Comparación de los promedios mensuales de las horas frío para el observatorio de Vitoria. 85 Tabla 105. Comparación de horas frío anuales contadas y obtenidas a partir de la fórmula para el observatorio de La Coruña. 86 Tabla 106. Comparación de los promedios mensuales de las horas frío para el observatorio de La Coruña.

Tabla 107. Comparación de horas frío anuales contadas y obtenidas a partir de la fórmula para el 87 observatorio de La Coruña-Alvedro.

Tabla 108. Comparación de los promedios mensuales de las horas frío para el observatorio de La CoruñaAlvedro.

Tabla 109. Comparación de horas frío anuales contadas y obtenidas a partir de la fórmula para el observatorio de Pontevedra. 88

Tabla 110. Comparación de los promedios mensuales de las horas frío para el observatorio de Pontevedra.

Tabla 111. Comparación de horas frío anuales contadas y obtenidas a partir de la fórmula para el observatorio de Vigo Peinador.

Tabla 112. Comparación de los promedios mensuales de las horas frío para el observatorio de Vigo Peinador.

Tabla 113. Comparación de horas frío anuales contadas y obtenidas a partir de la fórmula para el observatorio de Santiago.

Tabla 114. Comparación de los promedios mensuales de las horas frío para el observatorio de Santiago.

Tabla 115. Comparación de horas frío anuales contadas y obtenidas a partir de la fórmula para el observatorio de Lugo Rozas.

Tabla 116. Comparación de los promedios mensuales de las horas frío para el observatorio de Lugo Rozas.

Tabla 117. Comparación de horas frío anuales contadas y obtenidas a partir de la fórmula para el observatorio de Orense.

Tabla 118. Comparación de los promedios mensuales de las horas frío para el observatorio de Orense. 93 Tabla 119. Comparación de horas frío anuales contadas y obtenidas a partir de la fórmula para el observatorio de Ponferrada.

Tabla 120. Comparación de los promedios mensuales de las horas frío para el observatorio de Ponferrada. 
Tabla 121. Comparación de horas frío anuales contadas y obtenidas a partir de la fórmula para el observatorio de Almázcara.

Tabla 122. Comparación de los promedios mensuales de las horas frío para el observatorio de

Almázcara.

Tabla 123. Comparación de horas frío anuales contadas y obtenidas a partir de la fórmula para el observatorio de Soria.

Tabla 124. Comparación de los promedios mensuales de las horas frío para el observatorio de Soria. _ 96

Tabla 125. Comparación de horas frío anuales contadas y obtenidas a partir de la fórmula para el observatorio de Burgos Villafría.

Tabla 126. Comparación de los promedios mensuales de las horas frío para el observatorio de Burgos

Villafría.

Tabla 127. Comparación de horas frío anuales contadas y obtenidas a partir de la fórmula para el observatorio de León Virgen del Camino.

Tabla 128. Comparación de los promedios mensuales de las horas frío para el observatorio de León

Virgen del Camino.

Tabla 129. Comparación de horas frío anuales contadas y obtenidas a partir de la fórmula para el observatorio de Villanubla Valladolid.

Tabla 130. Comparación de los promedios mensuales de las horas frío para el observatorio de Villanubla Valladolid.

Tabla 131. Comparación de horas frío anuales contadas y obtenidas a partir de la fórmula para el observatorio de Valladolid CMT.

Tabla 132.Comparación de los promedios mensuales de las horas frío para el observatorio de Valladolid CMT.

Tabla 133. Comparación de horas frío anuales contadas y obtenidas a partir de la fórmula para el observatorio de Salamanca Matacán.

Tabla 134. Comparación de los promedios mensuales de las horas frío para el observatorio de Salamanca Matacán. 101

Tabla 135. Comparación de horas frío anuales contadas y obtenidas a partir de la fórmula para el observatorio de Segovia.

Tabla 136. Comparación de los promedios mensuales de las horas frío para el observatorio de Segovia.

Tabla 137. Comparación de horas frío anuales contadas y obtenidas a partir de la fórmula para el observatorio de Zamora.

Tabla 138. Comparación de los promedios mensuales de las horas frío para el observatorio de Zamora.

Tabla 139. Comparación de horas frío anuales contadas y obtenidas a partir de la fórmula para el observatorio de Huesca.

Tabla 140. Comparación de los promedios mensuales de las horas frío para el observatorio de Huesca.

Tabla 141. Comparación de horas frío anuales contadas y obtenidas a partir de la fórmula para el observatorio de Zaragoza aeropuerto.

Tabla 142. Comparación de los promedios mensuales de las horas frío para el observatorio de Zaragoza aeropuerto.

Tabla 143. Comparación de horas frío anuales contadas y obtenidas a partir de la fórmula para el observatorio de Lérida.

Tabla 144. Comparación de los promedios mensuales de las horas frío para el observatorio de Lérida. 107 Tabla 145. Comparación de horas frío anuales contadas y obtenidas a partir de la fórmula para el observatorio de Logroño Agoncillo.

Tabla 146. Comparación de los promedios mensuales de las horas frío para el observatorio de Logroño

Agoncillo.

Tabla 147. Comparación de horas frío anuales contadas y obtenidas a partir de la fórmula para el observatorio de Haro.

Tabla 148. Comparación de los promedios mensuales de las horas frío para el observatorio de Haro. 109 Tabla 149. Comparación de horas frío anuales contadas y obtenidas a partir de la fórmula para el observatorio de Pamplona-Noáin.

Tabla 150. Comparación de los promedios mensuales de las horas frío para el observatorio de PamplonaNoáin 
Tabla 151. Comparación de horas frío anuales contadas y obtenidas a partir de la fórmula para el observatorio de Barcelona.

Tabla 152. Comparación de los promedios mensuales de las horas frío para el observatorio de Barcelona.

Tabla 153. Comparación de horas frío anuales contadas y obtenidas a partir de la fórmula para el observatorio de Gerona.

Tabla 154. Comparación de los promedios mensuales de las horas frío para el observatorio de Gerona.

Tabla 155. Comparación de horas frío anuales contadas y obtenidas a partir de la fórmula para el 112 observatorio de Reus.

Tabla 156. Comparación de los promedios mensuales de las horas frío para el observatorio de Reus. 113 Tabla 157. Comparación de horas frío anuales contadas y obtenidas a partir de la fórmula para el observatorio de Tarragona.

Tabla 158. Comparación de los promedios mensuales de las horas frío para el observatorio de Tarragona.

Tabla 159. Comparación de horas frío anuales contadas y obtenidas a partir de la fórmula para el observatorio de Tortosa.

Tabla 160 . Comparación de los promedios mensuales de las horas frío para el observatorio de Tortosa.

Tabla 161. Comparación de horas frío anuales contadas y obtenidas a partir de la fórmula para el observatorio de Guadalajara.

Tabla 162. Comparación de los promedios mensuales de las horas frío para el observatorio de Guadalajara.

Tabla 163. Comparación de horas frío anuales contadas y obtenidas a partir de la fórmula para el observatorio de Madrid Barajas.

Tabla 164. Comparación de los promedios mensuales de las horas frío para el observatorio de Madrid

Barajas.

Tabla 165. Comparación de horas frío anuales contadas y obtenidas a partir de la fórmula para el observatorio de Madrid-Getafe

Tabla 166. Comparación de los promedios mensuales de las horas frío para el observatorio de MadridGetafe.

Tabla 167. Comparación de horas frío anuales contadas y obtenidas a partir de la fórmula para el observatorio de Navalmoral.

Tabla 168. Comparación de los promedios mensuales de las horas frío para el observatorio de Navalmoral.

Tabla 169. Comparación de horas frío anuales contadas y obtenidas a partir de la fórmula para el observatorio de Cáceres.

Tabla 170. Comparación de los promedios mensuales de las horas frío para el observatorio de Cáceres.

Tabla 171. Comparación de horas frío anuales contadas y obtenidas a partir de la fórmula para el observatorio de Plasencia.

Tabla 172. Comparación de los promedios mensuales de las horas frío para el observatorio de Plasencia.

Tabla 173. Comparación de horas frío anuales contadas y obtenidas a partir de la fórmula para el

Tabla 174.Comparación de los promedios mensuales de las horas frío para el observatorio de Toledo. 123 Tabla 175. Comparación de horas frío anuales contadas y obtenidas a partir de la fórmula para el observatorio de Trujillo.

Tabla 176. Comparación de los promedios mensuales de las horas frío para el observatorio de Trujillo.

Tabla 177. Comparación de horas frío anuales contadas y obtenidas a partir de la fórmula para el

Tabla 178. Comparación de horas frío anuales contadas y obtenidas a partir de la fórmula para el observatorio de Almagro.

Tabla 179. Comparación de los promedios mensuales de las horas frío para el observatorio de Almagro. 
Tabla 180. Comparación de horas frío anuales contadas y obtenidas a partir de la fórmula para el observatorio de Ciudad Real.

Tabla 181. Comparación de los promedios mensuales de las horas frío para el observatorio de Ciudad

Real.

Tabla 182. Comparación de horas frío anuales contadas y obtenidas a partir de la fórmula para el observatorio de Hinojosa del Duque. __ 127

Tabla 183. Comparación de los promedios mensuales de las horas frío para el observatorio de Hinojosa

del Duque.

Tabla 184. Comparación de horas frío anuales contadas y obtenidas a partir de la fórmula para el

observatorio de Talavera la Real.

Tabla 185.Comparación de los promedios mensuales de las horas frío para el observatorio de Talavera la

Real.

Tabla 186. Comparación de horas frío anuales contadas y obtenidas a partir de la fórmula para el observatorio de Mérida.

Tabla 187. Comparación de los promedios mensuales de las horas frío para el observatorio de Mérida.

Tabla 188. Comparación de horas frío anuales contadas y obtenidas a partir de la fórmula para el

observatorio de Sevilla San Pablo.

Tabla 189. Comparación de los promedios mensuales de las horas frío para el observatorio de Sevilla San

Pablo.

Tabla 190. Comparación de horas frío anuales contadas y obtenidas a partir de la fórmula para el observatorio de Écija.

Tabla 191. Comparación de los promedios mensuales de las horas frío para el observatorio de Écija. _ 132 Tabla 192. Comparación de horas frío anuales contadas y obtenidas a partir de la fórmula para el observatorio de Morón de la Frontera.

Tabla 193. Comparación de los promedios mensuales de las horas frío para el observatorio de Morón de la Frontera.

Tabla 194. Comparación de horas frío anuales contadas y obtenidas a partir de la fórmula para el observatorio del aeropuerto de Córdoba.

Tabla 195. Comparación de los promedios mensuales de las horas frío para el observatorio del aeropuerto de Córdoba.

Tabla 196. Comparación de horas frío anuales contadas y obtenidas a partir de la fórmula para el observatorio de Granada.

Tabla 197. Comparación de los promedios mensuales de las horas frío para el observatorio de Granada.

Tabla 198. Comparación de horas frío anuales contadas y obtenidas a partir de la fórmula para el 135 observatorio de Castellón. 136 Tabla 199. Comparación de los promedios mensuales de las horas frío para el observatorio de Castellón.

Tabla 200. Comparación de horas frío anuales contadas y obtenidas a partir de la fórmula para el observatorio de Valencia.

Tabla 201. Comparación de los promedios mensuales de las horas frío para el observatorio de Valencia.

Tabla 202. Comparación de horas frío anuales contadas y obtenidas a partir de la fórmula para el observatorio de Valencia Manises.

Tabla 203. Comparación de los promedios mensuales de las horas frío para el observatorio de Valencia

Manises.

Tabla 204. Comparación de horas frío anuales contadas y obtenidas a partir de la fórmula para el observatorio de Alicante.

Tabla 205. Comparación de los promedios mensuales de las horas frío para el observatorio de Alicante.

Tabla 206. Comparación de horas frío anuales contadas y obtenidas a partir de la fórmula para el observatorio de Alicante El Atlet.

Tabla 207. Comparación de los promedios mensuales de las horas frío para el observatorio de Alicante el Altet.

Tabla 208. Comparación de horas frío anuales contadas y obtenidas a partir de la fórmula para el 140 observatorio de Alcantarilla. 
Tabla 209. Comparación de los promedios mensuales de las horas frío para el observatorio de

Alcantarilla.

Tabla 210. Comparación de horas frío anuales contadas y obtenidas a partir de la fórmula para el

observatorio de San Javier.

Tabla 211. Comparación de los promedios mensuales de las horas frío para el observatorio de San Javier.

Tabla 212. Comparación de horas frío anuales contadas y obtenidas a partir de la fórmula para el observatorio de Málaga.

Tabla 213. Comparación de los promedios mensuales de las horas frío para el observatorio de Málaga.

Tabla 214.Comparación de horas frío anuales contadas y obtenidas a partir de la fórmula para el

observatorio de Soria.

Tabla 215. Comparación de los promedios mensuales de las horas frío para el observatorio de Soria. _ 145

Tabla 216. Comparación de horas frío anuales contadas y obtenidas a partir de la fórmula para el

observatorio de Molina de Aragón.

Tabla 217. Comparación de los promedios mensuales de las horas frío para el observatorio de Molina de

Aragón.

Tabla 218. Comparación de horas frío anuales contadas y obtenidas a partir de la fórmula para el observatorio de Daroca.

Tabla 219. Comparación de los promedios mensuales de las horas frío para el observatorio de Daroca.

Tabla 220. Comparación de horas frío anuales contadas y obtenidas a partir de la fórmula para el observatorio de Cuenca.

Tabla 221. Comparación de los promedios mensuales de las horas frío para el observatorio de Cuenca.

Tabla 222. Comparación de horas frío anuales contadas y obtenidas a partir de la fórmula para el observatorio de Teruel.

Tabla 224. Comparación de horas frío anuales contadas y obtenidas a partir de la fórmula para el observatorio de Albacete los llanos.

Tabla 225. Comparación de los promedios mensuales de las horas frío para el observatorio de Albacete

los Llanos.

Tabla 226. Tabla resumen horas frío.

Tabla 227. Comparación de horas de calor anuales contadas a partir de datos horarios en los siete observatorios de las zonas norte y noroeste: costa cantábrica.

Tabla 228. Comparación de horas de calor anuales contadas a partir de datos horarios en los cuatro observatorios de las zonas norte y noroeste: costa gallega.

Tabla 229. Comparación de horas de calor anuales contadas a partir de datos horarios en los cinco observatorios de las zonas norte y noroeste: interior de Galicia y el valle del Bierzo.

Tabla 230. Horas de calor contadas en datos horarios en el observatorio de Santiago Labacolla.

Tabla 231. Horas de calor contadas en datos horarios en el observatorio de Lugo Rozas.

Tabla 232. Horas de calor contadas en datos horarios en el observatorio de Orense.

Tabla 233. Horas de calor contadas en datos horarios en el observatorio de Ponferrada.

Tabla 234 Comparación de horas de calor anuales contadas a partir de datos horarios en los ocho observatorios de la meseta Norte.

Tabla 235. Horas de calor contadas en datos horarios en el observatorio de Soria.

Tabla 236. Horas de calor contadas en datos horarios en el observatorio de Burgos Villafría.

Tabla 237. Horas de calor contadas en datos horarios en el observatorio de León Virgen del Camino. 164

Tabla 238. Horas de calor contadas en datos horarios en el observatorio de Villanubla Valladolid. _ 165

Tabla 239. Horas de calor contadas en datos horarios en el observatorio de Valladolid CMT. ___ 165

Tabla 240. Horas de calor contadas en datos horarios en el observatorio de Segovia. ___ _ _ _ 166

Tabla 241. Horas de calor contadas en datos horarios en el observatorio de Zamora. —_ 167

Tabla 242. Horas de calor contadas en datos horarios en el observatorio de Salamanca Matacán. __ 168

Tabla 243. Comparación de horas de calor anuales contadas a partir de datos horarios en los tres

observatorios del valle del Ebro.

Tabla 244. Horas de calor contadas en datos horarios en el observatorio de Huesca. 170

Tabla 245. Horas de calor contadas en datos horarios en el observatorio de Zaragoza aeropuerto. _ 171 
Tabla 246. Horas de calor contadas en datos horarios en el observatorio de Lérida.

Tabla 247. Comparación de horas de calor anuales contadas a partir de datos horarios en los tres observatorios de la parte media de la cuenca del Ebro: Navarra y La Rioja.

Tabla 248. Horas de calor contadas en datos horarios en el observatorio de Pamplona Noáin. 173

Tabla 249. Horas de calor contadas en datos horarios en el observatorio de Haro. 174

Tabla 250. Horas de calor contadas en datos horarios en el observatorio de Logroño Agoncillo. __ 174

Tabla 251. Comparación de horas de calor anuales contadas a partir de datos horarios en los cinco

observatorios de la franja costera del noreste peninsular: costa catalana.

Tabla 252. Horas de calor contadas en datos horarios en el observatorio de Gerona.__ 177

Tabla 253. Horas de calor contadas en datos horarios en el observatorio de Barcelona. ___ 177

Tabla 254. Horas de calor contadas en datos horarios en el observatorio de Reus.__ 178

Tabla 255. Horas de calor contadas en datos horarios en el observatorio de Tarragona. __ 179

Tabla 256. Horas de calor contadas en datos horarios en el observatorio de Tortosa. __ 179

Tabla 257. Comparación de horas de calor anuales contadas a partir de datos horarios en los ocho observatorios de la cuenca del Tajo.

Tabla 258. Horas de calor contadas en datos horarios en el observatorio de Madrid Barajas.

Tabla 259. Horas de calor contadas en datos horarios en el observatorio de Guadalajara.

Tabla 260. Horas de calor contadas en datos horarios en el observatorio de Madrid Getafe.

Tabla 261. Horas de calor contadas en datos horarios en el observatorio de Navalmoral de la Mata. 184

Tabla 262. Horas de calor contadas en datos horarios en el observatorio de Cáceres.

Tabla 263. Horas de calor contadas en datos horarios en el observatorio de Plasencia.

Tabla 264. Horas de calor contadas en datos horarios en el observatorio de Toledo.

Tabla 265. Horas de calor contadas en datos horarios en el observatorio de Trujillo.

Tabla 267. Horas de calor contadas en datos horarios en el observatorio de Ciudad Real. 189

Tabla 268. Horas de calor contadas en datos horarios en el observatorio de Alcazar de San Juan. __ 189

Tabla 269. Horas de calor contadas en datos horarios en el observatorio de Almagro __ 190

Tabla 270. Horas de calor contadas en datos horarios en el observatorio de Hinojosa del Duque.__ 190

Tabla 271. Comparación de horas de calor anuales contadas a partir de datos horarios en los tres observatorios de la parte baja de la cuenca del Guadiana.

Tabla 272. Horas de calor contadas en datos horarios en el observatorio de Badajoz CMT.

Tabla 273. Horas de calor contadas en datos horarios en el observatorio de Talavera la Real.

Tabla 274. Horas de calor contadas en datos horarios en el observatorio de Mérida.

Tabla 275. Comparación de horas de calor anuales contadas a partir de datos horarios en los cuatro observatorios de la parte baja de la cuenca del Guadalquivir.

Tabla 276. Horas de calor contadas en datos horarios en el observatorio de Sevilla San Pablo.__ 195

Tabla 277. Horas de calor contadas en datos horarios en el observatorio de Écija. __ 196

Tabla 278. Horas de calor contadas en datos horarios en el observatorio de Morón__ 196

Tabla 279. Horas de calor contadas en datos horarios en el observatorio de Córdoba aeropuerto. __ 197

Tabla 280. Horas de calor contadas en datos horarios en el observatorio de Granada. ___ 198

Tabla 281. Comparación de horas de calor anuales contadas a partir de datos horarios en los cinco

observatorios de la franja costera de Levante: huerta levantina.

Tabla 282. Horas de calor contadas en datos horarios en el observatorio de Valencia.__ 200

Tabla 283. Horas de calor contadas en datos horarios en el observatorio de Valencia Manises. __ 200

Tabla 284. Horas de calor contadas en datos horarios en el observatorio de Castellón. ___ 201

Tabla 285. Horas de calor contadas en datos horarios en el observatorio de Alicante. $\quad 202$

Tabla 286. Horas de calor contadas en datos horarios en el observatorio de Alicante El Atlet.___ 202

Tabla 287. Comparación de horas de calor anuales contadas a partir de datos horarios en los tres

observatorios de la huerta murciana.

Tabla 288. Horas de calor contadas en datos horarios en el observatorio de Alcantarilla.

Tabla 289. Horas de calor contadas en datos horarios en el observatorio de San Javier. — 205

Tabla 290. Horas de calor contadas en datos horarios en el observatorio de Totana. —_ 205

Tabla 291. Horas de calor contadas en datos horarios en el observatorio de Málaga aeropuerto.__ 206

Tabla 292. Comparación de horas de calor anuales contadas a partir de datos horarios en los seis observatorios de las zonas altas del interior peninsular. 
Tabla 294. Horas de calor contadas en datos horarios en el observatorio de Albacete Los LLanos.

Tabla 295. Horas de calor contadas en datos horarios en el observatorio de Teruel.

Tabla 296. Horas de calor contadas en datos horarios en el observatorio de Daroca.

Tabla 297. Horas de calor contadas en datos horarios en el observatorio de Molina de Aragón. __ 211

Tabla 298. Horas de calor contadas en datos horarios en el observatorio de Soria.___ 212

Tabla 299. Comparación de horas de calor anuales contadas y obtenidas a partir de la fórmula para el

observatorio de Orense.

Tabla 300. Comparación de los promedios mensuales de las horas de calor correspondientes al periodo

2002-2011 para el observatorio de Orense.

Tabla 301. Comparación de horas de calor anuales contadas y obtenidas a partir de la fórmula para el observatorio de Ponferrada.

Tabla 302. Comparación de los promedios mensuales de las horas de calor correspondientes al periodo

2002-2011 para el observatorio de Ponferrada.

Tabla 303. Comparación de horas de calor anuales contadas y obtenidas a partir de la fórmula para el

observatorio de Soria.

Tabla 304. Comparación de los promedios mensuales de las horas de calor correspondientes al periodo

2002-2011 para el observatorio de Soria.

Tabla 305. Comparación de horas de calor anuales contadas y obtenidas a partir de la fórmula para el observatorio de Burgos Villafría.

Tabla 306. Comparación de los promedios mensuales de las horas de calor correspondientes al periodo

2002-2011 para el observatorio de Burgos Villafría.

Tabla 307. Comparación de horas de calor anuales contadas y obtenidas a partir de la fórmula para el

observatorio de León Virgen del Camino.

Tabla 308. Comparación de los promedios mensuales de las horas de calor correspondientes al periodo

2002-2011 para el observatorio de León Virgen del Camino.

Tabla 309. Comparación de horas de calor anuales contadas y obtenidas a partir de la fórmula para el

observatorio de Valladolid Villanubla.

Tabla 310.Comparación de los promedios mensuales de las horas de calor correspondientes al periodo

2002-2011 para el observatorio de Valladolid Villanubla.

Tabla 311. Comparación de horas de calor anuales contadas y obtenidas a partir de la fórmula para el observatorio de Valladolid CMT.

Tabla 312. Comparación de los promedios mensuales de las horas de calor correspondientes al periodo

2002-2011 para el observatorio de Valladolid CMT.

Tabla 313. Comparación de horas de calor anuales contadas y obtenidas a partir de la fórmula para el

observatorio de Segovia.

Tabla 314. Comparación de los promedios mensuales de las horas de calor correspondientes al periodo

2002-2011 para el observatorio de Segovia.

Tabla 315. Comparación de horas de calor anuales contadas y obtenidas a partir de la fórmula para el observatorio de Salamanca Matacán.

Tabla 316. Comparación de los promedios mensuales de las horas de calor correspondientes al periodo

2002-2011 para el observatorio de Salamanca Matacán.

Tabla 317. Comparación de horas de calor anuales contadas y obtenidas a partir de la fórmula para el

observatorio de Zamora.

Tabla 318. Comparación de los promedios mensuales de las horas de calor correspondientes al periodo

2002-2011 para el observatorio de Zamora.

223

Tabla 319. Comparación de horas de calor anuales contadas y obtenidas a partir de la fórmula para el

observatorio de Huesca.

Tabla 320. Comparación de los promedios mensuales de las horas de calor correspondientes al periodo

2002-2011 para el observatorio de Huesca.

Tabla 321. Comparación de horas de calor anuales contadas y obtenidas a partir de la fórmula para el

observatorio de Zaragoza aeropuerto.

Tabla 322. Comparación de los promedios mensuales de las horas de calor correspondientes al periodo

2002-2011 para el observatorio de Zaragoza aeropuerto.

Tabla 323. Comparación de horas de calor anuales contadas y obtenidas a partir de la fórmula para el observatorio de Lérida.

Tabla 324. Comparación de los promedios mensuales de las horas de calor correspondientes al periodo

2002-2011 para el observatorio de Lérida. 
Tabla 325. Comparación de horas de calor anuales contadas y obtenidas a partir de la fórmula para el observatorio de Logroño Agoncillo.

Tabla 326. Comparación de los promedios mensuales de las horas de calor correspondientes al periodo

2002-2011 para el observatorio de Logroño Agoncillo.

Tabla 327. Comparación de horas de calor anuales contadas y obtenidas a partir de la fórmula para el observatorio de Haro.

Tabla 328. Comparación de los promedios mensuales de las horas de calor correspondientes al periodo 2002-2011 para el observatorio de Haro.

Tabla 329. Comparación de horas de calor anuales contadas y obtenidas a partir de la fórmula para el observatorio de Pamplona Noáin.

Tabla 330. Comparación de los promedios mensuales de las horas de calor correspondientes al periodo

2002-2011 para el observatorio de Pamplona Noáin.

Tabla 331. Comparación de horas de calor anuales contadas y obtenidas a partir de la fórmula para el observatorio de Barcelona.

Tabla 332. Comparación de los promedios mensuales de las horas de calor correspondientes al periodo

2002-2011 para el observatorio de Barcelona.

Tabla 333. Comparación de horas de calor anuales contadas y obtenidas a partir de la fórmula para el observatorio de Gerona.

Tabla 334. Comparación de los promedios mensuales de las horas de calor correspondientes al periodo 2002-2011 para el observatorio de Gerona.

Tabla 335. Comparación de horas de calor anuales contadas y obtenidas a partir de la fórmula para el observatorio de Reus.

Tabla 336. Comparación de los promedios mensuales de las horas de calor correspondientes al period 2002-2011 para el observatorio de Reus.

Tabla 337. Comparación de horas de calor anuales contadas y obtenidas a partir de la fórmula para el observatorio de Tarragona.

Tabla 338. Comparación de los promedios mensuales de las horas de calor correspondientes al periodo 2002-2011 para el observatorio de Tarragona.

Tabla 339. Comparación de horas de calor anuales contadas y obtenidas a partir de la fórmula para el observatorio de Tortosa.

Tabla 340. Comparación de los promedios mensuales de las horas de calor correspondientes al periodo

2002-2011 para el observatorio de Tortosa.

Tabla 341. Comparación de horas de calor anuales contadas y obtenidas a partir de la fórmula para el observatorio de Madrid Barajas.

Tabla 342. Comparación de los promedios mensuales de las horas de calor correspondientes al periodo

2002-2011 para el observatorio de Madrid Barajas.

Tabla 343. Comparación de horas de calor anuales contadas y obtenidas a partir de la fórmula para el observatorio de Guadalajara.

Tabla 344. Comparación de los promedios mensuales de las horas de calor correspondientes al periodo

2002-2011 para el observatorio de Guadalajara.

Tabla 345. Comparación de horas de calor anuales contadas y obtenidas a partir de la fórmula para el observatorio de Madrid Getafe.

Tabla 346. Comparación de los promedios mensuales de las horas de calor correspondientes al periodo

2002-2011 para el observatorio de Madrid Getafe.

Tabla 347. Comparación de horas de calor anuales contadas y obtenidas a partir de la fórmula para el observatorio de Navalmoral de la Mata.

Tabla 348. Comparación de los promedios mensuales de las horas de calor correspondientes al periodo

2002-2011 para el observatorio de Navalmoral de la Mata.

Tabla 349. Comparación de horas de calor anuales contadas y obtenidas a partir de la fórmula para el observatorio de Cáceres.

observatorio de Cáceres. 240

Tabla 350. Comparación de los promedios mensuales de las horas de calor correspondientes al periodo

Tabla 351. Comparación de horas de calor anuales contadas y obtenidas a partir de la fórmula para el observatorio de Plasencia.

Tabla 352. Comparación de los promedios mensuales de las horas de calor correspondientes al periodo

2002-2011 para el observatorio de Plasencia. 
Tabla 353.Comparación de horas de calor anuales contadas y obtenidas a partir de la fórmula para el observatorio de Toledo.

Tabla 354. Comparación de los promedios mensuales de las horas de calor correspondientes al periodo

2002-2011 para el observatorio de Toledo.

Tabla 355. Comparación de horas de calor anuales contadas y obtenidas a partir de la fórmula para el

observatorio de Trujillo.

Tabla 356. Comparación de los promedios mensuales de las horas de calor correspondientes al periodo

2002-2011 para el observatorio de Trujillo.

Tabla 357. Comparación de horas de calor anuales contadas y obtenidas a partir de la fórmula para el observatorio de Alcazar de San Juan.

Tabla 358. Comparación de horas de calor anuales contadas y obtenidas a partir de la fórmula para el observatorio de Almagro.

Tabla 359. Comparación de los promedios mensuales de las horas de calor correspondientes al periodo 2002-2011 para el observatorio de Almagro.

Tabla 360. Comparación de horas de calor anuales contadas y obtenidas a partir de la fórmula para el observatorio de Ciudad Real.

Tabla 361. Comparación de los promedios mensuales de las horas de calor correspondientes al periodo 2002-2011 para el observatorio de Ciudad Real.

Tabla 362. Comparación de horas de calor anuales contadas y obtenidas a partir de la fórmula para el observatorio de Hinojosa del Duque.

Tabla 363. Comparación de los promedios mensuales de las horas de calor correspondientes al periodo

2002-2011 para el observatorio de Hinojosa del Duque.

Tabla 364. Comparación de horas de calor anuales contadas y obtenidas a partir de la fórmula para el observatorio de Talavera La Real.

Tabla 365. Comparación de los promedios mensuales de las horas de calor correspondientes al periodo

2002-2011 para el observatorio de Talavera La Real.

Tabla 366. Comparación de horas de calor anuales contadas y obtenidas a partir de la fórmula para el observatorio de Mérida.

Tabla 367. Comparación de los promedios mensuales de las horas de calor correspondientes al periodo

2002-2011 para el observatorio de Mérida.

Tabla 368. Comparación de horas de calor anuales contadas y obtenidas a partir de la fórmula para el observatorio de Sevilla San Pablo.

Tabla 369. Comparación de los promedios mensuales de las horas de calor correspondientes al periodo 2002-2011 para el observatorio de Sevilla San Pablo.

Tabla 370. Comparación de horas de calor anuales contadas y obtenidas a partir de la fórmula para el observatorio de Écija.

Tabla 371. Comparación de los promedios mensuales de las horas de calor correspondientes al periodo

2002-2011 para el observatorio de Écija.

Tabla 372. Comparación de horas de calor anuales contadas y obtenidas a partir de la fórmula para el observatorio del aeropuerto de Córdoba.

Tabla 373. Comparación de los promedios mensuales de las horas de calor correspondientes al periodo 2002-2011 para el observatorio del aeropuerto de Córdoba.

Tabla 374. Comparación de horas de calor anuales contadas y obtenidas a partir de la fórmula para el observatorio de la base aérea de Morón de la Frontera.

Tabla 375. Comparación de los promedios mensuales de las horas de calor correspondientes al periodo

2002-2011 para el observatorio de la base aérea de Morón de la Frontera.

Tabla 376. Comparación de horas de calor anuales contadas y obtenidas a partir de la fórmula para el observatorio de Granada.

Tabla 377. Comparación de los promedios mensuales de las horas de calor correspondientes al periodo

2002-2011 para el observatorio de Granada.

Tabla 378. Comparación de horas de calor anuales contadas y obtenidas a partir de la fórmula para el observatorio de Castellón.

Tabla 379. Comparación de los promedios mensuales de las horas de calor correspondientes al periodo

2002-2011 para el observatorio de Castellón.

Tabla 380. Comparación de horas de calor anuales contadas y obtenidas a partir de la fórmula para el observatorio de Valencia. 
Tabla 381. Comparación de los promedios mensuales de las horas de calor correspondientes al periodo

2002-2011 para el observatorio de Valencia.

Tabla 382. Comparación de horas de calor anuales contadas y obtenidas a partir de la fórmula para el observatorio de Valencia Manises.

Tabla 383. Comparación de los promedios mensuales de las horas de calor correspondientes al periodo

2002-2011 para el observatorio de Valencia Manises.

Tabla 384. Comparación de horas de calor anuales contadas y obtenidas a partir de la fórmula para el observatorio de Alicante.

Tabla 385. Comparación de los promedios mensuales de las horas de calor correspondientes al periodo

2002-2011 para el observatorio de Alicante.

Tabla 386. Comparación de horas de calor anuales contadas y obtenidas a partir de la fórmula para el observatorio de Alicante El Altet.

Tabla 387. Comparación de los promedios mensuales de las horas de calor correspondientes al periodo 2002-2011 para el observatorio de El Altet.

Tabla 388. Comparación de horas de calor anuales contadas y obtenidas a partir de la fórmula para el observatorio de la base aérea de San Javier.

Tabla 389. Comparación de los promedios mensuales de las horas de calor correspondientes al periodo

2002-2011 para el observatorio de la base aérea de San Javier.

Tabla 390. Comparación de horas de calor anuales contadas y obtenidas a partir de la fórmula para el observatorio de la base aérea de Alcantarilla.

Tabla 391. Comparación de los promedios mensuales de las horas de calor correspondientes al periodo

2002-2011 para el observatorio de la base aérea de Alcantarilla.

Tabla 392. Comparación de horas de calor anuales contadas y obtenidas a partir de la fórmula para el observatorio de Málaga aeropuerto.

Tabla 393. Comparación de los promedios mensuales de las horas de calor correspondientes al periodo

2002-2011 para el observatorio de Málaga aeropuerto.

Tabla 394. Comparación de horas de calor anuales contadas y obtenidas a partir de la fórmula para el observatorio de Soria.

Tabla 395. Comparación de los promedios mensuales de las horas de calor correspondientes al periodo

2002-2011 para el observatorio de Soria.

Tabla 396. Comparación de horas de calor anuales contadas y obtenidas a partir de la fórmula para el observatorio de Molina de Aragón.

2omparación de los promedios mensuales de las horas de calor correspondientes al periodo

2002-2011 para el observatorio de Molina de Aragón.

Tabla 398. Comparación de horas de calor anuales contadas y obtenidas a partir de la fórmula para el observatorio de Daroca.

Tabla 399. Comparación de los promedios mensuales de las horas de calor correspondientes al periodo

2002-2011 para el observatorio de Daroca.

Tabla 400. Comparación de horas de calor anuales contadas y obtenidas a partir de la fórmula para el observatorio de Cuenca.

Tabla 401. Comparación de los promedios mensuales de las horas de calor correspondientes al periodo 2002-2011 para el observatorio de Cuenca.

Tabla 402.Comparación de horas de calor anuales contadas y obtenidas a partir de la fórmula para el observatorio de Teruel.

Tabla 403. Comparación de los promedios mensuales de las horas de calor correspondientes al periodo

2002-2011 para el observatorio de Teruel.

Tabla 404. Comparación de horas de calor anuales contadas y obtenidas a partir de la fórmula para el observatorio de Albacete Los Lllanos.

Tabla 405. Comparación de los promedios mensuales de las horas de calor correspondientes al periodo

2002-2011 para el observatorio de Albacete Los LLanos.

Tabla 406. Tabla resumen horas de calor. 


\section{Índice de gráficas}

Gráfico 1. Comparación de horas frío (umbral 7ํ C) anuales en observatorios de la franja cantábrica. _ 10

Gráfico 2. Comparación de horas frío (umbral 7ํㅡ) anuales en observatorios de la costa gallega. 17

Gráfico 3. Comparación de horas frío (umbral 7ํㅡ) anuales en observatorios del interior de Galicia y el valle del Bierzo.

Gráfico 4. Comparación de horas frío (umbral 7ํㅡ) anuales en observatorios de la meseta Norte. __ 26

Gráfico 5. Comparación de horas frío (umbral 7으) anuales en observatorios del valle del Ebro. __ _ 33

Gráfico 6. Comparación de horas frío (umbral 7ํㅡ) anuales en observatorios de Navarra y La Rioja. _ 36

Gráfico 7. Comparación de horas frío (umbral 7으) anuales en observatorios de la franja costera del noreste peninsular: costa catalana.

Gráfico 8. Comparación de horas frío (umbral 7o C) anuales en observatorios de la cuenca del Tajo. _ 44

Gráfico 9. Comparación de horas frío (umbral $7{ }^{\circ} \mathrm{C}$ ) anuales en observatorios de la parte alta de la cuenca

del Guadiana.

Gráfico 10. Comparación de horas frío (umbral 7ํㅡ) anuales en observatorios de la parte baja de la cuenca del Guadiana.

Gráfico 11. Comparación de horas frío (umbral 7ํㅡ) anuales en observatorios de la parte baja de la cuenca del Guadalquivir.

Gráfico 12. Comparación de horas frío (umbral $7^{\circ} \mathrm{C}$ ) anuales en observatorios de la parte media de la cuenca del Guadalquivir.

Gráfico 13. Comparación de horas frío (umbral 7ํㅡ) anuales en los observatorios de la franja costera de Levante: huerta levantina.

Gráfico 14. Comparación de horas frío (umbral 7으) anuales en observatorios de la huerta murciana. _ 69

Gráfico 15. Comparación de horas frío (umbral 7으) anuales en observatorios de las zonas altas del interior peninsular.

Gráfico 16. Comparación de horas de calor (umbral 30C) en observatorios del interior de Galicia y el valle del Bierzo.

Gráfico 17. Comparación de horas de calor (umbral 30C) en observatorios de la meseta Norte.

Gráfico 18. Comparación de horas de calor (umbral 30ㄷ) anuales en observatorios del valle del Ebro. 169 Gráfico 19. Comparación de horas de calor (umbral $30^{\circ} \mathrm{C}$ ) anuales en los observatorios de la parte media de la cuenca del Ebro: Navarra y La Rioja.

Gráfico 20. Comparación de horas de calor (umbral $30^{\circ} \mathrm{C}$ ) anuales en observatorios de la franja costera del noreste peninsular: costa catalana.

Gráfico 21. Comparación de horas de calor (umbral 30C) anuales en observatorios de la cuenca del Tajo.

Gráfico 22. Comparación de horas de calor (umbral 30C) anuales en observatorios de la parte alta de la cuenca del Guadiana.

Gráfico 23. Comparación de horas de calor (umbral $30^{\circ} \mathrm{C}$ ) anuales en observatorios de la parte baja de la cuenca del Guadiana. 191

Gráfico 24. Comparación de horas de calor (umbral 30C) anuales en observatorios de la parte baja de la cuenca del Guadalquivir. 194 Gráfico 25. Comparación de horas de calor (umbral 30C) anuales en observatorios de la franja costera de Levante: huerta levantina.

Gráfico 26. Comparación de horas de calor (umbral 30C) anuales en los observatorios de la huerta murciana.

Gráfico 27. Comparación de horas de calor (umbral 30C) anuales en observatorios de las zonas altas del interior peninsular. 208 



\section{Introducción}

El conocimiento del número de horas en el que, en un determinado periodo de tiempo, las temperaturas están por debajo o por encima de determinados umbrales es muy útil no sólo en el sector agrícola sino también en el de la construcción y el energético. Permite, por ejemplo, determinar la viabilidad de distintos tipos de cultivo, así como las necesidades de calefacción y o refrigeración en los edificios.

Más que realizar un estudio, en este trabajo se persigue dar una idea aproximada del número de horas frío y horas de calor que se dan en las distintas zonas climáticas peninsulares, así como la aproximación que, a esos valores, proporciona la fórmula de Crossa-Raynaud, la más utilizada para su cálculo. No se trata de proponer, justificar o refutar determinadas hipótesis o métodos para el cálculo de horas frío o de calor, sino simplemente de aceptar la utilidad en las aplicaciones climáticas de estas variables derivadas y hacer un recuento de su número en varios observatorios de datos horarios fiables dentro de la Península para tener una idea aproximada, dentro de la zona que representan, tanto del número de horas reales en las que las temperaturas se hallan por debajo o por encima de determinados umbrales, como de lo que se aproxima la fórmula normalmente utilizada, la de Crossa-Raynaud. Este es el motivo de que no se proporcione la correspondiente bibliografía que acompañaría a un estudio que partiera de unas ideas para proponer otras.

Actualmente, en el sector agrícola se cuestiona la utilidad del concepto de horas frío, y se propone la utilización de unidades de frío. Una de las razones que se aducen es la dificultad de justificar que las horas con una temperatura una décima por encima del umbral puedan ser distintas para el desarrollo de las plantas que las horas en las que se ha dado una décima por debajo. Por otra parte, la forma en la que evoluciona la temperatura después de unas pocas horas frío influye también en el desarrollo de las plantas. En todo caso, aun admitiendo que el uso de variables más sofisticadas, como las propuestas unidades de frío, puede dar mejores resultados en determinados casos, la prueba de que el conocimiento de las horas frío y de calor es útil es que sigue utilizándose con éxito. 
Para determinar de forma exacta el número de horas frío y de calor en un observatorio es preciso disponer de las bandas del termógrafo y a partir de ellas determinar el tiempo en el que, cada día, las temperaturas están por debajo o por encima de los umbrales elegidos, o bien tener un aparato que mida la temperatura de forma continua y, por medio de un programa, computar el tiempo por encima o por debajo de los umbrales. El problema es que son pocos los observatorios que disponen de termógrafos 0 de tales aparatos, mientras que hay un buen número de ellos en los que se registran las temperaturas máxima y mínima diarias. Lo que se hace, entonces, cuando se solicitan el número de horas frío o de calor de un determinado punto o una determinada zona, es aplicar fórmulas empíricas basadas en los registros de las temperaturas máxima y mínima del observatorio fiable más cercano al punto solicitado.

Se han propuesto varias fórmulas y métodos para calcular las horas frío o de calor a partir de las máximas, mínimas o medias diarias, pero no hay ninguno que se adecúe a todas las zonas climáticas. Las fórmulas se basan en que las temperaturas a lo largo de un día forman aproximadamente una onda sinusoide entre los valores máximo y mínimo. Lógicamente, el valor obtenido a partir de la fórmula será más o menos acertado según que el registro de temperaturas se ajuste más o menos a la curva ideal. En el antiguo Instituto de Meteorología se decidió usar una de las fórmulas con más éxito, la fórmula de Crossa-Raynaud, aconsejada por la OMM y que se ajusta razonablemente bien en latitudes medias.

Fórmula de Crossa-Raynaud para el cálculo de horas frío:

Si Tmax. menor o igual que $7^{\circ} \mathrm{C}, \quad \mathrm{HF}=24$

Si Tmin. mayor o igual que $7^{\circ} \mathrm{C}, \quad \mathrm{HF}=0$

Para el resto de las situaciones:

$$
\mathrm{HF}=\frac{(-\operatorname{Tmin}}{\operatorname{Tmax}-\operatorname{Tmin}}{ }^{*} 24
$$


Fórmula de Crossa-Raynaud para el cálculo de horas de calor:

Si Tmax. es menor o igual que $30^{\circ} \mathrm{C}, \mathrm{HC}=0$

Para el resto de las situaciones:

$$
\mathrm{HC}=\frac{\operatorname{Tmax}-30}{\operatorname{Tmax}-\mathrm{Tmin}}
$$

Ambas fórmulas se basan en que la temperatura se ajusta a una función lineal del tiempo, la oscilación térmica diaria (en 24 horas) es un par de dientes de sierra.

Los datos que se proporcionan a partir de estas fórmulas pueden verse afectados en especial por dos tipos de errores que surgen de las hipótesis de partida. El primero es asumir que lo que se obtiene en un determinado punto (el del observatorio) es representativo (igual 0 muy parecido) de toda la zona; y el segundo es el error derivado del ajuste de la curva térmica real a la ideal de la fórmula; ajuste que, en general, varía entre unas zonas y otras. Las curvas de temperatura son semejantes en zonas climáticas uniformes. Pueden darse diferencias en determinados días, debido por ejemplo a la existencia de nubes en un sitio y ausencia en otro, pero en general y considerando intervalos más largos, semana, meses o años los cálculos para dos estaciones de la misma zona climática tendrán curvas semejantes. El análisis de Fourier proporcionaría curvas más ajustadas a las reales que aquellas en las que se basan las fórmulas propuestas y, por tanto, darían mejores aproximaciones (como se demuestra en el estudio Cálculo de la temperatura instantánea del aire a partir de la máxima y la mínima diarias y análisis de Fourier. Aplicación en la cuenca del Segura, llevado a cabo por Ramón Garrido Abenza y Francisco Martínez Cortés del Centro Meteorológico Territorial de Murcia).

Lo que se pretende en este trabajo es proporcionar una idea del orden de magnitud que suponen ambos tipos de error, mediante el conocimiento aproximado del grado de variación que 
se da en cada zona al cambiar de lugar en el que se toman las medidas de las temperaturas y comparando los valores sacados de datos horarios con los de la aplicación de la fórmula.

La elección de los umbrales se ha hecho en base a las peticiones que se recibían en el INM, y actualmente se reciben en AEMet, sobre esos datos: $7^{\circ} \mathrm{C}$ para las horas frío y $30^{\circ} \mathrm{C}$ para las horas de calor. Son los considerados de más relevancia en la agricultura en nuestro país (importantes para un buen número de cultivos) y también para el consumo energético. Así pues, las horas frío serán horas en las que las temperaturas están por debajo de $7^{\circ} \mathrm{C}$, y las horas de calor serán las horas en las que las temperaturas están por encima de $30^{\circ} \mathrm{C}$. De la misma forma podrían establecerse otros umbrales y se llegaría a resultados similares.

La OMM especifica la conveniencia de disponer de 30 años o más de datos para que los estadísticos de los elementos climáticos se hayan estabilizado. Pero debido a la escasez de datos horarios de las temperaturas, en este trabajo se opera sobre un periodo de 10 años (2002 a 2011), en los que se dispone de esos datos en un buen número de estaciones automáticas. Es importante tener en cuenta que las estaciones automáticas no miden exactamente lo mismo que las de termómetros de mercurio o de alcohol, que son los que miden las temperaturas máxima y mínima, y que para hacer más exacto el estudio habría que completarlo con una comparación de las temperaturas por ambos métodos.

El trabajo se limita a la España peninsular. Para un estudio posterior quedan los archipiélagos Balear y Canario. La España peninsular se ha dividido en zonas que, además de caracterizarse por cultivos agrícolas definidos dentro de un cierto rango, presenten una cierta homogeneidad fisiográfica que permite la extrapolación de los datos de un punto a lo que sucede en el entorno. Las zonas son las siguientes: 1) Norte y Noroeste: a) costa cantábrica, b) costa gallega, c) interior gallego y valle del Bierzo. 2) Meseta Norte. 3) Cuenca del Ebro: a) parte baja y relativamente llana del valle del Ebro y b) zonas de la parte media de la cuenca: Navarra y La Rioja. 4) Costa catalana. 5) Cuenca del Tajo. 6) Cuenca del Guadiana: a) parte baja y relativamente llana de la cuenca, b) parte alta de la cuenca, situada en la meseta Sur, principalmente en la Mancha. 7) Cuenca del Guadalquivir: a) parte baja y relativamente llana de la cuenca y b) parte media de la cuenca. 8) Levante: a) huerta levantina, b) huerta murciana. 9) Costa Sur. 10) Zonas altas del interior peninsular. 
Como se puede ver, las zonas son lo suficientemente amplias para que los valores que se proporcionan sean únicamente orientativos para la zona, en determinadas franjas de altitud.

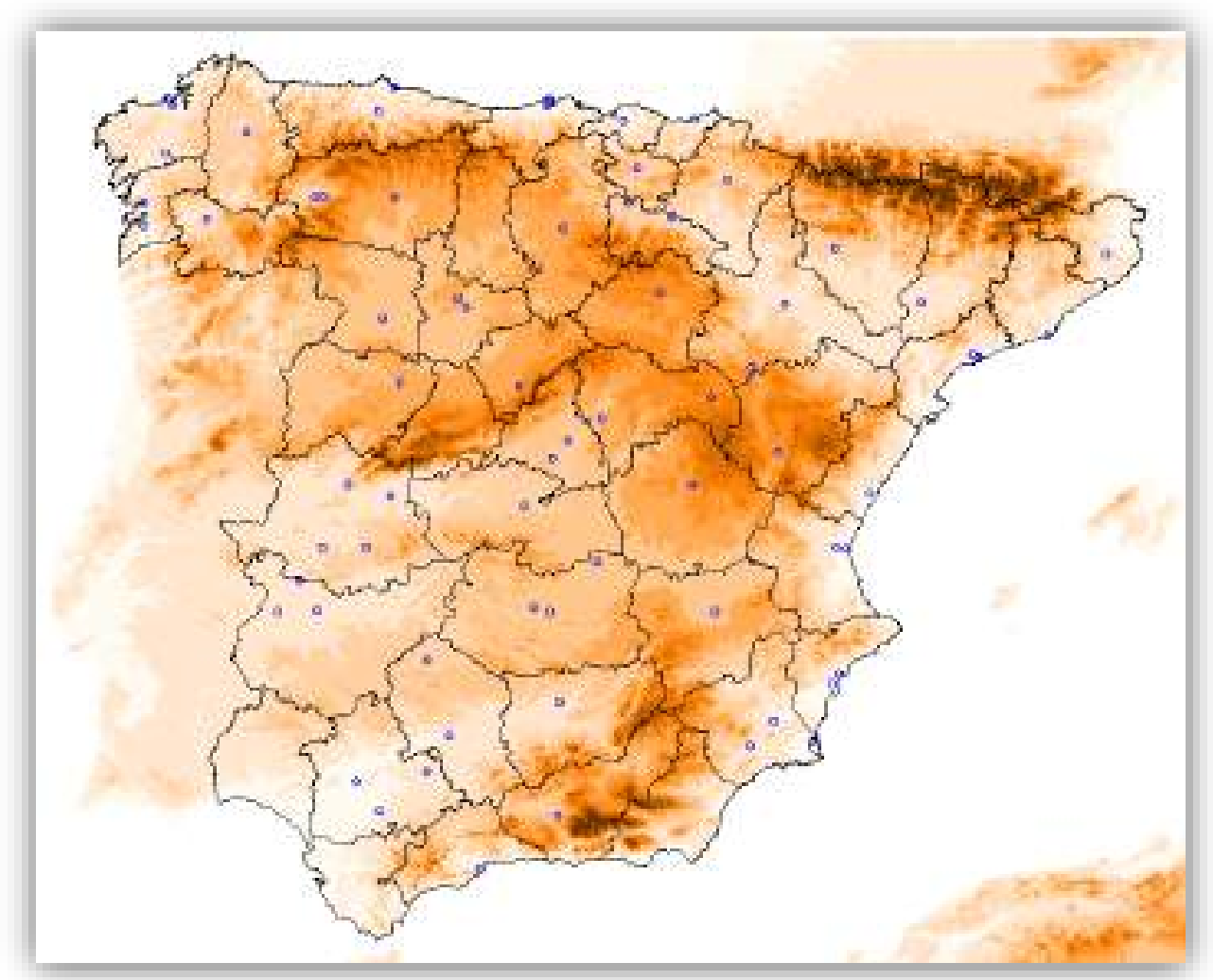

Figura 1. Localización de los observatorios meteorológicos empleados en el estudio.

Finalmente es importante tener también en cuenta de que se ha operado sobre años naturales, y en el caso de la agricultura, no es así como se acumulan las horas frío a lo largo del año. Para calcular lo que realmente influye en las plantas cada año sería conveniente seguir el ciclo más natural de desarrollo de los cultivos y utilizar el año agrícola: desde el 1 de octubre de un año al 30 de septiembre del año siguiente. De esta forma podrían darse diferencias notables en cada realización, cada año, pero no en las estadísticas finales. Por ejemplo, se obtendrían valores distintos para el año agrícola 2001-2002 que para el año 2002, para el año agrícola 2002-2003 que para los años 2002 y 2003, etc. Sin embargo, los promedios anuales para diez años, y más para un número mayor de años, serían muy parecidos. Lógicamente, para un estudio de las distintas estaciones del año, sería también más conveniente utilizar el año agrícola. Si el objetivo del estudio son las necesidades de calefacción, por ejemplo, no importa usar el año agrícola o el natural, aunque se podría ajustar el estudio en cada caso (cada zona o cada observatorio) a la temporada fría (en la que se precisa calefacción), y lo mismo sucedería con la necesidad de refrigeración, se ajustaría el estudio a la temporada cálida, el verano, cuando se precisa la refrigeración, pero en ese caso el año natural es adecuado. 


\section{Datos utilizados.}

El criterio de selección ha sido utilizar todos los observatorios que dispongan de registros de temperatura, tanto horarios como diarios de temperaturas máxima y mínima, correspondientes al periodo 2002-2011 (Tablas 1, 2 y 3). Se han descartado los datos de los observatorios que presentaban un número excesivo de lagunas (más de diez días al mes o más de un mes dentro de una determinada estación de frío 0 calor al año) 0 aquellos cuya fiabilidad fuese dudosa (coeficiente de correlación bajo, menor de 0.8 , con series de datos de la misma variable de observatorios cercanos).

Tabla 1. Datos descriptivos de los observatorios meteorológicos de la zona norte, noroeste y meseta Norte.

\begin{tabular}{|c|c|c|c|c|c|c|}
\hline \multicolumn{2}{|c|}{ ZONA } & NOMBRE & INDICATIVO & LONGITUD & LATITUD & ALTITUD \\
\hline \multirow{16}{*}{ Norte y noroeste } & \multirow{7}{*}{ Costa cantábrica } & San Sebastián-Igueldo & $1024 \mathrm{e}$ & $2^{\circ} 02^{\prime} 28^{\prime \prime} \mathrm{W}$ & $43^{\circ} 18^{\prime} 23^{\prime \prime} \mathrm{N}$ & $251 \mathrm{~m}$ \\
\hline & & Bilbao Aeropuerto & 1082 & $2^{\circ} 54^{\prime} 21^{\prime \prime} \mathrm{W}$ & $43^{\circ} 17^{\prime} 53^{\prime \prime} \mathrm{N}$ & $42 m$ \\
\hline & & Santander-Parayas & 1109 & $3^{\circ} 49^{\prime} 53^{\prime \prime} \mathrm{W}$ & $43^{\circ} 25^{\prime} 45^{\prime \prime} \mathrm{N}$ & $5 \mathrm{~m}$ \\
\hline & & Santander CMT & 1111 & $3^{\circ} 48^{\prime} 02^{\prime \prime} \mathrm{W}$ & $43^{\circ} 29^{\prime} 28^{\prime \prime}$ & $52 \mathrm{~m}$ \\
\hline & & Gijón-Musel & $1208 \mathrm{~h}$ & $5^{\circ} 42^{\prime} 03^{\prime \prime} \mathrm{W}$ & $43^{\circ} 33^{\prime} 36^{\prime \prime} \mathrm{N}$ & $5 \mathrm{~m}$ \\
\hline & & Oviedo & $1249 \mathrm{i}$ & $5^{0} 52^{\prime} 27^{\prime \prime} \mathrm{W}$ & $43^{\circ} 21^{\prime} 12^{\prime \prime} \mathrm{N}$ & $336 \mathrm{~m}$ \\
\hline & & Vitoria & 90910 & $2^{\circ} 44^{\prime} 06^{\prime \prime} \mathrm{W}$ & $42^{\circ} 52^{\prime} 55^{\prime \prime} \mathrm{N}$ & $513 \mathrm{~m}$ \\
\hline & \multirow{4}{*}{ Costa gallega } & La Coruña & 1387 & $8^{\circ} 25^{\prime} 10^{\prime \prime} \mathrm{W}$ & $43^{\circ} 22^{\prime} 02^{\prime \prime} \mathrm{N}$ & $58 \mathrm{~m}$ \\
\hline & & La Coruña-Alvedro & $1387 \mathrm{e}$ & $08^{\circ} 22^{\prime} 20^{\prime \prime} \mathrm{W}$ & $43^{\circ} 18^{\prime} 25^{\prime \prime} \mathrm{N}$ & $98 \mathrm{~m}$ \\
\hline & & Pontevedra & $1484 c$ & $08^{\circ} 37^{\prime} 39^{\prime \prime} \mathrm{W}$ & $42^{\circ} 25^{\prime} 56^{\prime \prime} \mathrm{N}$ & $107 \mathrm{~m}$ \\
\hline & & Vigo-Peinador & 1495 & $08^{\circ} 37^{\prime} 57^{\prime \prime} \mathrm{W}$ & $42^{\circ} 13^{\prime} 31^{\prime \prime} \mathrm{N}$ & $255 \mathrm{~m}$ \\
\hline & \multirow{5}{*}{$\begin{array}{l}\text { Interior gallego y } \\
\text { valle del Bierzo }\end{array}$} & Santiago-Labacolla & 1428 & $08^{\circ} 24^{\prime} 42^{\prime \prime} \mathrm{W}$ & $42^{\circ} 52^{\prime} 03^{\prime \prime} \mathrm{N}$ & $364 \mathrm{~m}$ \\
\hline & & Lugo-Las Rozas & 1505 & $07^{\circ} 28^{\prime} 54^{\prime \prime} \mathrm{W}$ & $43^{\circ} 05^{\prime} 47^{\prime \prime} \mathrm{N}$ & $444 \mathrm{~m}$ \\
\hline & & Ourense & $1690 a$ & $07^{\circ} 51^{\prime} 47^{\prime \prime} \mathrm{W}$ & $42^{\circ} 20^{\prime} 00^{\prime \prime} \mathrm{N}$ & $148 m$ \\
\hline & & Ponferrada & 1549 & $06^{\circ} 36^{\prime} 00^{\prime \prime} \mathrm{W}$ & $42^{\circ} 33^{\prime} 50^{\prime \prime} \mathrm{N}$ & $534 \mathrm{~m}$ \\
\hline & & Almázcara & $1556 x$ & $06^{\circ} 29^{\prime} 48^{\prime \prime} \mathrm{W}$ & $42^{\circ} 35^{\prime} 17^{\prime \prime} \mathrm{N}$ & $584 \mathrm{~m}$ \\
\hline \multirow{8}{*}{\multicolumn{2}{|c|}{ Meseta Norte }} & Zamora & 2614 & $05^{\circ} 44^{\prime} 07^{\prime \prime} \mathrm{W}$ & $41^{\circ} 30^{\prime} 56^{\prime \prime} \mathrm{N}$ & $656 \mathrm{~m}$ \\
\hline & & Valladolid & 2422 & $04^{\circ} 45^{\prime} 16^{\prime \prime} \mathrm{W}$ & $41^{\circ} 38^{\prime} 27^{\prime \prime} \mathrm{N}$ & $735 \mathrm{~m}$ \\
\hline & & Valladolid-Villanubla & 2539 & $04^{\circ} 51^{\prime} 20^{\prime \prime} \mathrm{W}$ & $41^{\circ} 42^{\prime} 43^{\prime \prime} \mathrm{N}$ & $846 \mathrm{~m}$ \\
\hline & & Salamanca-Matacán & 2867 & $05^{\circ} 29^{\prime} 54^{\prime \prime} \mathrm{W}$ & $40^{\circ} 57^{\prime} 34^{\prime \prime} \mathrm{N}$ & $790 \mathrm{~m}$ \\
\hline & & León-Virgen del camino & 2661 & $05^{\circ} 39^{\prime} 04^{\prime \prime} \mathrm{W}$ & $42^{\circ} 35^{\prime} 18^{\prime \prime} \mathrm{N}$ & $916 \mathrm{~m}$ \\
\hline & & Burgos-Villafría & 2331 & $03^{\circ} 37^{\prime} 17^{\prime \prime} \mathrm{W}$ & $42^{\circ} 21^{\prime} 22^{\prime \prime} \mathrm{N}$ & $891 \mathrm{~m}$ \\
\hline & & Soria & 2030 & $02^{\circ} 28^{\prime} 59^{\prime \prime} \mathrm{W}$ & $41^{\circ} 46^{\prime} 30^{\prime \prime} \mathrm{N}$ & $1082 \mathrm{~m}$ \\
\hline & & Segovia & 2465 & $04^{\circ} 07^{\prime} 35^{\prime \prime} \mathrm{W}$ & $40^{\circ} 56^{\prime} 43^{\prime \prime} \mathrm{N}$ & $1005 \mathrm{~m}$ \\
\hline
\end{tabular}


Tabla 2. Datos descriptivos de los observatorios meteorológicos de la zona de la cuenca del Ebro, Tajo, Guadiana, Guadalquivir, Levante y la franja costera catalana.

\begin{tabular}{|c|c|c|c|c|c|c|}
\hline \multicolumn{2}{|c|}{ ZONA } & NOMBRE & INDICATIVO & LONGITUD & LATITUD & ALTITUD \\
\hline \multirow{6}{*}{$\begin{array}{l}\text { Cuenca del } \\
\text { Ebro }\end{array}$} & \multirow{3}{*}{$\begin{array}{c}\text { Parte baja y } \\
\text { relativamente llana del } \\
\text { valle del Ebro }\end{array}$} & Huesca & $9901 x$ & $0^{\circ} 23^{\prime} 42^{\prime \prime} \mathrm{W}$ & $42^{\circ} 08^{\prime} 20^{\prime \prime} \mathrm{N}$ & $463 \mathrm{~m}$ \\
\hline & & Zaragoza aeropuerto & 9434 & $01^{\circ} 00^{\prime} 15^{\prime \prime} \mathrm{W}$ & $41^{\circ} 39^{\prime} 38^{\prime \prime} \mathrm{N}$ & $263 \mathrm{~m}$ \\
\hline & & Lérida & $9771 \mathrm{c}$ & $0^{\circ} 35^{\prime} 44^{\prime \prime} \mathrm{E}$ & $41^{\circ} 37^{\prime} 42^{\prime \prime} \mathrm{N}$ & $190 \mathrm{~m}$ \\
\hline & \multirow{3}{*}{$\begin{array}{c}\text { Zonas de otras partes } \\
\text { de la cuenca }\end{array}$} & Logroño-Agoncillo & 9170 & $02^{\circ} 19^{\prime} 52^{\prime \prime} \mathrm{W}$ & $42^{\circ} 27^{\prime} 08^{\prime \prime} \mathrm{N}$ & $353 \mathrm{~m}$ \\
\hline & & Haro automática & $9121 x$ & $02^{\circ} 51^{\prime} 17^{\prime \prime} \mathrm{W}$ & $42^{\circ} 34^{\prime} 31^{\prime \prime} \mathrm{N}$ & $465 \mathrm{~m}$ \\
\hline & & Pamplona-Noáin & $9263 d$ & $01^{\circ} 39^{\prime} 00^{\prime \prime} \mathrm{W}$ & $42^{\circ} 46^{\prime} 37^{\prime \prime} \mathrm{N}$ & $459 \mathrm{~m}$ \\
\hline \multirow{6}{*}{\multicolumn{2}{|c|}{ Franja costera catalana }} & Barcelona aeropuerto & 0076 & $02^{\circ} 04^{\prime} 12^{\prime \prime} \mathrm{E}$ & $41^{\circ} 17^{\prime} 34^{\prime \prime} \mathrm{N}$ & $4 \mathrm{~m}$ \\
\hline & & Gerona & 0370x & $02^{\circ} 47^{\prime} 01^{\prime \prime} \mathrm{E}$ & $41^{\circ} 58^{\prime} 02^{\prime \prime} \mathrm{N}$ & $90 \mathrm{~m}$ \\
\hline & & Reus aeropuerto & $0016 \mathrm{~A}$ & $01^{\circ} 10^{\prime} 44^{\prime \prime} \mathrm{E}$ & $41^{\circ} 08^{\prime} 59^{\prime \prime} \mathrm{N}$ & $71 \mathrm{~m}$ \\
\hline & & Tarragona & $0042 x$ & $01^{\circ} 14^{\prime} 53^{\prime \prime} \mathrm{E}$ & $41^{\circ} 07^{\prime} 14^{\prime \prime} \mathrm{N}$ & $42 m$ \\
\hline & & Tarragona, Fac. Geografía & $0042 y$ & $01^{\circ} 14^{\prime} 57^{\prime \prime} \mathrm{E}$ & $41^{\circ} 07^{\prime} 26^{\prime \prime} \mathrm{N}$ & $60 \mathrm{~m}$ \\
\hline & & Tortosa & $9881 a$ & $0^{\circ} 29^{\prime} 36 " \mathrm{E}$ & $40^{\circ} 49^{\prime} 13^{\prime \prime} \mathrm{N}$ & $47 \mathrm{~m}$ \\
\hline \multirow{8}{*}{\multicolumn{2}{|c|}{ Cuenca del Tajo }} & Guadalajara & $3168 c$ & $03^{\circ} 10^{\prime} 24^{\prime \prime} \mathrm{W}$ & $40^{\circ} 39^{\prime} 33^{\prime \prime} \mathrm{N}$ & $639 \mathrm{~m}$ \\
\hline & & Madrid-Barajas & 3129 & $03^{\circ} 33^{\prime} 20^{\prime \prime} \mathrm{W}$ & $40^{\circ} 28^{\prime} 20^{\prime \prime} \mathrm{N}$ & $609 \mathrm{~m}$ \\
\hline & & Getafe & 3200 & $03^{\circ} 43^{\prime} 20^{\prime \prime} \mathrm{W}$ & $40^{\circ} 17^{\prime} 58^{\prime \prime} \mathrm{N}$ & $620 \mathrm{~m}$ \\
\hline & & Navalmoral de la Mata & $3434 x$ & $05^{\circ} 54^{\prime} 37^{\prime \prime} \mathrm{W}$ & $39^{\circ} 56^{\prime} 45^{\prime \prime} \mathrm{N}$ & $269 \mathrm{~m}$ \\
\hline & & Toledo & $3260 b$ & $04^{\circ} 02^{\prime} 43^{\prime \prime} \mathrm{W}$ & $39^{\circ} 53^{\prime} 05^{\prime \prime} \mathrm{N}$ & $515 \mathrm{~m}$ \\
\hline & & Trujillo & $3463 x$ & $05^{\circ} 51^{\prime} 15^{\prime \prime} \mathrm{W}$ & $39^{\circ} 28^{\prime} 57^{\prime \prime} \mathrm{N}$ & $503 \mathrm{~m}$ \\
\hline & & Cáceres & $3469 a$ & $06^{\circ} 20^{\prime} 20^{\prime \prime} \mathrm{W}$ & $39^{\circ} 28^{\prime} 17^{\prime \prime} \mathrm{N}$ & $394 \mathrm{~m}$ \\
\hline & & Plasencia & $3519 x$ & $06^{\circ} 50^{\prime} 09^{\prime \prime} \mathrm{W}$ & $40^{\circ} 02^{\prime} 35^{\prime \prime} \mathrm{N}$ & $415 \mathrm{~m}$ \\
\hline \multirow{7}{*}{$\begin{array}{l}\text { Cuenca del } \\
\text { Guadiana }\end{array}$} & \multirow{4}{*}{$\begin{array}{c}\text { Parte alta situada en } \\
\text { la meseta Sur, } \\
\text { principalmente la } \\
\text { Mancha }\end{array}$} & Alcázar de San Juan & 4064 & $03^{\circ} 12^{\prime} 43^{\prime \prime} \mathrm{W}$ & $39^{\circ} 23^{\prime} 18^{\prime \prime} \mathrm{N}$ & $664 \mathrm{~m}$ \\
\hline & & Almagro & $4116 \mathrm{i}$ & $03^{\circ} 44^{\prime} 25^{\prime \prime} \mathrm{W}$ & $38^{\circ} 57^{\prime} 03^{\prime \prime} \mathrm{N}$ & $622 \mathrm{~m}$ \\
\hline & & Ciudad Real & 4121 & $03^{\circ} 55^{\prime} 13^{\prime \prime} \mathrm{W}$ & $38^{\circ} 59^{\prime} 21^{\prime \prime} \mathrm{N}$ & $628 \mathrm{~m}$ \\
\hline & & Hinojosa del Duque & $4267 x$ & $05^{\circ} 07^{\prime} 45^{\prime \prime} \mathrm{W}$ & $38^{\circ} 29^{\prime} 45^{\prime \prime} \mathrm{N}$ & $545 \mathrm{~m}$ \\
\hline & \multirow{3}{*}{$\begin{array}{c}\text { Parte baja y } \\
\text { relativamente llana de } \\
\text { la cuenca }\end{array}$} & Talavera la Real & 4452 & $06^{\circ} 48^{\prime} 50^{\prime \prime} \mathrm{W}$ & $38^{\circ} 52^{\prime} 59^{\prime \prime} \mathrm{N}$ & $185 \mathrm{~m}$ \\
\hline & & Badajoz CMT & $4478 x$ & $07^{\circ} 00^{\prime} 29^{\prime \prime} \mathrm{W}$ & $38^{\circ} 53^{\prime} 15^{\prime \prime} \mathrm{N}$ & $175 \mathrm{~m}$ \\
\hline & & Mérida & $4410 x$ & $06^{\circ} 23^{\prime} 08^{\prime \prime} \mathrm{W}$ & $38^{\circ} 54^{\prime} 57^{\prime \prime} \mathrm{N}$ & $227 \mathrm{~m}$ \\
\hline \multirow{6}{*}{$\begin{array}{l}\text { Cuenca del } \\
\text { Guadalquivir }\end{array}$} & \multirow{4}{*}{$\begin{array}{l}\text { Parte baja y } \\
\text { relativamente llana de } \\
\text { la cuenca }\end{array}$} & Sevilla-San Pablo & 5783 & $05^{\circ} 52^{\prime} 45^{\prime \prime} \mathrm{W}$ & $37^{\circ} 25^{\prime} 00^{\prime \prime} \mathrm{N}$ & $34 \mathrm{~m}$ \\
\hline & & Écija & $5641 x$ & $05^{\circ} 05^{\prime} 07^{\prime \prime} \mathrm{W}$ & $37^{\circ} 30^{\prime} 58^{\prime \prime} \mathrm{N}$ & $130 \mathrm{~m}$ \\
\hline & & Córdoba aeropuerto & 5402 & $04^{\circ} 50^{\prime} 46^{\prime \prime} \mathrm{W}$ & $37^{\circ} 50^{\prime} 39^{\prime \prime} \mathrm{N}$ & $90 \mathrm{~m}$ \\
\hline & & Morón de la Frontera & 5796 & $05^{\circ} 36^{\prime} 43^{\prime \prime} \mathrm{W}$ & $37^{\circ} 09^{\prime} 49^{\prime \prime} \mathrm{N}$ & $87 \mathrm{~m}$ \\
\hline & \multirow{2}{*}{$\begin{array}{c}\text { Parte media de la } \\
\text { cuenca }\end{array}$} & Granada base aérea & 5514 & $03^{\circ} 37^{\prime} 59^{\prime \prime} \mathrm{W}$ & $37^{\circ} 08^{\prime} 10^{\prime \prime} \mathrm{N}$ & $690 \mathrm{~m}$ \\
\hline & & Linares & $5279 x$ & $03^{\circ} 37^{\prime} 46^{\prime \prime} \mathrm{W}$ & $38^{\circ} 09^{\prime} 04^{\prime \prime} \mathrm{N}$ & $515 \mathrm{~m}$ \\
\hline \multirow{8}{*}{ Levante } & \multirow{5}{*}{ Huerta levantina } & Castellón & $8500 a$ & $00^{\circ} 04^{\prime} 19^{\prime \prime} \mathrm{W}$ & $39^{\circ} 57^{\prime} 26^{\prime \prime} \mathrm{N}$ & $43 \mathrm{~m}$ \\
\hline & & Valencia & 8416 & $00^{\circ} 21^{\prime} 59^{\prime \prime} \mathrm{W}$ & $39^{\circ} 28^{\prime} 50^{\prime \prime} \mathrm{N}$ & $11 \mathrm{~m}$ \\
\hline & & Valencia-Manises & $8414 a$ & $00^{\circ} 28^{\prime} 28^{\prime \prime} \mathrm{W}$ & $39^{\circ} 29^{\prime} 07^{\prime \prime} \mathrm{N}$ & $69 \mathrm{~m}$ \\
\hline & & Alicante & 8025 & $00^{\circ} 29^{\prime} 39^{\prime \prime} \mathrm{W}$ & $38^{\circ} 22^{\prime} 21^{\prime \prime} \mathrm{N}$ & $81 \mathrm{~m}$ \\
\hline & & Alicante-El Altet & 8019 & $00^{\circ} 34^{\prime} 15^{\prime \prime} \mathrm{W}$ & $38^{\circ} 16^{\prime} 58^{\prime \prime} \mathrm{N}$ & $43 \mathrm{~m}$ \\
\hline & \multirow{3}{*}{ Huerta murciana } & Base aérea de Alcantarilla & 7228 & $01^{\circ} 13^{\prime} 43^{\prime \prime} \mathrm{W}$ & $37^{\circ} 57^{\prime} 28^{\prime \prime} \mathrm{N}$ & $75 \mathrm{~m}$ \\
\hline & & Base aérea de San Javier & 7031 & $00^{\circ} 48^{\prime} 12^{\prime \prime} \mathrm{W}$ & $37^{\circ} 47^{\prime} 20^{\prime \prime} \mathrm{N}$ & $4 \mathrm{~m}$ \\
\hline & & Totana & $7218 x$ & $01^{\circ} 30^{\prime} 08^{\prime \prime} \mathrm{W}$ & $37^{\circ} 45^{\prime} 43^{\prime \prime} \mathrm{N}$ & $225 \mathrm{~m}$ \\
\hline
\end{tabular}


Tabla 3. Datos descriptivos de los observatorios meteorológicos de la costa Sur y las zonas altas del interior peninsular.

\begin{tabular}{|c|c|c|c|c|c|}
\hline ZONA & NOMBRE & INDICATIVO & LONGITUD & LATITUD & ALTITUD \\
\hline Costa Sur & Málaga aeropuerto & $6155 a$ & $04^{\circ} 28^{\prime} 56^{\prime \prime} \mathrm{W}$ & $36^{\circ} 39^{\prime} 58^{\prime \prime} \mathrm{N}$ & $5 \mathrm{~m}$ \\
\hline \multirow{6}{*}{$\begin{array}{c}\text { Zonas altas del interior } \\
\text { peninsular }\end{array}$} & Soria & 2030 & $02^{\circ} 28^{\prime} 59^{\prime \prime} \mathrm{W}$ & $41^{\circ} 46^{\prime} 30^{\prime \prime} \mathrm{N}$ & $1082 \mathrm{~m}$ \\
\hline & Daroca & 9390 & $01^{\circ} 24^{\prime} 36^{\prime \prime} \mathrm{W}$ & $41^{\circ} 06^{\prime} 52^{\prime \prime} \mathrm{N}$ & $779 \mathrm{~m}$ \\
\hline & Molina de Aragón & 3013 & $01^{\circ} 52^{\prime} 44^{\prime \prime} \mathrm{W}$ & $40^{\circ} 50^{\prime} 30^{\prime \prime} \mathrm{N}$ & $1056 \mathrm{~m}$ \\
\hline & Teruel & $8368 u$ & $01^{\circ} 07^{\prime} 27^{\prime \prime} \mathrm{W}$ & $40^{\circ} 21^{\prime} 02^{\prime \prime} \mathrm{N}$ & $900 \mathrm{~m}$ \\
\hline & Cuenca & 8096 & $02^{\circ} 07^{\prime} 55^{\prime \prime} \mathrm{W}$ & $40^{\circ} 04^{\prime} 02^{\prime \prime} \mathrm{N}$ & $945 \mathrm{~m}$ \\
\hline & Albacete Los Llanos & 8175 & $01^{\circ} 51^{\prime} 45^{\prime \prime} \mathrm{W}$ & $38^{\circ} 57^{\prime} 06^{\prime \prime} \mathrm{N}$ & $702 \mathrm{~m}$ \\
\hline
\end{tabular}




\section{Horas frío}

Se presenta en primer lugar el número de horas frío contadas a partir de los datos horarios de los observatorios elegidos en cada una de las zonas en las que se ha dividido la Península. Luego se proporciona la comparación de las horas frío contadas a partir de datos horarios y las horas frío obtenidas mediante la fórmula de Crossa-Raynaud.

\subsection{Horas frío (umbral 7ํㅡ) contadas a partir de datos horarios}

\subsubsection{Zonas norte y noroeste: a) costa cantábrica}

Observatorios: San Sebastián-Igueldo (1024e), Bilbao-Sondica (1082), Santander CMT (1111), Santander-Parayas (1109), Gijón Musel (1208h), Oviedo (1249l) y Vitoria (90910). Periodo: 2002 a 2011.

Tabla 4. Comparación de horas frío anuales contadas a partir de datos horarios en los siete observatorios de la zona norte y noroeste: costa cantábrica.

\begin{tabular}{|cccccccc|}
\hline & $\begin{array}{c}\text { S.Sebastián } \\
1024 \mathrm{e}\end{array}$ & $\begin{array}{c}\text { Bilbao } \\
\text { Sondica } \\
\mathbf{1 0 8 2}\end{array}$ & $\begin{array}{c}\text { Santander } \\
\text { CMT 1111 }\end{array}$ & $\begin{array}{c}\text { Santander } \\
\text { Parayas } \\
\mathbf{1 1 0 9}\end{array}$ & $\begin{array}{c}\text { Gijón } \\
\text { Musel } \\
\mathbf{1 2 0 8 h}\end{array}$ & $\begin{array}{c}\text { Oviedo } \\
\mathbf{1 2 4 9}\end{array}$ & $\begin{array}{c}\text { Vitoria } \\
\mathbf{9 0 9 1 0}\end{array}$ \\
\hline $\mathbf{A n ̃ o}$ & HF & HF & HF & HF & HF & HF & HF \\
\hline $\mathbf{2 0 0 2}$ & 304 & 405 & 47 & 285 & 98 & 812 & 1979 \\
\hline $\mathbf{2 0 0 3}$ & 863 & 704 & 346 & 578 & 323 & 1157 & 2099 \\
\hline $\mathbf{2 0 0 4}$ & 1218 & 956 & 387 & 712 & 393 & 1449 & 2696 \\
\hline $\mathbf{2 0 0 5}$ & 1687 & 1336 & 750 & 1070 & 622 & 1766 & 2866 \\
\hline $\mathbf{2 0 0 6}$ & 1196 & 968 & 461 & 828 & 480 & 1341 & 2250 \\
\hline $\mathbf{2 0 0 7}$ & 867 & 894 & 358 & 876 & 300 & 1211 & 2354 \\
\hline $\mathbf{2 0 0 8}$ & 773 & 591 & 197 & 565 & 316 & 1188 & 2375 \\
\hline $\mathbf{2 0 0 9}$ & 1044 & 949 & 476 & 846 & 533 & 1498 & 2366 \\
\hline $\mathbf{2 0 1 0}$ & 1423 & 1196 & 825 & 974 & 737 & 1629 & 2877 \\
\hline $\mathbf{2 0 1 1}$ & 634 & 652 & 261 & 612 & 222 & 962 & 1922 \\
\hline promedio & 1001 & 865 & 411 & 735 & 402 & 1301 & 2378 \\
\hline
\end{tabular}




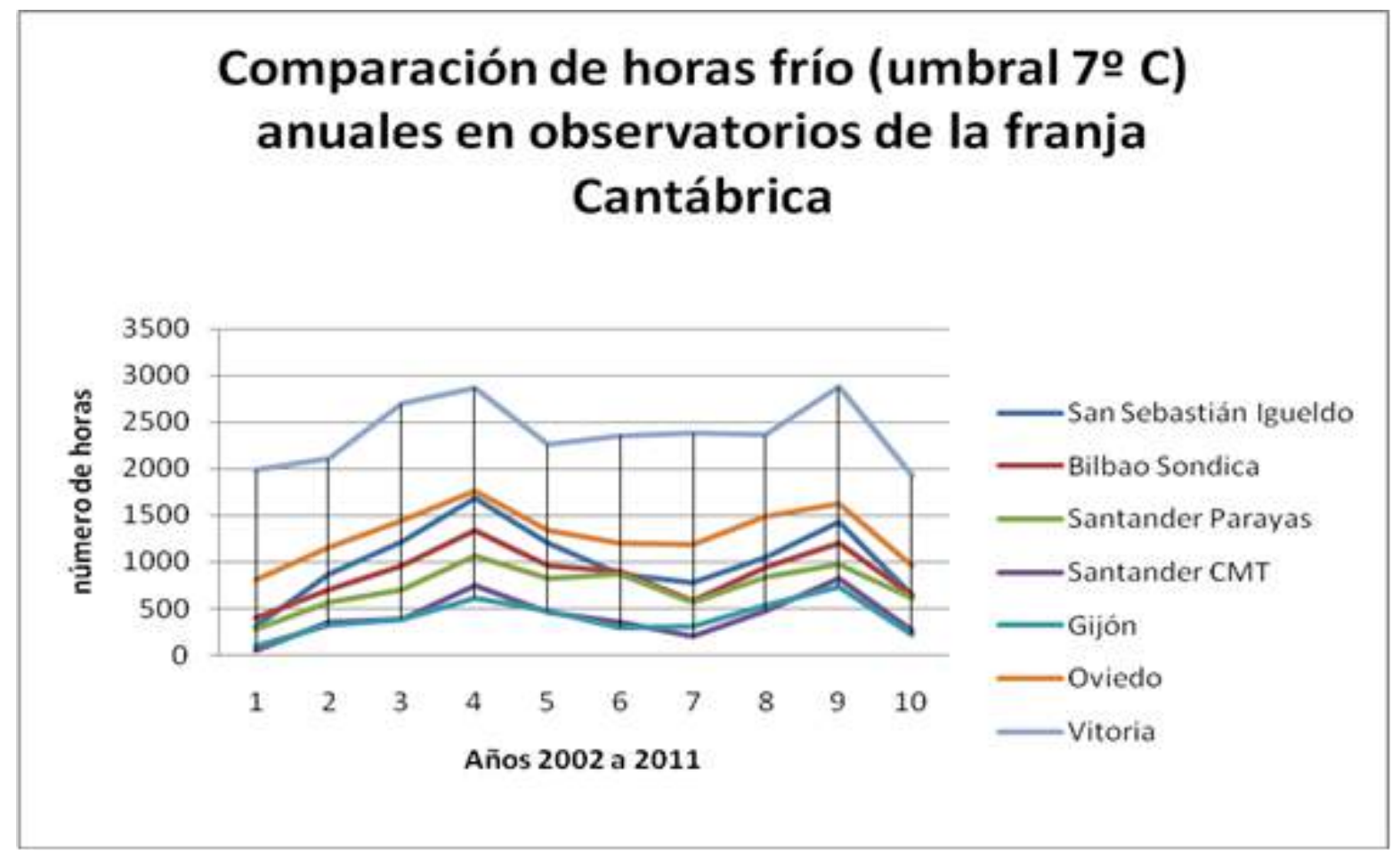

Gráfico 1. Comparación de horas frío (umbral 7ํㅡ) anuales en observatorios de la franja cantábrica.

Los datos son coherentes entre ellos, y muestran que en ciudades costeras con el observatorio al borde del mar se dan pocas horas frío debido al efecto regulador del agua del mar y a la isla de calor que proporciona la ciudad. Un poco hacia el interior, sin embargo, el número de horas frío sube rápidamente hasta situarse en torno a 800 anuales, que es lo que puede considerarse representativo de la franja costera fuera del borde del agua. En el interior, más lejos de la costa, se sobrepasa tal valor, no excesivamente en valles lluviosos de poca altitud (Oviedo tiene 1300 horas anuales), pero notablemente en zonas con una cierta altitud aunque estén cerca de la costa (Vitoria sobrepasa las 2300 horas).

\section{Horas frío contadas en datos horarios en cada uno de los observatorios}

San Sebastián Igueldo. Tiene en promedio unas 1000 horas frío (umbral $7^{\circ} \mathrm{C}$ ) al año, oscilando entre las 304 horas de 2002 y las 1687 de 2005. La variabilidad interanual, por tanto, es muy amplia; la diferencia entre el valor más alto y más bajo, en tan solo 10 años, sobrepasa el promedio.

De junio a septiembre, ambos incluidos, está libre de horas frío. Mayo y octubre tienen pocas y no todos los años. Abril una hora diaria de promedio y noviembre, dos. Enero, febrero y 
diciembre pasan de las 200 horas mensuales. Al igual que sucede con los valores anuales, la variabilidad de los distintos meses entre unos años y otros es muy marcada. Enero de 2002 tuvo 55 horas frío mientras que en enero de 2010 se dieron 358. Marzo de 2003 tuvo 7 horas mientras que marzo de 2004 alcanzó las 284 horas frío. En noviembre de 2002 no hubo horas frío en San Sebastián Igueldo, pero en noviembre de 2005 se dieron 155 horas frío.

Tabla 5. Horas frío contadas en datos horarios en el observatorio de San Sebastián Igueldo.

\begin{tabular}{cccccccccccccc}
\hline & ene & feb & mar & abril & may & jun & jul & ago & sept & oct & nov & dic & anual \\
\hline $\mathbf{2 0 0 2}$ & 55 & 94 & 58 & 50 & 4 & 0 & 0 & 0 & 0 & 0 & 0 & 43 & 304 \\
\hline $\mathbf{2 0 0 3}$ & 315 & 298 & 7 & 33 & 0 & 0 & 0 & 0 & 0 & 55 & 34 & 121 & 863 \\
\hline $\mathbf{2 0 0 4}$ & 206 & 339 & 284 & 55 & 35 & 0 & 0 & 0 & 0 & 0 & 114 & 185 & 1218 \\
\hline $\mathbf{2 0 0 5}$ & 253 & 450 & 271 & 82 & 0 & 0 & 0 & 0 & 0 & 0 & 155 & 476 & 1687 \\
\hline $\mathbf{2 0 0 6}$ & 301 & 473 & 93 & 26 & 0 & 0 & 0 & 0 & 0 & 0 & 15 & 288 & 1196 \\
\hline $\mathbf{2 0 0 7}$ & 230 & 80 & 166 & 26 & 0 & 0 & 0 & 0 & 0 & 5 & 126 & 234 & 867 \\
\hline $\mathbf{2 0 0 8}$ & 97 & 36 & 190 & 26 & 1 & 0 & 0 & 0 & 0 & 23 & 119 & 281 & 773 \\
\hline $\mathbf{2 0 0 9}$ & 318 & 280 & 121 & 14 & 0 & 0 & 0 & 0 & 0 & 32 & 10 & 269 & 1044 \\
\hline $\mathbf{2 0 1 0}$ & 358 & 268 & 236 & 20 & 8 & 0 & 0 & 0 & 0 & 11 & 143 & 379 & 1423 \\
\hline $\mathbf{2 0 1 1}$ & 333 & 107 & 104 & 0 & 0 & 0 & 0 & 0 & 0 & 3 & 4 & 83 & 634 \\
\hline Prom. & 247 & 243 & 153 & 33 & 5 & 0 & 0 & 0 & 0 & 13 & 72 & 236 & 1001 \\
\hline
\end{tabular}

Bilbao Sondica. Tiene en promedio más de 800 horas frío (umbral $7^{\circ} \mathrm{C}$ ) al año, oscilando entre las 405 horas de 2002 y las 1327 de 2005. La variabilidad interanual, por tanto, es muy amplia; la diferencia entre el valor más alto y más bajo, en tan solo 10 años, sobrepasa el promedio.

Junio, julio y agosto están libres de horas frío. En septiembre se dieron horas frío en un solo año de los 10 (septiembre de 2002, en una pequeña ola de frío acaecida en los últimos días del mes en esa zona). Octubre y mayo no llegan a la media hora diaria en promedio y no tienen horas frío todos los años. Abril tiene poco más de 1 hora diaria, y noviembre dos horas. Marzo tiene más de 100 horas mensuales. Enero, febrero y diciembre están cerca de las 200 horas frío; enero y febrero las sobrepasan, diciembre no llega. La variación entre unos años y otros en los distintos meses es muy grande. Por ejemplo en febrero de 2008 hubo 42 horas, mientras que se dieron 400 horas en febrero de 2005; diciembre tuvo 4 horas en 2002 y 309 en 2005. 
Tabla 6. Horas frío contadas en datos horarios en el observatorio de Bilbao Sondica.

\begin{tabular}{cccccccccccccc}
\hline & ene & feb & mar & abril & may & jun & jul & ago & sept & oct & nov & dic & anual \\
\hline $\mathbf{2 0 0 2}$ & 104 & 73 & 91 & 90 & 19 & 0 & 0 & 0 & 10 & 5 & 9 & 4 & 405 \\
$\mathbf{2 0 0 3}$ & 267 & 200 & 52 & 25 & 7 & 0 & 0 & 0 & 0 & 15 & 51 & 87 & 704 \\
$\mathbf{2 0 0 4}$ & 126 & 344 & 238 & 69 & 12 & 0 & 0 & 0 & 0 & 0 & 78 & 89 & 956 \\
$\mathbf{2 0 0 5}$ & 234 & 400 & 231 & 51 & 1 & 0 & 0 & 0 & 0 & 0 & 101 & 309 & 1327 \\
$\mathbf{2 0 0 6}$ & 228 & 349 & 84 & 48 & 7 & 0 & 0 & 0 & 0 & 0 & 20 & 232 & 968 \\
$\mathbf{2 0 0 7}$ & 216 & 57 & 163 & 39 & 0 & 0 & 0 & 0 & 0 & 23 & 152 & 244 & 894 \\
$\mathbf{2 0 0 8}$ & 122 & 42 & 61 & 30 & 1 & 0 & 0 & 0 & 0 & 37 & 67 & 231 & 591 \\
$\mathbf{2 0 0 9}$ & 252 & 234 & 159 & 15 & 5 & 0 & 0 & 0 & 0 & 44 & 8 & 232 & 949 \\
$\mathbf{2 0 1 0}$ & 280 & 236 & 181 & 34 & 10 & 0 & 0 & 0 & 0 & 33 & 114 & 308 & 1196 \\
$\mathbf{2 0 1 1}$ & 280 & 138 & 83 & 9 & 2 & 0 & 0 & 0 & 0 & 1 & 28 & 111 & 652 \\
Prom. & 211 & 207 & 134 & 41 & 6 & 0 & 0 & 0 & 1 & 16 & 63 & 185 & 864 \\
\hline
\end{tabular}

Santander. Tiene unas 400 horas frío (umbral $7^{\circ} \mathrm{C}$ ) al año, oscilando entre las 47 horas de 2002 y las 802 de 2010. La variabilidad interanual, por tanto, es muy amplia; la diferencia entre el valor más alto y más bajo, en tan solo 10 años, sobrepasa al promedio.

Comparando el número de horas frío de Santander con el de Santander Parayas se ve el efecto de isla de calor que proporciona la ciudad sumado al efecto regulador del agua. En la ciudad de Santander hay muchas menos horas frío que en el aeropuerto. Lógicamente, Santander Parayas proporciona un dato mucho más ajustado a lo que sucede en el entorno si tal dato se precisa para una planificación agrícola, y Santander proporciona un dato mejor si lo que se plantea es tomar medidas para un ahorro energético dentro de la ciudad.

Tabla 7. Horas frío contadas en datos horarios en el observatorio de Santander.

\begin{tabular}{cccccccccccccc}
\hline & ene & feb & mar & abril & may & jun & jul & ago & sept & oct & nov & dic & anual \\
\hline $\mathbf{2 0 0 2}$ & 5 & 0 & 21 & 15 & 0 & 0 & 0 & 0 & 0 & 4 & 0 & 2 & 47 \\
$\mathbf{2 0 0 3}$ & 175 & 122 & 14 & 0 & 0 & 0 & 0 & 0 & 0 & 9 & 0 & 21 & 341 \\
$\mathbf{2 0 0 4}$ & 28 & 185 & 140 & 10 & 0 & 0 & 0 & 0 & 0 & 3 & 5 & 16 & 387 \\
$\mathbf{2 0 0 5}$ & 100 & 230 & 179 & 3 & 0 & 0 & 0 & 0 & 0 & 0 & 43 & 194 & 749 \\
$\mathbf{2 0 0 6}$ & 135 & 217 & 17 & 5 & 0 & 0 & 0 & 0 & 0 & 0 & 0 & 86 & 460 \\
$\mathbf{2 0 0 7}$ & 124 & 11 & 58 & 10 & 0 & 0 & 0 & 0 & 0 & 0 & 44 & 109 & 356 \\
$\mathbf{2 0 0 8}$ & 30 & 22 & 11 & 0 & 0 & 0 & 0 & 0 & 0 & 0 & 32 & 102 & 197 \\
$\mathbf{2 0 0 9}$ & 169 & 124 & 31 & 0 & 0 & 0 & 0 & 0 & 0 & 0 & 0 & 152 & 476 \\
$\mathbf{2 0 1 0}$ & 208 & 188 & 96 & 1 & 5 & 0 & 0 & 0 & 0 & 0 & 68 & 236 & 802 \\
$\mathbf{2 0 1 1}$ & 187 & 15 & 17 & 0 & 0 & 0 & 0 & 0 & 0 & 0 & 0 & 40 & 259 \\
Prom. & 116 & 111 & 58 & 4 & 1 & 0 & 0 & 0 & 0 & 2 & 19 & 96 & 407 \\
\hline
\end{tabular}

De junio a septiembre está libre de horas frío. abril, mayo y octubre tienen muy pocas horas frío y no todos los años; mayo sólo un año. Noviembre, media hora diaria de promedio. Marzo dos horas diarias de promedio. Enero, febrero y diciembre poco más de 3 horas diarias de 
promedio. La variación es grande entre los meses de unos años y otros. Por ejemplo, febrero de 2002 no tuvo horas frío, mientras que febrero de 2005, 230 horas; en diciembre de 2002 hubo 2 horas y en 2010, 236. En enero de 2002 hubo 5 horas y en enero de 2010, 208.

Santander-Parayas. Tiene en promedio en torno a las 700 horas frío (umbral $7^{\circ} \mathrm{C}$ ) al año, oscilando entre las 285 horas de 2002 y las 1070 de 2005. La variabilidad interanual, por tanto, es muy amplia; la diferencia entre el valor más alto y más bajo, en tan solo 10 años, sobrepasa el promedio.

De junio a septiembre, ambos incluidos, no se dan horas frío. Mayo y octubre tienen pocas y no todos los años. Abril no llega a una hora diaria en promedio y noviembre no llega a dos. Enero, febrero se acercan a las 200 y diciembre tiene 150 horas mensuales. La variación es grande entre los meses de unos años y otros. Por ejemplo en febrero de 2002 hubo 13 horas, mientras que en febrero de 2004 se dieron 298; diciembre tuvo 2 horas en 2002 y 264 en 2010; noviembre tuvo 5 horas en 2009 y 132 en 2007.

Tabla 8. Horas frío contadas en datos horarios en el observatorio de Santander-Parayas.

\begin{tabular}{cccccccccccccc}
\hline & ene & feb & mar & abril & may & jun & jul & ago & sept & oct & nov & dic & anual \\
\hline $\mathbf{2 0 0 2}$ & 132 & 13 & 82 & 45 & 0 & 0 & 0 & 0 & 0 & 0 & 11 & 2 & 285 \\
$\mathbf{2 0 0 3}$ & 231 & 174 & 49 & 23 & 0 & 0 & 0 & 0 & 0 & 10 & 40 & 51 & 578 \\
$\mathbf{2 0 0 4}$ & 81 & 298 & 167 & 43 & 4 & 0 & 0 & 0 & 0 & 0 & 59 & 60 & 712 \\
\hline $\mathbf{2 0 0 5}$ & 220 & 310 & 205 & 12 & 0 & 0 & 0 & 0 & 0 & 0 & 83 & 240 & 1070 \\
$\mathbf{2 0 0 6}$ & 214 & 283 & 73 & 35 & 8 & 0 & 0 & 0 & 0 & 0 & 20 & 195 & 828 \\
\hline $\mathbf{2 0 0 7}$ & 185 & 43 & 120 & 22 & 3 & 0 & 0 & 0 & 0 & 25 & 132 & 244 & 774 \\
$\mathbf{2 0 0 8}$ & 137 & 98 & 41 & 24 & 6 & 0 & 0 & 0 & 0 & 18 & 44 & 197 & 565 \\
\hline $\mathbf{2 0 0 9}$ & 198 & 257 & 154 & 30 & 2 & 0 & 0 & 0 & 0 & 27 & 5 & 173 & 846 \\
$\mathbf{2 0 1 0}$ & 215 & 241 & 123 & 14 & 1 & 0 & 0 & 0 & 0 & 13 & 72 & 264 & 943 \\
\hline $\mathbf{2 0 1 1}$ & 236 & 87 & 71 & 4 & 0 & 0 & 0 & 0 & 0 & 12 & 47 & 65 & 522 \\
Prom. & 185 & 180 & 109 & 25 & 2 & 0 & 0 & 0 & 0 & 11 & 51 & 149 & 712 \\
\hline
\end{tabular}

Gijón. Tiene en promedio 400 horas frío (umbral $7^{\circ} \mathrm{C}$ ) al año, oscilando entre las 98 de 2002 y las 737 de 2010. La variabilidad interanual, por tanto, es muy amplia; la diferencia entre el valor más alto y más bajo, en tan solo 10 años, sobrepasa al promedio.

Comparando el número de horas frío de Gijón Musel con el de Santander se ve que son muy similares, en ambos se percibe el efecto de isla de calor que proporciona la ciudad y la proximidad, suavizadora de las temperaturas, del mar. Al igual que para Santander, ese número de horas frío es apropiado para cálculos que tengan que ver con el ahorro energético dentro de 
la ciudad, pero poco apropiado para la planificación agrícola de la zona fuera de la ciudad donde el número de horas frío es más elevado.

De mayo a octubre está libre de horas frío. Abril y noviembre no llegan a 1 hora diaria de promedio, abril está lejos y noviembre se acerca; marzo no llega a 2. Enero, febrero y diciembre tienen en torno a las 100 horas, es decir poco más de tres horas diarias en promedio. La variación es grande entre los meses de unos años y otros. Por ejemplo en febrero de 2007 tuvo 16 horas frío, y febrero de 2010, 196; diciembre tuvo 5 horas en 2002 y 206 en 2010.

Tabla 9. Horas frío contadas en datos horarios en el observatorio de Gijón.

\begin{tabular}{cccccccccccccc}
\hline & ene & feb & mar & abril & may & jun & jul & ago & sept & oct & nov & dic & anual \\
\hline $\mathbf{2 0 0 2}$ & 22 & 24 & 34 & 8 & 0 & 0 & 0 & 0 & 0 & 0 & 5 & 5 & 98 \\
$\mathbf{2 0 0 3}$ & 179 & 93 & 0 & 2 & 0 & 0 & 0 & 0 & 0 & 0 & 3 & 46 & 323 \\
$\mathbf{2 0 0 4}$ & 80 & 157 & 96 & 29 & 0 & 0 & 0 & 0 & 0 & 0 & 7 & 24 & 393 \\
\hline $\mathbf{2 0 0 5}$ & 100 & 189 & 140 & 11 & 0 & 0 & 0 & 0 & 0 & 0 & 40 & 142 & 622 \\
$\mathbf{2 0 0 6}$ & 164 & 179 & 30 & 4 & 0 & 0 & 0 & 0 & 0 & 0 & 1 & 89 & 467 \\
$\mathbf{2 0 0 7}$ & 90 & 16 & 23 & 6 & 0 & 0 & 0 & 0 & 0 & 0 & 30 & 135 & 300 \\
$\mathbf{2 0 0 8}$ & 51 & 47 & 37 & 4 & 0 & 0 & 0 & 0 & 0 & 0 & 43 & 134 & 316 \\
$\mathbf{2 0 0 9}$ & 176 & 128 & 46 & 7 & 0 & 0 & 0 & 0 & 0 & 0 & 1 & 175 & 533 \\
$\mathbf{2 0 1 0}$ & 174 & 196 & 87 & 2 & 0 & 0 & 0 & 0 & 0 & 0 & 72 & 206 & 737 \\
\hline $\mathbf{2 0 1 1}$ & 105 & 52 & 22 & 0 & 0 & 0 & 0 & 0 & 0 & 0 & 0 & 43 & 222 \\
Prom. & 114 & 108 & 52 & 7 & 0 & 0 & 0 & 0 & 0 & 0 & 20 & 100 & 401 \\
\hline
\end{tabular}

Oviedo. Tiene en promedio de 1300 horas frío (umbral $7^{\circ} \mathrm{C}$ ) al año, oscilando entre las 812 de 2002 y las 1766 de 2005. La variabilidad interanual es elevada.

Tabla 10. Horas frío contadas en datos horarios en el observatorio de Oviedo.

\begin{tabular}{cccccccccccccc}
\hline & ene & feb & mar & abril & may & jun & jul & ago & sept & oct & nov & dic & anual \\
\hline $\mathbf{2 0 0 2}$ & 171 & 147 & 131 & 153 & 25 & 0 & 0 & 0 & 3 & 10 & 65 & 107 & 812 \\
$\mathbf{2 0 0 3}$ & 384 & 251 & 52 & 61 & 10 & 0 & 0 & 0 & 0 & 72 & 74 & 253 & 1157 \\
$\mathbf{2 0 0 4}$ & 215 & 356 & 281 & 127 & 54 & 0 & 0 & 0 & 0 & 5 & 129 & 282 & 1449 \\
$\mathbf{2 0 0 5}$ & 306 & 497 & 244 & 98 & 1 & 0 & 0 & 0 & 0 & 2 & 197 & 421 & 1766 \\
$\mathbf{2 0 0 6}$ & 406 & 448 & 84 & 54 & 8 & 2 & 0 & 0 & 0 & 0 & 27 & 312 & 1341 \\
\hline $\mathbf{2 0 0 7}$ & 266 & 117 & 216 & 64 & 8 & 0 & 0 & 0 & 8 & 14 & 220 & 298 & 1211 \\
$\mathbf{2 0 0 8}$ & 174 & 117 & 186 & 72 & 9 & 0 & 0 & 0 & 0 & 68 & 211 & 351 & 1188 \\
\hline $\mathbf{2 0 0 9}$ & 338 & 314 & 236 & 140 & 6 & 0 & 0 & 0 & 0 & 31 & 73 & 360 & 1498 \\
$\mathbf{2 0 1 0}$ & 388 & 323 & 231 & 66 & 62 & 0 & 0 & 0 & 0 & 33 & 162 & 364 & 1629 \\
$\mathbf{2 0 1 1}$ & 326 & 194 & 143 & 12 & 0 & 0 & 0 & 0 & 0 & 9 & 44 & 234 & 962 \\
Prom. & 297 & 276 & 180 & 85 & 18 & 0 & 0 & 0 & 1 & 24 & 120 & 298 & 1301 \\
\hline
\end{tabular}


Junio, julio y agosto están libres de horas frío. Septiembre tiene muy pocas y pocos años. Mayo tiene una media hora diaria en promedio. Octubre no llega a la hora diaria de promedio. Abril no llega a las 100 horas, noviembre las sobrepasa y marzo no llega a las 200. Enero, febrero y diciembre se acercan a las 300 horas frío. La variación es grande entre los meses de unos años y otros. Por ejemplo en febrero de 2007 y 2008 tuvo 117 horas frío, y febrero de 2005, 497; noviembre de 2011 tuvo 44 horas frío, mientras que noviembre de 2007 tuvo 220 horas frío.

Vitoria. Tiene en promedio de 2400 horas frío (umbral $7^{\circ} \mathrm{C}$ ) al año, oscilando entre las 1922 horas de 2011 y las 2877 de 2010. La variabilidad interanual es elevada.

Puede haber horas frío (de umbral $7^{\circ} \mathrm{C}$ ) en todos los meses del año. No tiene meses libres de horas frío, si bien, junio, julio y agosto tienen muy pocas horas frío. Septiembre no llega a una hora diaria en promedio, y mayo sobrepasa las dos horas diarias; octubre tiene tres en promedio. Abril se acerca a las 200 horas mensuales, noviembre tiene 250, marzo sobrepasa las 300 , febrero las 400 , y enero y diciembre están en torno a las 500 horas frío. La variación es grande entre los meses de unos años y otros. Por ejemplo en febrero de 2007 tuvo 248 horas frío, y febrero de 2005, 606; diciembre de 2002 tuvo 281 horas frío, mientras que diciembre de 2010 tuvo 596 horas frío.

Tabla 11. . Horas frío contadas en datos horarios en el observatorio de Vitoria.

\begin{tabular}{cccccccccccccc}
\hline & ene & feb & mar & abril & may & jun & jul & ago & sept & oct & nov & dic & anual \\
\hline $\mathbf{2 0 0 2}$ & 444 & 344 & 247 & 269 & 106 & 15 & 13 & 4 & 56 & 60 & 140 & 281 & 1979 \\
$\mathbf{2 0 0 3}$ & 478 & 456 & 178 & 171 & 77 & 0 & 0 & 0 & 4 & 113 & 210 & 412 & 2099 \\
$\mathbf{2 0 0 4}$ & 426 & 536 & 458 & 275 & 93 & 0 & 9 & 0 & 8 & 16 & 375 & 500 & 2696 \\
$\mathbf{2 0 0 5}$ & 561 & 606 & 382 & 209 & 25 & 14 & 1 & 3 & 51 & 58 & 370 & 586 & 2866 \\
$\mathbf{2 0 0 6}$ & 616 & 532 & 209 & 148 & 49 & 22 & 0 & 1 & 0 & 12 & 122 & 539 & 2250 \\
$\mathbf{2 0 0 7}$ & 481 & 248 & 406 & 144 & 62 & 8 & 3 & 7 & 29 & 95 & 365 & 506 & 2354 \\
$\mathbf{2 0 0 8}$ & 389 & 286 & 364 & 183 & 51 & 10 & 3 & 0 & 42 & 189 & 306 & 552 & 2375 \\
$\mathbf{2 0 0 9}$ & 537 & 466 & 408 & 213 & 41 & 3 & 0 & 0 & 2 & 78 & 159 & 459 & 2366 \\
$\mathbf{2 0 1 0}$ & 601 & 438 & 374 & 153 & 180 & 11 & 1 & 1 & 47 & 143 & 332 & 596 & 2877 \\
$\mathbf{2 0 1 1}$ & 485 & 388 & 270 & 82 & 33 & 4 & 4 & 3 & 4 & 122 & 126 & 401 & 1922 \\
Prom. & 502 & 430 & 330 & 185 & 72 & 9 & 3 & 2 & 24 & 89 & 251 & 483 & 2378 \\
\hline
\end{tabular}


En las zonas urbanas al borde del mar hay pocas horas frío al año en la costa cantábrica, podría decirse que no mucho más de 400 horas anuales. El periodo de junio a septiembre está libre de horas frío, y mayo y octubre tienen muy pocas. Excepto algunos años de marzos 0 noviembres fríos, los tres meses de invierno acumulan la mayor de las horas frío anuales.

Fuera de las zonas urbanas, en entornos rurales, pero en altitudes bajas, próximas a la línea costera, el número anual de horas frío es considerablemente mayor, en torno a las 800 . También en esta zona hay un periodo, los meses de junio, julio y agosto que está libres de horas frío. Si a los meses de invierno: diciembre, enero y febrero se le añade marzo, se tiene la acumulación de la mayor parte de las horas frío que se producen al año.

En la parte que se halla entre la costa y la cara septentrional de la cordillera cantábrica, a altitudes por debajo de $600 \mathrm{~m}$, se sobrepasan las 2000 horas frío al año a medida que se asciende en altitud y se aleja de la costa. Por ejemplo, Vitoria tiene 2400 horas frío al año.

En el interior puede haber horas frío en todos los meses del año. El principio de la primavera y el otoño tienen más de 3 horas diarias. En invierno se pasa de las 400 ó 500 horas mensuales a medida que se asciende en altitud. En altitudes superiores a $600 \mathrm{~m}$ el número de horas frío es mucho mayor.

En todos los casos se da, y es preciso tenerlo en cuenta, una marcada variabilidad interanual y entre cada uno de los meses en los distintos años, y tal variabilidad es más acentuada cerca del mar. 
Observatorios: La Coruña (1387), La Coruña-Alvedro (1387e), Pontevedra (1484c), VigoPeinador (1495).

Tabla 12. Comparación de horas frío anuales contadas a partir de datos horarios en los cuatro observatorios de la zona norte y noroeste: costa gallega.

\begin{tabular}{|ccccc|}
\hline & $\begin{array}{c}\text { La Coruña } \\
\mathbf{1 3 8 7}\end{array}$ & $\begin{array}{c}\text { Coruña Alvedro } \\
\mathbf{1 3 8 7 e}\end{array}$ & $\begin{array}{c}\text { Pontevedra } \\
\mathbf{1 4 8 4 c}\end{array}$ & $\begin{array}{c}\text { Vigo Peinador } \\
\mathbf{1 4 9 5}\end{array}$ \\
\hline $\mathbf{A n ̃ o}$ & $\mathrm{HF}$ & $\mathrm{HF}$ & $\mathrm{HF}$ & Hf \\
\hline $\mathbf{2 0 0 2}$ & 49 & 453 & 348 & 454 \\
\hline $\mathbf{2 0 0 3}$ & 207 & 647 & 551 & 646 \\
\hline $\mathbf{2 0 0 4}$ & 195 & 794 & 792 & 884 \\
\hline $\mathbf{2 0 0 5}$ & 382 & 906 & 954 & 1230 \\
\hline $\mathbf{2 0 0 6}$ & 330 & 887 & 825 & 1064 \\
\hline $\mathbf{2 0 0 7}$ & 193 & 952 & 562 & 880 \\
\hline $\mathbf{2 0 0 8}$ & 135 & 748 & 506 & 774 \\
\hline $\mathbf{2 0 0 9}$ & 370 & 1008 & 842 & 980 \\
\hline $\mathbf{2 0 1 0}$ & 527 & 1072 & 957 & 938 \\
\hline $\mathbf{2 0 1 1}$ & 121 & 517 & 497 & 469 \\
\hline Promedio & 251 & 798 & 683 & 832 \\
\hline
\end{tabular}

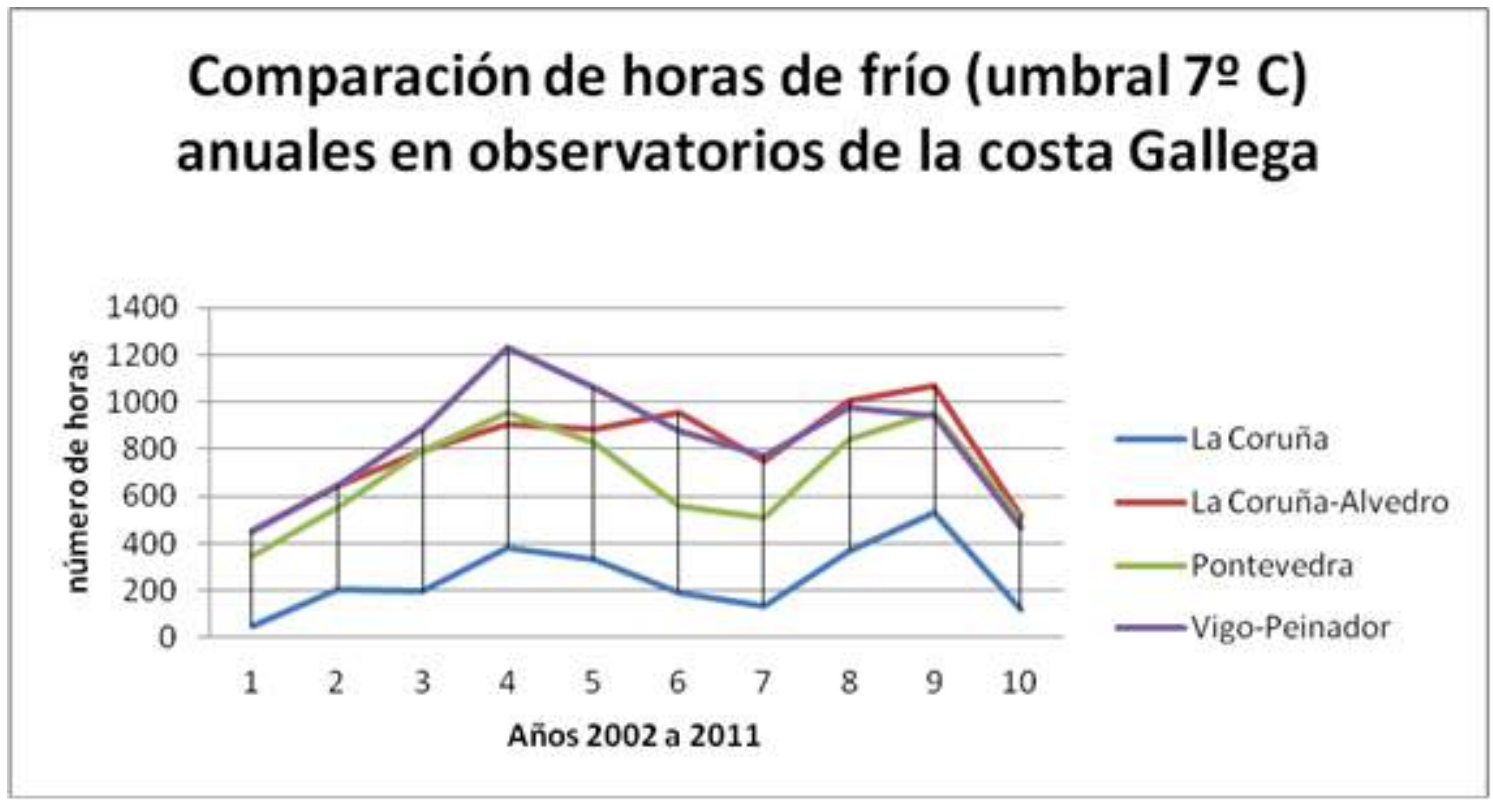

Gráfico 2. Comparación de horas frío (umbral 7ํㅡ) anuales en observatorios de la costa gallega.

Los datos son coherentes entre ellos, excepto el correspondiente al año 2007 de La CoruñaAlvedro, y muestran que en la franja costera se dan unas 800 horas frío anuales, si bien en las ciudades, dentro del casco urbano, y cerca del mar se da un menor número de horas. 


\section{Horas frío contadas en datos horarios en cada uno de los observatorios}

La Coruña. Tiene en promedio unas 250 horas frío (umbral $7^{\circ} \mathrm{C}$ ) al año, oscilando entre las 49 horas de 2002 y las 527 de 2010. Comparando el número de horas frío de La Coruña con el de La Coruña-Alvedro se ve el efecto de isla de calor que proporciona la ciudad y la cercanía al agua. En la ciudad hay muchas menos horas frío que en el aeropuerto. Lógicamente, La CoruñaAlvedro proporciona un dato mucho más ajustado a lo que sucede en el entorno, si tal dato se precisa para una planificación agrícola, y La Coruña proporciona un dato mejor si lo que se plantea es tomar medidas para un ahorro energético dentro de la ciudad.

El periodo comprendido de mayo a octubre está libre de horas frío; abril apenas tiene, marzo y noviembre no llegan a la hora diaria de promedio; enero, febrero y diciembre sobrepasan ligeramente las 2 horas diarias de promedio. Así como la variabilidad interanual es muy alta, la de los distintos meses en diferentes años es también muy marcada. Por ejemplo, enero de 2002 tuvo 1 hora de frío, mientras enero de 2010 tuvo 142 horas frío; diciembre del 2002 no tuvo horas frío, mientras que diciembre de 2009 tuvo 143 horas.

Tabla 13. Horas frío contadas en datos horarios en el observatorio de La Coruña.

\begin{tabular}{cccccccccccccc}
\hline & ene & feb & mar & abril & may & jun & jul & ago & sept & oct & nov & dic & anual \\
\hline $\mathbf{2 0 0 2}$ & 1 & 5 & 29 & 6 & 0 & 0 & 0 & 0 & 0 & 0 & 8 & 0 & 49 \\
$\mathbf{2 0 0 3}$ & 109 & 70 & 5 & 0 & 0 & 0 & 0 & 0 & 0 & 0 & 1 & 22 & 207 \\
$\mathbf{2 0 0 4}$ & 58 & 60 & 36 & 5 & 0 & 0 & 0 & 0 & 0 & 0 & 12 & 24 & 195 \\
$\mathbf{2 0 0 5}$ & 19 & 154 & 102 & 4 & 0 & 0 & 0 & 0 & 0 & 0 & 18 & 85 & 382 \\
$\mathbf{2 0 0 6}$ & 106 & 153 & 20 & 0 & 0 & 0 & 0 & 0 & 0 & 0 & 0 & 51 & 330 \\
$\mathbf{2 0 0 7}$ & 78 & 11 & 0 & 0 & 0 & 0 & 0 & 0 & 0 & 0 & 10 & 94 & 193 \\
$\mathbf{2 0 0 8}$ & 14 & 3 & 16 & 0 & 0 & 0 & 0 & 0 & 0 & 0 & 26 & 76 & 135 \\
$\mathbf{2 0 0 9}$ & 129 & 69 & 23 & 6 & 0 & 0 & 0 & 0 & 0 & 0 & 0 & 143 & 370 \\
$\mathbf{2 0 1 0}$ & 142 & 127 & 57 & 3 & 0 & 0 & 0 & 0 & 0 & 0 & 66 & 132 & 527 \\
$\mathbf{2 0 1 1}$ & 54 & 27 & 4 & 0 & 0 & 0 & 0 & 0 & 0 & 0 & 2 & 34 & 121 \\
Prom. & 71 & 68 & 29 & 2 & 0 & 0 & 0 & 0 & 0 & 0 & 14 & 66 & 251 \\
\hline
\end{tabular}

La Coruña Alvedro. Tiene en promedio unas 800 horas frío (umbral $7^{\circ} \mathrm{C}$ ) al año, oscilando entre las 453 horas de 2002 y las 1072 de 2010. La variabilidad interanual es muy marcada, el valor máximo supera al doble del valor mínimo.

Julio y agosto están libres de horas frío, junio y septiembre apenas tienen algún año, mayo no llega a la media hora diaria de promedio y octubre la sobrepasa. Abril tiene poco más de una hora diaria; marzo y noviembre están en torno a las 3 horas frío diarias de promedio; enero, 
febrero y diciembre están cerca de las 200 horas frío. La variación del número de horas de cada mes es grande entre unos años. Febrero de 2002 tuvo 84, febrero de 2005, 293; diciembre tuvo 48 horas en 2002 y 285 en 2009.

Tabla 14.Horas frío contadas en datos horarios en el observatorio de La Coruña Alvedro.

\begin{tabular}{cccccccccccccc}
\hline & ene & feb & mar & abril & may & jun & jul & ago & sept & oct & nov & dic & anual \\
\hline $\mathbf{2 0 0 2}$ & 115 & 84 & 79 & 74 & 6 & 0 & 0 & 0 & 0 & 0 & 47 & 48 & 453 \\
$\mathbf{2 0 0 3}$ & 210 & 135 & 75 & 16 & 10 & 0 & 0 & 0 & 0 & 27 & 49 & 125 & 647 \\
$\mathbf{2 0 0 4}$ & 127 & 233 & 94 & 47 & 15 & 0 & 0 & 0 & 0 & 0 & 114 & 164 & 794 \\
\hline $\mathbf{2 0 0 5}$ & 153 & 293 & 156 & 16 & 1 & 0 & 0 & 0 & 0 & 2 & 103 & 182 & 906 \\
$\mathbf{2 0 0 6}$ & 276 & 283 & 53 & 28 & 29 & 0 & 0 & 0 & 0 & 0 & 12 & 206 & 887 \\
\hline $\mathbf{2 0 0 7}$ & 229 & 78 & 78 & 54 & 1 & 1 & 0 & 0 & 11 & 31 & 212 & 257 & 952 \\
$\mathbf{2 0 0 8}$ & 118 & 129 & 71 & 50 & 6 & 0 & 0 & 0 & 0 & 52 & 129 & 193 & 748 \\
\hline $\mathbf{2 0 0 9}$ & 218 & 248 & 129 & 77 & 15 & 0 & 0 & 0 & 0 & 13 & 23 & 285 & 1008 \\
$\mathbf{2 0 1 0}$ & 233 & 233 & 148 & 49 & 19 & 0 & 0 & 0 & 7 & 45 & 119 & 219 & 1072 \\
\hline $\mathbf{2 0 1 1}$ & 159 & 120 & 97 & 16 & 0 & 0 & 0 & 0 & 0 & 6 & 32 & 87 & 517 \\
Prom. & 184 & 184 & 98 & 43 & 10 & 0 & 0 & 0 & 2 & 18 & 84 & 177 & 798 \\
\hline
\end{tabular}

Pontevedra. No llega en promedio a las 700 horas frío (umbral $7^{\circ} \mathrm{C}$ ) al año, oscilando entre las 348 horas de 2002 y las 957 de 2010. La variabilidad interanual es muy marcada, el valor máximo supera al doble del valor mínimo.

El periodo de junio a septiembre está libre de horas frío. Mayo y octubre tienen muy pocas y no todos los años. Abril tiene 1 hora diaria de promedio, noviembre 2. Enero, febrero y diciembre están en torno o ligeramente por encima de las 150 horas. La variación del número de horas de cada mes es grande entre unos años. Enero de 2008 tuvo 64 horas, mientras que enero de 2006 tuvo 282 horas frío; diciembre de 2002 tuvo 42 horas, mientras que diciembre de 2010 tuvo 260 horas.

Tabla 15. Horas frío contadas en datos horarios en el observatorio de Pontevedra.

\begin{tabular}{cccccccccccccc}
\hline & ene & feb & mar & abril & may & jun & jul & ago & sept & oct & nov & dic & anual \\
\hline $\mathbf{2 0 0 2}$ & 94 & 61 & 44 & 53 & 4 & 0 & 0 & 0 & 0 & 6 & 44 & 42 & 348 \\
$\mathbf{2 0 0 3}$ & 232 & 116 & 21 & 4 & 6 & 0 & 0 & 0 & 0 & 24 & 19 & 129 & 551 \\
$\mathbf{2 0 0 4}$ & 129 & 188 & 121 & 48 & 20 & 0 & 0 & 0 & 0 & 1 & 78 & 207 & 792 \\
$\mathbf{2 0 0 5}$ & 191 & 295 & 148 & 41 & 0 & 0 & 0 & 0 & 0 & 0 & 124 & 155 & 954 \\
$\mathbf{2 0 0 6}$ & 282 & 267 & 52 & 13 & 5 & 0 & 0 & 0 & 0 & 0 & 1 & 205 & 825 \\
$\mathbf{2 0 0 7}$ & 149 & 55 & 81 & 25 & 0 & 0 & 0 & 0 & 0 & 1 & 70 & 181 & 562 \\
$\mathbf{2 0 0 8}$ & 64 & 13 & 73 & 15 & 0 & 0 & 0 & 0 & 0 & 19 & 128 & 194 & 506 \\
\hline $\mathbf{2 0 0 9}$ & 272 & 170 & 61 & 68 & 10 & 0 & 0 & 0 & 0 & 0 & 49 & 212 & 842 \\
$\mathbf{2 0 1 0}$ & 203 & 195 & 107 & 36 & 17 & 0 & 0 & 0 & 0 & 0 & 139 & 260 & 957 \\
$\mathbf{2 0 1 1}$ & 155 & 126 & 59 & 4 & 0 & 0 & 0 & 0 & 0 & 0 & 11 & 142 & 497 \\
Prom. & 177 & 149 & 77 & 31 & 6 & 0 & 0 & 0 & 0 & 5 & 66 & 173 & 683 \\
\hline
\end{tabular}


Vigo-Peinador. En promedio tiene ligeramente por encima de las 800 horas frío (umbral $7^{\circ} \mathrm{C}$ ) al año, oscilando entre las 454 de 2002 y las 1230 de 2005. La variabilidad interanual es muy acusada, el valor máximo casi triplica al valor mínimo.

El periodo de junio a septiembre está prácticamente libre de horas frío. Mayo y octubre tienen muy pocas y no todos los años. Abril tiene 1 hora diaria de promedio, marzo y noviembre casi 3. Febrero no llega a las 200 horas frío en promedio, mientras que enero y diciembre las sobrepasan ligeramente. La diferencia entre los mismos meses en los diferentes años es muy marcada. Febrero de 2002 tuvo 74 horas, mientras que febrero de 2005 tuvo 363 horas frío. Noviembre de 2011 tuvo 8 horas frío, mientras que noviembre de 2008 tuvo 193 horas.

Tabla 16. Horas frío contadas en datos horarios en el observatorio de Vigo-Peinador.

\begin{tabular}{cccccccccccccc}
\hline & ene & feb & mar & abril & may & jun & jul & ago & sept & oct & nov & dic & anual \\
\hline $\mathbf{2 0 0 2}$ & 131 & 74 & 56 & 50 & 4 & 0 & 0 & 0 & 0 & 4 & 50 & 85 & 454 \\
$\mathbf{2 0 0 3}$ & 268 & 164 & 18 & 2 & 2 & 0 & 0 & 0 & 0 & 15 & 19 & 158 & 646 \\
$\mathbf{2 0 0 4}$ & 160 & 202 & 120 & 37 & 11 & 0 & 0 & 0 & 0 & 0 & 93 & 261 & 884 \\
$\mathbf{2 0 0 5}$ & 239 & 363 & 164 & 42 & 0 & 0 & 0 & 0 & 0 & 0 & 160 & 262 & 1230 \\
$\mathbf{2 0 0 6}$ & 392 & 312 & 55 & 15 & 3 & 0 & 0 & 0 & 0 & 0 & 15 & 272 & 1064 \\
$\mathbf{2 0 0 7}$ & 210 & 124 & 107 & 41 & 7 & 0 & 0 & 0 & 0 & 2 & 127 & 262 & 880 \\
$\mathbf{2 0 0 8}$ & 97 & 30 & 119 & 24 & 0 & 0 & 0 & 0 & 0 & 27 & 193 & 284 & 774 \\
$\mathbf{2 0 0 9}$ & 327 & 224 & 75 & 88 & 8 & 0 & 0 & 0 & 0 & 0 & 50 & 208 & 980 \\
$\mathbf{2 0 1 0}$ & 200 & 183 & 93 & 33 & 15 & 1 & 0 & 0 & 0 & 14 & 126 & 273 & 938 \\
$\mathbf{2 0 1 1}$ & 157 & 116 & 49 & 2 & 0 & 0 & 0 & 0 & 0 & 0 & 8 & 137 & 469 \\
Prom. & 218 & 179 & 86 & 33 & 5 & 0 & 0 & 0 & 0 & 6 & 84 & 220 & 832 \\
\hline
\end{tabular}

Resumen de horas frío contadas para la costa gallega por debajo de los 100 metros.

En las zonas urbanas al borde del mar hay pocas horas frío al año en la costa gallega, podría decirse que no supera las 300 horas anuales en promedio. El periodo de junio a septiembre está libre de horas frío, y mayo y octubre tienen muy pocas. Excepto algunos años de marzos o noviembres fríos, los tres meses de invierno acumulan la mayor de las horas frío anuales.

Fuera de las zonas urbanas, en entornos rurales, pero en altitudes bajas, próximas a la línea costera, el número anual de horas frío es considerablemente mayor, en torno a las 800 . También en esta zona hay un periodo, los meses de junio, julio y agosto que están libres de horas frío. Si a los meses de invierno: diciembre, enero y febrero se le añade marzo, se tiene la acumulación de la mayor parte de las horas frío que se producen al año. 
Es preciso tener en cuenta la marcada variabilidad interanual y entre cada uno de los meses en los distintos años, que es más acentuada junto al mar.

\subsubsection{Zonas norte y noroeste: c) interior de Galicia y el valle del Bierzo}

Observatorios: Santiago-Labacolla (1428), Lugo-Rozas (1505), Orense (1690a), Ponferrada (1549), Almázcara (1556x).

Tabla 17. Comparación de horas frío anuales contadas a partir de datos horarios en los cinco observatorios de la zona norte y noroeste: interior de Galicia y el valle del Bierzo.

\begin{tabular}{|cccccc|}
\hline & $\begin{array}{c}\text { Santiago } \\
\text { Labacolla } 1428\end{array}$ & $\begin{array}{c}\text { Lugo Rozas } \\
\mathbf{1 5 0 5}\end{array}$ & $\begin{array}{c}\text { Orense } \\
\mathbf{1 6 9 0}\end{array}$ & $\begin{array}{c}\text { Ponferrada } \\
\mathbf{1 5 4 9}\end{array}$ & $\begin{array}{c}\text { Almázcara } \\
\mathbf{1 5 5 6 x}\end{array}$ \\
\hline $\mathbf{A n ̃ o}$ & HF & HF & HF & HF & HF \\
\hline $\mathbf{2 0 0 2}$ & 1003 & & 1004 & 1778 & 2301 \\
\hline $\mathbf{2 0 0 3}$ & 1145 & 1853 & 1216 & 1849 & 2446 \\
\hline $\mathbf{2 0 0 4}$ & 1417 & 2201 & 1623 & 2413 & 3020 \\
\hline $\mathbf{2 0 0 5}$ & 1530 & 2360 & 1682 & 2427 & 3028 \\
\hline $\mathbf{2 0 0 6}$ & 1381 & 1954 & 1368 & 2064 & 2543 \\
\hline $\mathbf{2 0 0 7}$ & 1363 & 2018 & 1545 & 2279 & 3019 \\
\hline $\mathbf{2 0 0 8}$ & 1528 & 2091 & 1401 & 2163 & 2907 \\
\hline $\mathbf{2 0 0 9}$ & 1879 & 2118 & 1363 & 2063 & \\
\hline $\mathbf{2 0 1 0}$ & 1959 & 2219 & 1330 & 2333 & \\
\hline $\mathbf{2 0 1 1}$ & 1088 & 1643 & 1152 & 1902 & 2752 \\
\hline Promedio & 1429 & 2051 & 1368 & 2127 & \\
\hline
\end{tabular}

\section{Comparación de horas de frío (umbral 7으) anuales en observatorios del interior de Galicia y el valle del Bierzo}

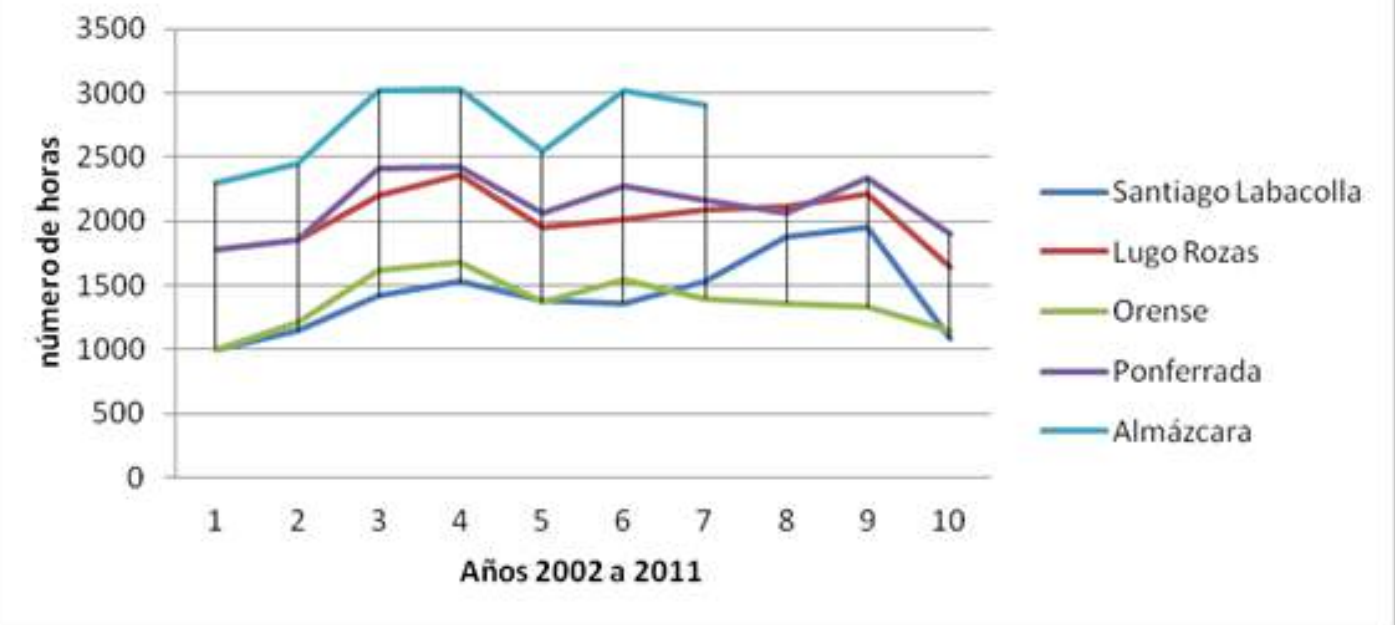

Gráfico 3. Comparación de horas frío (umbral 7ํㅡ) anuales en observatorios del interior de Galicia y el valle del Bierzo. 
Los datos son coherentes entre ellos, excepto los correspondientes a los años 2009 y 2010 en Orense, y muestran que en el interior de Galicia, en zonas de baja altitud y no alejadas de la costa, o en los valles amplios de baja altitud (Orense) se dan en torno a las 1500 horas frío anuales. En altitudes mayores, en torno a los $500 \mathrm{~m}$ se dan un poco más de 2000 horas en promedio. En las zonas alejadas del mar y valles altos se pueden dar 3000 horas y, desde luego, valores más altos en las partes altas de las zonas montañosas.

\section{Horas frío contadas en datos horarios en cada uno de los observatorios}

Santiago. Tiene en promedio en torno a 1500 horas frío (umbral $7^{\circ} \mathrm{C}$ ) al año, oscilando entre las 1003 horas de 2002 y las 1959 de 2010. La variabilidad interanual es alta, el valor mínimo es algo mayor que la mitad del valor más alto.

No tiene ningún mes libre de horas frío, si bien en los meses de verano, de junio a septiembre, hay muy pocas horas, ningún mes llega a las 15 horas. Mayo y octubre tienen de promedio 1 hora frío diaria. Abril y noviembre están alrededor de las 4 horas diarias de promedio. Marzo tiene 200 horas, y enero, febrero y diciembre en torno a las 300 horas. La variabilidad entre los distintos meses en los diferentes años es muy marcada. Enero de 2002 tuvo 174 horas, mientras que enero de 2006 tiene 433 horas frío. Noviembre de 2003 tuvo 57 horas, mientras que noviembre de 2008 tuvo 290 horas.

Tabla 18. Horas frío contadas en datos horarios en el observatorio de Santiago.

\begin{tabular}{cccccccccccccc}
\hline & ene & feb & mar & abril & may & jun & jul & ago & sept & oct & nov & dic & anual \\
\hline $\mathbf{2 0 0 2}$ & 174 & 166 & 145 & 195 & 46 & 1 & 1 & 0 & 2 & 17 & 110 & 146 & 1003 \\
$\mathbf{2 0 0 3}$ & 360 & 272 & 88 & 64 & 29 & 0 & 0 & 0 & 0 & 65 & 57 & 210 & 1145 \\
\hline $\mathbf{2 0 0 4}$ & 193 & 334 & 217 & 149 & 61 & 0 & 0 & 0 & 0 & 4 & 137 & 322 & 1417 \\
$\mathbf{2 0 0 5}$ & 286 & 463 & 203 & 87 & 12 & 0 & 0 & 0 & 3 & 8 & 199 & 269 & 1530 \\
\hline $\mathbf{2 0 0 6}$ & 433 & 407 & 87 & 57 & 30 & 2 & 0 & 1 & 1 & 6 & 22 & 335 & 1381 \\
\hline $\mathbf{2 0 0 7}$ & 300 & 188 & 253 & 86 & 19 & 0 & 0 & 0 & 0 & 26 & 194 & 297 & 1363 \\
\hline $\mathbf{2 0 0 8}$ & 222 & 71 & 232 & 137 & 21 & 24 & 1 & 24 & 1 & 116 & 290 & 389 & 1528 \\
\hline $\mathbf{2 0 0 9}$ & 398 & 371 & 268 & 259 & 38 & 0 & 1 & 1 & 48 & 33 & 81 & 381 & 1879 \\
\hline $\mathbf{2 0 1 0}$ & 400 & 381 & 314 & 118 & 91 & 25 & 0 & 0 & 50 & 16 & 223 & 341 & 1959 \\
\hline $\mathbf{2 0 1 1}$ & 303 & 249 & 171 & 19 & 0 & 26 & 0 & 0 & 0 & 18 & 64 & 238 & 1088 \\
Prom. & 307 & 290 & 198 & 117 & 35 & 8 & 0 & 3 & 11 & 31 & 138 & 293 & 1429 \\
\hline
\end{tabular}


Lugo Rozas. No tiene datos todos los meses de 2002. En el resto de los nueve años de 2003 a 2011 tiene en promedio ligeramente por encima de 2000 horas frío (umbral $7^{\circ} \mathrm{C}$ ) al año, oscilando entre las 1643 de 2011 y las 2360 de 2005. La variabilidad interanual es alta, el valor mínimo es algo mayor que la mitad del valor más alto.

No tiene meses libres de horas frío, si bien en los meses de verano hay muy pocas horas: junio 10 de promedio, julio y agosto, menos. Septiembre, una hora diaria de promedio. Mayo 2 horas diarias, octubre, 3. Abril pasa de 150 horas y noviembre de 200; marzo no llega a las 300; y enero, febrero y diciembre se acercan a las 400. La variabilidad entre los distintos meses en los diferentes años es muy marcada. Noviembre de 2006 tuvo 80 horas, mientras que noviembre de 2004 tuvo 335 horas. Marzo de 2006 tuvo 142 horas, mientras que marzo de 2009 tuvo 353 horas frío.

Tabla 19. Horas frío contadas en datos horarios en el observatorio de Lugo Rozas.

\begin{tabular}{ccccccccccccccc}
\hline \multicolumn{1}{c}{} & ene & feb & mar & abril & may & jun & jul & ago & sept & oct & nov & dic & anual \\
\hline $\mathbf{2 0 0 2}$ & & & & & & & & 15 & 50 & 57 & 172 & 204 & \\
\hline $\mathbf{2 0 0 3}$ & 463 & 326 & 187 & 130 & 99 & 3 & 8 & 0 & 8 & 132 & 170 & 327 & 1853 \\
\hline $\mathbf{2 0 0 4}$ & 260 & 432 & 308 & 249 & 104 & 0 & 6 & 2 & 14 & 22 & 335 & 469 & 2201 \\
\hline $\mathbf{2 0 0 5}$ & 389 & 533 & 299 & 147 & 63 & 10 & 0 & 3 & 59 & 84 & 313 & 460 & 2360 \\
\hline $\mathbf{2 0 0 6}$ & 543 & 509 & 142 & 124 & 69 & 22 & 0 & 0 & 6 & 43 & 80 & 416 & 1954 \\
\hline $\mathbf{2 0 0 7}$ & 352 & 210 & 322 & 151 & 66 & 12 & 7 & 9 & 41 & 122 & 328 & 398 & 2018 \\
\hline $\mathbf{2 0 0 8}$ & 348 & 276 & 279 & 172 & 22 & 16 & 3 & 2 & 52 & 174 & 306 & 441 & 2091 \\
\hline $\mathbf{2 0 0 9}$ & 416 & 453 & 353 & 245 & 69 & 0 & 4 & 0 & 17 & 64 & 92 & 405 & 2118 \\
\hline $\mathbf{2 0 1 0}$ & 411 & 352 & 312 & 145 & 103 & 11 & 0 & 0 & 39 & 125 & 261 & 460 & 2219 \\
\hline $\mathbf{2 0 1 1}$ & 344 & 335 & 256 & 68 & 17 & 17 & 0 & 7 & 8 & 117 & 169 & 305 & 1643 \\
\hline Prom. & 392 & 381 & 273 & 159 & 68 & 10 & 3 & 4 & 29 & 94 & 223 & 389 & 2051 \\
\hline
\end{tabular}

Orense. Tiene en promedio ligeramente por debajo de 1400 horas frío (umbral $7^{\circ} \mathrm{C}$ ) al año, oscilando entre las 1004 horas de 2002 y las 1682 de 2005. La variabilidad interanual es alta, el valor mínimo es algo mayor que la mitad del valor más alto.

Julio y agosto están libres de horas frío. Junio y septiembre tienen muy pocas y no todos los años, sobre todo junio. Mayo no llega a la hora diaria en promedio y octubre la sobrepasa. Abril 2 horas diarias. Marzo y noviembre están por encima de las 150 horas. Febrero no llega a las 300 horas, y enero y diciembre las sobrepasan. La variabilidad entre los distintos meses en los diferentes años es muy marcada. Enero de 2004 tuvo 208 horas frío, mientras que enero de 2006 tuvo 483; diciembre de 2002 tuvo 144 horas, mientras que diciembre de 2004 tuvo 435. 
Tabla 20. Horas frío contadas en datos horarios en el observatorio de Orense.

\begin{tabular}{cccccccccccccc}
\hline & ene & feb & mar & abril & may & jun & jul & ago & sept & oct & nov & dic & anual \\
\hline $\mathbf{2 0 0 2}$ & 275 & 163 & 152 & 127 & 35 & 2 & 0 & 0 & 5 & 16 & 85 & 144 & 1004 \\
$\mathbf{2 0 0 3}$ & 358 & 249 & 100 & 41 & 25 & 0 & 0 & 0 & 0 & 53 & 107 & 283 & 1216 \\
\hline $\mathbf{2 0 0 4}$ & 208 & 332 & 188 & 123 & 37 & 0 & 0 & 0 & 0 & 9 & 291 & 435 & 1623 \\
$\mathbf{2 0 0 5}$ & 386 & 367 & 210 & 68 & 13 & 0 & 0 & 0 & 6 & 23 & 226 & 383 & 1682 \\
$\mathbf{2 0 0 6}$ & 483 & 374 & 81 & 33 & 17 & 2 & 0 & 0 & 0 & 5 & 27 & 346 & 1368 \\
\hline $\mathbf{2 0 0 7}$ & 287 & 162 & 191 & 80 & 11 & 0 & 0 & 0 & 13 & 78 & 339 & 384 & 1545 \\
$\mathbf{2 0 0 8}$ & 265 & 194 & 154 & 57 & 15 & 0 & 0 & 0 & 4 & 103 & 255 & 354 & 1401 \\
\hline $\mathbf{2 0 0 9}$ & 289 & 345 & 181 & 121 & 30 & 0 & 0 & 0 & 0 & 37 & 62 & 298 & 1363 \\
$\mathbf{2 0 1 0}$ & 265 & 218 & 174 & 75 & 26 & 0 & 0 & 0 & 5 & 65 & 194 & 308 & 1330 \\
\hline $\mathbf{2 0 1 1}$ & 252 & 262 & 169 & 18 & 6 & 0 & 0 & 0 & 2 & 50 & 118 & 275 & 1152 \\
\hline Prom. & 307 & 267 & 160 & 74 & 22 & 0 & 0 & 0 & 4 & 44 & 170 & 321 & 1368 \\
\hline
\end{tabular}

Ponferrada. Tiene en promedio más de 2000 horas frío (umbral $7^{\circ} \mathrm{C}$ ) al año, oscilando entre las 1778 horas de 2002 y las 2427 de 2005 . La variabilidad interanual es alta, aunque menor que en Galicia.

Julio y agosto están libres de horas frío. Junio y septiembre tienen muy pocas y no todos los años. Mayo algo más de una hora diaria en promedio y octubre más de 2. Abril más de 100 horas y marzo más de 200 . Noviembre cerca de 300 y febrero de 400 . Enero y diciembre en torno a las 500 horas. La variabilidad entre los distintos meses en los diferentes años es muy marcada. Noviembre de 2009 tuvo 145 horas, mientras que noviembre de 2004 tuvo 460 horas. Marzo de 2006 tuvo 127 horas, mientras que marzo de 2010 tuvo 302 horas frío.

Tabla 21. Horas frío contadas en datos horarios en el observatorio de Ponferrada.

\begin{tabular}{cccccccccccccc}
\hline & ene & feb & mar & abril & may & jun & jul & ago & sept & oct & nov & dic & anual \\
\hline $\mathbf{2 0 0 2}$ & 474 & 329 & 214 & 178 & 66 & 5 & 0 & 0 & 15 & 34 & 232 & 231 & 1778 \\
$\mathbf{2 0 0 3}$ & 537 & 329 & 127 & 97 & 53 & 0 & 0 & 0 & 0 & 85 & 194 & 427 & 1849 \\
$\mathbf{2 0 0 4}$ & 377 & 429 & 256 & 183 & 83 & 0 & 0 & 0 & 0 & 29 & 460 & 596 & 2413 \\
\hline $\mathbf{2 0 0 5}$ & 626 & 532 & 232 & 105 & 18 & 0 & 0 & 0 & 12 & 47 & 339 & 516 & 2427 \\
$\mathbf{2 0 0 6}$ & 650 & 495 & 127 & 71 & 20 & 1 & 0 & 0 & 5 & 23 & 149 & 523 & 2064 \\
$\mathbf{2 0 0 7}$ & 463 & 276 & 299 & 92 & 32 & 1 & 0 & 0 & 9 & 108 & 444 & 555 & 2279 \\
$\mathbf{2 0 0 8}$ & 419 & 226 & 253 & 111 & 22 & 0 & 0 & 0 & 10 & 141 & 444 & 537 & 2163 \\
\hline $\mathbf{2 0 0 9}$ & 503 & 407 & 264 & 198 & 27 & 0 & 0 & 0 & 4 & 45 & 145 & 470 & 2063 \\
$\mathbf{2 0 1 0}$ & 512 & 400 & 302 & 91 & 72 & 4 & 0 & 0 & 7 & 100 & 297 & 548 & 2333 \\
\hline $\mathbf{2 0 1 1}$ & 456 & 417 & 232 & 27 & 7 & 0 & 0 & 0 & 5 & 90 & 216 & 452 & 1902 \\
Prom. & 502 & 384 & 231 & 115 & 40 & 1 & 0 & 0 & 7 & 70 & 292 & 486 & 2127 \\
\hline
\end{tabular}


Almázcara. Faltan datos de los tres últimos años. En los anteriores tiene un promedio de 2750 horas anuales, parecido a lo que hay en zonas de la meseta Norte.

No tiene meses libres de horas frío.

Tabla 22. Horas frío contadas en datos horarios en el observatorio de Almázcara.

\begin{tabular}{lccccccccccccc}
\hline & ene & feb & mar & abril & may & jun & jul & ago & sept & oct & nov & dic & anual \\
\hline $\mathbf{2 0 0 2}$ & 510 & 377 & 325 & 268 & 103 & 8 & 12 & 8 & 47 & 49 & 301 & 293 & 2301 \\
$\mathbf{2 0 0 3}$ & 600 & 379 & 203 & 164 & 97 & 6 & 5 & 4 & 19 & 177 & 274 & 518 & 2446 \\
$\mathbf{2 0 0 4}$ & 413 & 508 & 362 & 307 & 156 & 3 & 4 & 7 & 58 & 113 & 495 & 594 & 3020 \\
$\mathbf{2 0 0 5}$ & 618 & 555 & 322 & 201 & 85 & 6 & 4 & 18 & 86 & 131 & 413 & 589 & 3028 \\
$\mathbf{2 0 0 6}$ & 666 & 527 & 250 & 155 & 84 & 21 & 0 & 7 & 14 & 65 & 187 & 567 & 2543 \\
$\mathbf{2 0 0 7}$ & 507 & 337 & 393 & 182 & 93 & 26 & 8 & 30 & 69 & 258 & 502 & 614 & 3019 \\
$\mathbf{2 0 0 8}$ & 487 & 344 & 349 & 211 & 44 & 33 & 19 & 10 & 93 & 263 & 492 & 562 & 2907 \\
$\mathbf{2 0 0 9}$ & & & 393 & 309 & 99 & & & 2 & 80 & 122 & & 523 & \\
$\mathbf{2 0 1 0}$ & & & & & & & 9 & 72 & 207 & 423 & & \\
$\mathbf{2 0 1 1}$ & 482 & & 143 & 56 & 33 & 10 & 13 & 42 & & 286 & 524 & \\
Prom. & & & & & & & 11 & 58 & & & & 2752 \\
\hline
\end{tabular}

En el interior de Galicia, en zonas de baja altitud y no alejadas de la costa, o en los valles amplios de baja altitud (cuencas del Sil y del Miño en Orense) se dan en torno a las 1500 horas frío anuales. En altitudes mayores, en torno a los $500 \mathrm{~m}$, se dan un poco más de 2000 horas en promedio. En las zonas alejadas del mar y valles altos se pueden dar 3000 horas y, desde luego, valores más altos en las partes altas de las zonas montañosas.

En el interior, puede haber horas frío en todos los meses del año, aunque de mayo a septiembre hay muy pocas. El principio de la primavera y el otoño tienen más de 3 horas diarias en promedio. En invierno se pasa de las 400 o 500 horas mensuales sobre todo en el valle del Sil. Por supuesto en las zonas montañosas de estas dos cuencas, en altitudes superiores a 600 $\mathrm{m}$, el número de horas frío de cada mes y estación es mucho mayor.

Es preciso tener en cuenta la marcada variabilidad interanual y entre cada uno de los meses en los distintos años. 
Observatorios: León Virgen del camino (2661), Burgos Villafría (2331), Soria (2030), Zamora (2614), Valladolid (2422), Valladolid Villanubla (2539), Salamanca-Matacán (2867), Segovia (2465).

Tabla 23. Comparación de horas frío anuales contadas a partir de datos horarios en los ocho observatorios de la meseta Norte.

\begin{tabular}{|ccccccccc|}
\hline & $\begin{array}{c}\text { Soria } \\
\mathbf{2 0 3 0}\end{array}$ & $\begin{array}{c}\text { Burgos } \\
\text { Villafría } \\
\mathbf{2 3 3 1}\end{array}$ & $\begin{array}{c}\text { León V. del } \\
\text { Camino } \\
\mathbf{2 6 6 1}\end{array}$ & $\begin{array}{c}\text { Valladolid } \\
\text { Villanubla } \\
\mathbf{2 5 3 9}\end{array}$ & $\begin{array}{c}\text { Valladolid } \\
\mathbf{2 4 2 2}\end{array}$ & $\begin{array}{c}\text { Segovia } \\
\mathbf{2 4 6 5}\end{array}$ & $\begin{array}{c}\text { Zamora } \\
\mathbf{2 6 1 4}\end{array}$ & $\begin{array}{c}\text { Salamanca } \\
\text { Matacán } \\
\mathbf{2 6 6 7}\end{array}$ \\
\hline Año & HF & HF & HF & HF & HF & HF & HF & HF \\
\hline $\mathbf{2 0 0 2}$ & 3177 & 2921 & 2923 & 2624 & 2090 & 2316 & 1791 & 2188 \\
\hline $\mathbf{2 0 0 3}$ & 3074 & 3000 & 2876 & 2784 & 2350 & 2517 & 2049 & 2393 \\
\hline $\mathbf{2 0 0 4}$ & 3388 & 3493 & 3225 & 3190 & 2820 & 2981 & 2498 & 2802 \\
\hline $\mathbf{2 0 0 5}$ & 3290 & 3398 & 3083 & 3051 & 2691 & 2861 & 2520 & 2850 \\
\hline $\mathbf{2 0 0 6}$ & 2662 & 2759 & 2625 & 2612 & 2328 & 2308 & 2169 & 2431 \\
\hline $\mathbf{2 0 0 7}$ & 3213 & 3256 & 3036 & 3026 & 2606 & 2669 & 2322 & 2738 \\
\hline $\mathbf{2 0 0 8}$ & 3436 & 3173 & 3124 & 2991 & 2556 & 2640 & 2327 & 2772 \\
\hline $\mathbf{2 0 0 9}$ & 3044 & 2991 & 2911 & 2718 & 2343 & 2416 & 2096 & 2466 \\
\hline $\mathbf{2 0 1 0}$ & 3595 & 3522 & 3401 & 3139 & 2701 & 2769 & 2473 & 2718 \\
\hline $\mathbf{2 0 1 1}$ & 2764 & 2781 & 2681 & 2457 & 2115 & 2335 & 1950 & 2302 \\
\hline Prom & 3164 & 3129 & 2989 & 2859 & 2460 & 2581 & 2220 & 2566 \\
\hline
\end{tabular}

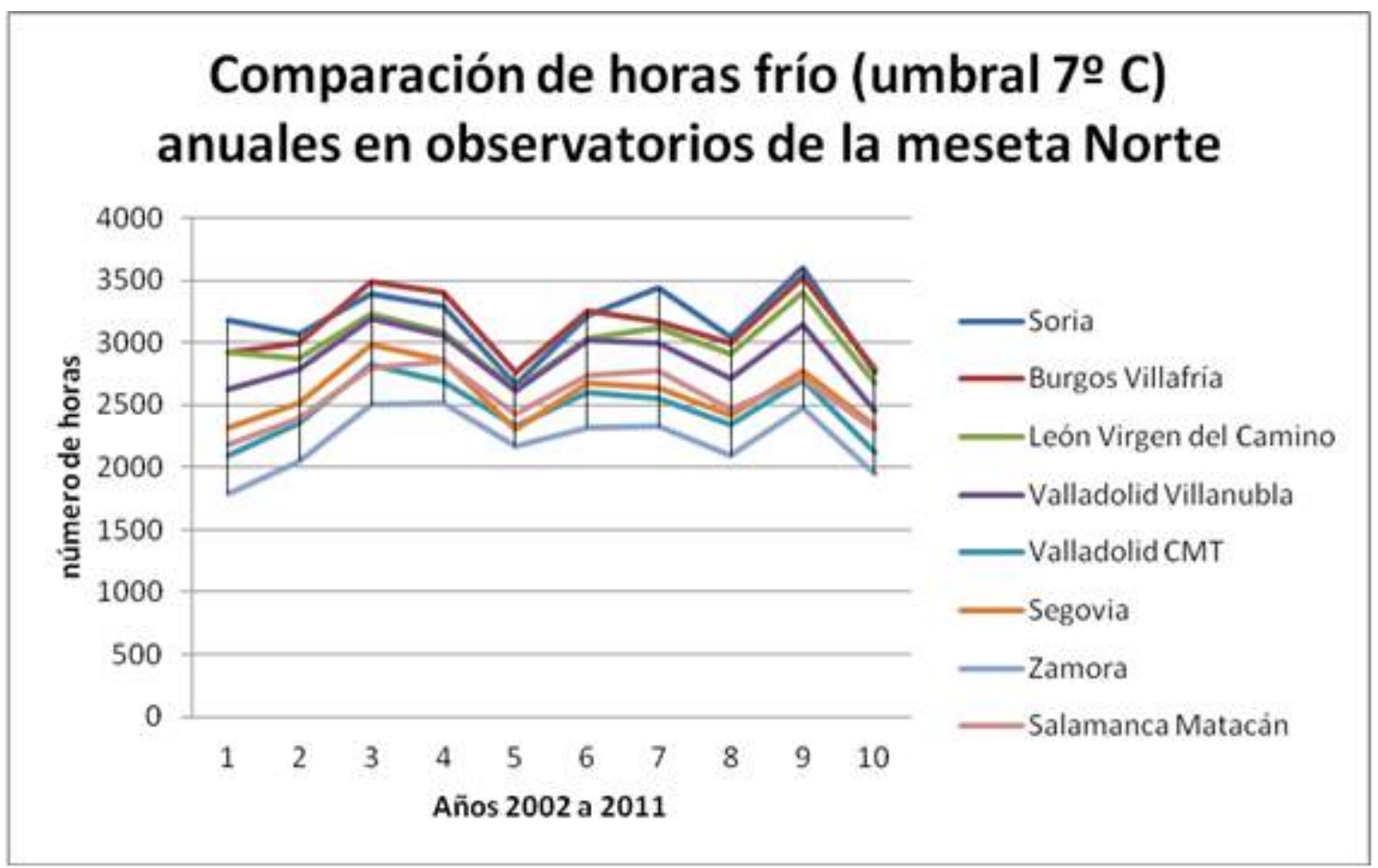

Gráfico 4. Comparación de horas frío (umbral 7ํㅡ) anuales en observatorios de la meseta Norte. 
Los datos son coherentes entre ellos y muestran que en la meseta Norte, dependiendo de la altitud, el número de horas frío anuales está entre 2000 y 3500. Por encima de 3000 horas en promedio en Burgos Villafría y Soria, en torno a 3000 en León Virgen del Camino y en Villanubla Valladolid, en torno a 2500 en Valladolid ciudad, Salamanca Matacán y Segovia, y en torno a 2200 en Zamora.

\section{Horas frío contadas en datos horarios en cada uno de los observatorios}

Soria. Tiene en promedio más de 3000 horas frío (umbral $7^{\circ} \mathrm{C}$ ) al año, oscilando entre las 3595 horas de 2010 y las 2662 de 2006.

No tiene meses libres de horas frío, si bien en los meses de verano hay muy pocas horas: junio 12 de promedio, julio, 3, y agosto, 1, y septiembre, 29. Abril (259) tiene en torno a las 8 horas diarias en promedio y mayo y octubre en torno a 4. Marzo y noviembre están en torno a las 400 horas, pero ambos meses pueden pasar de las 500 horas, es decir, más de 16 horas diarias. Enero y diciembre pasan de 600 horas, y febrero no llega. Enero, febrero y diciembre tienen en torno a 20 horas frío al día de promedio, es decir, más del $80 \%$ del tiempo.

Tabla 24. Horas frío contadas en datos horarios en el observatorio de Soria.

\begin{tabular}{cccccccccccccc}
\hline & ene & feb & mar & abr & may & jun & jul & ago & sep & oct & nov & dic & anual \\
\hline $\mathbf{2 0 0 2}$ & 653 & 490 & 429 & 311 & 177 & 37 & 0 & 0 & 47 & 91 & 411 & 531 & 3177 \\
$\mathbf{2 0 0 3}$ & 633 & 607 & 315 & 240 & 109 & 0 & 0 & 0 & 4 & 193 & 326 & 647 & 3074 \\
$\mathbf{2 0 0 4}$ & 500 & 547 & 523 & 408 & 168 & 0 & 12 & 0 & 11 & 130 & 461 & 628 & 3388 \\
\hline $\mathbf{2 0 0 5}$ & 626 & 627 & 394 & 264 & 78 & 1 & 0 & 0 & 48 & 103 & 493 & 656 & 3290 \\
\hline $\mathbf{2 0 0 6}$ & 688 & 537 & 370 & 175 & 76 & 10 & 0 & 0 & 6 & 41 & 165 & 594 & 2662 \\
\hline $\mathbf{2 0 0 7}$ & 586 & 455 & 494 & 223 & 100 & 13 & 1 & 0 & 31 & 193 & 467 & 650 & 3213 \\
\hline $\mathbf{2 0 0 8}$ & 580 & 487 & 472 & 265 & 90 & 23 & 8 & 0 & 76 & 246 & 538 & 651 & 3436 \\
\hline $\mathbf{2 0 0 9}$ & 640 & 513 & 431 & 376 & 75 & 1 & 0 & 0 & 10 & 79 & 315 & 604 & 3044 \\
\hline $\mathbf{2 0 1 0}$ & 692 & 583 & 474 & 234 & 233 & 19 & 0 & 0 & 38 & 245 & 519 & 558 & 3595 \\
\hline $\mathbf{2 0 1 1}$ & 599 & 488 & 475 & 90 & 30 & 14 & 6 & 6 & 14 & 163 & 259 & 620 & 2764 \\
\hline Prom. & 620 & 533 & 438 & 259 & 114 & 12 & 3 & 1 & 29 & 148 & 395 & 614 & 3164 \\
\hline
\end{tabular}

Burgos Villafría. Tiene en promedio más de 3000 horas frío (umbral $7^{\circ} \mathrm{C}$ ) al año, oscilando entre las 3522 horas de 2010 y las 2759 de 2006.

No tiene meses libres de horas frío, si bien en los meses de verano hay muy pocas horas: junio 16 de promedio, julio, 5, agosto, 2, y septiembre, 35. Mayo (122) y octubre (140) tienen más de 4 horas diarias. Abril (264). Marzo y noviembre están en torno a las 400 horas, pero 
ambos meses pueden pasar de las 500 horas, es decir, más de 16 horas diarias. Enero y diciembre pasan de 600 horas, y febrero de las 500 . Enero, febrero y diciembre tienen en torno a 20 horas frío al día de promedio, es decir, más del $80 \%$ del tiempo.

Tabla 25. Horas frío contadas en datos horarios en el observatorio de Burgos Villafría.

\begin{tabular}{|cccccccccccccc}
\hline & ene & feb & mar & abr & may & jun & jul & ago & sep & oct & nov & dic & anual \\
\hline $\mathbf{2 0 0 2}$ & 571 & 443 & 385 & 347 & 168 & 38 & 9 & 1 & 69 & 91 & 352 & 447 & 2921 \\
\hline $\mathbf{2 0 0 3}$ & 614 & 579 & 270 & 213 & 150 & 0 & 0 & 0 & 10 & 196 & 316 & 652 & 3000 \\
\hline $\mathbf{2 0 0 4}$ & 506 & 530 & 508 & 410 & 181 & 0 & 22 & 2 & 40 & 75 & 530 & 689 & 3493 \\
\hline $\mathbf{2 0 0 5}$ & 680 & 635 & 396 & 268 & 102 & 3 & 0 & 2 & 51 & 79 & 508 & 674 & 3398 \\
\hline $\mathbf{2 0 0 6}$ & 716 & 560 & 349 & 197 & 86 & 26 & 0 & 2 & 20 & 42 & 189 & 572 & 2759 \\
\hline $\mathbf{2 0 0 7}$ & 604 & 387 & 489 & 219 & 103 & 16 & 3 & 2 & 27 & 188 & 544 & 674 & 3256 \\
\hline $\mathbf{2 0 0 8}$ & 543 & 424 & 466 & 282 & 54 & 20 & 6 & 8 & 65 & 236 & 476 & 593 & 3173 \\
\hline $\mathbf{2 0 0 9}$ & 594 & 549 & 475 & 344 & 67 & 5 & 1 & 0 & 3 & 115 & 290 & 548 & 2991 \\
\hline $\mathbf{2 0 1 0}$ & 666 & 560 & 469 & 228 & 252 & 24 & 0 & 0 & 43 & 207 & 467 & 606 & 3522 \\
\hline $\mathbf{2 0 1 1}$ & 620 & 501 & 414 & 130 & 53 & 26 & 10 & 3 & 19 & 173 & 207 & 625 & 2781 \\
\hline Prom. & 611 & 517 & 422 & 264 & 122 & 16 & 5 & 2 & 35 & 140 & 388 & 608 & 3129 \\
\hline
\end{tabular}

León Virgen del Camino. Tiene en promedio en torno a 3000 horas frío (umbral $7^{\circ} \mathrm{C}$ ) al año, oscilando entre las 3401 horas de 2010 y las 2625 de 2006.

No tiene meses libres de horas frío, si bien en los meses de verano hay muy pocas horas: junio 13 de promedio, julio, 4, y agosto, 3, y septiembre, 20. Mayo (102) y octubre (119) tienen más de 3 horas diarias, y abril (218) alcanza las 7. Marzo y noviembre están ligeramente por debajo de las 400 horas, y sólo noviembre llega alguna vez a las 500 horas, es decir, más de 16 horas diarias. Enero y diciembre pasan ligeramente de 600 horas, y febrero de las 500, es decir entre 18 y 20 horas frío al día de promedio.

Tabla 26. Horas frío contadas en datos horarios en el observatorio de León Virgen del Camino.

\begin{tabular}{|c|c|c|c|c|c|c|c|c|c|c|c|c|c|}
\hline & ene & feb & mar & $a b r$ & may & jun & jul & ago & sep & oct & nov & dic & anual \\
\hline 2002 & 621 & 472 & 383 & 258 & 169 & 42 & 9 & 8 & 27 & 78 & 387 & 469 & 2923 \\
\hline 2003 & 621 & 573 & 246 & 188 & 105 & 0 & 0 & 0 & 5 & 181 & 306 & 651 & 2876 \\
\hline 2004 & 469 & 513 & 482 & 322 & 171 & 4 & 11 & 3 & 16 & 115 & 503 & 616 & 3225 \\
\hline 2005 & 695 & 592 & 367 & 219 & 86 & 1 & 0 & 0 & 22 & 76 & 408 & 617 & 3083 \\
\hline 2006 & 685 & 546 & 336 & 167 & 51 & 12 & 0 & 0 & 7 & 35 & 190 & 596 & 2625 \\
\hline 2007 & 627 & 449 & 430 & 160 & 104 & 22 & 4 & 10 & 30 & 124 & 448 & 628 & 3036 \\
\hline 2008 & 566 & 410 & 417 & 279 & 52 & 6 & 9 & 4 & 47 & 220 & 503 & 611 & 3124 \\
\hline 2009 & 625 & 490 & 379 & 328 & 78 & 2 & 3 & 0 & 16 & 70 & 306 & 614 & 2911 \\
\hline 2010 & 699 & 603 & 461 & 182 & 181 & 13 & 1 & 4 & 18 & 165 & 455 & 619 & 3401 \\
\hline 2011 & 626 & 499 & 413 & 76 & 24 & 23 & 3 & 3 & 8 & 126 & 293 & 587 & 2681 \\
\hline Prom. & 623 & 515 & 391 & 218 & 102 & 13 & 4 & 3 & 20 & 119 & 380 & 601 & 2989 \\
\hline
\end{tabular}


Villanubla Valladolid. Tiene en promedio algo más de 2800 horas frío (umbral $7^{\circ} \mathrm{C}$ ) al año, oscilando entre las 3190 horas de 2004 y las 2457 de 2011.

No tiene meses libres de horas frío, si bien en los meses de verano hay muy pocas horas: junio 10 de promedio, julio, 1, y agosto, 2, y septiembre, 17. Abril (201), mayo (92) y octubre (102), sólo abril tiene más de 3 horas diarias de frío. Marzo y noviembre están algo por debajo de las 400 horas, y sólo noviembre llega alguna vez a las 500 horas, es decir, más de 16 horas diarias, aunque hay meses de noviembre que baja a la mitad (unas 250 horas). Enero y diciembre están en torno a las 600 horas, y febrero de las 500 , es decir entre 18 y 20 horas diarias de frío de promedio.

Tabla 27. Horas frío contadas en datos horarios en el observatorio de Villanubla Valladolid.

\begin{tabular}{cccccccccccccc}
\hline & ene & feb & mar & abr & may & jun & jul & ago & sep & oct & nov & dic & anual \\
\hline $\mathbf{2 0 0 2}$ & 570 & 424 & 333 & 247 & 133 & 25 & 1 & 4 & 35 & 55 & 368 & 429 & 2624 \\
$\mathbf{2 0 0 3}$ & 622 & 554 & 213 & 191 & 94 & 0 & 0 & 0 & 5 & 155 & 287 & 663 & 2784 \\
$\mathbf{2 0 0 4}$ & 482 & 512 & 448 & 325 & 142 & 0 & 6 & 0 & 6 & 75 & 522 & 672 & 3190 \\
$\mathbf{2 0 0 5}$ & 682 & 595 & 334 & 200 & 68 & 0 & 0 & 1 & 18 & 58 & 452 & 643 & 3051 \\
$\mathbf{2 0 0 6}$ & 717 & 555 & 331 & 139 & 71 & 15 & 0 & 0 & 8 & 37 & 149 & 590 & 2612 \\
\hline $\mathbf{2 0 0 7}$ & 619 & 410 & 439 & 161 & 94 & 17 & 0 & 8 & 24 & 122 & 478 & 654 & 3026 \\
$\mathbf{2 0 0 8}$ & 529 & 370 & 427 & 250 & 45 & 6 & 5 & 6 & 36 & 187 & 535 & 595 & 2991 \\
\hline $\mathbf{2 0 0 9}$ & 589 & 491 & 355 & 290 & 63 & 7 & 0 & 0 & 14 & 83 & 284 & 542 & 2718 \\
$\mathbf{2 0 1 0}$ & 621 & 550 & 444 & 159 & 181 & 17 & 0 & 0 & 21 & 150 & 459 & 537 & 3139 \\
\hline $\mathbf{2 0 1 1}$ & 567 & 460 & 375 & 48 & 25 & 12 & 2 & 0 & 6 & 96 & 256 & 610 & 2457 \\
Prom. & 600 & 492 & 370 & 201 & 92 & 10 & 1 & 2 & 17 & 102 & 379 & 594 & 2859 \\
\hline
\end{tabular}

Valladolid CMT. Tiene en promedio ligeramente por debajo de 2500 horas frío (umbral $7^{\circ} \mathrm{C}$ ) al año, oscilando entre las 2820 horas de 2004 y las 2090 de 2002.

Agosto está libre de horas frío. Junio y julio tienen muy pocas y pocos años. Septiembre también tiene pocas horas y tampoco todos los años. Mayo pasa de 1 hora diaria en promedio, octubre de 2 y abril no llega a 5 . Marzo y noviembre sobrepasan las 300 horas mensuales. Enero, febrero y diciembre están en torno a las 500 horas. 
Tabla 28. Horas frío contadas en datos horarios en el observatorio de Valladolid CMT.

\begin{tabular}{cccccccccccccc}
\hline & ene & feb & mar & abr & may & jun & jul & ago & sep & oct & nov & dic & anual \\
\hline $\mathbf{2 0 0 2}$ & 497 & 368 & 271 & 210 & 74 & 8 & 0 & 0 & 25 & 32 & 251 & 354 & 2090 \\
$\mathbf{2 0 0 3}$ & 574 & 495 & 181 & 131 & 63 & 0 & 0 & 0 & 0 & 111 & 230 & 565 & 2350 \\
$\mathbf{2 0 0 4}$ & 448 & 495 & 376 & 254 & 79 & 0 & 0 & 0 & 0 & 35 & 485 & 648 & 2820 \\
\hline $\mathbf{2 0 0 5}$ & 667 & 578 & 290 & 117 & 26 & 0 & 0 & 0 & 10 & 29 & 403 & 571 & 2691 \\
$\mathbf{2 0 0 6}$ & 707 & 538 & 231 & 108 & 30 & 7 & 0 & 0 & 1 & 14 & 129 & 563 & 2328 \\
\hline $\mathbf{2 0 0 7}$ & 564 & 312 & 361 & 120 & 45 & 1 & 0 & 0 & 17 & 93 & 456 & 637 & 2606 \\
\hline $\mathbf{2 0 0 8}$ & 485 & 312 & 345 & 168 & 20 & 0 & 0 & 0 & 11 & 162 & 475 & 578 & 2556 \\
\hline $\mathbf{2 0 0 9}$ & 551 & 455 & 316 & 222 & 33 & 0 & 1 & 0 & 3 & 55 & 213 & 494 & 2343 \\
\hline $\mathbf{2 0 1 0}$ & 559 & 495 & 379 & 117 & 114 & 7 & 0 & 0 & 8 & 124 & 379 & 519 & 2701 \\
\hline $\mathbf{2 0 1 1}$ & 509 & 412 & 310 & 24 & 9 & 2 & 0 & 0 & 3 & 82 & 223 & 541 & 2115 \\
\hline Prom. & 556 & 446 & 306 & 147 & 49 & 3 & 0 & 0 & 8 & 74 & 324 & 547 & 2460 \\
\hline
\end{tabular}

Segovia. Tiene en promedio ligeramente superior a las 2500 horas frío (umbral $7^{\circ} \mathrm{C}$ ) al año, oscilando entre las 2981 horas de 2004 y las 2308 de 2006.

No tiene meses libres de horas frío, si bien en los meses de verano hay muy pocas horas: junio 9 de promedio, julio, 1, y agosto, 1, y septiembre, 13. Mayo y octubre tienen por debajo de 100 horas, menos de 3 horas diarias de frío, y abril casi 200, cerca de 6 horas diarias. Marzo y noviembre están por encima de las 300 horas, y noviembre oscila mucho, entre más de $500 \mathrm{y}$ algo más de 100 horas, entre unos años y otros. Enero y diciembre están algo por encima de 500 horas, y febrero, 450, es decir un poco por encima de las 16 horas diarias de frío de promedio.

Tabla 29. Horas frío contadas en datos horarios en el observatorio de Segovia.

\begin{tabular}{cccccccccccccc}
\hline & ene & feb & mar & abr & may & jun & jul & ago & sep & oct & nov & dic & anual \\
\hline $\mathbf{2 0 0 2}$ & 439 & 395 & 307 & 221 & 132 & 31 & 5 & 0 & 24 & 52 & 314 & 396 & 2316 \\
$\mathbf{2 0 0 3}$ & 615 & 534 & 161 & 166 & 102 & 0 & 0 & 0 & 3 & 99 & 268 & 569 & 2517 \\
$\mathbf{2 0 0 4}$ & 472 & 462 & 442 & 305 & 159 & 3 & 0 & 0 & 8 & 69 & 459 & 602 & 2981 \\
$\mathbf{2 0 0 5}$ & 607 & 613 & 302 & 188 & 41 & 0 & 0 & 2 & 19 & 30 & 440 & 619 & 2861 \\
$\mathbf{2 0 0 6}$ & 705 & 508 & 275 & 109 & 26 & 12 & 0 & 0 & 1 & 16 & 125 & 531 & 2308 \\
\hline $\mathbf{2 0 0 7}$ & 525 & 336 & 417 & 170 & 80 & 4 & 0 & 9 & 13 & 124 & 453 & 538 & 2669 \\
$\mathbf{2 0 0 8}$ & 443 & 259 & 400 & 188 & 30 & 14 & 0 & 0 & 25 & 168 & 528 & 585 & 2640 \\
\hline $\mathbf{2 0 0 9}$ & 567 & 460 & 303 & 291 & 47 & 0 & 0 & 0 & 21 & 61 & 212 & 454 & 2416 \\
$\mathbf{2 0 1 0}$ & 564 & 483 & 394 & 134 & 158 & 7 & 0 & 1 & 7 & 152 & 434 & 435 & 2769 \\
\hline $\mathbf{2 0 1 1}$ & 551 & 449 & 356 & 57 & 18 & 18 & 0 & 0 & 4 & 68 & 244 & 570 & 2335 \\
Prom. & 549 & 450 & 336 & 183 & 79 & 9 & 1 & 1 & 13 & 84 & 348 & 530 & 2581 \\
\hline
\end{tabular}


Zamora. Es la capital de la meseta Norte con menos horas frío; tiene un promedio ligeramente superior a las 2200 horas frío (umbral $7^{\circ} \mathrm{C}$ ) al año, oscilando entre las 2520 horas de 2005 y las 1791 de 2002.

Podría decirse que julio y agosto están libres de horas frío en Zamora, junio tiene 2 de promedio mensuales y septiembre, 7. Mayo no llega a las 50 y octubre no llega a las 100. Abril sobrepasa las 100, más de 3 horas diarias. Marzo y noviembre están por debajo de las 300 horas, y noviembre oscila mucho, entre 474 y 134 horas, entre unos años y otros. Enero y diciembre están en torno a las 500 horas, y febrero, 400, es decir entre 14 y 16 horas diarias de frío de promedio.

Tabla 30. Horas frío contadas en datos horarios en el observatorio de Zamora.

\begin{tabular}{cccccccccccccc}
\hline & ene & feb & mar & abr & may & jun & jul & ago & sep & oct & nov & dic & anual \\
\hline $\mathbf{2 0 0 2}$ & 474 & 333 & 238 & 169 & 43 & 3 & 0 & 0 & 20 & 40 & 175 & 296 & 1791 \\
\hline $\mathbf{2 0 0 3}$ & 518 & 430 & 175 & 121 & 36 & 0 & 0 & 0 & 0 & 93 & 189 & 487 & 2049 \\
\hline $\mathbf{2 0 0 4}$ & 364 & 471 & 310 & 215 & 67 & 0 & 0 & 0 & 1 & 17 & 474 & 579 & 2498 \\
\hline $\mathbf{2 0 0 5}$ & 655 & 537 & 262 & 103 & 23 & 0 & 0 & 0 & 14 & 40 & 364 & 522 & 2520 \\
$\mathbf{2 0 0 6}$ & 683 & 512 & 171 & 93 & 19 & 6 & 0 & 0 & 0 & 17 & 134 & 534 & 2169 \\
$\mathbf{2 0 0 7}$ & 480 & 252 & 308 & 126 & 31 & 0 & 0 & 0 & 16 & 112 & 429 & 568 & 2322 \\
\hline $\mathbf{2 0 0 8}$ & 433 & 292 & 297 & 149 & 15 & 0 & 0 & 0 & 8 & 155 & 421 & 557 & 2327 \\
\hline $\mathbf{2 0 0 9}$ & 516 & 440 & 305 & 192 & 25 & 0 & 0 & 0 & 1 & 39 & 146 & 432 & 2096 \\
\hline $\mathbf{2 0 1 0}$ & 463 & 450 & 349 & 117 & 94 & 5 & 0 & 0 & 4 & 101 & 345 & 545 & 2473 \\
\hline $\mathbf{2 0 1 1}$ & 463 & 400 & 260 & 37 & 9 & 5 & 0 & 0 & 2 & 83 & 221 & 470 & 1950 \\
\hline Prom. & 505 & 412 & 268 & 132 & 36 & 2 & 0 & 0 & 7 & 70 & 290 & 499 & 2220 \\
\hline
\end{tabular}

Salamanca Matacán. Tiene en promedio ligeramente superior a las 2500 horas frío (umbral $7^{\circ} \mathrm{C}$ ) al año, oscilando entre las 2850 horas de 2005 y las 2188 de 2002.

No tiene meses libres de horas frío, si bien en los meses de verano hay muy pocas horas: junio 5 de promedio, julio, 1, y agosto, 1, y septiembre, 26. También mayo tiene pocas horas, 59. Abril (182) y octubre (123), pasan de 4 horas diarias de frío. Marzo y noviembre están por encima de las 300 horas, y noviembre oscila mucho, entre más de 500 y 150 horas, entre unos años y otros. Enero y diciembre están algo por encima de 500 horas, y febrero, 450, es decir un poco por encima de las 16 horas diarias de frío de promedio. 
Tabla 31. Horas frío contadas en datos horarios en el observatorio de Salamanca Matacán.

\begin{tabular}{cccccccccccccc}
\hline & ene & feb & mar & abr & may & jun & jul & ago & sep & oct & nov & dic & anual \\
\hline $\mathbf{2 0 0 2}$ & 479 & 376 & 326 & 246 & 87 & 8 & 0 & 0 & 41 & 51 & 245 & 329 & 2188 \\
$\mathbf{2 0 0 3}$ & 567 & 489 & 202 & 148 & 56 & 0 & 0 & 0 & 0 & 109 & 256 & 566 & 2393 \\
$\mathbf{2 0 0 4}$ & 384 & 511 & 378 & 268 & 94 & 0 & 1 & 0 & 23 & 53 & 483 & 607 & 2802 \\
$\mathbf{2 0 0 5}$ & 643 & 579 & 320 & 166 & 38 & 0 & 0 & 0 & 51 & 93 & 415 & 545 & 2850 \\
$\mathbf{2 0 0 6}$ & 706 & 540 & 277 & 129 & 39 & 6 & 0 & 0 & 5 & 54 & 148 & 527 & 2431 \\
$\mathbf{2 0 0 7}$ & 544 & 327 & 363 & 205 & 62 & 11 & 2 & 3 & 18 & 184 & 480 & 539 & 2738 \\
$\mathbf{2 0 0 8}$ & 430 & 335 & 389 & 196 & 25 & 3 & 7 & 7 & 53 & 231 & 508 & 588 & 2772 \\
\hline $\mathbf{2 0 0 9}$ & 524 & 465 & 360 & 259 & 38 & 5 & 0 & 0 & 20 & 92 & 226 & 477 & 2466 \\
$\mathbf{2 0 1 0}$ & 504 & 458 & 394 & 135 & 117 & 12 & 0 & 0 & 27 & 191 & 395 & 485 & 2718 \\
\hline $\mathbf{2 0 1 1}$ & 520 & 429 & 345 & 68 & 29 & 8 & 1 & 2 & 18 & 173 & 233 & 476 & 2302 \\
Prom. & 530 & 451 & 335 & 182 & 59 & 5 & 1 & 1 & 26 & 123 & 339 & 514 & 2566 \\
\hline
\end{tabular}

Resumen de horas frío contadas para la meseta Norte en altitudes entre 650 y 950 metros.

Podría decirse que en la meseta Norte las horas frío sobrepasan en promedio las 2000 horas anuales en toda la meseta, y las 3000 horas en las altitudes superiores a los $850 \mathrm{~m}$.

En la meseta Norte, si se exceptúa una pequeña franja al oeste en las altitudes más bajas (en torno a los $600 \mathrm{~m}$ ), no hay meses libres de horas frío; si bien en verano hay muy pocas, y la mayoría de los días están libres de ellas. En primavera y otoño, sin embargo, hay en toda la zona 3 ó más horas frío diarias, y en los tres meses de invierno, enero, diciembre y febrero, las horas frío sobrepasan las 15 horas diarias en toda la zona; y en altitudes por encima de los 850 metros se alcanza un promedio de 20 horas diarias, lo que significa que más del $80 \%$ del tiempo se está por debajo de $7^{\circ} \mathrm{C}$.

Se puede señalar también que los meses de otoño, octubre y noviembre, son muy variables; hay años con muchas horas frío y otros con pocas. Algo parecido, pero menos marcado, sucede en los meses de primavera.

Es preciso tener en cuenta la marcada variabilidad interanual y entre cada uno de los meses en los distintos años. 
Observatorios: Huesca (9901x), Zaragoza aeropuerto (9434), Lérida (9771c).

Tabla 32. Comparación de horas frío anuales contadas a partir de datos horarios en los tres observatorios del valle del Ebro.

\begin{tabular}{|cccc|}
\hline Año & $\begin{array}{c}\text { Huesca } \\
9901 \mathbf{x}\end{array}$ & $\begin{array}{c}\text { Zaragoza } \\
\mathbf{9 4 3 4}\end{array}$ & $\begin{array}{c}\text { Lérida } \\
\mathbf{9 7 7 1 c}\end{array}$ \\
\hline $\mathbf{2 0 0 2}$ & HF & HF & HF \\
\hline $\mathbf{2 0 0 3}$ & 1651 & 967 & 1419 \\
\hline $\mathbf{2 0 0 4}$ & 1966 & 1357 & 1681 \\
\hline $\mathbf{2 0 0 5}$ & 2382 & 1616 & 2036 \\
\hline $\mathbf{2 0 0 6}$ & 2445 & 1938 & 2213 \\
\hline $\mathbf{2 0 0 7}$ & 2053 & 1525 & 1788 \\
\hline $\mathbf{2 0 0 8}$ & 2101 & 1383 & 1966 \\
\hline $\mathbf{2 0 0 9}$ & 2099 & 1290 & 1748 \\
\hline $\mathbf{2 0 1 0}$ & 2121 & 1376 & 1664 \\
\hline $\mathbf{2 0 1 1}$ & 2510 & 1710 & 1941 \\
\hline Promedio & 1728 & 1255 & 1552 \\
\hline
\end{tabular}

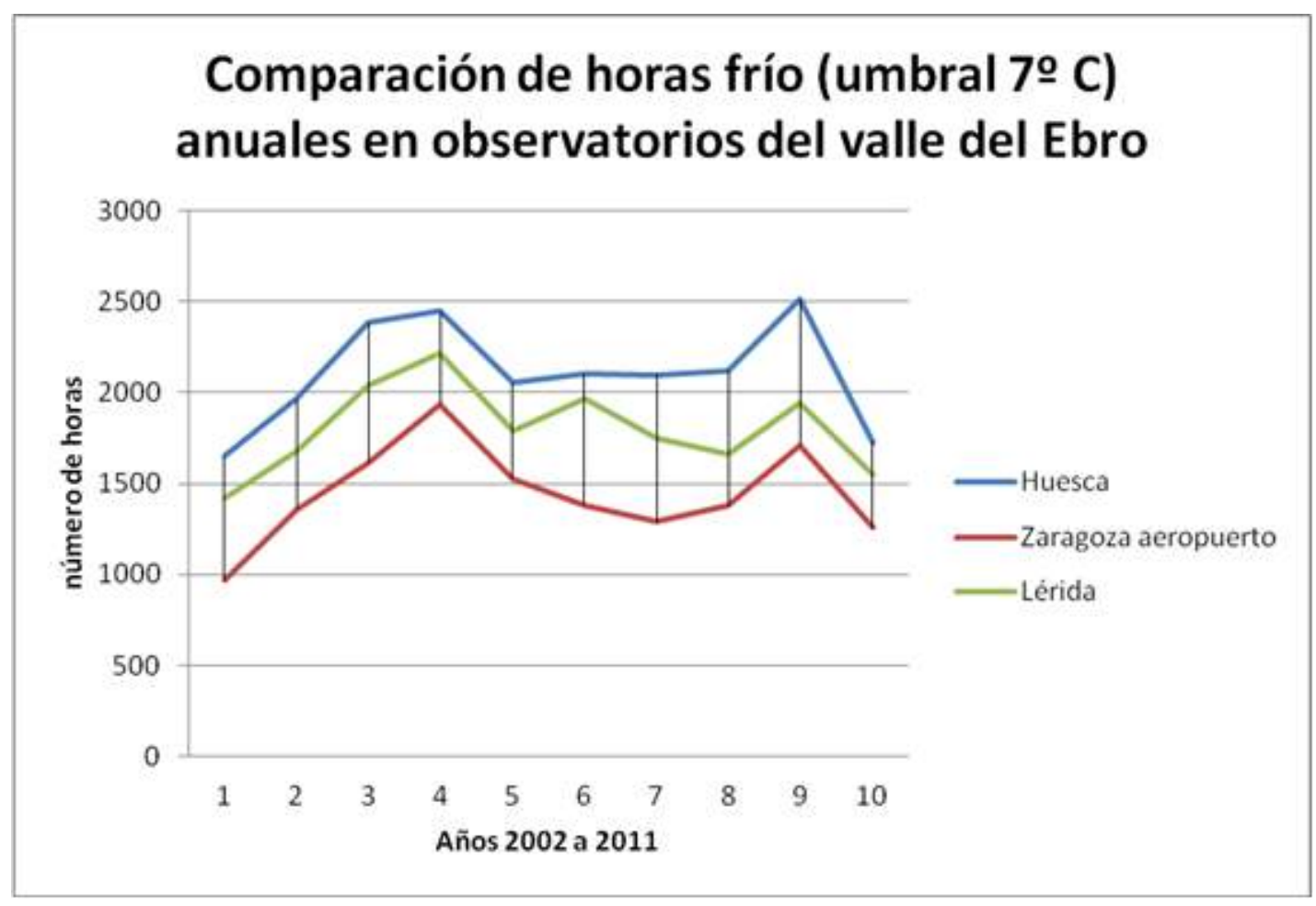

Gráfico 5. Comparación de horas frío (umbral 7ํㅡ) anuales en observatorios del valle del Ebro. 
Hay coherencia entre los datos, excepto en 2007 cuando Zaragoza y Huesca parecen discrepar en la evolución de lo que se obtiene en Lérida.

\section{$\underline{\text { Horas frío contadas en datos horarios en cada uno de los observatorios }}$}

Huesca. Tiene en promedio más de 2000 horas frío (umbral $7^{\circ} \mathrm{C}$ ) al año, oscilando entre las 1651 de 2002 y las 2510 de 2010.

Prácticamente podría decirse que junio, julio y agosto son meses libres de horas frío, si bien el único mes que en los diez años no tuvo horas frío fue julio. En junio y en agosto hubo un solo año con horas frío, en septiembre fueron tres años. Abril tiene un promedio de 3 horas diarias de frío, y mayo y octubre 1 hora diaria. Marzo y noviembre están en torno a las 240 horas. Febrero tiene 400 horas y enero y diciembre pasan de las 500 horas, es decir tienen en torno a 16 horas frío al día de promedio.

Tabla 33. Horas frío contadas en datos horarios en el observatorio de Huesca.

\begin{tabular}{cccccccccccccc}
\hline & ene & feb & mar & abr & may & jun & jul & ago & sep & oct & nov & dic & anual \\
\hline $\mathbf{2 0 0 2}$ & 533 & 311 & 153 & 113 & 45 & 4 & 0 & 0 & 9 & 9 & 143 & 331 & 1651 \\
\hline $\mathbf{2 0 0 3}$ & 553 & 450 & 114 & 81 & 14 & 0 & 0 & 0 & 0 & 81 & 166 & 507 & 1966 \\
$\mathbf{2 0 0 4}$ & 396 & 546 & 314 & 182 & 64 & 0 & 0 & 0 & 0 & 10 & 367 & 503 & 2382 \\
\hline $\mathbf{2 0 0 5}$ & 634 & 481 & 256 & 114 & 1 & 0 & 0 & 0 & 0 & 7 & 293 & 659 & 2445 \\
$\mathbf{2 0 0 6}$ & 647 & 477 & 226 & 81 & 20 & 0 & 0 & 0 & 0 & 4 & 47 & 551 & 2053 \\
\hline $\mathbf{2 0 0 7}$ & 534 & 288 & 256 & 77 & 23 & 0 & 0 & 5 & 8 & 21 & 369 & 520 & 2101 \\
\hline $\mathbf{2 0 0 8}$ & 427 & 251 & 292 & 112 & 1 & 0 & 0 & 0 & 0 & 71 & 370 & 575 & 2099 \\
\hline $\mathbf{2 0 0 9}$ & 612 & 441 & 241 & 153 & 11 & 0 & 0 & 0 & 0 & 34 & 163 & 466 & 2121 \\
$\mathbf{2 0 1 0}$ & 571 & 471 & 304 & 84 & 73 & 0 & 0 & 0 & 4 & 82 & 367 & 554 & 2510 \\
\hline $\mathbf{2 0 1 1}$ & 534 & 323 & 250 & 7 & 4 & 0 & 0 & 0 & 0 & 14 & 140 & 456 & 1728 \\
\hline Prom. & 544 & 404 & 241 & 100 & 26 & 0 & 0 & 1 & 2 & 33 & 243 & 512 & 2106 \\
\hline
\end{tabular}

Zaragoza aeropuerto. Tiene en promedio algo más de 1400 horas frío (umbral $7^{\circ} \mathrm{C}$ ) al año, oscilando entre las 967 de 2002 y las 1938 de 2005, como se ve una oscilación considerable, más del doble.

Los meses de verano: junio, julio, agosto y septiembre son meses libres de horas frío. Mayo y octubre tienen muy pocas horas frío y no todos los años; abril tiene en promedio algo más de 1 hora diaria; marzo y noviembre están en torno a las 150 horas, con una variación muy alta entre unos años y otros: en 2002 hubo en marzo 70 horas y en 2004, 260; en 2006 hubo en noviembre 
36 horas y en 2004,273 . Febrero está en las 300 horas de promedio, diciembre se acerca a las 400 y enero las sobrepasa. En los tres meses de invierno se dan variaciones muy grandes entre unos años y otros; por ejemplo, en diciembre de 2002 se dieron 171 horas y en 2006, 507.

Tabla 34. Horas frío contadas en datos horarios en el observatorio de Zaragoza aeropuerto.

\begin{tabular}{cccccccccccccc}
\hline & ene & feb & mar & abr & may & jun & jul & ago & sep & oct & nov & dic & anual \\
\hline $\mathbf{2 0 0 2}$ & 415 & 199 & 70 & 54 & 0 & 0 & 0 & 0 & 0 & 10 & 48 & 171 & 967 \\
\hline $\mathbf{2 0 0 3}$ & 386 & 324 & 131 & 45 & 0 & 0 & 0 & 0 & 0 & 24 & 125 & 322 & 1357 \\
\hline $\mathbf{2 0 0 4}$ & 254 & 446 & 260 & 83 & 14 & 0 & 0 & 0 & 0 & 5 & 273 & 281 & 1616 \\
\hline $\mathbf{2 0 0 5}$ & 541 & 450 & 234 & 53 & 0 & 0 & 0 & 0 & 0 & 3 & 178 & 479 & 1938 \\
\hline $\mathbf{2 0 0 6}$ & 494 & 389 & 81 & 16 & 1 & 0 & 0 & 0 & 0 & 0 & 36 & 507 & 1525 \\
\hline $\mathbf{2 0 0 7}$ & 458 & 148 & 142 & 36 & 7 & 0 & 0 & 0 & 0 & 16 & 158 & 418 & 1383 \\
\hline $\mathbf{2 0 0 8}$ & 335 & 212 & 145 & 28 & 0 & 0 & 0 & 0 & 0 & 22 & 157 & 391 & 1290 \\
\hline $\mathbf{2 0 0 9}$ & 454 & 292 & 121 & 33 & 0 & 0 & 0 & 0 & 0 & 11 & 74 & 391 & 1376 \\
\hline $\mathbf{2 0 1 0}$ & 425 & 316 & 216 & 22 & 6 & 0 & 0 & 0 & 0 & 15 & 207 & 503 & 1710 \\
\hline $\mathbf{2 0 1 1}$ & 465 & 236 & 148 & 1 & 0 & 0 & 0 & 0 & 0 & 7 & 111 & 287 & 1255 \\
\hline Prom. & 423 & 301 & 155 & 37 & 3 & 0 & 0 & 0 & 0 & 11 & 137 & 375 & 1442 \\
\hline
\end{tabular}

Lérida. Tiene en promedio 1800 horas frío (umbral $7^{\circ} \mathrm{C}$ ) al año, oscilando entre las 1419 de 2002 y las 2213 de 2005.

Junio, julio y agosto están libres de horas frío; septiembre no todos los años está libre, pero tiene muy pocas; también tiene muy pocas mayo y no todos los años. Abril y octubre en torno a 1 hora diaria de promedio; marzo se acerca a las 200 horas de promedio y noviembre las sobrepasa. Febrero sobrepasa las 300 , y enero y diciembre están en torno a las 500; enero ligeramente por encima y diciembre ligeramente por debajo. La variación entre unos años y otros es muy notable en diciembre, entre las 322 de 2002 y las 630 de 2005. También en noviembre, entre las 67 de 2006 y las 380 de 2007.

Tabla 35. Horas frío contadas en datos horarios en el observatorio de Lérida.

\begin{tabular}{cccccccccccccc}
\hline & ene & feb & mar & abr & may & jun & jul & ago & sep & oct & nov & dic & anual \\
\hline $\mathbf{2 0 0 2}$ & 529 & 281 & 85 & 46 & 8 & 0 & 0 & 0 & 7 & 6 & 135 & 322 & 1419 \\
$\mathbf{2 0 0 3}$ & 504 & 368 & 141 & 53 & 1 & 0 & 0 & 0 & 0 & 42 & 162 & 410 & 1681 \\
$\mathbf{2 0 0 4}$ & 365 & 508 & 278 & 97 & 12 & 0 & 0 & 0 & 0 & 15 & 363 & 398 & 2036 \\
\hline $\mathbf{2 0 0 5}$ & 625 & 433 & 245 & 51 & 0 & 0 & 0 & 0 & 0 & 6 & 223 & 630 & 2213 \\
$\mathbf{2 0 0 6}$ & 560 & 442 & 114 & 38 & 0 & 0 & 0 & 0 & 0 & 0 & 67 & 567 & 1788 \\
\hline $\mathbf{2 0 0 7}$ & 601 & 256 & 162 & 23 & 6 & 0 & 0 & 0 & 6 & 41 & 380 & 491 & 1966 \\
$\mathbf{2 0 0 8}$ & 461 & 224 & 161 & 32 & 0 & 0 & 0 & 0 & 0 & 37 & 334 & 499 & 1748 \\
\hline $\mathbf{2 0 0 9}$ & 491 & 317 & 209 & 50 & 2 & 0 & 0 & 0 & 0 & 31 & 128 & 436 & 1664 \\
$\mathbf{2 0 1 0}$ & 440 & 345 & 244 & 45 & 15 & 0 & 0 & 0 & 3 & 84 & 275 & 490 & 1941 \\
\hline $\mathbf{2 0 1 1}$ & 547 & 320 & 152 & 0 & 0 & 0 & 0 & 0 & 0 & 15 & 96 & 422 & 1552 \\
Prom. & 512 & 349 & 179 & 44 & 4 & 0 & 0 & 0 & 2 & 28 & 216 & 467 & 1801 \\
\hline
\end{tabular}


Observatorios: Pamplona Noáin (9263d), Haro automática (9121x) y Logroño-Agoncillo (9170).

Tabla 36. Comparación de horas frío anuales contadas a partir de datos horarios en los tres observatorios de la parte media de la cuenca del Ebro: Navarra y La Rioja.

\begin{tabular}{|c|ccc|}
\hline & $\begin{array}{c}\text { Pamplona Noáin } \\
\text { 9263d }\end{array}$ & $\begin{array}{c}\text { Haro aut. } \\
\mathbf{9 1 2 1 x}\end{array}$ & $\begin{array}{c}\text { Logroño Agoncillo } \\
\mathbf{9 1 7 0}\end{array}$ \\
\hline $\mathbf{A n ̃ o}$ & HF & HF & HF \\
\hline $\mathbf{2 0 0 2}$ & 1508 & & 1296 \\
\hline $\mathbf{2 0 0 3}$ & 1890 & & 1552 \\
\hline $\mathbf{2 0 0 4}$ & 2369 & 2328 & 1893 \\
\hline $\mathbf{2 0 0 5}$ & 2619 & 2506 & 2221 \\
\hline $\mathbf{2 0 0 6}$ & 1940 & 1964 & 1764 \\
\hline $\mathbf{2 0 0 7}$ & 1910 & 1929 & 1753 \\
\hline $\mathbf{2 0 0 8}$ & 2009 & & 1677 \\
\hline $\mathbf{2 0 0 9}$ & 2098 & & 1806 \\
\hline $\mathbf{2 0 1 0}$ & 2454 & 2613 & 2187 \\
\hline $\mathbf{2 0 1 1}$ & 1644 & 1738 & 1610 \\
\hline Promedio & 2044 & 2180 & 1776 \\
\hline
\end{tabular}

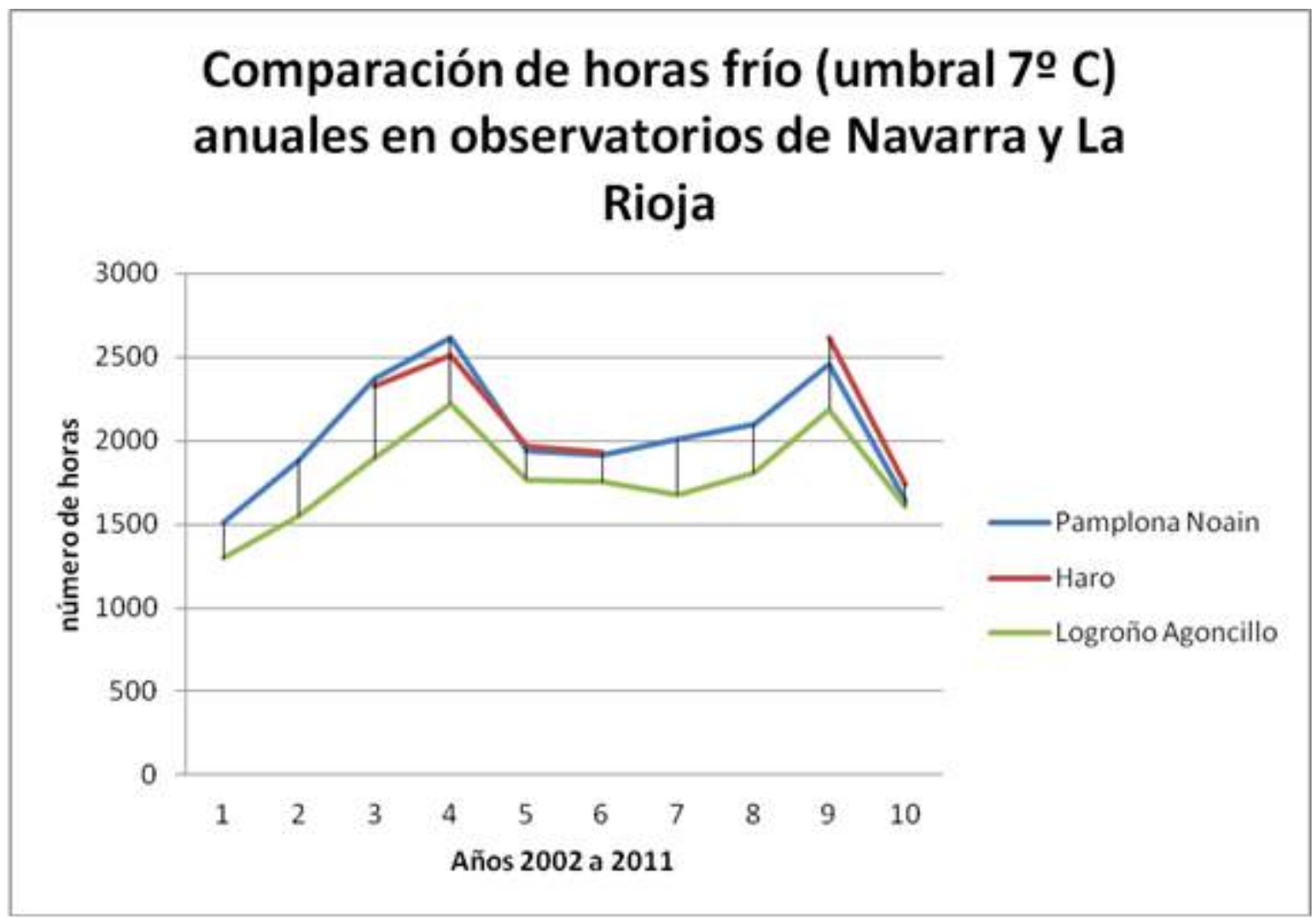

Gráfico 6. Comparación de horas frío (umbral 7ํㅡ) anuales en observatorios de Navarra y La Rioja.

Hay coherencia entre los datos. 


\section{Horas frío contadas en datos horarios en cada uno de los observatorios}

Pamplona-Noáin. Tiene en promedio en torno a las 2000 horas frío (umbral $7^{\circ} \mathrm{C}$ ) al año, oscilando entre las 1508 de 2002 y las 2619 de 2005.

Agosto está libre de horas frío, julio sólo las ha tenido en dos años (y apenas), y junio en tres años (y apenas). Septiembre hay años que tiene y otros que no, pero hay años que llega a tener hasta 18 horas. Mayo tiene todos los años y un promedio de 1 hora diaria. Octubre tiene de promedio 50 horas, pero puede haber años como 2006 que no tiene horas frío y otros como 2008 que llega a las 127. Abril pasa de las 100 y noviembre de las 200 . Febrero y diciembre están en torno a las 400 y enero le falta poco para las 500 , es decir, más de 16 horas diarias.

Tabla 37. Horas frío contadas en datos horarios en el observatorio de Pamplona-Noáin.

\begin{tabular}{cccccccccccccc}
\hline & ene & feb & mar & abr & may & jun & jul & ago & sep & oct & nov & dic & anual \\
\hline $\mathbf{2 0 0 2}$ & 390 & 313 & 157 & 176 & 72 & 3 & 0 & 0 & 16 & 34 & 103 & 244 & 1508 \\
\hline $\mathbf{2 0 0 3}$ & 484 & 460 & 147 & 115 & 31 & 0 & 5 & 0 & 0 & 70 & 171 & 407 & 1890 \\
$\mathbf{2 0 0 4}$ & 419 & 535 & 429 & 166 & 73 & 0 & 0 & 0 & 0 & 18 & 345 & 384 & 2369 \\
\hline $\mathbf{2 0 0 5}$ & 586 & 559 & 327 & 167 & 9 & 0 & 0 & 0 & 7 & 14 & 337 & 613 & 2619 \\
$\mathbf{2 0 0 6}$ & 565 & 503 & 201 & 88 & 33 & 2 & 0 & 0 & 0 & 0 & 54 & 494 & 1940 \\
\hline $\mathbf{2 0 0 7}$ & 472 & 193 & 312 & 90 & 14 & 0 & 1 & 0 & 18 & 49 & 290 & 471 & 1910 \\
$\mathbf{2 0 0 8}$ & 406 & 250 & 310 & 113 & 13 & 1 & 0 & 0 & 8 & 127 & 258 & 523 & 2009 \\
\hline $\mathbf{2 0 0 9}$ & 570 & 434 & 298 & 155 & 9 & 0 & 0 & 0 & 0 & 47 & 170 & 415 & 2098 \\
$\mathbf{2 0 1 0}$ & 591 & 403 & 328 & 97 & 84 & 0 & 0 & 0 & 17 & 81 & 304 & 549 & 2454 \\
$\mathbf{2 0 1 1}$ & 500 & 340 & 222 & 30 & 3 & 0 & 0 & 0 & 0 & 46 & 132 & 371 & 1644 \\
Prom. & 498 & 399 & 273 & 120 & 34 & 1 & 1 & 0 & 7 & 49 & 216 & 447 & 2044 \\
\hline
\end{tabular}

Haro. No tiene los 10 años de datos, sino ocho, de 2004 a 2011, y el promedio de horas frío anuales es de algo más de 2000, oscilando entre las 1738 de 2011 y las 2613 de 2010.

El mes de julio está libre de horas frío. Junio y agosto tienen pocas y pocos años. Septiembre tiene pocas horas y no todos los años. Mayo un promedio de una hora diaria y octubre, 2 horas diarias; abril pasa de las 100 horas y noviembre de las 200; febrero pasa de las 400 y enero y diciembre se acercan a las 500 . 
Tabla 38. Horas frío contadas en datos horarios en el observatorio de Haro.

\begin{tabular}{|cccccccccccccc}
\hline & ene & feb & mar & abr & may & jun & jul & ago & sep & oct & nov & dic & anual \\
\hline $\mathbf{2 0 0 2}$ & & & & & & & & & & & & & \\
\hline $\mathbf{2 0 0 3}$ & & & & & & & & & & & & & \\
\hline $\mathbf{2 0 0 4}$ & 380 & 551 & 354 & 191 & 52 & 0 & 0 & 0 & 1 & 12 & 347 & 440 & 2328 \\
\hline $\mathbf{2 0 0 5}$ & 578 & 582 & 315 & 145 & 12 & 0 & 0 & 0 & 21 & 20 & 322 & 511 & 2506 \\
\hline $\mathbf{2 0 0 6}$ & 588 & 485 & 141 & 71 & 21 & 4 & 0 & 0 & 0 & 8 & 99 & 547 & 1964 \\
\hline $\mathbf{2 0 0 7}$ & 445 & 200 & 336 & 86 & 26 & 0 & 0 & 0 & 9 & 65 & 286 & 476 & 1929 \\
\hline $\mathbf{2 0 0 8}$ & 375 & 253 & 307 & 140 & 19 & 0 & 0 & 0 & 16 & 151 & 270 & 527 & 2058 \\
\hline $\mathbf{2 0 0 9}$ & 521 & 435 & 338 & 168 & 18 & 1 & 0 & 1 & 0 & 66 & 120 & 452 & 2120 \\
\hline $\mathbf{2 0 1 0}$ & 592 & 445 & 333 & 109 & 134 & 1 & 0 & 0 & 9 & 105 & 304 & 581 & 2613 \\
\hline $\mathbf{2 0 1 1}$ & 467 & 393 & 236 & 40 & 8 & 0 & 0 & 1 & 1 & 89 & 119 & 384 & 1738 \\
\hline Prom. & 493 & 418 & 295 & 119 & 36 & 1 & 0 & 0 & 7 & 65 & 233 & 490 & 2157 \\
\hline
\end{tabular}

Logroño-Agoncillo. Tiene en promedio más de 1700 horas frío (umbral $7^{\circ} \mathrm{C}$ ) al año, oscilando entre las 1296 de 2002 y las 2221 de 2005.

Los meses de verano, junio, julio y agosto están libres de horas frío. Mayo y septiembre tienen muy pocas horas, si bien en mayo hay prácticamente todos los años alguna hora frío y en septiembre la mitad de los años no hay ninguna. Abril tiene más de 2 horas diarias de promedio y octubre poco más de una diaria. Marzo sobrepasa en promedio las 200 horas y noviembre no las alcanza. Enero y diciembre pasan de las 400 horas y febrero le falta poco para las 400.

Tabla 39. Horas frío contadas en datos horarios en el observatorio de Logroño-Agoncillo.

\begin{tabular}{cccccccccccccc}
\hline & ene & feb & mar & abr & may & jun & jul & ago & sep & oct & nov & dic & anual \\
\hline $\mathbf{2 0 0 2}$ & 419 & 263 & 112 & 92 & 11 & 0 & 0 & 0 & 6 & 23 & 141 & 229 & 1296 \\
$\mathbf{2 0 0 3}$ & 428 & 359 & 137 & 78 & 8 & 0 & 0 & 0 & 0 & 51 & 174 & 317 & 1552 \\
$\mathbf{2 0 0 4}$ & 319 & 498 & 317 & 139 & 41 & 0 & 0 & 0 & 0 & 15 & 274 & 290 & 1893 \\
$\mathbf{2 0 0 5}$ & 552 & 515 & 288 & 108 & 3 & 0 & 0 & 0 & 5 & 4 & 265 & 481 & 2221 \\
$\mathbf{2 0 0 6}$ & 507 & 439 & 140 & 48 & 18 & 0 & 0 & 0 & 0 & 5 & 78 & 515 & 1750 \\
$\mathbf{2 0 0 7}$ & 470 & 210 & 281 & 64 & 16 & 0 & 0 & 0 & 5 & 43 & 237 & 427 & 1753 \\
$\mathbf{2 0 0 8}$ & 340 & 268 & 236 & 90 & 8 & 0 & 0 & 0 & 6 & 97 & 195 & 436 & 1676 \\
$\mathbf{2 0 0 9}$ & 506 & 354 & 256 & 93 & 6 & 0 & 0 & 0 & 0 & 37 & 116 & 438 & 1806 \\
$\mathbf{2 0 1 0}$ & 514 & 406 & 277 & 74 & 47 & 0 & 0 & 0 & 2 & 74 & 260 & 533 & 2187 \\
$\mathbf{2 0 1 1}$ & 476 & 345 & 227 & 19 & 0 & 0 & 0 & 0 & 0 & 63 & 132 & 346 & 1608 \\
Prom. & 453 & 366 & 227 & 81 & 16 & 0 & 0 & 0 & 2 & 41 & 187 & 401 & 1774 \\
\hline
\end{tabular}


Podría decirse que en el Valle del Ebro por debajo de los 300 metros de altitud no se alcanzan las 2000 horas frío anuales en promedio, entre los 300 y los 500 metros están en torno a las 2000 horas, y por encima de los $500 \mathrm{~m}$ se superan las 2000 horas anuales.

En la parte baja del valle, por debajo de $300 \mathrm{~m}$, los meses de verano están libres o casi libres de horas frío. Entre $300 \mathrm{~m}$ y $500 \mathrm{~m}$ ya sólo julio y agosto pueden estar libres. Por encima de 500 metros no hay meses libres de horas frío. La primavera y el otoño, en la parte baja, tienen pocas horas frío. Pero los meses de invierno tienen más de 10 horas diarias de promedio, incluso en altitudes por debajo de los $300 \mathrm{~m}$.

Es preciso tener en cuenta la marcada variabilidad interanual y entre cada uno de los meses en los distintos años.

\subsubsection{Zona de la franja costera del noreste peninsular: costa catalana}

Observatorios: Barcelona (0076), Gerona (0370x), Reus (0016a), Tarragona (0042x y 0042y) y Tortosa (9881a).

Tabla 40. Comparación de horas frío anuales contadas a partir de datos horarios en los cinco observatorios de la franja costera del noreste peninsular: costa catalana.

\begin{tabular}{|cccccc|}
\hline Barcelona & $\begin{array}{c}\text { Gerona } \\
\mathbf{0 3 7 0 x}\end{array}$ & $\begin{array}{c}\text { Reus } \\
\mathbf{0 0 1 6 a}\end{array}$ & $\begin{array}{c}\text { Tarragona } \\
\mathbf{0 0 4 2 x} \mathbf{y}\end{array}$ & $\begin{array}{c}\text { Tortosa } \\
\mathbf{9 9 8 1 a}\end{array}$ \\
\hline $\mathbf{H n}$ & $\mathrm{HF}$ & $\mathrm{HF}$ & $\mathrm{HF}$ & $\mathrm{HF}$ & HF \\
\hline $\mathbf{2 0 0 3}$ & 465 & & 404 & 135 & 369 \\
\hline $\mathbf{2 0 0 4}$ & 573 & 1405 & 653 & 415 & 564 \\
\hline $\mathbf{2 0 0 5}$ & 375 & 1417 & 887 & 429 & 582 \\
\hline $\mathbf{2 0 0 6}$ & 1120 & 1937 & 1443 & 954 & 1101 \\
\hline $\mathbf{2 0 0 7}$ & 823 & 1137 & 985 & 469 & 767 \\
\hline $\mathbf{2 0 0 8}$ & 653 & 1330 & 990 & 396 & 602 \\
\hline $\mathbf{2 0 0 9}$ & 728 & 1256 & 1137 & 347 & 577 \\
\hline $\mathbf{2 0 1 0}$ & 1194 & & 1143 & 490 & 637 \\
\hline $\mathbf{2 0 1 1}$ & 685 & & 1387 & 794 & 910 \\
\hline promedio & 740 & 1414 & 972 & 478 & 664 \\
\hline
\end{tabular}




\section{Comparación de horas frío (umbral 7ํㅡ) anuales en observatorios de la franja costera del noreste peninsular}

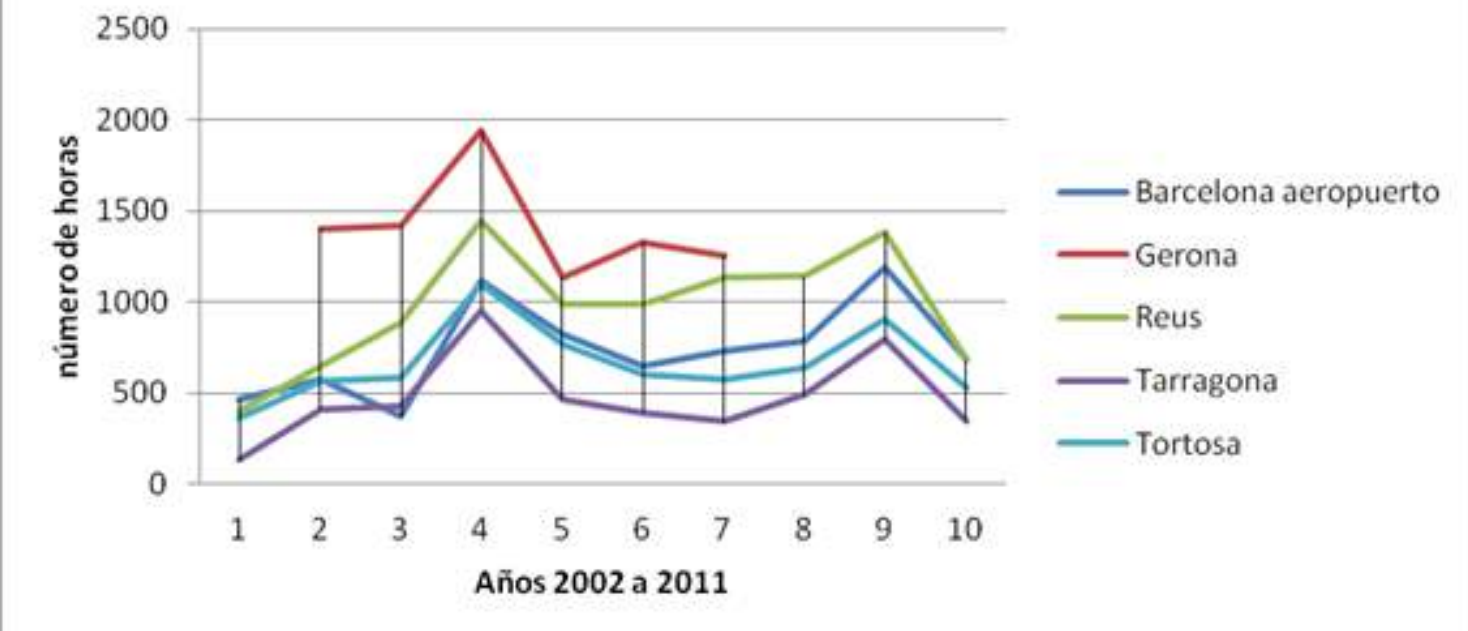

Gráfico 7. Comparación de horas frío (umbral 7ํㅡ) anuales en observatorios de la franja costera del noreste peninsular: costa catalana.

Los datos son coherentes entre ellos, y muestran que en el noreste peninsular, en la zona costera, no se llega a las 1000 horas frío anuales, excepto en el extremo norte y a cierta distancia de la costa.

\section{$\underline{\text { Horas frío contadas en datos horarios en cada uno de los observatorios }}$}

Barcelona. Tiene en promedio unas 750 horas frío (umbral $7^{\circ} \mathrm{C}$ ) al año, oscilando entre las 375 horas de 2004 y las 1192 de 2010.

De mayo a septiembre, ambos incluidos está libre de horas frío; también abril y octubre tienen muy pocas y no todos los años; marzo y noviembre están en torno a las dos horas diarias de promedio; febrero no llega a las 200 horas mensuales, y enero y diciembre las sobrepasan. Incluso en los meses de más horas frío hay grandes diferencias entre unos años y otros. Por ejemplo, diciembre de 2002 tuvo 53 horas, menos de dos horas diarias, mientras que diciembre de 2005 tuvo 428 horas, más de 13 horas diarias. Enero de 2004 tuvo 87 horas, mientras que enero de 2006 tuvo 323 horas. 
Tabla 41. Horas frío contadas en datos horarios en el observatorio de Barcelona.

\begin{tabular}{cccccccccccccc}
\hline & ene & feb & mar & abr & may & jun & jul & ago & sep & oct & nov & dic & anual \\
\hline $\mathbf{2 0 0 2}$ & 240 & 144 & 27 & 0 & 0 & 0 & 0 & 0 & 0 & 0 & 1 & 53 & 465 \\
\hline $\mathbf{2 0 0 3}$ & 273 & 202 & 19 & 6 & 0 & 0 & 0 & 0 & 0 & 0 & 0 & 73 & 573 \\
$\mathbf{2 0 0 4}$ & 87 & 91 & 53 & 2 & 0 & 0 & 0 & 0 & 0 & 0 & 47 & 95 & 375 \\
\hline $\mathbf{2 0 0 5}$ & 261 & 229 & 120 & 0 & 1 & 0 & 0 & 0 & 0 & 0 & 81 & 428 & 1120 \\
\hline $\mathbf{2 0 0 6}$ & 323 & 224 & 48 & 0 & 0 & 0 & 0 & 0 & 0 & 0 & 2 & 226 & 823 \\
\hline $\mathbf{2 0 0 7}$ & 170 & 52 & 48 & 0 & 0 & 0 & 0 & 0 & 0 & 0 & 131 & 252 & 653 \\
$\mathbf{2 0 0 8}$ & 140 & 108 & 62 & 0 & 0 & 0 & 0 & 0 & 0 & 22 & 123 & 273 & 728 \\
\hline $\mathbf{2 0 0 9}$ & 313 & 186 & 41 & 0 & 0 & 0 & 0 & 0 & 0 & 0 & 11 & 233 & 784 \\
\hline $\mathbf{2 0 1 0}$ & 310 & 244 & 195 & 4 & 0 & 0 & 0 & 0 & 0 & 7 & 139 & 293 & 1192 \\
\hline $\mathbf{2 0 1 1}$ & 261 & 181 & 70 & 0 & 0 & 0 & 0 & 0 & 0 & 0 & 8 & 165 & 685 \\
\hline Prom. & 238 & 166 & 68 & 1 & 0 & 0 & 0 & 0 & 0 & 3 & 54 & 209 & 740 \\
\hline
\end{tabular}

Gerona. Le faltan datos en 2002, 2006 y 2010 y no tiene datos en 2011. Para el resto el promedio es de poco más de 1400 horas anuales. Oscilando entre las 1256 de 2008 y 2009 y 1937 de 2005.

Junio, julio y agosto están libres de horas frío, mayo y septiembre tienen muy pocas y no todos los años, octubre tiene todos los años pero también muy pocas. Abril tiene entre una y dos horas diarias de promedio, marzo y noviembre tienen unas 170 horas, febrero no llega a las 300 , diciembre no llega a las 350 , y enero las sobrepasa ligeramente.

Tabla 42. Horas frío contadas en datos horarios en el observatorio de Gerona.

\begin{tabular}{cccccccccccccc}
\hline & ene & feb & mar & abr & may & jun & jul & ago & sep & oct & nov & dic & anual \\
\hline $\mathbf{2 0 0 2}$ & & & 114 & 22 & 8 & 0 & 0 & 0 & 6 & 0 & 105 & 286 & \\
$\mathbf{2 0 0 3}$ & 417 & 323 & 167 & 52 & 0 & 0 & 0 & 0 & 0 & 48 & 101 & 296 & 1404 \\
$\mathbf{2 0 0 4}$ & 314 & 312 & 203 & 72 & 15 & 0 & 0 & 0 & 0 & 10 & 209 & 282 & 1417 \\
$\mathbf{2 0 0 5}$ & 490 & 418 & 269 & 67 & 0 & 0 & 0 & 0 & 2 & 1 & 205 & 485 & 1937 \\
$\mathbf{2 0 0 6}$ & 389 & 277 & 132 & 31 & 0 & 0 & 0 & 0 & 0 & & & 308 & \\
$\mathbf{2 0 0 7}$ & 329 & 180 & 153 & 19 & 0 & 0 & 0 & 0 & 0 & 22 & 249 & 378 & 1330 \\
$\mathbf{2 0 0 8}$ & 244 & 213 & 163 & 52 & 0 & 0 & 0 & 0 & 0 & 25 & 219 & 340 & 1256 \\
$\mathbf{2 0 0 9}$ & 244 & 213 & 163 & 52 & 0 & 0 & 0 & 0 & 0 & 25 & 219 & 340 & 1256 \\
$\mathbf{2 0 1 0}$ & 400 & 299 & 162 & 44 & 0 & 0 & 0 & 0 & 0 & 25 & 96 & & \\
\hline $\mathbf{2 0 1 1}$ & & & & & & & & & & & & & \\
Prom. & 353 & 279 & 170 & 46 & 3 & 0 & 0 & 0 & 1 & 20 & 175 & 339 & 1433 \\
\hline
\end{tabular}

Reus. Tiene en promedio en torno a 1000 horas frío (umbral $7^{\circ} \mathrm{C}$ ) al año, oscilando entre las 404 horas de 2002 y las 1443 de 2005. 
De mayo a septiembre está prácticamente libre de horas frío. Octubre tiene muy pocas horas y no todos los años y abril no llega a hora diaria de promedio. Noviembre y marzo tienen poco más de 3 horas diarias de promedio. Febrero tiene 208 horas mensuales, diciembre 245 y enero sobrepasa las 250 horas.

Tabla 43. Horas frío contadas en datos horarios en el observatorio de Reus.

\begin{tabular}{cccccccccccccc}
\hline & ene & feb & mar & abr & may & jun & jul & ago & sep & oct & nov & dic & anual \\
\hline $\mathbf{2 0 0 2}$ & 198 & 88 & 26 & 10 & 0 & 0 & 0 & 0 & 0 & 0 & 29 & 53 & 404 \\
$\mathbf{2 0 0 3}$ & 239 & 206 & 46 & 13 & 0 & 0 & 0 & 0 & 0 & 3 & 13 & 133 & 653 \\
$\mathbf{2 0 0 4}$ & 110 & 227 & 126 & 34 & 0 & 0 & 0 & 0 & 0 & 6 & 179 & 199 & 881 \\
\hline $\mathbf{2 0 0 5}$ & 408 & 324 & 198 & 20 & 0 & 0 & 0 & 0 & 0 & 0 & 91 & 402 & 1443 \\
$\mathbf{2 0 0 6}$ & 310 & 280 & 55 & 16 & 0 & 0 & 0 & 0 & 0 & 0 & 18 & 305 & 984 \\
$\mathbf{2 0 0 7}$ & 292 & 111 & 92 & 9 & 0 & 0 & 0 & 0 & 1 & 3 & 202 & 280 & 990 \\
$\mathbf{2 0 0 8}$ & 288 & 177 & 124 & 19 & 0 & 0 & 0 & 0 & 0 & 23 & 220 & 284 & 1135 \\
$\mathbf{2 0 0 9}$ & 321 & 225 & 177 & 51 & 0 & 0 & 0 & 0 & 0 & 7 & 50 & 312 & 1143 \\
$\mathbf{2 0 1 0}$ & 328 & 286 & 240 & 35 & 8 & 0 & 0 & 0 & 4 & 25 & 142 & 319 & 1387 \\
$\mathbf{2 0 1 1}$ & 273 & 152 & 67 & 0 & 0 & 0 & 0 & 0 & 0 & 0 & 22 & 167 & 681 \\
Prom. & 277 & 208 & 115 & 21 & 1 & 0 & 0 & 0 & 1 & 7 & 97 & 245 & 970 \\
\hline
\end{tabular}

Tarragona. No llega en promedio a las 500 horas frío (umbral $7^{\circ} \mathrm{C}$ ) al año, oscilando entre las 135 horas de 2002 y las 954 de 2005.

De mayo a septiembre está libre de horas frío. Abril y octubre tienen muy pocas y no todos los años; noviembre tiene 1 hora diaria de promedio y marzo, 2; enero, febrero y diciembre están por encima de las 100 horas.

Tabla 44. Horas frío contadas en datos horarios en el observatorio de Tarragona.

\begin{tabular}{cccccccccccccc}
\hline & ene & feb & mar & abr & may & jun & jul & ago & sep & oct & nov & dic & anual \\
\hline $\mathbf{2 0 0 2}$ & 88 & 33 & 3 & 0 & 0 & 0 & 0 & 0 & 0 & 0 & 0 & 11 & 135 \\
$\mathbf{2 0 0 3}$ & 177 & 175 & 6 & 4 & 0 & 1 & 0 & 0 & 0 & 0 & 0 & 49 & 412 \\
$\mathbf{2 0 0 4}$ & 54 & 156 & 100 & 16 & 0 & 0 & 0 & 0 & 0 & 0 & 54 & 103 & 483 \\
$\mathbf{2 0 0 5}$ & 269 & 255 & 121 & 1 & 0 & 0 & 0 & 0 & 0 & 0 & 35 & 273 & 954 \\
$\mathbf{2 0 0 6}$ & 175 & 132 & 22 & 3 & 0 & 0 & 0 & 0 & 0 & 0 & 0 & 137 & 469 \\
\hline $\mathbf{2 0 0 7}$ & 98 & 32 & 39 & 0 & 0 & 0 & 0 & 0 & 0 & 0 & 57 & 170 & 396 \\
$\mathbf{2 0 0 8}$ & 41 & 12 & 45 & 1 & 0 & 0 & 0 & 0 & 0 & 6 & 70 & 148 & 323 \\
\hline $\mathbf{2 0 0 9}$ & 197 & 75 & 24 & 0 & 0 & 0 & 0 & 0 & 0 & 0 & 6 & 187 & 489 \\
$\mathbf{2 0 1 0}$ & 225 & 168 & 137 & 1 & 0 & 0 & 0 & 0 & 0 & 2 & 65 & 196 & 794 \\
\hline $\mathbf{2 0 1 1}$ & 170 & 62 & 50 & 0 & 0 & 0 & 0 & 0 & 0 & 0 & 0 & 70 & 352 \\
Prom. & 149 & 110 & 55 & 3 & 0 & 0 & 0 & 0 & 0 & 1 & 29 & 134 & 481 \\
\hline
\end{tabular}


Tortosa. Tiene en promedio menos de 700 horas frío (umbral $7^{\circ} \mathrm{C}$ ) al año, oscilando entre las 369 de 2002 y las 1101 de 2005.

De junio a septiembre está libre de horas frío. Mayo solo tiene 1 hora un año de los diez. Octubre tiene muy pocas y no todos los años. Abril tiene muy pocas. Noviembre sobrepasa ligeramente 1 hora diaria de promedio y marzo, 2 horas diarias de promedio. Febrero y diciembre están en torno a las 150 horas y enero 200 horas.

Tabla 45. Horas frío contadas en datos horarios en el observatorio de Tortosa.

\begin{tabular}{cccccccccccccc}
\hline & ene & feb & mar & abr & may & jun & jul & ago & sep & oct & nov & dic & anual \\
\hline $\mathbf{2 0 0 2}$ & 175 & 74 & 28 & 5 & 0 & 0 & 0 & 0 & 0 & 0 & 22 & 65 & 369 \\
\hline $\mathbf{2 0 0 3}$ & 210 & 160 & 81 & 2 & 0 & 0 & 0 & 0 & 0 & 3 & 0 & 108 & 564 \\
$\mathbf{2 0 0 4}$ & 80 & 209 & 94 & 22 & 1 & 0 & 0 & 0 & 0 & 0 & 76 & 100 & 582 \\
\hline $\mathbf{2 0 0 5}$ & 350 & 280 & 153 & 5 & 0 & 0 & 0 & 0 & 0 & 0 & 27 & 286 & 1101 \\
\hline $\mathbf{2 0 0 6}$ & 285 & 213 & 22 & 5 & 0 & 0 & 0 & 0 & 0 & 0 & 1 & 241 & 767 \\
\hline $\mathbf{2 0 0 7}$ & 203 & 75 & 60 & 0 & 0 & 0 & 0 & 0 & 0 & 0 & 74 & 190 & 602 \\
$\mathbf{2 0 0 8}$ & 165 & 113 & 38 & 2 & 0 & 0 & 0 & 0 & 0 & 11 & 71 & 177 & 577 \\
\hline $\mathbf{2 0 0 9}$ & 249 & 127 & 46 & 7 & 0 & 0 & 0 & 0 & 0 & 0 & 10 & 198 & 637 \\
$\mathbf{2 0 1 0}$ & 237 & 208 & 139 & 3 & 0 & 0 & 0 & 0 & 0 & 7 & 81 & 235 & 910 \\
\hline $\mathbf{2 0 1 1}$ & 262 & 104 & 69 & 0 & 0 & 0 & 0 & 0 & 0 & 0 & 9 & 85 & 529 \\
\hline Prom. & 222 & 156 & 73 & 5 & 0 & 0 & 0 & 0 & 0 & 2 & 37 & 169 & 664 \\
\hline
\end{tabular}

Resumen de horas frío contadas para la zona costera de noreste peninsular entre el nivel del mar y 300 metros

En la zona costera, por debajo de los $200 \mathrm{~m}$ de altitud no se llega a las 700 horas anuales, y desde mayo a septiembre, ambos incluidos, no hay horas frío; incluso en abril y octubre hay muy pocas horas. En los meses de invierno no se llega a las 200 horas.

En el interior, en altitudes por debajo de $300 \mathrm{~m}$, se puede pasar de las 1000 horas, pero también los meses de verano están libres de horas frío y los meses de invierno no tienen mucho más de 300 horas. En altitudes más altas, sobre todo en las zonas montañosas, aunque sean cercanas a la costa pueden darse muchas más horas frío.

Es preciso tener en cuenta la marcada variabilidad interanual y entre cada uno de los meses en los distintos años 


\subsubsection{Cuenca del Tajo}

Observatorios: Madrid-Barajas (3129), Guadalajara (3168c), Getafe (3200), Navalmoral de la Mata (3434x), Cáceres (3469a), Plasencia (3519x), Toledo (3260b) y Trujillo (3463x).

Tabla 46. Comparación de horas frío anuales contadas a partir de datos horarios en los ocho observatorios de la cuenca del Tajo.

\begin{tabular}{|c|c|c|c|c|c|c|c|c|}
\hline & $\begin{array}{c}\text { Madrid } \\
\text { Barajas } \\
3129\end{array}$ & $\begin{array}{c}\text { Guadal. } \\
3168 c\end{array}$ & $\begin{array}{c}\text { Madrid } \\
\text { Getafe } \\
3200\end{array}$ & $\begin{array}{c}\text { Navalm. } \\
3434 x\end{array}$ & $\begin{array}{c}\text { Cáceres } \\
\text { 3469a }\end{array}$ & $\begin{array}{c}\text { Plasen. } \\
3519 x\end{array}$ & $\begin{array}{l}\text { Toledo } \\
3260 b\end{array}$ & $\begin{array}{l}\text { Trujillo } \\
3463 x\end{array}$ \\
\hline Año & HF & $\mathrm{HF}$ & HF & HF & HF & $\mathrm{HF}$ & $\mathrm{HF}$ & $\mathrm{HF}$ \\
\hline 2002 & 1598 & 1983 & 1238 & 884 & 540 & 494 & 1122 & \\
\hline 2003 & 1730 & 2047 & 1499 & 1055 & 855 & 1044 & 1355 & \\
\hline 2004 & 2047 & 2377 & 1620 & 1351 & 1041 & & 1595 & 1448 \\
\hline 2005 & 2082 & 2580 & 1890 & 1691 & 1486 & 1490 & 1836 & 1682 \\
\hline 2006 & 1681 & 2178 & 1532 & 1374 & 1190 & 1229 & 1479 & 1323 \\
\hline 2007 & 1970 & 2506 & 1590 & & 1132 & & 1581 & 1347 \\
\hline 2008 & 1792 & 2358 & 1450 & & 944 & 1011 & 1375 & 1297 \\
\hline 2009 & 1793 & 2409 & 1467 & 1229 & 905 & 1148 & 1420 & 1150 \\
\hline 2010 & 2050 & 2582 & 1739 & 1326 & 1081 & & 1631 & 1339 \\
\hline 2011 & 1612 & 1791 & 1395 & & 943 & 1022 & 1352 & 1151 \\
\hline Prom. & 1836 & 2281 & 1542 & 1273 & 1012 & 1063 & 1475 & 1342 \\
\hline
\end{tabular}

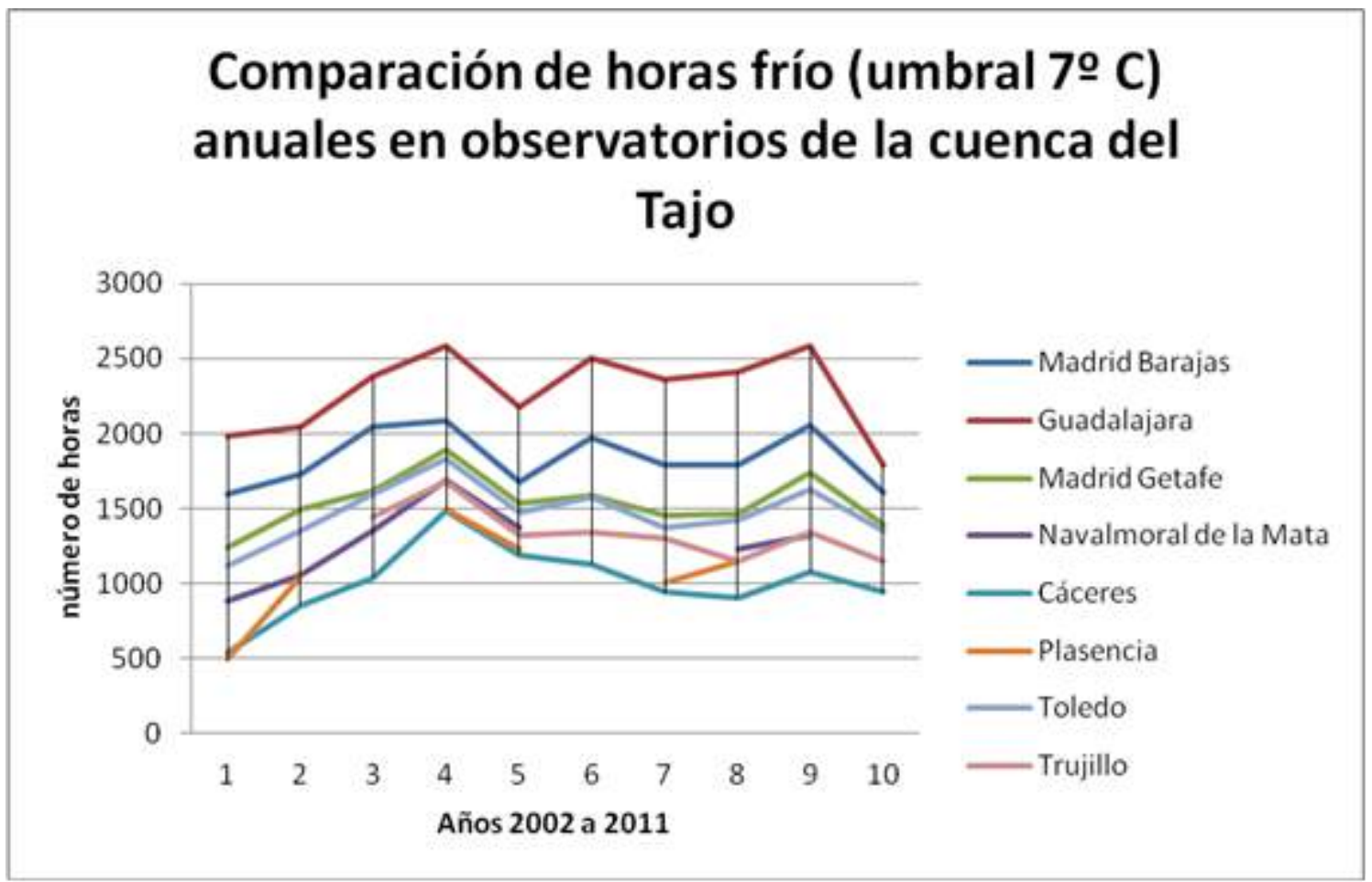

Gráfico 8. Comparación de horas frío (umbral 7ํㅡ) anuales en observatorios de la cuenca del Tajo. 
Los datos son coherentes entre ellos, más horas frío en la parte alta de la cuenca y menos a medida que se desciende en ella, pero la diferencia entre Madrid Barajas y Madrid Getafe es excesiva.

\section{$\underline{\text { Horas frío contadas en datos horarios en cada uno de los observatorios }}$}

Madrid Barajas. Tiene en promedio más de 1800 horas frío (umbral $7^{\circ} \mathrm{C}$ ) al año, oscilando entre las 1598 de 2002 y las 2082 de 2005.

Los meses de verano junio, julio y agosto están prácticamente libres de horas frío. También septiembre está casi libre de horas frío, solo ha tenido en tres años de los diez. Mayo llega a la media hora mensual de promedio, pero hay años, como el 2010, en las que se acerca a las 2 horas diarias de promedio. Octubre tiene 1 hora diaria de promedio y abril se acerca a las tres. Marzo y noviembre sobrepasan en promedio las 200 horas mensuales. Enero y diciembre pasan de las 400 horas y febrero está en torno a las 350.

Tabla 47. Horas frío contadas en datos horarios en el observatorio de Madrid Barajas.

\begin{tabular}{rrrrrrrrrrrrrr}
\hline & ene & feb & mar & abr & may & jun & jul & ago & sep & oct & nov & dic & anual \\
\hline $\mathbf{2 0 0 2}$ & 423 & 307 & 190 & 141 & 36 & 1 & 0 & 0 & 7 & 26 & 184 & 283 & 1598 \\
\hline 2003 & 446 & 391 & 157 & 56 & 8 & 0 & 0 & 0 & 0 & 37 & 157 & 478 & 1730 \\
$\mathbf{2 0 0 4}$ & 405 & 442 & 285 & 140 & 25 & 0 & 0 & 0 & 0 & 14 & 300 & 436 & 2047 \\
$\mathbf{2 0 0 5}$ & 530 & 491 & 237 & 71 & 10 & 0 & 0 & 0 & 7 & 10 & 303 & 423 & 2082 \\
$\mathbf{2 0 0 6}$ & 553 & 417 & 145 & 62 & 3 & 0 & 0 & 0 & 0 & 2 & 77 & 422 & 1681 \\
$\mathbf{2 0 0 7}$ & 511 & 198 & 239 & 91 & 9 & 0 & 0 & 0 & 5 & 46 & 357 & 514 & 1970 \\
$\mathbf{2 0 0 8}$ & 361 & 253 & 215 & 61 & 13 & 0 & 0 & 0 & 0 & 70 & 349 & 470 & 1792 \\
$\mathbf{2 0 0 9}$ & 480 & 390 & 233 & 130 & 0 & 0 & 1 & 0 & 0 & 24 & 141 & 395 & 1794 \\
$\mathbf{2 0 1 0}$ & 446 & 344 & 300 & 75 & 47 & 0 & 0 & 0 & 0 & 94 & 280 & 464 & 2050 \\
$\mathbf{2 0 1 1}$ & 464 & 343 & 204 & 5 & 2 & 0 & 0 & 1 & 0 & 14 & 128 & 452 & 1613 \\
Prom. & 462 & 358 & 221 & 83 & 15 & 0 & 0 & 0 & 2 & 34 & 228 & 434 & 1836 \\
\hline
\end{tabular}

Guadalajara. Tiene en promedio más de 2200 horas frío (umbral $7^{\circ} \mathrm{C}$ ) al año, oscilando entre las 1791 de 2011 y las 2582 de 2010.

Podría decirse que sólo julio es un mes libre de horas frío; junio tuvo horas frío en cuatro de los diez años y agosto en tres de los diez años, julio sólo en uno de los diez años. Septiembre osciló entre ninguna hora de frío en 2011 y 47 horas en 2005. Mayo tiene un promedio de 2 horas diarias de frío, octubre 3 horas diarias y abril cerca de 5 . Marzo y noviembre se acercan a las 300 horas; febrero tiene 400 horas, y enero y diciembre en torno a las 500 horas. 
Tabla 48. Horas frío contadas en datos horarios en el observatorio de Guadalajara.

\begin{tabular}{cccccccccccccc}
\hline & ene & feb & mar & abr & may & jun & jul & ago & sep & oct & nov & dic & anual \\
\hline $\mathbf{2 0 0 2}$ & 447 & 361 & 243 & 194 & 83 & 9 & 0 & 2 & 37 & 63 & 248 & 296 & 1983 \\
\hline $\mathbf{2 0 0 3}$ & 502 & 397 & 210 & 97 & 43 & 0 & 0 & 0 & 14 & 71 & 217 & 496 & 2047 \\
\hline $\mathbf{2 0 0 4}$ & 427 & 445 & 319 & 188 & 52 & 4 & 1 & 0 & 17 & 63 & 383 & 478 & 2377 \\
\hline $\mathbf{2 0 0 5}$ & 548 & 511 & 287 & 135 & 63 & 0 & 0 & 2 & 47 & 81 & 393 & 513 & 2580 \\
\hline $\mathbf{2 0 0 6}$ & 589 & 462 & 243 & 143 & 61 & 9 & 0 & 0 & 5 & 39 & 143 & 484 & 2178 \\
\hline $\mathbf{2 0 0 7}$ & 572 & 263 & 307 & 136 & 67 & 0 & 0 & 3 & 17 & 162 & 424 & 555 & 2506 \\
\hline $\mathbf{2 0 0 8}$ & 417 & 337 & 319 & 133 & 39 & 0 & 0 & 0 & 19 & 134 & 425 & 535 & 2358 \\
\hline $\mathbf{2 0 0 9}$ & 557 & 444 & 335 & 248 & 61 & 0 & 0 & 0 & 6 & 63 & 255 & 440 & 2409 \\
\hline $\mathbf{2 0 1 0}$ & 513 & 403 & 370 & 115 & 99 & 0 & 0 & 0 & 28 & 186 & 378 & 490 & 2582 \\
\hline $\mathbf{2 0 1 1}$ & 512 & 403 & 245 & 59 & 18 & 4 & 0 & 0 & 0 & 4 & 44 & 502 & 1791 \\
\hline Prom. & 508 & 403 & 288 & 145 & 59 & 3 & 0 & 1 & 19 & 87 & 291 & 479 & 2281 \\
\hline
\end{tabular}

Madrid-Getafe. El promedio de horas frío anuales es unas 1500 horas anuales, oscilando entre las 1238 de 2002 y las 1890 de 2005.

Los meses de julio y agosto están libres de horas frío; junio tiene solo 1 año con horas frío y lo mismo le pasa a septiembre. Mayo y octubre, aunque tienen horas frío casi todos los años, tienen muy pocas horas, no llegan a las 15 en promedio. Abril no llega a las 50 horas mensuales en promedio, y marzo y noviembre pasan de las 150; febrero pasa de las 300 y enero de las 400; diciembre tiene 400 .

Tabla 49. Horas frío contadas en datos horarios en el observatorio de Madrid-Getafe.

\begin{tabular}{cccccccccccccc}
\hline & ene & feb & mar & abr & may & jun & jul & ago & sep & oct & nov & dic & anual \\
\hline $\mathbf{2 0 0 2}$ & 387 & 254 & 140 & 87 & 16 & 0 & 0 & 0 & 0 & 6 & 124 & 224 & 1238 \\
\hline $\mathbf{2 0 0 3}$ & 448 & 357 & 91 & 38 & 2 & 0 & 0 & 0 & 0 & 23 & 89 & 451 & 1499 \\
$\mathbf{2 0 0 4}$ & 334 & 355 & 218 & 91 & 6 & 0 & 0 & 0 & 0 & 13 & 235 & 368 & 1620 \\
\hline $\mathbf{2 0 0 5}$ & 503 & 467 & 189 & 44 & 0 & 0 & 0 & 0 & 1 & 1 & 259 & 426 & 1890 \\
$\mathbf{2 0 0 6}$ & 546 & 406 & 121 & 13 & 0 & 0 & 0 & 0 & 0 & 0 & 47 & 399 & 1532 \\
\hline $\mathbf{2 0 0 7}$ & 510 & 146 & 152 & 67 & 5 & 0 & 0 & 0 & 0 & 4 & 265 & 441 & 1590 \\
\hline $\mathbf{2 0 0 8}$ & 324 & 179 & 145 & 19 & 1 & 0 & 0 & 0 & 0 & 36 & 305 & 441 & 1450 \\
\hline $\mathbf{2 0 0 9}$ & 463 & 333 & 112 & 81 & 1 & 0 & 0 & 0 & 0 & 2 & 80 & 395 & 1467 \\
$\mathbf{2 0 1 0}$ & 423 & 342 & 243 & 28 & 14 & 0 & 0 & 0 & 0 & 36 & 225 & 428 & 1739 \\
\hline $\mathbf{2 0 1 1}$ & 446 & 287 & 153 & 5 & 1 & 1 & 0 & 0 & 0 & 0 & 78 & 424 & 1395 \\
\hline Prom. & 438 & 313 & 156 & 47 & 5 & 0 & 0 & 0 & 0 & 12 & 171 & 400 & 1542 \\
\hline
\end{tabular}


Navalmoral. Le faltan datos en tres años: 2007, 2008 y 2011. En los siete restantes tiene en promedio en torno a las 1200 horas frío (umbral $7^{\circ} \mathrm{C}$ ) al año, oscilando entre las 884 de 2002 y las 1691 de 2005.

Junio, julio y agosto están prácticamente libres de horas frío, y septiembre sólo tuvo horas frío en dos de los años, y sólo una. También mayo tiene muy pocas horas frío, aunque las tiene casi todos los años. Octubre tiene de promedio 20 horas, pero puede haber años como 2010 que sobrepasa las 60 , dos horas diarias de promedio. Abril tiene algo más de 1 hora diaria de promedio, marzo en torno a 4 y noviembre en torno a 5. Febrero pasa de las 200 horas, y enero y diciembre están en torno a las 350 ; enero las sobrepasa y diciembre no las alcanza.

Tabla 50. Horas frío contadas en datos horarios en el observatorio de Navalmoral.

\begin{tabular}{cccccccccccccc}
\hline & ene & feb & mar & abr & may & jun & jul & ago & sep & oct & nov & dic & anual \\
\hline $\mathbf{2 0 0 2}$ & 284 & 213 & 84 & 47 & 14 & 0 & 0 & 0 & 0 & 3 & 50 & 189 & 884 \\
\hline $\mathbf{2 0 0 3}$ & 331 & 268 & 50 & 23 & 1 & 0 & 0 & 0 & 0 & 14 & 79 & 289 & 1055 \\
$\mathbf{2 0 0 4}$ & 284 & 219 & 143 & 56 & 11 & 0 & 0 & 0 & 0 & 11 & 249 & 378 & 1351 \\
\hline $\mathbf{2 0 0 5}$ & 517 & 403 & 167 & 32 & 0 & 0 & 0 & 0 & 0 & 9 & 194 & 369 & 1691 \\
\hline $\mathbf{2 0 0 6}$ & 462 & 356 & 102 & 14 & 6 & 0 & 0 & 0 & 0 & 0 & 44 & 390 & 1374 \\
\hline $\mathbf{2 0 0 7}$ & 436 & 110 & 136 & 63 & 6 & 0 & 0 & 0 & 1 & 53 & 364 & & \\
\hline $\mathbf{2 0 0 8}$ & & & & & 8 & 0 & & 0 & 1 & 29 & & 365 & \\
\hline $\mathbf{2 0 0 9}$ & 341 & 302 & 112 & 66 & 3 & 0 & 0 & 0 & 0 & 9 & 88 & 308 & 1229 \\
\hline $\mathbf{2 0 1 0}$ & 313 & 231 & 140 & 26 & 25 & 0 & 0 & 0 & 0 & 64 & 207 & 320 & 1326 \\
\hline $\mathbf{2 0 1 1}$ & 356 & 276 & & & 0 & 0 & 0 & 1 & 0 & 4 & 106 & 435 & \\
\hline Prom. & 369 & 264 & 117 & 41 & 7 & 0 & 0 & 0 & 0 & 20 & 153 & 338 & 1273 \\
\hline
\end{tabular}

Cáceres. Tiene en promedio 1000 horas frío (umbral $7^{\circ} \mathrm{C}$ ) al año, oscilando entre las $540 \mathrm{de}$ 2002 y las 1486 de 2005, como se ve una oscilación considerable, más del doble.

Los meses de verano: junio, julio, agosto y septiembre son meses libres de horas frío. Mayo y octubre tienen muy pocas horas frío y no todos los años. Abril no llega a 1 hora diaria de promedio, pero tiene una gran variación entre unos años y otros, de 3 horas todo el mes en 2011 a 63 horas en 2007. Marzo y noviembre están en torno a las 3 horas diarias de promedio. Febrero tiene 200 horas mensuales, enero 300 horas y diciembre no llega a las 300 . 
Tabla 51. Horas frío contadas en datos horarios en el observatorio de Cáceres.

\begin{tabular}{cccccccccccccc}
\hline & ene & feb & mar & abr & may & jun & jul & ago & sep & oct & nov & dic & anual \\
\hline $\mathbf{2 0 0 2}$ & 195 & 118 & 84 & 41 & 3 & 0 & 0 & 0 & 0 & 0 & 19 & 80 & 540 \\
\hline $\mathbf{2 0 0 3}$ & 293 & 233 & 39 & 11 & 0 & 0 & 0 & 0 & 0 & 10 & 33 & 236 & 855 \\
$\mathbf{2 0 0 4}$ & 178 & 203 & 119 & 58 & 2 & 0 & 0 & 0 & 0 & 0 & 154 & 327 & 1041 \\
\hline $\mathbf{2 0 0 5}$ & 456 & 372 & 148 & 34 & 0 & 0 & 0 & 0 & 0 & 0 & 164 & 312 & 1486 \\
$\mathbf{2 0 0 6}$ & 466 & 295 & 69 & 4 & 0 & 0 & 0 & 0 & 0 & 0 & 6 & 350 & 1190 \\
\hline $\mathbf{2 0 0 7}$ & 389 & 86 & 73 & 63 & 3 & 0 & 0 & 0 & 0 & 6 & 182 & 330 & 1132 \\
$\mathbf{2 0 0 8}$ & 159 & 89 & 99 & 10 & 2 & 0 & 0 & 0 & 0 & 12 & 234 & 337 & 942 \\
\hline $\mathbf{2 0 0 9}$ & 340 & 217 & 40 & 28 & 0 & 0 & 0 & 0 & 0 & 0 & 32 & 246 & 903 \\
\hline $\mathbf{2 0 1 0}$ & 270 & 227 & 155 & 22 & 17 & 0 & 0 & 0 & 0 & 14 & 132 & 244 & 1081 \\
\hline $\mathbf{2 0 1 1}$ & 318 & 185 & 91 & 3 & 0 & 0 & 0 & 0 & 0 & 0 & 50 & 296 & 943 \\
\hline Prom. & 306 & 203 & 92 & 27 & 3 & 0 & 0 & 0 & 0 & 4 & 101 & 276 & 1011 \\
\hline
\end{tabular}

Plasencia. Le faltan datos en tres años: 2004, 2007, y 2010. El resto tiene en promedio algo más de 1000 horas frío (umbral $7^{\circ} \mathrm{C}$ ) al año, oscilando entre las 490 de 2002 y las 1490 de 2005.

Los meses de verano: junio, julio, agosto y septiembre son meses libres de horas frío. Mayo y octubre tienen muy pocas horas frío y no todos los años. Abril en torno a la 1 hora diaria de promedio. Abril no llega a una hora diaria de promedio pero varía mucho de unos años a otros, de ninguna en 2011 a 49 horas en 2009. Marzo y noviembre están en torno a las 3 horas diarias de promedio. Febrero tiene 200 horas mensuales, enero pasa algo de las 300 , y diciembre no llega a 300.

Tabla 52. Horas frío contadas en datos horarios en el observatorio de Plasencia.

\begin{tabular}{cccccccccccccc}
\hline & ene & feb & mar & abr & may & jun & jul & ago & sep & oct & nov & dic & anual \\
\hline $\mathbf{2 0 0 2}$ & 168 & 77 & 65 & 31 & 4 & 0 & 0 & 0 & 0 & 0 & 50 & 95 & 490 \\
\hline $\mathbf{2 0 0 3}$ & 380 & 323 & 52 & 38 & 24 & 0 & 0 & 0 & 0 & 10 & 45 & 196 & 1068 \\
$\mathbf{2 0 0 4}$ & 162 & 182 & 92 & 29 & 3 & 0 & 0 & 0 & 0 & 0 & 110 & & \\
\hline $\mathbf{2 0 0 5}$ & 437 & 378 & 150 & 38 & 0 & 0 & 0 & 0 & 0 & 0 & 180 & 307 & 1490 \\
\hline $\mathbf{2 0 0 6}$ & 475 & 325 & 90 & 2 & 0 & 0 & 0 & 0 & 0 & 0 & 9 & 328 & 1229 \\
\hline $\mathbf{2 0 0 7}$ & 344 & 77 & & & 7 & 0 & 0 & 0 & 0 & 1 & 153 & 303 & \\
$\mathbf{2 0 0 8}$ & 203 & 61 & 106 & 18 & 2 & 0 & 0 & 0 & 0 & 21 & 259 & 341 & 1011 \\
\hline $\mathbf{2 0 0 9}$ & 397 & 236 & 45 & 49 & 0 & 0 & 0 & 0 & 0 & 0 & 50 & 371 & 1148 \\
\hline $\mathbf{2 0 1 0}$ & & & 217 & 31 & 28 & 0 & 0 & 0 & 0 & 16 & 231 & 369 & \\
\hline $\mathbf{2 0 1 1}$ & 388 & 209 & 76 & 0 & 0 & 0 & 0 & 0 & 0 & 0 & 37 & 312 & 1022 \\
\hline Prom. & 328 & 208 & 99 & 26 & 7 & 0 & 0 & 0 & 0 & 5 & 112 & 291 & 1065 \\
\hline
\end{tabular}


Toledo. No llega en promedio a las 1500 horas frío (umbral $7^{\circ} \mathrm{C}$ ) al año, oscilando entre las 1122 de 2002 y las 1836 de 2005, una oscilación considerable.

Los meses de verano: junio, julio, agosto y septiembre están prácticamente libres de horas frío. Mayo y octubre tienen pocas horas frío y no todos los años. Abril no llega a las 2 horas diarias de promedio, con gran variación entre unos años y otros. Marzo y noviembre están en torno a las 5 horas diarias de promedio. Febrero tiene cerca de 300 horas mensuales, diciembre cerca de 400 y enero sobrepasa las 400 horas.

Tabla 53. Horas frío contadas en datos horarios en el observatorio de Toledo.

\begin{tabular}{cccccccccccccc}
\hline & ene & feb & mar & abr & may & jun & jul & ago & sep & oct & nov & dic & anual \\
\hline $\mathbf{2 0 0 2}$ & 376 & 238 & 117 & 89 & 21 & 0 & 0 & 0 & 0 & 5 & 69 & 207 & 1122 \\
\hline $\mathbf{2 0 0 3}$ & 397 & 319 & 92 & 32 & 8 & 0 & 0 & 0 & 0 & 16 & 102 & 389 & 1355 \\
$\mathbf{2 0 0 4}$ & 311 & 337 & 198 & 96 & 11 & 0 & 0 & 0 & 0 & 9 & 250 & 383 & 1595 \\
\hline $\mathbf{2 0 0 5}$ & 509 & 441 & 174 & 54 & 0 & 0 & 0 & 0 & 1 & 1 & 243 & 413 & 1836 \\
\hline $\mathbf{2 0 0 6}$ & 523 & 372 & 112 & 11 & 0 & 0 & 0 & 0 & 0 & 0 & 56 & 405 & 1479 \\
\hline $\mathbf{2 0 0 7}$ & 446 & 137 & 155 & 86 & 4 & 0 & 0 & 0 & 1 & 27 & 299 & 426 & 1581 \\
\hline $\mathbf{2 0 0 8}$ & 291 & 173 & 154 & 24 & 0 & 0 & 0 & 0 & 0 & 35 & 272 & 426 & 1375 \\
\hline $\mathbf{2 0 0 9}$ & 418 & 309 & 154 & 81 & 0 & 0 & 0 & 0 & 0 & 8 & 77 & 373 & 1420 \\
\hline $\mathbf{2 0 1 0}$ & 402 & 301 & 221 & 37 & 28 & 0 & 0 & 0 & 0 & 39 & 218 & 385 & 1631 \\
\hline $\mathbf{2 0 1 1}$ & 428 & 253 & 144 & 0 & 0 & 0 & 0 & 0 & 0 & 6 & 93 & 428 & 1352 \\
\hline Prom. & 410 & 288 & 152 & 51 & 7 & 0 & 0 & 0 & 0 & 15 & 168 & 384 & 1475 \\
\hline
\end{tabular}

Trujillo. Tiene en promedio algo más de 1300 horas frío (umbral $7^{\circ} \mathrm{C}$ ) al año, oscilando entre las 1149 de 2011 y las 1682 de 2005.

Tabla 54. Horas frío contadas en datos horarios en el observatorio de Trujillo.

\begin{tabular}{|cccccccccccccc}
\hline & ene & feb & mar & abr & may & jun & jul & ago & sep & oct & nov & dic & anual \\
\hline $\mathbf{2 0 0 2}$ & & & & & & & & & & & & & \\
$\mathbf{2 0 0 3}$ & & & 93 & 49 & 16 & 0 & 0 & 0 & 0 & 20 & 85 & 487 & \\
$\mathbf{2 0 0 4}$ & 328 & 234 & 174 & 107 & 23 & 0 & 0 & 0 & 0 & 3 & 180 & 399 & 1448 \\
\hline $\mathbf{2 0 0 5}$ & 487 & 433 & 159 & 63 & 3 & 0 & 0 & 0 & 0 & 0 & 206 & 331 & 1682 \\
\hline $\mathbf{2 0 0 6}$ & 489 & 330 & 107 & 5 & 4 & 0 & 0 & 0 & 0 & 2 & 13 & 373 & 1323 \\
\hline $\mathbf{2 0 0 7}$ & 389 & 131 & 143 & 86 & 13 & 0 & 0 & 0 & 0 & 7 & 216 & 362 & 1347 \\
$\mathbf{2 0 0 8}$ & 242 & 142 & 172 & 46 & 6 & 0 & 0 & 0 & 0 & 25 & 267 & 395 & 1295 \\
\hline $\mathbf{2 0 0 9}$ & 405 & 269 & 54 & 77 & 0 & 0 & 0 & 0 & 0 & 0 & 61 & 284 & 1150 \\
$\mathbf{2 0 1 0}$ & 341 & 268 & 178 & 34 & 35 & 0 & 0 & 0 & 0 & 9 & 200 & 274 & 1339 \\
\hline $\mathbf{2 0 1 1}$ & 340 & 243 & 122 & 3 & 0 & 0 & 0 & 0 & 0 & 0 & 63 & 378 & 1149 \\
\hline Prom. & 378 & 256 & 134 & 52 & 11 & 0 & 0 & 0 & 0 & 7 & 143 & 365 & 1342 \\
\hline
\end{tabular}


Los meses de verano: junio, julio, agosto y septiembre son meses libres de horas frío. Mayo y octubre tienen muy pocas horas frío y no todos los años. Abril no llega a las 2 horas diarias de promedio, con una gran variación entre unos años y otros. Marzo y noviembre están por encima de las 4 horas diarias de promedio. Febrero tiene algo más de 250 horas mensuales, enero y diciembre más de 350 .

\section{Resumen de horas frío contadas para la cuenca del Tajo}

En la parte media de la cuenca del Tajo, en altitudes entre los 700 y los 500 m se alcanzan valores próximos a las 2000 horas frío anuales en promedio. En la parte más baja de la cuenca, por debajo de los 500 m, el número de horas frío anuales está en torno a las 1000 .

En la parte media de la cuenca no hay meses libres de horas frío. En la parte baja, por el contrario, están libres de horas frío los meses de junio, julio y agosto.

Es preciso tener en cuenta la marcada variabilidad interanual y entre cada uno de los meses en los distintos años.

\subsubsection{Cuenca del Guadiana: a) parte alta situada en la meseta Sur, principalmente} La Mancha

Observatorios: Ciudad Real (4121), Alcázar de San Juan (4064), Almagro (4116i), Hinojosa del Duque (4267x)

Tabla 55. Comparación de horas frío anuales contadas a partir de datos horarios en los cuatro observatorios de la parte alta de la Cuenca del Guadiana.

\begin{tabular}{|ccccc|}
\hline & $\begin{array}{c}\text { Ciudad Real } \\
\mathbf{4 1 2 1}\end{array}$ & $\begin{array}{c}\text { Alcázar de San Juan } \\
\mathbf{4 0 6 4}\end{array}$ & $\begin{array}{c}\text { Almagro } \\
\mathbf{4 1 1 6 i}\end{array}$ & $\begin{array}{c}\text { Hinojosa Duque } \\
\mathbf{4 2 6 7 x}\end{array}$ \\
\hline $\mathbf{A n ̃ ⿻}$ & HF & HF & HF & HF \\
\hline $\mathbf{2 0 0 2}$ & 1165 & & & 1202 \\
\hline $\mathbf{2 0 0 3}$ & 1407 & & & 1256 \\
\hline $\mathbf{2 0 0 4}$ & 1564 & & 1986 & \\
\hline $\mathbf{2 0 0 5}$ & 1917 & & 2249 & 1759 \\
\hline $\mathbf{2 0 0 6}$ & 1574 & & 1871 & 1550 \\
\hline $\mathbf{2 0 0 7}$ & 1776 & & 2162 & \\
\hline $\mathbf{2 0 0 8}$ & 1537 & 1817 & 1893 & \\
\hline $\mathbf{2 0 0 9}$ & 1399 & 1617 & 1743 & \\
\hline $\mathbf{2 0 1 0}$ & 1600 & 1895 & 1895 & \\
\hline $\mathbf{2 0 1 1}$ & 1405 & 1600 & 1649 & \\
\hline Prom. & 1534 & & 1931 & \\
\hline
\end{tabular}




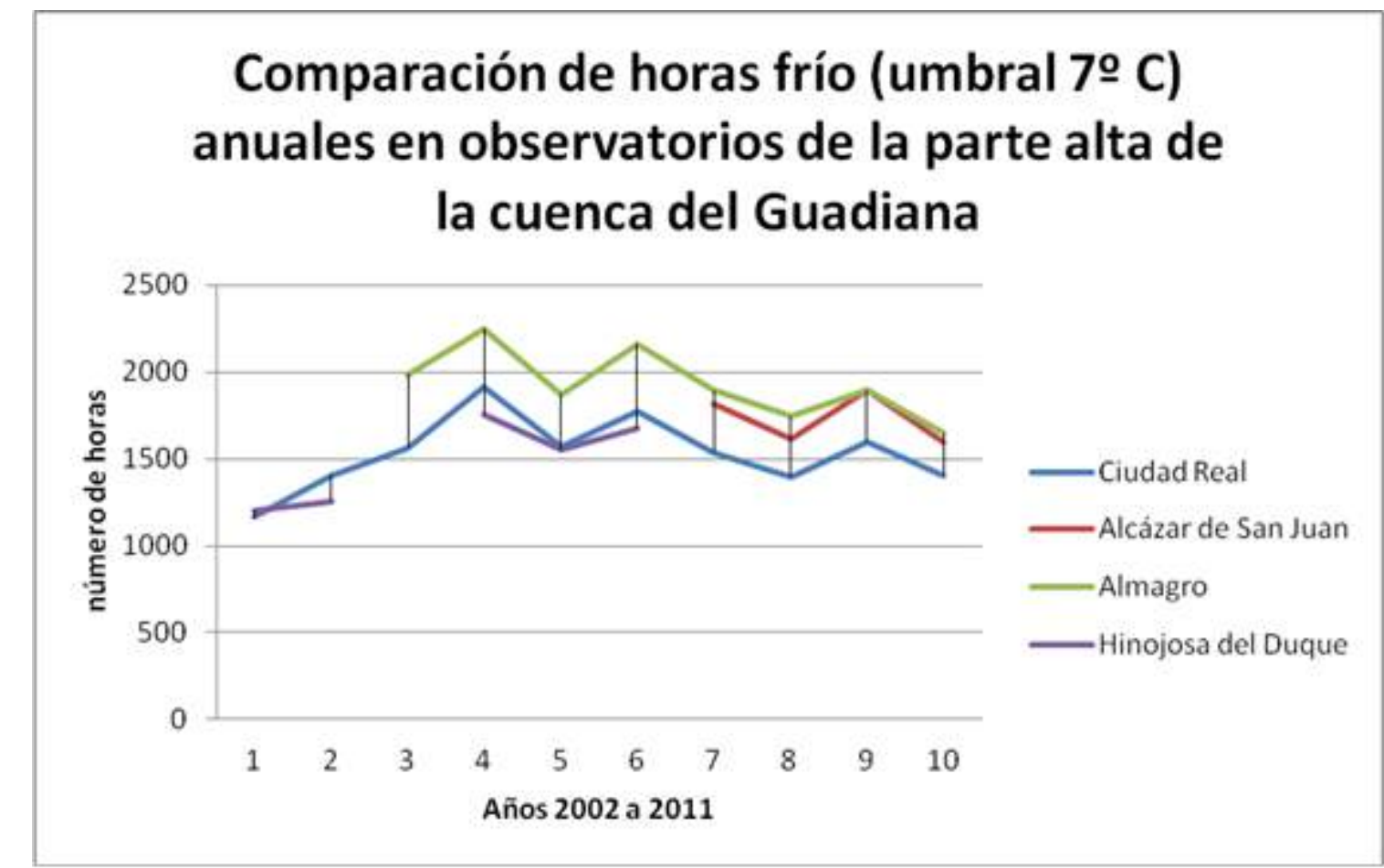

Gráfico 9. Comparación de horas frío (umbral $7^{\circ} \mathrm{C}$ ) anuales en observatorios de la parte alta de la cuenca del Guadiana.

Los datos son coherentes entre ellos.

\section{Horas frío contadas en datos horarios en cada uno de los observatorios}

Ciudad Real. Tiene en promedio 1500 horas frío (umbral $7^{\circ} \mathrm{C}$ ) al año, oscilando entre las 1165 horas de 2002 y las 1917 de 2005.

Tabla 56. Horas frío contadas en datos horarios en el observatorio de Ciudad Real.

\begin{tabular}{cccccccccccccc}
\hline & ene & feb & mar & abr & may & jun & jul & ago & sep & oct & nov & dic & anual \\
\hline $\mathbf{2 0 0 2}$ & 401 & 268 & 144 & 88 & 13 & 0 & 0 & 0 & 0 & 3 & 61 & 187 & 1165 \\
\hline $\mathbf{2 0 0 3}$ & 397 & 336 & 125 & 51 & 6 & 0 & 0 & 0 & 0 & 21 & 82 & 389 & 1407 \\
$\mathbf{2 0 0 4}$ & 280 & 304 & 171 & 90 & 2 & 0 & 0 & 0 & 0 & 7 & 291 & 419 & 1564 \\
\hline $\mathbf{2 0 0 5}$ & 545 & 451 & 198 & 52 & 0 & 0 & 0 & 0 & 0 & 0 & 251 & 420 & 1917 \\
$\mathbf{2 0 0 6}$ & 535 & 372 & 104 & 6 & 2 & 0 & 0 & 0 & 2 & 1 & 83 & 469 & 1574 \\
$\mathbf{2 0 0 7}$ & 555 & 157 & 177 & 98 & 1 & 0 & 0 & 0 & 0 & 16 & 312 & 460 & 1776 \\
$\mathbf{2 0 0 8}$ & 323 & 217 & 159 & 40 & 2 & 0 & 0 & 0 & 0 & 31 & 298 & 467 & 1537 \\
\hline $\mathbf{2 0 0 9}$ & 432 & 317 & 151 & 61 & 0 & 0 & 0 & 0 & 0 & 7 & 100 & 331 & 1399 \\
\hline $\mathbf{2 0 1 0}$ & 420 & 284 & 199 & 53 & 15 & 0 & 0 & 0 & 0 & 48 & 211 & 370 & 1600 \\
\hline $\mathbf{2 0 1 1}$ & 442 & 267 & 183 & 0 & 0 & 0 & 0 & 0 & 0 & 1 & 110 & 402 & 1405 \\
Prom. & 433 & 297 & 161 & 54 & 4 & 0 & 0 & 0 & 0 & 14 & 180 & 391 & 1534 \\
\hline
\end{tabular}


Los meses de verano: junio, julio, agosto y septiembre están prácticamente libres de horas frío. Mayo y octubre tienen muy pocas horas frío y no todos los años. Abril tiene cerca de 2 horas diarias en promedio. Marzo está en torno a las 150 horas, y noviembre no llega a las 200. Febrero no llega a las 300 horas mensuales, a diciembre le falta poco para las 400 y enero las sobrepasa.

Alcázar de San Juan. Tiene únicamente cuatro años completos de datos.

Tabla 57. Horas frío contadas en datos horarios en el observatorio de Alcazar de San Juan.

\begin{tabular}{|c|c|c|c|c|c|c|c|c|c|c|c|c|c|}
\hline & ene & feb & mar & $a b r$ & may & jun & jul & ago & sep & oct & nov & dic & anual \\
\hline \multicolumn{14}{|l|}{2002} \\
\hline \multicolumn{14}{|l|}{2003} \\
\hline \multicolumn{14}{|l|}{2004} \\
\hline \multicolumn{14}{|l|}{2005} \\
\hline \multicolumn{14}{|l|}{2006} \\
\hline 2007 & & & & & & & 0 & 0 & 447 & 21 & 315 & 489 & \\
\hline 2008 & 390 & 240 & 208 & 64 & 2 & 0 & 0 & 1 & 0 & 37 & 376 & 499 & 1817 \\
\hline 2009 & 479 & 367 & 164 & 119 & 3 & 0 & 0 & 0 & 0 & 10 & 72 & 403 & 1617 \\
\hline 2010 & 474 & 336 & 255 & 53 & 32 & 0 & 0 & 0 & 0 & 30 & 303 & 412 & 1895 \\
\hline 2011 & 488 & 311 & 197 & 1 & 0 & 0 & 0 & 0 & 0 & 12 & 112 & 479 & 1600 \\
\hline Prom. & 458 & 314 & 206 & 59 & 9 & 0 & 0 & 0 & 0 & 22 & 216 & 448 & 1732 \\
\hline
\end{tabular}

Almagro. Tiene 8 años completos de datos, de 2004 a 2011, con una media de algo más de 1900 horas anuales, oscilando en esos años entre las 1649 de 2011 y las 2249 de 2005.

Tabla 58. Horas frío contadas en datos horarios en el observatorio de Almagro.

\begin{tabular}{|cccccccccccccc}
\hline \multicolumn{2}{c}{ ene } & feb & mar & abr & may & jun & jul & ago & sep & oct & nov & dic & anual \\
\hline $\mathbf{2 0 0 2}$ & & & & & & & & & & & & & \\
\hline $\mathbf{2 0 0 3}$ & & & & & & 0 & 0 & 0 & 0 & 24 & 139 & 480 & \\
\hline $\mathbf{2 0 0 4}$ & 339 & 390 & 240 & 129 & 6 & 0 & 0 & 0 & 0 & 25 & 362 & 495 & 1986 \\
\hline $\mathbf{2 0 0 5}$ & 586 & 482 & 233 & 98 & 10 & 0 & 0 & 0 & 10 & 28 & 338 & 464 & 2249 \\
\hline $\mathbf{2 0 0 6}$ & 581 & 440 & 167 & 29 & 2 & 0 & 0 & 0 & 0 & 3 & 136 & 513 & 1871 \\
\hline $\mathbf{2 0 0 7}$ & 593 & 227 & 263 & 136 & 13 & 0 & 0 & 0 & 1 & 38 & 373 & 518 & 2162 \\
\hline $\mathbf{2 0 0 8}$ & 388 & 252 & 243 & 90 & 7 & 0 & 0 & 0 & 0 & 46 & 378 & 489 & 1893 \\
\hline $\mathbf{2 0 0 9}$ & 465 & 366 & 236 & 130 & 5 & 0 & 0 & 0 & 0 & 13 & 154 & 374 & 1743 \\
\hline $\mathbf{2 0 1 0}$ & 475 & 323 & 241 & 72 & 36 & 0 & 0 & 0 & 0 & 77 & 292 & 379 & 1895 \\
\hline $\mathbf{2 0 1 1}$ & 483 & 339 & 213 & 0 & 0 & 0 & 0 & 0 & 0 & 11 & 156 & 447 & 1649 \\
\hline Prom. & 489 & 352 & 230 & 86 & 10 & 0 & 0 & 0 & 1 & 29 & 259 & 462 & 1931 \\
\hline
\end{tabular}


Hinojosa del Duque. Tiene sólo 5 años de datos.

Tabla 59. Horas frío contadas en datos horarios en el observatorio de Hinojosa del Duque.

\begin{tabular}{cccccccccccccc}
\hline & ene & feb & mar & abr & may & jun & jul & ago & sep & oct & nov & dic & anual \\
\hline $\mathbf{2 0 0 2}$ & 375 & 281 & 161 & 84 & 22 & 0 & 0 & 0 & 0 & 9 & 80 & 190 & 1202 \\
\hline $\mathbf{2 0 0 3}$ & 403 & 310 & 115 & 53 & 4 & 0 & 0 & 0 & 0 & 13 & 46 & 312 & 1256 \\
$\mathbf{2 0 0 4}$ & 266 & & & 118 & 8 & 0 & 0 & 0 & 0 & 9 & 241 & 406 & \\
\hline $\mathbf{2 0 0 5}$ & 510 & 435 & 178 & 64 & 0 & 0 & 0 & 0 & 2 & 4 & 230 & 336 & 1759 \\
$\mathbf{2 0 0 6}$ & 473 & 372 & 136 & 18 & 0 & 0 & 0 & 0 & 0 & 0 & 67 & 484 & 1550 \\
\hline $\mathbf{2 0 0 7}$ & 493 & 165 & 206 & 89 & 8 & 0 & 0 & 0 & 0 & 20 & 295 & 401 & 1677 \\
$\mathbf{2 0 0 8}$ & 289 & 201 & 180 & 61 & 4 & 0 & 0 & 0 & 0 & 21 & 280 & & \\
\hline $\mathbf{2 0 0 9}$ & & & & 87 & 7 & 0 & 0 & 0 & 0 & 0 & 92 & 310 & \\
$\mathbf{2 0 1 0}$ & 372 & 234 & 166 & 61 & 29 & 0 & 0 & 0 & 0 & & & & \\
\hline $\mathbf{2 0 1 1}$ & 371 & 274 & 157 & 0 & 0 & 0 & 0 & 0 & 0 & & & & \\
\hline Prom. & 395 & 284 & 162 & 64 & 8 & 0 & 0 & 0 & 0 & 10 & 166 & 348 & 1489 \\
\hline
\end{tabular}

\subsubsection{Cuenca del Guadiana: b) parte baja y relativamente llana de la cuenca}

Observatorios: Talavera la Real (4452), Badajoz CMT (4478x) y Mérida (4410x).

Tabla 60. Comparación de horas frío anuales contadas a partir de datos horarios en los tres observatorios de la parte baja de la cuenca del Guadiana.

\begin{tabular}{|cccc|}
\hline & $\begin{array}{c}\text { Talavera la Real } \\
\mathbf{4 4 5 2}\end{array}$ & $\begin{array}{c}\text { Badajoz CMT } \\
\mathbf{4 4 7 8 x}\end{array}$ & $\begin{array}{c}\text { Mérida } \\
\mathbf{4 4 1 0 x}\end{array}$ \\
\hline Año & HF & HF & HF \\
\hline $\mathbf{2 0 0 2}$ & 554 & 1065 & \\
\hline $\mathbf{2 0 0 3}$ & 706 & 1007 & 795 \\
\hline $\mathbf{2 0 0 4}$ & 897 & & 978 \\
\hline $\mathbf{2 0 0 5}$ & 1376 & 1423 & 1472 \\
\hline $\mathbf{2 0 0 6}$ & 1083 & 996 & 1105 \\
\hline $\mathbf{2 0 0 7}$ & 1212 & 1129 & 1137 \\
\hline $\mathbf{2 0 0 8}$ & 927 & 1041 & 990 \\
\hline $\mathbf{2 0 0 9}$ & 753 & 838 & 818 \\
\hline $\mathbf{2 0 1 0}$ & 885 & 883 & 884 \\
\hline $\mathbf{2 0 1 1}$ & 943 & 875 & 942 \\
\hline Promedio & 934 & 1029 & 1013 \\
\hline
\end{tabular}




\section{Comparación de horas frío (umbral 7ำ C) anuales en observatorios de la parte baja de la cuenca del Guadiana}

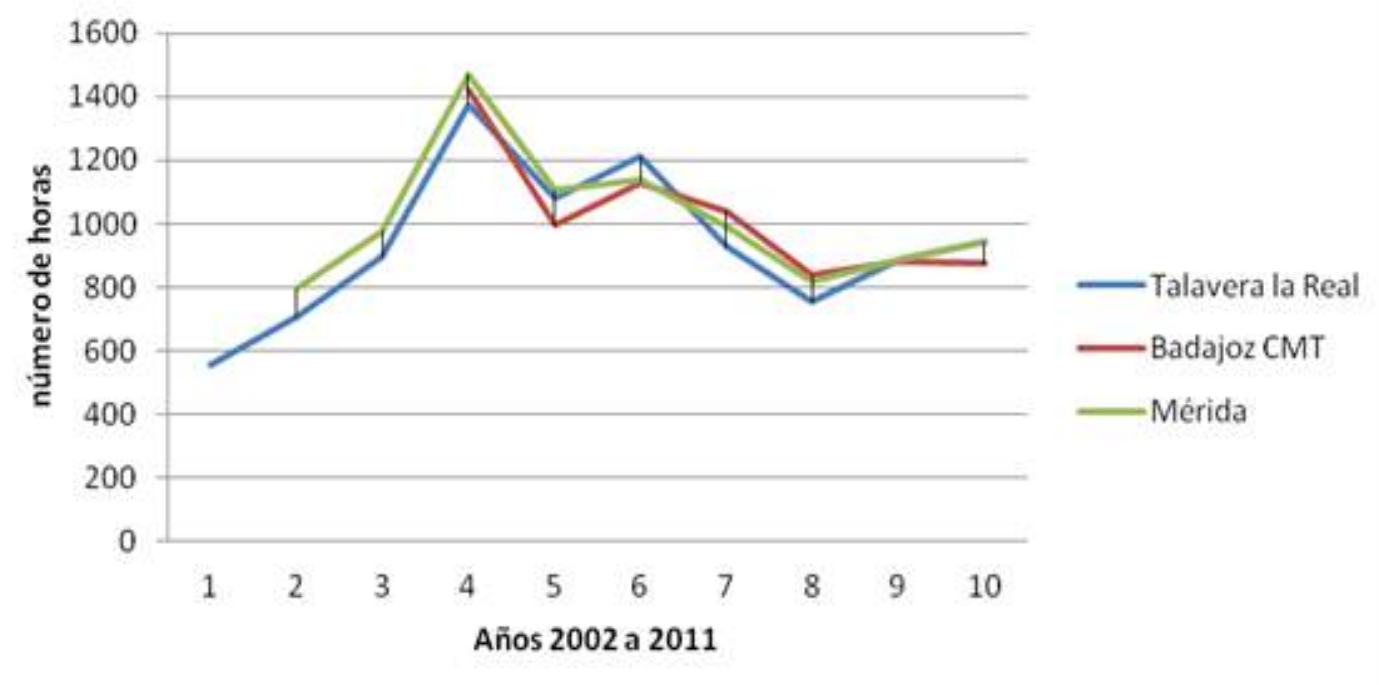

Gráfico 10. Comparación de horas frío (umbral 7ํㅡ) anuales en observatorios de la parte baja de la cuenca del Guadiana.

Al comparar las horas frío de los tres observatorios representativos de una zona de características fisiográficas y climáticas similares, aparece que los años 2002 y 2003 los datos de Badajoz CMT son muy diferentes y mayores que los de Talavera la Real y Mérida. Se considera, entonces, que los datos de esos años son erróneos en el observatorio de Badajoz CMT.

\section{Horas frío contadas en datos horarios en cada uno de los observatorios}

\section{Talavera la Real}

Tiene poco más de 900 horas frío (umbral $7^{\circ} \mathrm{C}$ ), oscilando entre las 554 de 2002 y las 1376 de 2005.

Los meses de junio, julio, agosto y septiembre están libres de horas frío. Mayo y octubre apenas tienen horas, y abril está en torno a la media hora diaria de promedio. Marzo y noviembre están en torno a las 100 horas mensuales de promedio, pero la variación entre unos años y otros es muy notable, en marzo entre las 35 de 2009 y 123 de 2005, y en noviembre entre las 20 de 2003 y las 255 de 2007. Febrero se acerca a las 200 horas de promedio y enero y diciembre las sobrepasan. Enero, con 279 de media, oscila entre las 453 de 2005 y las 165 de 2004; febrero 
con unas 187 de media, entre las 345 de 2005 y las 80 de 2007; y diciembre con 251 de media, entre 86 de 2002 y 318 en 2006 y 2011.

Tabla 61. Horas frío contadas en datos horarios en el observatorio de Talavera la Real.

\begin{tabular}{cccccccccccccc}
\hline & ene & feb & mar & abr & may & jun & jul & ago & sep & oct & nov & dic & anual \\
\hline $\mathbf{2 0 0 2}$ & 197 & 163 & 50 & 18 & 2 & 0 & 0 & 0 & 0 & 0 & 38 & 86 & 554 \\
\hline $\mathbf{2 0 0 3}$ & 255 & 177 & 41 & 13 & 0 & 0 & 0 & 0 & 0 & 5 & 20 & 195 & 706 \\
$\mathbf{2 0 0 4}$ & 165 & 149 & 92 & 31 & 0 & 0 & 0 & 0 & 0 & 1 & 152 & 307 & 897 \\
\hline $\mathbf{2 0 0 5}$ & 453 & 345 & 123 & 14 & 0 & 0 & 0 & 0 & 0 & 5 & 142 & 294 & 1376 \\
\hline $\mathbf{2 0 0 6}$ & 385 & 261 & 92 & 0 & 0 & 0 & 0 & 0 & 0 & 0 & 27 & 318 & 1083 \\
\hline $\mathbf{2 0 0 7}$ & 403 & 80 & 116 & 43 & 0 & 0 & 0 & 0 & 0 & 6 & 255 & 309 & 1212 \\
$\mathbf{2 0 0 8}$ & 215 & 103 & 78 & 13 & 0 & 0 & 0 & 0 & 0 & 11 & 220 & 287 & 927 \\
\hline $\mathbf{2 0 0 9}$ & 251 & 202 & 35 & 17 & 0 & 0 & 0 & 0 & 0 & 1 & 44 & 203 & 753 \\
\hline $\mathbf{2 0 1 0}$ & 239 & 179 & 102 & 30 & 5 & 0 & 0 & 0 & 0 & 37 & 101 & 192 & 885 \\
\hline $\mathbf{2 0 1 1}$ & 224 & 211 & 94 & 1 & 0 & 0 & 0 & 0 & 0 & 0 & 95 & 318 & 943 \\
\hline Prom. & 279 & 187 & 82 & 18 & 1 & 0 & 0 & 0 & 0 & 7 & 109 & 251 & 934 \\
\hline
\end{tabular}

Badajoz CMT. Eliminando los datos de los dos primeros años, 2002 y 2003, quedan los datos de los años 2004 a 2011.

Tiene en torno a 1000 horas frío (umbral $7^{\circ} \mathrm{C}$ ), oscilando entre las 838 horas de 2009 y las 1423 del 2005.

Tabla 62. Horas frío contadas en datos horarios en el observatorio de Badajoz CMT.

\begin{tabular}{|cccccccccccccc}
\hline \multicolumn{2}{c}{ ene } & feb & mar & abr & may & jun & jul & ago & sep & oct & nov & dic & anual \\
\hline $\mathbf{2 0 0 2}$ & & & & & & & & & & & & & \\
\hline $\mathbf{2 0 0 3}$ & & & & & & & & & & & & & \\
\hline $\mathbf{2 0 0 4}$ & 190 & 170 & 115 & 45 & 4 & 0 & 0 & 0 & 0 & 6 & & 380 & \\
\hline $\mathbf{2 0 0 5}$ & 481 & 370 & 126 & 28 & 0 & 0 & 0 & 0 & 0 & 3 & 134 & 281 & 1423 \\
\hline $\mathbf{2 0 0 6}$ & 387 & 249 & 57 & 0 & 0 & 0 & 0 & 0 & 0 & 0 & 8 & 295 & 996 \\
\hline $\mathbf{2 0 0 7}$ & 341 & 78 & 107 & 37 & 0 & 0 & 0 & 0 & 0 & 8 & 246 & 312 & 1129 \\
\hline $\mathbf{2 0 0 8}$ & 221 & 89 & 97 & 25 & 2 & 0 & 0 & 0 & 0 & 19 & 268 & 320 & 1041 \\
\hline $\mathbf{2 0 0 9}$ & 274 & 235 & 48 & 41 & 1 & 0 & 0 & 0 & 0 & 0 & 41 & 198 & 838 \\
\hline $\mathbf{2 0 1 0}$ & 232 & 175 & 115 & 32 & 8 & 0 & 0 & 0 & 0 & 22 & 97 & 202 & 883 \\
\hline $\mathbf{2 0 1 1}$ & 196 & 220 & 81 & 5 & 0 & 0 & 0 & 0 & 0 & 0 & 80 & 293 & 875 \\
\hline Prom. & 290 & 198 & 93 & 27 & 2 & 0 & 0 & 0 & 0 & 7 & 125 & 285 & 1026 \\
\hline
\end{tabular}

Los meses de junio, julio, agosto y septiembre están libres de horas frío. Abril (27), mayo (2) y octubre (7) tienen pocas horas. Marzo y noviembre están en torno a las 100 horas, pero la variación entre unos años y otros es muy notable, en marzo entre 48 de 2009 y 126 de 2005 y 2002, y en noviembre entre las 8 de 2006 y las 268 de 2008. Enero y diciembre pasan de 200 
horas. Enero 300 de media oscilando entre las 481 de 2005 y las 190 de 2004. Febrero se acerca a las 200 de media oscilando entre las 370 de 2005 y las 78 de 2007 y diciembre con 285 de media, entre 380 de 2004 y 198 de 2009 es el mes con menor oscilación relativa.

\section{Mérida}

Tiene más de 900 horas frío anuales, oscilando entre las 795 de 2003 y las 1472 de 2005.

Los meses de junio, julio, agosto y septiembre están libres de horas frío. Mayo y octubre apenas tienen horas, y abril está cercano a la hora diaria de promedio. Marzo y noviembre están en torno a las 100 horas, pero la variación entre unos años y otros es muy notable, en marzo entre las 36 de 2009 y las 127 de 2005, y en noviembre entre las 11 de 2006 y las 255 de 2008. Enero tiene 304 de media oscilando entre las 524 de 2005 y las 160 de 2004 . Febrero 197 de media, entre las 356 de 2005 y las 68 de 2007. Diciembre con 255 de media, entre 84 de 2002 y 364 de 2004.

Tabla 63. Horas frío contadas en datos horarios en el observatorio de Mérida.

\begin{tabular}{cccccccccccccc}
\hline & ene & feb & mar & abr & may & jun & jul & ago & sep & oct & nov & dic & anual \\
\hline $\mathbf{2 0 0 2}$ & & 199 & 71 & 32 & 7 & 0 & 0 & 0 & 0 & & 44 & 84 & \\
\hline $\mathbf{2 0 0 3}$ & 299 & 229 & 41 & 12 & 0 & 0 & 0 & 0 & 0 & 5 & 24 & 185 & 795 \\
$\mathbf{2 0 0 4}$ & 160 & 132 & 100 & 44 & 2 & 0 & 0 & 0 & 0 & 4 & 172 & 364 & 978 \\
\hline $\mathbf{2 0 0 5}$ & 524 & 356 & 127 & 23 & 0 & 0 & 0 & 0 & 0 & 0 & 156 & 286 & 1472 \\
\hline $\mathbf{2 0 0 6}$ & 385 & 288 & 90 & 8 & 2 & 0 & 0 & 0 & 0 & 0 & 11 & 321 & 1105 \\
\hline $\mathbf{2 0 0 7}$ & 414 & 68 & 113 & 25 & 1 & 0 & 0 & & 0 & 5 & 222 & 289 & 1137 \\
$\mathbf{2 0 0 8}$ & 192 & 77 & 103 & 17 & 0 & 0 & & & 0 & 11 & 255 & 335 & 990 \\
\hline $\mathbf{2 0 0 9}$ & 282 & 216 & 36 & 51 & 0 & 0 & 0 & 0 & 0 & 0 & 44 & 188 & 817 \\
$\mathbf{2 0 1 0}$ & 242 & 172 & 105 & 21 & 6 & 0 & 0 & 0 & 0 & 17 & 134 & 187 & 884 \\
\hline $\mathbf{2 0 1 1}$ & 236 & 234 & 76 & 4 & 0 & 0 & 0 & 0 & 0 & 0 & 82 & 310 & 942 \\
\hline Prom. & 304 & 197 & 86 & 24 & 2 & 0 & 0 & 0 & 0 & 5 & 114 & 255 & 987 \\
\hline
\end{tabular}

\section{Resumen de horas frío contadas para la cuenca del Guadiana.}

En la zona baja del valle del Guadiana, en altitudes por debajo de $400 \mathrm{~m}$, el número anual de horas frío tiene una gran variación interanual que oscila entre las 600 y las 1400 horas, con una media un poco superior a las 900 horas. Y se distribuyen a lo largo del año de la forma siguiente: junio, julio, agosto y septiembre están libres de horas frío. Abril, mayo y octubre tienen pocas horas frío, menos de 50 en los casos de meses más fríos. Marzo y noviembre están en torno a las 100 horas, marzo por debajo y noviembre por encima; si bien la variación interanual es muy 
alta, sobre todo en noviembre, mes en el que puede haber años con 20 horas frío y otros con más de 200. Febrero tiene de media cerca de 200 horas y, en general, está todos los años por encima de 100. Enero y diciembre están ligeramente por encima de las 250 horas, también con una gran variación interanual, sobre todo diciembre que oscila entre menos de 100 y más de 300. En enero no es infrecuente que se superen las 400 horas.

En la parte de la cuenca situada en la meseta sur, en La Mancha y entre los Montes de Toledo y la cordillera Bética, entre los 400 y 700 m, se dan en torno a las 1500 horas frío anuales, también con una notable oscilación entre unos años y otros, hay años con 1000 horas y otros con 2000. Los meses de junio, julio y agosto están libres de horas frío. Septiembre, mayo y octubre tienen pocas. Entre los tres meses de invierno, enero, febrero y diciembre, pasan de 600 horas. La diferencia entre los mismos meses en diferentes años es muy elevada; por ejemplo, noviembre de 2002 tuvo 61 horas en Ciudad Real, mientras que noviembre de 2008 alcanzó 298 horas; enero de 2004 tuvo 280, y enero de 2005, 545 horas frío.

Es preciso tener en cuenta la marcada variabilidad interanual y entre cada uno de los meses en los distintos años.

\subsubsection{Cuenca del Guadalquivir: a) parte baja y relativamente llana de la cuenca}

Observatorios: Sevilla-San Pablo (5783), Sevilla Tablada (5790), Écija (5641X), Base aérea de Morón (5796) y Córdoba (5402).

Tabla 64.Comparación de horas frío anuales contadas a partir de datos horarios en los cinco observatorios de la parte baja de la cuenca del Guadalquivir.

\begin{tabular}{|c|c|c|c|c|c|}
\hline & $\begin{array}{c}\text { Sevilla SP } \\
5783\end{array}$ & $\begin{array}{c}\text { Sevilla T } \\
5790\end{array}$ & $\begin{array}{l}\text { Écija } \\
5641 x\end{array}$ & $\begin{array}{c}\text { Morón } \\
5796\end{array}$ & $\begin{array}{c}\text { Córdoba aer. } \\
5402\end{array}$ \\
\hline Año & $\mathrm{HF}$ & $\mathrm{HF}$ & $\mathrm{HF}$ & $\mathrm{HF}$ & $\mathrm{HF}$ \\
\hline 2002 & & 217 & 653 & 480 & 535 \\
\hline 2003 & 274 & 426 & 614 & 540 & 646 \\
\hline 2004 & 280 & 464 & 1028 & 705 & 782 \\
\hline 2005 & 669 & 865 & 1333 & 986 & 1154 \\
\hline 2006 & 391 & 621 & 919 & 756 & 825 \\
\hline 2007 & 273 & 541 & 997 & 746 & 906 \\
\hline 2008 & 262 & & 850 & 625 & 836 \\
\hline 2009 & 276 & & & 497 & 696 \\
\hline 2010 & 251 & & & 419 & 592 \\
\hline 2011 & 276 & & 786 & 519 & 719 \\
\hline Promedio & 328 & 522 & 898 & 627 & 769 \\
\hline
\end{tabular}




\section{Comparación de horas frío (umbral 7으) anuales en observatorios de la parte baja de la cuenca del Guadalquivir}

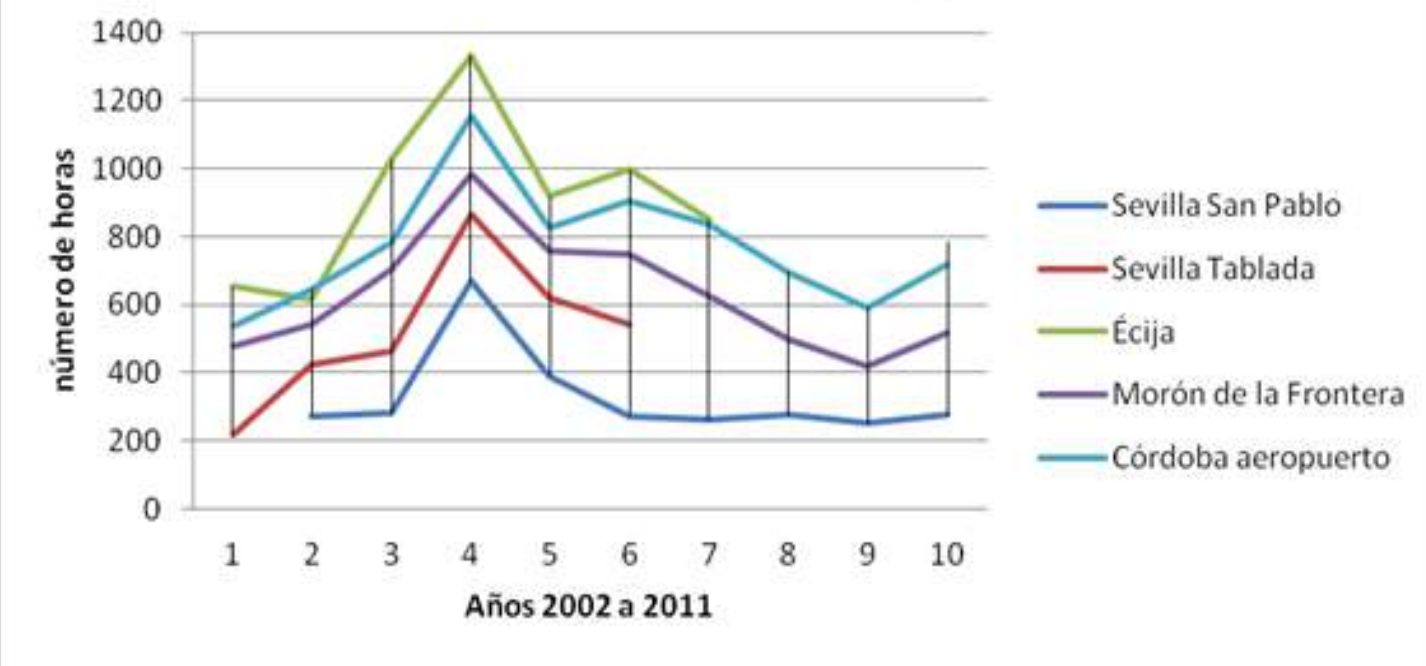

Gráfico 11. Comparación de horas frío (umbral 7ํㅡ) anuales en observatorios de la parte baja de la cuenca del Guadalquivir.

Como puede verse, el número anual de horas frío en el aeropuerto de Sevilla San Pablo parece muy homogéneo, excepto el año 2005, con 669 horas, están todos los años alrededor de las 300. Pero si se compara con los datos de Sevilla Tablada, se ve que la base aérea, que está muy cercana y debería tener unos datos muy similares, las horas frío anuales duplican a las del aeropuerto. Evidentemente, al menos en uno de los dos observatorios los datos son erróneos, probablemente los del aeropuerto de Sevilla San Pablo. Se puede señalar que, sólo con que se registrara una temperatura que fuera $1^{\circ} \mathrm{C}$ más alta de la que hubiera realmente, podrían justificarse esas diferencias.

Los datos de la base aérea de Morón y el aeropuerto de Córdoba son razonablemente homogéneos entre ellos, tienen una correlación de 0.88 , y como era de esperar el aeropuerto de Córdoba tiene unas 150 horas frío más al año que la base de Morón.

\section{$\underline{\text { Horas frío contadas en datos horarios en cada uno de los observatorios }}$}

Sevilla San Pablo y Sevilla Tablada. Deberían de tener un número de horas frío muy similar debido a la proximidad e igualdad del entorno. Sin embargo, se ve que en los años en los que ambos observatorios disponen de datos, los valores anuales de horas frío de la base aérea duplican a los del aeropuerto. Se consideran más fiables los de la base aérea, así que podría 
decirse que en Sevilla el promedio anual de horas frío es algo superior a 500, con una gran variabilidad interanual; mientras que 2002 tiene 217 horas, 2005 tiene 865 .

Sevilla podría considerarse libre de horas frío en los meses de mayo, junio, julio, agosto y septiembre. Abril y octubre tienen muy pocas horas frío y no todos los años. Marzo y noviembre están en torno a la media hora diaria en promedio. Febrero no llega a las 100 horas, diciembre está en torno a 150 horas y enero 200. La diferencia entre los valores del mismo mes unos años y otros es muy marcada.

Tabla 65. Horas frío contadas en datos horarios en el observatorio de Sevilla San Pablo.

\begin{tabular}{cccccccccccccc}
\hline & ene & feb & mar & abr & may & jun & jul & ago & sep & oct & nov & dic & anual \\
\hline $\mathbf{2 0 0 2}$ & & & & & & & & & & & & & \\
\hline $\mathbf{2 0 0 3}$ & 149 & 83 & 0 & 0 & 0 & 0 & 0 & 0 & 0 & 0 & 5 & 37 & 274 \\
\hline $\mathbf{2 0 0 4}$ & 83 & 18 & 35 & 1 & 0 & 0 & 0 & 0 & 0 & 1 & 40 & 102 & 280 \\
\hline $\mathbf{2 0 0 5}$ & 257 & 213 & 70 & 0 & 0 & 0 & 0 & 0 & 0 & 0 & 27 & 102 & 669 \\
\hline $\mathbf{2 0 0 6}$ & 173 & 101 & 8 & 0 & 0 & 0 & 0 & 0 & 0 & 0 & 0 & 109 & 391 \\
\hline $\mathbf{2 0 0 7}$ & 151 & 15 & 15 & 15 & 0 & 0 & 0 & 0 & 0 & 0 & 9 & 68 & 273 \\
\hline $\mathbf{2 0 0 8}$ & 45 & 2 & 22 & 0 & 0 & 0 & 0 & 0 & 0 & 0 & 33 & 160 & 262 \\
\hline $\mathbf{2 0 0 9}$ & 155 & 40 & 1 & 0 & 0 & 0 & 0 & 0 & 0 & 0 & 0 & 80 & 276 \\
\hline $\mathbf{2 0 1 0}$ & 84 & 59 & 21 & 0 & 0 & 0 & 0 & 0 & 0 & 0 & 15 & 72 & 251 \\
\hline $\mathbf{2 0 1 1}$ & 38 & 90 & 17 & 0 & 0 & 0 & 0 & 0 & 0 & 0 & 9 & 122 & 276 \\
Prom. & 126 & 69 & 21 & 2 & 0 & 0 & 0 & 0 & 0 & 0 & 15 & 95 & 328 \\
\hline
\end{tabular}

Tabla 66. Horas frío contadas en datos horarios en el observatorio de Sevilla Tablada.

\begin{tabular}{cccccccccccccc}
\hline & ene & feb & mar & abr & may & jun & jul & ago & sep & oct & nov & dic & anual \\
\hline $\mathbf{2 0 0 2}$ & 91 & 49 & 13 & 7 & 0 & 0 & 0 & 0 & 0 & 0 & 22 & 35 & 217 \\
\hline $\mathbf{2 0 0 3}$ & 196 & 140 & 1 & 0 & 0 & 0 & 0 & 0 & 0 & 1 & 16 & 72 & 426 \\
\hline $\mathbf{2 0 0 4}$ & 129 & 36 & 46 & 5 & 0 & 0 & 0 & 0 & 0 & 0 & 81 & 167 & 464 \\
\hline $\mathbf{2 0 0 5}$ & 329 & 291 & 61 & 0 & 0 & 0 & 0 & 0 & 0 & 0 & 53 & 131 & 865 \\
$\mathbf{2 0 0 6}$ & 238 & 148 & 29 & 0 & 0 & 0 & 0 & 0 & 0 & 0 & 0 & 206 & 621 \\
$\mathbf{2 0 0 7}$ & 220 & 37 & 37 & 22 & 0 & 0 & 0 & 0 & 0 & 0 & 46 & 179 & 541 \\
$\mathbf{2 0 0 8}$ & 15 & 36 & 3 & & 0 & 0 & 0 & 0 & 8 & 85 & 243 & & \\
\hline $\mathbf{2 0 0 9}$ & 88 & 8 & 14 & 0 & 0 & 0 & 0 & 0 & 0 & 10 & & & \\
\hline $\mathbf{2 0 1 0}$ & 75 & & & & & & & & & & & &
\end{tabular}

Écija. Tiene 7 años de datos completos en el periodo 2002 y 2011. En esos siete años tiene cerca de 900 horas anuales de promedio, y una gran variabilidad interanual, entre las más de 1300 horas de 2005 y las cerca de 600 de 2003. 
Los cuatro meses que podrían considerarse de verano en Écija: junio, julio, agosto y septiembre, está libres de horas frío. Mayo y octubre tienen muy pocas horas frío y no todos los años. Abril no llega a la hora diaria en promedio, y marzo y noviembre están en torno a las tres horas diarias en promedio. Febrero no llega a las 200 horas, diciembre las sobrepasa y enero tiene en torno a las 275 mensuales. La diferencia entre los valores del mismo mes unos años y otros es muy marcada. Por ejemplo, enero de 2008 tuvo 185 horas, mientras que en enero de 2005 se dieron 421; en febrero de 2008 hubo 70 horas mientras que en febrero de 2005 hubo 333.

Tabla 67. Horas frío contadas en datos horarios en el observatorio de Écija.

\begin{tabular}{cccccccccccccc}
\hline & ene & feb & mar & abr & may & jun & jul & ago & sep & oct & nov & dic & anual \\
\hline $\mathbf{2 0 0 2}$ & 243 & 204 & 46 & 23 & 7 & 0 & 0 & 0 & 0 & 0 & 36 & 94 & 653 \\
\hline $\mathbf{2 0 0 3}$ & 207 & 160 & 35 & 15 & 0 & 0 & 0 & 0 & 0 & & 20 & 170 & 607 \\
$\mathbf{2 0 0 4}$ & 232 & 170 & 108 & 62 & 3 & 0 & 0 & 0 & 0 & 1 & 165 & 286 & 1027 \\
\hline $\mathbf{2 0 0 5}$ & 421 & 333 & 123 & 19 & 3 & 0 & 0 & 0 & 0 & 0 & 193 & 241 & 1333 \\
$\mathbf{2 0 0 6}$ & 312 & 204 & 69 & 0 & 0 & 0 & 0 & 0 & 0 & 0 & 25 & 309 & 919 \\
\hline $\mathbf{2 0 0 7}$ & 379 & 82 & 138 & 52 & 0 & 0 & 0 & 0 & 0 & 0 & 102 & 244 & 997 \\
$\mathbf{2 0 0 8}$ & 185 & 70 & 113 & 24 & 0 & 0 & 0 & 0 & 0 & 10 & 160 & 288 & 850 \\
$\mathbf{2 0 0 9}$ & 262 & 160 & 31 & 30 & 0 & 0 & 0 & 0 & 0 & 0 & 56 & & \\
\hline $\mathbf{2 0 1 0}$ & & 110 & 85 & 24 & 6 & 0 & 0 & 0 & 0 & 10 & 91 & 146 & \\
\hline $\mathbf{2 0 1 1}$ & 195 & 184 & 71 & 0 & 0 & 0 & 0 & 0 & 0 & 0 & 64 & 272 & 786 \\
\hline Prom. & 271 & 168 & 82 & 25 & 2 & 0 & 0 & 0 & 0 & 2 & 91 & 228 & 897 \\
\hline
\end{tabular}

Morón de la Frontera. Tiene en promedio poco más de 600 horas frío (umbral $7^{\circ} \mathrm{C}$ ) al año, oscilando entre las 986 horas de 2005 y las 419 de 2010 (es decir, se da una gran variabilidad interanual).

Los cuatro meses que podrían considerarse de verano en Córdoba: junio, julio, agosto y septiembre, está libres de horas frío. Mayo y octubre tienen muy pocas horas frío y no todos los años, de hecho, mayo sólo tuvo un año, y fueron 3. Abril tiene un promedio de 12 horas y noviembre 46 y marzo 58, uno por debajo de una hora diaria en promedio, y los otros dos por debajo de las dos. Febrero y diciembre están en torno a las 150 horas, y enero tiene en torno a las 200. La diferencia entre los valores del mismo mes unos años y otros es muy marcada. Por ejemplo, enero de 2011 tuvo 95 horas, mientras que en enero de 2005 se dieron 380; en febrero de 2008 hubo 56 horas mientras que en febrero de 2005 hubo 302. 
Tabla 68. Horas frío contadas en datos horarios en el observatorio de Morón de la Frontera.

\begin{tabular}{cccccccccccccc}
\hline & ene & feb & mar & abr & may & jun & jul & ago & sep & oct & nov & dic & anual \\
\hline $\mathbf{2 0 0 2}$ & 174 & 161 & 41 & 10 & 0 & 0 & 0 & 0 & 0 & 2 & 26 & 66 & 480 \\
\hline $\mathbf{2 0 0 3}$ & 212 & 172 & 14 & 8 & 0 & 0 & 0 & 0 & 0 & 4 & 11 & 119 & 540 \\
\hline $\mathbf{2 0 0 4}$ & 154 & 120 & 74 & 22 & 0 & 0 & 0 & 0 & 0 & 0 & 134 & 201 & 705 \\
\hline $\mathbf{2 0 0 5}$ & 380 & 302 & 91 & 15 & 0 & 0 & 0 & 0 & 0 & 0 & 40 & 158 & 986 \\
\hline $\mathbf{2 0 0 6}$ & 287 & 178 & 57 & 0 & 0 & 0 & 0 & 0 & 0 & 0 & 4 & 230 & 756 \\
\hline $\mathbf{2 0 0 7}$ & 323 & 60 & 79 & 34 & 0 & 0 & 0 & 0 & 0 & 0 & 59 & 191 & 746 \\
\hline $\mathbf{2 0 0 8}$ & 134 & 56 & 90 & 6 & 0 & 0 & 0 & 0 & 0 & 8 & 96 & 235 & 625 \\
\hline $\mathbf{2 0 0 9}$ & 195 & 121 & 16 & 10 & 0 & 0 & 0 & 0 & 0 & 0 & 25 & 130 & 497 \\
\hline $\mathbf{2 0 1 0}$ & 115 & 85 & 61 & 13 & 3 & 0 & 0 & 0 & 0 & 4 & 39 & 99 & 419 \\
\hline $\mathbf{2 0 1 1}$ & 95 & 162 & 60 & 0 & 0 & 0 & 0 & 0 & 0 & 0 & 26 & 176 & 519 \\
\hline Prom. & 207 & 142 & 58 & 12 & 0 & 0 & 0 & 0 & 0 & 2 & 46 & 161 & 627 \\
\hline
\end{tabular}

Aeropuerto de Córdoba. Tiene en promedio cerca de 800 horas frío (umbral $7^{\circ} \mathrm{C}$ ) al año, oscilando entre las 1154 horas de 2005 y las 535 de 2002 (es decir, se da una gran variabilidad interanual).

Los cuatro meses que podrían considerarse de verano en Córdoba: junio, julio, agosto y septiembre, están libres de horas frío. Mayo y octubre tienen muy pocas horas frío y no todos los años. Abril no llega a la hora diaria en promedio, y marzo y noviembre están en torno a las dos horas diarias en promedio. Febrero tiene unas 150 horas, diciembre pasa ligeramente de las 200 horas y enero tiene en torno a las 250. La diferencia entre los valores del mismo mes unos años y otros es muy marcada. Por ejemplo, enero de 2010 tuvo 167 horas, mientras que en enero de 2005 se dieron 434; en febrero de 2007 hubo 55 horas mientras que en febrero de 2005 hubo 316.

Tabla 69. Horas frío contadas en datos horarios en el observatorio del aeropuerto de Córdoba.

\begin{tabular}{cccccccccccccc}
\hline & ene & feb & mar & abr & may & jun & jul & ago & sep & oct & nov & dic & anual \\
\hline $\mathbf{2 0 0 2}$ & 208 & 173 & 22 & 5 & 4 & 0 & 0 & 0 & 0 & 0 & 41 & 82 & 535 \\
$\mathbf{2 0 0 3}$ & 270 & 180 & 21 & 9 & 0 & 0 & 0 & 0 & 0 & 2 & 16 & 148 & 646 \\
$\mathbf{2 0 0 4}$ & 179 & 111 & 77 & 17 & 2 & 0 & 0 & 0 & 0 & 0 & 158 & 238 & 782 \\
$\mathbf{2 0 0 5}$ & 434 & 316 & 116 & 6 & 0 & 0 & 0 & 0 & 0 & 0 & 85 & 197 & 1154 \\
$\mathbf{2 0 0 6}$ & 286 & 190 & 45 & 0 & 0 & 0 & 0 & 0 & 0 & 0 & 1 & 303 & 825 \\
$\mathbf{2 0 0 7}$ & 349 & 55 & 105 & 14 & 0 & 0 & 0 & 0 & 0 & 0 & 129 & 254 & 906 \\
$\mathbf{2 0 0 8}$ & 177 & 92 & 84 & 21 & 0 & 0 & 0 & 0 & 0 & 12 & 147 & 303 & 836 \\
$\mathbf{2 0 0 9}$ & 253 & 167 & 24 & 16 & 0 & 0 & 0 & 0 & 0 & 0 & 43 & 193 & 696 \\
$\mathbf{2 0 1 0}$ & 167 & 109 & 64 & 18 & 3 & 0 & 0 & 0 & 0 & 6 & 65 & 160 & 592 \\
$\mathbf{2 0 1 1}$ & 183 & 180 & 55 & 0 & 0 & 0 & 0 & 0 & 0 & 1 & 35 & 265 & 719 \\
Prom. & 251 & 157 & 61 & 11 & 1 & 0 & 0 & 0 & 0 & 2 & 72 & 214 & 769 \\
\hline
\end{tabular}


Observatorios: Granada (5514) y Linares VOR (5279x).

Tabla 70. Comparación de horas frío anuales contadas a partir de datos horarios en los dos observatorios de la parte media de la cuenca del Guadalquivir.

\begin{tabular}{|ccc|}
\hline & $\begin{array}{c}\text { Granada } \\
\mathbf{5 5 1 4}\end{array}$ & $\begin{array}{c}\text { Linares } \\
\mathbf{5 2 7 9 x}\end{array}$ \\
\hline Año & HF & HF \\
\hline $\mathbf{2 0 0 2}$ & 1211 & \\
\hline $\mathbf{2 0 0 3}$ & 1321 & \\
\hline $\mathbf{2 0 0 4}$ & 1386 & 1367 \\
\hline $\mathbf{2 0 0 5}$ & 1768 & 1086 \\
\hline $\mathbf{2 0 0 6}$ & 1491 & 910 \\
\hline $\mathbf{2 0 0 7}$ & 1522 & \\
\hline $\mathbf{2 0 0 8}$ & 1574 & \\
\hline $\mathbf{2 0 0 9}$ & 1341 & 983 \\
\hline $\mathbf{2 0 1 0}$ & 1194 \\
\hline $\mathbf{2 0 1 1}$ & 1339 \\
\hline Promedio & 1415 \\
\hline
\end{tabular}

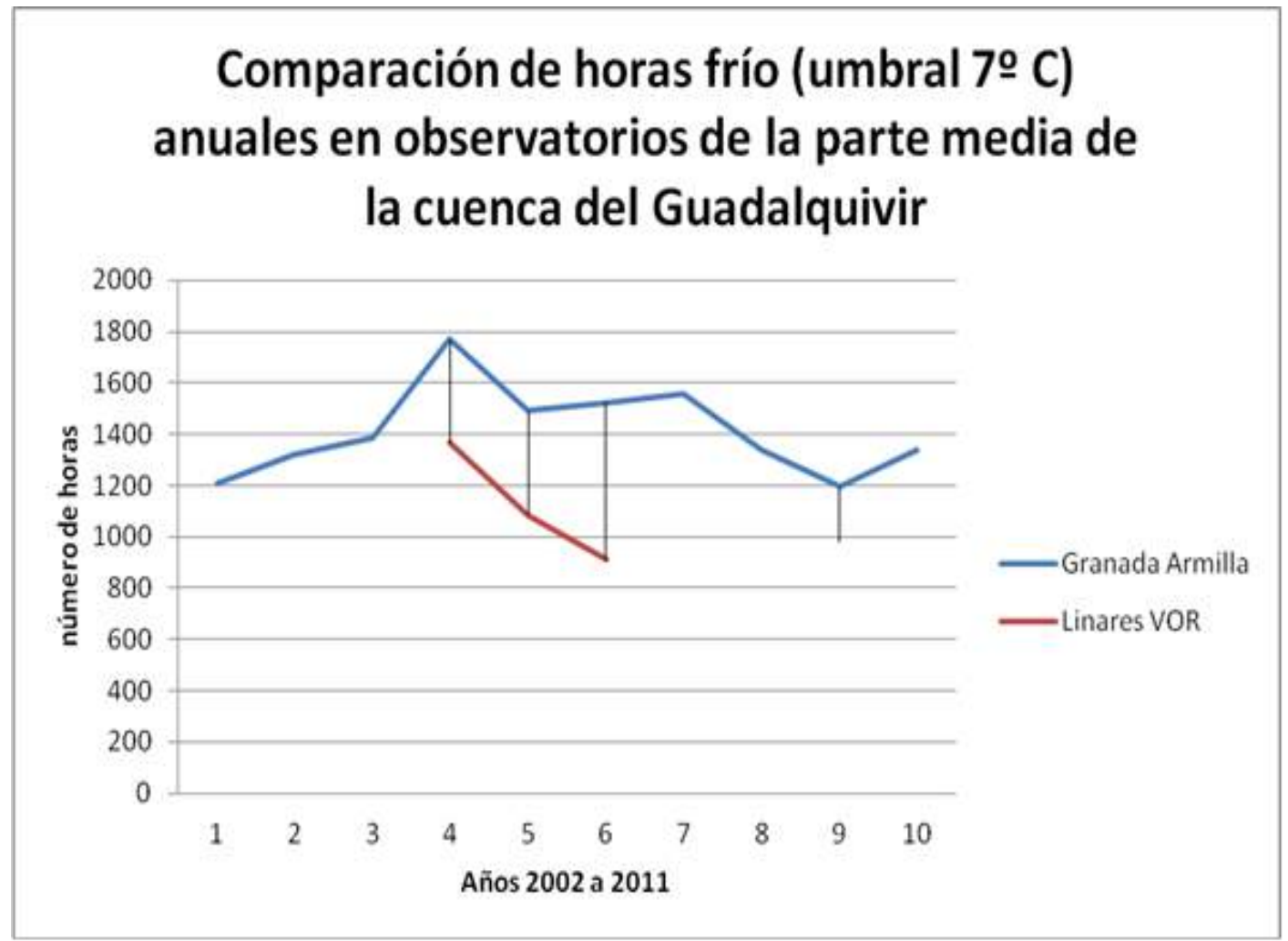

Gráfico 12. Comparación de horas frío (umbral 7ํㅡ) anuales en observatorios de la parte media de la cuenca del Guadalquivir. 


\section{Horas frío contadas en datos horarios en cada uno de los observatorios}

Granada. Tiene en promedio unas 1400 horas frío (umbral $7^{\circ} \mathrm{C}$ ) al año, oscilando entre las 1768 horas de 2005 y las 1194 de 2010. La variabilidad interanual es mucho menor que en el bajo Guadalquivir.

Los cuatro meses que podrían considerarse de verano en Granada: junio, julio, agosto y septiembre, está libres de horas frío. Mayo y octubre tienen muy pocas horas frío, aunque casi todos los años. Abril tiene cerca de dos horas diaria en promedio, y marzo y noviembre están en torno a las 150 horas mensuales en promedio. Febrero tiene unas 270 horas, diciembre 350 horas y enero tiene en torno a las 400. La diferencia entre los valores del mismo mes unos años y otros es notable para los dos últimos meses del año. Por ejemplo, noviembre de 2003 tuvo 75 horas, mientras que noviembre de 2008 tuvo 291.

Tabla 71. Horas frío contadas en datos horarios en el observatorio de Granada.

\begin{tabular}{cccccccccccccc}
\hline & ene & feb & mar & abr & may & jun & jul & ago & sep & oct & nov & dic & anual \\
\hline $\mathbf{2 0 0 2}$ & 336 & 240 & 130 & 116 & 26 & 0 & 0 & 0 & 0 & 11 & 109 & 242 & 1211 \\
\hline $\mathbf{2 0 0 3}$ & 443 & 322 & 102 & 54 & 1 & 0 & 0 & 0 & 0 & 10 & 75 & 314 & 1321 \\
$\mathbf{2 0 0 4}$ & 315 & 227 & 146 & 66 & 14 & 0 & 0 & 0 & 0 & 11 & 208 & 399 & 1386 \\
\hline $\mathbf{2 0 0 5}$ & 489 & 435 & 190 & 35 & 0 & 0 & 0 & 0 & 0 & 5 & 262 & 352 & 1768 \\
\hline $\mathbf{2 0 0 6}$ & 501 & 327 & 133 & 11 & 0 & 0 & 0 & 0 & 0 & 0 & 96 & 422 & 1491 \\
\hline $\mathbf{2 0 0 7}$ & 451 & 166 & 202 & 77 & 1 & 0 & 0 & 0 & 0 & 14 & 214 & 397 & 1522 \\
$\mathbf{2 0 0 8}$ & 358 & 204 & 172 & 58 & 3 & 0 & 0 & 0 & 0 & 26 & 291 & 447 & 1559 \\
\hline $\mathbf{2 0 0 9}$ & 459 & 290 & 142 & 91 & 6 & 0 & 0 & 0 & 0 & 1 & 97 & 255 & 1341 \\
$\mathbf{2 0 1 0}$ & 342 & 215 & 147 & 39 & 13 & 0 & 0 & 0 & 0 & 28 & 170 & 240 & 1194 \\
\hline $\mathbf{2 0 1 1}$ & 341 & 285 & 162 & 0 & 1 & 0 & 0 & 0 & 0 & 2 & 134 & 413 & 1339 \\
\hline Prom. & 404 & 271 & 153 & 55 & 7 & 0 & 0 & 0 & 0 & 11 & 166 & 348 & 1413 \\
\hline
\end{tabular}

Linares VOR. Tiene solamente cuatro años completos de datos, poco para sacar conclusiones.

Tabla 72. Horas frío contadas en datos horarios en el observatorio de Linares VOR.

\begin{tabular}{|c|c|c|c|c|c|c|c|c|c|c|c|c|c|}
\hline & ene & feb & mar & $a b r$ & may & jun & jul & ago & sep & oct & nov & dic & anual \\
\hline \multicolumn{14}{|l|}{2002} \\
\hline \multicolumn{14}{|l|}{2003} \\
\hline 2004 & & & 102 & 44 & 1 & 0 & 0 & 0 & 0 & 3 & 83 & & \\
\hline 2005 & 373 & 379 & 151 & 25 & 0 & 0 & 0 & 0 & 0 & 0 & 164 & 275 & 1367 \\
\hline 2006 & 415 & 285 & 70 & 1 & 0 & 0 & 0 & 0 & 0 & 0 & 9 & 306 & 1086 \\
\hline 2007 & 305 & 81 & 110 & 85 & 0 & 0 & 0 & 0 & 0 & 0 & 97 & 232 & 910 \\
\hline 2008 & 171 & 62 & 109 & 22 & 0 & 0 & 0 & 0 & 0 & 26 & 168 & & \\
\hline 2009 & & & 81 & 47 & & & 0 & 0 & 0 & & 35 & 246 & \\
\hline 2010 & 324 & 227 & 0 & 0 & 6 & 0 & 0 & 0 & 0 & 4 & 155 & 267 & 983 \\
\hline \multicolumn{14}{|l|}{2011} \\
\hline Prom. & & & & & & & & & & & & & \\
\hline
\end{tabular}


Podría concluirse que en el bajo Guadalquivir, por debajo de $200 \mathrm{~m}$ de altitud se da entre las 500 y las 800 horas frío anuales. En el Genil a la altura de Granada y en zonas de altitud semejante se dan unas 1500 horas, y en zonas más altas, pero no pertenecientes a las cordilleras Bética y Penibética pueden alcanzarse las 2000 horas.

Es preciso tener en cuenta la marcada variabilidad interanual y entre cada uno de los meses en los distintos años.

\subsubsection{Levante: a) franja costera de Levante: huerta levantina}

Observatorios: Castellón (8500a), Valencia CMT (8416), Valencia-Manises (8414a), Alicante (8025), Alicante-El Altet (8019).

Tabla 73. Comparación de horas frío anuales contadas a partir de datos horarios en los cinco observatorios de la franja costera de Levante: huerta levantina.

\begin{tabular}{|cccccc|}
\hline & $\begin{array}{c}\text { Castellón } \\
\mathbf{8 5 0 0 a}\end{array}$ & $\begin{array}{c}\text { Valencia CMT } \\
\mathbf{8 4 1 6}\end{array}$ & $\begin{array}{c}\text { Valencia Manises } \\
\mathbf{8 4 1 4 a}\end{array}$ & $\begin{array}{c}\text { Alicante } \\
\mathbf{8 0 2 5}\end{array}$ & $\begin{array}{c}\text { Alicante El Altet } \\
\mathbf{8 0 1 9}\end{array}$ \\
\hline Años & HF & HF & HF & HF & HF \\
\hline $\mathbf{2 0 0 2}$ & 133 & 49 & 242 & 218 & 349 \\
\hline $\mathbf{2 0 0 3}$ & 350 & 267 & 474 & 301 & 243 \\
\hline $\mathbf{2 0 0 4}$ & 315 & 149 & 453 & 266 & 379 \\
\hline $\mathbf{2 0 0 5}$ & 849 & & 1073 & 667 & 768 \\
\hline $\mathbf{2 0 0 6}$ & 409 & 184 & 782 & 290 & 406 \\
\hline $\mathbf{2 0 0 7}$ & 304 & 210 & 775 & 272 & 404 \\
\hline $\mathbf{2 0 0 8}$ & 324 & 192 & 833 & 332 & 475 \\
\hline $\mathbf{2 0 0 9}$ & 454 & 300 & 872 & 254 & 440 \\
\hline $\mathbf{2 0 1 0}$ & 601 & 468 & 1052 & 418 & 420 \\
\hline $\mathbf{2 0 1 1}$ & 331 & 252 & 704 & 326 & 266 \\
\hline promedio & 407 & 230 & 726 & 334 & 415 \\
\hline
\end{tabular}




\section{Comparación de horas frío (umbral 7으) anuales en observatorios de la franja costera de Levante}

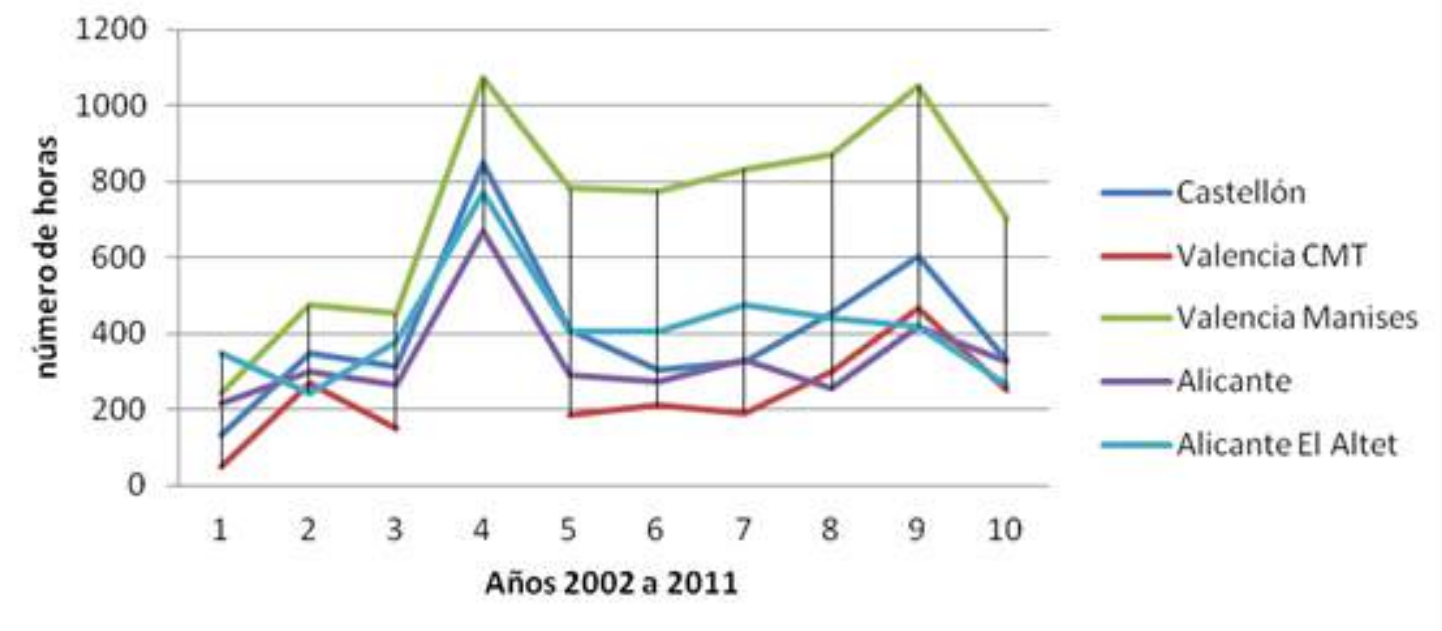

Gráfico 13. Comparación de horas frío (umbral 7ำ) anuales en los observatorios de la franja costera de Levante: huerta levantina.

Los datos no parecen totalmente coherentes entre ellos. Se dan diferencias aparentemente excesivas entre Valencia y Valencia Manises entre 2004 y 2011. Por ejemplo, sorprende que en el año 2008 Manises (aerop. de Valencia) tenga 833 horas frío y Valencia 191. Sorprende también que en 2009 Alicante tenga 254 horas y El Altet tenga 440.

\section{Horas frío contadas en datos horarios en cada uno de los observatorios}

Castellón. Tiene en promedio unas 400 horas frío (umbral $7^{\circ} \mathrm{C}$ ) al año, oscilando entre las 133 de 2002 y las 849 de 2005.

Desde abril a octubre, Castellón está libre de horas frío, aunque abril y octubre tienen alguna hora algún año. Noviembre está en la media hora de promedio, y marzo algo más de una hora diaria de promedio. Febrero y diciembre tienen en promedio tres horas diarias y enero está en torno a 5. La oscilación entre unos meses y otros correspondientes a años distintos puede ser muy marcada. Por ejemplo, diciembre de 2002 tuvo sólo 4 horas frío, mientras que diciembre de 2005 tuvo 180; enero de 2004 tuvo 83 horas, mientas que enero de 2005 tuvo 283. 
Tabla 74. Horas frío contadas en datos horarios en el observatorio de Castellón.

\begin{tabular}{rrrrrrrrrrrrrr}
\hline & ene & feb & mar & abr & may & jun & jul & ago & sep & oct & nov & dic & anual \\
\hline $\mathbf{2 0 0 2}$ & 85 & 43 & 1 & 0 & 0 & 0 & 0 & 0 & 0 & 0 & 0 & 4 & 133 \\
$\mathbf{2 0 0 3}$ & 139 & 117 & 27 & 1 & 0 & 0 & 0 & 0 & 0 & 0 & 0 & 66 & 350 \\
$\mathbf{2 0 0 4}$ & 83 & 79 & 63 & 0 & 0 & 0 & 0 & 0 & 0 & 0 & 15 & 75 & 315 \\
$\mathbf{2 0 0 5}$ & 283 & 237 & 119 & 0 & 0 & 0 & 0 & 0 & 0 & 0 & 30 & 180 & 849 \\
$\mathbf{2 0 0 6}$ & 150 & 120 & 22 & 0 & 0 & 0 & 0 & 0 & 0 & 0 & 0 & 117 & 409 \\
$\mathbf{2 0 0 7}$ & 96 & 15 & 13 & 0 & 0 & 0 & 0 & 0 & 0 & 0 & 44 & 136 & 304 \\
$\mathbf{2 0 0 8}$ & 106 & 19 & 33 & 0 & 0 & 0 & 0 & 0 & 0 & 3 & 32 & 131 & 324 \\
$\mathbf{2 0 0 9}$ & 222 & 100 & 2 & 0 & 0 & 0 & 0 & 0 & 0 & 0 & 3 & 127 & 454 \\
$\mathbf{2 0 1 0}$ & 163 & 142 & 98 & 0 & 0 & 0 & 0 & 0 & 0 & 0 & 31 & 167 & 601 \\
$\mathbf{2 0 1 1}$ & 172 & 76 & 30 & 0 & 0 & 0 & 0 & 0 & 0 & 0 & 0 & 53 & 331 \\
Prom. & 150 & 95 & 41 & 0 & 0 & 0 & 0 & 0 & 0 & 0 & 16 & 106 & 407 \\
\hline
\end{tabular}

Valencia. Tiene en promedio de 250 horas frío (umbral $7^{\circ} \mathrm{C}$ ) al año, oscilando entre las 49 de 2002 y las 467 de 2010 (Hay que señalar que no se tienen datos del año 2005).

De abril a octubre, Valencia está libre de horas frío. Marzo y noviembre tienen pocas horas y no todos los años. Febrero no llega a las 2 horas diarias de promedio, diciembre las sobrepasa en poco, y enero tiene 3 horas diarias de promedio. La oscilación entre unos meses y otros correspondientes a años distintos puede ser muy marcada. Por ejemplo, diciembre de 2002 no tuvo horas frío, mientras que diciembre de 2010 tuvo 125; enero de 2002 tuvo 32 horas, mientas que enero de 2009 tuvo 158.

Tabla 75.Horas frío contadas en datos horarios en el observatorio de Valencia.

\begin{tabular}{|c|c|c|c|c|c|c|c|c|c|c|c|c|c|}
\hline & ene & feb & mar & $a b r$ & may & jun & jul & ago & sep & oct & nov & dic & anual \\
\hline 2002 & 32 & 15 & 2 & 0 & 0 & 0 & 0 & 0 & 0 & 0 & 0 & 0 & 49 \\
\hline 2003 & 126 & 87 & 13 & 0 & 0 & 0 & 0 & 0 & 0 & 0 & 0 & 41 & 267 \\
\hline 2004 & 54 & 41 & 54 & 0 & 0 & 0 & 0 & 0 & 0 & 0 & 14 & 50 & 213 \\
\hline \multicolumn{14}{|l|}{2005} \\
\hline 2006 & 100 & 83 & 13 & 0 & 0 & 0 & 0 & 0 & 0 & 0 & 0 & 88 & 284 \\
\hline 2007 & 69 & 10 & 10 & 0 & 0 & 0 & 0 & 0 & 0 & 0 & 32 & 89 & 210 \\
\hline 2008 & 42 & 11 & 9 & 0 & 0 & 0 & 0 & 0 & 0 & 0 & 24 & 105 & 191 \\
\hline 2009 & 158 & 40 & 0 & 0 & 0 & 0 & 0 & 0 & 0 & 0 & 0 & 102 & 300 \\
\hline 2010 & 138 & 114 & 78 & 0 & 0 & 0 & 0 & 0 & 0 & 0 & 12 & 125 & 467 \\
\hline 2011 & 114 & 79 & 28 & 0 & 0 & 0 & 0 & 0 & 0 & 0 & 0 & 31 & 252 \\
\hline Prom. & 93 & 53 & 23 & 0 & 0 & 0 & 0 & 0 & 0 & 0 & 9 & 70 & 248 \\
\hline
\end{tabular}


Valencia Manises. El promedio de horas frío anuales es de algo más de 700 horas anuales, oscilando entre las 242 de 2002 y las 1072 de 2005.

Los meses de mayo a septiembre están libres de horas frío. Abril y octubre tienen muy pocas y no todos los años. Noviembre tiene en promedio 2 horas diarias y marzo no llega a tres. Febrero tiene en promedio 150 horas, diciembre no llega a las 200, y enero las sobrepasa.

Tabla 76. Horas frío contadas en datos horarios en el observatorio de Valencia Manises.

\begin{tabular}{rrrrrrrrrrrrrr}
\hline & ene & feb & mar & abr & may & jun & jul & ago & sep & oct & nov & dic & anual \\
\hline $\mathbf{2 0 0 2}$ & 115 & 73 & 17 & 0 & 0 & 0 & 0 & 0 & 0 & 0 & 6 & 31 & 242 \\
$\mathbf{2 0 0 3}$ & 153 & 156 & 52 & 4 & 0 & 0 & 0 & 0 & 0 & 2 & 1 & 106 & 474 \\
$\mathbf{2 0 0 4}$ & 114 & 100 & 73 & 8 & 0 & 0 & 0 & 0 & 0 & 0 & 55 & 103 & 453 \\
$\mathbf{2 0 0 5}$ & 324 & 257 & 108 & 3 & 0 & 0 & 0 & 0 & 0 & 0 & 113 & 267 & 1072 \\
$\mathbf{2 0 0 6}$ & 284 & 227 & 41 & 0 & 0 & 0 & 0 & 0 & 0 & 0 & 3 & 227 & 782 \\
$\mathbf{2 0 0 7}$ & 268 & 45 & 79 & 6 & 0 & 0 & 0 & 0 & 0 & 0 & 156 & 221 & 775 \\
$\mathbf{2 0 0 8}$ & 192 & 113 & 51 & 5 & 0 & 0 & 0 & 0 & 0 & 7 & 153 & 312 & 833 \\
$\mathbf{2 0 0 9}$ & 266 & 212 & 126 & 26 & 0 & 0 & 0 & 0 & 0 & 0 & 32 & 210 & 872 \\
$\mathbf{2 0 1 0}$ & 232 & 216 & 156 & 29 & 0 & 0 & 0 & 0 & 0 & 31 & 109 & 277 & 1050 \\
$\mathbf{2 0 1 1}$ & 295 & 180 & 117 & 1 & 0 & 0 & 0 & 0 & 0 & 0 & 7 & 103 & 703 \\
Prom. & 224 & 158 & 82 & 8 & 0 & 0 & 0 & 0 & 0 & 4 & 64 & 186 & 726 \\
\hline
\end{tabular}

Alicante. Tiene en promedio algo más de 300 horas frío (umbral $7^{\circ} \mathrm{C}$ ) al año, oscilando entre las 218 de 2002 y las 667 de 2005.

Tabla 77. Horas frío contadas en datos horarios en el observatorio de Alicante.

\begin{tabular}{rrrrrrrrrrrrrr}
\hline & ene & feb & mar & abr & may & jun & jul & ago & sep & oct & nov & dic & anual \\
\hline $\mathbf{2 0 0 2}$ & 86 & 88 & 17 & 0 & 0 & 0 & 0 & 0 & 0 & 0 & 0 & 27 & 218 \\
$\mathbf{2 0 0 3}$ & 117 & 82 & 25 & 4 & 0 & 0 & 0 & 0 & 0 & 0 & 0 & 73 & 301 \\
$\mathbf{2 0 0 4}$ & 87 & 43 & 26 & 3 & 0 & 0 & 0 & 0 & 0 & 0 & 32 & 75 & 266 \\
$\mathbf{2 0 0 5}$ & 248 & 191 & 91 & 6 & 0 & 0 & 0 & 0 & 0 & 0 & 33 & 98 & 667 \\
$\mathbf{2 0 0 6}$ & 144 & 68 & 18 & 0 & 0 & 0 & 0 & 0 & 0 & 0 & 0 & 60 & 290 \\
$\mathbf{2 0 0 7}$ & 84 & 16 & 24 & 0 & 0 & 0 & 0 & 0 & 0 & 0 & 41 & 107 & 272 \\
$\mathbf{2 0 0 8}$ & 74 & 45 & 35 & 0 & 0 & 0 & 0 & 0 & 0 & 0 & 41 & 137 & 332 \\
$\mathbf{2 0 0 9}$ & 109 & 71 & 6 & 0 & 0 & 0 & 0 & 0 & 0 & 0 & 0 & 68 & 254 \\
$\mathbf{2 0 1 0}$ & 100 & 75 & 78 & 0 & 0 & 0 & 0 & 0 & 0 & 4 & 10 & 151 & 418 \\
$\mathbf{2 0 1 1}$ & 94 & 113 & 44 & 0 & 0 & 0 & 0 & 0 & 0 & 0 & 4 & 71 & 326 \\
Prom. & 114 & 79 & 36 & 1 & 0 & 0 & 0 & 0 & 0 & 0 & 16 & 87 & 334 \\
\hline
\end{tabular}


Los meses de abril a octubre están prácticamente libres de horas frío. Octubre tuvo un año 4 horas y abril también algunas horas algún año. Noviembre media hora diaria de promedio y marzo 1 hora. Febrero algo más de 2 horas, diciembre no llega a tres, y enero las sobrepasa. La oscilación entre unos meses y otros correspondientes a años distintos puede ser muy marcada. Por ejemplo, diciembre de 2002 tuvo 27 horas frío, mientras que diciembre de 2010 tuvo 151.

Alicante El Altet. Tiene en promedio algo más de 400 horas frío (umbral $7^{\circ} \mathrm{C}$ ) al año, oscilando entre las 243 de 2003 y las 768 de 2005.

Los meses de abril a octubre están prácticamente libres de horas frío. Octubre tuvo un par de años y abril también algunas horas algún año. Noviembre no llega a una hora diaria de promedio y marzo no llega a 2 . Febrero 3 horas, diciembre y enero 4 horas diarias.

Tabla 78. Horas frío contadas en datos horarios en el observatorio de Alicante El Altet.

\begin{tabular}{rrrrrrrrrrrrrr}
\hline & ene & feb & mar & abr & may & jun & jul & ago & sep & oct & nov & dic & anual \\
\hline $\mathbf{2 0 0 2}$ & 54 & 49 & 4 & 0 & 0 & 0 & 0 & 0 & 0 & 0 & 0 & 242 & 349 \\
$\mathbf{2 0 0 3}$ & 86 & 58 & 20 & 2 & 0 & 0 & 0 & 0 & 0 & 0 & 1 & 76 & 243 \\
$\mathbf{2 0 0 4}$ & 97 & 103 & 42 & 11 & 0 & 0 & 0 & 0 & 0 & 0 & 35 & 90 & 378 \\
$\mathbf{2 0 0 5}$ & 263 & 212 & 128 & 5 & 0 & 0 & 0 & 0 & 0 & 0 & 44 & 116 & 768 \\
$\mathbf{2 0 0 6}$ & 161 & 121 & 29 & 0 & 0 & 0 & 0 & 0 & 0 & 0 & 0 & 88 & 399 \\
$\mathbf{2 0 0 7}$ & 137 & 25 & 52 & 0 & 0 & 0 & 0 & 0 & 0 & 1 & 57 & 132 & 404 \\
$\mathbf{2 0 0 8}$ & 127 & 60 & 49 & 3 & 0 & 0 & 0 & 0 & 0 & 0 & 81 & 155 & 475 \\
$\mathbf{2 0 0 9}$ & 151 & 118 & 66 & 5 & 0 & 0 & 0 & 0 & 0 & 0 & 6 & 94 & 440 \\
$\mathbf{2 0 1 0}$ & 110 & 91 & 75 & 2 & 0 & 0 & 0 & 0 & 0 & 2 & 8 & 132 & 420 \\
$\mathbf{2 0 1 1}$ & 87 & 99 & 35 & 0 & 0 & 0 & 0 & 0 & 0 & 0 & 0 & 45 & 266 \\
Prom. & 127 & 94 & 50 & 3 & 0 & 0 & 0 & 0 & 0 & 0 & 23 & 117 & 414 \\
\hline
\end{tabular}

\subsubsection{Levante: b) huerta murciana}

Observatorios: Base aérea de Alcantarilla (7228), Base aérea de San Javier (7031) y Totana (automática y manual) (7218x). 
Tabla 79. Comparación de horas frío anuales contadas a partir de datos horarios en los tres observatorios de la huerta murciana.

\begin{tabular}{|cccc|}
\hline & $\begin{array}{c}\text { Alcantarilla } \\
\mathbf{7 2 2 8}\end{array}$ & $\begin{array}{c}\text { San Javier } \\
\mathbf{7 0 3 1}\end{array}$ & $\begin{array}{c}\text { Totana } \\
\mathbf{7 2 1 8 x}\end{array}$ \\
\hline Año & HF & HF & HF \\
\hline $\mathbf{2 0 0 2}$ & 410 & 209 & \\
\hline $\mathbf{2 0 0 3}$ & 468 & 269 & \\
\hline $\mathbf{2 0 0 4}$ & 444 & 335 & \\
\hline $\mathbf{2 0 0 5}$ & 933 & 628 & \\
\hline $\mathbf{2 0 0 6}$ & 488 & 339 & \\
\hline $\mathbf{2 0 0 7}$ & 558 & & \\
\hline $\mathbf{2 0 0 8}$ & 492 & & \\
\hline $\mathbf{2 0 0 9}$ & 559 & 506 & \\
\hline $\mathbf{2 0 1 0}$ & 613 & 564 & \\
\hline $\mathbf{2 0 1 1}$ & 464 & 348 \\
\hline promedio & 543 & 400 \\
\hline
\end{tabular}

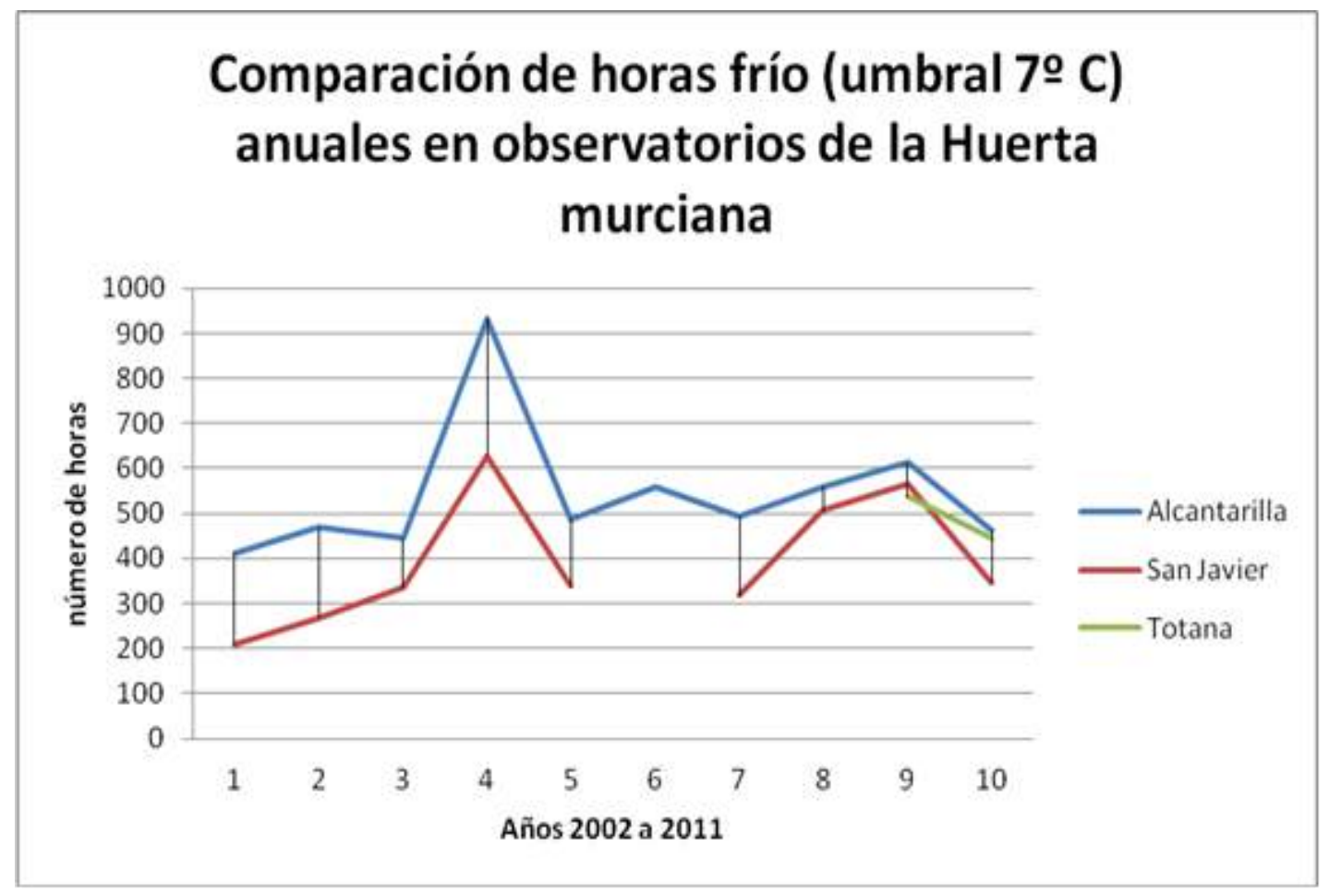

Gráfico 14. Comparación de horas frío (umbral 7ºC) anuales en observatorios de la huerta murciana.

\section{Horas frío contadas en datos horarios en cada uno de los observatorios}

Alcantarilla. El promedio anual de horas frío en Alcantarilla es algo superior a 500 horas, pero hay una gran variación entre unos años y otros, puede alcanzar las 933 horas, como en 2005, o ser de 410 horas como en 2002. 
Si se exceptúa el año 2005 podría decirse que el número de horas frío que se acumulan en enero es bastante regular en Alcantarilla y está entre las 150 y 200 horas; sin embargo en 2005 hubo 301 horas frío, lo que hace pensar que hay años que el número de horas frío es muy superior a la media, 191 horas. En diciembre el número de horas frío es algo inferior a 150, pero en vez de haber valores anómalos por exceso, los hay por defecto: en 2002 hubo únicamente 64 horas y en 2004, 78 horas. En febrero el promedio es algo superior a las 100 horas, con años como el 2005 con 222 horas, y años como el 2007 con 38 horas. Los meses de marzo y noviembre hay mucha variación entre unos años y otros, con valores tan bajos como 10 horas y valores superiores a las 100 horas (número de horas más frecuente en febrero). Abril y octubre tienen un número muy bajo de horas frío, inferior a 10 horas, pero se puede destacar que en casi todos los abriles hay alguna hora frío.

Tabla 80. Horas frío contadas en datos horarios en el observatorio de Alcantarilla.

\begin{tabular}{cccccccccccccc}
\hline & ene & feb & mar & abr & may & jun & jul & ago & sep & oct & nov & dic & anual \\
\hline $\mathbf{2 0 0 2}$ & 181 & 109 & 35 & 6 & 1 & 0 & 0 & 0 & 0 & 0 & 14 & 64 & 410 \\
\hline $\mathbf{2 0 0 3}$ & 183 & 106 & 36 & 8 & 0 & 0 & 0 & 0 & 0 & 0 & 9 & 126 & 468 \\
$\mathbf{2 0 0 4}$ & 136 & 101 & 45 & 9 & 0 & 0 & 0 & 0 & 0 & 1 & 74 & 78 & 444 \\
\hline $\mathbf{2 0 0 5}$ & 301 & 222 & 123 & 3 & 0 & 0 & 0 & 0 & 0 & 0 & 65 & 219 & 933 \\
$\mathbf{2 0 0 6}$ & 203 & 115 & 27 & 0 & 0 & 0 & 0 & 0 & 0 & 0 & 11 & 132 & 488 \\
\hline $\mathbf{2 0 0 7}$ & 195 & 38 & 46 & 2 & 0 & 0 & 0 & 0 & 0 & 0 & 101 & 176 & 558 \\
$\mathbf{2 0 0 8}$ & 190 & 54 & 23 & 7 & 0 & 0 & 0 & 0 & 0 & 2 & 71 & 145 & 492 \\
$\mathbf{2 0 0 9}$ & 198 & 124 & 59 & 4 & 0 & 0 & 0 & 0 & 0 & 0 & 15 & 159 & 559 \\
$\mathbf{2 0 1 0}$ & 155 & 121 & 71 & 9 & 0 & 0 & 0 & 0 & 0 & 13 & 50 & 194 & 613 \\
\hline $\mathbf{2 0 1 1}$ & 171 & 140 & 36 & 3 & 0 & 0 & 0 & 0 & 0 & 0 & 12 & 102 & 464 \\
Prom. & 191 & 113 & 50 & 5 & 0 & 0 & 0 & 0 & 0 & 2 & 42 & 140 & 543 \\
\hline
\end{tabular}

\section{San Javier}

En San Javier, debido a la influencia suavizadora de las temperaturas del mar, el número de horas frío es menor que en Alcantarilla, en promedio 400 anuales; y aunque en enero y diciembre pueden alcanzarse también valores próximos a las 200 horas, pueden darse valores $\tan$ bajos como 36 horas en diciembre de 2002. Lo mismo sucede en febrero. En marzo el promedio está por debajo de 50 horas, y en abril y octubre es de 3 y 1 horas respectivamente. 
Tabla 81. Horas frío contadas en datos horarios en el observatorio de San Javier.

\begin{tabular}{cccccccccccccc}
\hline & ene & feb & mar & abr & may & jun & jul & ago & sep & oct & nov & dic & anual \\
\hline $\mathbf{2 0 0 2}$ & 82 & 72 & 12 & 6 & 0 & 0 & 0 & 0 & 0 & 0 & 1 & 36 & 209 \\
\hline $\mathbf{2 0 0 3}$ & 108 & 73 & 7 & 3 & 0 & 0 & 0 & 0 & 0 & 0 & 1 & 77 & 269 \\
$\mathbf{2 0 0 4}$ & 135 & 57 & 30 & 3 & 0 & 0 & 0 & 0 & 0 & 0 & 51 & 59 & 335 \\
\hline $\mathbf{2 0 0 5}$ & 237 & 163 & 97 & 3 & 0 & 0 & 0 & 0 & 0 & 0 & 38 & 90 & 628 \\
$\mathbf{2 0 0 6}$ & 137 & 115 & 25 & 0 & 0 & 0 & 0 & 0 & 0 & 0 & 4 & 58 & 339 \\
\hline $\mathbf{2 0 0 7}$ & 174 & 22 & 31 & 1 & 0 & 0 & 0 & & & & & & \\
$\mathbf{2 0 0 8}$ & & & 70 & 0 & 0 & 0 & 0 & 0 & 0 & 6 & 61 & 181 & \\
\hline $\mathbf{2 0 0 9}$ & 177 & 110 & 43 & 4 & 0 & 0 & 0 & 0 & 0 & 1 & 15 & 156 & 506 \\
$\mathbf{2 0 1 0}$ & 188 & 107 & 70 & 10 & 0 & 0 & 0 & 0 & 0 & 1 & 22 & 166 & 564 \\
\hline $\mathbf{2 0 1 1}$ & 117 & 147 & 34 & 1 & 0 & 0 & 0 & 0 & 0 & 0 & 0 & 49 & 348 \\
\hline Prom. & 151 & 96 & 42 & 3 & 0 & 0 & 0 & 0 & 0 & 1 & 21 & 97 & 400 \\
\hline
\end{tabular}

\section{Totana}

Tiene sólo tres años de datos.

Tabla 82. Horas frío contadas en datos horarios en el observatorio de Totana.

\begin{tabular}{|c|c|c|c|c|c|c|c|c|c|c|c|c|c|}
\hline & ene & feb & mar & $a b r$ & may & jun & jul & ago & sep & oct & nov & dic & anual \\
\hline \multicolumn{14}{|l|}{2002} \\
\hline \multicolumn{14}{|l|}{2003} \\
\hline \multicolumn{14}{|l|}{2004} \\
\hline \multicolumn{14}{|l|}{2005} \\
\hline \multicolumn{14}{|l|}{2006} \\
\hline \multicolumn{14}{|l|}{2007} \\
\hline 2008 & 146 & 40 & 29 & 0 & 0 & 0 & 0 & 0 & 0 & 1 & 47 & 148 & 411 \\
\hline \multicolumn{14}{|l|}{2009} \\
\hline 2010 & 136 & 132 & 71 & 0 & 0 & 0 & 0 & 0 & 0 & 1 & 33 & 165 & 538 \\
\hline 2011 & 167 & 127 & 41 & 0 & 0 & 0 & 0 & 0 & 0 & 0 & 7 & 105 & 447 \\
\hline Prom. & & & & & & & & & & & & & \\
\hline
\end{tabular}

\section{Resumen de horas frío contadas para Levante.}

Podría decirse que en la costa levantina, tanto las huertas de Castellón, como las de Valencia, Alicante y Murcia, por debajo de los $100 \mathrm{~m}$ de altitud no se alcanzan las 500 horas frío anuales en promedio. Un poco hacia el interior, en altitudes algo mayores y a varios kilómetros de la costa, el número de horas frío sube para situarse en promedio por encima de 500 . En la costa los meses de abril a octubre están libres de horas frío; un poco hacia el interior el periodo libre de horas frío es de mayo a septiembre.

Es preciso tener en cuenta la marcada variabilidad interanual y entre cada uno de los meses en los distintos años. 
Málaga aeropuerto (6155a)

Horas frío contadas en datos horarios en el observatorio.

Tabla 83. Horas frío contadas en datos horarios en el observatorio de Málaga aeropuerto.

\begin{tabular}{cccccccccccccc}
\hline & ene & feb & mar & abr & may & jun & jul & ago & sep & oct & nov & dic & anual \\
\hline $\mathbf{2 0 0 2}$ & 29 & 25 & 0 & 0 & 0 & 0 & 0 & 0 & 0 & 0 & 0 & 6 & 60 \\
\hline $\mathbf{2 0 0 3}$ & 83 & 35 & 0 & 1 & 0 & 0 & 0 & 0 & 0 & 0 & 0 & 41 & 160 \\
$\mathbf{2 0 0 4}$ & 38 & 13 & 25 & 0 & 0 & 0 & 0 & 0 & 0 & 0 & 20 & 34 & 130 \\
\hline $\mathbf{2 0 0 5}$ & 158 & 108 & 42 & 0 & 0 & 0 & 0 & 0 & 0 & 0 & 7 & 29 & 344 \\
$\mathbf{2 0 0 6}$ & 83 & 54 & 6 & 0 & 0 & 0 & 0 & 0 & 0 & 0 & 0 & 56 & 199 \\
\hline $\mathbf{2 0 0 7}$ & 117 & 6 & 8 & 1 & 0 & 0 & 0 & 0 & 0 & 0 & 5 & 32 & 169 \\
$\mathbf{2 0 0 8}$ & 16 & 1 & 7 & 0 & 0 & 0 & 0 & 0 & 0 & 0 & 40 & 61 & 125 \\
\hline $\mathbf{2 0 0 9}$ & 122 & 20 & 1 & 0 & 0 & 0 & 0 & 0 & 0 & 0 & 0 & 16 & 159 \\
$\mathbf{2 0 1 0}$ & 55 & 11 & 17 & 0 & 0 & 0 & 0 & 0 & 0 & 0 & 0 & 19 & 102 \\
\hline $\mathbf{2 0 1 1}$ & 12 & 43 & 19 & 0 & 0 & 0 & 0 & 0 & 0 & 0 & 1 & 19 & 94 \\
Prom. & 71 & 32 & 13 & 0 & 0 & 0 & 0 & 0 & 0 & 0 & 7 & 31 & 154 \\
\hline
\end{tabular}

Málaga tiene en torno a las 150 horas frío anuales, si bien la diferencia entre unos años y otros es muy notable, supera a la media. En el periodo considerado pasa de 344 horas en 2005, el año de más horas frío a 60 en 2002, el año de menos horas frío.

De mayo a octubre está libre de horas frío. También podría considerarse el mes de abril libre de horas frío porque sólo se dieron en dos años y una sola hora en todo el mes. Tampoco en noviembre se dan horas frío todos los años. En enero, febrero y diciembre se dan horas frío todos los años, pero con una gran variación entre unos años y otros. Por ejemplo, en febrero de 2008 hubo una hora frío en todo el mes, mientras que en febrero de 2005 se dieron 108 horas. En enero de 2011 hubo 12 horas, mientras que en enero de 2005 hubo 158 horas.

\section{Resumen de horas frío contadas en la costa Sur.}

Lo que sucede en Málaga podría extenderse a toda la franja costera al mar de Alborán, desde Almería al Estrecho, y considerar que en esta zona a nivel del mar, o por debajo de $75 \mathrm{~m}$, se dan unas 150 horas de promedio anuales, con años que no llegan a 100 y otros que pueden sobrepasar las 300 .

Es preciso tener en cuenta la marcada variabilidad interanual y entre cada uno de los meses en los distintos años. 
Observatorios: Albacete los Llanos (8175), Cuenca (8096), Teruel (8368u), Daroca (9390), Molina de Aragón (3013), Soria (2030).

Tabla 84. Comparación de horas frío anuales contadas a partir de datos horarios en los seis observatorios de las zonas altas del interior peninsular.

\begin{tabular}{|ccccccc|}
\hline & $\begin{array}{c}\text { Albacete Los Llanos } \\
\mathbf{8 1 7 5}\end{array}$ & $\begin{array}{c}\text { Cuenca } \\
\mathbf{8 0 9 6}\end{array}$ & $\begin{array}{c}\text { Teruel } \\
\mathbf{8 3 6 8 u}\end{array}$ & $\begin{array}{c}\text { Daroca } \\
\mathbf{9 3 9 0}\end{array}$ & $\begin{array}{c}\text { Molina de Aragón } \\
\mathbf{3 0 1 3}\end{array}$ & $\begin{array}{c}\text { Soria } \\
\mathbf{2 0 3 0}\end{array}$ \\
\hline $\mathbf{A n ̃ o}$ & HF & HF & HF & HF & HF & HF \\
\hline $\mathbf{2 0 0 2}$ & 1536 & 2259 & 2670 & 1880 & 3232 & 3177 \\
\hline $\mathbf{2 0 0 3}$ & 1762 & 2270 & 2659 & 2079 & 3128 & 3074 \\
\hline $\mathbf{2 0 0 4}$ & 1957 & 2450 & 2973 & 2600 & 3512 & 3388 \\
\hline $\mathbf{2 0 0 5}$ & 2197 & 2495 & 2964 & 2633 & 3563 & 3290 \\
\hline $\mathbf{2 0 0 6}$ & 1803 & 2092 & 2526 & 2129 & 2984 & 2662 \\
\hline $\mathbf{2 0 0 7}$ & 2038 & 2428 & 2878 & 2483 & 3458 & 3213 \\
\hline $\mathbf{2 0 0 8}$ & 1865 & 2241 & 2739 & 2403 & 3445 & 3436 \\
\hline $\mathbf{2 0 0 9}$ & 1863 & 2281 & 2743 & 2366 & 3166 & 3044 \\
\hline $\mathbf{2 0 1 0}$ & 2079 & 2599 & 2992 & 2637 & 3518 & 3595 \\
\hline $\mathbf{2 0 1 1}$ & 1714 & 1938 & 2316 & 2066 & 3079 & 2764 \\
\hline Promedio & 1881 & 2305 & 2746 & 2328 & 3309 & 3281 \\
\hline
\end{tabular}

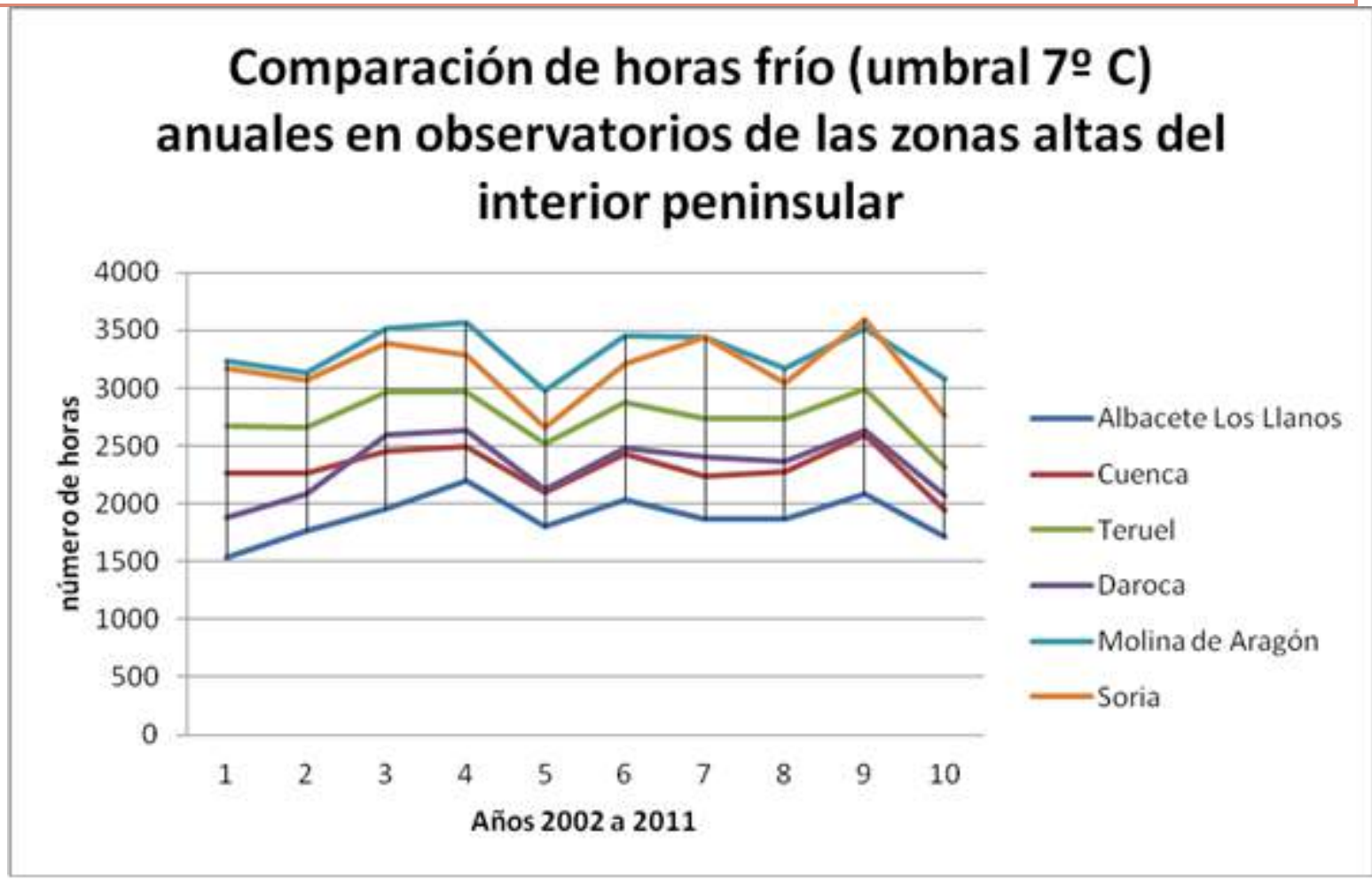

Gráfico 15. Comparación de horas frío (umbral 7ํㅡ) anuales en observatorios de las zonas altas del interior peninsular. 
Los datos son coherentes entre ellos y muestran que en las zonas altas del interior peninsular el número de horas frío anuales está entre 1800 y 3500.

\section{$\underline{\text { Horas frío contadas en datos horarios en cada uno de los observatorios }}$}

Albacete. Tiene en promedio ligeramente por debajo de 1900 horas frío (umbral $7^{\circ} \mathrm{C}$ ) al año, oscilando entre las 2197 horas de 2005 y las 1536 de 2002.

Julio está libre de horas frío, agosto, junio y septiembre tienen pocas y pocos años. Mayo y octubre no llegan a una hora diaria. Abril tiene 3 horas diarias en promedio. Marzo y noviembre cerca de las 250 horas. Febrero pasa de 350 horas, diciembre pasa de 400 y enero se acerca a las 500 .

Tabla 85. Horas frío contadas en datos horarios en el observatorio de Albacete.

\begin{tabular}{cccccccccccccc}
\hline & ene & feb & mar & abr & may & jun & jul & ago & sep & oct & nov & dic & anual \\
\hline $\mathbf{2 0 0 2}$ & 430 & 314 & 216 & 108 & 54 & 2 & 0 & 0 & 0 & 18 & 155 & 239 & 1536 \\
$\mathbf{2 0 0 3}$ & 478 & 405 & 189 & 89 & 26 & 0 & 0 & 0 & 0 & 22 & 132 & 421 & 1762 \\
$\mathbf{2 0 0 4}$ & 356 & 395 & 279 & 145 & 14 & 0 & 0 & 0 & 0 & 25 & 314 & 429 & 1957 \\
$\mathbf{2 0 0 5}$ & 551 & 501 & 235 & 86 & 7 & 0 & 0 & 0 & 8 & 7 & 340 & 462 & 2197 \\
$\mathbf{2 0 0 6}$ & 598 & 428 & 155 & 34 & 0 & 0 & 0 & 0 & 0 & 1 & 125 & 462 & 1803 \\
$\mathbf{2 0 0 7}$ & 556 & 183 & 275 & 133 & 18 & 0 & 0 & 0 & 1 & 38 & 368 & 466 & 2038 \\
$\mathbf{2 0 0 8}$ & 388 & 255 & 210 & 66 & 5 & 1 & 0 & 0 & 0 & 43 & 392 & 505 & 1865 \\
$\mathbf{2 0 0 9}$ & 521 & 405 & 256 & 133 & 15 & 0 & 0 & 2 & 0 & 7 & 152 & 372 & 1863 \\
$\mathbf{2 0 1 0}$ & 470 & 359 & 287 & 83 & 45 & 0 & 0 & 1 & 1 & 70 & 321 & 442 & 2079 \\
$\mathbf{2 0 1 1}$ & 490 & 363 & 231 & 18 & 0 & 0 & 0 & 0 & 0 & 17 & 139 & 456 & 1714 \\
Prom. & 484 & 361 & 233 & 90 & 18 & 0 & 0 & 0 & 1 & 25 & 244 & 425 & 1881 \\
\hline
\end{tabular}

Cuenca. Tiene en promedio 2300 horas frío (umbral $7^{\circ} \mathrm{C}$ ) al año, oscilando entre las 2599 horas de 2010 y las 1938 de 2011.

Julio y agosto están libres de horas frío, y junio y septiembre tienen pero pocas. Mayo tiene más de una hora diaria de promedio y octubre se acerca a las dos. Abril tiene 141 horas y marzo y noviembre están en torno a las 300 horas frío. Febrero pasa de 400 y diciembre y enero están en torno a las 500 . 
Tabla 86. Horas frío contadas en datos horarios en el observatorio de Cuenca.

\begin{tabular}{cccccccccccccc}
\hline & ene & feb & mar & abr & may & jun & jul & ago & sep & oct & nov & dic & anual \\
\hline $\mathbf{2 0 0 2}$ & 548 & 355 & 323 & 206 & 101 & 11 & 0 & 0 & 16 & 56 & 271 & 372 & 2259 \\
\hline $\mathbf{2 0 0 3}$ & 567 & 511 & 242 & 122 & 32 & 0 & 0 & 0 & 0 & 47 & 208 & 541 & 2270 \\
$\mathbf{2 0 0 4}$ & 423 & 449 & 374 & 220 & 64 & 0 & 0 & 0 & 4 & 62 & 365 & 489 & 2450 \\
\hline $\mathbf{2 0 0 5}$ & 544 & 550 & 289 & 119 & 24 & 0 & 0 & 0 & 19 & 27 & 389 & 534 & 2495 \\
\hline $\mathbf{2 0 0 6}$ & 651 & 488 & 254 & 71 & 6 & 0 & 0 & 0 & 0 & 6 & 136 & 480 & 2092 \\
\hline $\mathbf{2 0 0 7}$ & 563 & 333 & 348 & 153 & 46 & 3 & 0 & 0 & 8 & 71 & 381 & 522 & 2428 \\
$\mathbf{2 0 0 8}$ & 437 & 305 & 300 & 140 & 12 & 0 & 0 & 0 & 2 & 77 & 421 & 547 & 2241 \\
\hline $\mathbf{2 0 0 9}$ & 574 & 453 & 300 & 229 & 12 & 0 & 0 & 0 & 0 & 27 & 232 & 454 & 2281 \\
\hline $\mathbf{2 0 1 0}$ & 544 & 468 & 343 & 131 & 108 & 5 & 0 & 0 & 9 & 118 & 416 & 457 & 2599 \\
\hline $\mathbf{2 0 1 1}$ & 500 & 400 & 328 & 14 & 6 & 0 & 0 & 0 & 0 & 24 & 155 & 511 & 1938 \\
\hline Prom. & 535 & 431 & 310 & 141 & 41 & 2 & 0 & 0 & 6 & 52 & 297 & 491 & 2305 \\
\hline
\end{tabular}

Teruel. Tiene en promedio en torno a 2700 horas frío (umbral $7^{\circ} \mathrm{C}$ ) al año, oscilando entre las 2992 horas de 2010 y las 2316 de 2011.

Julio y agosto, aunque tienen horas frío algún año, podrían considerarse meses libres de horas frío. Junio y septiembre tienen casi todos los años pero pocas, menos de 1 hora diaria en promedio. Octubre tiene 100 horas y abril 200. Marzo y noviembre pasan de 350 horas, febrero se acerca a las 500 horas, y enero y diciembre las sobrepasan.

Tabla 87. Horas frío contadas en datos horarios en el observatorio de Teruel.

\begin{tabular}{rrrrrrrrrrrrrr}
\hline & ene & feb & mar & abr & may & jun & jul & ago & sep & oct & nov & dic & anual \\
\hline $\mathbf{2 0 0 2}$ & 573 & 429 & 344 & 255 & 143 & 15 & 0 & 0 & 46 & 158 & 292 & 415 & 2670 \\
$\mathbf{2 0 0 3}$ & 586 & 531 & 300 & 200 & 64 & 0 & 0 & 0 & 18 & 103 & 310 & 547 & 2659 \\
$\mathbf{2 0 0 4}$ & 475 & 511 & 427 & 285 & 103 & 3 & 3 & 0 & 22 & 108 & 440 & 596 & 2973 \\
$\mathbf{2 0 0 5}$ & 593 & 590 & 363 & 184 & 45 & 0 & 0 & 0 & 37 & 92 & 463 & 597 & 2964 \\
$\mathbf{2 0 0 6}$ & 675 & 529 & 283 & 159 & 32 & 23 & 0 & 1 & 11 & 47 & 203 & 563 & 2526 \\
$\mathbf{2 0 0 7}$ & 567 & 388 & 426 & 209 & 64 & 2 & 0 & 3 & 21 & 146 & 456 & 596 & 2878 \\
$\mathbf{2 0 0 8}$ & 502 & 371 & 387 & 172 & 36 & 15 & 0 & 0 & 26 & 134 & 485 & 611 & 2739 \\
$\mathbf{2 0 0 9}$ & 621 & 478 & 413 & 287 & 52 & 9 & 0 & 0 & 8 & 84 & 310 & 481 & 2743 \\
$\mathbf{2 0 1 0}$ & 591 & 456 & 399 & 186 & 162 & 10 & 0 & 0 & 32 & 187 & 447 & 522 & 2992 \\
\hline $\mathbf{2 0 1 1}$ & 532 & 420 & 369 & 86 & 22 & 1 & 0 & 2 & 10 & 103 & 221 & 550 & 2316 \\
Prom. & 572 & 470 & 371 & 202 & 72 & 8 & 0 & 1 & 23 & 116 & 363 & 548 & 2746 \\
\hline
\end{tabular}


Daroca. Tiene en promedio ligeramente superior a las 2300 horas frío (umbral $7^{\circ} \mathrm{C}$ ) al año, oscilando entre las 1880 de 2002 y las 2637 de 2010.

Julio y agosto están libres de horas frío, aunque no todos los años en el caso de agosto, se dio una hora en el mes en uno de los años. Junio tiene muy pocas horas y no todos los años. Septiembre tiene también pocas horas, pero en su caso, casi todos los años. Mayo no llega a las 2 horas diarias de promedio y octubre se acerca a las 3 . Abril tiene 150 horas y noviembre se acerca a las 300 . Marzo sobrepasa las 300 y febrero las 400, diciembre se acerca a las 500 y enero las sobrepasa. En noviembre se da una gran diferencia entre unos años y otros, entre las 114 de 2006 y las 437 de 2007.

Tabla 88. Horas frío contadas en datos horarios en el observatorio de Daroca.

\begin{tabular}{cccccccccccccc}
\hline & ene & feb & mar & abr & may & jun & jul & ago & sep & oct & nov & dic & anual \\
\hline $\mathbf{2 0 0 2}$ & 467 & 350 & 259 & 173 & 60 & 4 & 0 & 0 & 33 & 62 & 178 & 294 & 1880 \\
$\mathbf{2 0 0 3}$ & 484 & 460 & 199 & 125 & 35 & 0 & 0 & 0 & 0 & 98 & 221 & 457 & 2079 \\
$\mathbf{2 0 0 4}$ & 404 & 501 & 388 & 244 & 58 & 0 & 0 & 0 & 11 & 36 & 412 & 546 & 2600 \\
\hline $\mathbf{2 0 0 5}$ & 578 & 579 & 318 & 142 & 29 & 0 & 0 & 0 & 27 & 39 & 368 & 553 & 2633 \\
$\mathbf{2 0 0 6}$ & 648 & 498 & 181 & 93 & 18 & 12 & 0 & 0 & 2 & 20 & 114 & 543 & 2129 \\
\hline $\mathbf{2 0 0 7}$ & 539 & 263 & 345 & 151 & 52 & 0 & 0 & 1 & 19 & 127 & 437 & 549 & 2483 \\
$\mathbf{2 0 0 8}$ & 435 & 323 & 353 & 126 & 19 & 2 & 0 & 0 & 36 & 129 & 426 & 554 & 2403 \\
$\mathbf{2 0 0 9}$ & 554 & 464 & 387 & 240 & 39 & 1 & 0 & 0 & 10 & 68 & 189 & 414 & 2366 \\
$\mathbf{2 0 1 0}$ & 547 & 389 & 346 & 146 & 149 & 8 & 0 & 0 & 20 & 170 & 365 & 497 & 2637 \\
$\mathbf{2 0 1 1}$ & 491 & 409 & 343 & 55 & 19 & 2 & 0 & 0 & 9 & 98 & 173 & 467 & 2066 \\
Prom. & 515 & 424 & 312 & 150 & 48 & 3 & 0 & 0 & 17 & 85 & 288 & 487 & 2328 \\
\hline
\end{tabular}

Molina de Aragón. Tiene en promedio 3300 horas frío (umbral $7^{\circ} \mathrm{C}$ ) al año, oscilando entre las 3563 horas de 2005 y las 2984 de 2006.

No tiene meses libres de horas frío, si bien en los meses de verano hay muy pocas horas: junio, julio y agosto tienen menos de 1 hora diaria en promedio; septiembre tiene algo más de 2 horas diarias; mayo tienen 4 horas diarias en promedio; octubre tiene 200 horas mensuales, y abril casi 300. Marzo y noviembre están en torno a las 400 horas, pero noviembre puede pasar de las 500 horas, es decir, más de 16 horas diarias. Febrero tiene 500 horas en promedio, diciembre no llega a las 600 y enero las sobrepasa. 
Tabla 89. Horas frío contadas en datos horarios en el observatorio de Molina de Aragón.

\begin{tabular}{cccccccccccccc}
\hline & ene & feb & mar & abr & may & jun & jul & ago & sep & oct & nov & dic & anual \\
\hline $\mathbf{2 0 0 2}$ & 622 & 453 & 425 & 333 & 207 & 33 & 15 & 4 & 99 & 195 & 387 & 459 & 3232 \\
\hline $\mathbf{2 0 0 3}$ & 629 & 563 & 329 & 271 & 120 & 0 & 1 & 0 & 44 & 152 & 394 & 625 & 3128 \\
$\mathbf{2 0 0 4}$ & 471 & 506 & 467 & 353 & 205 & 19 & 17 & 11 & 88 & 195 & 532 & 648 & 3512 \\
\hline $\mathbf{2 0 0 5}$ & 638 & 609 & 411 & 288 & 122 & 6 & 7 & 9 & 108 & 191 & 524 & 650 & 3563 \\
$\mathbf{2 0 0 6}$ & 690 & 557 & 380 & 235 & 91 & 38 & 0 & 17 & 36 & 102 & 232 & 606 & 2984 \\
\hline $\mathbf{2 0 0 7}$ & 626 & 452 & 464 & 265 & 130 & 27 & 7 & 26 & 75 & 274 & 495 & 617 & 3458 \\
\hline $\mathbf{2 0 0 8}$ & 572 & 472 & 454 & 267 & 102 & 42 & 3 & 3 & 94 & 227 & 556 & 653 & 3445 \\
\hline $\mathbf{2 0 0 9}$ & 635 & 525 & 475 & 364 & 122 & 34 & 5 & 0 & 44 & 156 & 337 & 469 & 3166 \\
\hline $\mathbf{2 0 1 0}$ & 607 & 511 & 470 & 245 & 227 & 27 & 0 & 11 & 64 & 276 & 543 & 537 & 3518 \\
\hline $\mathbf{2 0 1 1}$ & 580 & 498 & 470 & 189 & 61 & 27 & 12 & 11 & 56 & 244 & 329 & 602 & 3079 \\
\hline Prom. & 607 & 515 & 435 & 281 & 139 & 25 & 7 & 9 & 71 & 201 & 433 & 587 & 3309 \\
\hline
\end{tabular}

Soria. Como se ha descrito ya para la meseta Norte, Soria tiene en promedio más de 3000 horas frío (umbral $7^{\circ} \mathrm{C}$ ) al año, oscilando entre las 3595 horas de 2010 y las 2662 de 2006.

No tiene meses libres de horas frío, si bien en los meses de verano hay muy pocas horas: junio 12 de promedio, julio, 3, y agosto, 1, y septiembre, 29. Abril (259) tiene en torno a las 8 horas diarias en promedio y mayo y octubre a las 4 horas. Marzo y noviembre están en torno a las 400 horas, pero ambos meses pueden pasar de las 500 horas, es decir, más de 16 horas diarias. Enero y diciembre pasan de 600 horas, y febrero no llega. Enero, febrero y diciembre tienen en torno a 20 horas frío al día de promedio, es decir, más del $80 \%$ del tiempo.

Tabla 90. Horas frío contadas en datos horarios en el observatorio de Soria.

\begin{tabular}{|cccccccccccccc}
\hline & ene & feb & mar & abr & may & jun & jul & ago & sep & oct & nov & dic & anual \\
\hline $\mathbf{2 0 0 2}$ & 653 & 490 & 429 & 311 & 177 & 37 & 0 & 0 & 47 & 91 & 411 & 531 & 3177 \\
\hline $\mathbf{2 0 0 3}$ & 633 & 607 & 315 & 240 & 109 & 0 & 0 & 0 & 4 & 193 & 326 & 647 & 3074 \\
\hline $\mathbf{2 0 0 4}$ & 500 & 547 & 523 & 408 & 168 & 0 & 12 & 0 & 11 & 130 & 461 & 628 & 3388 \\
\hline $\mathbf{2 0 0 5}$ & 626 & 627 & 394 & 264 & 78 & 1 & 0 & 0 & 48 & 103 & 493 & 656 & 3290 \\
\hline $\mathbf{2 0 0 6}$ & 688 & 537 & 370 & 175 & 76 & 10 & 0 & 0 & 6 & 41 & 165 & 594 & 2662 \\
\hline $\mathbf{2 0 0 7}$ & 586 & 455 & 494 & 223 & 100 & 13 & 1 & 0 & 31 & 193 & 467 & 650 & 3213 \\
\hline $\mathbf{2 0 0 8}$ & 580 & 487 & 472 & 265 & 90 & 23 & 8 & 0 & 76 & 246 & 538 & 651 & 3436 \\
\hline $\mathbf{2 0 0 9}$ & 640 & 513 & 431 & 376 & 75 & 1 & 0 & 0 & 10 & 79 & 315 & 604 & 3044 \\
\hline $\mathbf{2 0 1 0}$ & 692 & 583 & 474 & 234 & 233 & 19 & 0 & 0 & 38 & 245 & 519 & 558 & 3595 \\
\hline $\mathbf{2 0 1 1}$ & 599 & 488 & 475 & 90 & 30 & 14 & 6 & 6 & 14 & 163 & 259 & 620 & 2764 \\
\hline Prom. & 620 & 533 & 438 & 259 & 114 & 12 & 3 & 1 & 29 & 148 & 395 & 614 & 3164 \\
\hline
\end{tabular}


En las zonas altas del interior se sobrepasan en promedio las 2000 horas frío anuales en las altitudes entre 700 y 900 m y están por encima de las 3000 horas en las altitudes superiores a los $900 \mathrm{~m}$.

Por encima de $800 \mathrm{~m}$ de altitud no hay meses libres de horas frío; si bien en verano hay muy pocas y la mayoría de sus días están libres de ellas. En primavera y otoño, sin embargo, hay en toda la zona tres o más horas frío diarias; y en los tres meses de invierno, enero, diciembre y febrero, las horas frío sobrepasan las 15 horas diarias en altitudes por encima de los $700 \mathrm{~m}$. En altitudes por encima de 900 metros se alcanza un promedio de 20 horas diarias, lo que significa que más del $80 \%$ del tiempo la temperatura está por debajo de $7^{\circ} \mathrm{C}$.

Es preciso tener en cuenta la marcada variabilidad interanual y entre cada uno de los meses en los distintos años. 


\subsubsection{Zonas norte y noroeste: a) costa cantábrica}

San Sebastián-Igueldo. La fórmula de Crossa-Raynaud da prácticamente las horas frío que se producen. Es una aproximación excelente.

Tabla 91. Comparación de horas frío anuales contadas y obtenidas a partir de la fórmula para el observatorio de San Sebastián-Igueldo.

HF anuales contadas $\quad \mathrm{HF}$ anuales por fórmula \% fórmula resp a cont

\begin{tabular}{|c|ccc|}
\hline 2002 & 304 & 338 & 111 \\
2003 & 863 & 845 & 98 \\
2004 & 1218 & 1191 & 98 \\
2005 & 1687 & 1717 & 102 \\
2006 & 1196 & 1178 & 99 \\
2007 & 867 & 870 & 100 \\
2008 & 773 & 830 & 107 \\
2009 & 1044 & 1086 & 104 \\
2010 & 1423 & 1405 & 99 \\
2011 & 634 & 650 & 103 \\
\hline Promedio & 1001 & 1011 & 101
\end{tabular}

Tabla 92. Comparación de los promedios mensuales de las horas frío para el observatorio de San SebastiánIgueldo.

\section{HF prom mensual contadas}

enero
febrero
marzo
abril
mayo
junio
julio
agosto
septiembre
octubre
noviembre
diciembre
anual

\begin{tabular}{|c|}
\hline 247 \\
\hline 24 \\
153 \\
\hline 33 \\
5 \\
0 \\
0 \\
0 \\
0 \\
0 \\
1 \\
7 \\
\hline 236 \\
10 \\
\hline
\end{tabular}

\section{HF prom mensual por \% fórmula resp a fórmula cont}

101

99

100
103

$33 \quad 34$

5

$0 \quad 0$

0

0 0

0

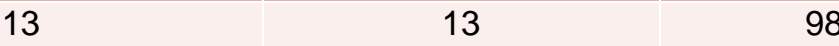

\begin{tabular}{|l|r|r}
72 & 76 & 106
\end{tabular}

\begin{tabular}{|l|l|}
236 & 241 \\
\hline
\end{tabular}

\begin{tabular}{|l|l|r|}
\hline 1001 & 1011 & 101
\end{tabular}

Mes a mes se ve que la fórmula se ajusta a las horas frío que se producen realmente. 
Bilbao Sondica. La fórmula de Crossa-Raynaud subestima ligeramente las horas frío, en promedio da un $94 \%$ de las horas reales, y por tanto es una buena aproximación.

Tabla 93.Comparación de horas frío anuales contadas y obtenidas a partir de la fórmula para el observatorio de Bilbao Sondica.

\begin{tabular}{|c|c|c|c|}
\hline & HF anuales contadas & HF anuales por fórmula & $\%$ fórmula resp a cont \\
\hline 2002 & 405 & 348 & 86 \\
\hline 2003 & 704 & 714 & 101 \\
\hline 2004 & 956 & 914 & 96 \\
\hline 2005 & 1327 & 1249 & 94 \\
\hline 2006 & 968 & 931 & 96 \\
\hline 2007 & 894 & 829 & 93 \\
\hline 2008 & 591 & 582 & 98 \\
\hline 2009 & 949 & 870 & 92 \\
\hline 2010 & 1196 & 1145 & 96 \\
\hline 2011 & 652 & 545 & 84 \\
\hline Promedio & 864 & 813 & 94 \\
\hline
\end{tabular}

La aproximación de las horas frío de la fórmula es muy buena en los meses que hay más horas frío, lo que refuerza la idea de que la fórmula de Crossa-Raynaud es muy buena aproximación al número de horas reales en este observatorio.

Tabla 94. Comparación de los promedios mensuales de las horas frío para el observatorio de Bilbao Sondica.

\begin{tabular}{|c|c|c|c|}
\hline & $\begin{array}{l}\text { HF prom mensual } \\
\text { contadas }\end{array}$ & $\begin{array}{l}\text { HF prom mensual por } \\
\text { fórmula }\end{array}$ & $\begin{array}{c}\% \text { fórmula resp a } \\
\text { cont }\end{array}$ \\
\hline enero & 211 & 202 & 96 \\
\hline febrero & 207 & 194 & 93 \\
\hline marzo & 134 & 125 & 93 \\
\hline abril & 41 & 35 & 86 \\
\hline mayo & 6 & 5 & \\
\hline junio & 0 & 0 & \\
\hline julio & 0 & 0 & \\
\hline agosto & 0 & 0 & \\
\hline septiembre & 1 & 1 & \\
\hline octubre & 16 & 11 & 73 \\
\hline noviembre & 63 & 56 & 89 \\
\hline diciembre & 185 & 185 & 100 \\
\hline anual & 864 & 813 & 94 \\
\hline
\end{tabular}


Santander Parayas. La fórmula de Crossa-Raynaud da prácticamente las horas frío que se producen, y por tanto es una aproximación excelente.

Tabla 95. .Comparación de horas frío anuales contadas y obtenidas a partir de la fórmula para el observatorio de Santander Parayas.

\begin{tabular}{|c|ccc|}
\hline & HF anuales contadas & HF anuales por fórmula & \% fórmula resp a cont \\
\hline 2002 & 285 & 268 & 94 \\
2003 & 578 & 599 & 104 \\
2004 & 712 & 715 & 100 \\
2005 & 1070 & 1039 & 97 \\
2006 & 828 & 851 & 103 \\
2007 & 774 & 752 & 97 \\
2008 & 565 & 588 & 104 \\
2009 & 846 & 827 & 98 \\
2010 & 943 & 948 & 101 \\
2011 & 522 & 507 & 97 \\
Promedio & 712 & 709 & 100
\end{tabular}

Mes a mes se ve que la fórmula se ajusta más a lo contado en los meses que hay más horas frío, lo que refuerza la idea de que la fórmula de Crossa-Raynaud es una muy buena aproximación del número de las horas frío reales.

Tabla 96. Comparación de los promedios mensuales de las horas frío para el observatorio de Santander Parayas.

\section{HF prom mensual HF prom mensual \% fórmula resp. a} contadas

\section{por fórmula cont}

\begin{tabular}{|c|c|c|c|}
\hline enero & 185 & 183 & 99 \\
\hline febrero & 180 & 181 & 100 \\
\hline marzo & 109 & 110 & 101 \\
\hline abril & 25 & 23 & 91 \\
\hline mayo & 2 & 2 & 75 \\
\hline junio & 0 & 0 & \\
\hline julio & 0 & 0 & \\
\hline agosto & 0 & 0 & 84 \\
\hline septiembre & 0 & 0 & 87 \\
\hline octubre & 11 & 9 & 106 \\
\hline noviembre & 51 & 45 & 100 \\
\hline diciembre & 149 & 158 & \\
\hline anual & 712 & 709 & \\
\hline
\end{tabular}


Santander. La fórmula de Crossa-Raynaud da prácticamente las horas frío que se producen. Es, por tanto, una aproximación excelente.

Tabla 97. Comparación de horas frío anuales contadas y obtenidas a partir de la fórmula para el observatorio de Santander.

HF anuales contadas HF anuales por fórmula \% fórmula resp a cont

\begin{tabular}{|c|ccc|}
\hline 2002 & 47 & 48 & 101 \\
2003 & 341 & 339 & 100 \\
2004 & 387 & 422 & 109 \\
2005 & 749 & 774 & 103 \\
2006 & 460 & 460 & 100 \\
2007 & 356 & 322 & 90 \\
2008 & 197 & 227 & 115 \\
2009 & 476 & 492 & 103 \\
2010 & 802 & 775 & 97 \\
2011 & 259 & 217 & 84 \\
Promedio & 407 & 407 & 100
\end{tabular}

Tabla 98. Comparación de los promedios mensuales de las horas frío para el observatorio de Santander. HF prom mensual HF prom mensual \% fórmula resp contadas por fórmula a cont

\begin{tabular}{|c|c|c|c|}
\hline enero & 116 & 117 & 101 \\
\hline febrero & 111 & 113 & 102 \\
\hline marzo & 58 & 61 & 104 \\
\hline abril & 4 & 6 & \\
\hline mayo & 1 & 0 & \\
\hline junio & 0 & 0 & \\
\hline julio & 0 & 0 & \\
\hline agosto & 0 & 0 & \\
\hline septiembre & 0 & 0 & 93 \\
\hline octubre & 2 & 1 & 95 \\
\hline noviembre & 19 & 18 & 100 \\
\hline diciembre & 96 & 91 & \\
\hline anual & 407 & 407 & \\
\hline
\end{tabular}

Mes a mes se ve que la fórmula se ajusta a lo contado en los meses que hay más horas frío, lo que refuerza la idea de que la fórmula de Crossa-Raynaud es una muy buena aproximación del número de horas reales. 
Gijón Musel. La fórmula de Crossa-Raynaud da prácticamente las horas frío que se producen, y por tanto es una aproximación excelente.

Tabla 99. Comparación de horas frío anuales contadas y obtenidas a partir de la fórmula para el observatorio de Gijón Musel.

HF anuales contadas HF anuales por fórmula \% fórmula resp a cont

\begin{tabular}{|c|ccc|}
2002 & 98 & 89 & 91 \\
2003 & 323 & 356 & 110 \\
2004 & 393 & 402 & 102 \\
2005 & 622 & 628 & 101 \\
2006 & 467 & 426 & 91 \\
2007 & 300 & 302 & 101 \\
2008 & 316 & 321 & 102 \\
2009 & 533 & 591 & 111 \\
2010 & 737 & 720 & 98 \\
2011 & 222 & 195 & 88 \\
Promedio & 401 & 403 & 100
\end{tabular}

Tabla 100. Comparación de los promedios mensuales de las horas frío para el observatorio de Gijón Musel.

\begin{tabular}{|c|c|c|c|}
\hline & $\begin{array}{c}\text { HF prom mensual } \\
\text { contadas }\end{array}$ & $\begin{array}{c}\text { HF prom mensual } \\
\text { por fórmula }\end{array}$ & $\begin{array}{c}\text { \% fórmula resp a } \\
\text { cont }\end{array}$ \\
\hline enero & 114 & 111 & 97 \\
febrero & 108 & 113 & 104 \\
marzo & 52 & 57 & 111 \\
\hline abril & 7 & 8 & \\
mayo & 0 & 0 & \\
junio & 0 & 0 & \\
julio & 1 & 0 & \\
agosto & 0 & 0 & \\
septiembre & 0 & 0 & \\
\hline octubre & 0 & 0 & 97 \\
noviembre & 20 & 20 & 95 \\
diciembre & 100 & 95 & 100 \\
\hline anual & 401 & 403 & \\
\hline
\end{tabular}

La fórmula se ajusta a lo contado en los meses que hay más horas frío, lo que refuerza la idea de que la fórmula de Crossa-Raynaud es una muy buena aproximación del número de horas reales. 
Oviedo. La fórmula de Crossa-Raynaud subestima las horas frío en un 10\%, en promedio da un $90 \%$ de las horas reales, sin embargo hay años en los que baja al $82 \%$.

Tabla 101. Comparación de horas frío anuales contadas y obtenidas a partir de la fórmula para el observatorio de Oviedo.

HF anuales contadas HF anuales por fórmula \% fórmula resp a cont

\begin{tabular}{|c|ccc|}
\hline 2002 & 812 & 664 & 82 \\
2003 & 1157 & 983 & 85 \\
2004 & 1449 & 1295 & 89 \\
2005 & 1766 & 1628 & 92 \\
2006 & 1341 & 1251 & 93 \\
2007 & 1211 & 1109 & 92 \\
2008 & 1188 & 1089 & 92 \\
2009 & 1498 & 1334 & 89 \\
2010 & 1629 & 1542 & 95 \\
2011 & 962 & 836 & 87 \\
Promedio & 1301 & 1173 & 90
\end{tabular}

Tabla 102. Comparación de los promedios mensuales de las horas frío para el observatorio de Oviedo.

HF prom mensual HF prom mensual \% fórmula resp a contadas por fórmula cont

\begin{tabular}{|c|c|c|c|}
\hline enero & 297 & 285 & 96 \\
\hline febrero & 276 & 245 & 89 \\
\hline marzo & 180 & 159 & 88 \\
\hline abril & 85 & 71 & 84 \\
\hline mayo & 18 & 16 & 86 \\
\hline junio & 0 & 0 & \\
julio & 0 & 0 & \\
agosto & 0 & 0 & \\
\hline septiembre & 1 & 1 & 66 \\
\hline octubre & 24 & 16 & 88 \\
\hline noviembre & 120 & 106 & 92 \\
\hline diciembre & 298 & 275 & 90 \\
anual & 1301 & 1173 & \\
\hline
\end{tabular}

La fórmula subestima las horas frío menos en los meses que hay más horas frío; lo que refuerza la idea de que la fórmula de Crossa-Raynaud es una buena aproximación al número de horas reales. 
Vitoria. La fórmula de Crossa-Raynaud se ajusta a las horas frío contadas; en promedio da un $98 \%$ de las horas reales, y por tanto es una aproximación excelente.

Tabla 103. Comparación de horas frío anuales contadas y obtenidas a partir de la fórmula para el observatorio de Vitoria.

\begin{tabular}{|c|ccc|}
\multicolumn{2}{|c|}{ HF anuales contadas } & HF anuales por fórmula & \% fórmula resp a cont \\
\hline 2002 & 1979 & 1915 & 97 \\
2003 & 2099 & 2095 & 100 \\
2004 & 2696 & 2618 & 97 \\
2005 & 2866 & 2820 & 98 \\
2006 & 2250 & 2237 & 99 \\
2007 & 2354 & 2329 & 99 \\
2008 & 2375 & 2370 & 100 \\
2009 & 2366 & 2288 & 97 \\
2010 & 2877 & 2784 & 97 \\
2011 & 1922 & 1875 & 98 \\
Promedio & 2378 & 2333 & 98
\end{tabular}

Tabla 104. Comparación de los promedios mensuales de las horas frío para el observatorio de Vitoria.

\begin{tabular}{|c|c|c|c|}
\hline & $\begin{array}{c}\text { HF prom mensual } \\
\text { contadas }\end{array}$ & $\begin{array}{c}\text { HF prom } \\
\text { mensual por } \\
\text { fórmula }\end{array}$ & $\begin{array}{c}\text { \% fórmula resp } \\
\text { a cont }\end{array}$ \\
\hline $\begin{array}{c}\text { enero } \\
\text { febrero }\end{array}$ & 502 & 500 & 100 \\
marzo & 430 & 424 & 99 \\
abril & 330 & 322 & 98 \\
\hline mayo & 185 & 173 & 94 \\
\hline junio & 72 & 64 & 90 \\
\hline julio & 9 & 7 & \\
\hline agosto & 3 & 3 & \\
\hline septiembre & 2 & 2 & 75 \\
\hline octubre & 24 & 18 & 86 \\
\hline noviembre & 89 & 76 & 98 \\
\hline diciembre & 251 & 246 & 103 \\
\hline anual & 483 & 497 & 98 \\
\hline
\end{tabular}

En los meses en los que hay más horas frío, la fórmula da prácticamente las horas frío que se producen realmente, lo que refuerza la idea de que la fórmula de Crossa-Raynaud es una aproximación excelente al número de horas reales. 
La fórmula de Crossa-Raynaud es una aproximación muy buena en toda la franja costera cantábrica, no sólo en las proximidades del mar sino también en las zonas mucho más frías del interior. En toda esta zona, por tanto, no se precisan temperaturas horarias para dar una buena aproximación de las horas frío, basta tener el registro de las máximas y mínimas diarias para dar valores de las horas frío muy próximos a los reales. Puede usarse la fórmula con la confianza de ajustarse a los valores reales.

\subsubsection{Zonas norte y noroeste: b) costa gallega}

La Coruña. La fórmula de Crossa-Raynaud subestima las horas frío, en promedio da un $91 \%$ de las horas reales, pero hay años en los que tal aproximación baja hasta valores cercanos al $80 \%$.

Tabla 105. Comparación de horas frío anuales contadas y obtenidas a partir de la fórmula para el observatorio de La Coruña. $\mathrm{HF}$ anuales contadas HF anuales por fórmula \% fórmula resp a cont

\begin{tabular}{|c|ccc|}
\hline 2002 & 49 & 56 & 115 \\
2003 & 207 & 215 & 104 \\
2004 & 195 & 204 & 104 \\
2005 & 382 & 342 & 90 \\
2006 & 330 & 294 & 89 \\
2007 & 193 & 167 & 87 \\
2008 & 135 & 110 & 82 \\
2009 & 370 & 311 & 84 \\
2010 & 527 & 460 & 87 \\
2011 & 121 & 120 & 100 \\
Promedio & 251 & 228 & 91
\end{tabular}


Tabla 106. Comparación de los promedios mensuales de las horas frío para el observatorio de La Coruña.

\begin{tabular}{|c|c|c|c|}
\hline & $\begin{array}{c}\text { HF prom mensual } \\
\text { contadas }\end{array}$ & $\begin{array}{c}\text { HF prom mensual } \\
\text { por fórmula }\end{array}$ & $\begin{array}{c}\text { \% fórmula resp } \\
\text { a cont }\end{array}$ \\
\hline enero & 71 & 68 & 96 \\
febrero & 68 & 64 & 95 \\
marzo & 29 & 26 & 87 \\
abril & 2 & 3 & \\
mayo & 0 & 0 & \\
junio & 0 & 0 & \\
julio & 0 & 0 & \\
agosto & 0 & 0 & \\
septiembre & 0 & 0 & \\
\hline octubre & 0 & 0 & 87 \\
noviembre & 14 & 12 & 82 \\
diciembre & 66 & 54 & 91 \\
\hline anual & 251 & 228 & \\
\hline
\end{tabular}

La Coruña-Alvedro. La fórmula de Crossa-Raynaud subestima ligeramente las horas frío, en promedio da un $95 \%$ de las horas reales, y por tanto es una muy buena aproximación.

Tabla 107. Comparación de horas frío anuales contadas y obtenidas a partir de la fórmula para el observatorio de La Coruña-Alvedro.

HF anuales contadas HF anuales por fórmula \% fórmula resp a cont

\begin{tabular}{|c|ccc|}
\hline 2002 & 453 & 436 & 96 \\
2003 & 647 & 667 & 103 \\
2004 & 794 & 809 & 102 \\
2005 & 906 & 904 & 100 \\
2006 & 887 & 836 & 94 \\
2007 & 952 & 824 & 87 \\
2008 & 748 & 660 & 88 \\
2009 & 1008 & 982 & 97 \\
2010 & 1072 & 1009 & 94 \\
2011 & 517 & 455 & 88 \\
\hline Promedio & 798 & 758 & 95
\end{tabular}

La subestima de horas frío de la fórmula es muy baja los meses que hay más horas frío, lo que refuerza la idea de que la fórmula de Crossa-Raynaud es una muy buena aproximación al número de horas reales. 
Tabla 108. Comparación de los promedios mensuales de las horas frío para el observatorio de La CoruñaAlvedro.

\begin{tabular}{|c|c|c|c|}
\hline & $\begin{array}{c}\text { HF prom mensual } \\
\text { contadas }\end{array}$ & $\begin{array}{c}\text { HF prom } \\
\text { mensual por } \\
\text { fórmula }\end{array}$ & $\begin{array}{c}\text { \% fórmula resp } \\
\text { a cont }\end{array}$ \\
\hline enero & 184 & 184 & 100 \\
febrero & 184 & 181 & 98 \\
\hline marzo & 98 & 98 & 100 \\
\hline abril & 43 & 42 & 99 \\
\hline mayo & 10 & 8 & \\
\hline junio & 0 & 0 & \\
\hline julio & 0 & 0 & \\
\hline agosto & 0 & 0 & \\
\hline septiembre & 2 & 1 & 55 \\
\hline octubre & 18 & 10 & 84 \\
\hline noviembre & 84 & 70 & 93 \\
\hline diciembre & 177 & 164 & 95 \\
\hline anual & 798 & 758 & \\
\hline
\end{tabular}

Pontevedra. La fórmula de Crossa-Raynaud subestima las horas frío, en promedio da un $90 \%$ de las horas reales, y por tanto es una aproximación aceptable.

Tabla 109. Comparación de horas frío anuales contadas y obtenidas a partir de la fórmula para el observatorio de Pontevedra.

$\mathrm{HF}$ anuales contadas $\mathrm{HF}$ anuales por fórmula \% fórmula resp a cont

\begin{tabular}{|c|lll|}
\hline 2002 & 348 & 307 & 88 \\
2003 & 551 & 522 & 95 \\
2004 & 792 & 672 & 85 \\
2005 & 954 & 850 & 89 \\
2006 & 825 & 752 & 91 \\
2007 & 562 & 504 & 90 \\
2008 & 506 & 477 & 94 \\
2009 & 842 & 761 & 90 \\
2010 & 957 & 872 & 91 \\
2011 & 497 & 452 & 91 \\
Promedio & 683 & 617 & 90
\end{tabular}

Mes a mes se ve que apenas hay subestima de horas frío de la fórmula en los meses que hay más horas frío, lo que refuerza la idea de que cuando hay muchas horas frío la fórmula de Crossa-Raynaud es una buena aproximación del número de horas reales. 
Tabla 110. Comparación de los promedios mensuales de las horas frío para el observatorio de Pontevedra.

\begin{tabular}{|c|c|c|c|}
\hline & $\begin{array}{c}\text { HF prom mensual } \\
\text { contadas }\end{array}$ & $\begin{array}{c}\text { HF prom mensual } \\
\text { por fórmula }\end{array}$ & $\begin{array}{c}\text { \% fórmula resp } \\
\text { a cont }\end{array}$ \\
\hline enero & 177 & 169 & 96 \\
febrero & 149 & 132 & 89 \\
\hline marzo & 77 & 67 & 87 \\
\hline abril & 31 & 26 & 83 \\
mayo & 6 & 4 & \\
junio & 0 & 0 & \\
julio & 0 & 0 & \\
agosto & 0 & 0 & \\
\hline septiembre & 0 & 0 & 79 \\
\hline octubre & 5 & 4 & 85 \\
\hline noviembre & 66 & 57 & 92 \\
\hline diciembre & 173 & 158 & 90 \\
\hline anual & 683 & 617 & \\
\hline
\end{tabular}

Vigo Peinador. La fórmula de Crossa-Raynaud subestima las horas frío, en promedio da un $86 \%$ de las horas reales, y por tanto es una aproximación aceptable.

Tabla 111. Comparación de horas frío anuales contadas y obtenidas a partir de la fórmula para el observatorio de Vigo Peinador.

HF anuales contadas HF anuales por fórmula \% fórmula resp a cont

\begin{tabular}{|c|ccc|}
\hline 2002 & 454 & 403 & 89 \\
2003 & 646 & 606 & 94 \\
2004 & 884 & 758 & 86 \\
2005 & 1230 & 1024 & 83 \\
2006 & 1064 & 912 & 86 \\
2007 & 880 & 750 & 85 \\
2008 & 774 & 681 & 88 \\
2009 & 980 & 845 & 86 \\
2010 & 938 & 818 & 87 \\
2011 & 469 & 370 & 79 \\
Promedio & 832 & 717 & 86
\end{tabular}

La subestima mensual de horas frío de la fórmula es similar a la anual en los meses que hay más horas frío. 
Tabla 112. Comparación de los promedios mensuales de las horas frío para el observatorio de Vigo Peinador.

\begin{tabular}{|c|c|c|c|}
\hline & $\begin{array}{l}\text { HF prom mensual } \\
\text { contadas }\end{array}$ & $\begin{array}{l}\text { HF prom mensual } \\
\text { por fórmula }\end{array}$ & $\begin{array}{c}\% \text { fórmula resp } \\
\text { a cont }\end{array}$ \\
\hline enero & 218 & 197 & 90 \\
\hline febrero & 179 & 150 & 84 \\
\hline marzo & 86 & 78 & 91 \\
\hline abril & 33 & 30 & 89 \\
\hline mayo & 5 & 4 & \\
\hline junio & 0 & 0 & \\
\hline julio & 0 & 0 & \\
\hline agosto & 0 & 0 & \\
\hline septiembre & 0 & 0 & \\
\hline octubre & 6 & 4 & 70 \\
\hline noviembre & 84 & 70 & 83 \\
\hline diciembre & 220 & 183 & 83 \\
\hline anual & 832 & 717 & 86 \\
\hline
\end{tabular}

\subsubsection{Zonas norte y noroeste: c) interior de Galicia y el valle del Bierzo}

Santiago. La fórmula de Crossa-Raynaud subestima las horas frío, en promedio da un $87 \%$ de las horas reales, pero es una subestima uniforme a lo largo de los años y por tanto es una aproximación aceptable.

Tabla 113. Comparación de horas frío anuales contadas y obtenidas a partir de la fórmula para el observatorio de Santiago.

HF anuales contadas $\quad \mathrm{HF}$ anuales por fórmula \% fórmula resp a 
Tabla 114. Comparación de los promedios mensuales de las horas frío para el observatorio de Santiago.

\begin{tabular}{|c|c|c|c|}
\hline & $\begin{array}{c}\text { HF prom mensual } \\
\text { contadas }\end{array}$ & $\begin{array}{c}\text { HF prom } \\
\text { mensual por } \\
\text { fórmula }\end{array}$ & $\begin{array}{c}\text { \% fórmula resp } \\
\text { a cont }\end{array}$ \\
\hline enero & 307 & 292 & 95 \\
\hline febrero & 290 & 257 & 89 \\
\hline marzo & 198 & 165 & 83 \\
\hline abril & 117 & 91 & \\
mayo & 35 & 26 & \\
\hline junio & 8 & 0 & \\
\hline julio & 0 & 1 & \\
\hline agosto & 3 & 0 & \\
\hline septiembre & 11 & 0 & \\
\hline octubre & 31 & 21 & 92 \\
\hline noviembre & 138 & 127 & 91 \\
\hline diciembre & 293 & 267 & 87 \\
\hline anual & 1429 & 1247 & \\
\hline
\end{tabular}

La subestima de horas frío de la fórmula es baja en los meses que hay más horas frío, lo que refuerza la idea de que la fórmula de Crossa-Raynaud es una aproximación aceptable del número de horas reales.

Lugo Rozas. La fórmula de Crossa-Raynaud subestima ligeramente las horas frío, en promedio da un $94 \%$ de las horas reales, y por tanto es una muy buena aproximación.

Tabla 115. Comparación de horas frío anuales contadas y obtenidas a partir de la fórmula para el observatorio de Lugo Rozas.

\begin{tabular}{|c|c|c|c|}
\hline & HF anuales contadas & HF anuales por fórmula & $\%$ fórmula resp a cont \\
\hline \multicolumn{4}{|l|}{2002} \\
\hline 2003 & 1853 & 1848 & 100 \\
\hline 2004 & 2201 & 2205 & 100 \\
\hline 2005 & 2360 & 2224 & 94 \\
\hline 2006 & 1954 & 1792 & 92 \\
\hline 2007 & 2018 & 1920 & 95 \\
\hline 2008 & 2091 & 1878 & 90 \\
\hline 2009 & 2118 & 1899 & 90 \\
\hline 2010 & 2219 & 2087 & 94 \\
\hline 2011 & 1643 & 1501 & 91 \\
\hline Promedio & 2051 & 1928 & 94 \\
\hline
\end{tabular}


Tabla 116. Comparación de los promedios mensuales de las horas frío para el observatorio de Lugo Rozas.

\begin{tabular}{|c|c|c|c|}
\hline & $\begin{array}{c}\text { HF prom mensual } \\
\text { contadas }\end{array}$ & $\begin{array}{c}\text { HF prom } \\
\text { mensual por } \\
\text { fórmula }\end{array}$ & $\begin{array}{c}\text { \% fórmula resp } \\
\text { a cont }\end{array}$ \\
\hline enero & 392 & 392 & 100 \\
febrero & 381 & 356 & 94 \\
marzo & 273 & 247 & 90 \\
abril & 159 & 142 & 89 \\
\hline mayo & 68 & 61 & 90 \\
\hline junio & 10 & 7 & 71 \\
julio & 3 & 2 & 66 \\
\hline agosto & 4 & 2 & 66 \\
\hline septiembre & 29 & 17 & 56 \\
\hline octubre & 94 & 69 & 73 \\
noviembre & 223 & 211 & 95 \\
diciembre & 389 & 395 & 102 \\
\hline anual & 2051 & 1928 & 94 \\
\hline
\end{tabular}

En los meses que hay más horas frío, la fórmula de Crossa-Raynaud da las horas reales.

Orense. La fórmula de Crossa-Raynaud subestima las horas frío, en promedio da un $82 \%$ de las horas reales; hay años en los que se acerca al $90 \%$, mientras que otros baja al $75 \%$.

Tabla 117. Comparación de horas frío anuales contadas y obtenidas a partir de la fórmula para el observatorio de Orense.

HF anuales contadas HF anuales por fórmula \% fórmula resp a cont

\begin{tabular}{|c|ccc|}
\hline 2002 & 1004 & 828 & 82 \\
2003 & 1216 & 976 & 80 \\
2004 & 1623 & 1296 & 80 \\
2005 & 1682 & 1372 & 82 \\
2006 & 1368 & 1142 & 83 \\
2007 & 1545 & 1262 & 82 \\
2008 & 1401 & 1054 & 75 \\
2009 & 1363 & 1117 & 82 \\
2010 & 1330 & 1199 & 90 \\
2011 & 1152 & 934 & 81 \\
Promedio & 1368 & 1118 & 82
\end{tabular}


Tabla 118.Comparación de los promedios mensuales de las horas frío para el observatorio de Orense.

\begin{tabular}{|c|c|c|c|}
\hline & $\begin{array}{c}\text { HF prom mensual } \\
\text { contadas }\end{array}$ & $\begin{array}{c}\text { HF prom } \\
\text { mensual por } \\
\text { fórmula }\end{array}$ & $\begin{array}{c}\text { \% fórmula resp } \\
\text { a cont }\end{array}$ \\
\hline enero & 307 & 269 & 88 \\
febrero & 267 & 221 & 83 \\
marzo & 160 & 125 & 78 \\
abril & 74 & 55 & \\
mayo & 22 & 14 & \\
junio & 0 & 0 & \\
julio & 0 & 0 & \\
agosto & 0 & 0 & \\
septiembre & 4 & 1 & 73 \\
octubre & 44 & 24 & 88 \\
noviembre & 170 & 125 & 82 \\
diciembre & 321 & 283 & \\
anual & 1368 & 1118 & \\
\hline
\end{tabular}

La subestima de horas frío de la fórmula es menor en los meses que hay más horas frío, pero sigue siendo superior al $10 \%$.

Ponferrada. La fórmula de Crossa-Raynaud subestima las horas frío, en promedio da un $92 \%$ de las horas reales, y por tanto es una buena aproximación.

Tabla 119. Comparación de horas frío anuales contadas y obtenidas a partir de la fórmula para el observatorio de Ponferrada.

HF anuales contadas HF anuales por fórmula $\begin{aligned} & \text { \% fórmula } \\ & \text { resp a cont }\end{aligned}$

\begin{tabular}{|c|ccc|}
\hline 2002 & 1778 & 1640 & 92 \\
2003 & 1849 & 1817 & 98 \\
2004 & 2413 & 2307 & 96 \\
2005 & 2427 & 2310 & 95 \\
2006 & 2064 & 1923 & 93 \\
2007 & 2279 & 2021 & 89 \\
2008 & 2163 & 1912 & 88 \\
2009 & 2063 & 1838 & 89 \\
2010 & 2333 & 2123 & 91 \\
2011 & 1902 & 1732 & 91 \\
Promedio & 2127 & 1962 & 92
\end{tabular}


Tabla 120. Comparación de los promedios mensuales de las horas frío para el observatorio de Ponferrada.

\begin{tabular}{|c|c|c|c|}
\hline & $\begin{array}{c}\text { HF prom mensual } \\
\text { contadas }\end{array}$ & $\begin{array}{c}\text { HF prom } \\
\text { mensual por } \\
\text { fórmula }\end{array}$ & $\begin{array}{c}\text { \% fórmula resp } \\
\text { a cont }\end{array}$ \\
\hline enero & 502 & 478 & 95 \\
febrero & 384 & 347 & 90 \\
marzo & 231 & 209 & 91 \\
abril & 115 & 99 & 86 \\
\hline mayo & 40 & 32 & 81 \\
\hline junio & 1 & 1 & 83 \\
julio & 0 & 0 & \\
\hline agosto & 0 & 0 & \\
\hline septiembre & 7 & 5 & 70 \\
\hline octubre & 70 & 53 & 76 \\
noviembre & 292 & 260 & 89 \\
diciembre & 486 & 478 & 98 \\
anual & 2127 & 1962 & 92 \\
\hline
\end{tabular}

En los meses en los que hay más horas frío, la fórmula apenas subestima el número de horas reales.

Almázcara. La fórmula de Crossa-Raynaud subestima las horas frío, pero lo hace en menos del $10 \%$ en los años en los que hay datos en ese periodo, y por tanto es una buena aproximación.

Tabla 121. Comparación de horas frío anuales contadas y obtenidas a partir de la fórmula para el observatorio de Almázcara.

HF anuales contadas HF anuales por fórmula \% fórmula resp a cont

\begin{tabular}{|c|ccc|}
2002 & 2301 & 2176 & 95 \\
2003 & 2446 & 2353 & 96 \\
2004 & 3020 & 2836 & 94 \\
2005 & 3028 & 2805 & 93 \\
2006 & 2543 & 2383 & 94 \\
2007 & 3019 & 2738 & 91 \\
2008 & 2907 & 2623 & 90 \\
2009 & & 2502 & \\
2010 & & 2918 & \\
2011 & & 2444 & \\
Promedio & & 2578 &
\end{tabular}

Nota. El promedio para las horas frío calculadas por fórmula corresponde al de los diez años. 
Tabla 122. Comparación de los promedios mensuales de las horas frío para el observatorio de Almázcara.

\begin{tabular}{|c|c|c|c|}
\hline & $\begin{array}{c}\text { HF prom mensual } \\
\text { contadas }\end{array}$ & $\begin{array}{c}\text { HF prom } \\
\text { mensual por } \\
\text { fórmula }\end{array}$ & $\begin{array}{c}\text { \% fórmula resp } \\
\text { a cont }\end{array}$ \\
\hline enero & 543 & 525 & 97 \\
febrero & 432 & 416 & 96 \\
marzo & 315 & 291 & 92 \\
abril & 213 & 190 & 89 \\
\hline mayo & 95 & 81 & 86 \\
junio & 15 & 10 & \\
julio & 7 & 4 & \\
\hline agosto & 12 & 7 & \\
\hline septiembre & 55 & 32 & 76 \\
\hline octubre & 151 & 115 & 94 \\
noviembre & 381 & 358 & 99 \\
diciembre & 534 & 530 & 93 \\
\hline anual & 2752 & 2559 & \\
\hline
\end{tabular}

Nota. Estos promedios mensuales y anual corresponden a los siete años de datos del 2002 al 2008.

La fórmula de Crossa-Raynaud es una buena aproximación en la costa gallega. En general, la fórmula subestima ligeramente las horas frío reales, siempre menos de un $10 \%$ y en los meses de más horas frío la subestima es menor.

También es una buena aproximación en el interior de Galicia, excepto Orense. La fórmula subestima las horas frío reales, pero lo hace en menos de un $10 \%$ y en los meses de más horas frío la subestima es menor. Puede decirse que, en toda esta zona, por tanto, no se precisan temperaturas horarias para dar una buena aproximación de las horas frío, basta tener el registro de las máximas y mínimas diarias para dar valores de las horas frío muy próximos a los reales, y tener en cuenta esa pequeña subestima. 
Soria. La fórmula de Crossa-Raynaud subestima ligeramente las horas frío, en promedio da un $93 \%$ de las horas reales, y es una aproximación uniforme a los largo de los años. Por tanto, es una muy buena aproximación.

Tabla 123. Comparación de horas frío anuales contadas y obtenidas a partir de la fórmula para el observatorio de Soria.

HF anuales Contadas HF anuales por fórmula \% fórmula resp a cont

\begin{tabular}{|c|lll|}
\hline 2002 & 3177 & 2877 & 91 \\
2003 & 3074 & 2873 & 93 \\
2004 & 3388 & 3128 & 92 \\
2005 & 3290 & 3061 & 93 \\
2006 & 2662 & 2497 & 94 \\
2007 & 3213 & 2986 & 93 \\
2008 & 3436 & 3163 & 92 \\
2009 & 3044 & 2839 & 93 \\
2010 & 3595 & 3459 & 96 \\
2011 & 2764 & 2538 & 92 \\
promedio & 3164 & 2987 & 93
\end{tabular}

Tabla 124. Comparación de los promedios mensuales de las horas frío para el observatorio de Soria.

\begin{tabular}{|c|c|c|c|}
\hline & $\begin{array}{c}\text { HF prom mensual } \\
\text { contadas }\end{array}$ & $\begin{array}{c}\text { HF prom mensual } \\
\text { por fórmula }\end{array}$ & $\begin{array}{c}\text { \% fórmula resp a } \\
\text { cont }\end{array}$ \\
\hline enero & 620 & 595 & 96 \\
febrero & 533 & 509 & 95 \\
\hline marzo & 438 & 401 & 92 \\
\hline abril & 259 & 234 & 90 \\
mayo & 114 & 95 & 84 \\
junio & 12 & 10 & 85 \\
\hline julio & 3 & 2 & 55 \\
\hline agosto & 1 & 1 & 100 \\
\hline septiembre & 29 & 20 & 70 \\
\hline octubre & 148 & 120 & 81 \\
\hline noviembre & 395 & 369 & 93 \\
\hline diciembre & 614 & 586 & 95 \\
anual & 3164 & 2987 & 93 \\
\hline
\end{tabular}

La aproximación de la fórmula es mayor en los meses en los que hay más horas frío, lo que refuerza la idea de que la fórmula de Crossa-Raynaud es una muy buena aproximación al número de horas reales. 
Burgos Villafría. La fórmula de Crossa-Raynaud subestima ligeramente las horas frío, en promedio da un $94 \%$ de las horas reales, y es una aproximación uniforme a los largo de los años. Por tanto, es una muy buena aproximación.

Tabla 125. Comparación de horas frío anuales contadas y obtenidas a partir de la fórmula para el observatorio de Burgos Villafría.

HF anuales Contadas HF anuales por fórmula \% fórmula resp a cont

\begin{tabular}{|c|ccc|}
\hline 2002 & 2921 & 2629 & 90 \\
2003 & 3000 & 2739 & 91 \\
2004 & 3493 & 3200 & 92 \\
2005 & 3398 & 3181 & 94 \\
2006 & 2759 & 2594 & 94 \\
2007 & 3256 & 3065 & 94 \\
2008 & 3173 & 2958 & 93 \\
2009 & 2991 & 2849 & 95 \\
2010 & 3522 & 3421 & 97 \\
2011 & 2781 & 2635 & 95 \\
promedio & 3129 & 2927 & 94
\end{tabular}

Tabla 126. Comparación de los promedios mensuales de las horas frío para el observatorio de Burgos Villafría.

\begin{tabular}{|c|c|c|c|}
\hline & $\begin{array}{c}\text { HF prom mensual } \\
\text { contadas }\end{array}$ & $\begin{array}{c}\text { HF prom mensual } \\
\text { por fórmula }\end{array}$ & $\begin{array}{c}\text { \% fórmula resp a } \\
\text { cont }\end{array}$ \\
\hline enero & 611 & 599 & 98 \\
febrero & 517 & 503 & 97 \\
marzo & 422 & 386 & 91 \\
abril & 264 & 226 & 86 \\
mayo & 122 & 98 & 81 \\
\hline junio & 16 & 11 & 72 \\
julio & 5 & 3 & 57 \\
agosto & 2 & 1 & 74 \\
\hline septiembre & 35 & 25 & 72 \\
\hline octubre & 140 & 113 & 80 \\
noviembre & 388 & 366 & 94 \\
diciembre & 608 & 596 & 98 \\
anual & 3129 & 2927 & 94 \\
\hline
\end{tabular}

La aproximación de la fórmula es mayor en los meses en los que hay más horas frío, lo que refuerza la idea de que la fórmula de Crossa-Raynaud es una muy buena aproximación al número de horas reales. 
León Virgen del Camino. La fórmula de Crossa-Raynaud subestima ligeramente las horas frío, en promedio da un $97 \%$ de las horas reales, y es una aproximación uniforme a los largo de los años. Por tanto, es una muy buena aproximación.

Tabla 127. Comparación de horas frío anuales contadas y obtenidas a partir de la fórmula para el observatorio de León Virgen del Camino.

HF anuales Contadas HF anuales por fórmula \% fórmula resp a cont

\begin{tabular}{|c|ccc|}
\hline 2002 & 2923 & 2837 & 97 \\
2003 & 2876 & 2844 & 99 \\
2004 & 3225 & 3174 & 98 \\
2005 & 3083 & 3004 & 97 \\
2006 & 2625 & 2607 & 99 \\
2007 & 3036 & 2899 & 95 \\
2008 & 3124 & 2902 & 93 \\
2009 & 2911 & 2800 & 96 \\
2010 & 3401 & 3346 & 98 \\
2011 & 2681 & 2563 & 96 \\
Promedio & 2989 & 2898 & 97
\end{tabular}

Tabla 128. Comparación de los promedios mensuales de las horas frío para el observatorio de León Virgen del Camino.

\begin{tabular}{|c|c|c|c|}
\hline & $\begin{array}{c}\text { HF prom mensual } \\
\text { contadas }\end{array}$ & $\begin{array}{c}\text { HF prom } \\
\text { mensual por } \\
\text { fórmula }\end{array}$ & $\begin{array}{c}\text { \% fórmula resp } \\
\text { a cont }\end{array}$ \\
\hline enero & 623 & 619 & 99 \\
\hline febrero & 515 & 499 & 97 \\
\hline marzo & 391 & 371 & 95 \\
abril & 218 & 209 & 96 \\
\hline mayo & 102 & 97 & 95 \\
\hline junio & 13 & 11 & 88 \\
\hline julio & 4 & 3 & 83 \\
agosto & 3 & 2 & 75 \\
\hline septiembre & 20 & 15 & 75 \\
\hline octubre & 119 & 107 & 90 \\
noviembre & 380 & 377 & 99 \\
diciembre & 601 & 588 & 98 \\
anual & 2989 & 2898 & 97 \\
\hline
\end{tabular}

La fórmula apenas subestima las horas frío en los meses que hay un mayor número de ellas, lo que refuerza la idea de que la fórmula de Crossa-Raynaud es una aproximación excelente al número de horas reales. 
Villanubla Valladolid. La fórmula de Crossa-Raynaud subestima ligeramente las horas frío, en promedio da un $97 \%$ de las horas reales, y es una aproximación uniforme a los largo de los años. Por tanto, es una muy buena aproximación.

Tabla 129. Comparación de horas frío anuales contadas y obtenidas a partir de la fórmula para el observatorio de Villanubla Valladolid.

$$
\text { HF anuales Contadas HF anuales por fórmula } \begin{gathered}
\% \text { fórmula resp } \\
\text { a cont }
\end{gathered}
$$

\begin{tabular}{|c|ccc|}
\hline 2002 & 2624 & 2552 & a cont \\
2003 & 2784 & 2728 & 97 \\
2004 & 3190 & 3098 & 98 \\
2005 & 3051 & 2972 & 97 \\
2006 & 2612 & 2579 & 97 \\
2007 & 3026 & 2838 & 99 \\
2008 & 2991 & 2829 & 94 \\
2009 & 2718 & 2608 & 95 \\
2010 & 3139 & 3052 & 96 \\
2011 & 2457 & 2346 & 97 \\
promedio & 2859 & 2760 & 95 \\
\hline
\end{tabular}

Tabla 130. Comparación de los promedios mensuales de las horas frío para el observatorio de Villanubla Valladolid.

\begin{tabular}{|c|c|c|c|} 
& $\begin{array}{c}\text { HF prom mensual } \\
\text { contadas }\end{array}$ & $\begin{array}{c}\text { HF prom mensual } \\
\text { por fórmula }\end{array}$ & $\begin{array}{c}\text { \% fórmula resp a } \\
\text { cont }\end{array}$ \\
\hline enero & 600 & 593 & 99 \\
febrero & 492 & 473 & 96 \\
marzo & 370 & 349 & 94 \\
\hline abril & 201 & 193 & 96 \\
mayo & 92 & 86 & 94 \\
junio & 10 & 9 & 88 \\
julio & 1 & 2 & \\
agosto & 2 & 1 & 66 \\
\hline septiembre & 17 & 15 & 85 \\
\hline octubre & 102 & 92 & 90 \\
\hline noviembre & 379 & 359 & 95 \\
diciembre & 594 & 589 & 99 \\
\hline anual & 2859 & 2760 & 97 \\
\hline
\end{tabular}

La fórmula apenas subestima las horas frío en los meses que hay un mayor número de ellas, lo que refuerza la idea de que la fórmula de Crossa-Raynaud es una aproximación excelente al número de horas reales. 
Valladolid CMT. La fórmula de Crossa-Raynaud subestima ligeramente las horas frío, en promedio da un $94 \%$ de las horas reales, y es una aproximación uniforme a los largo de los años. Por tanto, es una muy buena aproximación.

Tabla 131. Comparación de horas frío anuales contadas y obtenidas a partir de la fórmula para el observatorio de Valladolid CMT.

HF anuales Contadas HF anuales por fórmula \% fórmula resp a cont

\begin{tabular}{|c|lll|}
\hline 2002 & 2090 & 1899 & 91 \\
2003 & 2350 & 2210 & 94 \\
2004 & 2820 & 2690 & 95 \\
2005 & 2691 & 2612 & 97 \\
2006 & 2328 & 2233 & 96 \\
2007 & 2606 & 2435 & 93 \\
2008 & 2556 & 2377 & 93 \\
2009 & 2343 & 2175 & 93 \\
2010 & 2701 & 2534 & 94 \\
2011 & 2115 & 1948 & 92 \\
promedio & 2460 & 2311 & 94
\end{tabular}

Tabla 132.Comparación de los promedios mensuales de las horas frío para el observatorio de Valladolid CMT.

\begin{tabular}{|c|ccc|}
\hline & $\begin{array}{c}\text { HF prom mensual } \\
\text { contadas }\end{array}$ & $\begin{array}{c}\text { HF prom mensual } \\
\text { por fórmula }\end{array}$ & $\begin{array}{c}\text { \% fórmula resp a } \\
\text { cont }\end{array}$ \\
\hline enero & 556 & 545 & 98 \\
febrero & 446 & 423 & 95 \\
marzo & 306 & 274 & 90 \\
\hline abril & 147 & 128 & 87 \\
mayo & 49 & 39 & 80 \\
junio & 3 & 1 & 60 \\
julio & 0 & 0 & \\
agosto & 0 & 0 & \\
\hline septiembre & 8 & 5 & 61 \\
\hline octubre & 74 & 58 & 79 \\
noviembre & 324 & 299 & 92 \\
diciembre & 547 & 538 & 98 \\
anual & 2460 & 2311 & 94 \\
\hline
\end{tabular}

La fórmula apenas subestima las horas frío en los meses que hay un mayor número de ellas, lo que refuerza la idea de que la fórmula de Crossa-Raynaud es una aproximación excelente al número de horas reales. 
Salamanca Matacán. La fórmula de Crossa-Raynaud subestima ligeramente las horas frío, en promedio da un 95\% de las horas reales, y es una aproximación uniforme a los largo de los años. Por tanto, es una muy buena aproximación.

Tabla 133. Comparación de horas frío anuales contadas y obtenidas a partir de la fórmula para el observatorio de Salamanca Matacán.

\section{HF anuales contadas HF anuales por fórmula \% fórmula resp a cont}

\begin{tabular}{|c|lll|}
\hline 2002 & 2188 & 2126 & 97 \\
2003 & 2393 & 2322 & 97 \\
2004 & 2802 & 2766 & 99 \\
2005 & 2850 & 2742 & 96 \\
2006 & 2431 & 2325 & 96 \\
2007 & 2738 & 2525 & 92 \\
2008 & 2772 & 2587 & 93 \\
2009 & 2466 & 2325 & 94 \\
2010 & 2718 & 2641 & 97 \\
2011 & 2302 & 2137 & 93 \\
promedio & 2566 & 2449 & 95
\end{tabular}

Tabla 134. Comparación de los promedios mensuales de las horas frío para el observatorio de Salamanca Matacán.

\begin{tabular}{|c|c|c|c|}
\hline & $\begin{array}{c}\text { HF prom mensual } \\
\text { contadas }\end{array}$ & $\begin{array}{c}\text { HF prom mensual } \\
\text { por fórmula }\end{array}$ & $\begin{array}{c}\text { \% fórmula resp } \\
\text { a cont }\end{array}$ \\
\hline $\begin{array}{c}\text { enero } \\
\text { febrero }\end{array}$ & 530 & 524 & 99 \\
marzo & 451 & 433 & 96 \\
abril & 335 & 313 & 93 \\
mayo & 182 & 165 & 91 \\
\hline junio & 59 & 53 & 91 \\
julio & 5 & 5 & \\
agosto & 1 & 1 & \\
septiembre & 1 & 1 & 71 \\
\hline octubre & 26 & 18 & 81 \\
noviembre & 123 & 100 & 96 \\
diciembre & 339 & 326 & 99 \\
anual & 514 & 510 & 95 \\
\hline
\end{tabular}

La fórmula apenas subestima las horas frío en los meses que hay un mayor número de ellas, lo que refuerza la idea de que la fórmula de Crossa-Raynaud es una aproximación excelente al número de horas reales. 
Segovia. La fórmula de Crossa-Raynaud subestima ligeramente las horas frío, en promedio da un $95 \%$ de las horas reales, y es una aproximación uniforme a lo largo de los años. Por tanto, es una muy buena aproximación.

Tabla 135. Comparación de horas frío anuales contadas y obtenidas a partir de la fórmula para el observatorio de Segovia.

\begin{tabular}{|c|c|c|c|}
\hline & HF anuales contadas & HF anuales por fórmula & $\%$ fórmula resp a cont \\
\hline 2002 & 2316 & 2256 & 97 \\
\hline 2003 & 2517 & 2384 & 95 \\
\hline 2004 & 2981 & 2803 & 94 \\
\hline 2005 & 2861 & 2769 & 97 \\
\hline 2006 & 2308 & 2235 & 97 \\
\hline 2007 & 2669 & 2552 & 96 \\
\hline 2008 & 2640 & 2455 & 93 \\
\hline 2009 & 2416 & 2285 & 95 \\
\hline 2010 & 2769 & 2686 & 97 \\
\hline 2011 & 2335 & 2100 & 90 \\
\hline promedio & 2581 & 2452 & 95 \\
\hline
\end{tabular}

Tabla 136. Comparación de los promedios mensuales de las horas frío para el observatorio de Segovia.

\begin{tabular}{|c|c|c|c|}
\hline & $\begin{array}{c}\text { HF prom mensual } \\
\text { contadas }\end{array}$ & $\begin{array}{c}\text { HF prom mensual } \\
\text { por fórmula }\end{array}$ & $\begin{array}{c}\text { \% fórmula resp } \\
\text { a cont }\end{array}$ \\
\hline enero & 549 & 533 & 97 \\
febrero & 450 & 431 & 96 \\
\hline marzo & 336 & 316 & 94 \\
\hline abril & 183 & 169 & 93 \\
\hline mayo & 79 & 70 & 88 \\
\hline junio & 9 & 6 & \\
\hline julio & 1 & 0 & \\
\hline agosto & 1 & 1 & \\
\hline septiembre & 13 & 10 & 76 \\
\hline octubre & 84 & 70 & 84 \\
\hline noviembre & 348 & 328 & 94 \\
\hline diciembre & 530 & 519 & 98 \\
\hline anual & 2581 & 2452 & 95 \\
\hline
\end{tabular}

La fórmula apenas subestima las horas frío en los meses que hay un mayor número de ellas, lo que refuerza la idea de que la fórmula de Crossa-Raynaud es una aproximación excelente al número de horas reales. 
Zamora. La fórmula de Crossa-Raynaud subestima ligeramente las horas frío, en promedio da un $95 \%$ de las horas reales, y es una aproximación uniforme a los largo de los años. Por tanto, es una muy buena aproximación.

Tabla 137. Comparación de horas frío anuales contadas y obtenidas a partir de la fórmula para el observatorio de Zamora.

\begin{tabular}{|c|ccc|}
\hline \multicolumn{2}{|c}{ HF anuales contadas } & HF anuales por fórmula & $\%$ fórmula resp a cont \\
\hline 2002 & 1791 & 1665 & 93 \\
2003 & 2049 & 1936 & 95 \\
2004 & 2498 & 2415 & 97 \\
2005 & 2520 & 2487 & 99 \\
2006 & 2169 & 2110 & 97 \\
2007 & 2322 & 2201 & 95 \\
2008 & 2327 & 2139 & 92 \\
2009 & 2096 & 1937 & 92 \\
2010 & 2473 & 2329 & 94 \\
2011 & 1950 & 1784 & 91 \\
promedio & 2220 & 2100 & 95
\end{tabular}

Tabla 138. Comparación de los promedios mensuales de las horas frío para el observatorio de Zamora.

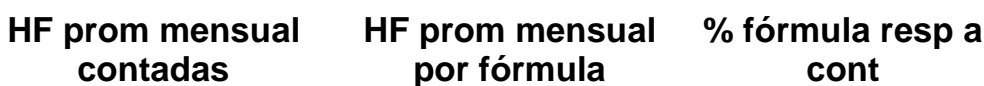

\begin{tabular}{|c|c}
\hline enero \\
febrero \\
marzo \\
abril \\
\hline mayo \\
junio \\
julio \\
agosto \\
septiembre \\
octubre \\
noviembre \\
diciembre \\
anual
\end{tabular}

505

412

268

132

36

2

0

0

7
70

70

290

499

2220 cont

\begin{tabular}{l|l}
501 & 99
\end{tabular}

$395 \quad 96$

\begin{tabular}{l|l}
244 & 91
\end{tabular}

$112 \quad 85$

\begin{tabular}{l|l}
28 & 78
\end{tabular}

$\begin{array}{ll}28 & 46\end{array}$

0

0

\begin{tabular}{l|l}
5 & 71
\end{tabular}

54
548

\begin{tabular}{l|l}
267 & 92
\end{tabular}

$493 \quad 99$

\begin{tabular}{l|l}
2100 & 95
\end{tabular}

La fórmula apenas subestima las horas frío en los meses que hay un mayor número de ellas, lo que refuerza la idea de que la fórmula de Crossa-Raynaud es una aproximación excelente al número de horas reales. 
La fórmula de Crossa-Raynaud proporciona una muy buena aproximación al número de horas frío (de umbral $7^{\circ} \mathrm{C}$ ) en la meseta Norte. La fórmula subestima las horas frío reales, pero lo hace en menos de un $5 \% \mathrm{y}$, en general, en los meses de más horas frío la subestima es menor. Puede decirse que, en toda esta zona, por tanto, no se precisan temperaturas horarias para dar una muy buena aproximación de las horas frío, basta tener el registro de las máximas y mínimas diarias para dar valores de las horas frío muy próximos a los reales, y tener en cuenta esa pequeña subestima.

\subsubsection{Cuenca del Ebro: a) parte baja y relativamente llana del valle del Ebro}

Huesca. La fórmula de Crossa-Raynaud subestima las horas frío en torno al 10\%. Da en promedio un $89 \%$ de las horas reales y, excepto un año en el que baja al $82 \%$, da una aproximación uniforme en los distintos años. Por tanto, no es una mala aproximación.

Tabla 139. Comparación de horas frío anuales contadas y obtenidas a partir de la fórmula para el observatorio de Huesca.

\begin{tabular}{|c|c|c|c|}
\hline & HF anuales contadas & HF anuales por fórmula & $\%$ fórmula resp a cont \\
\hline 2002 & 1651 & 1355 & 82 \\
\hline 2003 & 1966 & 1788 & 91 \\
\hline 2004 & 2382 & 2168 & 91 \\
\hline 2005 & 2445 & 2308 & 94 \\
\hline 2006 & 2053 & 1888 & 92 \\
\hline 2007 & 2101 & 1834 & 87 \\
\hline 2008 & 2099 & 1831 & 87 \\
\hline 2009 & 2121 & 1845 & 87 \\
\hline 2010 & 2510 & 2252 & 90 \\
\hline 2011 & 1728 & 1493 & 86 \\
\hline Promedio & 2106 & 1876 & 89 \\
\hline
\end{tabular}


Tabla 140. Comparación de los promedios mensuales de las horas frío para el observatorio de Huesca.

\begin{tabular}{|c|c|c|c|}
\hline & $\begin{array}{l}\text { HF prom mensual } \\
\text { contadas }\end{array}$ & $\begin{array}{l}\text { HF prom } \\
\text { mensual por } \\
\text { fórmula }\end{array}$ & $\begin{array}{c}\% \text { fórmula resp } \\
\text { a cont }\end{array}$ \\
\hline enero & 544 & 508 & 93 \\
\hline febrero & 404 & 355 & 88 \\
\hline marzo & 241 & 204 & 85 \\
\hline abril & 100 & 79 & 79 \\
\hline mayo & 26 & 18 & 71 \\
\hline junio & 0 & 0 & 66 \\
\hline julio & 0 & 0 & \\
\hline agosto & 1 & 0 & 0 \\
\hline septiembre & 2 & 2 & 95 \\
\hline octubre & 33 & 27 & 81 \\
\hline noviembre & 243 & 206 & 85 \\
\hline diciembre & 512 & 477 & 93 \\
\hline anual & 2106 & 1876 & 89 \\
\hline
\end{tabular}

La aproximación de la fórmula es mayor en los meses en los que hay más horas frío, lo que refuerza la idea de que la fórmula de Crossa-Raynaud es una buena aproximación al número de horas reales.

Zaragoza aeropuerto. La fórmula de Crossa-Raynaud subestima ligeramente las horas frío, en promedio da un $95 \%$ de las horas reales, y aunque oscila entre el $90 \%$ y el $98 \%$ en unos años y otros, puede considerarse una muy buena aproximación.

Tabla 141. Comparación de horas frío anuales contadas y obtenidas a partir de la fórmula para el observatorio de Zaragoza aeropuerto.

HF anuales contadas HF anuales por fórmula \% fórmula resp a cont

\begin{tabular}{|c|ccc|}
\hline 2002 & 967 & 872 & 90 \\
2003 & 1357 & 1237 & 91 \\
2004 & 1616 & 1477 & 91 \\
2005 & 1938 & 1862 & 96 \\
2006 & 1525 & 1489 & 98 \\
2007 & 1383 & 1322 & 96 \\
2008 & 1290 & 1247 & 97 \\
2009 & 1376 & 1312 & 95 \\
2010 & 1710 & 1680 & 98 \\
2011 & 1255 & 1132 & 90 \\
Promedio & 1442 & 1363 & 95
\end{tabular}


Tabla 142. Comparación de los promedios mensuales de las horas frío para el observatorio de Zaragoza aeropuerto.

\begin{tabular}{|c|c|c|c|}
\hline & $\begin{array}{l}\text { HF prom mensual } \\
\text { contadas }\end{array}$ & $\begin{array}{l}\text { HF prom mensual } \\
\text { por fórmula }\end{array}$ & $\begin{array}{c}\% \text { fórmula resp a } \\
\text { cont }\end{array}$ \\
\hline enero & 423 & 406 & 96 \\
\hline febrero & 301 & 281 & 93 \\
\hline marzo & 155 & 140 & 91 \\
\hline abril & 37 & 32 & 87 \\
\hline mayo & 3 & 2 & 74 \\
\hline junio & 0 & 0 & \\
\hline julio & 0 & 0 & \\
\hline agosto & 0 & 0 & \\
\hline septiembre & 0 & 0 & \\
\hline octubre & 11 & 10 & 92 \\
\hline noviembre & 137 & 129 & 94 \\
\hline diciembre & 375 & 362 & 97 \\
\hline anual & 1442 & 1363 & 95 \\
\hline
\end{tabular}

La fórmula apenas subestima las horas frío en los meses que hay un mayor número de ellas, lo que refuerza la idea de que la fórmula de Crossa-Raynaud es una aproximación muy buena al número de horas reales.

Lérida. La fórmula de Crossa-Raynaud subestima las horas frío, en promedio da un $91 \%$ de las horas reales, y es una aproximación uniforme a los largo de los años. Por tanto, es una buena aproximación.

Tabla 143. Comparación de horas frío anuales contadas y obtenidas a partir de la fórmula para el observatorio de Lérida. HF anuales contadas HF anuales por fórmula \% fórmula resp a cont

\begin{tabular}{|c|ccc|}
\hline 2002 & 1419 & 1235 & 87 \\
2003 & 1681 & 1524 & 91 \\
2004 & 2036 & 1823 & 90 \\
2005 & 2213 & 2056 & 93 \\
2006 & 1788 & 1708 & 96 \\
2007 & 1966 & 1793 & 91 \\
2008 & 1748 & 1599 & 91 \\
2009 & 1664 & 1495 & 90 \\
2010 & 1941 & 1803 & 93 \\
2011 & 1552 & 1425 & 92 \\
Promedio & 1801 & 1646 & 91
\end{tabular}


Tabla 144. Comparación de los promedios mensuales de las horas frío para el observatorio de Lérida.

\begin{tabular}{|c|c|c|c|}
\hline & $\begin{array}{c}\text { HF prom mensual } \\
\text { contadas }\end{array}$ & $\begin{array}{l}\text { HF prom mensual } \\
\text { por fórmula }\end{array}$ & $\begin{array}{c}\% \text { fórmula resp a } \\
\text { cont }\end{array}$ \\
\hline enero & 512 & 480 & 94 \\
\hline febrero & 349 & 317 & 91 \\
\hline marzo & 179 & 154 & 86 \\
\hline abril & 44 & 36 & 82 \\
\hline mayo & 4 & 5 & 104 \\
\hline junio & 0 & 0 & \\
\hline julio & 0 & 0 & \\
\hline agosto & 0 & 0 & \\
\hline septiembre & 2 & 1 & 84 \\
\hline octubre & 28 & 21 & 77 \\
\hline noviembre & 216 & 189 & 87 \\
\hline diciembre & 467 & 444 & 95 \\
\hline anual & 1801 & 1646 & 91 \\
\hline
\end{tabular}

La aproximación de la fórmula es mayor en los meses en los que hay más horas frío, lo que refuerza la idea de que la fórmula de Crossa-Raynaud es una buena aproximación al número de horas reales.

\subsubsection{Cuenca del Ebro: b) zonas de la parte media de la cuenca: Navarra y La Rioja.}

Logroño Agoncillo. La fórmula de Crossa-Raynaud subestima ligeramente las horas frío, en promedio da un 95\% de las horas reales y, excepto el año 2011 que da un 89\%, la aproximación es uniforme a lo largo de los años. Por tanto puede considerarse una muy buena aproximación.

Tabla 145. Comparación de horas frío anuales contadas y obtenidas a partir de la fórmula para el observatorio de Logroño Agoncillo.

HF anuales contadas HF anuales por fórmula \% fórmula resp a cont

\begin{tabular}{c|ccc}
2002 & 1296 & 1221 & 94 \\
2003 & 1552 & 1539 & 99 \\
2004 & 1893 & 1841 & 97 \\
2005 & 2221 & 2207 & 99 \\
2006 & 1750 & 1693 & 97 \\
2007 & 1753 & 1580 & 90 \\
2008 & 1676 & 1552 & 93 \\
2009 & 1806 & 1677 & 93 \\
2010 & 2187 & 2126 & 97 \\
2011 & 1608 & 1434 & 89 \\
Promedio & 1774 & 1687 & 95
\end{tabular}


Tabla 146. Comparación de los promedios mensuales de las horas frío para el observatorio de Logroño Agoncillo.

\begin{tabular}{|c|c|c|c|}
\hline & $\begin{array}{c}\text { HF prom mensual } \\
\text { contadas }\end{array}$ & $\begin{array}{c}\text { HF prom mensual } \\
\text { por fórmula }\end{array}$ & $\begin{array}{c}\text { \% fórmula resp a } \\
\text { cont }\end{array}$ \\
\hline enero & 453 & 439 & 97 \\
\hline febrero & 366 & 346 & 95 \\
\hline marzo & 227 & 205 & 90 \\
\hline abril & 81 & 71 & 88 \\
\hline mayo & 16 & 14 & 86 \\
\hline junio & 0 & 0 & \\
\hline julio & 0 & 0 & \\
\hline agosto & 0 & 0 & 100 \\
\hline septiembre & 2 & 2 & 79 \\
\hline octubre & 41 & 33 & 95 \\
\hline noviembre & 187 & 179 & 99 \\
\hline diciembre & 401 & 399 & 95 \\
\hline anual & 1774 & 1687 & \\
\hline
\end{tabular}

La fórmula apenas subestima las horas frío en los meses que hay un mayor número de ellas, lo que refuerza la idea de que la fórmula de Crossa-Raynaud es una aproximación muy buena al número de horas reales.

Haro. La fórmula de Crossa-Raynaud subestima ligeramente las horas frío, en promedio da un $94 \%$ de las horas reales, y es una aproximación uniforme a lo largo de los años. Por tanto, es una aproximación muy buena.

Tabla 147. Comparación de horas frío anuales contadas y obtenidas a partir de la fórmula para el observatorio de Haro.

HF anuales contadas HF anuales por fórmula \% fórmula resp a cont

\begin{tabular}{|c|ccc|}
\hline 2002 & & & \\
2003 & & 2204 & 95 \\
2004 & 2328 & 2427 & 97 \\
2005 & 2506 & 1890 & 96 \\
2006 & 1964 & 1849 & 96 \\
2007 & 1929 & 1913 & 93 \\
2008 & 2058 & 1907 & 90 \\
2009 & 2120 & 2476 & 95 \\
2010 & 2613 & 1602 & 92 \\
2011 & 1738 & 2034 & 94 \\
\hline Promedio & 2157 & &
\end{tabular}


Tabla 148. Comparación de los promedios mensuales de las horas frío para el observatorio de Haro.

\begin{tabular}{|c|c|c|c|}
\hline & $\begin{array}{c}\text { HF prom mensual } \\
\text { contadas }\end{array}$ & $\begin{array}{l}\text { HF prom mensual } \\
\text { por fórmula }\end{array}$ & $\begin{array}{c}\% \text { fórmula resp a } \\
\text { cont }\end{array}$ \\
\hline enero & 493 & 480 & 97 \\
\hline febrero & 418 & 401 & 96 \\
\hline marzo & 295 & 267 & 91 \\
\hline abril & 119 & 101 & 85 \\
\hline mayo & 36 & 28 & 77 \\
\hline junio & 1 & 0 & \\
\hline julio & 0 & 0 & \\
\hline agosto & 0 & 0 & \\
\hline septiembre & 7 & 4 & 55 \\
\hline octubre & 65 & 49 & 76 \\
\hline noviembre & 233 & 218 & 93 \\
\hline diciembre & 490 & 486 & 99 \\
\hline anual & 2157 & 2034 & 94 \\
\hline
\end{tabular}

La fórmula apenas subestima las horas frío en los meses que hay un mayor número de ellas, lo que refuerza la idea de que la fórmula de Crossa-Raynaud es una aproximación muy buena al número de horas reales.

Pamplona-Noáin. La fórmula de Crossa-Raynaud subestima ligeramente las horas frío, en promedio da un $94 \%$ de las horas reales, y es una aproximación uniforme a los largo de los años. Por tanto, es una aproximación muy buena.

Tabla 149. Comparación de horas frío anuales contadas y obtenidas a partir de la fórmula para el observatorio de Pamplona-Noáin.

$\mathrm{HF}$ anuales contadas HF anuales por fórmula \% fórmula resp a cont

\begin{tabular}{|c|ccc|}
\hline 2002 & 1508 & 1388 & 92 \\
2003 & 1890 & 1839 & 97 \\
2004 & 2369 & 2244 & 95 \\
2005 & 2619 & 2462 & 94 \\
2006 & 1940 & 1778 & 92 \\
2007 & 1910 & 1786 & 94 \\
2008 & 2009 & 1902 & 95 \\
2009 & 2098 & 1885 & 90 \\
2010 & 2454 & 2330 & 95 \\
2011 & 1644 & 1506 & 92 \\
\hline Promedio & 2044 & 1912 & 94
\end{tabular}


Tabla 150. Comparación de los promedios mensuales de las horas frío para el observatorio de PamplonaNoáin

\begin{tabular}{|c|c|c|c|}
\hline & $\begin{array}{c}\text { HF prom mensual } \\
\text { contadas }\end{array}$ & $\begin{array}{c}\text { HF prom mensual } \\
\text { por fórmula }\end{array}$ & $\begin{array}{c}\text { \% fórmula resp } \\
\text { a cont }\end{array}$ \\
\hline enero & 498 & 477 & 96 \\
febrero & 399 & 377 & 94 \\
marzo & 273 & 247 & 90 \\
abril & 120 & 93 & 78 \\
\hline mayo & 34 & 26 & 76 \\
junio & 1 & 0 & \\
julio & 1 & 0 & \\
\hline agosto & 0 & 0 & 48 \\
\hline septiembre & 7 & 3 & 70 \\
\hline octubre & 49 & 34 & 92 \\
\hline noviembre & 216 & 200 & 102 \\
\hline diciembre & 447 & 455 & 94 \\
\hline anual & 2044 & 1912 & \\
\hline
\end{tabular}

La fórmula apenas subestima las horas frío en los meses que hay un mayor número de ellas, lo que refuerza la idea de que la fórmula de Crossa-Raynaud es una aproximación muy buena al número de horas reales.

\section{Resumen para la cuenca del Ebro}

La fórmula de Crossa-Raynaud proporciona una buena aproximación al número de horas frío reales en la cuenca del Ebro. Por debajo de los 800 metros de altitud, que es lo que se ha comprobado, la fórmula subestima las horas frío reales, pero lo hace en menos de un $5 \%$, y en los meses de más horas frío la subestima es menor. Puede decirse que, en toda esta zona (valle del Ebro por debajo de los 800 metros), no se precisan temperaturas horarias para dar una buena aproximación de las horas frío, basta tener el registro de las máximas y mínimas diarias para dar valores de las horas frío muy próximos a los reales, y tener en cuenta esa pequeña subestima. Es esperable también que en las zonas altas de la cuenca del Ebro, en los Pirineos por el norte y el sistema lbérico por el sur, haya muchas más horas frío y la aproximación siga siendo muy buena. 
Barcelona. La fórmula de Crossa-Raynaud subestima las horas frío, en promedio da un $86 \%$ de las horas reales, pero hay una gran variación entre unos años y otros (los hay que da el valor real y otros sólo el $76 \%)$, por tanto no es una buena aproximación.

Tabla 151. Comparación de horas frío anuales contadas y obtenidas a partir de la fórmula para el observatorio de Barcelona. HF anuales contadas HF anuales por fórmula \% fórmula resp a cont

\begin{tabular}{|c|c|c|c|}
\hline 2002 & 465 & 447 & 96 \\
\hline 2003 & 573 & 547 & 95 \\
\hline 2004 & 375 & 374 & 100 \\
\hline 2005 & 1120 & 987 & 88 \\
\hline 2006 & 823 & 676 & 82 \\
\hline 2007 & 653 & 499 & 76 \\
\hline 2008 & 728 & 569 & 78 \\
\hline 2009 & 784 & 662 & 84 \\
\hline 2010 & 1192 & 1101 & 92 \\
\hline 2011 & 685 & 539 & 79 \\
\hline Promedio & 740 & 638 & 86 \\
\hline
\end{tabular}

Tabla 152. Comparación de los promedios mensuales de las horas frío para el observatorio de Barcelona.

\section{HF prom mensual HF prom mensual por \% fórmula resp a contadas} fórmula cont

\begin{tabular}{|c|c|c|c|}
\hline enero & 238 & 207 & 87 \\
\hline febrero & 166 & 149 & 90 \\
\hline marzo & 68 & 66 & 97 \\
\hline abril & 1 & 2 & 163 \\
mayo & 0 & 0 & 0 \\
\hline junio & 0 & 0 & \\
julio & 0 & 0 & \\
agosto & 0 & 2 & \\
\hline septiembre & 0 & 0 & 61 \\
\hline octubre & 3 & 2 & 77 \\
\hline noviembre & 54 & 42 & 81 \\
\hline diciembre & 209 & 170 & 86 \\
\hline anual & 740 & 638 & \\
\hline
\end{tabular}

Mes a mes se ve que la subestima de horas frío de la fórmula es de esa misma magnitud, cercana al $15 \%$, en los meses en los que hay más horas frío. 
Gerona. La fórmula de Crossa-Raynaud subestima las horas frío, en promedio da un $83 \%$ de las horas reales, y con variaciones importantes entre unos años y otros. Por tanto, no es una buena aproximación.

Tabla 153. Comparación de horas frío anuales contadas y obtenidas a partir de la fórmula para el observatorio de Gerona.

\begin{tabular}{|c|c|c|c|}
\hline & HF anuales contadas & HF anuales por fórmula & $\%$ fórmula resp a cont \\
\hline \multicolumn{4}{|l|}{2002} \\
\hline 2003 & 1404 & 1218 & 87 \\
\hline 2004 & 1417 & 1242 & 88 \\
\hline 2005 & 1937 & 1771 & 91 \\
\hline 2006 & & 1020 & \\
\hline 2007 & 1330 & 1039 & 78 \\
\hline 2008 & 1256 & 1021 & 81 \\
\hline 2009 & 1256 & 1021 & 81 \\
\hline \multicolumn{4}{|l|}{2010} \\
\hline \multicolumn{4}{|l|}{2011} \\
\hline Promedio & 1433 & 1190 & 83 \\
\hline
\end{tabular}

Tabla 154. Comparación de los promedios mensuales de las horas frío para el observatorio de Gerona.

\begin{tabular}{|c|c|c|c|}
\hline & $\begin{array}{c}\text { HF prom mensual } \\
\text { contadas }\end{array}$ & $\begin{array}{c}\text { HF prom mensual } \\
\text { por fórmula }\end{array}$ & $\begin{array}{c}\text { \% fórmula resp a } \\
\text { cont }\end{array}$ \\
\hline enero & 353 & 306 & 87 \\
febrero & 279 & 247 & 89 \\
marzo & 170 & 138 & 82 \\
\hline abril & 46 & 32 & 70 \\
mayo & 3 & 2 & 70 \\
\hline junio & 0 & 0 & \\
\hline julio & 0 & 0 & \\
\hline agosto & 0 & 0 & \\
\hline septiembre & 1 & 0 & 69 \\
\hline octubre & 20 & 13 & 70 \\
\hline noviembre & 175 & 123 & 89 \\
\hline diciembre & 339 & 301 & 83 \\
\hline anual & 1433 & 1190 & \\
\hline
\end{tabular}

La subestima de horas frío de la fórmula es más baja los meses que hay más horas frío, en este caso se acerca al $90 \%$ de las horas reales.

Reus. La fórmula de Crossa-Raynaud subestima ligeramente las horas frío, en promedio da un $96 \%$ de las horas reales, pero se da una gran variación entre unos años y otros, así que no puede considerarse tan buena aproximación como da el promedio. 
Tabla 155. Comparación de horas frío anuales contadas y obtenidas a partir de la fórmula para el observatorio de Reus.

\begin{tabular}{|c|c|c|c|}
\hline & HF anuales contadas & HF anuales por fórmula & \% fórmula resp a cont \\
\hline 2002 & 404 & 433 & 107 \\
\hline 2003 & 653 & 699 & 107 \\
\hline 2004 & 881 & 840 & 95 \\
\hline 2005 & 1443 & 1337 & 93 \\
\hline 2006 & 984 & 929 & 94 \\
\hline 2007 & 990 & 844 & 85 \\
\hline 2008 & 1137 & 1036 & 91 \\
\hline 2009 & 1143 & 1104 & 97 \\
\hline 2010 & 1387 & 1425 & 103 \\
\hline 2011 & 681 & 633 & 93 \\
\hline Promedio & 970 & 928 & 96 \\
\hline
\end{tabular}

Tabla 156. Comparación de los promedios mensuales de las horas frío para el observatorio de Reus.

\begin{tabular}{|c|c|c|c|}
\hline & $\begin{array}{l}\text { HF prom mensual } \\
\text { contadas }\end{array}$ & $\begin{array}{l}\text { HF prom mensual } \\
\text { por fórmula }\end{array}$ & $\begin{array}{c}\% \text { fórmula resp a } \\
\text { cont }\end{array}$ \\
\hline enero & 277 & 266 & 96 \\
\hline febrero & 208 & 201 & 97 \\
\hline marzo & 115 & 114 & 99 \\
\hline abril & 21 & 20 & 99 \\
\hline mayo & 1 & 1 & \\
\hline junio & 0 & 0 & \\
\hline julio & 0 & 0 & \\
\hline agosto & 0 & 0 & \\
\hline septiembre & 1 & 0 & \\
\hline octubre & 7 & 7 & \\
\hline noviembre & 97 & 89 & 92 \\
\hline diciembre & 245 & 229 & 93 \\
\hline anual & 970 & 928 & 96 \\
\hline
\end{tabular}

Mes a mes se ve que también es baja la subestima de horas frío en los meses que hay más horas frío, lo que indica que la fórmula de Crossa-Raynaud es una buena aproximación del número de horas frío reales.

Tarragona. La fórmula de Crossa-Raynaud subestima las horas frío, en promedio da un $90 \%$ de las horas reales, pero hay una gran variación entre unos años y otros, lo que pone en duda que sea una buena aproximación. 
Tabla 157. Comparación de horas frío anuales contadas y obtenidas a partir de la fórmula para el observatorio de Tarragona.

HF anuales contadas HF anuales por fórmula \% fórmula resp a cont

\begin{tabular}{|c|c|c|c|}
\hline 2002 & 135 & 154 & 114 \\
\hline 2003 & 412 & 408 & 99 \\
\hline 2004 & 483 & 439 & 91 \\
\hline 2005 & 954 & 828 & 87 \\
\hline 2006 & 469 & 435 & 93 \\
\hline 2007 & 396 & 341 & 86 \\
\hline 2008 & 323 & 317 & 98 \\
\hline 2009 & 489 & 400 & 82 \\
\hline 2010 & 794 & 726 & 91 \\
\hline 2011 & 352 & 293 & 83 \\
\hline promedio & 481 & 434 & 90 \\
\hline
\end{tabular}

Tabla 158. Comparación de los promedios mensuales de las horas frío para el observatorio de Tarragona.

\begin{tabular}{|c|c|c|c|}
\hline & $\begin{array}{l}\text { HF prom mensual } \\
\text { contadas }\end{array}$ & $\begin{array}{l}\text { HF prom mensual } \\
\text { por fórmula }\end{array}$ & $\begin{array}{c}\% \text { fórmula resp a } \\
\text { cont }\end{array}$ \\
\hline enero & 149 & 138 & 92 \\
\hline febrero & 110 & 101 & 92 \\
\hline marzo & 55 & 54 & 99 \\
\hline abril & 3 & 3 & \\
\hline mayo & 0 & 0 & \\
\hline junio & 0 & 0 & \\
\hline julio & 0 & 0 & \\
\hline agosto & 0 & 0 & \\
\hline septiembre & 0 & 0 & \\
\hline octubre & 1 & 1 & \\
\hline noviembre & 29 & 24 & 84 \\
\hline diciembre & 134 & 113 & 84 \\
\hline anual & 481 & 434 & 90 \\
\hline
\end{tabular}

Mes a mes se ve que en enero y febrero la subestima es del 8\% (buena aproximación) pero en diciembre es del 16\% (una aproximación peor).

Tortosa. La fórmula de Crossa-Raynaud subestima las horas frío, en promedio da un $82 \%$ de las horas reales, con una variación importante entre unos años y otros, hay años como 2002 en los que la subestima es del $29 \%$, por tanto no es una buena aproximación. 
Tabla 159. Comparación de horas frío anuales contadas y obtenidas a partir de la fórmula para el observatorio de Tortosa.

HF anuales contadas HF anuales por fórmula \% fórmula resp a cont

\begin{tabular}{|c|ccc|}
\hline 2002 & 369 & 262 & 71 \\
2003 & 564 & 464 & 82 \\
2004 & 582 & 445 & 77 \\
2005 & 1101 & 936 & 85 \\
2006 & 767 & 612 & 80 \\
2007 & 602 & 460 & 76 \\
2008 & 577 & 461 & 80 \\
2009 & 637 & 568 & 89 \\
2010 & 910 & 812 & 89 \\
2011 & 529 & 393 & 74 \\
\hline Promedio & 664 & 541 & 82
\end{tabular}

Tabla 160. Comparación de los promedios mensuales de las horas frío para el observatorio de Tortosa.

HF prom mensua contadas

$\mathrm{HF}$ prom mensual \% fórmula resp a por fórmula cont

\begin{tabular}{|c|}
\hline enero \\
febrero \\
marzo \\
abril \\
mayo \\
junio \\
julio \\
agosto \\
septiembre \\
octubre \\
noviembre \\
diciembre \\
anual
\end{tabular}

\begin{tabular}{|c|c|}
22 \\
156 \\
73 \\
5 \\
0 \\
0 \\
0 \\
0 \\
0 \\
0 \\
2 \\
37 \\
169 \\
664
\end{tabular}

222

180

81

\begin{tabular}{|r|r|r|}
156 \\
\hline
\end{tabular}

\begin{tabular}{|l|l|l|}
\hline 73 & 54 & 74
\end{tabular}

5

0

$0 \quad 0$

0

$\begin{array}{ll}0 & 0\end{array}$

0

2

$37 \quad 28$

\begin{tabular}{|l|l|l|}
\hline 169 & 151 & 89 \\
\hline 664 & 541 & 82 \\
\hline
\end{tabular}

La subestima mensual de horas frío de la fórmula es similar a la anual en los meses que hay más horas frío. 
La fórmula de Crossa-Raynaud no es una buena aproximación en la zona de la franja costera catalana. Hay diferencias importantes entre unos observatorios y otros e igualmente importantes entre unos años y otros. Por tanto, en esta zona sería preferible disponer de las temperaturas horarias o usar los datos de la estación que disponga de temperaturas horarias más cercana, si se puede encontrar una de una altitud parecida y una distancia al mar similar.

\subsubsection{Cuenca del Tajo}

Guadalajara. La fórmula de Crossa-Raynaud subestima ligeramente las horas frío, en promedio da un $94 \%$ de las horas reales, y es una aproximación uniforme a los largo de los años. Por tanto, es una aproximación muy buena.

\begin{tabular}{|c|c|c|c|}
\hline & HF anuales contadas & HF anuales por fórmula & \% fórmula resp a cont \\
\hline 2002 & 1983 & 1846 & 93 \\
\hline 2003 & 2047 & 1906 & 93 \\
\hline 2004 & 2377 & 2140 & 90 \\
\hline 2005 & 2580 & 2463 & 95 \\
\hline 2006 & 2178 & 2032 & 93 \\
\hline 2007 & 2506 & 2310 & 92 \\
\hline 2008 & 2358 & 2230 & 95 \\
\hline 2009 & 2409 & 2247 & 93 \\
\hline 2010 & 2582 & 2488 & 96 \\
\hline 2011 & 1791 & 1670 & 93 \\
\hline Promedio & 2281 & 2133 & 94 \\
\hline
\end{tabular}

La aproximación de la fórmula es mayor en los meses en los que hay más horas frío, lo que refuerza la idea de que la fórmula de Crossa-Raynaud es una buena aproximación al número de horas reales. 
Tabla 162. Comparación de los promedios mensuales de las horas frío para el observatorio de Guadalajara.

\begin{tabular}{|c|c|c|c|}
\hline & $\begin{array}{c}\text { HF prom mensual } \\
\text { contadas }\end{array}$ & $\begin{array}{c}\text { HF prom mensual } \\
\text { por fórmula }\end{array}$ & $\begin{array}{c}\text { \% fórmula resp } \\
\text { a cont }\end{array}$ \\
\hline enero & 508 & 493 & 97 \\
febrero & 403 & 385 & 96 \\
\hline marzo & 288 & 271 & 94 \\
\hline abril & 145 & 127 & 88 \\
\hline mayo & 59 & 49 & \\
junio & 3 & 2 & \\
\hline julio & 0 & 0 & \\
agosto & 1 & 0 & \\
\hline septiembre & 19 & 12 & 72 \\
\hline octubre & 87 & 62 & 91 \\
\hline noviembre & 291 & 265 & 97 \\
\hline diciembre & 479 & 467 & 94 \\
\hline anual & 2281 & 2133 & \\
\hline
\end{tabular}

La aproximación de la fórmula es mayor en los meses en los que hay más horas frío, lo que refuerza la idea de que la fórmula de Crossa-Raynaud es una buena aproximación al número de horas reales.

Madrid Barajas. La fórmula de Crossa-Raynaud subestima ligeramente las horas frío, en promedio da un $96 \%$ de las horas reales, pero la variación entre unos años y otros es grande, hay años con ligera sobrestima y años con subestima del 10\%, así que la aproximación no es tan buena como indica el promedio.

Tabla 163.Comparación de horas frío anuales contadas y obtenidas a partir de la fórmula para el observatorio de Madrid Barajas.

HF anuales contadas HF anuales por fórmula \% fórmula resp a cont

\begin{tabular}{|c|ccc|}
\hline 2002 & 1598 & 1656 & 104 \\
2003 & 1730 & 1766 & 102 \\
2004 & 2047 & 1991 & 97 \\
2005 & 2082 & 2058 & 99 \\
2006 & 1681 & 1580 & 94 \\
2007 & 1970 & 1801 & 91 \\
2008 & 1792 & 1682 & 94 \\
2009 & 1794 & 1702 & 95 \\
2010 & 2050 & 1972 & 96 \\
2011 & 1613 & 1451 & 90 \\
Promedio & 1836 & 1766 & 96
\end{tabular}


Tabla 164. Comparación de los promedios mensuales de las horas frío para el observatorio de Madrid Barajas.

\begin{tabular}{|c|c|c|c|}
\hline & $\begin{array}{c}\text { HF prom mensual } \\
\text { contadas }\end{array}$ & $\begin{array}{c}\text { HF prom mensual } \\
\text { por fórmula }\end{array}$ & $\begin{array}{c}\text { \% fórmula resp a } \\
\text { cont }\end{array}$ \\
\hline enero & 462 & 451 & 98 \\
\hline febrero & 358 & 339 & 95 \\
marzo & 221 & 215 & 98 \\
\hline abril & 83 & 80 & 96 \\
\hline mayo & 15 & 16 & \\
\hline junio & 0 & 0 & \\
\hline julio & 0 & 0 & \\
\hline agosto & 0 & 0 & \\
\hline septiembre & 2 & 2 & 84 \\
\hline octubre & 34 & 28 & \\
\hline noviembre & 228 & 213 & 93 \\
\hline diciembre & 434 & 421 & 97 \\
\hline anual & 1836 & 1766 & 96 \\
\hline
\end{tabular}

La aproximación de la fórmula es mayor en los meses en los que hay más horas frío, lo que refuerza la idea de que la fórmula de Crossa-Raynaud es una buena aproximación al número de horas reales.

\section{Madrid-Getafe.}

Podría decirse que la fórmula de Crossa-Raynaud da las horas frío, en promedio da un $98 \%$ de las horas reales, pero hay una cierta variación entre unos años y otros; aun así, puede considerarse una muy buena aproximación.

Tabla 165. Comparación de horas frío anuales contadas y obtenidas a partir de la fórmula para el observatorio de Madrid-Getafe

$\mathrm{HF}$ anuales contadas HF anuales por fórmula \% fórmula resp a cont

\begin{tabular}{|c|ccc|}
\hline 2002 & 1238 & 1258 & 102 \\
2003 & 1499 & 1480 & 99 \\
2004 & 1620 & 1622 & 100 \\
2005 & 1890 & 1887 & 100 \\
2006 & 1532 & 1506 & 98 \\
2007 & 1590 & 1472 & 93 \\
2008 & 1450 & 1371 & 95 \\
2009 & 1467 & 1407 & 96 \\
2010 & 1739 & 1750 & 101 \\
2011 & 1395 & 1319 & 95 \\
Promedio & 1542 & 1507 & 98
\end{tabular}


Tabla 166. Comparación de los promedios mensuales de las horas frío para el observatorio de MadridGetafe.

\begin{tabular}{|c|c|c|c|}
\hline & $\begin{array}{c}\text { HF prom mensual } \\
\text { contadas }\end{array}$ & $\begin{array}{c}\text { HF prom mensual } \\
\text { por fórmula }\end{array}$ & $\begin{array}{c}\text { \% fórmula resp a } \\
\text { cont }\end{array}$ \\
\hline enero & 438 & 427 & 97 \\
febrero & 313 & 303 & 97 \\
marzo & 156 & 156 & 100 \\
abril & 47 & 47 & 100 \\
\hline mayo & 5 & 5 & \\
junio & 0 & 0 & \\
julio & 0 & 0 & \\
\hline agosto & 0 & 0 & 87 \\
\hline septiembre & 0 & 0 & 100 \\
\hline octubre & 12 & 11 & 97 \\
\hline noviembre & 171 & 170 & \\
\hline diciembre & 400 & 388 & 98 \\
\hline anual & 1542 & 1507 & \\
\hline & & & \\
\hline
\end{tabular}

La fórmula de Crossa-Raynaud da una excelente aproximación al número de horas frío reales en todos los meses.

\section{Navalmoral}

La fórmula de Crossa-Raynaud subestima las horas frío en un $10 \%$, en promedio da un $90 \%$ de las horas reales y, aunque hay variación entre unos años y otros, puede considerarse una aproximación aceptable.

Tabla 167. Comparación de horas frío anuales contadas y obtenidas a partir de la fórmula para el observatorio de Navalmoral.

HF anuales contadas HF anuales por fórmula \% fórmula resp a cont

\begin{tabular}{|c|ccc|}
\hline 2002 & 884 & 771 & 87 \\
2003 & 1055 & 939 & 89 \\
2004 & 1351 & 1146 & 85 \\
2005 & 1691 & 1581 & 93 \\
2006 & 1374 & 1224 & 89 \\
2007 & & & \\
2008 & & & 90 \\
2009 & 1229 & 1106 & 95 \\
2010 & 1326 & 1253 & 90 \\
2011 & & & \\
Promedio & 1273 & 1135 &
\end{tabular}


Tabla 168. Comparación de los promedios mensuales de las horas frío para el observatorio de Navalmoral.

\begin{tabular}{|c|c|c|c|}
\hline & $\begin{array}{c}\text { HF prom mensual } \\
\text { contadas }\end{array}$ & $\begin{array}{l}\text { HF prom mensual } \\
\text { por fórmula }\end{array}$ & $\begin{array}{c}\% \text { fórmula resp a } \\
\text { cont }\end{array}$ \\
\hline enero & 369 & 325 & 88 \\
\hline febrero & 264 & 227 & 86 \\
\hline marzo & 117 & 109 & 94 \\
\hline abril & 41 & 32 & 78 \\
\hline mayo & 7 & 6 & \\
\hline junio & 0 & 0 & \\
\hline julio & 0 & 0 & \\
\hline agosto & 0 & 0 & \\
\hline septiembre & 0 & 0 & \\
\hline octubre & 20 & 12 & 62 \\
\hline noviembre & 153 & 120 & 78 \\
\hline diciembre & 338 & 304 & 90 \\
\hline anual & 1273 & 1135 & 90 \\
\hline
\end{tabular}

Mes a mes se ve que la subestima de horas frío de la fórmula en los meses que hay más horas frío está también en torno al 10\%.

Cáceres. La fórmula de Crossa-Raynaud subestima ligeramente las horas frío, en promedio da un $94 \%$ de las horas reales, pero la variación entre unos años y otros es grande, lo que rebaja la bondad de la aproximación que da el promedio.

Tabla 169. Comparación de horas frío anuales contadas y obtenidas a partir de la fórmula para el observatorio de Cáceres. HF anuales contadas $\mathrm{HF}$ anuales por fórmula \% fórmula resp a cont

\begin{tabular}{|c|ccc|}
\hline 2002 & 540 & 546 & 101 \\
2003 & 855 & 853 & 100 \\
2004 & 1041 & 1010 & 97 \\
2005 & 1486 & 1338 & 90 \\
2006 & 1190 & 1032 & 87 \\
2007 & 1132 & 1065 & 94 \\
2008 & 942 & 847 & 90 \\
2009 & 905 & 879 & 97 \\
2010 & 1081 & 1095 & 101 \\
2011 & 943 & 885 & 94 \\
\hline Promedio & 1011 & 955 & 94
\end{tabular}


Tabla 170. Comparación de los promedios mensuales de las horas frío para el observatorio de Cáceres.

HF prom mensual

contadas

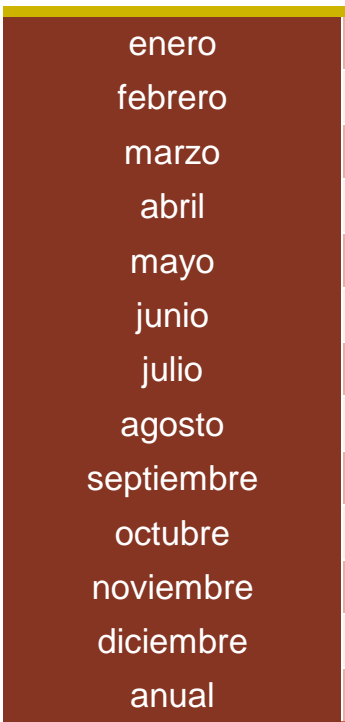

306

(20.20

\begin{tabular}{|c|c|c|}
\hline 101 & 88 & 87 \\
\hline 276 & 258 & 93 \\
\hline 1011 & 955 & 94 \\
\hline
\end{tabular}

Mes a mes se ve que la subestima de horas frío de la fórmula es pequeña en los meses que hay más horas frío, lo que refuerza la idea de que la fórmula de Crossa-Raynaud es una buena aproximación del número de horas reales.

Plasencia. La fórmula de Crossa-Raynaud subestima las horas frío, en promedio da un $89 \%$ de las horas reales, y es una aproximación uniforme a los largo de los años. Por tanto, es una aproximación aceptable.

Tabla 171. Comparación de horas frío anuales contadas y obtenidas a partir de la fórmula para el observatorio de Plasencia.

$\mathrm{HF}$ anuales contadas $\mathrm{HF}$ anuales por fórmula \% fórmula resp a cont

\begin{tabular}{c|ccc}
2002 & 490 & 459 & 93 \\
2003 & 1068 & 973 & 91 \\
2004 & & & \\
2005 & 1490 & 1344 & 90 \\
2006 & 1229 & 1090 & 88 \\
2007 & & & 87 \\
2008 & 1011 & 880 & 91 \\
2009 & 1148 & 1042 & \\
2010 & & & 85 \\
2011 & 1022 & 865 & 89
\end{tabular}


Tabla 172. Comparación de los promedios mensuales de las horas frío para el observatorio de Plasencia.

\begin{tabular}{|c|c|c|c|}
\hline & $\begin{array}{c}\text { HF prom mensual } \\
\text { contadas }\end{array}$ & $\begin{array}{l}\text { HF prom mensual } \\
\text { por fórmula }\end{array}$ & $\begin{array}{c}\% \text { fórmula resp a } \\
\text { cont }\end{array}$ \\
\hline enero & 328 & 298 & 91 \\
\hline febrero & 208 & 192 & 93 \\
\hline marzo & 99 & 86 & 86 \\
\hline abril & 26 & 25 & 94 \\
\hline mayo & 7 & 3 & \\
\hline junio & 0 & 0 & \\
\hline julio & 0 & 0 & \\
\hline agosto & 0 & 0 & \\
\hline septiembre & 1 & 0 & \\
\hline octubre & 5 & 2 & 50 \\
\hline noviembre & 112 & 93 & 83 \\
\hline diciembre & 291 & 262 & 90 \\
\hline anual & 1065 & 962 & 90 \\
\hline
\end{tabular}

También en los meses que hay más horas frío, la subestima está en torno al 10\%.

\section{Toledo}

La fórmula de Crossa-Raynaud subestima ligeramente las horas frío, en promedio da un 93\% de las horas reales y, excepto en 2011 que da el 86\%, la variación es homogénea entre unos años y otros. Por tanto puede considerarse una buena aproximación.

Tabla 173. Comparación de horas frío anuales contadas y obtenidas a partir de la fórmula para el observatorio de Toledo.

HF anuales contadas HF anuales por fórmula \% fórmula resp a cont

\begin{tabular}{|c|ccc|}
\hline 2002 & 1122 & 1043 & 93 \\
2003 & 1355 & 1288 & 95 \\
2004 & 1595 & 1487 & 93 \\
2005 & 1836 & 1786 & 97 \\
2006 & 1479 & 1368 & 93 \\
2007 & 1581 & 1458 & 92 \\
2008 & 1375 & 1278 & 93 \\
2009 & 1420 & 1323 & 93 \\
2010 & 1631 & 1537 & 94 \\
2011 & 1352 & 1167 & 86 \\
\hline Promedio & 1475 & 1374 & 93
\end{tabular}


Tabla 174.Comparación de los promedios mensuales de las horas frío para el observatorio de Toledo.

\begin{tabular}{|c|c|c|c|}
\hline & $\begin{array}{l}\text { HF prom mensual } \\
\text { contadas }\end{array}$ & $\begin{array}{l}\text { HF prom mensual por } \\
\text { fórmula }\end{array}$ & $\begin{array}{c}\% \text { fórmula resp a } \\
\text { cont }\end{array}$ \\
\hline enero & 410 & 389 & 95 \\
\hline febrero & 288 & 264 & 92 \\
\hline marzo & 152 & 145 & 96 \\
\hline abril & 51 & 45 & 88 \\
\hline mayo & 7 & 5 & \\
\hline junio & 0 & 0 & \\
\hline julio & 0 & 0 & \\
\hline agosto & 0 & 0 & \\
\hline septiembre & 0 & 0 & \\
\hline octubre & 15 & 12 & 85 \\
\hline noviembre & 168 & 150 & 89 \\
\hline diciembre & 384 & 362 & 94 \\
\hline anual & 1475 & 1374 & 93 \\
\hline
\end{tabular}

La aproximación de la fórmula es mayor en los meses en los que hay más horas frío, lo que refuerza la idea de que la fórmula de Crossa-Raynaud es una buena aproximación al número de horas reales.

\section{Trujillo}

La fórmula de Crossa-Raynaud subestima ligeramente las horas frío, en promedio da un $92 \%$ de las horas reales, pero se da una gran variación entre unos años y otros, lo que rebaja la bondad de la aproximación que da el promedio.

Tabla 175. Comparación de horas frío anuales contadas y obtenidas a partir de la fórmula para el observatorio de Trujillo.

\begin{tabular}{|c|ccc|}
\hline \multicolumn{1}{|c|}{ HF anuales contadas } & HF anuales por fórmula & \% fórmula resp a cont \\
\hline 2002 & & & \\
2003 & & & \\
2004 & 1448 & 1315 & 91 \\
2006 & 1682 & 1535 & 91 \\
2007 & 1323 & 1196 & 90 \\
2008 & 1347 & 1192 & 88 \\
2009 & 1295 & 1138 & 88 \\
2010 & 1150 & 1102 & 96 \\
2011 & 1339 & 1339 & 100 \\
Promedio & 1149 & 1032 & 90 \\
\hline
\end{tabular}


Tabla 176. Comparación de los promedios mensuales de las horas frío para el observatorio de Trujillo.

\begin{tabular}{|c|c|c|c|}
\hline & $\begin{array}{c}\text { HF prom mensual } \\
\text { contadas }\end{array}$ & $\begin{array}{c}\text { HF prom mensual } \\
\text { por fórmula }\end{array}$ & $\begin{array}{c}\text { \% fórmula resp a } \\
\text { cont }\end{array}$ \\
\hline enero & 378 & 374 & 99 \\
febrero & 256 & 240 & 94 \\
marzo & 134 & 126 & 95 \\
abril & 52 & 45 & 86 \\
\hline mayo & 12 & 9 & \\
junio & 0 & 0 & \\
julio & 0 & 0 & \\
agosto & 0 & 0 & \\
septiembre & 0 & 0 & \\
\hline octubre & 7 & 8 & 86 \\
noviembre & 143 & 124 & 91 \\
diciembre & 365 & 331 & 92 \\
anual & 1342 & 1231 & \\
\hline
\end{tabular}

En el mes de enero la aproximación es casi perfecta, en el resto de los meses en los que hay muchas horas frío, la aproximación es similar a la del promedio anual.

En general, la fórmula da una buena aproximación en la cuenca del Tajo; sin embargo en dos de los observatorios, ambos de la parte baja de la cuenca, la aproximación es peor, baja del $95 \%$ al 90\%. Como hay otro observatorio en esa parte baja donde la aproximación es muy buena, no puede sacarse en conclusión que la aproximación en esa parte sea mala. En todo caso si podría decirse que en la parte baja, donde se dan menos horas frío, la aproximación de la fórmula de Crossa-Raynaud es inferior a la que proporciona en la zona alta, donde hay más horas frío. Como conclusión, la aproximación podría usarse en toda la zona. No obstante, habría que tener en cuenta la variación que se da en la aproximación de unos años y otros, así que sería preferible comparar los datos con los del observatorio más cercano que disponga de datos horarios de las temperaturas. 


\subsubsection{Cuenca del Guadiana: a) parte alta situada en la meseta Sur, principalmente La Mancha}

Alcázar de San Juan. Sólo pueden compararse las horas contadas y las calculadas mediante fórmula en cuatro años, muy poco para sacar conclusiones.

Tabla 177. Comparación de horas frío anuales contadas y obtenidas a partir de la fórmula para el observatorio de Alcázar de San Juan.

\begin{tabular}{|c|ccc|}
\hline \multicolumn{2}{|c|}{ HF anuales contadas } & HF anuales por fórmula & \% fórmula resp a cont \\
\hline 2002 & & & \\
2003 & & & \\
2004 & & & \\
2005 & & & 80 \\
2006 & & 1457 & 88 \\
2007 & 1817 & 1416 & 80 \\
2008 & 1617 & 1525 & 78 \\
2009 & 1895 & 1245 & \\
2010 & 1600 & & \\
2011 & & & \\
promedio & & & \\
\hline
\end{tabular}

Almagro. Dispone de ocho años de datos para comparar en el periodo. En esos ocho años el promedio de subestima es del 8\%, y es una aproximación uniforme a los largo de los años. Por tanto, es una buena aproximación.

Tabla 178. Comparación de horas frío anuales contadas y obtenidas a partir de la fórmula para el observatorio de Almagro.

\begin{tabular}{|c|c|c|c|}
\hline & HF anuales contadas & HF anuales por fórmula & $\%$ fórmula resp a cont \\
\hline \multicolumn{4}{|l|}{2002} \\
\hline \multicolumn{4}{|l|}{2003} \\
\hline 2004 & 1986 & 1796 & 90 \\
\hline 2005 & 2249 & 2111 & 94 \\
\hline 2006 & 1871 & 1700 & 91 \\
\hline 2007 & 2162 & 1932 & 89 \\
\hline 2008 & 1893 & 1778 & 94 \\
\hline 2009 & 1743 & 1607 & 92 \\
\hline 2010 & 1895 & 1796 & 95 \\
\hline 2011 & 1649 & 1485 & 90 \\
\hline promedio & 1931 & 1776 & 92 \\
\hline
\end{tabular}


Tabla 179. Comparación de los promedios mensuales de las horas frío para el observatorio de Almagro.

HF prom mensual contadas

489
352

352

230

86

10

0

0

0

1

29

29

259

462

1931

HF prom mensual \% fórmula resp por fórmula a cont

\begin{tabular}{|c|c|}
\hline 463 & 95 \\
\hline 317 & 90 \\
\hline 210 & 92 \\
\hline 78 & 91 \\
\hline 9 & 91 \\
0 & \\
0 & \\
\hline 0 & \\
\hline 1 & 94 \\
\hline 28 & 86 \\
\hline 436 & 94 \\
\hline 1776 & 92 \\
\hline
\end{tabular}

Mes a mes, la subestima es menor en los dos meses en los que hay más horas frío, lo que refuerza la idea de que la fórmula da una buena aproximación.

Ciudad Real. La fórmula subestima las horas frío pero se aproxima hasta el $92 \%$ de lo real y es una aproximación uniforme a los largo de los años. Por tanto, es una buena aproximación.

Tabla 180. Comparación de horas frío anuales contadas y obtenidas a partir de la fórmula para el observatorio de Ciudad Real. HF anuales contadas HF anuales por fórmula \% fórmula resp a cont

\begin{tabular}{|c|ccc|}
\hline 2002 & 1165 & 1020 & 88 \\
2003 & 1407 & 1336 & 95 \\
2004 & 1564 & 1396 & 89 \\
2005 & 1917 & 1831 & 96 \\
2006 & 1574 & 1432 & 91 \\
2007 & 1776 & 1565 & 88 \\
2008 & 1537 & 1435 & 93 \\
2009 & 1399 & 1297 & 93 \\
2010 & 1600 & 1533 & 96 \\
2011 & 1405 & 1259 & 90 \\
promedio & 1534 & 1410 & 92
\end{tabular}


Tabla 181. Comparación de los promedios mensuales de las horas frío para el observatorio de Ciudad Real.

\begin{tabular}{|c|c|c|c|}
\hline & $\begin{array}{l}\text { HF prom mensual } \\
\text { contadas }\end{array}$ & $\begin{array}{l}\text { HF prom mensual } \\
\text { por fórmula }\end{array}$ & $\begin{array}{c}\% \text { fórmula resp a } \\
\text { cont }\end{array}$ \\
\hline enero & 433 & 413 & 95 \\
\hline febrero & 297 & 270 & 91 \\
\hline marzo & 161 & 142 & 88 \\
\hline abril & 54 & 47 & 86 \\
\hline mayo & 4 & 3 & 79 \\
\hline junio & 0 & 0 & \\
\hline julio & 0 & 0 & \\
\hline agosto & 0 & 0 & \\
\hline septiembre & 0 & 0 & 0 \\
\hline octubre & 14 & 10 & 77 \\
\hline noviembre & 180 & 157 & 87 \\
\hline diciembre & 391 & 368 & 94 \\
\hline anual & 1534 & 1410 & 92 \\
\hline
\end{tabular}

En los dos meses de más horas frío, enero y diciembre, la aproximación es aún mejor.

Hinojosa del Duque. Hay cinco años de datos para comparar, pero el resultado en esos cinco años es similar a lo que se obtiene en Ciudad Real y en Almagro, una subestima menor del $10 \%$, y aún mejor para los meses con más horas de frío.

Tabla 182. Comparación de horas frío anuales contadas y obtenidas a partir de la fórmula para el observatorio de Hinojosa del Duque.

HF anuales contadas HF anuales por fórmula \% fórmula resp a cont

\begin{tabular}{|c|ccc|}
\hline 2002 & 1202 & 1048 & 87 \\
2003 & 1256 & 1241 & 99 \\
2004 & & & \\
2005 & 1759 & 1661 & 94 \\
2006 & 1550 & 1335 & 86 \\
2007 & 1677 & 1460 & 87 \\
2008 & & & \\
2009 & & & 91 \\
2010 & & & \\
2011 & & 1349 & \\
promedio & 1489 & &
\end{tabular}


Tabla 183. Comparación de los promedios mensuales de las horas frío para el observatorio de Hinojosa del Duque.

\begin{tabular}{|c|c|c|c|}
\hline & $\begin{array}{c}\text { HF prom mensual } \\
\text { contadas }\end{array}$ & $\begin{array}{c}\text { HF prom mensual } \\
\text { por fórmula }\end{array}$ & $\begin{array}{c}\text { \% fórmula resp a } \\
\text { cont }\end{array}$ \\
\hline enero & 395 & 373 & 95 \\
\hline febrero & 284 & 259 & 91 \\
\hline marzo & 162 & 147 & 91 \\
\hline abril & 64 & 55 & \\
\hline mayo & 8 & 6 & \\
\hline junio & 0 & 0 & \\
\hline julio & 0 & 0 & \\
\hline agosto & 0 & 0 & \\
\hline septiembre & 0 & 0 & \\
\hline octubre & 10 & 9 & 84 \\
\hline noviembre & 166 & 140 & 92 \\
\hline diciembre & 348 & 320 & 91 \\
\hline anual & 1489 & 1349 & \\
\hline
\end{tabular}

\subsubsection{Cuenca del Guadiana: b) parte baja y relativamente llana de la cuenca}

Nota. No se ha hecho la comparación de horas frío contadas y por fórmula para el observatorio de Badajoz CMT por falta de datos.

Talavera la Real. La fórmula subestima las horas reales en un 15\%, con variaciones según los años entre un $7 \%$ y un $20 \%$. Por tanto, no es una buena aproximación.

Tabla 184. Comparación de horas frío anuales contadas y obtenidas a partir de la fórmula para el observatorio de Talavera la Real.

HF anuales contadas HF anuales por fórmula \% fórmula resp a cont

\begin{tabular}{|c|ccc|}
\hline 2002 & 554 & 486 & 88 \\
2003 & 706 & 650 & 92 \\
2004 & 897 & 754 & 84 \\
2005 & 1376 & 1210 & 88 \\
2006 & 1083 & 894 & 83 \\
2007 & 1212 & 964 & 80 \\
2008 & 927 & 746 & 80 \\
2009 & 753 & 661 & 88 \\
2010 & 885 & 820 & 93 \\
2011 & 943 & 772 & 82 \\
\hline Promedio & 934 & 796 & 85
\end{tabular}


Tabla 185.Comparación de los promedios mensuales de las horas frío para el observatorio de Talavera la Real.

\begin{tabular}{|c|c|c|c|}
\hline & $\begin{array}{c}\text { HF prom mensual } \\
\text { contadas }\end{array}$ & $\begin{array}{c}\text { HF prom mensual } \\
\text { por fórmula }\end{array}$ & $\begin{array}{c}\text { \% fórmula resp a } \\
\text { cont }\end{array}$ \\
\hline enero & 279 & 243 & 87 \\
febrero & 187 & 161 & 86 \\
marzo & 82 & 68 & 83 \\
abril & 18 & 15 & 83 \\
mayo & 1 & 1 & \\
junio & 0 & 0 & \\
julio & 0 & 0 & \\
\hline agosto & 0 & 0 & \\
\hline septiembre & 0 & 0 & 72 \\
\hline octubre & 7 & 5 & 76 \\
\hline noviembre & 109 & 84 & 87 \\
\hline diciembre & 251 & 219 & 85 \\
\hline anual & 934 & 796 & \\
\hline
\end{tabular}

Mérida. La fórmula subestima las horas reales en un $17 \%$, con variaciones según los años entre un $7 \%$ y un $23 \%$ Por tanto, no es una buena aproximación.

Tabla 186. Comparación de horas frío anuales contadas y obtenidas a partir de la fórmula para el observatorio de Mérida.

\begin{tabular}{|c|ccc|}
\multicolumn{2}{|c|}{ HF anuales contadas } & HF anuales por fórmula & \% fórmula resp a cont \\
\hline 2002 & & & \\
2003 & 795 & 664 & 84 \\
2004 & 978 & 754 & 77 \\
2005 & 1472 & 1228 & 83 \\
2006 & 1105 & 890 & 81 \\
2007 & 1137 & 854 & 75 \\
2008 & 990 & 781 & 79 \\
2009 & 817 & 680 & 83 \\
2010 & 884 & 824 & 93 \\
2011 & 942 & 719 & 76 \\
promedio & 987 & 822 & 83 \\
\hline
\end{tabular}


Tabla 187. Comparación de los promedios mensuales de las horas frío para el observatorio de Mérida.

HF prom mensual contadas

\begin{tabular}{|c|}
\hline enero \\
febrero \\
marzo \\
abril \\
mayo \\
junio \\
julio \\
agosto \\
septiembre \\
octubre \\
noviembre \\
diciembre \\
anual
\end{tabular}

\begin{tabular}{|cc}
2 \\
\hline
\end{tabular}

304

255

\section{HF pror} por fórmula
\% fórmula resp a cont

82
81

85

85

$24 \quad 20$

$2 \quad 2$

$0 \quad 0$

$0 \quad 0$

$0 \quad 0$

$0 \quad 0$

$5 \quad 3$

\begin{tabular}{l|l|r|}
114 & 81 & 71
\end{tabular}

211

83

$987 \quad 822$

\section{Resumen para la cuenca del Guadiana}

En la parte baja de la cuenca del Guadiana, en altitudes por debajo de los $300 \mathrm{~m}$, donde las horas frío no son abundantes, la fórmula de Crossa-Raynaud subestima los valores reales en porcentajes cercanos al $20 \%$ y con una gran variación entre unos años y otros. No puede considerarse, por tanto, una buena aproximación; y eso es preciso tenerlo en cuenta en los casos en los que por falta de datos horarios no quede más remedio que aplicar la fórmula.

Por el contrario, en partes más altas de la cuenca, donde las horas frío son más abundantes, la aproximación es mejor, aunque también en esas zonas se dé una considerable variación entre unos años y otros. Algo que sería preferible tener en cuenta en los casos en los que no se disponga de datos horarios. 
Sevilla San Pablo.

Tabla 188. Comparación de horas frío anuales contadas y obtenidas a partir de la fórmula para el observatorio de Sevilla San Pablo.

\begin{tabular}{|c|ccc|}
\hline & HF anuales contadas & HF anuales por fórmula & $\%$ fórmula resp a cont \\
\hline 2002 & & & \\
2003 & 274 & 257 & 94 \\
2004 & 280 & 251 & 90 \\
2005 & 669 & 609 & 91 \\
2006 & 391 & 324 & 83 \\
2007 & 273 & 234 & 86 \\
2008 & 262 & 234 & 89 \\
2009 & 276 & 255 & 92 \\
2010 & 251 & 225 & 90 \\
2011 & 276 & 195 & 71 \\
\hline Promedio & 328 & 287 & 87
\end{tabular}

Tabla 189. Comparación de los promedios mensuales de las horas frío para el observatorio de Sevilla San Pablo.

\section{HF prom mensual contadas}

\section{HF prom mensual \% fórmula resp a por fórmula cont}

\begin{tabular}{|c|c|}
\hline enero \\
febrero \\
marzo \\
abril \\
mayo \\
junio \\
julio \\
\hline agosto \\
\hline septiembre \\
octubre \\
noviembre \\
diciembre \\
anual
\end{tabular}

\begin{tabular}{|c|c}
126 \\
69 \\
21 \\
2 \\
0 \\
0 \\
0 \\
0 \\
0 \\
15 \\
95
\end{tabular}

126

112

89

69

61

88

21

2

0

0

0

0

0

0

\begin{tabular}{l|l|l}
15 & 14 & 94
\end{tabular}

$95 \quad 81 \quad 85$

\begin{tabular}{l|l|l}
328 & 287 & 87
\end{tabular}

La fórmula subestima en promedio en un 13\%, da el $87 \%$ de las horas reales, con una gran variación entre unos años y otros. Por tanto no puede considerarse una buena aproximación. 
Écija. La fórmula subestima en un $20 \%$ las horas reales y con una variación considerable entre unos años y otros. Por tanto no es una buena aproximación.

Tabla 190. Comparación de horas frío anuales contadas y obtenidas a partir de la fórmula para el observatorio de Écija.

HF anuales contadas HF anuales por fórmula \% fórmula resp a cont

\begin{tabular}{|c|ccc|}
\hline 2002 & 653 & 470 & 72 \\
2003 & 607 & 525 & 86 \\
2004 & 1027 & 757 & 74 \\
2005 & 1333 & 1144 & 86 \\
2006 & 919 & 755 & 82 \\
2007 & 997 & 755 & 76 \\
2008 & 850 & 708 & 83 \\
2009 & & & \\
2010 & & & 77 \\
2011 & 786 & 602 & 80 \\
\hline Promedio & 897 & 714 &
\end{tabular}

Tabla 191.Comparación de los promedios mensuales de las horas frío para el observatorio de Écija.

\begin{tabular}{|c|c|c|c|}
\hline & $\begin{array}{l}\text { HF prom mensual } \\
\text { contadas }\end{array}$ & $\begin{array}{l}\text { HF prom mensual } \\
\text { por fórmula }\end{array}$ & $\begin{array}{c}\% \text { fórmula resp a } \\
\text { cont }\end{array}$ \\
\hline enero & 271 & 217 & 80 \\
\hline febrero & 168 & 135 & 81 \\
\hline marzo & 82 & 69 & 85 \\
\hline abril & 25 & 18 & 72 \\
\hline mayo & 2 & 1 & 67 \\
\hline junio & 0 & 0 & \\
\hline julio & 0 & 0 & \\
\hline agosto & 0 & 0 & \\
\hline septiembre & 0 & 0 & \\
\hline octubre & 2 & 2 & 92 \\
\hline noviembre & 91 & 68 & 75 \\
\hline diciembre & 228 & 185 & 81 \\
\hline anual & 897 & 714 & 80 \\
\hline
\end{tabular}


Morón de la Frontera. La fórmula subestima en un 17\% las horas reales, con una variación importante entre unos años y otros. Por tanto no es una buena aproximación.

Tabla 192. Comparación de horas frío anuales contadas y obtenidas a partir de la fórmula para el observatorio de Morón de la Frontera.

\begin{tabular}{|c|ccc|}
\hline \multicolumn{2}{|c|}{ HF anuales contadas } & HF anuales por fórmula & \% fórmula resp a cont \\
\hline 2002 & 480 & 365 & 76 \\
2003 & 540 & 463 & 86 \\
2004 & 705 & 596 & 85 \\
2005 & 986 & 884 & 90 \\
2006 & 756 & 620 & 82 \\
2007 & 746 & 559 & 75 \\
2008 & 625 & 532 & 85 \\
2009 & 497 & 441 & 89 \\
2010 & 419 & 385 & 92 \\
2011 & 519 & 388 & 75 \\
Promedio & 627 & 523 & 83
\end{tabular}

Tabla 193. Comparación de los promedios mensuales de las horas frío para el observatorio de Morón de la Frontera.

\section{HF prom mensual HF prom mensual \% fórmula resp a contadas} por fórmula cont

\begin{tabular}{|c|c|c|c|}
\hline enero & 207 & 176 & 85 \\
\hline febrero & 142 & 119 & 84 \\
\hline marzo & 58 & 55 & 94 \\
\hline abril & 12 & 11 & 91 \\
\hline mayo & 0 & 1 & \\
\hline junio & 0 & 0 & \\
\hline julio & 0 & 0 & \\
\hline agosto & 0 & 0 & \\
\hline septiembre & 0 & 0 & 94 \\
\hline octubre & 2 & 2 & 75 \\
\hline noviembre & 46 & 35 & 78 \\
\hline diciembre & 161 & 126 & 83 \\
\hline anual & 627 & 523 & \\
\hline
\end{tabular}

Aeropuerto de Córdoba. La fórmula subestima en un $21 \%$ las horas reales, con una variación importante entre unos años y otros. Por tanto no es una buena aproximación. 
Tabla 194. Comparación de horas frío anuales contadas y obtenidas a partir de la fórmula para el observatorio del aeropuerto de Córdoba.

$\mathrm{HF}$ anuales contadas $\mathrm{HF}$ anuales por fórmula \% fórmula resp a cont

\begin{tabular}{|c|ccc|}
\hline 2002 & 535 & 417 & 78 \\
2003 & 646 & 561 & 87 \\
2004 & 782 & 636 & 81 \\
2005 & 1154 & 1008 & 87 \\
2006 & 825 & 649 & 79 \\
2007 & 906 & 623 & 69 \\
2008 & 836 & 647 & 77 \\
2009 & 696 & 566 & 81 \\
2010 & 592 & 488 & 82 \\
2011 & 719 & 499 & 69 \\
Promedio & 769 & 609 & 79
\end{tabular}

Tabla 195. Comparación de los promedios mensuales de las horas frío para el observatorio del aeropuerto de Córdoba.

\section{HF prom mensual} contadas enero

febrero

marzo

abril

mayo

junio

julio

agosto

septiembre

octubre

noviembre

diciembre

anual

\begin{tabular}{|c|c|c|}
\hline contadas & por fórmula & cont \\
\hline 251 & 203 & 81 \\
\hline 157 & 127 & 81 \\
\hline 61 & 53 & 86 \\
\hline 11 & 9 & 81 \\
\hline 1 & 1 & 63 \\
\hline 0 & 0 & \\
\hline 0 & 0 & \\
\hline 0 & 0 & \\
\hline 0 & 0 & 61 \\
\hline 2 & 1 & 73 \\
\hline 72 & 53 & 76 \\
\hline 214 & 163 & 79 \\
\hline 769 & 609 & \\
\hline
\end{tabular}

\subsubsection{Cuenca del Guadalquivir: b) parte media de la cuenca}

Granada. La fórmula subestima en un $7 \%$ en promedio los valores reales y, aunque hay una considerable variación entre unos años y otros, puede considerarse una aproximación aceptable. 
Tabla 196. Comparación de horas frío anuales contadas y obtenidas a partir de la fórmula para el observatorio de Granada.

HF anuales contadas HF anuales por fórmula \% fórmula resp a cont

\begin{tabular}{|c|ccc|}
\hline 2002 & 1211 & 1127 & 93 \\
2003 & 1321 & 1261 & 95 \\
2004 & 1386 & 1257 & 91 \\
2005 & 1768 & 1596 & 90 \\
2006 & 1491 & 1406 & 94 \\
2007 & 1522 & 1353 & 89 \\
2008 & 1559 & 1419 & 91 \\
2009 & 1341 & 1300 & 97 \\
2010 & 1194 & 1208 & 101 \\
2011 & 1339 & 1195 & 89 \\
promedio & 1413 & 1312 & 93
\end{tabular}

Tabla 197. Comparación de los promedios mensuales de las horas frío para el observatorio de Granada.

\begin{tabular}{|c|c|c|c|}
\hline & $\begin{array}{c}\text { HF prom mensual } \\
\text { contadas }\end{array}$ & $\begin{array}{c}\text { HF prom mensual } \\
\text { por fórmula }\end{array}$ & $\begin{array}{c}\text { \% fórmula resp a } \\
\text { cont }\end{array}$ \\
\hline enero & 404 & 370 & 92 \\
febrero & 271 & 258 & 95 \\
\hline marzo & 153 & 149 & 98 \\
\hline abril & 55 & 58 & 106 \\
\hline mayo & 7 & 7 & 109 \\
junio & 0 & 0 & \\
julio & 0 & 0 & \\
agosto & 0 & 0 & \\
septiembre & 0 & 0 & 92 \\
\hline octubre & 11 & 10 & 88 \\
noviembre & 166 & 145 & 90 \\
diciembre & 348 & 314 & 93 \\
anual & 1413 & 1312 & \\
\hline
\end{tabular}

\section{Resumen para la cuenca del Guadalquivir}

En la parte baja de la cuenca del Guadalquivir, en altitudes por debajo de los $200 \mathrm{~m}$, donde las horas frío no son abundantes, la fórmula de Crossa-Raynaud subestima los valores reales en porcentajes en torno al $20 \%$, con una gran variación entre unos años y otros. Por tanto, es una aproximación deficiente, que es preciso tener en cuenta en los casos en los que por falta de datos horarios no quede más remedio que aplicar la fórmula. 
Por el contrario, en partes más altas de la cuenca, donde las horas frío son más abundantes, la aproximación es mejor, subestima en torno al 10\%, pero la variación entre unos años y otros sigue siendo considerable. Sería preferible tenerlo también en cuenta en los casos en los que no se disponga de datos horarios.

\subsubsection{Levante: a) franja costera de Levante: huerta levantina}

Castellón. La fórmula de Crossa-Raynaud subestima las horas frío en un 21\%, da un $79 \%$ de las horas reales, con una gran variación entre unos años y otros. Por tanto no da una buena aproximación.

Tabla 198. Comparación de horas frío anuales contadas y obtenidas a partir de la fórmula para el observatorio de Castellón.

HF anuales contadas HF anuales por fórmula \% fórmula resp a cont

\begin{tabular}{|c|ccc|}
\hline 2002 & 133 & 87 & 65 \\
2003 & 350 & 272 & 78 \\
2004 & 315 & 241 & 77 \\
2005 & 849 & 647 & 76 \\
2006 & 409 & 328 & 80 \\
2007 & 304 & 232 & 76 \\
2008 & 324 & 255 & 79 \\
2009 & 454 & 363 & 80 \\
2010 & 601 & 545 & 91 \\
2011 & 331 & 250 & 75 \\
Promedio & 407 & 322 & 79 \\
\hline
\end{tabular}

Tabla 199. Comparación de los promedios mensuales de las horas frío para el observatorio de Castellón.

\begin{tabular}{|c|c|c|c|}
\hline & $\begin{array}{l}\text { HF prom mensual } \\
\text { contadas }\end{array}$ & $\begin{array}{l}\text { HF prom mensual } \\
\text { por fórmula }\end{array}$ & $\begin{array}{c}\% \text { fórmula resp a } \\
\text { cont }\end{array}$ \\
\hline enero & 150 & 119 & 79 \\
\hline febrero & 95 & 75 & 79 \\
\hline marzo & 41 & 32 & 79 \\
\hline abril & 0 & 1 & \\
\hline mayo & 0 & 0 & \\
\hline junio & 0 & 0 & \\
\hline julio & 0 & 0 & \\
\hline agosto & 0 & 0 & \\
\hline septiembre & 0 & 0 & \\
\hline octubre & 0 & 0 & \\
\hline noviembre & 16 & 13 & 84 \\
\hline diciembre & 106 & 82 & 78 \\
\hline anual & 407 & 322 & 79 \\
\hline
\end{tabular}


Valencia. La fórmula de Crossa-Raynaud subestima las horas frío en un $21 \%$, da un $79 \%$ de las horas reales, con una gran variación entre unos años y otros. Por tanto no da una buena aproximación.

Tabla 200. Comparación de horas frío anuales contadas y obtenidas a partir de la fórmula para el observatorio de Valencia.

\begin{tabular}{|c|ccc|}
\hline & HF anuales contadas & HF anuales por fórmula & \% fórmula resp a cont \\
\hline 2002 & 49 & 42 & 85 \\
2003 & 267 & 219 & 82 \\
2004 & 213 & 160 & 75 \\
2005 & & & 81 \\
2006 & 284 & 230 & 75 \\
2007 & 210 & 159 & 72 \\
2008 & 191 & 137 & 73 \\
2009 & 300 & 218 & 87 \\
2010 & 467 & 407 & 81 \\
2011 & 252 & 204 & 79 \\
\hline Promedio & 248 & 197 & \\
\hline
\end{tabular}

Tabla 201. Comparación de los promedios mensuales de las horas frío para el observatorio de Valencia.

\section{HF prom mensual HF prom mensual \% fórmula resp a contadas}

\begin{tabular}{c} 
enero \\
febrero \\
marzo \\
abril \\
mayo \\
junio \\
\hline julio \\
agosto \\
septiembre \\
octubre \\
noviembre \\
diciembre \\
anual
\end{tabular}

\begin{tabular}{|c|c|c|}
\hline 93 & 74 & 80 \\
\hline 53 & 44 & 82 \\
\hline 23 & 19 & 83 \\
\hline 0 & 0 & \\
\hline 0 & 0 & \\
\hline 0 & 0 & \\
\hline 0 & 0 & \\
\hline 0 & 0 & \\
\hline 0 & 0 & 75 \\
\hline 0 & 0 & 76 \\
\hline 9 & 7 & 79 \\
\hline 70 & 54 & \\
\hline 248 & 197 & \\
\hline
\end{tabular}

En todos los casos la subestima es similar, en torno al $80 \%$.

Valencia Manises. Podría decirse que la fórmula de Crossa-Raynaud da, en promedio, un $85 \%$ de las horas reales, con una gran variación entre unos años y otros. Por tanto no da una buena aproximación. 
Tabla 202. Comparación de horas frío anuales contadas y obtenidas a partir de la fórmula para el observatorio de Valencia Manises.

$\mathrm{HF}$ anuales contadas $\mathrm{HF}$ anuales por fórmula \% fórmula resp a cont

\begin{tabular}{|c|ccc|}
\hline 2002 & 242 & 185 & 76 \\
2003 & 474 & 407 & 86 \\
2004 & 453 & 400 & 88 \\
2005 & 1072 & 894 & 83 \\
2006 & 782 & 683 & 87 \\
2007 & 775 & 605 & 78 \\
2008 & 833 & 670 & 80 \\
2009 & 872 & 772 & 89 \\
2010 & 1050 & 973 & 93 \\
2011 & 703 & 582 & 83 \\
\hline Promedio & 726 & 617 & 85
\end{tabular}

Tabla 203. Comparación de los promedios mensuales de las horas frío para el observatorio de Valencia Manises.

\begin{tabular}{|c|c|c|c|}
\hline & $\begin{array}{c}\text { HF prom mensual } \\
\text { contadas }\end{array}$ & $\begin{array}{c}\text { HF prom mensual } \\
\text { por fórmula }\end{array}$ & $\begin{array}{c}\text { \% fórmula resp a } \\
\text { cont }\end{array}$ \\
\hline enero & 224 & 191 & 85 \\
febrero & 158 & 141 & 89 \\
marzo & 82 & 72 & 87 \\
abril & 8 & 8 & 92 \\
mayo & 0 & 0 & \\
junio & 0 & 0 & \\
\hline julio & 0 & 0 & \\
\hline agosto & 0 & 0 & \\
septiembre & 0 & 0 & 71 \\
\hline octubre & 4 & 3 & 75 \\
\hline noviembre & 64 & 48 & 84 \\
\hline diciembre & 186 & 156 & 85 \\
\hline anual & 726 & 617 & \\
\hline
\end{tabular}

La fórmula de Crossa-Raynaud una aproximación del $85 \%$ al número de horas reales en los meses que importan, los que hay más horas frío.

Alicante. La fórmula de Crossa-Raynaud subestima las horas frío en un 17\%, en promedio da un $83 \%$ de las horas reales, con una gran variación entre unos años y otros. Por tanto no da una buena aproximación. 
Tabla 204. Comparación de horas frío anuales contadas y obtenidas a partir de la fórmula para el observatorio de Alicante.

HF anuales contadas HF anuales por fórmula \% fórmula resp a cont

\begin{tabular}{|c|lll|}
\hline 2002 & 218 & 146 & 67 \\
2003 & 301 & 266 & 88 \\
2004 & 266 & 212 & 80 \\
2005 & 667 & 555 & 83 \\
2006 & 290 & 269 & 93 \\
2007 & 272 & 208 & 77 \\
2008 & 332 & 272 & 82 \\
2009 & 254 & 215 & 85 \\
2010 & 418 & 359 & 86 \\
2011 & 326 & 259 & 80 \\
Promedio & 334 & 276 & 83
\end{tabular}

Tabla 205. Comparación de los promedios mensuales de las horas frío para el observatorio de Alicante.

\begin{tabular}{|c|c|c|c|}
\hline & $\begin{array}{l}\text { HF prom mensual } \\
\text { contadas }\end{array}$ & $\begin{array}{l}\text { HF prom mensual } \\
\text { por fórmula }\end{array}$ & $\begin{array}{c}\% \text { fórmula resp a } \\
\text { cont }\end{array}$ \\
\hline enero & 114 & 94 & 82 \\
\hline febrero & 79 & 68 & 86 \\
\hline marzo & 36 & 30 & 81 \\
\hline abril & 1 & 1 & \\
\hline mayo & 0 & 0 & \\
\hline junio & 0 & 0 & \\
\hline julio & 0 & 0 & \\
\hline agosto & 0 & 0 & \\
\hline septiembre & 0 & 0 & \\
\hline octubre & 0 & 0 & \\
\hline noviembre & 16 & 13 & 83 \\
\hline diciembre & 87 & 70 & 81 \\
\hline anual & 334 & 276 & 83 \\
\hline
\end{tabular}

La subestima es similar en los meses en los que hay horas frío.

Alicante El Altet. La fórmula de Crossa-Raynaud subestima en un 13\% las horas frío, en promedio da un $87 \%$ de las horas reales, con una gran variación entre unos años y otros. Por tanto no da una buena aproximación. No se consideran los datos de 2002, muy probablemente erróneos. 
Tabla 206. Comparación de horas frío anuales contadas y obtenidas a partir de la fórmula para el observatorio de Alicante El Atlet.

HF anuales contadas HF anuales por fórmula \% fórmula resp a cont

\begin{tabular}{|c|lll|}
\hline 2002 & 349 & 128 & 37 \\
2003 & 243 & 240 & 99 \\
2004 & 378 & 340 & 90 \\
2005 & 768 & 702 & 91 \\
2006 & 399 & 400 & 99 \\
2007 & 404 & 339 & 84 \\
2008 & 475 & 408 & 86 \\
2009 & 440 & 393 & 89 \\
2010 & 420 & 408 & 97 \\
2011 & 266 & 253 & 95 \\
Promedio & 414 & 361 & 87
\end{tabular}

Tabla 207. Comparación de los promedios mensuales de las horas frío para el observatorio de Alicante el Altet.

HF prom mensual contadas

\begin{tabular}{|c|}
\hline 127 \\
94 \\
50 \\
3 \\
0 \\
0 \\
0 \\
0 \\
0 \\
0 \\
23 \\
117 \\
414
\end{tabular}

HF prom mensual \% fórmula resp a por fórmula cont

enero
febrero
marzo
abril
mayo
junio
julio
agosto
septiembre
octubre
noviembre
diciembre
anual

27

121

95

94

89

95

50

$3 \quad 3$

0

$\begin{array}{ll}0 & 0\end{array}$

\begin{tabular}{l|l}
0 & 0
\end{tabular}

$0 \quad 0$

\begin{tabular}{l|l}
0 & 0
\end{tabular}

$0 \quad 0$

$23 \quad 21$

\begin{tabular}{ll}
17 & 84 \\
\hline
\end{tabular}

\begin{tabular}{l|l}
01 & 90
\end{tabular}

\begin{tabular}{l|l}
117 & 361
\end{tabular}

72

\begin{tabular}{l|r}
861 & 87
\end{tabular}

En los meses de enero y febrero, meses de más horas frío junto con diciembre, la aproximación es buena, del 95\%. Sin embargo, en diciembre la aproximación es mala del $72 \%$.

\subsubsection{Levante: b) huerta murciana}

Alcantarilla. Hay años en los que los valores que se obtienen con la fórmula se ajustan a los contados; en otros, sin embargo, se subestima en torno al 10\%. Hay una gran variación entre 
unos años y otros, y se da la particularidad de que los últimos 4 años así como el 2006 la fórmula no subestima sino que sobrestima, lo que hace sospechar de la bondad de los datos.

Tabla 208. Comparación de horas frío anuales contadas y obtenidas a partir de la fórmula para el observatorio de Alcantarilla.

HF anuales contadas HF anuales por fórmula \% fórmula resp a cont

\begin{tabular}{|c|ccc|}
2002 & 410 & 374 & 91 \\
2003 & 468 & 465 & 99 \\
2004 & 444 & 418 & 94 \\
2005 & 933 & 866 & 93 \\
2006 & 488 & 500 & 103 \\
2007 & 558 & 497 & 89 \\
2008 & 492 & 522 & 106 \\
2009 & 559 & 582 & 104 \\
2010 & 613 & 692 & 113 \\
2011 & 464 & 535 & 115 \\
promedio & 543 & 545 & 100
\end{tabular}

Tabla 209. Comparación de los promedios mensuales de las horas frío para el observatorio de Alcantarilla.

\begin{tabular}{|c|c|c|c|}
\hline & $\begin{array}{l}\text { HF prom mensual } \\
\text { contadas }\end{array}$ & $\begin{array}{l}\text { HF prom mensual } \\
\text { por fórmula }\end{array}$ & $\begin{array}{c}\% \text { fórmula resp } \\
\text { a cont }\end{array}$ \\
\hline enero & 191 & 184 & 96 \\
\hline febrero & 113 & 112 & 99 \\
\hline marzo & 50 & 52 & 103 \\
\hline abril & 5 & 7 & \\
\hline mayo & 0 & 0 & \\
\hline junio & 0 & 0 & \\
\hline julio & 0 & 0 & \\
\hline agosto & 0 & 0 & \\
\hline septiembre & 0 & 0 & \\
\hline octubre & 2 & 2 & \\
\hline noviembre & 42 & 45 & 107 \\
\hline diciembre & 140 & 143 & 102 \\
\hline anual & 543 & 545 & 100 \\
\hline
\end{tabular}

Mes a mes, se ve que en enero, que es cuando el número de horas frío es mayor, hay una subestima ligera (del 4\%) que hace pensar que la fórmula puede utilizarse para el cálculo de las horas frío. 
San Javier. En promedio la subestima que da la fórmula es pequeña, pero hay que poner estos datos en entredicho porque hay grandes diferencias entre unos años y otros, así, mientras que en el 2003 hay una sobrestima por la fórmula del 14 \%, en el año 2009 hay una subestima por la fórmula del $17 \%$.

Tabla 210. Comparación de horas frío anuales contadas y obtenidas a partir de la fórmula para el observatorio de San Javier. HF anuales contadas HF anuales por fórmula \% fórmula resp a cont

\begin{tabular}{|c|ccc|}
2002 & 209 & 209 & 100 \\
2003 & 269 & 307 & 114 \\
2004 & 335 & 355 & 106 \\
2005 & 628 & 610 & 97 \\
2006 & 339 & 311 & \\
2007 & & & 82 \\
2008 & & & \\
2009 & 506 & 422 & 94 \\
2010 & 564 & 528 & 91 \\
2011 & 348 & 316 & 96 \\
promedio & 400 & 382 & \\
\hline
\end{tabular}

Tabla 211. Comparación de los promedios mensuales de las horas frío para el observatorio de San Javier.

\section{HF prom mensual HF prom mensual \% fórmula resp a contadas por fórmula cont}

\begin{tabular}{|c|c|c|c|}
\hline enero & 151 & 141 & 94 \\
\hline febrero & 96 & 92 & 96 \\
\hline marzo & 42 & 43 & 102 \\
\hline abril & 3 & 4 & \\
\hline mayo & 0 & 0 & \\
\hline junio & 0 & 0 & \\
julio & 0 & 0 & \\
\hline agosto & 0 & 0 & \\
\hline septiembre & 0 & 0 & 95 \\
\hline octubre & 1 & 0 & 91 \\
\hline noviembre & 21 & 20 & 96 \\
\hline diciembre & 97 & 88 & \\
\hline anual & 400 & 382 & \\
\hline
\end{tabular}

En los promedios mensuales, en los meses en los que hay mayor número de horas frío, se da una subestima menor del $10 \%$. 
Totana. Hay sólo tres años de datos y la subestima parece importante en los meses en los que hay más horas frío, una subestima en torno al $20 \%$.

\section{Resumen para Levante y huerta de Murcia}

Se dan subestimas importantes y una gran variación entre unos años y otros, lo que hace desconfiar tanto de la bondad de los datos como de la bondad de la fórmula para el cálculo de las horas frío en Levante. Los datos obtenidos para la huerta levantina (Castellón, Valencia y Alicante) dan datos coherentes con otras zonas donde hay pocas horas frío: la fórmula da una subestima en torno al 15\%, que habría que tener en cuenta en los cálculos de esta variable. En la huerta murciana no se produce en promedio diferencia entre lo contado y lo obtenido por fórmula, pero parecen datos dudosos por la gran variación con sesgo de unos años a otros. Habría que comparar con los datos horarios del observatorio más cercano que disponga de ellos.

\subsubsection{Costa Sur}

Málaga. La fórmula subestima en un $20 \%$ las horas contadas, con una gran variación entre unos años y otros. Por tanto no da una buena aproximación.

Tabla 212. Comparación de horas frío anuales contadas y obtenidas a partir de la fórmula para el observatorio de Málaga.

$\mathrm{HF}$ anuales contadas $\mathrm{HF}$ anuales por fórmula \% fórmula resp a cont

\begin{tabular}{|c|ccc|}
\hline 2002 & 60 & 45 & 75 \\
2003 & 160 & 116 & 72 \\
2004 & 130 & 108 & 83 \\
2005 & 344 & 287 & 83 \\
2006 & 199 & 143 & 72 \\
2007 & 169 & 130 & 77 \\
2008 & 125 & 92 & 74 \\
2009 & 159 & 136 & 86 \\
2010 & 102 & 96 & 95 \\
2011 & 94 & 79 & 84 \\
Promedio & 154 & 123 & 80
\end{tabular}


Tabla 213. Comparación de los promedios mensuales de las horas frío para el observatorio de Málaga.

\begin{tabular}{|c|c|c|c|}
\hline & $\begin{array}{l}\text { HF prom mensual } \\
\text { contadas }\end{array}$ & $\begin{array}{l}\text { HF prom mensual } \\
\text { por fórmula }\end{array}$ & $\begin{array}{c}\% \text { fórmula resp a } \\
\text { cont }\end{array}$ \\
\hline enero & 71 & 55 & 77 \\
\hline febrero & 32 & 27 & 85 \\
\hline marzo & 13 & 11 & 91 \\
\hline abril & 0 & 0 & \\
\hline mayo & 0 & 0 & \\
\hline junio & 0 & 0 & \\
\hline julio & 0 & 0 & \\
\hline agosto & 0 & 0 & \\
\hline septiembre & 0 & 0 & \\
\hline octubre & 0 & 0 & \\
\hline noviembre & 7 & 5 & 72 \\
\hline diciembre & 31 & 25 & 79 \\
\hline anual & 154 & 123 & 80 \\
\hline
\end{tabular}

En la franja costera del sur, en altitudes próximas a nivel del mar, la aproximación no es buena. Habría que comparar con los datos horarios del observatorio más cercano que disponga de ellos.

\subsubsection{Zonas altas del interior peninsular}

Soria. La fórmula de Crossa-Raynaud subestima ligeramente las horas frío, en promedio da un $93 \%$ de las horas reales, con poca variación entre unos años y otros. Por tanto es una muy buena aproximación. 
Tabla 214.Comparación de horas frío anuales contadas y obtenidas a partir de la fórmula para el observatorio de Soria.

HF anuales contadas HF anuales por fórmula \% fórmula resp a cont

\begin{tabular}{|c|lll|}
\hline 2002 & 3177 & 2877 & 91 \\
2003 & 3074 & 2873 & 93 \\
2004 & 3388 & 3128 & 92 \\
2005 & 3290 & 3061 & 93 \\
2006 & 2662 & 2497 & 94 \\
2007 & 3213 & 2986 & 93 \\
2008 & 3436 & 3163 & 92 \\
2009 & 3044 & 2839 & 93 \\
2010 & 3595 & 3459 & 96 \\
2011 & 2764 & 2538 & 92 \\
Promedio & 3164 & 2987 & 93
\end{tabular}

Tabla 215.Comparación de los promedios mensuales de las horas frío para el observatorio de Soria.

\begin{tabular}{|c|c|c|c|}
\hline & $\begin{array}{c}\text { HF prom mensual } \\
\text { contadas }\end{array}$ & $\begin{array}{c}\text { HF prom mensual } \\
\text { por fórmula }\end{array}$ & $\begin{array}{c}\text { \% fórmula resp } \\
\text { a cont }\end{array}$ \\
\hline enero & 620 & 595 & 96 \\
\hline febrero & 533 & 509 & 95 \\
\hline marzo & 438 & 401 & 92 \\
abril & 259 & 234 & 90 \\
mayo & 114 & 95 & 84 \\
\hline junio & 12 & 10 & 85 \\
\hline julio & 3 & 2 & 55 \\
\hline agosto & 1 & 1 & 100 \\
septiembre & 29 & 20 & 70 \\
\hline octubre & 148 & 120 & 81 \\
\hline noviembre & 395 & 369 & 93 \\
\hline diciembre & 614 & 586 & 95 \\
anual & 3164 & 2987 & 93 \\
\hline
\end{tabular}

La aproximación de la fórmula es mayor en los meses en los que hay más horas frío, lo que refuerza la idea de que la fórmula de Crossa-Raynaud es una muy buena aproximación al número de horas reales.

Molina de Aragón. La fórmula de Crossa-Raynaud subestima ligeramente las horas frío, en promedio da un $94 \%$ de las horas reales, con poca variación entre unos años y otros. Por tanto es una muy buena aproximación. 
Tabla 216. Comparación de horas frío anuales contadas y obtenidas a partir de la fórmula para el observatorio de Molina de Aragón.

HF anuales contadas HF anuales por fórmula \% fórmula resp a cont

\begin{tabular}{|c|lll|}
\hline 2002 & 3232 & 3080 & 95 \\
2003 & 3128 & 3050 & 98 \\
2004 & 3512 & 3377 & 96 \\
2005 & 3563 & 3355 & 94 \\
2006 & 2984 & 2776 & 93 \\
2007 & 3458 & 3242 & 94 \\
2008 & 3445 & 3242 & 94 \\
2009 & 3166 & 2927 & 92 \\
2010 & 3518 & 3215 & 91 \\
2011 & 3079 & 2757 & 90 \\
Promedio & 3309 & 3102 & 94 \\
\hline
\end{tabular}

Tabla 217. Comparación de los promedios mensuales de las horas frío para el observatorio de Molina de Aragón.

\section{HF prom mensual} contadas
HF prom mensual \% fórmula resp a por fórmula

enero
febrero
marzo
abril
mayo
junio
julio
agosto
septiembre
octubre
noviembre
diciembre
anual

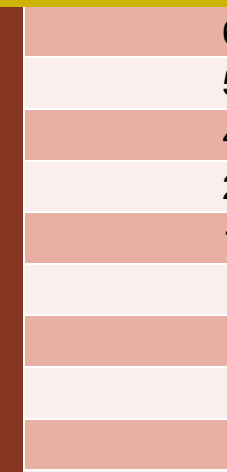

607

590

492

435

$281 \quad 258$

118

18

5

7

9

$71 \quad 48$

68

$6 \quad 62$

\begin{tabular}{|c|c|c|}
\hline 201 & 168 & 84 \\
\hline 433 & 417 & 96 \\
\hline 587 & 576 & 98 \\
\hline 3309 & 3102 & 94 \\
\hline
\end{tabular}

\begin{tabular}{|c|c|c|}
\hline 201 & 168 & 84 \\
\hline 433 & 417 & 96 \\
\hline 587 & 576 & 98 \\
\hline 3309 & 3102 & 94 \\
\hline
\end{tabular}

\begin{tabular}{l|l}
48 & 68
\end{tabular}

\begin{tabular}{|c|c|c|}
\hline 201 & 168 & 84 \\
\hline 433 & 417 & 96 \\
\hline 587 & 576 & 98 \\
\hline 3309 & 3102 & 94 \\
\hline
\end{tabular}

La aproximación de la fórmula es mayor en los meses en los que hay más horas frío, lo que refuerza la idea de que la fórmula de Crossa-Raynaud es una muy buena aproximación al número de horas reales.

Daroca. La fórmula de Crossa-Raynaud subestima ligeramente las horas frío, en promedio da un $94 \%$ de las horas reales, con poca variación entre unos años y otros. Por tanto es una muy buena aproximación. 
Tabla 218. Comparación de horas frío anuales contadas y obtenidas a partir de la fórmula para el observatorio de Daroca.

HF anuales contadas HF anuales por fórmula \% fórmula resp a cont

\begin{tabular}{|c|ccc|}
\hline 2002 & 1880 & 1778 & 95 \\
2003 & 2079 & 2005 & 96 \\
2004 & 2600 & 2492 & 96 \\
2005 & 2633 & 2510 & 95 \\
2006 & 2129 & 1988 & 93 \\
2007 & 2483 & 2317 & 93 \\
2008 & 2403 & 2217 & 92 \\
2009 & 2366 & 2207 & 93 \\
2010 & 2637 & 2541 & 96 \\
2011 & 2066 & 1866 & 90 \\
\hline Promedio & 2328 & 2192 & 94 \\
\hline
\end{tabular}

Tabla 219. Comparación de los promedios mensuales de las horas frío para el observatorio de Daroca.

\begin{tabular}{|c|c|c|c|}
\hline & $\begin{array}{c}\text { HF prom mensual } \\
\text { contadas }\end{array}$ & $\begin{array}{c}\text { HF prom mensual } \\
\text { por fórmula }\end{array}$ & $\begin{array}{c}\text { \% fórmula resp a } \\
\text { cont }\end{array}$ \\
\hline enero & 515 & 503 & 98 \\
\hline febrero & 424 & 403 & 95 \\
\hline marzo & 312 & 291 & 93 \\
\hline abril & 150 & 136 & 91 \\
mayo & 48 & 40 & 83 \\
\hline junio & 3 & 2 & 76 \\
\hline julio & 0 & 0 & \\
\hline agosto & 0 & 0 & 63 \\
\hline septiembre & 17 & 11 & 77 \\
\hline octubre & 85 & 65 & 92 \\
\hline noviembre & 288 & 265 & 98 \\
\hline diciembre & 487 & 478 & 94 \\
\hline anual & 2328 & 2192 & \\
\hline
\end{tabular}

La aproximación de la fórmula es mayor en los meses en los que hay más horas frío, lo que refuerza la idea de que la fórmula de Crossa-Raynaud es una muy buena aproximación al número de horas reales.

Cuenca. La fórmula de Crossa-Raynaud subestima las horas frío, en promedio da un $91 \%$ de las horas reales, con poca variación entre unos años y otros. Por tanto es una buena aproximación. 
Tabla 220. Comparación de horas frío anuales contadas y obtenidas a partir de la fórmula para el observatorio de Cuenca.

HF anuales contadas HF anuales por fórmula \% fórmula resp a cont

\begin{tabular}{|c|lll|}
\hline 2002 & 2259 & 2057 & 91 \\
2003 & 2270 & 2084 & 92 \\
2004 & 2450 & 2209 & 90 \\
2005 & 2495 & 2361 & 95 \\
2006 & 2092 & 1962 & 94 \\
2007 & 2428 & 2124 & 87 \\
2008 & 2241 & 2072 & 92 \\
2009 & 2281 & 2082 & 91 \\
2010 & 2599 & 2393 & 92 \\
2011 & 1938 & 1698 & 88 \\
Promedio & 2305 & 2104 & 91
\end{tabular}

Tabla 221. Comparación de los promedios mensuales de las horas frío para el observatorio de Cuenca.

\begin{tabular}{|c|c|c|c|}
\hline & $\begin{array}{l}\text { HF prom mensual } \\
\text { contadas }\end{array}$ & $\begin{array}{l}\text { HF prom mensual } \\
\text { por fórmula }\end{array}$ & $\begin{array}{c}\% \text { fórmula resp a } \\
\text { cont }\end{array}$ \\
\hline enero & 535 & 505 & 94 \\
\hline febrero & 431 & 398 & 92 \\
\hline marzo & 310 & 277 & 89 \\
\hline abril & 141 & 120 & 85 \\
\hline mayo & 41 & 34 & 82 \\
\hline junio & 2 & 1 & \\
\hline julio & 0 & 0 & \\
\hline agosto & 0 & 0 & \\
\hline septiembre & 6 & 3 & 54 \\
\hline octubre & 52 & 39 & 76 \\
\hline noviembre & 297 & 260 & 87 \\
\hline diciembre & 491 & 467 & 95 \\
\hline anual & 2305 & 2104 & 91 \\
\hline
\end{tabular}

La aproximación de la fórmula es mayor en los meses en los que hay más horas frío, lo que refuerza la idea de que la fórmula de Crossa-Raynaud es una buena aproximación al número de horas reales.

Teruel. La fórmula de Crossa-Raynaud subestima ligeramente las horas frío, en promedio da un $94 \%$ de las horas reales, con poca variación entre unos años y otros. Por tanto es una muy buena aproximación. 
Tabla 222. Comparación de horas frío anuales contadas y obtenidas a partir de la fórmula para el observatorio de Teruel.

HF anuales contadas HF anuales por fórmula \% fórmula resp a cont

\begin{tabular}{|c|ccc|}
\hline 2002 & 2670 & 2462 & 92 \\
2003 & 2659 & 2515 & 95 \\
2004 & 2973 & 2795 & 94 \\
2005 & 2964 & 2809 & 95 \\
2006 & 2526 & 2399 & 95 \\
2007 & 2878 & 2652 & 92 \\
2008 & 2739 & 2644 & 97 \\
2009 & 2743 & 2574 & 94 \\
2010 & 2992 & 2860 & 96 \\
2011 & 2316 & 2106 & 91 \\
\hline Promedio & 2746 & 2582 & 94
\end{tabular}

Tabla 223. Comparación de los promedios mensuales de las horas frío para el observatorio de Teruel.

HF prom mensual HF prom mensual \% fórmula resp a contadas por fórmula cont

\begin{tabular}{|c|c|c|c|}
\hline enero & 572 & 555 & 97 \\
febrero & 470 & 449 & 96 \\
\hline marzo & 371 & 341 & 92 \\
\hline abril & 202 & 183 & 90 \\
\hline mayo & 72 & 63 & 87 \\
junio & 8 & 7 & \\
julio & 0 & 0 & \\
agosto & 1 & 0 & 69 \\
septiembre & 23 & 16 & 83 \\
\hline octubre & 116 & 96 & 93 \\
noviembre & 363 & 339 & 97 \\
diciembre & 548 & 532 & 94 \\
\hline anual & 2746 & 2582 & \\
\hline
\end{tabular}

La aproximación de la fórmula es mayor en los meses en los que hay más horas frío, lo que refuerza la idea de que la fórmula de Crossa-Raynaud es una muy buena aproximación al número de horas reales.

Albacete Los Llanos. La fórmula de Crossa-Raynaud subestima ligeramente las horas frío, en promedio da un $94 \%$ de las horas reales, con poca variación entre unos años y otros. Por tanto es una muy buena aproximación. 
Tabla 224. Comparación de horas frío anuales contadas y obtenidas a partir de la fórmula para el observatorio de Albacete los llanos.

HF anuales contadas HF anuales por fórmula \% fórmula resp a cont

\begin{tabular}{|c|ccc|}
\hline 2002 & 1536 & 1507 & 98 \\
2003 & 1762 & 1779 & 101 \\
2004 & 1957 & 1889 & 97 \\
2005 & 2197 & 2121 & 97 \\
2006 & 1803 & 1677 & 93 \\
2007 & 2038 & 1850 & 91 \\
2008 & 1865 & 1739 & 93 \\
2009 & 1863 & 1711 & 92 \\
2010 & 2079 & 1941 & 93 \\
2011 & 1714 & 1513 & 88 \\
Promedio & 1881 & 1773 & 94
\end{tabular}

Tabla 225. Comparación de los promedios mensuales de las horas frío para el observatorio de Albacete los Llanos.

\begin{tabular}{|c|c|c|c|}
\hline & $\begin{array}{c}\text { HF prom mensual } \\
\text { contadas }\end{array}$ & $\begin{array}{c}\text { HF prom mensual } \\
\text { por fórmula }\end{array}$ & $\begin{array}{c}\text { \% fórmula resp a } \\
\text { cont }\end{array}$ \\
\hline enero & 484 & 465 & 96 \\
febrero & 361 & 341 & 94 \\
marzo & 233 & 221 & 95 \\
\hline abril & 90 & 82 & 91 \\
mayo & 18 & 15 & 82 \\
junio & 0 & 0 & \\
julio & 0 & 0 & \\
agosto & 0 & 0 & \\
septiembre & 1 & 1 & \\
\hline octubre & 25 & 22 & 89 \\
noviembre & 244 & 220 & 90 \\
\hline diciembre & 425 & 407 & 96 \\
anual & 1881 & 1773 & 94 \\
\hline
\end{tabular}

La aproximación de la fórmula es mayor en los meses en los que hay más horas frío, lo que refuerza la idea de que la fórmula de Crossa-Raynaud es una muy buena aproximación al número de horas reales.

\section{Resumen para las zonas altas del interior peninsular}

La aproximación que da la fórmula respecto a las horas contadas es superior al $90 \%$ en todos los casos y bastante uniforme entre unos años y otros. La fórmula subestima ligeramente las horas reales y por tanto es una aproximación muy buena, sobre todo en los meses en los que hay más horas frío. 
Zona: corresponde a zonas climáticas con un cierto grado de homogeneidad en cuanto a la altitud y las condiciones fisiográficas con respecto a los observatorios utilizados como referencia. Debido al bajo número de observatorios utilizados y a la gran variedad de tipos de suelo, cubierta vegetal, orientación, etc., las altitudes son únicamente orientativas y no cubren todo el rango de las que se dan en cada zona. Zonas:

Costa cantábrica ciudades costeras

Costa cantábrica en altitudes menores de $350 \mathrm{~m}$

Costa cantábrica entre 350 y $600 \mathrm{~m}$ de altitud

Costa gallega ciudades costeras

Costa gallega en altitudes menores de $350 \mathrm{~m}$

Interior gallego y El Bierzo en valles por debajo de $600 \mathrm{~m}$

Meseta Norte entre $600 \mathrm{~m}$ y $800 \mathrm{~m}$ de altitud

Meseta Norte entre 800 y $1000 \mathrm{~m}$ de altitud

Cuenca del Ebro en altitudes menores de $300 \mathrm{~m}$

Cuenca del Ebro entre $300 \mathrm{~m}$ y $500 \mathrm{~m}$ de altitud

Costa catalana muy próximo al mar hasta $100 \mathrm{~m}$ de altitud

Costa catalana entre 100 y $300 \mathrm{~m}$ de altitud

Cuenca del Tajo en altitudes menores de $500 \mathrm{~m}$

Cuenca del Tajo entre $500 \mathrm{~m}$ y $700 \mathrm{~m}$ de altitud

Cuenca de Guadiana en altitudes menores de $300 \mathrm{~m}$

Cuenca de Guadiana entre 500 y $700 \mathrm{~m}$ de altitud

Cuenca del Guadalquivir en altitudes menores de $300 \mathrm{~m}$

Cuenca del Guadalquivir en valles entre $500 \mathrm{~m}$ y $700 \mathrm{~m}$

Levante y Murcia ciudades costeras

Levante y Murcia, zona de huerta en altitudes menores de $150 \mathrm{~m}$

Costa Sur en altitudes menores de $100 \mathrm{~m}$ junto al mar

Zonas altas del interior peninsular entre 700 y $900 \mathrm{~m}$

Zonas altas del interior peninsular entre 900 y $1100 \mathrm{~m}$

Promedio anual de horas frío. Se pone una aproximación al número de horas frío que corresponde al máximo sacado de los observatorios utilizados como referencia y, por tanto, se 
refiere en cada zona a la mayor altitud del intervalo. En igualdad del resto de las condiciones que influyen en las temperaturas diarias, a menor altitud se darán menos horas frío. Es una aproximación que redondea al alza debido a que, por la gran variabilidad interanual, se dan años con muchas más horas que las que da el promedio. Sobre este punto es preciso insistir en que la variación entre unos años y otros es, en general, muy elevada; en casos del orden de magnitud de ese promedio.

Promedio mensual de horas frío. Se pone el máximo aproximado del promedio mensual de horas frío en los meses de invierno (diciembre, enero y febrero) de los observatorios utilizados como referencia que dan un mayor número de horas frío. Igual que en el caso de la acumulación anual, se refiere en cada zona a la mayor altitud del intervalo y se redondea al alza porque la variación entre unos años y otros para los mismos meses es muy elevada; en muchos casos del orden de magnitud de ese promedio.

Meses completamente libres de horas frío.

Meses en los que se dan horas de frío todos los años

Variabilidad. Da idea de la variabilidad interanual y entre cada uno de los meses en los distintos años.

Muy marcada. La diferencia entre el año con un mayor número de horas frío y el año con menor número de horas es superior al $60 \%$ del promedio anual.

Marcada. La diferencia entre el año con un mayor número de horas y el año con menor número de horas está comprendida entre el $40 \%$ y el $60 \%$ del promedio anual, es decir, es del orden de la mitad del promedio anual.

Media. La diferencia entre el año con un mayor número de horas y el año con menor número de horas está comprendida entre el $20 \%$ y el $40 \%$ del promedio anual.

Baja. La diferencia entre el año con un mayor número de horas y el año con menor número de horas está por debajo del $20 \%$ del promedio anual.

Aproximación de la fórmula. Da idea de la aproximación promedio que proporciona la fórmula respecto al número de horas frío anuales sacado de los datos horarios. 
Buena. La diferencia entre el promedio anual del número de horas frío que da la fórmula y el que se saca de los datos horarios es menor que el $10 \%$ del valor que se saca de los datos horarios.

Aceptable. La diferencia entre el promedio anual del número de horas frío que da la fórmula y el que se saca de los datos horarios está comprendida entre el $10 \%$ y el $20 \%$ del valor sacado de los datos horarios.

Mala. La diferencia entre el promedio anual del número de horas frío que da la fórmula y el que se saca de los datos horarios es superior al $20 \%$ del valor sacado de los datos horarios.

Uniformidad de la aproximación. Da idea de las diferencias en la aproximación en los distintos años, medida según la diferencia entre los años en los que tal aproximación es mejor y peor. Ejemplo: si la aproximación promedio es del $92 \%$, y el año en el que la aproximación es mejor es del $95 \%$, y el año en el que es peor es del $85 \%$, la diferencia entre ellos es de un $10 \%$; esta diferencia es superior al 10\% de la aproximación promedio, que sería 9,2\%.

Uniforme. La oscilación entre la aproximación más alta y la más baja es igual o menor que el $10 \%$ de la aproximación media.

Poco uniforme. La oscilación entre la aproximación más alta y la más baja está comprendida entre el $10 \%$ y el $20 \%$ de la aproximación media.

Dispar. La oscilación entre la aproximación más alta y la más baja es mayor que el $20 \%$ de la aproximación media. 
Tabla 226. Tabla resumen horas frío.

\begin{tabular}{|c|c|c|c|c|c|c|c|}
\hline Zona & $\begin{array}{c}\text { Promedio } \\
\text { anual } \\
\text { de horas frio } \\
\end{array}$ & $\begin{array}{c}\text { Promedio } \\
\text { mensual } \\
\text { de horas frío }\end{array}$ & Meses libres de horas frío & Meses con horas frío & Variabilidad & $\begin{array}{l}\text { Aproximación de la } \\
\text { fórmula }\end{array}$ & $\begin{array}{l}\text { Uniformidad de la } \\
\text { aproximación }\end{array}$ \\
\hline Costa cantábrica ciudades costeras & 500 & 150 & $\begin{array}{l}\text { junio, julio, agosto, } \\
\text { septiembre }\end{array}$ & $\begin{array}{l}\text { enero, febrero, marzo, } \\
\text { diciembre }\end{array}$ & $\begin{array}{c}\text { Muy } \\
\text { marcada }\end{array}$ & Buena & Poco uniforme \\
\hline $\begin{array}{l}\text { Costa cantábrica } \\
<350 \mathrm{~m} \text { de altitud }\end{array}$ & 1500 & 300 & junio, julio, agosto & $\begin{array}{l}\text { enero, febrero, marzo, abril, } \\
\text { noviembre, diciembre }\end{array}$ & $\begin{array}{c}\text { Muy } \\
\text { marcada }\end{array}$ & Buena & Poco uniforme \\
\hline $\begin{array}{c}\text { Costa cantábrica } \\
350-600 \mathrm{~m} \text { de altitud }\end{array}$ & 2500 & 500 & ninguno & $\begin{array}{l}\text { enero, febrero, marzo, abril, mayo, } \\
\text { octubre, noviembre, diciembre }\end{array}$ & Marcada & Buena & Uniforme \\
\hline $\begin{array}{c}\text { Costa gallega } \\
\text { ciudades costeras }\end{array}$ & 500 & 150 & $\begin{array}{l}\text { junio, julio, agosto, } \\
\text { septiembre }\end{array}$ & $\begin{array}{l}\text { enero, febrero, marzo, } \\
\text { diciembre }\end{array}$ & $\begin{array}{c}\text { Muy } \\
\text { marcada }\end{array}$ & Buena & Poco uniforme \\
\hline $\begin{array}{c}\text { Costa gallega } \\
<350 \mathrm{~m} \text { de altitud } \\
\end{array}$ & 1500 & 300 & julio, agosto, septiembre & $\begin{array}{c}\text { enero, febrero, marzo, abril, } \\
\text { noviembre, diciembre }\end{array}$ & $\begin{array}{c}\text { Muy } \\
\text { marcada }\end{array}$ & Aceptable o Buena & Poco uniforme \\
\hline $\begin{array}{l}\text { Interior gallego y El Bierzo en valles } \\
<600 \mathrm{~m}\end{array}$ & 2500 & 500 & $\begin{array}{l}\text { junio, julio, agosto, } \\
\text { septiembre }\end{array}$ & $\begin{array}{l}\text { enero, febrero, marzo, abril, mayo, } \\
\text { octubre, noviembre, diciembre }\end{array}$ & Media & Aceptable o Buena & Poco uniforme \\
\hline $\begin{array}{c}\text { Meseta Norte } \\
600-800 \mathrm{~m} \text { de altitud }\end{array}$ & 2600 & 550 & julio, agosto & $\begin{array}{l}\text { enero, febrero, marzo, abril, mayo, } \\
\text { octubre, noviembre, diciembre }\end{array}$ & Media & Buena & Uniforme \\
\hline $\begin{array}{c}\text { Meseta Norte } \\
800-1000 \mathrm{~m} \text { de altitud }\end{array}$ & 3200 & 650 & ninguno & $\begin{array}{l}\text { enero, febrero, marzo abril, mayo, septiembre, octubre, } \\
\text { noviembre, diciembre }\end{array}$ & Media & Buena & Uniforme \\
\hline $\begin{array}{l}\text { Cuenca del Ebro } \\
<300 \mathrm{~m} \text { de altitud }\end{array}$ & 2000 & 500 & junio, julio, agosto & $\begin{array}{c}\text { enero, febrero, marzo, abril, } \\
\text { noviembre, diciembre }\end{array}$ & Marcada & Buena & Uniforme \\
\hline $\begin{array}{l}\text { Cuenca del Ebro } \\
300-500 \mathrm{~m} \text { de altitud }\end{array}$ & 2200 & 550 & agosto & $\begin{array}{l}\text { enero, febrero, marzo, abril, mayo, } \\
\text { octubre, noviembre, diciembre }\end{array}$ & Marcada & Buena & Uniforme \\
\hline $\begin{array}{c}\text { Costa catalana } \\
<100 \mathrm{~m} \text { de altitud }\end{array}$ & 700 & 250 & $\begin{array}{c}\text { junio, julio, agosto, } \\
\text { septiembre }\end{array}$ & $\begin{array}{l}\text { enero, febrero, marzo, } \\
\text { diciembre }\end{array}$ & $\begin{array}{c}\text { Muy } \\
\text { marcada }\end{array}$ & Aceptable & Dispar \\
\hline $\begin{array}{c}\text { Costa catalana } \\
100-300 \mathrm{~m} \text { de altitud }\end{array}$ & 1500 & 350 & junio, julio, agosto & $\begin{array}{c}\text { enero, febrero, marzo, abril, } \\
\text { noviembre, diciembre }\end{array}$ & $\begin{array}{c}\text { Muy } \\
\text { marcada }\end{array}$ & Aceptable & Poco uniforme \\
\hline $\begin{array}{l}\text { Cuenca del Tajo } \\
<500 \mathrm{~m} \text { de altitud }\end{array}$ & 1500 & 350 & $\begin{array}{l}\text { junio, julio, agosto, } \\
\text { septiembre }\end{array}$ & $\begin{array}{l}\text { enero, febrero, marzo, abril, } \\
\text { noviembre, diciembre }\end{array}$ & $\begin{array}{c}\text { Muy } \\
\text { marcada }\end{array}$ & Buena & Poco uniforme \\
\hline $\begin{array}{c}\text { Cuenca del Tajo } \\
500-700 \mathrm{~m} \text { de altitud }\end{array}$ & 2300 & 500 & ninguno & $\begin{array}{l}\text { enero, febrero, marzo, abril, mayo, } \\
\text { octubre, noviembre, diciembre }\end{array}$ & Marcada & Buena & Uniforme \\
\hline $\begin{array}{c}\text { Cuenca del Guadiana } \\
<300 \mathrm{~m} \text { de altitud } \\
\end{array}$ & 1000 & 300 & $\begin{array}{c}\text { junio, julio, agosto, } \\
\text { septiembre }\end{array}$ & $\begin{array}{l}\text { enero, febrero, marzo, } \\
\text { noviembre, diciembre }\end{array}$ & $\begin{array}{c}\text { Muy } \\
\text { marcada }\end{array}$ & Aceptable & Poco uniforme \\
\hline $\begin{array}{l}\text { Cuenca del Guadiana } \\
500-700 \mathrm{~m} \text { de altitud }\end{array}$ & 2000 & 500 & junio, julio, agosto & $\begin{array}{l}\text { enero, febrero, marzo, } \\
\text { noviembre, diciembre }\end{array}$ & Marcada & Buena & Uniforme \\
\hline $\begin{array}{l}\text { Cuenca del Guadalquivir } \\
<300 \mathrm{~m} \text { de altitud }\end{array}$ & 1000 & 300 & $\begin{array}{l}\text { junio, julio, agosto, } \\
\text { septiembre }\end{array}$ & $\begin{array}{l}\text { enero, febrero, marzo, } \\
\text { noviembre, diciembre }\end{array}$ & $\begin{array}{c}\text { Muy } \\
\text { marcada }\end{array}$ & Aceptable o Mala & Dispar \\
\hline $\begin{array}{l}\text { Cuenca del Guadalquivir } \\
\text { en valles altos } 500-700 \mathrm{~m}\end{array}$ & 1500 & 400 & $\begin{array}{c}\text { junio, julio, agosto, } \\
\text { septiembre }\end{array}$ & $\begin{array}{c}\text { enero, febrero, marzo, abril, } \\
\text { noviembre, diciembre }\end{array}$ & Marcada & Buena & Poco uniforme \\
\hline $\begin{array}{l}\text { Levante y Murcia } \\
\text { ciudades costeras }\end{array}$ & 400 & 150 & $\begin{array}{c}\text { mayo, junio, julio, agosto, } \\
\text { septiembre }\end{array}$ & $\begin{array}{c}\text { enero, febrero, marzo, } \\
\text { diciembre }\end{array}$ & $\begin{array}{c}\text { Muy } \\
\text { marcada }\end{array}$ & Mala & Dispar \\
\hline $\begin{array}{c}\text { Levante y Murcia } \\
\text { huerta }<150 \mathrm{~m} \text { de altitud }\end{array}$ & 800 & 250 & $\begin{array}{l}\text { mayo, junio, julio, agosto, } \\
\text { septiembre }\end{array}$ & $\begin{array}{l}\text { enero, febrero, marzo, } \\
\text { noviembre, diciembre }\end{array}$ & $\begin{array}{c}\text { Muy } \\
\text { marcada }\end{array}$ & Aceptable & Poco uniforme \\
\hline $\begin{array}{c}\text { Costa Sur } \\
<100 \mathrm{~m} \text { junto al mar }\end{array}$ & 200 & 100 & $\begin{array}{l}\text { mayo, junio, julio, agosto, } \\
\text { septiembre }\end{array}$ & enero, febrero, diciembre & $\begin{array}{c}\text { Muy } \\
\text { marcada }\end{array}$ & Mala & Dispar \\
\hline $\begin{array}{c}\text { Zonas altas interior peninsular 700-900 } \\
\mathrm{m} \text { de altitud }\end{array}$ & 2800 & 600 & ninguno & $\begin{array}{l}\text { enero, febrero, marzo, abril, } \\
\text { octubre, noviembre, diciembre }\end{array}$ & Media & Buena & Uniforme \\
\hline $\begin{array}{l}\text { Zonas altas interior peninsular 900-1100 } \\
\mathrm{m} \text { de altitud }\end{array}$ & 3300 & 650 & ninguno & $\begin{array}{l}\text { enero, febrero, marzo abril, mayo, septiembre, octubre, } \\
\text { noviembre, diciembre }\end{array}$ & Media & Buena & Uniforme \\
\hline
\end{tabular}




\section{Horas de calor}

Se presenta en primer lugar el número de horas de calor contadas a partir de los datos horarios de los observatorios elegidos en cada una de las zonas en las que se ha dividido la Península. Luego se proporciona la comparación de las horas de calor contadas a partir de datos horarios y las horas de calor obtenidas mediante la fórmula de Crossa-Raynaud.

\subsection{Horas de calor (umbral 30을 Contadas a partir de datos horarios}

\subsubsection{Zonas norte y noroeste: a) costa cantábrica}

Observatorios: San Sebastián-Igueldo (1024e), Bilbao-Sondica (1082), Santander-Parayas (1109), Santander CMT (1111), Gijón Musel (1208h), Oviedo (1249l) y Vitoria (90910). Periodo: 2002 a 2011

Tabla 227. Comparación de horas de calor anuales contadas a partir de datos horarios en los siete observatorios de las zonas norte y noroeste: costa cantábrica.

\begin{tabular}{|cccccccc|}
\hline Año & $\begin{array}{c}\text { Igueldo } \\
\mathbf{1 0 2 4 e}\end{array}$ & $\begin{array}{c}\text { Bilbao } \\
\mathbf{1 0 8 2}\end{array}$ & $\begin{array}{c}\text { Parayas } \\
\mathbf{1 1 0 9}\end{array}$ & $\begin{array}{c}\text { Santander } \\
\mathbf{1 1 1 1}\end{array}$ & $\begin{array}{c}\text { Gijón musel } \\
\mathbf{1 2 0 8 h}\end{array}$ & $\begin{array}{c}\text { Oviedo } \\
\mathbf{1 2 4 9}\end{array}$ & $\begin{array}{c}\text { Vitoria } \\
\mathbf{9 0 9 1 0}\end{array}$ \\
\hline $\mathbf{2 0 0 2}$ & 1 & 8 & 1 & 0 & 0 & 0 & 59 \\
\hline $\mathbf{2 0 0 3}$ & 52 & 122 & 17 & 6 & 1 & 41 & 203 \\
\hline $\mathbf{2 0 0 4}$ & 17 & 59 & 8 & 0 & 0 & 3 & 50 \\
\hline $\mathbf{2 0 0 5}$ & 52 & 85 & 9 & 2 & 0 & 13 & 85 \\
\hline $\mathbf{2 0 0 6}$ & 24 & 81 & 25 & 5 & 0 & 14 & 105 \\
\hline $\mathbf{2 0 0 7}$ & 12 & 43 & 0 & 0 & 0 & 6 & 65 \\
\hline $\mathbf{2 0 0 8}$ & 12 & 29 & 1 & 0 & 0 & 0 & 44 \\
\hline $\mathbf{2 0 0 9}$ & 17 & 53 & 6 & 3 & 0 & 5 & 114 \\
\hline $\mathbf{2 0 1 0}$ & 5 & 32 & 0 & 0 & 0 & 3 & 74 \\
\hline $\mathbf{2 0 1 1}$ & 26 & 99 & 28 & 2 & 0 & 15 & 81 \\
\hline Promedio & 22 & 61 & 10 & 2 & 0 & 10 & 88 \\
\hline
\end{tabular}


Los datos son coherentes entre ellos, y muestran que en la franja costera entre el Cantábrico y la cordillera cantábrica no se llega a las 100 horas de calor (umbral $30^{\circ} \mathrm{C}$ ) anuales, y en la costa, al borde del mar, apenas hay días en los que se superen o siquiera alcancen los $30^{\circ} \mathrm{C}$.

\subsubsection{Zonas norte y noroeste: b) costa gallega}

Observatorios: La Coruña (1387), La Coruña-Alvedro (1387e), Pontevedra (1484c), VigoPeinador (1495).

Tabla 228.Comparación de horas de calor anuales contadas a partir de datos horarios en los cuatro observatorios de las zonas norte y noroeste: costa gallega.

\begin{tabular}{|ccccc|}
\hline Año & $\begin{array}{c}\text { La Coruña } \\
\mathbf{1 3 8 7}\end{array}$ & $\begin{array}{c}\text { Alvedro } \\
\mathbf{1 3 8 7 e}\end{array}$ & $\begin{array}{c}\text { Pontevedra } \\
\mathbf{1 4 8 4 c}\end{array}$ & $\begin{array}{c}\text { Vigo } \\
\mathbf{1 4 9 5}\end{array}$ \\
\hline $\mathbf{2 0 0 2}$ & $\mathrm{HC}$ & $\mathrm{HC}$ & $\mathrm{HC}$ & $\mathrm{HC}$ \\
\hline $\mathbf{2 0 0 3}$ & 6 & 2 & 18 & 10 \\
\hline $\mathbf{2 0 0 4}$ & 0 & 26 & 100 & 96 \\
\hline $\mathbf{2 0 0 5}$ & 4 & 0 & 48 & 28 \\
\hline $\mathbf{2 0 0 6}$ & 5 & 33 & 122 & 64 \\
\hline $\mathbf{2 0 0 7}$ & 0 & 26 & 135 & 50 \\
\hline $\mathbf{2 0 0 8}$ & 0 & 4 & 30 & 1 \\
\hline $\mathbf{2 0 0 9}$ & 0 & 6 & 28 & 4 \\
\hline $\mathbf{2 0 1 0}$ & 0 & 6 & 30 & 20 \\
\hline $\mathbf{2 0 1 1}$ & 4 & 3 & 104 & 74 \\
\hline Promedio & 2 & 24 & 39 & 16 \\
\hline
\end{tabular}

Los datos son coherentes entre ellos, y muestran que en la franja costera no se llega a las 100 horas de calor anuales, y en la costa, al borde del mar apenas hay días en los que se superen 0 siquiera alcancen $\operatorname{los} 30^{\circ} \mathrm{C}$.

\subsubsection{Zonas norte y noroeste: c) interior de Galicia y el valle del Bierzo}

Observatorios: Santiago-Labacolla (1428), Lugo-Rozas (1505), Orense (1690a), Ponferrada (1549), Almázcara (1556x). 
Tabla 229. Comparación de horas de calor anuales contadas a partir de datos horarios en los cinco observatorios de las zonas norte y noroeste: interior de Galicia y el valle del Bierzo.

\begin{tabular}{|cccccc|}
\hline & $\begin{array}{c}\text { Santiago } \\
\mathbf{1 4 2 8}\end{array}$ & $\begin{array}{c}\text { Lugo } \\
\mathbf{1 5 0 5}\end{array}$ & $\begin{array}{c}\text { Orense } \\
\mathbf{1 6 9 0 a}\end{array}$ & $\begin{array}{c}\text { Ponferrada } \\
\mathbf{1 5 4 9}\end{array}$ & $\begin{array}{c}\text { Almázcara } \\
\mathbf{1 5 5 6 x}\end{array}$ \\
\hline $\mathbf{A n ̃ o}$ & $\mathrm{HC}$ & $\mathrm{HC}$ & $\mathrm{HC}$ & $\mathrm{HC}$ & HC \\
\hline $\mathbf{2 0 0 2}$ & 13 & & 207 & 132 & 78 \\
\hline $\mathbf{2 0 0 3}$ & 91 & 118 & 386 & 303 & 153 \\
\hline $\mathbf{2 0 0 4}$ & 37 & 23 & 302 & 176 & 78 \\
\hline $\mathbf{2 0 0 5}$ & 77 & 51 & 365 & 301 & 151 \\
\hline $\mathbf{2 0 0 6}$ & 84 & 68 & 424 & 287 & 167 \\
\hline $\mathbf{2 0 0 7}$ & 23 & 13 & 230 & 125 & 61 \\
\hline $\mathbf{2 0 0 8}$ & 9 & 6 & 170 & 133 & 89 \\
\hline $\mathbf{2 0 0 9}$ & 13 & 33 & 291 & 207 & \\
\hline $\mathbf{2 0 1 0}$ & 46 & 34 & 417 & 310 & 111 \\
\hline $\mathbf{2 0 1 1}$ & 27 & 51 & 320 & 160 & \\
\hline Promedio & 42 & 44 & 311 & 213 & \\
\hline
\end{tabular}

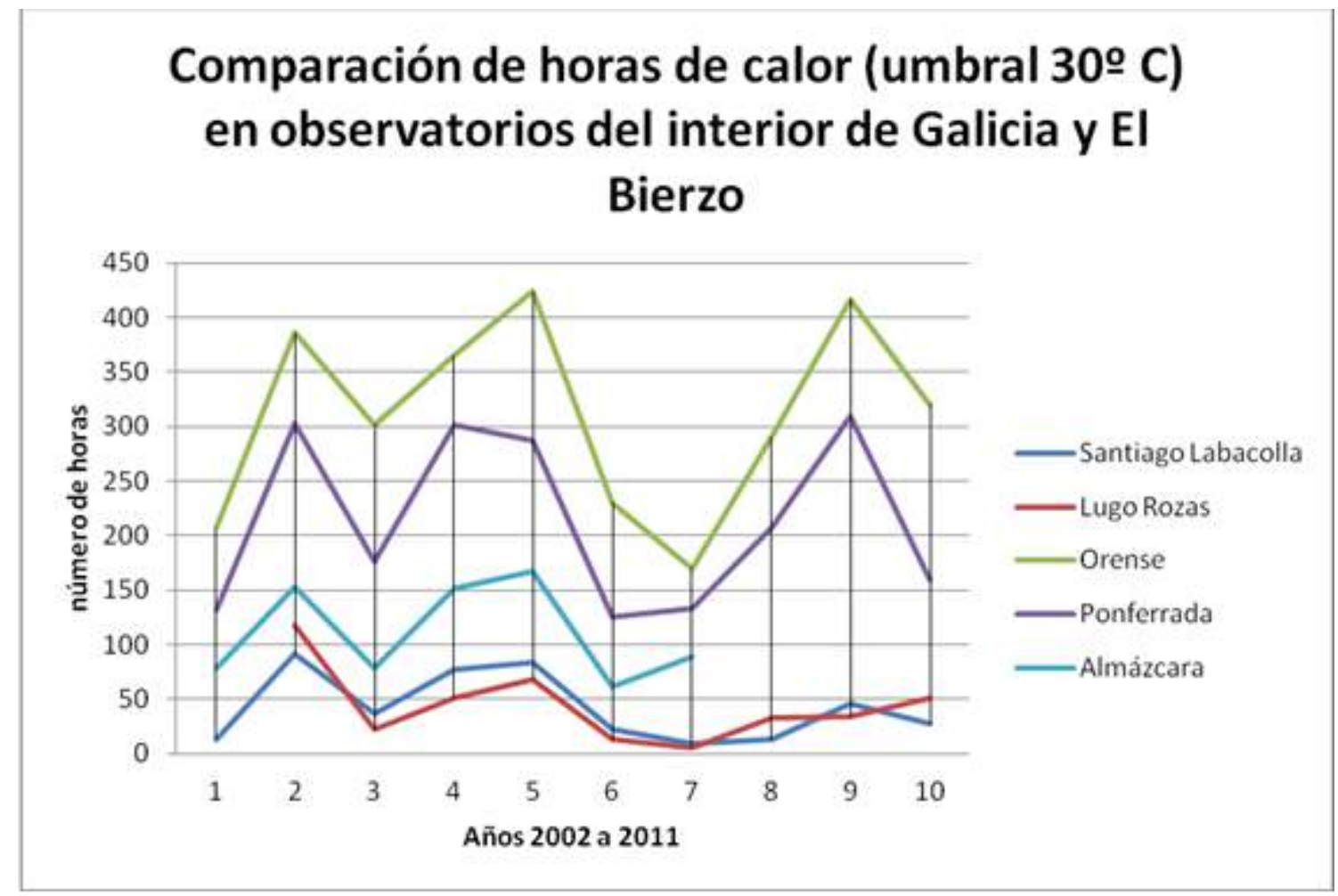

Gráfico 16. Comparación de horas de calor (umbral 30C) en observatorios del interior de Galicia y el valle del Bierzo. 


\section{Horas de calor contadas en datos horarios en cada uno de los observatorios}

Santiago Labacolla. No llega en promedio a las 50 horas de calor (umbral $30^{\circ} \mathrm{C}$ ) al año, y ningún mes tiene horas de calor todos los años.

Tabla 230. Horas de calor contadas en datos horarios en el observatorio de Santiago Labacolla.

\begin{tabular}{cccccccccccccc}
\hline & ene & feb & mar & abr & may & jun & jul & ago & sep & oct & nov & dic & anual \\
\hline $\mathbf{2 0 0 2}$ & 0 & 0 & 0 & 0 & 0 & 2 & 0 & 11 & 0 & 0 & 0 & 0 & 13 \\
$\mathbf{2 0 0 3}$ & 0 & 0 & 0 & 0 & 0 & 18 & 0 & 60 & 13 & 0 & 0 & 0 & 91 \\
$\mathbf{2 0 0 4}$ & 0 & 0 & 0 & 0 & 0 & 11 & 26 & 0 & 0 & 0 & 0 & 0 & 37 \\
$\mathbf{2 0 0 5}$ & 0 & 0 & 0 & 0 & 0 & 28 & 27 & 21 & 1 & 0 & 0 & 0 & 77 \\
$\mathbf{2 0 0 6}$ & 0 & 0 & 0 & 0 & 4 & 17 & 30 & 11 & 22 & 0 & 0 & 0 & 84 \\
$\mathbf{2 0 0 7}$ & 0 & 0 & 0 & 0 & 0 & 0 & 7 & 11 & 5 & 0 & 0 & 0 & 23 \\
$\mathbf{2 0 0 8}$ & 0 & 0 & 0 & 0 & 0 & 0 & 6 & 3 & 0 & 0 & 0 & 0 & 9 \\
$\mathbf{2 0 0 9}$ & 0 & 0 & 0 & 0 & 1 & 1 & 0 & 11 & 0 & 0 & 0 & 0 & 13 \\
$\mathbf{2 0 1 0}$ & 0 & 0 & 0 & 0 & 5 & 7 & 16 & 13 & 5 & 0 & 0 & 0 & 46 \\
$\mathbf{2 0 1 1}$ & 0 & 0 & 0 & 0 & 0 & 16 & 4 & 7 & 0 & 0 & 0 & 0 & 27 \\
Prom. & 0 & 0 & 0 & 0 & 1 & 10 & 12 & 15 & 5 & 0 & 0 & 0 & 42 \\
\hline
\end{tabular}

Lugo Rozas. No llega en promedio a las 50 horas de calor (umbral $30^{\circ} \mathrm{C}$ ) al año, y solamente el mes de agosto tiene alguna hora de calor todos los años.

Tabla 231. Horas de calor contadas en datos horarios en el observatorio de Lugo Rozas.

\begin{tabular}{cccccccccccccc}
\hline & ene & feb & mar & abr & may & jun & jul & ago & sep & oct & nov & dic & anual \\
\hline $\mathbf{2 0 0 2}$ & & & & & & & & 5 & 0 & 0 & 0 & 0 & \\
$\mathbf{2 0 0 3}$ & 0 & 0 & 0 & 0 & 4 & 13 & 0 & 79 & 22 & 0 & 0 & 0 & 118 \\
$\mathbf{2 0 0 4}$ & 0 & 0 & 0 & 0 & 0 & 9 & 10 & 4 & 0 & 0 & 0 & 0 & 23 \\
$\mathbf{2 0 0 5}$ & 0 & 0 & 0 & 0 & 3 & 16 & 18 & 6 & 8 & 0 & 0 & 0 & 51 \\
$\mathbf{2 0 0 6}$ & 0 & 0 & 0 & 0 & 0 & 9 & 25 & 6 & 28 & 0 & 0 & 0 & 68 \\
$\mathbf{2 0 0 7}$ & 0 & 0 & 0 & 0 & 0 & 0 & 3 & 10 & 0 & 0 & 0 & 0 & 13 \\
$\mathbf{2 0 0 8}$ & 0 & 0 & 0 & 0 & 0 & 0 & 0 & 6 & 0 & 0 & 0 & 0 & 6 \\
$\mathbf{2 0 0 9}$ & 0 & 0 & 0 & 0 & 5 & 0 & 1 & 21 & 6 & 0 & 0 & 0 & 33 \\
$\mathbf{2 0 1 0}$ & 0 & 0 & 0 & 0 & 2 & 2 & 6 & 16 & 8 & 0 & 0 & 0 & 34 \\
$\mathbf{2 0 1 1}$ & 0 & 0 & 0 & 6 & 0 & 20 & 3 & 11 & 7 & 4 & 0 & 0 & 51 \\
Prom. & 0 & 0 & 0 & 1 & 2 & 8 & 7 & 16 & 8 & 0 & 0 & 0 & 44 \\
\hline
\end{tabular}


Orense. Tiene en promedio de 300 horas de calor (umbral $30^{\circ} \mathrm{C}$ ) al año, oscilando entre las 170 horas de 2008 y las 424 de 2006.

Los tres primeros y dos últimos meses del años están libres de horas de calor. En octubre de 2011 se dieron 45 horas, el único octubre junto con el de 2005, que tuvo una hora, en el que hubo horas de calor. Abril tiene horas de calor casi todos los años, pero muy pocas, y mayo tiene casi todos los años y está en torno a la media hora diaria en promedio. Septiembre no llega a las dos horas diarias, junio las sobrepasa ligeramente, y julio y agosto tienen en promedio en torno a las 3 horas diarias.

La variabilidad es muy grande entre unos años y otros, tanto en el valor anual como en las de los distintos meses.

Tabla 232. Horas de calor contadas en datos horarios en el observatorio de Orense.

\begin{tabular}{rrrrrrrrrrrrrr}
\hline & ene & feb & mar & abr & may & jun & jul & ago & sep & oct & nov & dic & anual \\
\hline $\mathbf{2 0 0 2}$ & 0 & 0 & 0 & 15 & 9 & 47 & 70 & 48 & 18 & 0 & 0 & 0 & 207 \\
$\mathbf{2 0 0 3}$ & 0 & 0 & 0 & 0 & 27 & 73 & 61 & 161 & 64 & 0 & 0 & 0 & 386 \\
$\mathbf{2 0 0 4}$ & 0 & 0 & 0 & 3 & 12 & 123 & 111 & 31 & 22 & 0 & 0 & 0 & 302 \\
$\mathbf{2 0 0 5}$ & 0 & 0 & 0 & 0 & 11 & 110 & 89 & 118 & 36 & 1 & 0 & 0 & 365 \\
$\mathbf{2 0 0 6}$ & 0 & 0 & 0 & 2 & 17 & 74 & 136 & 118 & 77 & 0 & 0 & 0 & 424 \\
$\mathbf{2 0 0 7}$ & 0 & 0 & 0 & 3 & 11 & 11 & 70 & 55 & 80 & 0 & 0 & 0 & 230 \\
$\mathbf{2 0 0 8}$ & 0 & 0 & 0 & 4 & 0 & 34 & 62 & 65 & 5 & 0 & 0 & 0 & 170 \\
$\mathbf{2 0 0 9}$ & 0 & 0 & 0 & 0 & 32 & 59 & 26 & 102 & 72 & 0 & 0 & 0 & 291 \\
$\mathbf{2 0 1 0}$ & 0 & 0 & 0 & 1 & 37 & 69 & 128 & 135 & 47 & 0 & 0 & 0 & 417 \\
$\mathbf{2 0 1 1}$ & 0 & 0 & 0 & 14 & 18 & 46 & 51 & 91 & 55 & 45 & 0 & 0 & 320 \\
Prom. & 0 & 0 & 0 & 4 & 17 & 65 & 80 & 92 & 48 & 5 & 0 & 0 & 311 \\
\hline
\end{tabular}

Ponferrada. Tiene en promedio algo más de 200 horas de calor (umbral $30^{\circ} \mathrm{C}$ ) al año, oscilando entre las 125 horas de 2007 y las 310 de 2010.

Los tres primeros y dos últimos meses del año están libres de horas de calor. Octubre y abril las han tenido, muy pocas, un solo año en el periodo de diez. Mayo tiene muy pocas, y septiembre no llega a 1 hora diaria; para ambos meses hay años en los que no se dan horas de calor. Junio no llega a las dos horas diarias en promedio, y julio y agosto las sobrepasan ligeramente. 
La variabilidad es muy grande entre unos años y otros, tanto en el valor anual como en las de los distintos meses.

Tabla 233. Horas de calor contadas en datos horarios en el observatorio de Ponferrada.

\begin{tabular}{cccccccccccccc}
\hline & ene & feb & mar & abr & may & jun & jul & ago & sep & oct & nov & dic & anual \\
\hline $\mathbf{2 0 0 2}$ & 0 & 0 & 0 & 0 & 0 & 44 & 60 & 28 & 0 & 0 & 0 & 0 & 132 \\
$\mathbf{2 0 0 3}$ & 0 & 0 & 0 & 0 & 12 & 70 & 57 & 126 & 38 & 0 & 0 & 0 & 303 \\
$\mathbf{2 0 0 4}$ & 0 & 0 & 0 & 0 & 0 & 80 & 77 & 19 & 0 & 0 & 0 & 0 & 176 \\
$\mathbf{2 0 0 5}$ & 0 & 0 & 0 & 0 & 10 & 73 & 98 & 107 & 13 & 0 & 0 & 0 & 301 \\
$\mathbf{2 0 0 6}$ & 0 & 0 & 0 & 0 & 17 & 48 & 92 & 85 & 45 & 0 & 0 & 0 & 287 \\
$\mathbf{2 0 0 7}$ & 0 & 0 & 0 & 0 & 0 & 0 & 50 & 39 & 36 & 0 & 0 & 0 & 125 \\
$\mathbf{2 0 0 8}$ & 0 & 0 & 0 & 0 & 0 & 31 & 54 & 48 & 0 & 0 & 0 & 0 & 133 \\
$\mathbf{2 0 0 9}$ & 0 & 0 & 0 & 0 & 19 & 49 & 25 & 82 & 32 & 0 & 0 & 0 & 207 \\
$\mathbf{2 0 1 0}$ & 0 & 0 & 0 & 0 & 13 & 36 & 128 & 99 & 34 & 0 & 0 & 0 & 310 \\
$\mathbf{2 0 1 1}$ & 0 & 0 & 0 & 4 & 0 & 35 & 32 & 59 & 24 & 6 & 0 & 0 & 160 \\
Prom. & 0 & 0 & 0 & 0 & 7 & 47 & 67 & 69 & 22 & 1 & 0 & 0 & 213 \\
\hline
\end{tabular}

Resumen de horas de calor contadas para el interior de Galicia y el valle del Bierzo.

Los datos son coherentes entre ellos, y muestran que en el interior de Galicia, si se exceptúan los valles amplios de baja altitud (como el del Miño en Orense) en el sur de la región, las horas de calor no llegan a las 100 anuales. En esos valles y en el valle del Bierzo, sin embargo, se sobrepasan las 200 horas y se puede llegar a las 300 .

Es importante tener en cuenta la gran variabilidad entre unos años y otros y entre los mismos meses de los distintos años.

\subsubsection{Meseta Norte}

Observatorios: Soria (2030), Burgos Villafría (2331), León Virgen del camino (2661), Valladolid Villanubla (2539), Valladolid (2422), Segovia (2465), Zamora (2614), Salamanca (2867). 
Tabla 234 Comparación de horas de calor anuales contadas a partir de datos horarios en los ocho observatorios de la meseta Norte.

\begin{tabular}{|cccccccccc|}
\hline & $\begin{array}{c}\text { Soria } \\
\mathbf{2 0 3 0}\end{array}$ & $\begin{array}{c}\text { Villafría } \\
\mathbf{2 3 3 1}\end{array}$ & $\begin{array}{c}\text { León } \\
\mathbf{2 6 6 1}\end{array}$ & $\begin{array}{c}\text { Villanubla } \\
\mathbf{2 5 3 9}\end{array}$ & $\begin{array}{c}\text { Valladolid } \\
\mathbf{2 4 2 2}\end{array}$ & $\begin{array}{c}\text { Segovia } \\
\mathbf{2 4 6 5}\end{array}$ & $\begin{array}{c}\text { Zamora } \\
\mathbf{2 6 1 4}\end{array}$ & $\begin{array}{c}\text { Salamanca } \\
\mathbf{2 8 9 7}\end{array}$ \\
\hline $\mathbf{A n ̃ o}$ & $\mathrm{HC}$ & $\mathrm{HC}$ & $\mathrm{HC}$ & $\mathrm{HC}$ & $\mathrm{HC}$ & $\mathrm{HC}$ & $\mathrm{HC}$ & HC \\
\hline $\mathbf{2 0 0 2}$ & 92 & 101 & 53 & 141 & 230 & 148 & 207 & 158 \\
\hline $\mathbf{2 0 0 3}$ & 245 & 250 & 172 & 249 & 356 & 314 & 350 & 272 \\
\hline $\mathbf{2 0 0 4}$ & 87 & 109 & 46 & 128 & 228 & 154 & 255 & 173 \\
\hline $\mathbf{2 0 0 5}$ & 169 & 174 & 100 & 208 & 330 & 261 & 336 & 279 \\
\hline $\mathbf{2 0 0 6}$ & 128 & 199 & 93 & 198 & 314 & 207 & 368 & 260 \\
\hline $\mathbf{2 0 0 7}$ & 72 & 75 & 25 & 88 & 131 & 114 & 146 & 169 \\
\hline $\mathbf{2 0 0 8}$ & 68 & 63 & 36 & 89 & 159 & 120 & 207 & 206 \\
\hline $\mathbf{2 0 0 9}$ & 191 & 128 & 74 & 162 & 280 & 241 & 341 & 303 \\
\hline $\mathbf{2 0 1 0}$ & 133 & 94 & 99 & 165 & 246 & 189 & 348 & 300 \\
\hline $\mathbf{2 0 1 1}$ & 64 & 83 & 56 & 125 & 220 & 169 & 270 & 204 \\
\hline Prom. & 125 & 128 & 75 & 155 & 249 & 192 & 283 & 232 \\
\hline
\end{tabular}

Comparación de horas de calor (umbral 30 은 C) en observatorios de la meseta Norte

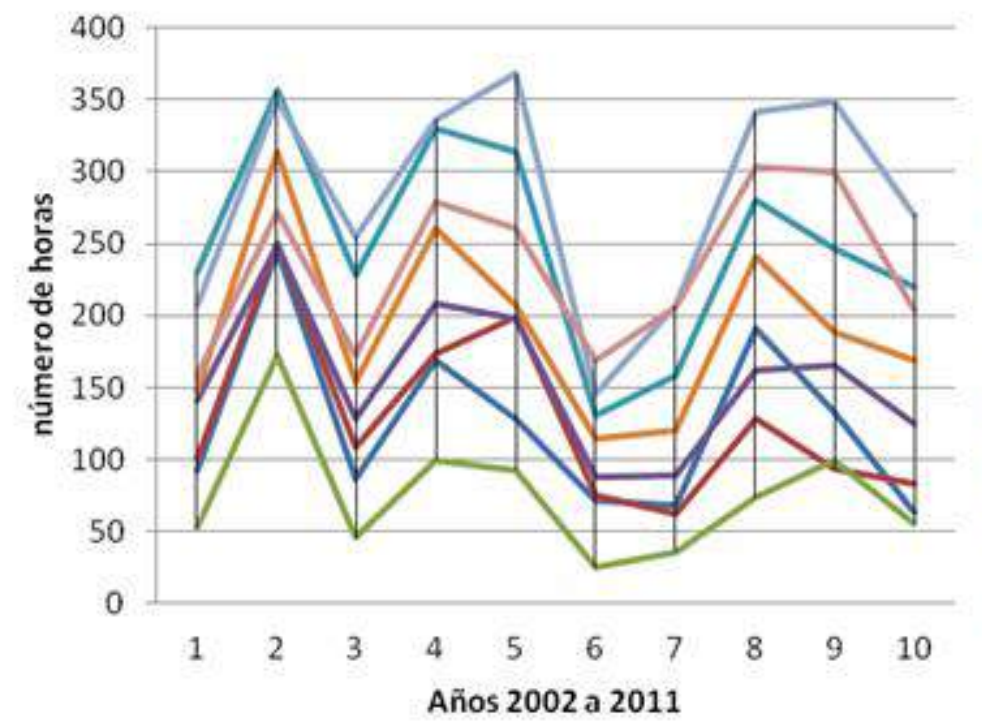

Soria

Burgos Villafría

León Virgen del Camino

- Valladolid Villanubla

- Valladolid CMT

Segovia

Zamora

_- Salamanca Matacán

Años 2002 a 2011

Gráfico 17. Comparación de horas de calor (umbral 30C) en observatorios de la meseta Norte. 
Los datos son coherentes entre ellos, aunque sorprende el bajo número de horas que hay en León Virgen del Camino respecto a los demás observatorios.

\section{Horas de calor contadas en datos horarios en cada uno de los observatorios}

Soria. No llega en promedio a las 150 horas de calor (umbral $30^{\circ} \mathrm{C}$ ) al año, oscilando entre las 245 horas de 2003 y las 68 de 2008.

Los cuatro primeros meses del año y los tres últimos están libres de horas de calor. Puede decirse que prácticamente sólo los meses de verano, junio, julio, agosto y septiembre las tienen; julio y agosto en torno a las 50 horas mensuales de promedio; junio no llega a las 30 y septiembre apenas tiene horas de calor. Se puede señalar que en septiembre son más los años en los que no hay horas de calor, aunque algún año, como el 2006, haya habido 31.

La variabilidad es muy grande entre unos años y otros, tanto en el valor anual como en los de los distintos meses. Por ejemplo, en agosto de 2003 hubo 117 horas, mientras que en 2002, 2004 y 2006 sólo hubo 12, 13 y 13 respectivamente.

Tabla 235. Horas de calor contadas en datos horarios en el observatorio de Soria.

\begin{tabular}{cccccccccccccc}
\hline & ene & feb & mar & abr & may & jun & jul & ago & sep & oct & nov & dic & anual \\
\hline $\mathbf{2 0 0 2}$ & 0 & 0 & 0 & 0 & 0 & 43 & 37 & 12 & 0 & 0 & 0 & 0 & 92 \\
\hline $\mathbf{2 0 0 3}$ & 0 & 0 & 0 & 0 & 0 & 49 & 79 & 117 & 0 & 0 & 0 & 0 & 245 \\
$\mathbf{2 0 0 4}$ & 0 & 0 & 0 & 0 & 0 & 31 & 43 & 13 & 0 & 0 & 0 & 0 & 87 \\
\hline $\mathbf{2 0 0 5}$ & 0 & 0 & 0 & 0 & 1 & 23 & 82 & 60 & 3 & 0 & 0 & 0 & 169 \\
\hline $\mathbf{2 0 0 6}$ & 0 & 0 & 0 & 0 & 2 & 13 & 69 & 13 & 31 & 0 & 0 & 0 & 128 \\
\hline $\mathbf{2 0 0 7}$ & 0 & 0 & 0 & 0 & 0 & 2 & 39 & 31 & 0 & 0 & 0 & 0 & 72 \\
\hline $\mathbf{2 0 0 8}$ & 0 & 0 & 0 & 0 & 0 & 0 & 27 & 41 & 0 & 0 & 0 & 0 & 68 \\
\hline $\mathbf{2 0 0 9}$ & 0 & 0 & 0 & 0 & 0 & 16 & 95 & 80 & 0 & 0 & 0 & 0 & 191 \\
\hline $\mathbf{2 0 1 0}$ & 0 & 0 & 0 & 0 & 0 & 0 & 72 & 61 & 0 & 0 & 0 & 0 & 133 \\
\hline $\mathbf{2 0 1 1}$ & 0 & 0 & 0 & 0 & 0 & 40 & 30 & 53 & 12 & 0 & 0 & 0 & 135 \\
\hline Prom. & 0 & 0 & 0 & 0 & 0 & 22 & 57 & 48 & 5 & 0 & 0 & 0 & 132 \\
\hline
\end{tabular}


Burgos Villafría. No llega en promedio a las 150 horas de calor (umbral $30^{\circ} \mathrm{C}$ ) al año, oscilando entre las 250 horas de 2003 y las 63 de 2008.

Los cinco primeros meses del año y los tres últimos están libres de horas de calor; sólo los meses de verano, junio, julio, agosto y septiembre, tienen horas de calor. Julio y agosto tienen en torno a las 50 horas de promedio; junio no llega a las 30 y septiembre apenas tiene horas de calor. Se puede señalar que en septiembre son más los años en los que no hay horas de calor, aunque algún año, como el 2006, haya 46.

Entre unos años y otros hay una gran variabilidad; y lo mismo sucede en los meses, por ejemplo, en agosto de 2003 hubo 141 horas, mientras que en 2006 sólo hubo 13 horas.

Tabla 236. Horas de calor contadas en datos horarios en el observatorio de Burgos Villafría.

\begin{tabular}{cccccccccccccc}
\hline & ene & feb & mar & abr & may & jun & jul & ago & sep & oct & nov & dic & anual \\
\hline $\mathbf{2 0 0 2}$ & 0 & 0 & 0 & 0 & 0 & 35 & 39 & 27 & 0 & 0 & 0 & 0 & 101 \\
\hline 2003 & 0 & 0 & 0 & 0 & 0 & 51 & 58 & 141 & 0 & 0 & 0 & 0 & 250 \\
$\mathbf{2 0 0 4}$ & 0 & 0 & 0 & 0 & 0 & 19 & 55 & 34 & 1 & 0 & 0 & 0 & 109 \\
\hline 2005 & 0 & 0 & 0 & 0 & 0 & 47 & 67 & 47 & 13 & 0 & 0 & 0 & 174 \\
$\mathbf{2 0 0 6}$ & 0 & 0 & 0 & 0 & 0 & 23 & 117 & 13 & 46 & 0 & 0 & 0 & 199 \\
$\mathbf{2 0 0 7}$ & 0 & 0 & 0 & 0 & 0 & 0 & 44 & 31 & 0 & 0 & 0 & 0 & 75 \\
$\mathbf{2 0 0 8}$ & 0 & 0 & 0 & 0 & 0 & 4 & 27 & 32 & 0 & 0 & 0 & 0 & 63 \\
$\mathbf{2 0 0 9}$ & 0 & 0 & 0 & 0 & 0 & 13 & 40 & 74 & 1 & 0 & 0 & 0 & 128 \\
$\mathbf{2 0 1 0}$ & 0 & 0 & 0 & 0 & 0 & 0 & 49 & 45 & 0 & 0 & 0 & 0 & 94 \\
\hline $\mathbf{2 0 1 1}$ & 0 & 0 & 0 & 0 & 0 & 25 & 4 & 46 & 8 & 0 & 0 & 0 & 83 \\
Prom. & & & & & 0 & 22 & 50 & 49 & 7 & & & & 128 \\
\hline
\end{tabular}

León Virgen del Camino. No llega a las 100 horas de calor (umbral $30^{\circ} \mathrm{C}$ ) al año, oscilando entre las 172 horas de 2003 y las 25 de 2007.

Los cuatro primeros meses del año y los tres últimos están libres de horas de calor; sólo los meses de verano, junio, julio, agosto y septiembre, las tienen. Julio y agosto tienen en torno a las 30 mensuales de promedio; junio y septiembre apenas tienen, aunque se puede señalar que en septiembre, mes en el que son más los años en los que no hay horas de calor, hay años, como el 2006, que tienen 35 horas de calor. 
La variabilidad es muy grande entre unos años y otros, tanto en el valor anual como en los de los distintos meses. Por ejemplo, en agosto de 2003 hubo 100 horas, mientras que en 2006 sólo hubo 5 horas.

Tabla 237. Horas de calor contadas en datos horarios en el observatorio de León Virgen del Camino.

\begin{tabular}{cccccccccccccc}
\hline & ene & feb & mar & abr & may & jun & jul & ago & sep & oct & nov & dic & anual \\
\hline $\mathbf{2 0 0 2}$ & 0 & 0 & 0 & 0 & 0 & 21 & 24 & 8 & 0 & 0 & 0 & 0 & 53 \\
$\mathbf{2 0 0 3}$ & 0 & 0 & 0 & 0 & 0 & 31 & 41 & 100 & 0 & 0 & 0 & 0 & 172 \\
$\mathbf{2 0 0 4}$ & 0 & 0 & 0 & 0 & 0 & 15 & 22 & 9 & 0 & 0 & 0 & 0 & 46 \\
\hline $\mathbf{2 0 0 5}$ & 0 & 0 & 0 & 0 & 0 & 19 & 41 & 40 & 0 & 0 & 0 & 0 & 100 \\
$\mathbf{2 0 0 6}$ & 0 & 0 & 0 & 0 & 0 & 6 & 47 & 5 & 35 & 0 & 0 & 0 & 93 \\
$\mathbf{2 0 0 7}$ & 0 & 0 & 0 & 0 & 0 & 0 & 12 & 13 & 0 & 0 & 0 & 0 & 25 \\
$\mathbf{2 0 0 8}$ & 0 & 0 & 0 & 0 & 0 & 1 & 12 & 23 & 0 & 0 & 0 & 0 & 36 \\
$\mathbf{2 0 0 9}$ & 0 & 0 & 0 & 0 & 0 & 7 & 8 & 57 & 2 & 0 & 0 & 0 & 74 \\
$\mathbf{2 0 1 0}$ & 0 & 0 & 0 & 0 & 0 & 0 & 65 & 33 & 1 & 0 & 0 & 0 & 99 \\
\hline $\mathbf{2 0 1 1}$ & 0 & 0 & 0 & 0 & 0 & 20 & 2 & 34 & 0 & 0 & 0 & 0 & 56 \\
Prom. & 0 & 0 & 0 & 0 & 0 & 12 & 27 & 32 & 4 & 0 & 0 & 0 & 75 \\
\hline
\end{tabular}

Villanubla Valladolid. Tiene en promedio poco más de 150 horas de calor (umbral $30^{\circ} \mathrm{C}$ ) al año, oscilando entre las 249 horas de 2003 y las 88 de 2007.

Los cuatro primeros meses del año y los tres últimos están libres de horas de calor. Los meses de verano, junio, julio, agosto y septiembre, y algún año mayo, tienen horas de calor. Julio y agosto tienen de promedio cerca de 60 horas mensuales; junio, 30, y septiembre apenas tiene. Se puede señalar que en septiembre hay años sin horas de calor y otros como el 2006 que tiene 55, casi dos horas diarias en promedio.

La variabilidad es muy grande entre unos años y otros, tanto en el valor anual como en los de los distintos meses. Por ejemplo, en agosto de 2003 hubo 136 horas, mientras que en 2006 sólo hubo 17 horas. 
Tabla 238. Horas de calor contadas en datos horarios en el observatorio de Villanubla Valladolid.

\begin{tabular}{cccccccccccccc}
\hline & ene & feb & mar & abr & may & jun & jul & ago & sep & oct & nov & dic & anual \\
\hline $\mathbf{2 0 0 2}$ & 0 & 0 & 0 & 0 & 0 & 63 & 57 & 21 & 0 & 0 & 0 & 0 & 141 \\
$\mathbf{2 0 0 3}$ & 0 & 0 & 0 & 0 & 0 & 50 & 63 & 136 & 0 & 0 & 0 & 0 & 249 \\
$\mathbf{2 0 0 4}$ & 0 & 0 & 0 & 0 & 0 & 35 & 63 & 29 & 1 & 0 & 0 & 0 & 128 \\
$\mathbf{2 0 0 5}$ & 0 & 0 & 0 & 0 & 10 & 47 & 72 & 72 & 7 & 0 & 0 & 0 & 208 \\
$\mathbf{2 0 0 6}$ & 0 & 0 & 0 & 0 & 0 & 30 & 96 & 17 & 55 & 0 & 0 & 0 & 198 \\
$\mathbf{2 0 0 7}$ & 0 & 0 & 0 & 0 & 0 & 0 & 56 & 32 & 0 & 0 & 0 & 0 & 88 \\
$\mathbf{2 0 0 8}$ & 0 & 0 & 0 & 0 & 0 & 17 & 32 & 40 & 0 & 0 & 0 & 0 & 89 \\
$\mathbf{2 0 0 9}$ & 0 & 0 & 0 & 0 & 0 & 21 & 33 & 97 & 11 & 0 & 0 & 0 & 162 \\
$\mathbf{2 0 1 0}$ & 0 & 0 & 0 & 0 & 0 & 5 & 88 & 72 & 0 & 0 & 0 & 0 & 165 \\
$\mathbf{2 0 1 1}$ & 0 & 0 & 0 & 0 & 0 & 35 & 14 & 61 & 15 & 0 & 0 & 0 & 125 \\
Prom. & 0 & 0 & 0 & 0 & 1 & 30 & 57 & 58 & 9 & 0 & 0 & 0 & 155 \\
\hline
\end{tabular}

Valladolid CMT. Tiene un promedio de 250 horas de calor (umbral $30^{\circ} \mathrm{C}$ ) al año, oscilando entre las 356 horas de 2003 y las 131 de 2007.

Los cuatro primeros meses del año y los tres últimos están libres de horas de calor. Los meses de verano, junio, julio, agosto y septiembre, y algún año mayo, tienen horas de calor. Julio y agosto tienen de promedio en torno a 90 horas; junio casi 60 y septiembre apenas tiene. Se puede señalar que en septiembre hay años que no tienen horas de calor, aunque algún año, como el 2006, haya 62.

La variabilidad es muy grande entre unos años y otros, tanto en el valor anual como en los de los distintos meses. Por ejemplo, en agosto de 2003 hubo 168 horas, mientras que en 2006 sólo hubo 38 horas.

Tabla 239. Horas de calor contadas en datos horarios en el observatorio de Valladolid CMT.

\begin{tabular}{cccccccccccccc}
\hline & ene & feb & mar & abr & may & jun & jul & ago & sep & oct & nov & dic & anual \\
\hline $\mathbf{2 0 0 2}$ & 0 & 0 & 0 & 0 & 0 & 109 & 77 & 44 & 0 & 0 & 0 & 0 & 230 \\
\hline 2003 & 0 & 0 & 0 & 0 & 2 & 89 & 94 & 168 & 3 & 0 & 0 & 0 & 356 \\
$\mathbf{2 0 0 4}$ & 0 & 0 & 0 & 0 & 0 & 71 & 104 & 51 & 2 & 0 & 0 & 0 & 228 \\
\hline $\mathbf{2 0 0 5}$ & 0 & 0 & 0 & 0 & 17 & 81 & 101 & 114 & 17 & 0 & 0 & 0 & 330 \\
$\mathbf{2 0 0 6}$ & 0 & 0 & 0 & 0 & 14 & 52 & 148 & 38 & 62 & 0 & 0 & 0 & 314 \\
$\mathbf{2 0 0 7}$ & 0 & 0 & 0 & 0 & 0 & 4 & 80 & 47 & 0 & 0 & 0 & 0 & 131 \\
$\mathbf{2 0 0 8}$ & 0 & 0 & 0 & 0 & 0 & 37 & 56 & 66 & 0 & 0 & 0 & 0 & 159 \\
$\mathbf{2 0 0 9}$ & 0 & 0 & 0 & 0 & 4 & 46 & 87 & 123 & 20 & 0 & 0 & 0 & 280 \\
$\mathbf{2 0 1 0}$ & 0 & 0 & 0 & 0 & 0 & 22 & 127 & 97 & 0 & 0 & 0 & 0 & 246 \\
\hline $\mathbf{2 0 1 1}$ & 0 & 0 & 0 & 0 & 0 & 51 & 46 & 86 & 37 & 0 & 0 & 0 & 220 \\
Prom. & 0 & 0 & 0 & 0 & 4 & 56 & 92 & 83 & 14 & 0 & 0 & 0 & 249 \\
\hline
\end{tabular}


Segovia. Tiene en promedio cerca de 200 horas de calor (umbral $30^{\circ} \mathrm{C}$ ) al año, oscilando entre las 314 horas de 2003 y las 114 de 2007.

Los cuatro primeros meses del año y los tres últimos están libres de horas de calor. Los meses de verano, junio, julio, agosto y septiembre, y algún año mayo, tienen horas de calor. Julio y agosto tienen de promedio más de 60 horas; junio, 35, y septiembre apenas tiene. Se puede señalar que en septiembre hay años sin horas de calor y otros como el 2006 que tiene 44.

La variabilidad es muy grande entre unos años y otros, tanto en el valor anual como en los de los distintos meses. Por ejemplo, en agosto de 2003 hubo 152 horas, mientras que en 2002 sólo hubo 23 horas.

Tabla 240. Horas de calor contadas en datos horarios en el observatorio de Segovia.

\begin{tabular}{cccccccccccccc}
\hline & ene & feb & mar & abr & may & jun & jul & ago & sep & oct & nov & dic & anual \\
\hline $\mathbf{2 0 0 2}$ & 0 & 0 & 0 & 0 & 0 & 66 & 59 & 23 & 0 & 0 & 0 & 0 & 148 \\
\hline $\mathbf{2 0 0 3}$ & 0 & 0 & 0 & 0 & 0 & 72 & 90 & 152 & 0 & 0 & 0 & 0 & 314 \\
$\mathbf{2 0 0 4}$ & 0 & 0 & 0 & 0 & 0 & 35 & 84 & 35 & 0 & 0 & 0 & 0 & 154 \\
\hline $\mathbf{2 0 0 5}$ & 0 & 0 & 0 & 0 & 10 & 37 & 99 & 104 & 11 & 0 & 0 & 0 & 261 \\
$\mathbf{2 0 0 6}$ & 0 & 0 & 0 & 0 & 3 & 31 & 102 & 27 & 44 & 0 & 0 & 0 & 207 \\
\hline $\mathbf{2 0 0 7}$ & 0 & 0 & 0 & 0 & 0 & 0 & 68 & 46 & 0 & 0 & 0 & 0 & 114 \\
$\mathbf{2 0 0 8}$ & 0 & 0 & 0 & 0 & 0 & 19 & 49 & 52 & 0 & 0 & 0 & 0 & 120 \\
\hline $\mathbf{2 0 0 9}$ & 0 & 0 & 0 & 0 & 0 & 26 & 76 & 126 & 13 & 0 & 0 & 0 & 241 \\
$\mathbf{2 0 1 0}$ & 0 & 0 & 0 & 0 & 0 & 6 & 110 & 73 & 0 & 0 & 0 & 0 & 189 \\
\hline $\mathbf{2 0 1 1}$ & 0 & 0 & 0 & 0 & 0 & 57 & 26 & 70 & 16 & 0 & 0 & 0 & 169 \\
Prom. & 0 & 0 & 0 & 0 & 1 & 35 & 76 & 71 & 8 & 0 & 0 & 0 & 192 \\
\hline
\end{tabular}

Zamora. Tiene en promedio cerca de 300 horas de calor (umbral $30^{\circ} \mathrm{C}$ ) al año, oscilando entre las 368 horas de 2006 y las 146 de 2007.

Los cuatro primeros meses del año y los tres últimos están libres de horas de calor. Sólo los meses de verano, junio, julio, agosto y septiembre, y algún año mayo, tienen horas de calor. Julio, de promedio, pasa de 100 horas; agosto tiene 90 , junio 70 y septiembre apenas tiene. Se puede señalar que en septiembre hay años sin horas de calor y otros como en 2006 que tiene 66, dos horas diarias. 
La variabilidad es muy grande entre unos años y otros, tanto en el valor anual como en los de los distintos meses. Por ejemplo, en agosto de 2003 hubo 152 horas, mientras que en 2002 sólo hubo 48 horas.

Tabla 241. Horas de calor contadas en datos horarios en el observatorio de Zamora.

\begin{tabular}{cccccccccccccc}
\hline & ene & feb & mar & abr & may & jun & jul & ago & sep & oct & nov & dic & anual \\
\hline $\mathbf{2 0 0 2}$ & 0 & 0 & 0 & 0 & 0 & 84 & 75 & 48 & 0 & 0 & 0 & 0 & 207 \\
$\mathbf{2 0 0 3}$ & 0 & 0 & 0 & 0 & 9 & 98 & 90 & 152 & 1 & 0 & 0 & 0 & 350 \\
$\mathbf{2 0 0 4}$ & 0 & 0 & 0 & 0 & 0 & 98 & 108 & 49 & 0 & 0 & 0 & 0 & 255 \\
$\mathbf{2 0 0 5}$ & 0 & 0 & 0 & 1 & 12 & 93 & 108 & 106 & 16 & 0 & 0 & 0 & 336 \\
$\mathbf{2 0 0 6}$ & 0 & 0 & 0 & 0 & 17 & 59 & 162 & 64 & 66 & 0 & 0 & 0 & 368 \\
$\mathbf{2 0 0 7}$ & 0 & 0 & 0 & 0 & 0 & 4 & 89 & 53 & 0 & 0 & 0 & 0 & 146 \\
$\mathbf{2 0 0 8}$ & 0 & 0 & 0 & 0 & 0 & 69 & 65 & 73 & 0 & 0 & 0 & 0 & 207 \\
$\mathbf{2 0 0 9}$ & 0 & 0 & 0 & 0 & 17 & 76 & 94 & 130 & 24 & 0 & 0 & 0 & 341 \\
$\mathbf{2 0 1 0}$ & 0 & 0 & 0 & 0 & 7 & 47 & 169 & 125 & 0 & 0 & 0 & 0 & 348 \\
\hline $\mathbf{2 0 1 1}$ & 0 & 0 & 0 & 0 & 5 & 62 & 71 & 93 & 39 & 0 & 0 & 0 & 270 \\
Prom. & 0 & 0 & 0 & 0 & 7 & 69 & 103 & 89 & 15 & 0 & 0 & 0 & 283 \\
\hline
\end{tabular}

Salamanca Matacán. Tiene en promedio más de 200 horas de calor (umbral $30^{\circ} \mathrm{C}$ ) al año, oscilando entre las 303 horas de 2009 y las 158 de 2002.

Los cuatro primeros meses del año y los tres últimos están libres de horas de calor. Sólo los meses de verano, junio, julio, agosto y septiembre, y algún año mayo, tienen horas de calor. Julio y agosto, de promedio, están por debajo de 90 horas; junio no llega a 60 y septiembre apenas tiene. Se puede señalar que en septiembre hay años sin horas de calor y otros como el 2006 que tiene 47, casi dos horas diarias en promedio.

La variabilidad es muy grande entre unos años y otros, tanto en el valor anual como en los de los distintos meses. Por ejemplo, en agosto de 2003 hubo 131 horas, mientras que en 2002 sólo hubo 22 horas. 
Tabla 242. Horas de calor contadas en datos horarios en el observatorio de Salamanca Matacán.

\begin{tabular}{cccccccccccccc}
\hline & ene & feb & mar & abr & may & jun & jul & ago & sep & oct & nov & dic & anual \\
\hline $\mathbf{2 0 0 2}$ & 0 & 0 & 0 & 0 & 0 & 77 & 59 & 22 & 0 & 0 & 0 & 0 & 158 \\
$\mathbf{2 0 0 3}$ & 0 & 0 & 0 & 0 & 0 & 64 & 77 & 131 & 0 & 0 & 0 & 0 & 272 \\
$\mathbf{2 0 0 4}$ & 0 & 0 & 0 & 0 & 0 & 61 & 85 & 27 & 0 & 0 & 0 & 0 & 173 \\
\hline $\mathbf{2 0 0 5}$ & 0 & 0 & 0 & 0 & 12 & 69 & 90 & 96 & 12 & 0 & 0 & 0 & 279 \\
$\mathbf{2 0 0 6}$ & 0 & 0 & 0 & 0 & 13 & 41 & 107 & 52 & 47 & 0 & 0 & 0 & 260 \\
$\mathbf{2 0 0 7}$ & 0 & 0 & 0 & 0 & 0 & 6 & 99 & 64 & 0 & 0 & 0 & 0 & 169 \\
$\mathbf{2 0 0 8}$ & 0 & 0 & 0 & 0 & 0 & 64 & 74 & 68 & 0 & 0 & 0 & 0 & 206 \\
$\mathbf{2 0 0 9}$ & 0 & 0 & 0 & 0 & 11 & 57 & 78 & 130 & 27 & 0 & 0 & 0 & 303 \\
$\mathbf{2 0 1 0}$ & 0 & 0 & 0 & 0 & 3 & 31 & 149 & 117 & 0 & 0 & 0 & 0 & 300 \\
$\mathbf{2 0 1 1}$ & 0 & 0 & 0 & 0 & 1 & 50 & 58 & 87 & 7 & 1 & 0 & 0 & 204 \\
Prom. & 0 & 0 & 0 & 0 & 4 & 52 & 88 & 79 & 9 & 0 & 0 & 0 & 232 \\
\hline
\end{tabular}

Resumen de horas de calor contadas para la meseta Norte en altitudes entre 650 y 950 metros.

En la meseta Norte, por debajo de $1000 \mathrm{~m}$ de altitud y dependiendo de ella, el número de horas de calor (umbral $30^{\circ} \mathrm{C}$ ) anuales está entre 50 y 350 . En los observatorios de las capitales provinciales se dan por encima de 200 horas en promedio en Valladolid, Salamanca y Zamora, cerca de las 200 horas en Segovia, en torno a 120 horas en Soria y Burgos y 75 horas en León.

Dentro de la escasez de horas de calor (umbral $30^{\circ} \mathrm{C}$ ), es preciso tener en cuenta la gran variabilidad entre unos años y otros, tanto en lo que se acumula cada año, como lo que se acumula en cada mes de los distintos años.

\subsubsection{Cuenca del Ebro: a) parte baja y relativamente llana del valle del Ebro}

Observatorios: Huesca (9901x), Zaragoza aeropuerto (9434), Lérida (9771c). 
Tabla 243. Comparación de horas de calor anuales contadas a partir de datos horarios en los tres observatorios del valle del Ebro.

\begin{tabular}{|cccc|}
\hline Año & $\begin{array}{c}\text { Huesca } \\
9901 \mathbf{x}\end{array}$ & $\begin{array}{c}\text { Zaragoza } \\
\mathbf{9 4 3 4}\end{array}$ & $\begin{array}{c}\text { Lérida } \\
\mathbf{9 7 7 1 c}\end{array}$ \\
\hline $\mathbf{2 0 0 2}$ & 264 & $\mathrm{HC}$ & $\mathrm{HC}$ \\
\hline $\mathbf{2 0 0 3}$ & 547 & 282 & 296 \\
\hline $\mathbf{2 0 0 4}$ & 256 & 635 & 604 \\
\hline $\mathbf{2 0 0 5}$ & 374 & 435 & 347 \\
\hline $\mathbf{2 0 0 6}$ & 307 & 441 & 382 \\
\hline $\mathbf{2 0 0 7}$ & 186 & 462 & 492 \\
\hline $\mathbf{2 0 0 8}$ & 247 & 302 & 301 \\
\hline $\mathbf{2 0 0 9}$ & 359 & 396 & 338 \\
\hline $\mathbf{2 0 1 0}$ & 333 & 569 & 484 \\
\hline $\mathbf{2 0 1 1}$ & 342 & 424 & 392 \\
\hline Promedio & 322 & 462 & 392 \\
\hline & & 441 & 403 \\
\hline
\end{tabular}

\section{Comparación de horas de calor (umbral 30응 C) anuales en observatorios del valle del} Ebro

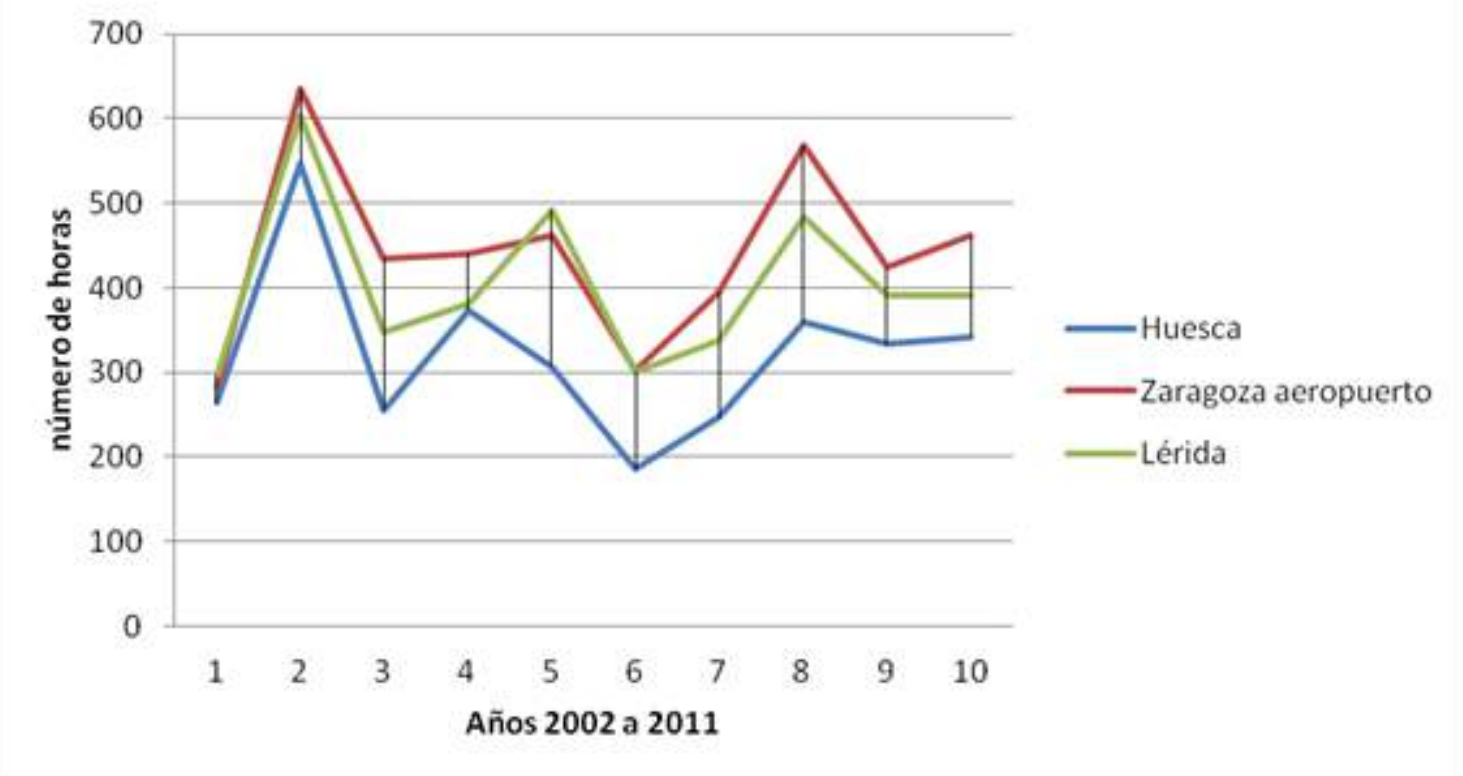

Gráfico 18. Comparación de horas de calor (umbral 30ㄷ) anuales en observatorios del valle del Ebro.

Son datos coherentes entre ellos. 


\section{$\underline{\text { Horas de calor contadas en datos horarios en cada uno de los observatorios }}$}

Huesca. Tiene en promedio algo más de 300 horas de calor (umbral $30^{\circ} \mathrm{C}$ ) anuales, oscilando entre las 186 de 2007 y las 547 de 2003.

Los cuatro primeros y los tres últimos meses del año no tienen horas de calor. Mayo y septiembre tienen muy pocas y no todos los años; junio tiene una media ligeramente superior a las dos horas diarias en promedio; julio y agosto pasan de las 100 horas mensuales.

Es muy marcada la variabilidad interanual y la que se da en cada mes en los distintos años.

Tabla 244. Horas de calor contadas en datos horarios en el observatorio de Huesca.

\begin{tabular}{cccccccccccccc}
\hline & ene & feb & mar & abr & may & jun & jul & ago & sep & oct & nov & dic & anual \\
\hline $\mathbf{2 0 0 2}$ & 0 & 0 & 0 & 0 & 2 & 122 & 90 & 50 & 0 & 0 & 0 & 0 & 264 \\
\hline $\mathbf{2 0 0 3}$ & 0 & 0 & 0 & 0 & 11 & 154 & 164 & 216 & 2 & 0 & 0 & 0 & 547 \\
$\mathbf{2 0 0 4}$ & 0 & 0 & 0 & 0 & 0 & 74 & 95 & 71 & 16 & 0 & 0 & 0 & 256 \\
\hline $\mathbf{2 0 0 5}$ & 0 & 0 & 0 & 0 & 1 & 110 & 160 & 75 & 28 & 0 & 0 & 0 & 374 \\
$\mathbf{2 0 0 6}$ & 0 & 0 & 0 & 0 & 27 & 46 & 174 & 29 & 31 & 0 & 0 & 0 & 307 \\
$\mathbf{2 0 0 7}$ & 0 & 0 & 0 & 0 & 0 & 17 & 92 & 77 & 0 & 0 & 0 & 0 & 186 \\
$\mathbf{2 0 0 8}$ & 0 & 0 & 0 & 0 & 0 & 42 & 104 & 97 & 4 & 0 & 0 & 0 & 247 \\
$\mathbf{2 0 0 9}$ & 0 & 0 & 0 & 0 & 2 & 80 & 145 & 129 & 3 & 0 & 0 & 0 & 359 \\
$\mathbf{2 0 1 0}$ & 0 & 0 & 0 & 0 & 0 & 30 & 176 & 120 & 7 & 0 & 0 & 0 & 333 \\
\hline $\mathbf{2 0 1 1}$ & 0 & 0 & 0 & 0 & 9 & 53 & 68 & 164 & 48 & 0 & 0 & 0 & 342 \\
\hline Prom. & 0 & 0 & 0 & 0 & 5 & 73 & 127 & 103 & 14 & 0 & 0 & 0 & 322 \\
\hline
\end{tabular}

\section{Zaragoza aeropuerto.}

Tiene en promedio más de 400 horas de calor (umbral $30^{\circ} \mathrm{C}$ ) anuales, oscilando entre las 282 de 2002 y las 635 de 2003.

Los tres primeros y los dos últimos meses del año no tienen horas de calor. Abril y octubre tienen muy pocas y pocos años; mayo tiene todos los años pero muy pocas. Junio, julio y agosto pasan en promedio de las 100 horas mensuales, y septiembre tiene 30 .

Es muy marcada la variabilidad interanual y la que se da entre cada mes en los distintos años. 
Tabla 245. Horas de calor contadas en datos horarios en el observatorio de Zaragoza aeropuerto.

\begin{tabular}{cccccccccccccc}
\hline & ene & feb & mar & abr & may & jun & jul & ago & sep & oct & nov & dic & anual \\
\hline $\mathbf{2 0 0 2}$ & 0 & 0 & 0 & 0 & 2 & 124 & 90 & 66 & 0 & 0 & 0 & 0 & 282 \\
$\mathbf{2 0 0 3}$ & 0 & 0 & 0 & 0 & 26 & 172 & 197 & 240 & 0 & 0 & 0 & 0 & 635 \\
$\mathbf{2 0 0 4}$ & 0 & 0 & 0 & 0 & 2 & 125 & 128 & 134 & 40 & 6 & 0 & 0 & 435 \\
$\mathbf{2 0 0 5}$ & 0 & 0 & 0 & 10 & 24 & 114 & 163 & 100 & 30 & 0 & 0 & 0 & 441 \\
$\mathbf{2 0 0 6}$ & 0 & 0 & 0 & 0 & 35 & 82 & 235 & 39 & 71 & 0 & 0 & 0 & 462 \\
$\mathbf{2 0 0 7}$ & 0 & 0 & 0 & 0 & 7 & 52 & 134 & 104 & 5 & 0 & 0 & 0 & 302 \\
$\mathbf{2 0 0 8}$ & 0 & 0 & 0 & 2 & 1 & 71 & 161 & 129 & 32 & 0 & 0 & 0 & 396 \\
\hline $\mathbf{2 0 0 9}$ & 0 & 0 & 0 & 0 & 23 & 131 & 196 & 183 & 35 & 1 & 0 & 0 & 569 \\
$\mathbf{2 0 1 0}$ & 0 & 0 & 0 & 0 & 1 & 74 & 198 & 126 & 25 & 0 & 0 & 0 & 424 \\
\hline $\mathbf{2 0 1 1}$ & 0 & 0 & 0 & 4 & 14 & 86 & 92 & 201 & 62 & 3 & 0 & 0 & 462 \\
Prom. & 0 & 0 & 0 & 2 & 14 & 103 & 159 & 132 & 30 & 1 & 0 & 0 & 441 \\
\hline
\end{tabular}

\section{Lérida.}

Tiene en promedio unas 400 horas de calor (umbral $30^{\circ} \mathrm{C}$ ) anuales, oscilando entre las 296 de 2002 y las 604 de 2003.

Los tres primeros y dos últimos meses del año no tienen horas de calor. Abril y octubre tienen muy pocas y pocos años. Mayo tiene menos de media hora diaria en promedio y septiembre, menos de una hora. Julio y agosto pasan de las 100 horas mensuales y junio no las alcanza.

Es muy marcada la variabilidad interanual y la que se da entre cada mes en los distintos años.

Tabla 246. Horas de calor contadas en datos horarios en el observatorio de Lérida.

\begin{tabular}{cccccccccccccc}
\hline & ene & feb & mar & abr & may & jun & jul & ago & sep & Oct & nov & dic & anual \\
\hline $\mathbf{2 0 0 2}$ & 0 & 0 & 0 & 0 & 2 & 115 & 115 & 63 & 1 & 0 & 0 & 0 & 296 \\
$\mathbf{2 0 0 3}$ & 0 & 0 & 0 & 0 & 22 & 172 & 184 & 226 & 0 & 0 & 0 & 0 & 604 \\
$\mathbf{2 0 0 4}$ & 0 & 0 & 0 & 0 & 0 & 104 & 108 & 104 & 27 & 4 & 0 & 0 & 347 \\
$\mathbf{2 0 0 5}$ & 0 & 0 & 0 & 5 & 14 & 103 & 165 & 67 & 28 & 0 & 0 & 0 & 382 \\
$\mathbf{2 0 0 6}$ & 0 & 0 & 0 & 0 & 31 & 82 & 240 & 82 & 57 & 0 & 0 & 0 & 492 \\
$\mathbf{2 0 0 7}$ & 0 & 0 & 0 & 0 & 11 & 46 & 132 & 100 & 12 & 0 & 0 & 0 & 301 \\
$\mathbf{2 0 0 8}$ & 0 & 0 & 0 & 0 & 1 & 65 & 116 & 133 & 23 & 0 & 0 & 0 & 338 \\
$\mathbf{2 0 0 9}$ & 0 & 0 & 0 & 0 & 17 & 105 & 179 & 159 & 22 & 2 & 0 & 0 & 484 \\
$\mathbf{2 0 1 0}$ & 0 & 0 & 0 & 0 & 7 & 53 & 192 & 124 & 16 & 0 & 0 & 0 & 392 \\
$\mathbf{2 0 1 1}$ & 0 & 0 & 0 & 4 & 17 & 69 & 73 & 165 & 64 & 0 & 0 & 0 & 392 \\
Prom. & 0 & 0 & 0 & 1 & 12 & 91 & 150 & 122 & 25 & 1 & 0 & 0 & 403 \\
\hline
\end{tabular}


Observatorios: Pamplona Noáin (9263d), Haro automática (9121x) y Logroño-Agoncillo (9170),

Tabla 247. Comparación de horas de calor anuales contadas a partir de datos horarios en los tres observatorios de la parte media de la cuenca del Ebro: Navarra y La Rioja.

\begin{tabular}{|cccc|}
\hline & $\begin{array}{c}\text { Pamplona Noáin } \\
\text { 9263d }\end{array}$ & $\begin{array}{c}\text { Haro automática } \\
\text { 9121x }\end{array}$ & $\begin{array}{c}\text { Logroño-Agoncillo } \\
\text { 9170 }\end{array}$ \\
\hline HC & HC & HC \\
\hline $\mathbf{2 0 0 2}$ & & & 162 \\
\hline $\mathbf{2 0 0 3}$ & 138 & & 439 \\
\hline $\mathbf{2 0 0 4}$ & 366 & & 217 \\
\hline $\mathbf{2 0 0 5}$ & 159 & 138 & 308 \\
\hline $\mathbf{2 0 0 6}$ & 193 & 215 & 284 \\
\hline $\mathbf{2 0 0 7}$ & 189 & 188 & 168 \\
\hline $\mathbf{2 0 0 8}$ & 140 & 113 & 168 \\
\hline $\mathbf{2 0 0 9}$ & 138 & 100 & 307 \\
\hline $\mathbf{2 0 1 0}$ & 262 & 218 & 224 \\
\hline $\mathbf{2 0 1 1}$ & 177 & 157 & 231 \\
\hline promedio & 210 & 141 & 251 \\
\hline
\end{tabular}

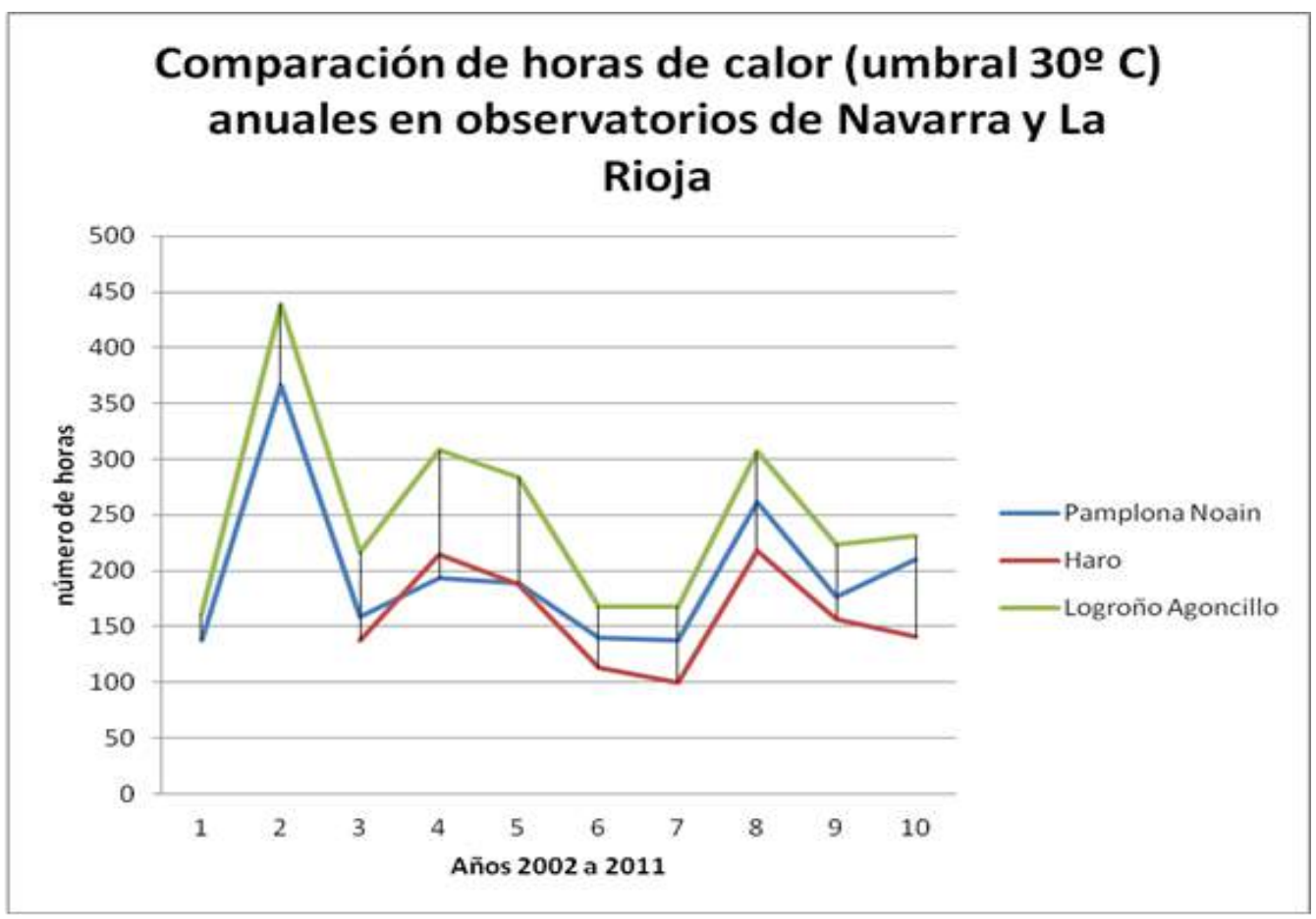

Gráfico 19. Comparación de horas de calor (umbral 30ㄷ) anuales en los observatorios de la parte media de la cuenca del Ebro: Navarra y La Rioja.

Los datos son coherentes entre ellos. 


\section{Horas de calor contadas en datos horarios en cada uno de los observatorios}

Pamplona-Noáin. Tiene en promedio unas 200 horas de calor (umbral $30^{\circ} \mathrm{C}$ ) anuales, oscilando entre las 138 de 2002 y 2008 y las 366 de 2003.

Los cuatro primeros y los dos últimos meses del año no tienen horas de calor. Octubre apenas tiene dos años de los diez del periodo; mayo y septiembre tienen muy pocas y no todos los años; julio y agosto pasan en promedio de las 50 horas de calor mensuales, y junio no llega a ellas.

Es muy marcada la variabilidad interanual y la que se da entre cada mes en los distintos años.

Tabla 248. Horas de calor contadas en datos horarios en el observatorio de Pamplona Noáin.

\begin{tabular}{cccccccccccccc}
\hline & ene & feb & mar & abr & may & jun & jul & ago & sep & oct & nov & dic & anual \\
\hline $\mathbf{2 0 0 2}$ & 0 & 0 & 0 & 0 & 5 & 67 & 37 & 29 & 0 & 0 & 0 & 0 & 138 \\
\hline $\mathbf{2 0 0 3}$ & 0 & 0 & 0 & 0 & 15 & 101 & 81 & 169 & 0 & 0 & 0 & 0 & 366 \\
\hline $\mathbf{2 0 0 4}$ & 0 & 0 & 0 & 0 & 0 & 34 & 59 & 50 & 13 & 3 & 0 & 0 & 159 \\
\hline $\mathbf{2 0 0 5}$ & 0 & 0 & 0 & 0 & 13 & 70 & 64 & 28 & 18 & 0 & 0 & 0 & 193 \\
\hline $\mathbf{2 0 0 6}$ & 0 & 0 & 0 & 0 & 2 & 31 & 108 & 2 & 46 & 0 & 0 & 0 & 189 \\
\hline $\mathbf{2 0 0 7}$ & 0 & 0 & 0 & 0 & 0 & 30 & 50 & 60 & 0 & 0 & 0 & 0 & 140 \\
\hline $\mathbf{2 0 0 8}$ & 0 & 0 & 0 & 0 & 0 & 23 & 62 & 47 & 6 & 0 & 0 & 0 & 138 \\
\hline $\mathbf{2 0 0 9}$ & 0 & 0 & 0 & 0 & 1 & 46 & 87 & 104 & 21 & 3 & 0 & 0 & 262 \\
\hline $\mathbf{2 0 1 0}$ & 0 & 0 & 0 & 0 & 0 & 12 & 82 & 66 & 17 & 0 & 0 & 0 & 177 \\
\hline $\mathbf{2 0 1 1}$ & 0 & 0 & 0 & 0 & 6 & 41 & 19 & 106 & 38 & 0 & 0 & 0 & 210 \\
\hline Prom. & 0 & 0 & 0 & 0 & 4 & 46 & 65 & 66 & 16 & 1 & 0 & 0 & 197 \\
\hline
\end{tabular}

Haro. Tiene datos completos en ocho de los diez años, del 2004 al 2011. En esos ocho años tiene en promedio unas 150 horas de calor (umbral $30^{\circ} \mathrm{C}$ ) anuales, oscilando entre las 100 de 2008 y las 218 de 2009.

Los tres primeros y los tres últimos meses del año no tienen horas de calor. Abril tiene muy pocas y sólo un año; mayo y septiembre tienen también pocas y no todos los años; julio pasa en promedio de las 50 horas mensuales, agosto no las alcanza y junio se queda en 30 .

En este caso, al faltarle datos de los años 2002 y 2003, los más extremos, no es tan marcada la variabilidad interanual. 
Tabla 249. Horas de calor contadas en datos horarios en el observatorio de Haro.

\begin{tabular}{|c|c|c|c|c|c|c|c|c|c|c|c|c|c|}
\hline & ene & feb & mar & $a b r$ & may & jun & jul & ago & sep & oct & nov & dic & anual \\
\hline \multicolumn{14}{|l|}{2002} \\
\hline \multicolumn{14}{|l|}{2003} \\
\hline 2004 & 0 & 0 & 0 & 0 & 0 & 36 & 59 & 37 & 6 & 0 & 0 & 0 & 138 \\
\hline 2005 & 0 & 0 & 0 & 0 & 15 & 67 & 74 & 41 & 18 & 0 & 0 & 0 & 215 \\
\hline 2006 & 0 & 0 & 0 & 0 & 3 & 34 & 99 & 9 & 43 & 0 & 0 & 0 & 188 \\
\hline 2007 & 0 & 0 & 0 & 0 & 0 & 12 & 49 & 52 & 0 & 0 & 0 & 0 & 113 \\
\hline 2008 & 0 & 0 & 0 & 0 & 0 & 15 & 46 & 35 & 4 & 0 & 0 & 0 & 100 \\
\hline 2009 & 0 & 0 & 0 & 0 & 4 & 50 & 76 & 80 & 8 & 0 & 0 & 0 & 218 \\
\hline 2010 & 0 & 0 & 0 & 0 & 0 & 9 & 64 & 63 & 21 & 0 & 0 & 0 & 157 \\
\hline 2011 & 0 & 0 & 0 & 2 & 5 & 33 & 15 & 64 & 22 & 0 & 0 & 0 & 141 \\
\hline Prom. & 0 & 0 & 0 & 0 & 3 & 32 & 60 & 48 & 15 & 0 & 0 & 0 & 159 \\
\hline
\end{tabular}

Logroño- Agoncillo. Tiene en promedio unas 250 horas de calor (umbral $30^{\circ} \mathrm{C}$ ) anuales, oscilando entre las 162 de 2002 y las 439 de 2003.

Los tres primeros y los dos últimos meses del año no tienen horas de calor. Abril y octubre tienen muy pocas y muy pocos años; mayo y septiembre tienen también pocas y no todos los años; julio y agosto no llegan en promedio a 100 horas mensuales y junio pasa ligeramente de 50.

Es muy marcada la variabilidad interanual y la que se da entre los mismos meses de distintos años.

Tabla 250. Horas de calor contadas en datos horarios en el observatorio de Logroño Agoncillo.

\begin{tabular}{rrrrrrrrrrrrrr}
\hline & ene & feb & mar & abr & may & jun & jul & ago & sep & oct & nov & dic & anual \\
\hline $\mathbf{2 0 0 2}$ & 0 & 0 & 0 & 0 & 3 & 68 & 48 & 43 & 0 & 0 & 0 & 0 & 162 \\
$\mathbf{2 0 0 3}$ & 0 & 0 & 0 & 0 & 16 & 106 & 126 & 191 & 0 & 0 & 0 & 0 & 439 \\
$\mathbf{2 0 0 4}$ & 0 & 0 & 0 & 0 & 0 & 68 & 86 & 56 & 7 & 0 & 0 & 0 & 217 \\
$\mathbf{2 0 0 5}$ & 0 & 0 & 0 & 1 & 11 & 95 & 119 & 62 & 20 & 0 & 0 & 0 & 308 \\
$\mathbf{2 0 0 6}$ & 0 & 0 & 0 & 0 & 10 & 55 & 160 & 11 & 48 & 0 & 0 & 0 & 284 \\
$\mathbf{2 0 0 7}$ & 0 & 0 & 0 & 0 & 0 & 26 & 80 & 60 & 2 & 0 & 0 & 0 & 168 \\
$\mathbf{2 0 0 8}$ & 0 & 0 & 0 & 0 & 0 & 24 & 67 & 69 & 8 & 0 & 0 & 0 & 168 \\
$\mathbf{2 0 0 9}$ & 0 & 0 & 0 & 0 & 4 & 62 & 105 & 116 & 20 & 0 & 0 & 0 & 307 \\
$\mathbf{2 0 1 0}$ & 0 & 0 & 0 & 0 & 0 & 20 & 103 & 80 & 21 & 0 & 0 & 0 & 224 \\
$\mathbf{2 0 1 1}$ & 0 & 0 & 0 & 3 & 6 & 42 & 35 & 111 & 27 & 7 & 0 & 0 & 231 \\
Prom. & 0 & 0 & 0 & 0 & 5 & 57 & 93 & 80 & 15 & 1 & 0 & 0 & 251 \\
\hline
\end{tabular}


Las horas de calor en el valle del Ebro, por debajo de $600 \mathrm{~m}$ de altitud, están entre las 150 y las 450 anuales, dependiendo de la altitud, la orientación del lugar y la distancia al mar (presencia de nubes que influye en las máximas).

Es importante tener en cuenta que la variabilidad interanual, y la que se da entre los mismos meses en los distintos años, es muy marcada.

\subsubsection{Zona de la franja costera del noreste peninsular: costa catalana}

Observatorios: Barcelona (0076), Gerona (0370x), Reus (0016a), Tarragona (0042x y 0042y) y Tortosa (9881a).

Tabla 251. Comparación de horas de calor anuales contadas a partir de datos horarios en los cinco observatorios de la franja costera del noreste peninsular: costa catalana.

\begin{tabular}{|cccccc|}
\hline Año & $\begin{array}{c}\text { Gerona } \\
\text { 0370 }\end{array}$ & $\begin{array}{c}\text { Barcelona } \\
\mathbf{7 6}\end{array}$ & $\begin{array}{c}\text { Reus } \\
\mathbf{0 0 1 6 a}\end{array}$ & $\begin{array}{c}\text { Tarragona } \\
\mathbf{0 0 4 2 \times / 0 0 4 2 y}\end{array}$ & $\begin{array}{c}\text { Tortosa } \\
\mathbf{9 9 8 1 a}\end{array}$ \\
\hline $\mathbf{2 0 0 2}$ & 159 & & HC & HC & HC \\
\hline $\mathbf{2 0 0 3}$ & 554 & 399 & 34 & 45 & 285 \\
\hline $\mathbf{2 0 0 4}$ & 212 & 57 & 146 & & 582 \\
\hline $\mathbf{2 0 0 5}$ & 254 & 27 & 92 & 28 & 449 \\
\hline $\mathbf{2 0 0 6}$ & 295 & 193 & 283 & 73 & 540 \\
\hline $\mathbf{2 0 0 7}$ & 210 & 16 & 91 & 3 & 319 \\
\hline $\mathbf{2 0 0 8}$ & 239 & 50 & 33 & 31 & 344 \\
\hline $\mathbf{2 0 0 9}$ & & 85 & 64 & 89 & 546 \\
\hline $\mathbf{2 0 1 0}$ & & 45 & 52 & 45 & 518 \\
\hline $\mathbf{2 0 1 1}$ & & 53 & 88 & 22 & 500 \\
\hline promedio & 275 & 103 & 126 & 62 & 443 \\
\hline
\end{tabular}




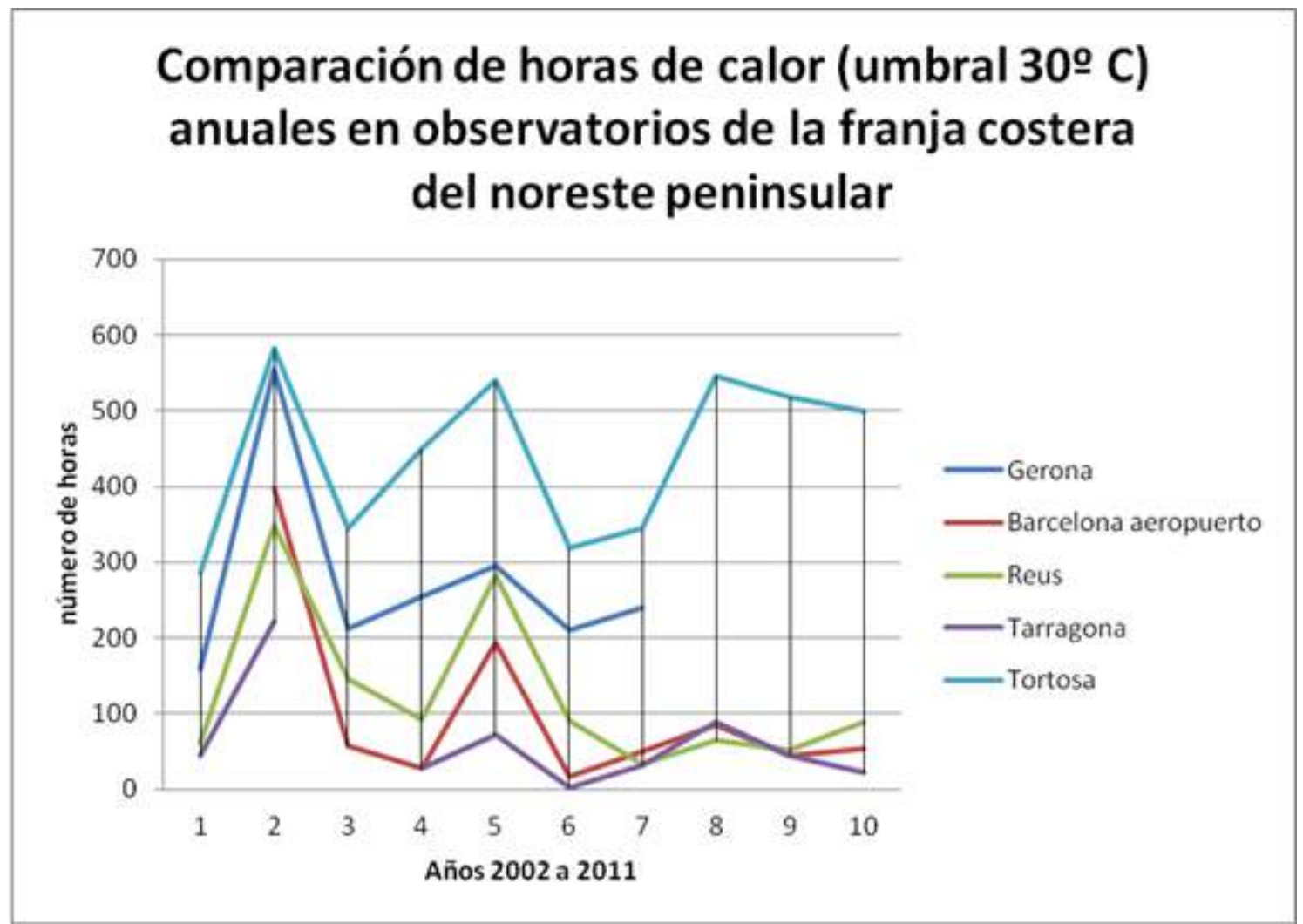

Gráfico 20. Comparación de horas de calor (umbral $30 \circ \mathrm{C}$ ) anuales en observatorios de la franja costera del noreste peninsular: costa catalana.

Los datos de Reus, Barcelona y Tarragona son coherentes entre ellos y, en cuanto a la evolución, lo son los de los 5 observatorios. Sin embargo, teniendo en cuenta el efecto suavizador de la cercanía al mar, sorprende que en los años 2008, 2009 y 2010 no haya apenas diferencia entre los datos de Tarragona y Barcelona, al borde del mar, y los de Reus, lo suficientemente tierra adentro para tener más horas de calor.

\section{Horas de calor contadas en datos horarios en cada uno de los observatorios}

Gerona. Faltan datos los tres últimos años, en el resto el promedio no llega a las 300 horas de calor (umbral $30^{\circ} \mathrm{C}$ ) al año, oscilando entre las 159 horas de 2002 y las 554 de 2003.

Los cuatro primeros y los dos últimos meses del año no tienen horas de calor. Mayo y octubre apenas tienen y muy pocos años; septiembre tiene también pocas horas de calor; junio y agosto tienen en promedio cerca de 80 horas de calor mensuales, y julio, 100. 
Es muy marcada la variabilidad interanual y la que se da entre los mismos meses de distintos años.

Tabla 252. Horas de calor contadas en datos horarios en el observatorio de Gerona.

\begin{tabular}{cccccccccccccc}
\hline & ene & feb & mar & abr & may & jun & jul & ago & sep & oct & nov & dic & anual \\
\hline $\mathbf{2 0 0 2}$ & 0 & 0 & 0 & 0 & 0 & 86 & 50 & 23 & 0 & 0 & 0 & 0 & 159 \\
$\mathbf{2 0 0 3}$ & 0 & 0 & 0 & 0 & 9 & 149 & 155 & 240 & 1 & 0 & 0 & 0 & 554 \\
$\mathbf{2 0 0 4}$ & 0 & 0 & 0 & 0 & 0 & 40 & 80 & 85 & 4 & 3 & 0 & 0 & 212 \\
$\mathbf{2 0 0 5}$ & 0 & 0 & 0 & 0 & 0 & 97 & 116 & 28 & 13 & 0 & 0 & 0 & 254 \\
$\mathbf{2 0 0 6}$ & 0 & 0 & 0 & 0 & 15 & 49 & 210 & 7 & 14 & 1 & 0 & 0 & 296 \\
$\mathbf{2 0 0 7}$ & 0 & 0 & 0 & 0 & 3 & 26 & 103 & 69 & 9 & 0 & 0 & 0 & 210 \\
$\mathbf{2 0 0 8}$ & 0 & 0 & 0 & 0 & & 64 & 79 & 90 & 6 & 0 & 0 & 0 & 239 \\
\hline $\mathbf{2 0 0 9}$ & 0 & 0 & 0 & 0 & 0 & 55 & 109 & & & 0 & 0 & & \\
$\mathbf{2 0 1 0}$ & & & & & & & & & & & & & \\
\hline $\mathbf{2 0 1 1}$ & & & & & & & & & & & & & \\
Prom. & 0 & 0 & 0 & 0 & 4 & 71 & 113 & 77 & 7 & 1 & 0 & 0 & 275 \\
\hline
\end{tabular}

Barcelona. Tiene en promedio algo menos de 100 horas de calor (umbral $30^{\circ} \mathrm{C}$ ) al año, oscilando entre la ausencia de horas de calor de 2002 y las 399 de 2003.

En los cinco primeros y los tres últimos meses del año no se dan horas de calor. Junio y septiembre tienen muy pocas y no todos los años; julio y agosto no llegan en promedio a las 50 mensuales.

Es muy marcada la variabilidad interanual y la que se da entre los mismos meses de distintos años.

Tabla 253. Horas de calor contadas en datos horarios en el observatorio de Barcelona.

\begin{tabular}{cccccccccccccc}
\hline & ene & feb & mar & abr & may & jun & jul & ago & sep & oct & nov & dic & anual \\
\hline $\mathbf{2 0 0 2}$ & 0 & 0 & 0 & 0 & 0 & 0 & 0 & 0 & 0 & 0 & 0 & 0 & 0 \\
\hline $\mathbf{2 0 0 3}$ & 0 & 0 & 0 & 0 & 0 & 63 & 110 & 226 & 0 & 0 & 0 & 0 & 399 \\
\hline $\mathbf{2 0 0 4}$ & 0 & 0 & 0 & 0 & 0 & 4 & 2 & 26 & 25 & 0 & 0 & 0 & 57 \\
\hline $\mathbf{2 0 0 5}$ & 0 & 0 & 0 & 0 & 0 & 19 & 8 & 0 & 0 & 0 & 0 & 0 & 27 \\
$\mathbf{2 0 0 6}$ & 0 & 0 & 0 & 0 & 0 & 2 & 160 & 24 & 7 & 0 & 0 & 0 & 193 \\
\hline $\mathbf{2 0 0 7}$ & 0 & 0 & 0 & 0 & 0 & 0 & 0 & 16 & 0 & 0 & 0 & 0 & 16 \\
\hline $\mathbf{2 0 0 8}$ & 0 & 0 & 0 & 0 & 0 & 2 & 7 & 38 & 3 & 0 & 0 & 0 & 50 \\
\hline $\mathbf{2 0 0 9}$ & 0 & 0 & 0 & 0 & 0 & 4 & 28 & 53 & 0 & 0 & 0 & 0 & 85 \\
$\mathbf{2 0 1 0}$ & 0 & 0 & 0 & 0 & 0 & 0 & 29 & 16 & 0 & 0 & 0 & 0 & 45 \\
\hline $\mathbf{2 0 1 1}$ & 0 & 0 & 0 & 0 & 0 & 2 & 1 & 50 & 0 & 0 & 0 & 0 & 53 \\
Prom. & 0 & 0 & 0 & 0 & 0 & 10 & 35 & 45 & 4 & 0 & 0 & 0 & 93 \\
\hline
\end{tabular}


Reus. Tiene en promedio poco más de 100 horas de calor (umbral $30^{\circ} \mathrm{C}$ ) al año, oscilando entre las 33 horas de 2008 y las 348 de 2003.

Los cuatro primeros y los dos últimos meses del año están libres de horas de calor. Mayo y octubre apenas tienen algún año con horas de calor; septiembre tiene también muy pocas y no todos los años; julio y agosto tienen en promedio en torno a las 50 mensuales, y junio no llega a las 30 .

Es muy marcada la variabilidad interanual y la que se da entre los mismos meses de distintos años.

Tabla 254. Horas de calor contadas en datos horarios en el observatorio de Reus.

\begin{tabular}{cccccccccccccc}
\hline & ene & feb & mar & abr & may & jun & jul & ago & sep & oct & nov & dic & anual \\
\hline $\mathbf{2 0 0 2}$ & 0 & 0 & 0 & 0 & 0 & 24 & 25 & 13 & 0 & 0 & 0 & 0 & 62 \\
$\mathbf{2 0 0 3}$ & 0 & 0 & 0 & 0 & 0 & 75 & 89 & 183 & 1 & 0 & 0 & 0 & 348 \\
$\mathbf{2 0 0 4}$ & 0 & 0 & 0 & 0 & 0 & 20 & 28 & 94 & 4 & 0 & 0 & 0 & 146 \\
\hline $\mathbf{2 0 0 5}$ & 0 & 0 & 0 & 0 & 0 & 30 & 39 & 18 & 5 & 0 & 0 & 0 & 92 \\
$\mathbf{2 0 0 6}$ & 0 & 0 & 0 & 0 & 0 & 20 & 187 & 62 & 14 & 0 & 0 & 0 & 283 \\
\hline $\mathbf{2 0 0 7}$ & 0 & 0 & 0 & 0 & 3 & 12 & 29 & 45 & 2 & 0 & 0 & 0 & 91 \\
$\mathbf{2 0 0 8}$ & 0 & 0 & 0 & 0 & 0 & 1 & 8 & 24 & 0 & 0 & 0 & 0 & 33 \\
$\mathbf{2 0 0 9}$ & 0 & 0 & 0 & 0 & 0 & 4 & 9 & 47 & 4 & 0 & 0 & 0 & 64 \\
$\mathbf{2 0 1 0}$ & 0 & 0 & 0 & 0 & 3 & 7 & 23 & 19 & 0 & 0 & 0 & 0 & 52 \\
\hline $\mathbf{2 0 1 1}$ & 0 & 0 & 0 & 0 & 0 & 5 & 10 & 58 & 4 & 11 & 0 & 0 & 88 \\
Prom. & 0 & 0 & 0 & 0 & 1 & 20 & 45 & 56 & 3 & 1 & 0 & 0 & 126 \\
\hline
\end{tabular}

Tarragona. Faltan datos en uno de los años, en el resto tiene en promedio unas 60 horas de calor (umbral $30^{\circ} \mathrm{C}$ ) al año, oscilando entre las 3 horas de 2007 y las 221 de 2003.

Los cuatro primeros y los dos últimos meses no tienen horas de calor. Mayo, octubre y septiembre apenas tienen algún año; junio tiene muy pocas horas de calor; agosto tiene en promedio 30 horas mensuales y julio no llega a ellas.

Es muy marcada la variabilidad interanual y la que se da entre los mismos meses de distintos años. 
Tabla 255. Horas de calor contadas en datos horarios en el observatorio de Tarragona.

\begin{tabular}{cccccccccccccc}
\hline & ene & feb & mar & abr & may & jun & jul & ago & sep & oct & nov & dic & anual \\
\hline $\mathbf{2 0 0 2}$ & 0 & 0 & 0 & 0 & 0 & 8 & 28 & 9 & 0 & 0 & 0 & 0 & 45 \\
\hline 2003 & 0 & 0 & 0 & 0 & 0 & 19 & 47 & 155 & 0 & 0 & 0 & 0 & 221 \\
$\mathbf{2 0 0 4}$ & 0 & 0 & 0 & 0 & 0 & 1 & 4 & & 0 & 0 & & 0 & \\
$\mathbf{2 0 0 5}$ & 0 & 0 & 0 & 0 & 0 & 14 & 13 & 0 & 1 & 0 & 0 & 0 & 28 \\
$\mathbf{2 0 0 6}$ & 0 & 0 & 0 & 0 & 0 & 0 & 57 & 14 & 2 & 0 & 0 & 0 & 73 \\
\hline $\mathbf{2 0 0 7}$ & 0 & 0 & 0 & 0 & 0 & 1 & 2 & 0 & 0 & 0 & 0 & 0 & 3 \\
$\mathbf{2 0 0 8}$ & 0 & 0 & 0 & 0 & 0 & 0 & 6 & 25 & 0 & 0 & 0 & 0 & 31 \\
$\mathbf{2 0 0 9}$ & 0 & 0 & 0 & 0 & 0 & 1 & 32 & 49 & 6 & 1 & 0 & 0 & 89 \\
$\mathbf{2 0 1 0}$ & 0 & 0 & 0 & 0 & 3 & 0 & 16 & 26 & 0 & 0 & 0 & 0 & 45 \\
\hline $\mathbf{2 0 1 1}$ & 0 & 0 & 0 & 0 & 0 & 1 & 8 & 9 & 3 & 1 & 0 & 0 & 22 \\
Prom. & 0 & 0 & 0 & 0 & 0 & 5 & 21 & 32 & 1 & 0 & 0 & 0 & 62 \\
\hline
\end{tabular}

Tortosa. Tiene en promedio más de 400 horas de calor (umbral $30^{\circ} \mathrm{C}$ ) al año, oscilando entre las 285 horas de 2002 y las 582 de 2003.

Los tres primeros y los dos últimos meses del año están libres de horas de calor. Abril y octubre tienen muy pocas horas y muy pocos años; mayo tiene muy pocas y no todos los años; julio y agosto tienen en promedio 150 horas de calor mensuales; junio cerca de 100 y septiembre pasa ligeramente de 30.

Es muy marcada la variabilidad interanual y la que se da entre los mismos meses de distintos años.

Tabla 256. Horas de calor contadas en datos horarios en el observatorio de Tortosa.

\begin{tabular}{cccccccccccccc}
\hline & ene & feb & mar & abr & may & jun & jul & ago & sep & oct & nov & dic & anual \\
\hline $\mathbf{2 0 0 2}$ & 0 & 0 & 0 & 1 & 0 & 90 & 115 & 74 & 5 & 0 & 0 & 0 & 285 \\
$\mathbf{2 0 0 3}$ & 0 & 0 & 0 & 0 & 1 & 159 & 182 & 226 & 14 & 0 & 0 & 0 & 582 \\
$\mathbf{2 0 0 4}$ & 0 & 0 & 0 & 0 & 0 & 77 & 83 & 165 & 19 & 0 & 0 & 0 & 344 \\
$\mathbf{2 0 0 5}$ & 0 & 0 & 0 & 0 & 3 & 121 & 186 & 101 & 38 & 0 & 0 & 0 & 449 \\
$\mathbf{2 0 0 6}$ & 0 & 0 & 0 & 0 & 28 & 58 & 248 & 161 & 41 & 4 & 0 & 0 & 540 \\
$\mathbf{2 0 0 7}$ & 0 & 0 & 0 & 0 & 20 & 35 & 114 & 115 & 35 & 0 & 0 & 0 & 319 \\
$\mathbf{2 0 0 8}$ & 0 & 0 & 0 & 0 & 0 & 65 & 107 & 138 & 34 & 0 & 0 & 0 & 344 \\
\hline $\mathbf{2 0 0 9}$ & 0 & 0 & 0 & 0 & 5 & 108 & 176 & 209 & 48 & 0 & 0 & 0 & 546 \\
$\mathbf{2 0 1 0}$ & 0 & 0 & 0 & 0 & 23 & 54 & 233 & 163 & 45 & 0 & 0 & 0 & 518 \\
\hline $\mathbf{2 0 1 1}$ & 0 & 0 & 0 & 5 & 17 & 54 & 123 & 161 & 100 & 40 & 0 & 0 & 500 \\
Prom. & 0 & 0 & 0 & 1 & 10 & 82 & 157 & 151 & 38 & 4 & 0 & 0 & 443 \\
\hline
\end{tabular}


Resumen de horas de calor contadas para la zona costera de noreste peninsular entre el nivel del mar y 300 metros.

En la costa noreste, por debajo de $300 \mathrm{~m}$, el número de horas de calor anuales oscila entre las menos de 100 al borde del mar y más de 400 del interior. El número de horas de calor aumenta de forma notable a medida que el lugar se aleja de la costa y la influencia suavizadora del mar.

Es importante tener en cuenta que la variabilidad interanual, y la que se da entre cada mes con horas de calor en los distintos años, es muy marcada.

\subsubsection{Cuenca del Tajo}

Observatorios: Madrid-Barajas (3129), Guadalajara (3168c), Getafe (3200), Navalmoral (3434x), Cáceres (3469a), Plasencia (3519x), Toledo (3260b) y Trujillo (3463x).

Tabla 257. Comparación de horas de calor anuales contadas a partir de datos horarios en los ocho observatorios de la cuenca del Tajo.

\begin{tabular}{|ccccccccc|} 
& $\begin{array}{c}\text { Barajas } \\
\mathbf{3 1 2 9}\end{array}$ & $\begin{array}{c}\text { Guadalajara } \\
\mathbf{3 1 6 8 c}\end{array}$ & $\begin{array}{c}\text { Getafe } \\
\mathbf{3 2 0 0}\end{array}$ & $\begin{array}{c}\text { Navalmoral } \\
\mathbf{3 4 3 4 x}\end{array}$ & $\begin{array}{c}\text { Cáceres } \\
\mathbf{3 4 6 9 a}\end{array}$ & $\begin{array}{c}\text { Plasencia } \\
\mathbf{3 5 1 9 x}\end{array}$ & $\begin{array}{c}\text { Toledo } \\
\mathbf{3 2 6 0 b}\end{array}$ & $\begin{array}{c}\text { Trujillo } \\
\mathbf{3 4 6 3 x}\end{array}$ \\
\hline $\mathbf{A n ̃ o}$ & $\mathrm{HC}$ & $\mathrm{HC}$ & $\mathrm{HC}$ & $\mathrm{HC}$ & $\mathrm{HC}$ & $\mathrm{HC}$ & $\mathrm{HC}$ & HC \\
\hline $\mathbf{2 0 0 2}$ & 423 & 447 & 435 & 749 & 594 & 620 & 636 & \\
\hline $\mathbf{2 0 0 3}$ & 611 & 705 & 688 & 864 & 762 & & 848 & 671 \\
\hline $\mathbf{2 0 0 4}$ & 485 & 417 & 518 & 801 & 773 & 859 & 708 & 694 \\
\hline $\mathbf{2 0 0 5}$ & 809 & 648 & 647 & 860 & 768 & 709 & 822 & 774 \\
\hline $\mathbf{2 0 0 6}$ & 795 & 579 & 625 & 815 & 793 & 669 & 798 & 848 \\
\hline $\mathbf{2 0 0 7}$ & 443 & 323 & 305 & 566 & 443 & 387 & 484 & 399 \\
\hline $\mathbf{2 0 0 8}$ & 571 & & 434 & & 506 & 389 & 594 & 409 \\
\hline $\mathbf{2 0 0 9}$ & 836 & 624 & 687 & 948 & 733 & & 803 & 633 \\
\hline $\mathbf{2 0 1 0}$ & 623 & 457 & 631 & 842 & 822 & 688 & 695 & 724 \\
\hline $\mathbf{2 0 1 1}$ & 610 & 286 & 549 & 807 & 657 & 564 & 780 & 511 \\
\hline Prom. & 621 & 498 & 552 & 806 & 685 & 611 & 717 & 629 \\
\hline
\end{tabular}




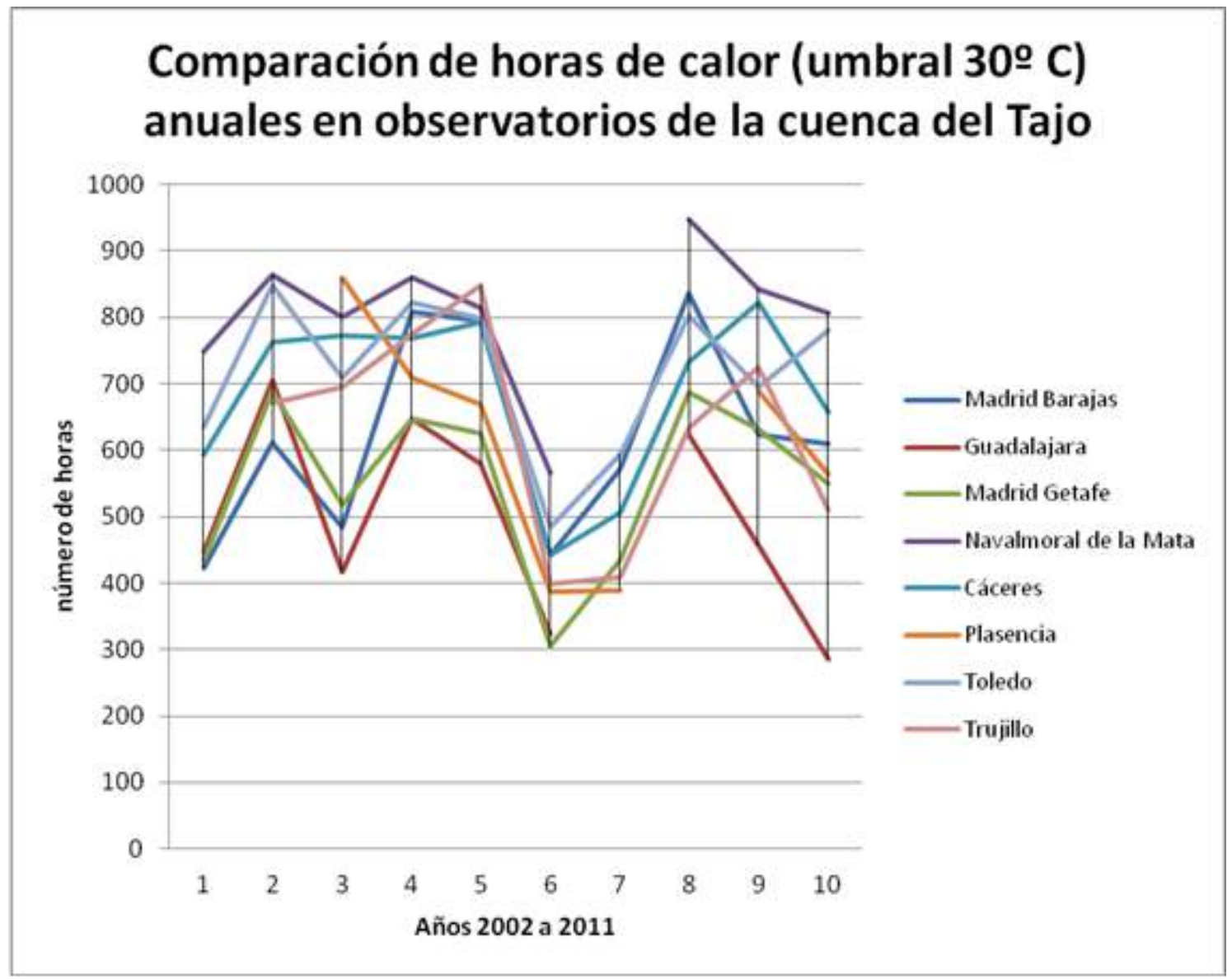

Gráfico 21. Comparación de horas de calor (umbral 30ㅇ) anuales en observatorios de la cuenca del Tajo.

La evolución a lo largo del tiempo tendría que ser similar en todos los observatorios de la misma zona, algo que no se cumple en algunos casos. En Plasencia hay notablemente menos horas de calor en 2005 que en 2004, lo contrario a los que sucede en el resto de los observatorios, excepto Cáceres que tiene valores parecidos para ambos años. Del mismo modo, entre 2009 y 2010 se produce un notable aumento de horas de calor en Cáceres y Trujillo, mientras que en el resto se produce un notable descenso. Por otra parte, llama la atención la diferencia existente entre los observatorios de Madrid Barajas y Madrid Getafe en cinco de los años, cuando lo esperable sería encontrar valores muy similares en ambos observatorios, algo que sí sucede en los tres primeros años y los dos últimos. 


\section{Horas de calor contadas en datos horarios en cada uno de los observatorios}

Madrid Barajas. Tiene en promedio más de 600 horas de calor (umbral $30^{\circ} \mathrm{C}$ ) al año, oscilando entre las 423 horas de 2002 y las 836 de 2009.

Las horas de calor se reparten entre los meses de mayo a octubre, aunque octubre tiene muy pocas y pocos años. También mayo y septiembre tienen muy pocas horas, si bien casi todos los años; junio tiene más de 100 horas de promedio y julio y agosto en torno a las 200.

Es marcada la variabilidad interanual, así como la que se da entre los mismos meses en los distintos años. Por ejemplo, en julio de 2002 hubo 152 horas, mientras que en julio de 2006 hubo 317 horas.

Tabla 258. Horas de calor contadas en datos horarios en el observatorio de Madrid Barajas.

\begin{tabular}{cccccccccccccc}
\hline & ene & feb & mar & abr & may & jun & jul & ago & sep & oct & nov & dic & anual \\
\hline $\mathbf{2 0 0 2}$ & 0 & 0 & 0 & 0 & 2 & 149 & 152 & 118 & 2 & 0 & 0 & 0 & 423 \\
$\mathbf{2 0 0 3}$ & 0 & 0 & 0 & 0 & 16 & 176 & 199 & 211 & 9 & 0 & 0 & 0 & 611 \\
$\mathbf{2 0 0 4}$ & 0 & 0 & 0 & 0 & 0 & 106 & 204 & 133 & 40 & 2 & 0 & 0 & 485 \\
$\mathbf{2 0 0 5}$ & 0 & 0 & 0 & 0 & 32 & 211 & 280 & 235 & 47 & 4 & 0 & 0 & 809 \\
$\mathbf{2 0 0 6}$ & 0 & 0 & 0 & 0 & 46 & 146 & 317 & 196 & 90 & 0 & 0 & 0 & 795 \\
$\mathbf{2 0 0 7}$ & 0 & 0 & 0 & 0 & 7 & 43 & 186 & 150 & 57 & 0 & 0 & 0 & 443 \\
$\mathbf{2 0 0 8}$ & 0 & 0 & 0 & 0 & 0 & 114 & 223 & 212 & 22 & 0 & 0 & 0 & 571 \\
$\mathbf{2 0 0 9}$ & 0 & 0 & 0 & 0 & 35 & 166 & 282 & 286 & 67 & 0 & 0 & 0 & 836 \\
$\mathbf{2 0 1 0}$ & 0 & 0 & 0 & 0 & 7 & 80 & 275 & 209 & 52 & 0 & 0 & 0 & 623 \\
$\mathbf{2 0 1 1}$ & 0 & 0 & 0 & 0 & 9 & 133 & 175 & 205 & 69 & 19 & 0 & 0 & 610 \\
Prom. & 0 & 0 & 0 & 0 & 15 & 132 & 229 & 196 & 46 & 3 & 0 & 0 & 621 \\
\hline
\end{tabular}

Guadalajara. Tiene en promedio de 500 horas de calor (umbral $30^{\circ} \mathrm{C}$ ) al año, oscilando entre las 286 de 2011 y las 648 de 2005.

Las horas de calor se reparten entre los meses de mayo a octubre, aunque octubre tiene muy pocas y pocos años. También mayo y septiembre tienen muy pocas horas, aunque casi todos los años. Junio tiene más de 100 horas mensuales de promedio, julio cerca de 200 y agosto 150. 
La variabilidad interanual, así como la que se da entre cada mes con horas de calor en los distintos años, es muy marcada. Por ejemplo, en julio de 2011 hubo 69 horas, mientras que en julio de 2006 hubo 247 horas.

Tabla 259. Horas de calor contadas en datos horarios en el observatorio de Guadalajara.

\begin{tabular}{cccccccccccccc}
\hline & ene & feb & mar & abr & may & jun & jul & ago & sep & oct & nov & dic & anual \\
\hline $\mathbf{2 0 0 2}$ & 0 & 0 & 0 & 0 & 8 & 153 & 142 & 131 & 13 & 0 & 0 & 0 & 447 \\
$\mathbf{2 0 0 3}$ & 0 & 0 & 0 & 0 & 27 & 203 & 228 & 224 & 23 & 0 & 0 & 0 & 705 \\
$\mathbf{2 0 0 4}$ & 0 & 0 & 0 & 0 & 0 & 145 & 190 & 100 & 71 & 11 & 0 & 0 & 517 \\
$\mathbf{2 0 0 5}$ & 0 & 0 & 0 & 3 & 37 & 162 & 230 & 178 & 35 & 3 & 0 & 0 & 648 \\
$\mathbf{2 0 0 6}$ & 0 & 0 & 0 & 0 & 29 & 116 & 247 & 127 & 60 & 0 & 0 & 0 & 579 \\
$\mathbf{2 0 0 7}$ & 0 & 0 & 0 & 0 & 2 & 32 & 145 & 111 & 33 & 0 & 0 & 0 & 323 \\
$\mathbf{2 0 0 8}$ & 0 & 0 & 0 & 0 & 0 & & & & 4 & 0 & 0 & 0 & \\
\hline $\mathbf{2 0 0 9}$ & 0 & 0 & 0 & 0 & 21 & 134 & 228 & 202 & 39 & 0 & 0 & 0 & 624 \\
$\mathbf{2 0 1 0}$ & 0 & 0 & 0 & 0 & 0 & 33 & 237 & 172 & 15 & 0 & 0 & 0 & 457 \\
$\mathbf{2 0 1 1}$ & 0 & 0 & 0 & 0 & 9 & 74 & 69 & 107 & 27 & 0 & 0 & 0 & 286 \\
Prom. & 0 & 0 & 0 & 0 & 13 & 117 & 191 & 150 & 32 & 1 & 0 & 0 & 510 \\
\hline
\end{tabular}

Madrid Getafe. Tiene en promedio poco más de 550 horas de calor anuales, oscilando entre las 305 de 2007 y las 688 de 2003.

Las horas de calor se reparten entre los meses de mayo a octubre, aunque octubre tiene muy pocas y pocos años. También mayo y septiembre tienen muy pocas horas, aunque casi todos los años. Junio tiene más de 100 horas de promedio, julio más de 200 y agosto no llega a las 200.

Tabla 260. Horas de calor contadas en datos horarios en el observatorio de Madrid Getafe.

\begin{tabular}{|c|c|c|c|c|c|c|c|c|c|c|c|c|c|}
\hline & ene & feb & mar & $a b r$ & may & jun & jul & ago & sep & oct & nov & dic & anual \\
\hline 2002 & 0 & 0 & 0 & 0 & 3 & 152 & 159 & 118 & 3 & 0 & 0 & 0 & 435 \\
\hline 2003 & 0 & 0 & 0 & 0 & 16 & 177 & 232 & 246 & 17 & 0 & 0 & 0 & 688 \\
\hline 2004 & 0 & 0 & 0 & 0 & 0 & 138 & 205 & 124 & 50 & 1 & 0 & 0 & 518 \\
\hline 2005 & 0 & 0 & 0 & 0 & 25 & 156 & 244 & 194 & 28 & 0 & 0 & 0 & 647 \\
\hline 2006 & 0 & 0 & 0 & 0 & 34 & 92 & 263 & 162 & 74 & 0 & 0 & 0 & 625 \\
\hline 2007 & 0 & 0 & 0 & 0 & 3 & 18 & 150 & 110 & 24 & 0 & 0 & 0 & 305 \\
\hline 2008 & 0 & 0 & 0 & 0 & 0 & 93 & 167 & 171 & 3 & 0 & 0 & 0 & 434 \\
\hline 2009 & 0 & 0 & 0 & 0 & 16 & 143 & 234 & 249 & 45 & 0 & 0 & 0 & 687 \\
\hline 2010 & 0 & 0 & 0 & 0 & 7 & 72 & 287 & 214 & 51 & 0 & 0 & 0 & 631 \\
\hline 2011 & 0 & 0 & 0 & 0 & 8 & 124 & 157 & 189 & 65 & 6 & 0 & 0 & 549 \\
\hline Prom. & 0 & 0 & 0 & 0 & 11 & 117 & 210 & 178 & 36 & 1 & 0 & 0 & 552 \\
\hline
\end{tabular}


La variabilidad interanual, así como la que se da entre los mismos meses en los distintos años, es muy marcada. Por ejemplo, en julio de 2007 hubo 150 horas, mientras que en julio de 2010 hubo 287 horas.

Navalmoral de la Mata. Tiene en promedio cerca de 800 horas de calor (umbral $30^{\circ} \mathrm{C}$ ) al año, oscilando entre las 566 horas de 2007 y las 948 de 2009.

Los meses de enero, febrero, marzo, noviembre y diciembre no tienen horas de calor. Abril y octubre tienen sólo algunos años y muy pocas; mayo no llega a las 30 horas de promedio y septiembre se acerca a 100; junio pasa de 150 y julio y agosto están en torno a las 250 horas mensuales.

La variabilidad interanual, así como la que se da entre los mismos meses en los distintos años, es muy marcada.

Tabla 261. Horas de calor contadas en datos horarios en el observatorio de Navalmoral de la Mata.

\begin{tabular}{cccccccccccccc}
\hline & ene & feb & mar & abr & may & jun & jul & ago & sep & oct & nov & dic & anual \\
\hline $\mathbf{2 0 0 2}$ & 0 & 0 & 0 & 1 & 29 & 205 & 266 & 213 & 35 & 0 & 0 & 0 & 749 \\
$\mathbf{2 0 0 3}$ & 0 & 0 & 0 & 0 & 30 & 207 & 238 & 292 & 97 & 0 & 0 & 0 & 864 \\
$\mathbf{2 0 0 4}$ & 0 & 0 & 0 & 0 & 5 & 205 & 267 & 179 & 118 & 27 & 0 & 0 & 801 \\
$\mathbf{2 0 0 5}$ & 0 & 0 & 0 & 4 & 35 & 212 & 274 & 255 & 75 & 5 & 0 & 0 & 860 \\
$\mathbf{2 0 0 6}$ & 0 & 0 & 0 & 0 & 47 & 160 & 294 & 234 & 100 & 0 & 0 & 0 & 835 \\
$\mathbf{2 0 0 7}$ & 0 & 0 & 0 & 0 & 15 & 74 & 190 & 184 & 103 & 0 & 0 & 0 & 566 \\
$\mathbf{2 0 0 8}$ & 0 & 0 & 0 & 0 & 0 & 132 & 160 & 251 & 49 & 0 & 0 & 0 & 592 \\
$\mathbf{2 0 0 9}$ & 0 & 0 & 0 & 0 & 57 & 186 & 292 & 299 & 109 & 5 & 0 & 0 & 948 \\
$\mathbf{2 0 1 0}$ & 0 & 0 & 0 & 0 & 21 & 124 & 321 & 282 & 94 & 0 & 0 & 0 & 842 \\
$\mathbf{2 0 1 1}$ & 0 & 0 & 0 & 0 & 27 & 157 & 245 & 217 & 118 & 43 & 0 & 0 & 807 \\
Prom. & 0 & 0 & 0 & 1 & 27 & 166 & 255 & 241 & 90 & 8 & 0 & 0 & 786 \\
\hline
\end{tabular}

Cáceres. Tiene en promedio cerca de 700 horas de calor (umbral $30^{\circ} \mathrm{C}$ ) al año, oscilando entre las 443 horas de 2007 y las 822 de 2010.

Hay horas de calor de mayo a octubre, aunque estos dos meses tienen pocas horas y octubre sólo unos pocos años. Julio y agosto pasan en promedio de las 200 horas de calor mensuales, junio se acerca a las 150 y septiembre tiene poco más de 60. 
La variabilidad interanual, así como la que se da entre los mismos meses en los distintos años, es muy marcada.

Tabla 262. Horas de calor contadas en datos horarios en el observatorio de Cáceres.

\begin{tabular}{cccccccccccccc}
\hline & ene & feb & mar & abr & may & jun & jul & ago & sep & oct & nov & dic & anual \\
\hline $\mathbf{2 0 0 2}$ & 0 & 0 & 0 & 0 & 19 & 168 & 215 & 172 & 20 & 0 & 0 & 0 & 594 \\
\hline $\mathbf{2 0 0 3}$ & 0 & 0 & 0 & 0 & 27 & 184 & 205 & 287 & 59 & 0 & 0 & 0 & 762 \\
$\mathbf{2 0 0 4}$ & 0 & 0 & 0 & 0 & 4 & 220 & 266 & 168 & 82 & 33 & 0 & 0 & 773 \\
\hline $\mathbf{2 0 0 5}$ & 0 & 0 & 0 & 0 & 29 & 190 & 242 & 243 & 59 & 5 & 0 & 0 & 768 \\
$\mathbf{2 0 0 6}$ & 0 & 0 & 0 & 0 & 42 & 118 & 278 & 245 & 110 & 0 & 0 & 0 & 793 \\
\hline $\mathbf{2 0 0 7}$ & 0 & 0 & 0 & 0 & 12 & 37 & 180 & 139 & 75 & 0 & 0 & 0 & 443 \\
$\mathbf{2 0 0 8}$ & 0 & 0 & 0 & 0 & 0 & 123 & 182 & 182 & 19 & 0 & 0 & 0 & 506 \\
\hline $\mathbf{2 0 0 9}$ & 0 & 0 & 0 & 0 & 36 & 150 & 207 & 264 & 76 & 0 & 0 & 0 & 733 \\
$\mathbf{2 0 1 0}$ & 0 & 0 & 0 & 0 & 15 & 101 & 324 & 298 & 84 & 0 & 0 & 0 & 822 \\
\hline $\mathbf{2 0 1 1}$ & 0 & 0 & 0 & 0 & 11 & 132 & 201 & 183 & 89 & 41 & 0 & 0 & 657 \\
Prom. & 0 & 0 & 0 & 0 & 20 & 142 & 230 & 218 & 67 & 8 & 0 & 0 & 685 \\
\hline
\end{tabular}

Plasencia. Pasa en promedio ligeramente de las 600 horas de calor (umbral $30^{\circ} \mathrm{C}$ ) al año, oscilando entre las 367 horas de 2007 y las 859 de 2004.

Hay horas de calor de mayo a octubre, aunque estos dos meses tienen pocas horas y octubre sólo unos pocos años. Julio y agosto están en promedio en torno a las 200 horas mensuales, junio pasa de 100 y septiembre de 50 .

Tabla 263. Horas de calor contadas en datos horarios en el observatorio de Plasencia.

\begin{tabular}{cccccccccccccc}
\hline & ene & feb & mar & abr & may & jun & jul & ago & sep & oct & nov & dic & anual \\
\hline $\mathbf{2 0 0 2}$ & 0 & 0 & 0 & 0 & 16 & 179 & 224 & 181 & 20 & 0 & 0 & 0 & 620 \\
$\mathbf{2 0 0 3}$ & 0 & 0 & 0 & 0 & 20 & 165 & 201 & & & 0 & 0 & 0 & \\
$\mathbf{2 0 0 4}$ & 0 & 0 & 0 & 0 & 6 & 236 & 321 & 203 & 60 & 33 & 0 & 0 & 859 \\
$\mathbf{2 0 0 5}$ & 0 & 0 & 0 & 0 & 17 & 168 & 248 & 230 & 42 & 4 & 0 & 0 & 709 \\
$\mathbf{2 0 0 6}$ & 0 & 0 & 0 & 0 & 28 & 92 & 234 & 224 & 91 & 0 & 0 & 0 & 669 \\
\hline $\mathbf{2 0 0 7}$ & 0 & 0 & 0 & 0 & 9 & 20 & 166 & 112 & 60 & 0 & 0 & 0 & 367 \\
\hline $\mathbf{2 0 0 8}$ & 0 & 0 & 0 & 0 & 0 & 91 & 127 & 162 & 9 & 0 & 0 & 0 & 389 \\
\hline $\mathbf{2 0 0 9}$ & 0 & 0 & 0 & 0 & 22 & 130 & 177 & 241 & 63 & 1 & 0 & 0 & 634 \\
\hline $\mathbf{2 0 1 0}$ & 0 & 0 & 0 & 0 & 9 & 87 & 278 & 244 & 70 & 0 & 0 & 0 & 688 \\
\hline $\mathbf{2 0 1 1}$ & 0 & 0 & 0 & 0 & 10 & 98 & 180 & 164 & 70 & 42 & 0 & 0 & 564 \\
Prom. & 0 & 0 & 0 & 0 & 14 & 127 & 216 & 196 & 55 & 8 & 0 & 0 & 611 \\
\hline
\end{tabular}


La variabilidad interanual, así como la que se da entre los mismos meses en los distintos años, es muy marcada.

Toledo. Pasa en promedio ligeramente de las 700 horas de calor (umbral $30^{\circ} \mathrm{C}$ ) al año, oscilando entre las 484 horas de 2007 y las 848 de 2003.

Hay horas de calor de abril a octubre, aunque estos dos meses tienen pocas horas y muy pocos años; mayo tiene también pocas horas pero casi todos los años; septiembre pasa en promedio de 60 horas de calor, junio tiene 150, agosto más de 200 y julio casi 250.

La variabilidad interanual, así como la que se da entre los mismos meses en los distintos años, es muy marcada.

Tabla 264. Horas de calor contadas en datos horarios en el observatorio de Toledo.

\begin{tabular}{cccccccccccccc}
\hline & ene & feb & mar & abr & may & jun & jul & ago & sep & oct & nov & dic & anual \\
\hline $\mathbf{2 0 0 2}$ & 0 & 0 & 0 & 0 & 18 & 189 & 217 & 184 & 28 & 0 & 0 & 0 & 636 \\
$\mathbf{2 0 0 3}$ & 0 & 0 & 0 & 0 & 33 & 222 & 257 & 283 & 53 & 0 & 0 & 0 & 848 \\
$\mathbf{2 0 0 4}$ & 0 & 0 & 0 & 0 & 3 & 166 & 240 & 168 & 112 & 19 & 0 & 0 & 708 \\
$\mathbf{2 0 0 5}$ & 0 & 0 & 0 & 7 & 46 & 204 & 278 & 231 & 52 & 4 & 0 & 0 & 822 \\
$\mathbf{2 0 0 6}$ & 0 & 0 & 0 & 0 & 45 & 127 & 312 & 211 & 103 & 0 & 0 & 0 & 798 \\
$\mathbf{2 0 0 7}$ & 0 & 0 & 0 & 0 & 6 & 43 & 201 & 168 & 66 & 0 & 0 & 0 & 484 \\
$\mathbf{2 0 0 8}$ & 0 & 0 & 0 & 0 & 0 & 130 & 209 & 222 & 33 & 0 & 0 & 0 & 594 \\
$\mathbf{2 0 0 9}$ & 0 & 0 & 0 & 0 & 32 & 171 & 256 & 267 & 74 & 3 & 0 & 0 & 803 \\
$\mathbf{2 0 1 0}$ & 0 & 0 & 0 & 0 & 14 & 99 & 282 & 238 & 62 & 0 & 0 & 0 & 695 \\
$\mathbf{2 0 1 1}$ & 0 & 0 & 0 & 0 & 18 & 168 & 221 & 232 & 107 & 34 & 0 & 0 & 780 \\
Prom. & 0 & 0 & 0 & 1 & 22 & 152 & 247 & 220 & 69 & 6 & 0 & 0 & 717 \\
\hline
\end{tabular}

Trujillo. En promedio pasa de las 600 horas de calor (umbral $30^{\circ} \mathrm{C}$ ) al año, oscilando entre las 399 horas de 2007 y las 848 de 2006.

Hay horas de calor de mayo a octubre, aunque estos dos meses tienen pocas horas y no todos los años; septiembre tiene en promedio 60 horas de calor, junio pasa de 100, mientras que julio y agosto pasan ligeramente de 200. 
La variabilidad interanual, así como la que se da entre los mismos meses en los distintos años, es muy marcada.

Tabla 265. Horas de calor contadas en datos horarios en el observatorio de Trujillo.

\begin{tabular}{cccccccccccccc}
\hline & ene & feb & mar & abr & may & jun & jul & ago & sep & oct & nov & dic & anual \\
\hline $\mathbf{2 0 0 2}$ & & & & & & & & & & & & & \\
\hline $\mathbf{2 0 0 3}$ & 0 & 0 & 0 & 0 & 13 & 156 & 198 & 266 & 38 & 0 & 0 & 0 & 671 \\
$\mathbf{2 0 0 4}$ & 0 & 0 & 0 & 0 & 1 & 201 & 253 & 136 & 77 & 26 & 0 & 0 & 694 \\
\hline $\mathbf{2 0 0 5}$ & 0 & 0 & 0 & 0 & 24 & 186 & 261 & 248 & 51 & 4 & 0 & 0 & 774 \\
$\mathbf{2 0 0 6}$ & 0 & 0 & 0 & 0 & 43 & 135 & 291 & 261 & 117 & 1 & 0 & 0 & 848 \\
\hline $\mathbf{2 0 0 7}$ & 0 & 0 & 0 & 0 & 12 & 26 & 170 & 134 & 57 & 0 & 0 & 0 & 399 \\
$\mathbf{2 0 0 8}$ & 0 & 0 & 0 & 0 & 0 & 100 & 136 & 163 & 10 & 0 & 0 & 0 & 409 \\
\hline $\mathbf{2 0 0 9}$ & 0 & 0 & 0 & 0 & 29 & 138 & 185 & 233 & 48 & 0 & 0 & 0 & 633 \\
\hline $\mathbf{2 0 1 0}$ & 0 & 0 & 0 & 0 & 9 & 80 & 295 & 264 & 76 & 0 & 0 & 0 & 724 \\
\hline $\mathbf{2 0 1 1}$ & 0 & 0 & 0 & 0 & 0 & 106 & 159 & 156 & 66 & 24 & 0 & 0 & 511 \\
Prom. & 0 & 0 & 0 & 0 & 15 & 125 & 216 & 207 & 60 & 6 & 0 & 0 & 629 \\
\hline
\end{tabular}

\section{Resumen de horas de calor contadas para la cuenca del Tajo}

La parte media de la cuenca, la situada en la meseta Sur por debajo de 700 metros de altitud tiene más de 500 horas de calor al año en promedio. La parte más baja de la cuenca, situada dentro de la Península y por debajo de $500 \mathrm{~m}$ de altitud, pasa de las 700 horas anuales.

Es importante tener en cuenta que la variabilidad interanual, así como la que se da entre los mismos meses en los distintos años, es muy marcada.

\subsubsection{Cuenca del Guadiana: a) parte alta situada en la meseta Sur, principalmente La Mancha}

Observatorios: Ciudad Real (4121), Alcázar de San Juan (4064), Almagro (4116i), Hinojosa del Duque (4267x). 
Tabla 266. Comparación de horas de calor anuales contadas a partir de datos horarios en los cuatro observatorios de la parte alta de la cuenca del Guadiana.

\begin{tabular}{|ccccc|}
\hline & $\begin{array}{c}\text { Ciudad Real } \\
\mathbf{4 1 2 1}\end{array}$ & $\begin{array}{c}\text { Alcázar SJ } \\
\mathbf{4 0 6 4}\end{array}$ & $\begin{array}{c}\text { Almagro } \\
\mathbf{4 1 1 6 i}\end{array}$ & $\begin{array}{c}\text { Hinojosa } \\
\mathbf{4 2 6 7 x}\end{array}$ \\
\hline $\mathbf{A n ̃ o}$ & $\mathrm{HC}$ & $\mathrm{HC}$ & $\mathrm{HC}$ & $\mathrm{HC}$ \\
\hline $\mathbf{2 0 0 2}$ & 636 & & & 699 \\
\hline $\mathbf{2 0 0 3}$ & 789 & & 767 & 880 \\
\hline $\mathbf{2 0 0 4}$ & 733 & & 727 & \\
\hline $\mathbf{2 0 0 5}$ & 817 & & 817 & 905 \\
\hline $\mathbf{2 0 0 6}$ & 821 & & 810 & 878 \\
\hline $\mathbf{2 0 0 7}$ & 507 & & 504 & 585 \\
\hline $\mathbf{2 0 0 8}$ & 582 & 589 & 571 & 605 \\
\hline $\mathbf{2 0 0 9}$ & 846 & 793 & 851 & 867 \\
\hline $\mathbf{2 0 1 0}$ & 754 & 666 & 728 & 840 \\
\hline $\mathbf{2 0 1 1}$ & 727 & 730 & 722 & 836 \\
\hline promedio & 721 & 695 & 722 & 788 \\
\hline
\end{tabular}

\section{Comparación de horas de calor (umbral 30은 C) anuales en observatorios de la parte alta de la cuenca del Guadiana}

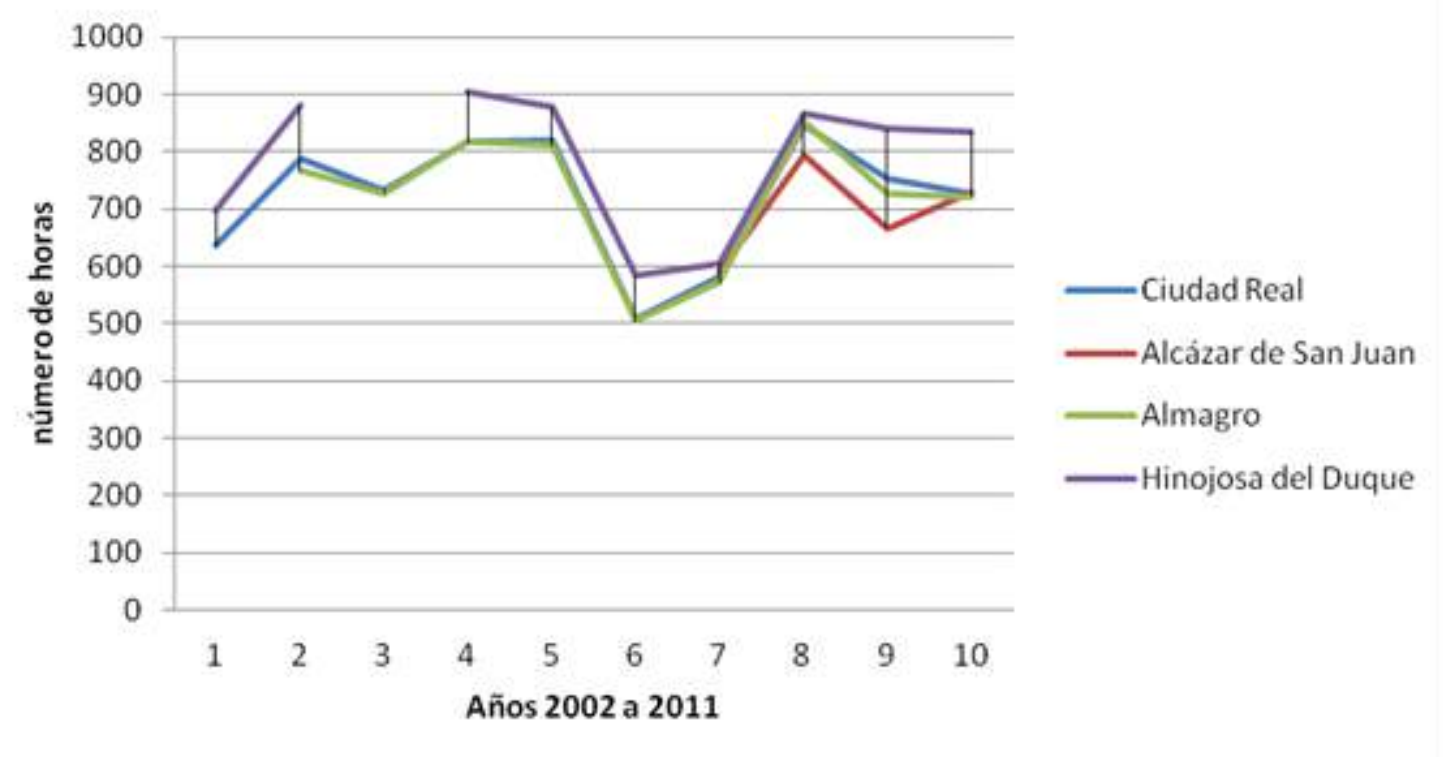

Gráfico 22. Comparación de horas de calor (umbral 30 ㄷ) anuales en observatorios de la parte alta de la cuenca del Guadiana.

Los datos son coherentes entre ellos. 


\section{Horas de calor contadas en datos horarios en cada uno de los observatorios}

Ciudad Real. Tiene en promedio algo más de 700 horas de calor (umbral $30^{\circ} \mathrm{C}$ ) al año, oscilando entre las 846 de 2009 y las 507 de 2007.

Los meses con horas de calor son los de verano: junio tiene 150 horas de promedio, agosto más de 200 , julio algo más de 250 y septiembre cerca de 60 . Tanto junio como septiembre tienen una gran variabilidad entre unos años y otros. Mayo y octubre tienen también horas de calor, y hay un año en que abril también tiene. El resto de los meses no tienen horas de calor.

Tabla 267. Horas de calor contadas en datos horarios en el observatorio de Ciudad Real.

\begin{tabular}{cccccccccccccc}
\hline & ene & feb & mar & abr & may & jun & jul & ago & sep & oct & nov & dic & anual \\
\hline $\mathbf{2 0 0 2}$ & 0 & 0 & 0 & 0 & 20 & 202 & 224 & 174 & 16 & 0 & 0 & 0 & 636 \\
\hline $\mathbf{2 0 0 3}$ & 0 & 0 & 0 & 0 & 21 & 218 & 274 & 251 & 25 & 0 & 0 & 0 & 789 \\
$\mathbf{2 0 0 4}$ & 0 & 0 & 0 & 0 & 0 & 155 & 269 & 189 & 103 & 17 & 0 & 0 & 733 \\
\hline $\mathbf{2 0 0 5}$ & 0 & 0 & 0 & 3 & 45 & 189 & 283 & 253 & 42 & 2 & 0 & 0 & 817 \\
$\mathbf{2 0 0 6}$ & 0 & 0 & 0 & 0 & 48 & 146 & 310 & 233 & 82 & 2 & 0 & 0 & 821 \\
\hline $\mathbf{2 0 0 7}$ & 0 & 0 & 0 & 0 & 10 & 50 & 217 & 185 & 45 & 0 & 0 & 0 & 507 \\
\hline $\mathbf{2 0 0 8}$ & 0 & 0 & 0 & 0 & 0 & 123 & 199 & 236 & 24 & 0 & 0 & 0 & 582 \\
\hline $\mathbf{2 0 0 9}$ & 0 & 0 & 0 & 0 & 41 & 186 & 279 & 263 & 73 & 4 & 0 & 0 & 846 \\
\hline $\mathbf{2 0 1 0}$ & 0 & 0 & 0 & 0 & 25 & 106 & 317 & 248 & 58 & 0 & 0 & 0 & 754 \\
\hline $\mathbf{2 0 1 1}$ & 0 & 0 & 0 & 0 & 9 & 167 & 210 & 232 & 93 & 16 & 0 & 0 & 727 \\
Prom. & 0 & 0 & 0 & 0 & 22 & 154 & 258 & 226 & 56 & 4 & 0 & 0 & 721 \\
\hline
\end{tabular}

Alcázar de San Juan. El promedio de los cuatro años de datos que tiene es de unas 700 horas de calor (umbral $30^{\circ} \mathrm{C}$ ) anuales, que se concentran en los meses de junio, julio y agosto $\mathrm{y}$, en menor medida, septiembre; también mayo, abril y octubre pueden tener horas de calor. El resto de los meses no tiene.

\begin{tabular}{|c|c|c|c|c|c|c|c|c|c|c|c|c|c|}
\hline & ene & feb & mar & $a b r$ & may & jun & jul & ago & sep & oct & nov & dic & anual \\
\hline \multicolumn{14}{|l|}{2002} \\
\hline \multicolumn{14}{|l|}{2003} \\
\hline \multicolumn{14}{|l|}{2004} \\
\hline \multicolumn{14}{|l|}{2005} \\
\hline \multicolumn{14}{|l|}{2006} \\
\hline 2007 & & & & & & & 235 & 159 & 25 & 0 & 0 & 0 & \\
\hline 2008 & 0 & 0 & 0 & 0 & 0 & 122 & 220 & 229 & 18 & 0 & 0 & 0 & 589 \\
\hline 2009 & 0 & 0 & 0 & 0 & 32 & 163 & 277 & 262 & 59 & 0 & 0 & 0 & 793 \\
\hline 2010 & 0 & 0 & 0 & 0 & 6 & 93 & 302 & 215 & 50 & 0 & 0 & 0 & 666 \\
\hline 2011 & 0 & 0 & 0 & 3 & 15 & 170 & 217 & 234 & 84 & 7 & 0 & 0 & 730 \\
\hline Prom. & 0 & 0 & 0 & 1 & 13 & 137 & 250 & 220 & 47 & 1 & 0 & 0 & 695 \\
\hline
\end{tabular}


Almagro. Le falta un año de datos; en los nueve restantes el promedio es de algo más de 700 horas de calor (umbral $30^{\circ} \mathrm{C}$ ) al año, oscilando entre las 851 de 2009 y las 504 de 2007. Los meses con horas de calor son los de verano: junio tiene casi 150 horas de promedio, agosto más de 200, julio algo más de 250 , y septiembre algo más de 60 , si bien en este mes se da una gran variabilidad entre unos años y otros, en 2004 tuvo 115 horas y en 2008, sólo 22. Abril, mayo y octubre tienen también alguna hora de calor, el resto de los meses carecen de ellas.

\begin{tabular}{|c|c|c|c|c|c|c|c|c|c|c|c|c|c|}
\hline & ene & feb & mar & $a b r$ & may & jun & jul & ago & sep & oct & nov & dic & anual \\
\hline \multicolumn{14}{|l|}{2002} \\
\hline 2003 & & & & & 10 & 215 & 265 & 248 & 29 & 0 & 0 & 0 & 767 \\
\hline 2004 & 0 & 0 & 0 & 0 & 0 & 151 & 257 & 189 & 115 & 15 & 0 & 0 & 727 \\
\hline 2005 & 0 & 0 & 0 & 3 & 44 & 197 & 282 & 238 & 50 & 3 & 0 & 0 & 817 \\
\hline 2006 & 0 & 0 & 0 & 0 & 50 & 141 & 305 & 229 & 83 & 2 & 0 & 0 & 810 \\
\hline 2007 & 0 & 0 & 0 & 0 & 9 & 50 & 219 & 183 & 43 & 0 & 0 & 0 & 504 \\
\hline 2008 & 0 & 0 & 0 & 0 & 0 & 121 & 200 & 228 & 22 & 0 & 0 & 0 & 571 \\
\hline 2009 & 0 & 0 & 0 & 0 & 37 & 185 & 281 & 269 & 73 & 6 & 0 & 0 & 851 \\
\hline 2010 & 0 & 0 & 0 & 0 & 15 & 107 & 305 & 237 & 64 & 0 & 0 & 0 & 728 \\
\hline 2011 & 0 & 0 & 0 & 0 & 10 & 175 & 218 & 231 & 77 & 11 & 0 & 0 & 722 \\
\hline Prom. & 0 & 0 & 0 & 0 & 21 & 149 & 259 & 228 & 62 & 4 & 0 & 0 & 722 \\
\hline
\end{tabular}

Hinojosa del Duque. En uno de los años le faltan datos, en los nueve restantes el promedio es de cerca de 800 horas de calor (umbral $30^{\circ} \mathrm{C}$ ) al año, oscilando entre las 905 de 2005 y las 585 de 2007. Los meses con horas de calor son los de verano: junio tiene más de 150 horas de promedio, agosto más de 250 , julio casi 275 , y septiembre más de 60 . Tanto junio como septiembre tienen una gran variabilidad entre unos años y otros. Mayo y octubre tienen también horas de calor, hay años que abril las tiene incluso; el resto de los meses no tienen horas de calor.

Tabla 270. Horas de calor contadas en datos horarios en el observatorio de Hinojosa del Duque.

\begin{tabular}{rrrrrrrrrrrrrr}
\hline & ene & feb & mar & abr & may & jun & jul & ago & sep & oct & nov & dic & anual \\
\hline $\mathbf{2 0 0 2}$ & 0 & 0 & 0 & 0 & 32 & 193 & 241 & 204 & 29 & 0 & 0 & 0 & 699 \\
$\mathbf{2 0 0 3}$ & 0 & 0 & 0 & 0 & 58 & 218 & 258 & 278 & 68 & 0 & 0 & 0 & 880 \\
$\mathbf{2 0 0 4}$ & 0 & 0 & 0 & 0 & 2 & 222 & & & 76 & 34 & 0 & 0 & \\
$\mathbf{2 0 0 5}$ & 0 & 0 & 0 & 5 & 44 & 212 & 294 & 282 & 63 & 5 & 0 & 0 & 905 \\
$\mathbf{2 0 0 6}$ & 0 & 0 & 0 & 0 & 44 & 141 & 315 & 271 & 105 & 2 & 0 & 0 & 878 \\
$\mathbf{2 0 0 7}$ & 0 & 0 & 0 & 0 & 13 & 59 & 260 & 191 & 62 & 0 & 0 & 0 & 585 \\
$\mathbf{2 0 0 8}$ & 0 & 0 & 0 & 0 & 0 & 144 & 199 & 232 & 30 & 0 & 0 & 0 & 605 \\
$\mathbf{2 0 0 9}$ & 0 & 0 & 0 & 0 & 39 & 168 & 279 & 300 & 76 & 5 & 0 & 0 & 867 \\
$\mathbf{2 0 1 0}$ & 0 & 0 & 0 & 0 & 8 & 136 & 347 & 293 & 56 & 0 & 0 & 0 & 840 \\
$\mathbf{2 0 1 1}$ & 0 & 0 & 0 & 0 & 15 & 169 & 255 & 266 & 98 & 33 & 0 & 0 & 836 \\
Prom. & 0 & 0 & 0 & 1 & 26 & 166 & 272 & 257 & 66 & 8 & 0 & 0 & 788 \\
\hline & & & & & & 0 & 0 & & & & & &
\end{tabular}




\subsubsection{Cuenca del Guadiana: b) parte baja y relativamente llana de la cuenca}

Observatorios: Badajoz CMT (4478x), Talavera la Real (4452), y Mérida (4410x).

Tabla 271. Comparación de horas de calor anuales contadas a partir de datos horarios en los tres observatorios de la parte baja de la cuenca del Guadiana.

\begin{tabular}{|cccc|}
\hline Años & $\begin{array}{c}\text { Badajoz CMT } \\
\mathbf{4 4 7 8 x}\end{array}$ & $\begin{array}{c}\text { Talavera la Real } \\
\mathbf{4 4 5 2}\end{array}$ & $\begin{array}{c}\text { Mérida } \\
\mathbf{4 4 1 0 x}\end{array}$ \\
\hline $\mathbf{2 0 0 2}$ & & HC & HC \\
\hline $\mathbf{2 0 0 3}$ & & 594 & 637 \\
\hline $\mathbf{2 0 0 4}$ & 755 & 766 & 900 \\
\hline $\mathbf{2 0 0 5}$ & 895 & 736 & 755 \\
\hline $\mathbf{2 0 0 6}$ & 935 & 804 & 841 \\
\hline $\mathbf{2 0 0 7}$ & 673 & 797 & 817 \\
\hline $\mathbf{2 0 0 8}$ & 519 & 567 & \\
\hline $\mathbf{2 0 0 9}$ & 859 & 576 & \\
\hline $\mathbf{2 0 1 0}$ & 882 & 782 & 767 \\
\hline $\mathbf{2 0 1 1}$ & 810 & 823 & 817 \\
\hline promedio & 750 & 719 & 737 \\
\hline
\end{tabular}

\section{Comparación de horas de calor (umbral $30 \circ \mathrm{C}$ ) anuales en observatorios de la parte baja de la cuenca del Guadiana}

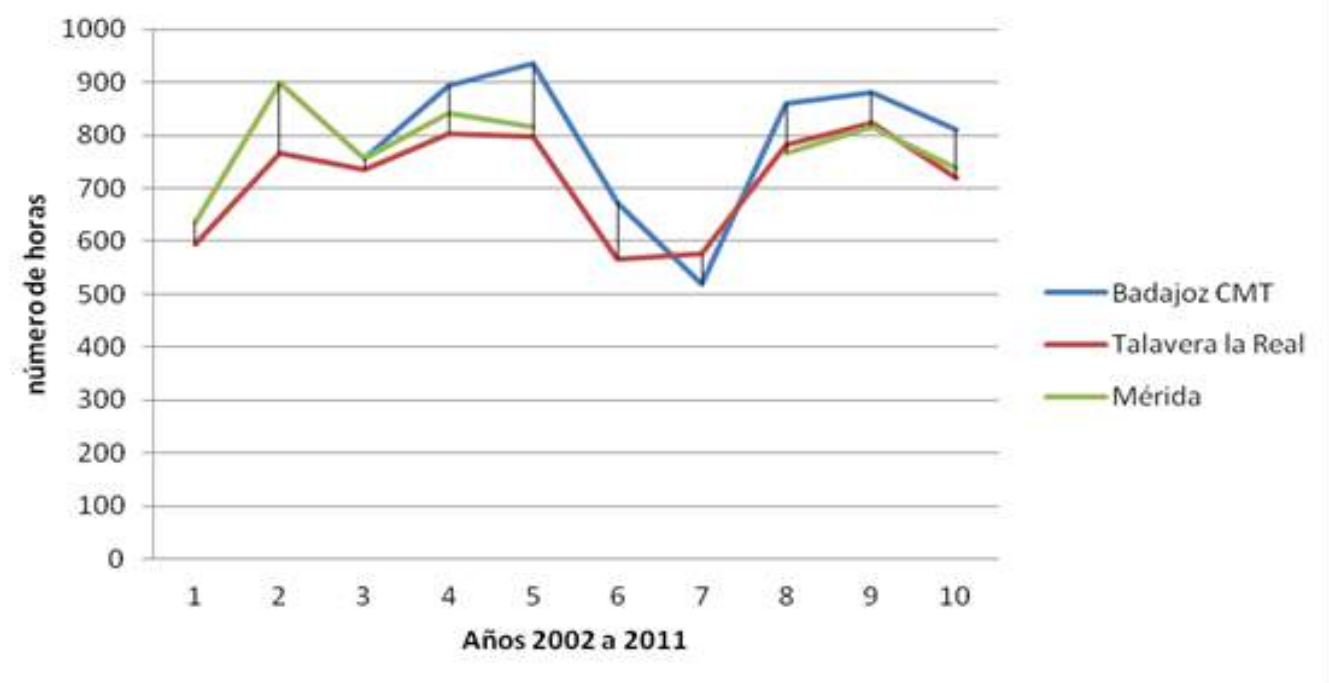

Gráfico 23. Comparación de horas de calor (umbral 30C) anuales en observatorios de la parte baja de la cuenca del Guadiana.

El gráfico muestra que los valores son coherentes entre ellos. 


\section{Horas de calor contadas en datos horarios en cada uno de los observatorios}

Badajoz CMT. Se han quitado los datos de los dos primeros años por ser probablemente erróneos. En los ocho años restantes, el promedio se acerca a las 800 horas de calor (umbral $30^{\circ} \mathrm{C}$ ) anuales. Enero, febrero, marzo, noviembre y diciembre no tienen horas de calor. Abril y octubre tienen pocas horas de calor y no todos los años. Mayo no llega a las 50 horas de calor en promedio, septiembre tiene en torno a 100 horas, junio cerca de 150, julio y agosto pasan de 200 horas de calor.

Tabla 272. Horas de calor contadas en datos horarios en el observatorio de Badajoz CMT.

\begin{tabular}{llllllllllllll}
\hline & ene & feb & mar & abr & may & jun & jul & ago & sep & oct & nov & dic & anual \\
\hline $\mathbf{2 0 0 2}$ & & & & & & & & & & & & & \\
$\mathbf{2 0 0 3}$ & & & & & & & & & & & & & \\
$\mathbf{2 0 0 4}$ & 0 & 0 & 0 & 3 & 3 & 240 & 249 & 143 & 86 & 31 & 0 & 0 & 755 \\
$\mathbf{2 0 0 5}$ & 0 & 0 & 0 & 9 & 46 & 205 & 239 & 263 & 113 & 20 & 0 & 0 & 895 \\
$\mathbf{2 0 0 6}$ & 0 & 0 & 0 & 4 & 71 & 147 & 283 & 282 & 140 & 8 & 0 & 0 & 935 \\
$\mathbf{2 0 0 7}$ & 0 & 0 & 0 & 0 & 39 & 94 & 234 & 203 & 103 & 0 & 0 & 0 & 673 \\
$\mathbf{2 0 0 8}$ & 0 & 0 & 0 & 7 & 3 & 134 & 169 & 172 & 34 & 0 & 0 & 0 & 519 \\
$\mathbf{2 0 0 9}$ & 0 & 0 & 0 & 0 & 67 & 169 & 222 & 271 & 110 & 20 & 0 & 0 & 859 \\
$\mathbf{2 0 1 0}$ & 0 & 0 & 0 & 4 & 42 & 137 & 305 & 297 & 97 & 0 & 0 & 0 & 882 \\
\hline $\mathbf{2 0 1 1}$ & 0 & 0 & 0 & 21 & 58 & 129 & 214 & 200 & 124 & 64 & 0 & 0 & 810 \\
Prom. & 0 & 0 & 0 & 6 & 41 & 157 & 239 & 229 & 101 & 18 & 0 & 0 & 791 \\
\hline
\end{tabular}

Talavera la Real. Tiene en torno a las 700 horas de calor (umbral $30^{\circ} \mathrm{C}$ ) anuales, pero oscila entre 567 de 2007 y 823 de 2010. Enero, febrero, marzo, noviembre y diciembre están libres de horas de calor. Abril, mayo y octubre tienen en promedio menos de 40; septiembre cerca de $90 \mathrm{y}$ junio cerca de 150; julio y agosto pasan de 200 horas de calor mensuales.

Tabla 273. Horas de calor contadas en datos horarios en el observatorio de Talavera la Real.

\begin{tabular}{cccccccccccccc}
\hline & ene & feb & mar & abr & may & jun & jul & ago & sep & oct & nov & dic & anual \\
\hline $\mathbf{2 0 0 2}$ & 0 & 0 & 0 & 3 & 30 & 140 & 214 & 174 & 33 & 0 & 0 & 0 & 594 \\
$\mathbf{2 0 0 3}$ & 0 & 0 & 0 & 0 & 60 & 161 & 182 & 260 & 103 & 0 & 0 & 0 & 766 \\
$\mathbf{2 0 0 4}$ & 0 & 0 & 0 & 0 & 7 & 214 & 237 & 155 & 93 & 30 & 0 & 0 & 736 \\
$\mathbf{2 0 0 5}$ & 0 & 0 & 0 & 7 & 42 & 194 & 227 & 242 & 80 & 12 & 0 & 0 & 804 \\
$\mathbf{2 0 0 6}$ & 0 & 0 & 0 & 3 & 49 & 129 & 253 & 255 & 106 & 2 & 0 & 0 & 797 \\
$\mathbf{2 0 0 7}$ & 0 & 0 & 0 & 0 & 29 & 66 & 210 & 180 & 82 & 0 & 0 & 0 & 567 \\
$\mathbf{2 0 0 8}$ & 0 & 0 & 0 & 4 & 1 & 139 & 188 & 202 & 42 & 0 & 0 & 0 & 576 \\
$\mathbf{2 0 0 9}$ & 0 & 0 & 0 & 0 & 72 & 150 & 206 & 255 & 86 & 13 & 0 & 0 & 782 \\
$\mathbf{2 0 1 0}$ & 0 & 0 & 0 & 7 & 32 & 116 & 288 & 288 & 92 & 0 & 0 & 0 & 823 \\
\hline $\mathbf{2 0 1 1}$ & 0 & 0 & 0 & 13 & 41 & 123 & 202 & 177 & 108 & 55 & 0 & 0 & 719 \\
Prom. & 0 & 0 & 0 & 4 & 36 & 143 & 221 & 219 & 83 & 11 & 0 & 0 & 716 \\
\hline
\end{tabular}


Mérida. Le faltan datos en dos de los años; en los ocho restantes tiene en promedio entre $600 \mathrm{y}$ 900 horas de calor (umbral $30^{\circ} \mathrm{C}$ ) anuales. Enero, febrero, marzo, noviembre y diciembre no tienen horas de calor. Abril y octubre tienen muy pocas; mayo en promedio pasa ligeramente de 30; septiembre no llega a 100; junio está cerca de 150 horas de calor; julio y agosto sobrepasan las 200.

Tabla 274. Horas de calor contadas en datos horarios en el observatorio de Mérida.

\begin{tabular}{cccccccccccccc}
\hline & ene & feb & mar & abr & may & jun & jul & ago & sep & oct & nov & dic & anual \\
\hline $\mathbf{2 0 0 2}$ & 0 & 0 & 0 & 5 & 36 & 146 & 220 & 182 & 34 & 14 & 0 & 0 & 637 \\
$\mathbf{2 0 0 3}$ & 0 & 0 & 0 & 0 & 65 & 199 & 200 & 298 & 137 & 1 & 0 & 0 & 900 \\
$\mathbf{2 0 0 4}$ & 0 & 0 & 0 & 0 & 5 & 214 & 239 & 157 & 105 & 35 & 0 & 0 & 755 \\
\hline $\mathbf{2 0 0 5}$ & 0 & 0 & 0 & 12 & 43 & 206 & 237 & 252 & 80 & 11 & 0 & 0 & 841 \\
$\mathbf{2 0 0 6}$ & 0 & 0 & 0 & 5 & 46 & 130 & 264 & 257 & 111 & 4 & 0 & 0 & 817 \\
$\mathbf{2 0 0 7}$ & 0 & 0 & 0 & 0 & 25 & 66 & 207 & & 88 & 0 & 0 & 0 & \\
$\mathbf{2 0 0 8}$ & 0 & 0 & 0 & 3 & 7 & 129 & & & 26 & 0 & 0 & 0 & \\
\hline $\mathbf{2 0 0 9}$ & 0 & 0 & 0 & 0 & 66 & 154 & 196 & 246 & 92 & 13 & 0 & 0 & 767 \\
$\mathbf{2 0 1 0}$ & 0 & 0 & 0 & 5 & 38 & 115 & 276 & 289 & 94 & 0 & 0 & 0 & 817 \\
\hline $\mathbf{2 0 1 1}$ & 0 & 0 & 0 & 7 & 50 & 118 & 203 & 190 & 107 & 62 & 0 & 0 & 737 \\
Prom. & 0 & 0 & 0 & 4 & 38 & 148 & 227 & 234 & 87 & 14 & 0 & 0 & 774 \\
\hline
\end{tabular}

\section{Resumen de horas de calor contadas para la cuenca del Guadiana.}

En el valle del Guadiana por debajo de $700 \mathrm{~m}$ de altitud el número medio de horas de calor anuales supera las 700, tanto en las partes más bajas de la cuenca (Extremadura) como en la zona de la Mancha. En los meses de enero, febrero, marzo, noviembre y diciembre no se dan horas de calor. En abril y octubre hay muy pocas horas de calor, y no todos los años. En mayo hay también pocas horas de calor, no llega a 50 de media, pero hay todos los años. Junio en promedio está cerca de 150 y tiene mucha variación interanual, entre algo más de 50 y algo más de 200 horas. Julio y agosto tienen más de 200 horas y la variabilidad entre unos años y otros es menor, entre más de 150 y 300 horas. Septiembre no llega a 100 horas y muestra una gran variabilidad entre unos años y otros. 


\subsubsection{Cuenca del Guadalquivir: a) parte baja y relativamente llana de la cuenca}

Observatorios: Sevilla-San Pablo (5783), Écija (5641x), Base aérea de Morón (5796) y Córdoba aeropuerto (5402).

Tabla 275. Comparación de horas de calor anuales contadas a partir de datos horarios en los cuatro observatorios de la parte baja de la cuenca del Guadalquivir.

\begin{tabular}{|ccccc|}
\hline & $\begin{array}{c}\text { Sevilla SP } \\
\mathbf{5 7 8 3}\end{array}$ & $\begin{array}{c}\text { Écija } \\
\mathbf{5 6 4 1 \mathbf { x }}\end{array}$ & $\begin{array}{c}\text { Morón } \\
\mathbf{5 7 9 6}\end{array}$ & $\begin{array}{c}\text { Córdoba aer. } \\
\mathbf{5 4 0 2}\end{array}$ \\
\hline $\mathbf{A n ̃ o}$ & $\mathrm{HC}$ & $\mathrm{HC}$ & $\mathrm{HC}$ & $\mathrm{HC}$ \\
\hline $\mathbf{2 0 0 2}$ & 693 & 708 & 575 & 753 \\
\hline $\mathbf{2 0 0 3}$ & 1048 & 1099 & 896 & 1103 \\
\hline $\mathbf{2 0 0 4}$ & 1050 & 987 & 883 & 1050 \\
\hline $\mathbf{2 0 0 5}$ & 1017 & 830 & 852 & 1102 \\
\hline $\mathbf{2 0 0 6}$ & 1020 & 979 & 853 & 1092 \\
\hline $\mathbf{2 0 0 7}$ & 796 & 831 & 645 & 886 \\
\hline $\mathbf{2 0 0 8}$ & 859 & 841 & 733 & 896 \\
\hline $\mathbf{2 0 0 9}$ & 1072 & 1027 & 890 & 1107 \\
\hline $\mathbf{2 0 1 0}$ & 1045 & 802 & 862 & 972 \\
\hline $\mathbf{2 0 1 1}$ & 1091 & 883 & 906 & 1009 \\
\hline Promedio & 969 & 899 & 810 & 997 \\
\hline
\end{tabular}

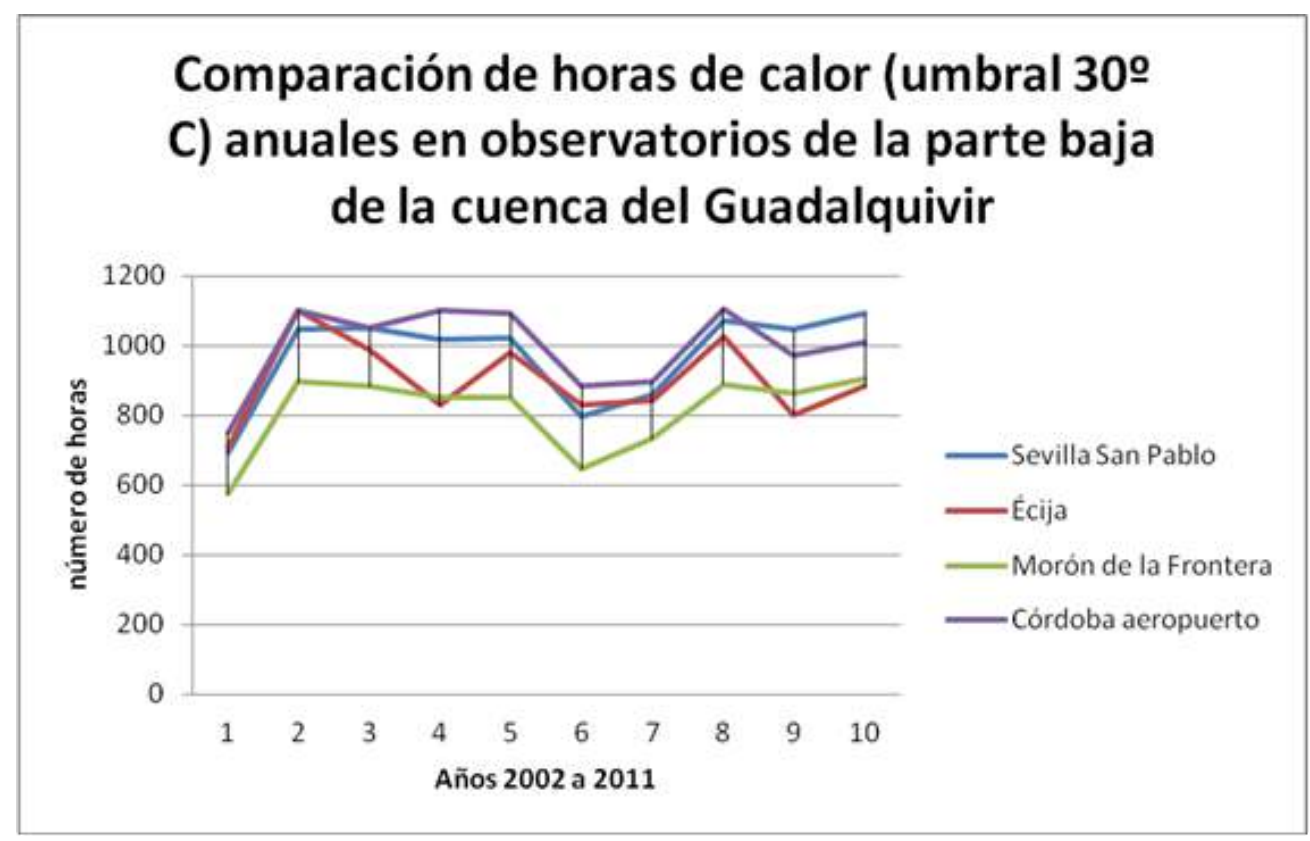

Gráfico 24. Comparación de horas de calor (umbral 30C) anuales en observatorios de la parte baja de la cuenca del Guadalquivir. 
Excepto el valor de Écija para 2005 y quizá para 2010, ambos un poco bajos, los datos son coherentes entre ellos.

\section{Horas de calor contadas en datos horarios en cada uno de los observatorios}

Sevilla San Pablo. Sevilla San Pablo y Sevilla Tablada deberían de tener un número de horas de calor muy similar debido a la proximidad e igualdad del entorno. Sin embargo, se ve que en los años en los que ambos observatorios disponen de datos, los valores anuales de horas de calor de la base aérea son bastante menores que los del aeropuerto. Comparándolos con los de otros observatorios de la parte baja de la cuenca se concluye que parecen más fiables los del aeropuerto.

En promedio, el observatorio de Sevilla San Pablo registra cerca de 1000 horas de calor (umbral $30^{\circ} \mathrm{C}$ ) al año y, aunque en la mayoría de los años el valor está alrededor de 1000, puede haber años, como el 2002, en que no se alcanzan las 700 horas. En Sevilla San Pablo sólo están libres de horas de calor los tres meses de invierno: diciembre, enero y febrero; en los demás, incluso en marzo y noviembre pueden darse años en los que algún día se alcancen o sobrepasen los $30^{\circ} \mathrm{C}$. Julio y agosto están en promedio cercanos a las 300 horas de calor; septiembre sobrepasa las 100 horas de promedio y junio se acerca a las 200. Mayo tiene cerca de dos horas de calor diarias en promedio, y octubre cerca de una hora diaria.

Tabla 276. Horas de calor contadas en datos horarios en el observatorio de Sevilla San Pablo.

\begin{tabular}{cccccccccccccc}
\hline & ene & feb & mar & abr & may & jun & jul & ago & sep & oct & nov & dic & anual \\
\hline $\mathbf{2 0 0 2}$ & 0 & 0 & 2 & 16 & 55 & 151 & 251 & 180 & 35 & 3 & 0 & 0 & 693 \\
$\mathbf{2 0 0 3}$ & 0 & 0 & 0 & 0 & 96 & 196 & 272 & 328 & 156 & 0 & 0 & 0 & 1048 \\
$\mathbf{2 0 0 4}$ & 0 & 0 & 0 & 0 & 26 & 256 & 330 & 250 & 143 & 45 & 0 & 0 & 1050 \\
\hline $\mathbf{2 0 0 5}$ & 0 & 0 & 0 & 10 & 77 & 234 & 276 & 284 & 117 & 19 & 0 & 0 & 1017 \\
$\mathbf{2 0 0 6}$ & 0 & 0 & 0 & 1 & 79 & 155 & 346 & 268 & 157 & 14 & 0 & 0 & 1020 \\
\hline $\mathbf{2 0 0 7}$ & 0 & 0 & 0 & 0 & 50 & 106 & 299 & 226 & 108 & 7 & 0 & 0 & 796 \\
$\mathbf{2 0 0 8}$ & 0 & 0 & 0 & 0 & 13 & 208 & 278 & 286 & 74 & 0 & 0 & 0 & 859 \\
$\mathbf{2 0 0 9}$ & 0 & 0 & 0 & 2 & 60 & 201 & 310 & 335 & 114 & 48 & 2 & 0 & 1072 \\
$\mathbf{2 0 1 0}$ & 0 & 0 & 0 & 15 & 61 & 124 & 347 & 351 & 146 & 1 & 0 & 0 & 1045 \\
$\mathbf{2 0 1 1}$ & 0 & 0 & 0 & 25 & 68 & 215 & 256 & 279 & 164 & 84 & 0 & 0 & 1091 \\
Prom. & 0 & 0 & 0 & 7 & 59 & 185 & 297 & 279 & 121 & 22 & 0 & 0 & 969 \\
\hline
\end{tabular}


Écija. Tiene en promedio 900 horas de calor (umbral $30^{\circ} \mathrm{C}$ ) al año, oscilando entre las 708 de 2002 y las 1099 de 2003. No hay horas de calor en los tres meses de invierno, más marzo y noviembre. Julio y agosto están en promedio cercanos a las 300 horas de calor; septiembre sobrepasa las 100 horas de promedio y junio se acerca a las 200. Mayo tiene hora y media diaria en promedio y octubre media.

Tabla 277. Horas de calor contadas en datos horarios en el observatorio de Écija.

\begin{tabular}{cccccccccccccc}
\hline & ene & feb & mar & abr & may & jun & jul & ago & sep & oct & nov & dic & anual \\
\hline $\mathbf{2 0 0 2}$ & 0 & 0 & 0 & 5 & 35 & 160 & 266 & 187 & 55 & 0 & 0 & 0 & 708 \\
\hline $\mathbf{2 0 0 3}$ & 0 & 0 & 0 & 0 & 101 & 224 & 300 & 318 & 156 & & 0 & 0 & 1099 \\
$\mathbf{2 0 0 4}$ & 0 & 0 & 0 & 3 & 28 & 241 & 301 & 237 & 133 & 44 & 0 & 0 & 987 \\
$\mathbf{2 0 0 5}$ & 0 & 0 & 0 & 1 & 51 & 205 & 256 & 243 & 65 & 9 & 0 & 0 & 830 \\
\hline $\mathbf{2 0 0 6}$ & 0 & 0 & 0 & 0 & 47 & 109 & 313 & 260 & 99 & 3 & 0 & 0 & 831 \\
\hline $\mathbf{2 0 0 7}$ & 0 & 0 & 0 & 0 & 70 & 161 & 329 & 263 & 141 & 15 & 0 & 0 & 979 \\
$\mathbf{2 0 0 8}$ & 0 & 0 & 0 & 3 & 5 & 189 & 276 & 288 & 80 & 0 & 0 & 0 & 841 \\
\hline $\mathbf{2 0 0 9}$ & 0 & 0 & 0 & 0 & 54 & 191 & 321 & 327 & 100 & 34 & 0 & 0 & 1027 \\
$\mathbf{2 0 1 0}$ & 0 & 0 & 0 & 2 & 26 & 122 & 331 & 320 & 110 & 1 & 0 & 0 & 912 \\
\hline $\mathbf{2 0 1 1}$ & 0 & 0 & 0 & 5 & 26 & 176 & 253 & 262 & 117 & 44 & 0 & 0 & 883 \\
\hline Prom. & 0 & 0 & 0 & 2 & 44 & 178 & 295 & 271 & 106 & 17 & 0 & 0 & 910 \\
\hline
\end{tabular}

Morón. Tiene en promedio 800 horas de calor al año y, aunque en la mayoría de los años el valor está entre 800 y 900 horas, puede haber años, como el 2002, en los que no se alcancen las 600 horas. No hay horas de calor en los tres meses de invierno, diciembre, enero y febrero, más marzo y noviembre. Julio y agosto están en promedio en torno a las 250 horas de calor mensuales; septiembre sobrepasa las 100 horas y junio tiene aproximadamente 150. Mayo sobrepasa la hora diaria en promedio y octubre no llega a ella.

Tabla 278. Horas de calor contadas en datos horarios en el observatorio de Morón

\begin{tabular}{cccccccccccccc}
\hline & ene & feb & mar & abr & may & jun & jul & ago & sep & oct & nov & dic & anual \\
\hline $\mathbf{2 0 0 2}$ & 0 & 0 & 0 & 10 & 36 & 125 & 225 & 149 & 29 & 1 & 0 & 0 & 575 \\
$\mathbf{2 0 0 3}$ & 0 & 0 & 0 & 0 & 71 & 162 & 242 & 286 & 135 & 0 & 0 & 0 & 896 \\
$\mathbf{2 0 0 4}$ & 0 & 0 & 0 & 0 & 13 & 205 & 284 & 213 & 120 & 48 & 0 & 0 & 883 \\
$\mathbf{2 0 0 5}$ & 0 & 0 & 0 & 4 & 57 & 201 & 231 & 249 & 92 & 18 & 0 & 0 & 852 \\
$\mathbf{2 0 0 6}$ & 0 & 0 & 0 & 0 & 64 & 121 & 280 & 239 & 138 & 11 & 0 & 0 & 853 \\
$\mathbf{2 0 0 7}$ & 0 & 0 & 0 & 0 & 36 & 78 & 246 & 192 & 86 & 7 & 0 & 0 & 645 \\
$\mathbf{2 0 0 8}$ & 0 & 0 & 0 & 2 & 4 & 166 & 249 & 249 & 63 & 0 & 0 & 0 & 733 \\
$\mathbf{2 0 0 9}$ & 0 & 0 & 0 & 0 & 41 & 159 & 268 & 282 & 101 & 39 & 0 & 0 & 890 \\
$\mathbf{2 0 1 0}$ & 0 & 0 & 0 & 11 & 46 & 92 & 290 & 303 & 120 & 0 & 0 & 0 & 862 \\
$\mathbf{2 0 1 1}$ & 0 & 0 & 0 & 11 & 42 & 168 & 222 & 237 & 148 & 78 & 0 & 0 & 906 \\
Prom. & 0 & 0 & 0 & 4 & 41 & 148 & 254 & 240 & 103 & 20 & 0 & 0 & 810 \\
\hline
\end{tabular}


Córdoba aeropuerto. Tiene en promedio mil horas de calor (umbral $30^{\circ} \mathrm{C}$ ) al año y, aunque en la mayoría de los años el valor está alrededor de 1000, puede haber años, como el 2002, en los que no se alcancen las 800 horas. No hay horas de calor en los tres meses de invierno, diciembre, enero y febrero, más marzo y noviembre. Julio y agosto están en promedio en torno a las 300 horas de calor mensuales; septiembre sobrepasa las $100 \mathrm{y}$ junio se acerca a las 200. Mayo tiene aproximadamente dos horas diarias en promedio y octubre media hora.

Tabla 279. Horas de calor contadas en datos horarios en el observatorio de Córdoba aeropuerto.

\begin{tabular}{cccccccccccccc}
\hline & ene & feb & mar & abr & may & jun & jul & ago & sep & oct & nov & dic & anual \\
\hline $\mathbf{2 0 0 2}$ & 0 & 0 & 0 & 8 & 51 & 162 & 282 & 204 & 46 & 0 & 0 & 0 & 753 \\
\hline $\mathbf{2 0 0 3}$ & 0 & 0 & 0 & 0 & 84 & 226 & 291 & 335 & 167 & 0 & 0 & 0 & 1103 \\
\hline $\mathbf{2 0 0 4}$ & 0 & 0 & 0 & 0 & 17 & 240 & 318 & 269 & 163 & 43 & 0 & 0 & 1050 \\
\hline $\mathbf{2 0 0 5}$ & 0 & 0 & 0 & 13 & 82 & 249 & 317 & 295 & 126 & 20 & 0 & 0 & 1102 \\
\hline $\mathbf{2 0 0 6}$ & 0 & 0 & 0 & 1 & 86 & 190 & 361 & 285 & 148 & 21 & 0 & 0 & 1092 \\
\hline $\mathbf{2 0 0 7}$ & 0 & 0 & 0 & 0 & 39 & 119 & 329 & 271 & 117 & 11 & 0 & 0 & 886 \\
\hline $\mathbf{2 0 0 8}$ & 0 & 0 & 0 & 0 & 11 & 200 & 300 & 307 & 78 & 0 & 0 & 0 & 896 \\
\hline $\mathbf{2 0 0 9}$ & 0 & 0 & 0 & 0 & 79 & 207 & 336 & 339 & 103 & 43 & 0 & 0 & 1107 \\
$\mathbf{2 0 1 0}$ & 0 & 0 & 0 & 11 & 56 & 127 & 338 & 321 & 119 & 0 & 0 & 0 & 972 \\
\hline $\mathbf{2 0 1 1}$ & 0 & 0 & 0 & 10 & 49 & 200 & 272 & 277 & 146 & 55 & 0 & 0 & 1009 \\
Prom. & 0 & 0 & 0 & 4 & 55 & 192 & 314 & 290 & 121 & 19 & 0 & 0 & 997 \\
\hline
\end{tabular}

\subsubsection{Cuenca del Guadalquivir: b) parte media de la cuenca: Granada}

Sólo Granada base aérea (5514) tiene datos completos y fiables.

\section{Horas de calor contadas en datos horarios del observatorio.}

Granada. Tiene en promedio 600 horas de calor (umbral $30^{\circ} \mathrm{C}$ ) al año, entre las 477 de 2007 y las 697 de 2009.

Los meses de invierno más marzo y noviembre no tienen horas de calor. Abril tuvo horas de calor un solo año en el periodo de diez considerado. Mayo y octubre tienen muy pocas y no todos los años. Septiembre tiene poco más de una hora diaria en promedio y junio, cuatro. Julio y agosto están en torno a las 200 mensuales, julio las sobrepasa y agosto no llega. 
Tabla 280. Horas de calor contadas en datos horarios en el observatorio de Granada.

\begin{tabular}{cccccccccccccc}
\hline & ene & feb & mar & abr & may & jun & jul & ago & sep & oct & nov & dic & anual \\
\hline $\mathbf{2 0 0 2}$ & 0 & 0 & 0 & 0 & 11 & 154 & 186 & 123 & 14 & 0 & 0 & 0 & 488 \\
\hline $\mathbf{2 0 0 3}$ & 0 & 0 & 0 & 0 & 13 & 171 & 219 & 209 & 29 & 0 & 0 & 0 & 641 \\
$\mathbf{2 0 0 4}$ & 0 & 0 & 0 & 0 & 0 & 139 & 232 & 197 & 80 & 24 & 0 & 0 & 672 \\
\hline $\mathbf{2 0 0 5}$ & 0 & 0 & 0 & 0 & 24 & 162 & 224 & 185 & 30 & 0 & 0 & 0 & 625 \\
$\mathbf{2 0 0 6}$ & 0 & 0 & 0 & 0 & 47 & 94 & 273 & 190 & 51 & 8 & 0 & 0 & 663 \\
\hline $\mathbf{2 0 0 7}$ & 0 & 0 & 0 & 0 & 12 & 31 & 224 & 182 & 28 & 0 & 0 & 0 & 477 \\
$\mathbf{2 0 0 8}$ & 0 & 0 & 0 & 0 & 0 & 100 & 201 & 203 & 28 & 0 & 0 & 0 & 532 \\
\hline $\mathbf{2 0 0 9}$ & 0 & 0 & 0 & 0 & 22 & 156 & 272 & 190 & 45 & 12 & 0 & 0 & 697 \\
$\mathbf{2 0 1 0}$ & 0 & 0 & 0 & 0 & 7 & 80 & 267 & 214 & 46 & 3 & 0 & 0 & 617 \\
\hline $\mathbf{2 0 1 1}$ & 0 & 0 & 0 & 2 & 0 & 135 & 181 & 199 & 64 & 7 & 0 & 0 & 588 \\
\hline Prom. & 0 & 0 & 0 & 0 & 14 & 122 & 228 & 189 & 42 & 5 & 0 & 0 & 600 \\
\hline
\end{tabular}

Resumen de horas de calor contadas en la cuenca del Guadalquivir.

Podría concluirse que en el bajo Guadalquivir, por debajo de $250 \mathrm{~m}$ de altitud se dan en promedio más de 800 horas de calor anuales. En la parte media de la cuenca, pero por debajo de $600 \mathrm{~m}$ de altitud se dan en por encima de 600 horas de calor; en general, a igualdad de otros factores, más horas cuanto menor sea la altitud. En el Genil, a la altitud de Granada, y en zonas de altitud semejante, se dan también 600 o más horas.

\subsubsection{Levante: a) franja costera de Levante: huerta levantina}

Observatorios: Valencia (8416), Valencia-Manises (8414a), Castellón (8500a), Alicante (8025), Alicante-El Altet (8019).

Tabla 281. Comparación de horas de calor anuales contadas a partir de datos horarios en los cinco observatorios de la franja costera de Levante: huerta levantina.

\begin{tabular}{|cccccc|}
\hline & $\begin{array}{c}\text { Valencia } \\
\mathbf{8 4 1 6}\end{array}$ & $\begin{array}{c}\text { Manises } \\
\mathbf{8 4 1 4 a}\end{array}$ & $\begin{array}{c}\text { Castellón } \\
\mathbf{8 5 0 0 a}\end{array}$ & $\begin{array}{c}\text { Alicante } \\
\mathbf{8 0 2 5}\end{array}$ & $\begin{array}{c}\text { El Altet } \\
\mathbf{8 0 1 9}\end{array}$ \\
\hline $\mathbf{A n ̃ o}$ & $\mathrm{HC}$ & $\mathrm{HC}$ & $\mathrm{HC}$ & $\mathrm{HC}$ & $\mathrm{HC}$ \\
\hline $\mathbf{2 0 0 2}$ & 83 & 89 & 104 & 72 & 29 \\
\hline $\mathbf{2 0 0 3}$ & 497 & 490 & 560 & 458 & 486 \\
\hline $\mathbf{2 0 0 4}$ & 218 & 243 & 255 & 213 & 216 \\
\hline $\mathbf{2 0 0 5}$ & & 289 & 271 & 175 & 148 \\
\hline $\mathbf{2 0 0 6}$ & 62 & 416 & 270 & 233 & 139 \\
\hline $\mathbf{2 0 0 7}$ & 73 & 159 & 144 & 168 & 80 \\
\hline $\mathbf{2 0 0 8}$ & 58 & 288 & 171 & 166 & 98 \\
\hline $\mathbf{2 0 0 9}$ & 89 & 245 & 258 & 216 & 113 \\
\hline $\mathbf{2 0 1 0}$ & 87 & 213 & 226 & 206 & 166 \\
\hline $\mathbf{2 0 1 1}$ & 53 & 135 & 198 & 223 & 214 \\
\hline promedio & 136 & 257 & 246 & 213 & 169 \\
\hline
\end{tabular}




\section{Comparación de horas de calor (umbral 30 ㅇ) anuales en observatorios de la franja costera de Levante}

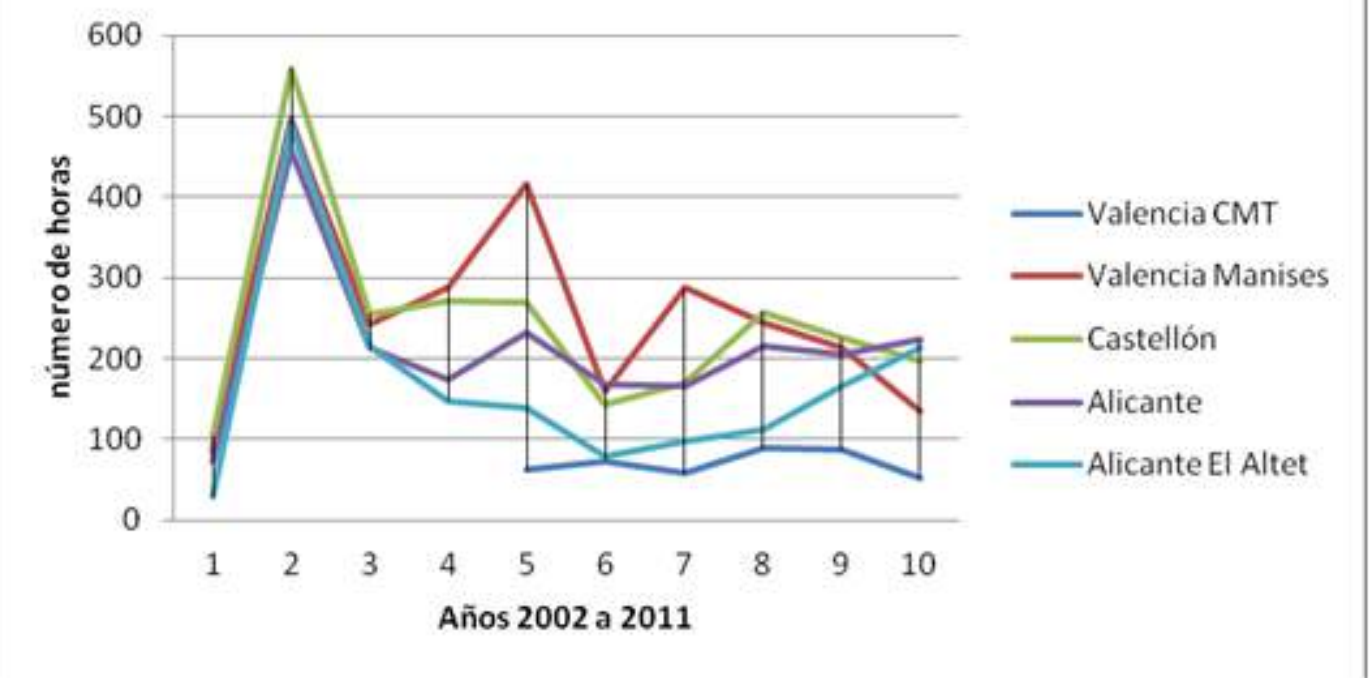

Gráfico 25. Comparación de horas de calor (umbral 30ㄷ) anuales en observatorios de la franja costera de Levante: huerta levantina.

Los datos parecen coherentes en la evolución, pero resulta sospechoso que sean con datos tan similares entre ellos en los tres primeros años, de 2002 a 2004 y relativamente tan distintos en los restantes, de 2005 a 2011. También llama la atención que Valencia CMT (ciudad) tenga 62 horas en 2006 mientras que Manises llegue a las 416. Lógicamente el mar ejerce una influencia suavizante y se dan más horas de nieblas matinales, cosa que no ocurre unos pocos kilómetros tierra adentro; pero como se ve el resto de los años esa diferencia es excesiva. Posiblemente, rebajando el umbral a $25^{\circ} \mathrm{C}$ aparecerán muchas más horas y que los distintos observatorios den datos más coherentes.

\section{Horas de calor contadas en datos horarios en cada uno de los observatorios}

Valencia. Tiene en promedio algo más de 100 horas de calor (umbral $30^{\circ} \mathrm{C}$ ) al año, oscilando entre las 53 horas de 2011 y las 497 de 2003.

Las horas de calor se reparten entre los meses de mayo a septiembre, aunque mayo y septiembre tienen muy pocas horas. Tampoco abril y octubre tienen apenas horas de calor. Junio no llega en promedio a las 30 horas, julio las sobrepasa ligeramente mientras que agosto sobrepasa las 60. 
La variabilidad interanual, así como la que se da entre los mismos meses de los distintos años, es muy marcada.

Tabla 282. Horas de calor contadas en datos horarios en el observatorio de Valencia.

\begin{tabular}{cccccccccccccc}
\hline & ene & feb & mar & abr & may & jun & jul & ago & sep & oct & nov & dic & anual \\
\hline $\mathbf{2 0 0 2}$ & 0 & 0 & 0 & 0 & 0 & 19 & 29 & 25 & 10 & 0 & 0 & 0 & 83 \\
$\mathbf{2 0 0 3}$ & 0 & 0 & 0 & 0 & 0 & 109 & 149 & 235 & 4 & 0 & 0 & 0 & 497 \\
$\mathbf{2 0 0 4}$ & 0 & 0 & 0 & 0 & 0 & 29 & 36 & 138 & 9 & 6 & 0 & 0 & 218 \\
$\mathbf{2 0 0 5}$ & 0 & 0 & 0 & & & & & & & & & & \\
$\mathbf{2 0 0 6}$ & 0 & 0 & 0 & 0 & 0 & 4 & 32 & 14 & 4 & 8 & 0 & 0 & 62 \\
$\mathbf{2 0 0 7}$ & 0 & 0 & 0 & 0 & 14 & 18 & 14 & 27 & 0 & 0 & 0 & 0 & 73 \\
$\mathbf{2 0 0 8}$ & 0 & 0 & 0 & 0 & 0 & 5 & 3 & 22 & 28 & 0 & 0 & 0 & 58 \\
\hline $\mathbf{2 0 0 9}$ & 0 & 0 & 0 & 0 & 0 & 3 & 29 & 48 & 6 & 3 & 0 & 0 & 89 \\
$\mathbf{2 0 1 0}$ & 0 & 0 & 0 & 0 & 9 & 1 & 10 & 51 & 16 & 0 & 0 & 0 & 87 \\
\hline $\mathbf{2 0 1 1}$ & 0 & 0 & 0 & 1 & 2 & 0 & 10 & 35 & 4 & 1 & 0 & 0 & 53 \\
Prom. & 0 & 0 & 0 & 0 & 3 & 21 & 35 & 66 & 9 & 2 & 0 & 0 & 136 \\
\hline
\end{tabular}

Valencia Manises. Tiene en promedio 250 horas de calor (umbral $30^{\circ} \mathrm{C}$ ) al año, oscilando entre las 89 horas de 2002 y las 490 de 2003.

Las horas de calor se reparten entre los meses de abril a octubre; si bien, abril y octubre tienen muy pocas y pocos años; mayo y septiembre tienen también pocas y no todos los años; junio en promedio pasa de 30 horas de calor; julio y agosto se acercan a 100.

La variabilidad interanual, así como la que se da entre los mismos meses de los distintos años, es muy marcada.

Tabla 283. Horas de calor contadas en datos horarios en el observatorio de Valencia Manises.

\begin{tabular}{ccccccccccccccc}
\hline & ene & feb & mar & abr & may & jun & jul & ago & sep & oct & nov & dic & anual \\
\hline $\mathbf{2 0 0 2}$ & 0 & 0 & 0 & 0 & 0 & 22 & 37 & 24 & 6 & 0 & 0 & 0 & 89 \\
$\mathbf{2 0 0 3}$ & 0 & 0 & 0 & 0 & 5 & 99 & 154 & 222 & 10 & 0 & 0 & 0 & 490 \\
$\mathbf{2 0 0 4}$ & 0 & 0 & 0 & 0 & 0 & 43 & 40 & 146 & 10 & 4 & 0 & 0 & 243 \\
$\mathbf{2 0 0 5}$ & 0 & 0 & 0 & 0 & 3 & 69 & 123 & 57 & 37 & 0 & 0 & 0 & 289 \\
$\mathbf{2 0 0 6}$ & 0 & 0 & 0 & 0 & 4 & 25 & 235 & 126 & 15 & 11 & 0 & 0 & 416 \\
$\mathbf{2 0 0 7}$ & 0 & 0 & 0 & 0 & 18 & 34 & 47 & 60 & 0 & 0 & 0 & 0 & 159 \\
$\mathbf{2 0 0 8}$ & 0 & 0 & 0 & 0 & 0 & 44 & 94 & 113 & 37 & 0 & 0 & 0 & 288 \\
$\mathbf{2 0 0 9}$ & 0 & 0 & 0 & 0 & 0 & 24 & 60 & 148 & 13 & 0 & 0 & 0 & 245 \\
$\mathbf{2 0 1 0}$ & 0 & 0 & 0 & 0 & 9 & 10 & 89 & 78 & 27 & 0 & 0 & 0 & 213 \\
$\mathbf{2 0 1 1}$ & 0 & 0 & 0 & 2 & 8 & 0 & 21 & 79 & 23 & 2 & 0 & 0 & 135 \\
Prom. & 0 & 0 & 0 & 0 & 5 & 37 & 90 & 105 & 18 & 2 & 0 & 0 & 257 \\
\hline
\end{tabular}


Castellón. Tiene en promedio unas 250 horas de calor (umbral $30^{\circ} \mathrm{C}$ ) al año, oscilando entre las 104 horas de 2002 y las 560 de 2003.

Las horas de calor se reparten entre los meses de mayo a octubre, aunque mayo, y octubre tienen muy pocas y pocos años. septiembre tiene también pocas y no todos los años; junio en promedio pasa de 30 horas de calor; julio y agosto se acercan a 100.

La variabilidad interanual, así como la que se da entre los mismos meses de los distintos años, es muy marcada.

Tabla 284. Horas de calor contadas en datos horarios en el observatorio de Castellón.

\begin{tabular}{cccccccccccccc}
\hline & ene & feb & mar & abr & may & jun & jul & ago & sep & oct & nov & dic & anual \\
\hline $\mathbf{2 0 0 2}$ & 0 & 0 & 0 & 0 & 0 & 42 & 36 & 19 & 7 & 0 & 0 & 0 & 104 \\
$\mathbf{2 0 0 3}$ & 0 & 0 & 0 & 0 & 0 & 138 & 175 & 247 & 0 & 0 & 0 & 0 & 560 \\
$\mathbf{2 0 0 4}$ & 0 & 0 & 0 & 0 & 0 & 42 & 56 & 150 & 4 & 3 & 0 & 0 & 255 \\
\hline $\mathbf{2 0 0 5}$ & 0 & 0 & 0 & 0 & 0 & 68 & 130 & 52 & 21 & 0 & 0 & 0 & 271 \\
$\mathbf{2 0 0 6}$ & 0 & 0 & 0 & 0 & 4 & 17 & 181 & 58 & 6 & 4 & 0 & 0 & 270 \\
$\mathbf{2 0 0 7}$ & 0 & 0 & 0 & 0 & 7 & 12 & 54 & 71 & 0 & 0 & 0 & 0 & 144 \\
$\mathbf{2 0 0 8}$ & 0 & 0 & 0 & 0 & 0 & 36 & 43 & 70 & 22 & 0 & 0 & 0 & 171 \\
$\mathbf{2 0 0 9}$ & 0 & 0 & 0 & 0 & 0 & 19 & 76 & 143 & 20 & 0 & 0 & 0 & 258 \\
$\mathbf{2 0 1 0}$ & 0 & 0 & 0 & 0 & 13 & 9 & 127 & 61 & 19 & 0 & 0 & 0 & 229 \\
\hline $\mathbf{2 0 1 1}$ & 0 & 0 & 0 & 0 & 1 & 7 & 35 & 109 & 46 & 0 & 0 & 0 & 198 \\
Prom. & 0 & 0 & 0 & 0 & 3 & 39 & 91 & 98 & 15 & 1 & 0 & 0 & 246 \\
\hline
\end{tabular}

Alicante. Tiene en promedio algo más de 200 horas de calor (umbral $30^{\circ} \mathrm{C}$ ) al año, oscilando entre las 72 horas de 2002 y las 458 de 2003.

Las horas de calor se reparten entre los meses de mayo a octubre, aunque mayo, septiembre y octubre tienen muy pocas horas y pocos años; junio tiene en promedio cerca de 30 horas de calor, julio 70 y agosto 90 .

La variabilidad interanual, así como la que se da entre los mismos meses de los distintos años, es muy marcada. 
Tabla 285. Horas de calor contadas en datos horarios en el observatorio de Alicante.

\begin{tabular}{cccccccccccccc}
\hline & ene & feb & mar & abr & may & jun & jul & ago & sep & oct & nov & dic & anual \\
\hline $\mathbf{2 0 0 2}$ & 0 & 0 & 0 & 0 & 2 & 12 & 29 & 14 & 15 & 0 & 0 & 0 & 72 \\
\hline $\mathbf{2 0 0 3}$ & 0 & 0 & 0 & 0 & 0 & 107 & 123 & 210 & 18 & 0 & 0 & 0 & 458 \\
$\mathbf{2 0 0 4}$ & 0 & 0 & 0 & 0 & 0 & 45 & 30 & 106 & 30 & 2 & 0 & 0 & 213 \\
\hline $\mathbf{2 0 0 5}$ & 0 & 0 & 0 & 0 & 0 & 40 & 74 & 31 & 30 & 0 & 0 & 0 & 175 \\
$\mathbf{2 0 0 6}$ & 0 & 0 & 0 & 0 & 0 & 7 & 168 & 40 & 10 & 8 & 0 & 0 & 233 \\
\hline $\mathbf{2 0 0 7}$ & 0 & 0 & 0 & 0 & 16 & 9 & 37 & 106 & 0 & 0 & 0 & 0 & 168 \\
$\mathbf{2 0 0 8}$ & 0 & 0 & 0 & 0 & 0 & 19 & 38 & 77 & 32 & 0 & 0 & 0 & 166 \\
\hline $\mathbf{2 0 0 9}$ & 0 & 0 & 0 & 0 & 0 & 30 & 68 & 99 & 17 & 2 & 0 & 0 & 216 \\
$\mathbf{2 0 1 0}$ & 0 & 0 & 0 & 0 & 0 & 4 & 84 & 100 & 18 & 0 & 0 & 0 & 206 \\
\hline $\mathbf{2 0 1 1}$ & 0 & 0 & 0 & 3 & 1 & 4 & 48 & 132 & 27 & 8 & 0 & 0 & 223 \\
\hline Prom. & 0 & 0 & 0 & 0 & 2 & 28 & 70 & 92 & 20 & 2 & 0 & 0 & 213 \\
\hline
\end{tabular}

Alicante El Altet. Tiene en promedio algo más de 150 horas de calor (umbral $30^{\circ} \mathrm{C}$ ) al año, oscilando entre las 29 horas de 2002 y las 486 de 2003.

Las horas de calor se reparten entre los meses de abril a octubre, aunque abril, mayo y octubre tienen muy pocas horas y pocos años; septiembre tiene casi todos los años pero también pocas; junio en promedio no llega a 30 horas de calor; julio no llega a 60 y agosto las sobrepasa.

La variabilidad interanual, así como la que se da entre los mismos meses de los distintos años, es muy marcada.

Tabla 286. Horas de calor contadas en datos horarios en el observatorio de Alicante El Atlet.

\begin{tabular}{cccccccccccccc}
\hline & ene & feb & mar & abr & may & jun & jul & ago & sep & oct & nov & dic & anual \\
\hline $\mathbf{2 0 0 2}$ & 0 & 0 & 0 & 0 & 0 & 0 & 15 & 1 & 13 & 0 & 0 & 0 & 29 \\
\hline $\mathbf{2 0 0 3}$ & 0 & 0 & 0 & 0 & 0 & 85 & 154 & 231 & 15 & 1 & 0 & 0 & 486 \\
$\mathbf{2 0 0 4}$ & 0 & 0 & 0 & 0 & 0 & 43 & 30 & 125 & 18 & 0 & 0 & 0 & 216 \\
\hline $\mathbf{2 0 0 5}$ & 0 & 0 & 0 & 0 & 0 & 39 & 56 & 34 & 19 & 0 & 0 & 0 & 148 \\
\hline $\mathbf{2 0 0 6}$ & 0 & 0 & 0 & 0 & 0 & 2 & 90 & 29 & 5 & 13 & 0 & 0 & 139 \\
$\mathbf{2 0 0 7}$ & 0 & 0 & 0 & 0 & 5 & 14 & 22 & 39 & 0 & 0 & 0 & 0 & 80 \\
$\mathbf{2 0 0 8}$ & 0 & 0 & 0 & 0 & 0 & 12 & 23 & 49 & 14 & 0 & 0 & 0 & 98 \\
$\mathbf{2 0 0 9}$ & 0 & 0 & 0 & 0 & 0 & 18 & 43 & 44 & 8 & 0 & 0 & 0 & 113 \\
$\mathbf{2 0 1 0}$ & 0 & 0 & 0 & 0 & 0 & 0 & 65 & 81 & 20 & 0 & 0 & 0 & 166 \\
\hline $\mathbf{2 0 1 1}$ & 0 & 0 & 0 & 5 & 7 & 9 & 49 & 103 & 35 & 6 & 0 & 0 & 214 \\
Prom. & 0 & 0 & 0 & 1 & 1 & 22 & 55 & 74 & 15 & 2 & 0 & 0 & 169 \\
\hline
\end{tabular}


Observatorios: Base aérea de Alcantarilla (7228), Base aérea de San Javier (7031) y Totana (7218x) (automática y manual).

Tabla 287. Comparación de horas de calor anuales contadas a partir de datos horarios en los tres observatorios de la huerta murciana.

\begin{tabular}{|cccc|}
\hline & $\begin{array}{c}\text { Alcantarilla } \\
\mathbf{7 2 2 8}\end{array}$ & $\begin{array}{c}\text { San Javier } \\
\mathbf{7 0 3 1}\end{array}$ & $\begin{array}{c}\text { Totana } \\
\mathbf{7 2 1 8 x}\end{array}$ \\
\hline $\mathbf{A n ̃ o}$ & $\mathrm{HC}$ & $\mathrm{HC}$ & $\mathrm{HC}$ \\
\hline $\mathbf{2 0 0 2}$ & 459 & 32 & \\
\hline $\mathbf{2 0 0 3}$ & 871 & 199 & \\
\hline $\mathbf{2 0 0 4}$ & 675 & 126 & \\
\hline $\mathbf{2 0 0 5}$ & 636 & 75 & \\
\hline $\mathbf{2 0 0 6}$ & 705 & 95 & \\
\hline $\mathbf{2 0 0 7}$ & 569 & & \\
\hline $\mathbf{2 0 0 8}$ & 646 & 119 & 535 \\
\hline $\mathbf{2 0 0 9}$ & 771 & 137 & 696 \\
\hline $\mathbf{2 0 1 0}$ & 593 & 71 & 495 \\
\hline $\mathbf{2 0 1 1}$ & 734 & 148 & 612 \\
\hline Promedio & 663 & 119 & 585 \\
\hline
\end{tabular}

\section{Comparación de horas de calor (umbral 30은 C) anuales en observatorios de la Huerta murciana}

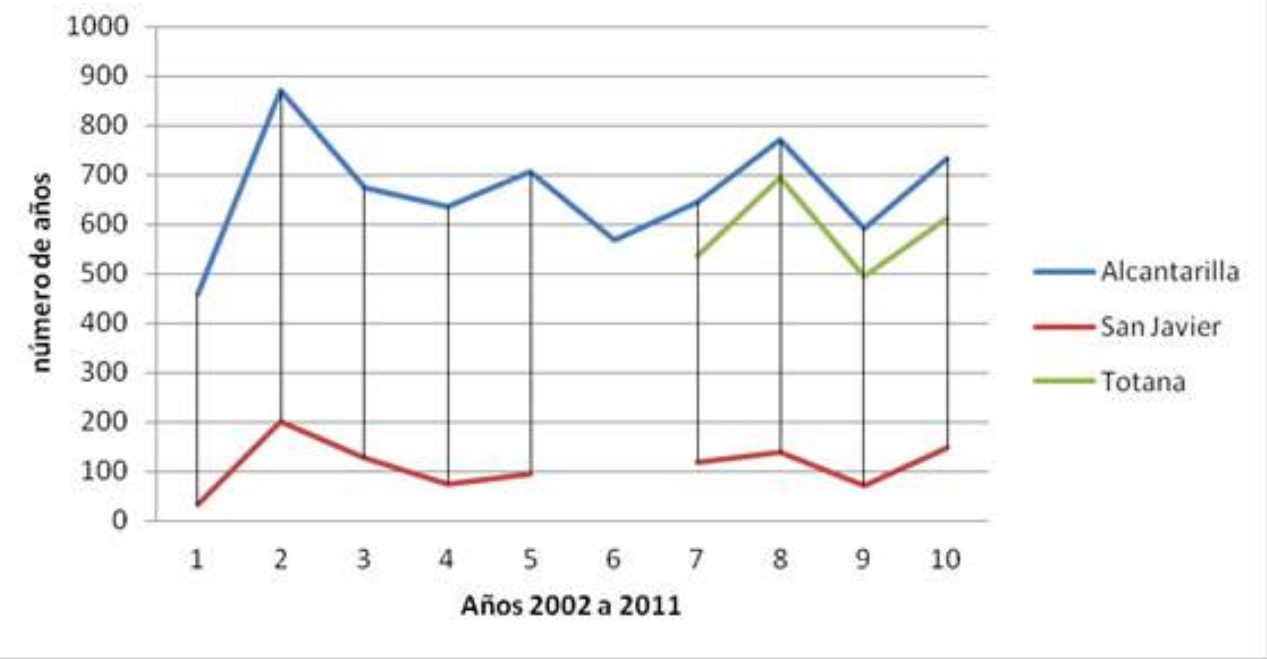

Gráfico 26. Comparación de horas de calor (umbral 30ㅇ) anuales en los observatorios de la huerta murciana. 
Los datos son coherentes y puede verse la clara influencia del agua al borde del mar. Un par de decenas de kilómetros tierra adentro, en altitudes bajas, se dan muchas más horas de calor.

\section{Horas de calor contadas en datos horarios en cada uno de los observatorios}

Alcantarilla. El promedio anual es algo mayor de 650 horas de calor (umbral $30^{\circ} \mathrm{C}$ ), pero hay variaciones importantes entre unos años y otros, de las 459 horas de 2002 a las 871 de 2003.

En los meses con más horas el promedio es de algo menos de 250 horas para julio, con variaciones entre las 170 horas de 2004 y las 297 de 2006; y algo más de 200 para agosto, con variación entre las 137 horas de 2002 y las 290 de 2003. Junio supera las 100 horas de promedio y septiembre las 50, pero en ambos meses la variación relativa entre unos años y otros es aún mayor. Mayo no llega a 30 horas; en abril y octubre se dan muy pocas horas de calor y no todos los años.

La variabilidad interanual, así como la que se da entre los mismos meses de los distintos años, es muy marcada.

Tabla 288. Horas de calor contadas en datos horarios en el observatorio de Alcantarilla.

\begin{tabular}{|c|c|c|c|c|c|c|c|c|c|c|c|c|c|}
\hline & ene & feb & mar & $a b r$ & may & jun & jul & ago & sep & oct & nov & dic & anual \\
\hline 2002 & 0 & 0 & 3 & 4 & 6 & 93 & 173 & 137 & 43 & 0 & 0 & 0 & 459 \\
\hline 2003 & 0 & 0 & 0 & 0 & 23 & 201 & 293 & 290 & 54 & 10 & 0 & 0 & 871 \\
\hline 2004 & 0 & 0 & 0 & & 13 & 137 & 170 & 260 & 76 & 19 & 0 & 0 & 675 \\
\hline 2005 & 0 & 0 & 0 & 0 & 25 & 158 & 241 & 161 & 50 & 1 & 0 & 0 & 636 \\
\hline 2006 & 0 & 0 & 3 & 1 & 35 & 92 & 297 & 176 & 72 & 29 & 0 & 0 & 705 \\
\hline 2007 & 0 & 0 & 0 & 0 & 52 & 124 & 202 & 176 & 15 & 0 & 0 & 0 & 569 \\
\hline 2008 & 0 & 0 & 0 & 0 & 0 & 113 & 228 & 228 & 77 & 0 & 0 & 0 & 646 \\
\hline 2009 & 0 & 0 & 0 & 0 & 9 & 175 & 285 & 240 & 47 & 15 & 0 & 0 & 771 \\
\hline 2010 & 0 & 0 & 0 & 4 & 27 & 68 & 250 & 191 & 50 & 3 & 0 & 0 & 593 \\
\hline 2011 & 0 & 0 & 0 & 10 & 34 & 107 & 213 & 248 & 105 & 17 & 0 & 0 & 734 \\
\hline Prom. & 0 & 0 & 0 & 3 & 24 & 117 & 236 & 217 & 59 & 7 & 0 & 0 & 663 \\
\hline
\end{tabular}

San Javier. En San Javier se nota claramente la influencia del mar y son pocas las horas de calor que se dan a lo largo del año, en torno a 100, y los meses de julio y agosto no llegan a 50 mensuales en promedio, aunque se acercan; junio y septiembre no llegan a 20 horas, y en mayo y octubre apenas se dan horas de calor. 
La variabilidad interanual, así como la que se da entre los mismos meses de los distintos años, es muy marcada.

Tabla 289. Horas de calor contadas en datos horarios en el observatorio de San Javier.

\begin{tabular}{cccccccccccccc}
\hline & ene & feb & mar & abr & may & jun & jul & ago & sep & oct & nov & dic & anual \\
\hline $\mathbf{2 0 0 2}$ & 0 & 0 & 0 & 0 & 0 & 0 & 17 & 11 & 4 & 0 & 0 & 0 & 32 \\
$\mathbf{2 0 0 3}$ & 0 & 0 & 0 & 0 & 0 & 25 & 46 & 117 & 10 & 1 & 0 & 0 & 199 \\
$\mathbf{2 0 0 4}$ & 0 & 0 & 0 & 0 & 0 & 26 & 13 & 81 & 6 & 0 & 0 & 0 & 126 \\
\hline $\mathbf{2 0 0 5}$ & 0 & 0 & 0 & 0 & 1 & 10 & 39 & 19 & 6 & 0 & 0 & 0 & 75 \\
$\mathbf{2 0 0 6}$ & 0 & 0 & 0 & 0 & 0 & 2 & 52 & 31 & 2 & 8 & 0 & 0 & 95 \\
$\mathbf{2 0 0 7}$ & 0 & 0 & 0 & 0 & 6 & & & & & & & & \\
$\mathbf{2 0 0 8}$ & 0 & 0 & 0 & 0 & 0 & 12 & 50 & 41 & 16 & 0 & 0 & 0 & 119 \\
\hline $\mathbf{2 0 0 9}$ & 0 & 0 & 0 & 0 & 0 & 23 & 65 & 33 & 16 & 0 & 0 & 0 & 137 \\
$\mathbf{2 0 1 0}$ & 0 & 0 & 0 & 0 & 4 & 0 & 17 & 43 & 7 & 0 & 0 & 0 & 71 \\
\hline $\mathbf{2 0 1 1}$ & 0 & 0 & 0 & 0 & 4 & 20 & 56 & 56 & 11 & 1 & 0 & 0 & 148 \\
Prom. & 0 & 0 & 0 & 0 & 3 & 14 & 47 & 43 & 13 & 0 & 0 & 0 & 119 \\
\hline
\end{tabular}

Totana. Dispone sólo de 4 años de datos, pero puede decirse que en Totana ocurre algo parecido a Alcantarilla. En agosto y julio el número de horas en las que las temperaturas igualan o superan los $30^{\circ} \mathrm{C}$ es bastante uniforme en esos 4 años, y puede superar las 200 horas; en junio y septiembre hay una considerable variación entre unos años y otros. También se dan horas de calor en abril, mayo y octubre.

Tabla 290. Horas de calor contadas en datos horarios en el observatorio de Totana.

\begin{tabular}{|c|c|c|c|c|c|c|c|c|c|c|c|c|c|}
\hline & ene & feb & mar & $a b r$ & may & jun & jul & ago & Sep & oct & nov & dic & anual \\
\hline \multicolumn{14}{|l|}{2002} \\
\hline \multicolumn{14}{|l|}{2003} \\
\hline \multicolumn{14}{|l|}{2004} \\
\hline \multicolumn{14}{|l|}{2005} \\
\hline \multicolumn{14}{|l|}{2006} \\
\hline \multicolumn{14}{|l|}{2007} \\
\hline 2008 & 0 & 0 & 0 & 0 & 0 & 88 & 203 & 187 & 57 & 0 & 0 & 0 & 535 \\
\hline 2009 & 0 & 0 & 0 & 0 & 22 & 151 & 255 & 223 & 39 & 6 & 0 & 0 & 696 \\
\hline 2010 & 0 & 0 & 0 & 0 & 19 & 52 & 218 & 171 & 31 & 4 & 0 & 0 & 495 \\
\hline 2011 & 0 & 0 & 0 & 8 & 17 & 80 & 183 & 232 & 80 & 12 & 0 & 0 & 612 \\
\hline Prom. & & & & & & & & & & & & & \\
\hline
\end{tabular}




\section{Resumen de horas de calor contadas para Levante.}

En la franja costera, pegado al mar, el número de horas de calor es muy bajo; en promedio está entre las 100 y 200 horas anuales. Pero el número de horas aumenta rápidamente a medida que se aleja de la costa, y en el interior, por debajo de los $100 \mathrm{~m}$ de altitud, en las Huertas murciana y de Levante, el número anual de horas de calor está alrededor de las 600 .

Es importante tener en cuenta que la variabilidad interanual, así como la que se da entre cada mes en los distintos años, es muy marcada.

\subsubsection{Costa Sur}

Observatorio: Málaga aeropuerto (6155a).

Horas de calor contadas en datos horarios en el observatorio.

Tabla 291. Horas de calor contadas en datos horarios en el observatorio de Málaga aeropuerto.

\begin{tabular}{cccccccccccccc}
\hline & ene & feb & mar & abr & may & jun & jul & ago & sep & oct & nov & dic & anual \\
\hline $\mathbf{2 0 0 2}$ & 0 & 0 & 0 & 3 & 9 & 28 & 69 & 70 & 18 & 0 & 0 & 0 & 197 \\
$\mathbf{2 0 0 3}$ & 0 & 0 & 0 & 0 & 6 & 83 & 139 & 148 & 39 & 0 & 0 & 0 & 415 \\
$\mathbf{2 0 0 4}$ & 0 & 0 & 0 & 0 & 0 & 28 & 46 & 127 & 33 & 0 & 0 & 0 & 234 \\
$\mathbf{2 0 0 5}$ & 0 & 0 & 0 & 0 & 11 & 58 & 138 & 50 & 29 & 0 & 0 & 0 & 286 \\
$\mathbf{2 0 0 6}$ & 0 & 0 & 0 & 0 & 12 & 34 & 92 & 72 & 12 & 8 & 0 & 0 & 230 \\
$\mathbf{2 0 0 7}$ & 0 & 0 & 0 & 0 & 14 & 61 & 100 & 115 & 6 & 0 & 0 & 0 & 296 \\
$\mathbf{2 0 0 8}$ & 0 & 0 & 0 & 0 & 4 & 15 & 122 & 103 & 22 & 0 & 0 & 0 & 266 \\
$\mathbf{2 0 0 9}$ & 0 & 0 & 0 & 0 & 0 & 36 & 125 & 68 & 12 & 13 & 0 & 0 & 254 \\
$\mathbf{2 0 1 0}$ & 0 & 0 & 0 & 0 & 3 & 18 & 74 & 88 & 16 & 0 & 0 & 0 & 199 \\
$\mathbf{2 0 1 1}$ & 0 & 0 & 0 & 4 & 0 & 26 & 99 & 121 & 31 & 0 & 0 & 0 & 281 \\
Prom. & 0 & 0 & 0 & 1 & 6 & 39 & 100 & 96 & 22 & 2 & 0 & 0 & 266 \\
\hline
\end{tabular}

Tiene en promedio algo más de 250 horas anuales, aunque un año pasa de 400 horas (2003) y otros que no alcanzan las 200 (2002 y 2010). Los meses de invierno más marzo y noviembre no tienen horas de calor. Abril y octubre tienen muy pocas y no todos los años. Tampoco mayo tiene horas de calor todos los años. Junio y septiembre tienen en promedio en torno a las 30 horas de calor; julio y agosto tienen 100 horas mensuales. 
En la franja costera, junto al mar se dan en torno a las 200 horas, pero muy posiblemente, a partir de unos pocos kilómetros de la costa, por debajo de $300 \mathrm{~m}$ de altitud, antes de la cordillera Penibética, se den hasta 600 horas de calor, igual que sucede en las huertas de Levante y Murcia.

\subsubsection{Zonas altas del interior peninsular}

Observatorios: Cuenca (8096), Albacete los Llanos (8175), Teruel (8368u), Daroca (9390), Molina de Aragón (3013), Soria (2030).

Tabla 292. Comparación de horas de calor anuales contadas a partir de datos horarios en los seis observatorios de las zonas altas del interior peninsular.

\begin{tabular}{|ccccccc|}
\hline & $\begin{array}{c}\text { Cuenca } \\
\mathbf{8 0 9 6}\end{array}$ & $\begin{array}{c}\text { Albacete Los } \\
\text { Llanos } \\
\mathbf{8 1 7 5}\end{array}$ & $\begin{array}{c}\text { Teruel } \\
\mathbf{8 3 6 8 u}\end{array}$ & $\begin{array}{c}\text { Daroca } \\
\mathbf{9 3 9 0}\end{array}$ & $\begin{array}{c}\text { Molina de } \\
\text { Aragón } \\
\mathbf{3 0 1 3}\end{array}$ & $\begin{array}{c}\text { Soria } \\
\mathbf{2 0 3 0}\end{array}$ \\
\hline $\mathbf{A n ̃ o}$ & $\mathrm{HC}$ & $\mathrm{HC}$ & $\mathrm{HC}$ & $\mathrm{HC}$ & $\mathrm{HC}$ & $\mathrm{HC}$ \\
\hline $\mathbf{2 0 0 2}$ & 237 & 365 & 161 & 255 & 112 & 92 \\
\hline $\mathbf{2 0 0 3}$ & 432 & 571 & 326 & 499 & 287 & 245 \\
\hline $\mathbf{2 0 0 4}$ & 295 & 445 & 205 & 272 & 141 & 87 \\
\hline $\mathbf{2 0 0 5}$ & 413 & 476 & 307 & 362 & 234 & 169 \\
\hline $\mathbf{2 0 0 6}$ & 396 & 528 & 251 & 348 & 173 & 128 \\
\hline $\mathbf{2 0 0 7}$ & 238 & 350 & 184 & 239 & 129 & 72 \\
\hline $\mathbf{2 0 0 8}$ & 316 & 431 & 230 & 308 & 143 & 68 \\
\hline $\mathbf{2 0 0 9}$ & 553 & 615 & 410 & 486 & 293 & 191 \\
\hline $\mathbf{2 0 1 0}$ & 386 & 483 & 252 & 338 & 185 & 133 \\
\hline $\mathbf{2 0 1 1}$ & 377 & 498 & 334 & 405 & 151 & 135 \\
\hline Promedio & 364 & 476 & 266 & 351 & 185 & 132 \\
\hline
\end{tabular}




\section{Comparación de horas de calor (umbral 30응 C) anuales en observatorios de las zonas altas del interior peninsular}

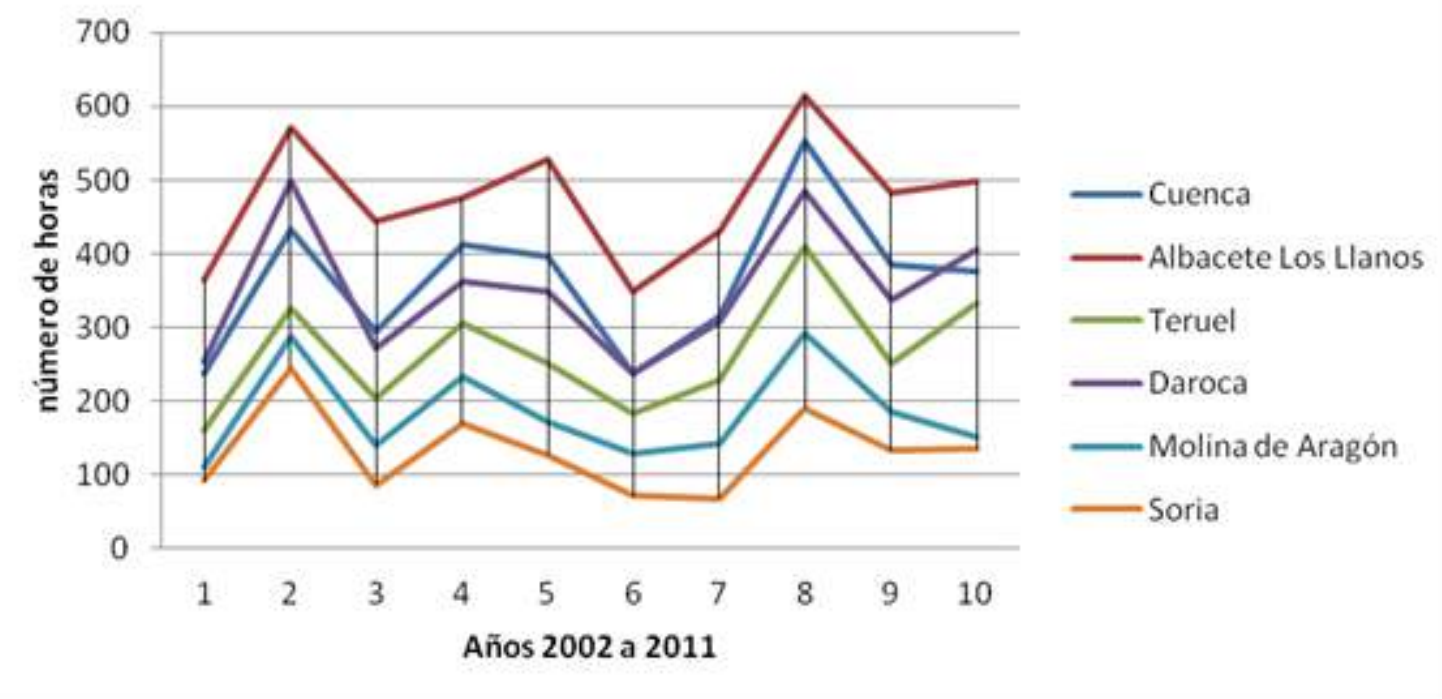

Gráfico 27. Comparación de horas de calor (umbral 30C) anuales en observatorios de las zonas altas del interior peninsular.

Son datos coherentes entre ellos.

\section{Horas de calor contadas en datos horarios en cada uno de los observatorios}

Cuenca. Tiene en promedio poco más de 350 horas de calor (umbral $30^{\circ} \mathrm{C}$ ) al año, oscilando entre las 553 horas de 2009 y las 237 de 2002.

Hay seis meses del año que no tienen horas de calor, los cuatro primeros y los dos últimos. Mayo y octubre apenas las tienen; septiembre tiene pocas, aunque hay años que se acerca a 60 horas de calor. Las horas de calor se acumulan en julio, en torno a 150 en promedio, y agosto, más de 150.

La variabilidad interanual, así como la que se da entre los mismos meses de los distintos años, es muy marcada. Por ejemplo, en julio de 2011 hubo 81 horas mientras que en el mismo mes en 2009 y 2010 se dieron 215 horas. 
Tabla 293. Horas de calor contadas en datos horarios en el observatorio de Cuenca.

\begin{tabular}{cccccccccccccc}
\hline & ene & feb & mar & abr & may & jun & jul & ago & sep & oct & nov & dic & anual \\
\hline $\mathbf{2 0 0 2}$ & 0 & 0 & 0 & 0 & 0 & 92 & 94 & 51 & 0 & 0 & 0 & 0 & 237 \\
$\mathbf{2 0 0 3}$ & 0 & 0 & 0 & 0 & 0 & 108 & 177 & 147 & 0 & 0 & 0 & 0 & 432 \\
$\mathbf{2 0 0 4}$ & 0 & 0 & 0 & 0 & 0 & 68 & 128 & 93 & 4 & 2 & 0 & 0 & 295 \\
\hline $\mathbf{2 0 0 5}$ & 0 & 0 & 0 & 0 & 15 & 84 & 157 & 140 & 17 & 0 & 0 & 0 & 413 \\
$\mathbf{2 0 0 6}$ & 0 & 0 & 0 & 0 & 13 & 33 & 195 & 112 & 43 & 0 & 0 & 0 & 396 \\
\hline $\mathbf{2 0 0 7}$ & 0 & 0 & 0 & 0 & 0 & 17 & 127 & 86 & 8 & 0 & 0 & 0 & 238 \\
\hline $\mathbf{2 0 0 8}$ & 0 & 0 & 0 & 0 & 0 & 65 & 119 & 132 & 0 & 0 & 0 & 0 & 316 \\
\hline $\mathbf{2 0 0 9}$ & 0 & 0 & 0 & 0 & 7 & 120 & 215 & 190 & 21 & 0 & 0 & 0 & 553 \\
$\mathbf{2 0 1 0}$ & 0 & 0 & 0 & 0 & 0 & 13 & 215 & 139 & 19 & 0 & 0 & 0 & 386 \\
\hline $\mathbf{2 0 1 1}$ & 0 & 0 & 0 & 0 & 0 & 80 & 81 & 150 & 56 & 10 & 0 & 0 & 377 \\
Prom. & 0 & 0 & 0 & 0 & 4 & 68 & 151 & 124 & 17 & 1 & 0 & 0 & 364 \\
\hline
\end{tabular}

Albacete Los Llanos. Se acerca a las 500 horas de calor (umbral $30^{\circ} \mathrm{C}$ ) al año, oscilando entre las 615 horas de 2009 y las 350 de 2007.

Seis meses del año no tienen horas de calor, los cuatro primeros y los dos últimos. Mayo y octubre apenas tienen y no todos los años. Septiembre tiene todos los años pero en promedio no llega a las 30. Las horas de calor se acumulan en junio, en torno a 90 , julio, 200, y agosto, algo más de 150.

La variabilidad de la acumulación anual, así como la de los meses de julio y agosto no es muy marcada, pero sí lo es la de junio y septiembre.

Tabla 294. Horas de calor contadas en datos horarios en el observatorio de Albacete Los LLanos.

\begin{tabular}{cccccccccccccc}
\hline & ene & feb & mar & abr & may & jun & jul & ago & sep & oct & nov & dic & anual \\
\hline $\mathbf{2 0 0 2}$ & 0 & 0 & 0 & 0 & 0 & 114 & 147 & 102 & 2 & 0 & 0 & 0 & 365 \\
$\mathbf{2 0 0 3}$ & 0 & 0 & 0 & 0 & 3 & 145 & 223 & 197 & 3 & 0 & 0 & 0 & 571 \\
$\mathbf{2 0 0 4}$ & 0 & 0 & 0 & 0 & 0 & 97 & 157 & 149 & 42 & 0 & 0 & 0 & 445 \\
$\mathbf{2 0 0 5}$ & 0 & 0 & 0 & 0 & 4 & 101 & 203 & 141 & 27 & 0 & 0 & 0 & 476 \\
$\mathbf{2 0 0 6}$ & 0 & 0 & 0 & 0 & 27 & 60 & 257 & 133 & 47 & 4 & 0 & 0 & 528 \\
$\mathbf{2 0 0 7}$ & 0 & 0 & 0 & 0 & 0 & 31 & 192 & 120 & 7 & 0 & 0 & 0 & 350 \\
$\mathbf{2 0 0 8}$ & 0 & 0 & 0 & 0 & 0 & 66 & 176 & 175 & 14 & 0 & 0 & 0 & 431 \\
\hline $\mathbf{2 0 0 9}$ & 0 & 0 & 0 & 0 & 7 & 142 & 241 & 195 & 27 & 3 & 0 & 0 & 615 \\
$\mathbf{2 0 1 0}$ & 0 & 0 & 0 & 0 & 5 & 45 & 233 & 174 & 26 & 0 & 0 & 0 & 483 \\
\hline $\mathbf{2 0 1 1}$ & 0 & 0 & 0 & 0 & 0 & 111 & 149 & 186 & 48 & 4 & 0 & 0 & 498 \\
Prom. & 0 & 0 & 0 & 0 & 5 & 91 & 198 & 157 & 24 & 1 & 0 & 0 & 476 \\
\hline
\end{tabular}


Teruel. Tiene en promedio algo superior a 250 horas de calor (umbral $30^{\circ} \mathrm{C}$ ) al año, oscilando entre las 410 horas de 2009 y las 161 de 2002.

Seis meses del año no tienen horas de calor, los cuatro primeros y los dos últimos. Mayo y octubre apenas tienen y no todos los años; septiembre tiene pocas y no todos los años. Las horas de calor acumulan en junio, cerca de 50 en promedio, julio, en torno a 120, y agosto, 90.

La variabilidad interanual, así como la que se da entre los mismos meses de los distintos años, es muy marcada. Por ejemplo, en agosto de 2011 hubo 142 horas mientras que en el mismo mes en 2002 hubo 27 horas.

Tabla 295. Horas de calor contadas en datos horarios en el observatorio de Teruel.

\begin{tabular}{cccccccccccccc}
\hline & ene & feb & mar & abr & may & jun & jul & ago & sep & oct & nov & dic & anual \\
\hline $\mathbf{2 0 0 2}$ & 0 & 0 & 0 & 0 & 0 & 82 & 52 & 27 & 0 & 0 & 0 & 0 & 161 \\
\hline $\mathbf{2 0 0 3}$ & 0 & 0 & 0 & 0 & 0 & 53 & 148 & 125 & 0 & 0 & 0 & 0 & 326 \\
$\mathbf{2 0 0 4}$ & 0 & 0 & 0 & 0 & 0 & 45 & 74 & 78 & 7 & 1 & 0 & 0 & 205 \\
\hline $\mathbf{2 0 0 5}$ & 0 & 0 & 0 & 0 & 11 & 48 & 143 & 92 & 13 & 0 & 0 & 0 & 307 \\
$\mathbf{2 0 0 6}$ & 0 & 0 & 0 & 0 & 9 & 25 & 136 & 48 & 32 & 1 & 0 & 0 & 251 \\
$\mathbf{2 0 0 7}$ & 0 & 0 & 0 & 0 & 0 & 13 & 103 & 68 & 0 & 0 & 0 & 0 & 184 \\
$\mathbf{2 0 0 8}$ & 0 & 0 & 0 & 0 & 0 & 21 & 105 & 103 & 1 & 0 & 0 & 0 & 230 \\
\hline $\mathbf{2 0 0 9}$ & 0 & 0 & 0 & 0 & 4 & 75 & 179 & 135 & 17 & 0 & 0 & 0 & 410 \\
$\mathbf{2 0 1 0}$ & 0 & 0 & 0 & 0 & 0 & 3 & 153 & 87 & 9 & 0 & 0 & 0 & 252 \\
\hline $\mathbf{2 0 1 1}$ & 0 & 0 & 0 & 0 & 4 & 58 & 81 & 142 & 46 & 3 & 0 & 0 & 334 \\
Prom. & 0 & 0 & 0 & 0 & 3 & 42 & 117 & 91 & 13 & 1 & 0 & 0 & 266 \\
\hline
\end{tabular}

Daroca. Tiene en promedio 350 horas de calor (umbral $30^{\circ} \mathrm{C}$ ) al año, oscilando entre las 499 horas de 2003 y las 239 de 2007.

Cinco meses del año no tienen horas de calor, los tres primeros y los dos últimos. Abril, mayo y octubre apenas tienen y no todos los años; septiembre tiene pocas y no todos los años; junio en promedio pasa ligeramente de 60 , julio no llega a 150 y agosto está en torno a 100.

La variabilidad interanual, así como la que se da entre los mismos meses de los distintos años, es muy marcada. 
Tabla 296. Horas de calor contadas en datos horarios en el observatorio de Daroca.

\begin{tabular}{cccccccccccccc}
\hline & ene & feb & mar & abr & may & jun & jul & ago & sep & oct & nov & dic & anual \\
\hline $\mathbf{2 0 0 2}$ & 0 & 0 & 0 & 0 & 2 & 114 & 81 & 58 & 0 & 0 & 0 & 0 & 255 \\
$\mathbf{2 0 0 3}$ & 0 & 0 & 0 & 0 & 6 & 131 & 172 & 188 & 2 & 0 & 0 & 0 & 499 \\
$\mathbf{2 0 0 4}$ & 0 & 0 & 0 & 0 & 0 & 65 & 114 & 71 & 16 & 6 & 0 & 0 & 272 \\
$\mathbf{2 0 0 5}$ & 0 & 0 & 0 & 0 & 15 & 77 & 149 & 101 & 20 & 0 & 0 & 0 & 362 \\
$\mathbf{2 0 0 6}$ & 0 & 0 & 0 & 0 & 25 & 46 & 195 & 27 & 55 & 0 & 0 & 0 & 348 \\
\hline $\mathbf{2 0 0 7}$ & 0 & 0 & 0 & 0 & 0 & 29 & 123 & 81 & 6 & 0 & 0 & 0 & 239 \\
$\mathbf{2 0 0 8}$ & 0 & 0 & 0 & 0 & 2 & 51 & 142 & 106 & 7 & 0 & 0 & 0 & 308 \\
$\mathbf{2 0 0 9}$ & 0 & 0 & 0 & 0 & 9 & 81 & 206 & 167 & 22 & 1 & 0 & 0 & 486 \\
$\mathbf{2 0 1 0}$ & 0 & 0 & 0 & 0 & 0 & 28 & 177 & 108 & 25 & 0 & 0 & 0 & 338 \\
\hline $\mathbf{2 0 1 1}$ & 0 & 0 & 0 & 1 & 7 & 50 & 96 & 184 & 63 & 4 & 0 & 0 & 405 \\
Prom. & 0 & 0 & 0 & 0 & 7 & 67 & 146 & 109 & 22 & 1 & 0 & 0 & 351 \\
\hline
\end{tabular}

Molina de Aragón. Tiene menos de 200 horas de calor (umbral $30^{\circ} \mathrm{C}$ ) al año, oscilando entre las 293 horas de 2009 y las 112 de 2002.

Los meses de verano, junio, julio, agosto y septiembre, acumulan las horas de calor. Julio y agosto tienen en promedio algo más de 60 horas de calor mensuales; junio algo más de $30 \mathrm{y}$ septiembre apenas tiene horas de calor. Mayo tiene muy pocas horas y pocos años.

La variabilidad interanual, así como la que se da entre los mismos meses de los distintos años, es muy marcada.

Tabla 297. Horas de calor contadas en datos horarios en el observatorio de Molina de Aragón.

\begin{tabular}{cccccccccccccc}
\hline & ene & feb & mar & abr & may & jun & jul & ago & sep & oct & nov & dic & anual \\
\hline $\mathbf{2 0 0 2}$ & 0 & 0 & 0 & 0 & 0 & 69 & 33 & 10 & 0 & 0 & 0 & 0 & 112 \\
$\mathbf{2 0 0 3}$ & 0 & 0 & 0 & 0 & 0 & 59 & 103 & 125 & 0 & 0 & 0 & 0 & 287 \\
$\mathbf{2 0 0 4}$ & 0 & 0 & 0 & 0 & 0 & 40 & 66 & 35 & 0 & 0 & 0 & 0 & 141 \\
$\mathbf{2 0 0 5}$ & 0 & 0 & 0 & 0 & 16 & 28 & 96 & 84 & 10 & 0 & 0 & 0 & 234 \\
$\mathbf{2 0 0 6}$ & 0 & 0 & 0 & 0 & 9 & 19 & 91 & 23 & 31 & 0 & 0 & 0 & 173 \\
$\mathbf{2 0 0 7}$ & 0 & 0 & 0 & 0 & 0 & 0 & 75 & 54 & 0 & 0 & 0 & 0 & 129 \\
$\mathbf{2 0 0 8}$ & 0 & 0 & 0 & 0 & 0 & 24 & 66 & 53 & 0 & 0 & 0 & 0 & 143 \\
$\mathbf{2 0 0 9}$ & 0 & 0 & 0 & 0 & 0 & 54 & 123 & 113 & 3 & 0 & 0 & 0 & 293 \\
$\mathbf{2 0 1 0}$ & 0 & 0 & 0 & 0 & 0 & 8 & 115 & 60 & 2 & 0 & 0 & 0 & 185 \\
$\mathbf{2 0 1 1}$ & 0 & 0 & 0 & 0 & 0 & 40 & 14 & 72 & 25 & 0 & 0 & 0 & 151 \\
Prom. & 0 & 0 & 0 & 0 & 3 & 34 & 78 & 63 & 7 & 0 & 0 & 0 & 185 \\
\hline
\end{tabular}


Soria. No llega en promedio a las 150 horas de calor (umbral $30^{\circ} \mathrm{C}$ ) al año, oscilando entre las 245 horas de 2003 y las 68 de 2008.

Los cuatro primeros meses del año y los tres últimos están libres de horas de calor. Puede decirse que prácticamente sólo los meses de verano, junio, julio, agosto y septiembre las tienen; julio y agosto en torno a las 50 horas mensuales de promedio; junio no llega a las 30 y septiembre apenas tiene horas de calor. Se puede señalar que en septiembre son más los años en los que no hay horas de calor, aunque algún año, como el 2006, haya habido 31.

La variabilidad es muy grande entre unos años y otros, tanto en el valor anual como en los de los distintos meses. Por ejemplo, en agosto de 2003 hubo 117 horas, mientras que en 2002, 2004 y 2006 sólo hubo 12, 13 y 13 respectivamente.

Tabla 298. Horas de calor contadas en datos horarios en el observatorio de Soria.

\begin{tabular}{cccccccccccccc}
\hline & ene & feb & mar & abr & may & jun & jul & ago & sep & oct & nov & dic & anual \\
\hline $\mathbf{2 0 0 2}$ & 0 & 0 & 0 & 0 & 0 & 43 & 37 & 12 & 0 & 0 & 0 & 0 & 92 \\
\hline $\mathbf{2 0 0 3}$ & 0 & 0 & 0 & 0 & 0 & 49 & 79 & 117 & 0 & 0 & 0 & 0 & 245 \\
$\mathbf{2 0 0 4}$ & 0 & 0 & 0 & 0 & 0 & 31 & 43 & 13 & 0 & 0 & 0 & 0 & 87 \\
$\mathbf{2 0 0 5}$ & 0 & 0 & 0 & 0 & 1 & 23 & 82 & 60 & 3 & 0 & 0 & 0 & 169 \\
$\mathbf{2 0 0 6}$ & 0 & 0 & 0 & 0 & 2 & 13 & 69 & 13 & 31 & 0 & 0 & 0 & 128 \\
\hline $\mathbf{2 0 0 7}$ & 0 & 0 & 0 & 0 & 0 & 2 & 39 & 31 & 0 & 0 & 0 & 0 & 72 \\
\hline $\mathbf{2 0 0 8}$ & 0 & 0 & 0 & 0 & 0 & 0 & 27 & 41 & 0 & 0 & 0 & 0 & 68 \\
\hline $\mathbf{2 0 0 9}$ & 0 & 0 & 0 & 0 & 0 & 16 & 95 & 80 & 0 & 0 & 0 & 0 & 191 \\
$\mathbf{2 0 1 0}$ & 0 & 0 & 0 & 0 & 0 & 0 & 72 & 61 & 0 & 0 & 0 & 0 & 133 \\
\hline $\mathbf{2 0 1 1}$ & 0 & 0 & 0 & 0 & 0 & 40 & 30 & 53 & 12 & 0 & 0 & 0 & 135 \\
Prom. & 0 & 0 & 0 & 0 & 0 & 22 & 57 & 48 & 5 & 0 & 0 & 0 & 132 \\
\hline
\end{tabular}

Resumen de horas de calor contadas para zonas altas del interior en altitudes entre 600 y 1000 metros.

En esta zona peninsular se dan pocas horas de calor (umbral $30^{\circ} \mathrm{C}$ ). Por debajo de $1100 \mathrm{~m}$, varían con la altitud y la orientación entre las poco más de 100, como sucede en Soria, y las cerca de 500 de Albacete. 
4.2 Comparación de horas de calor contadas a partir de datos horarios y horas de calor obtenidas a partir de la fórmula de Crossa-Raynaud

\subsubsection{Zonas norte y noroeste: a) costa cantábrica}

Si se pone el umbral en $30^{\circ} \mathrm{C}$, en esta zona no se llega a las 100 horas de calor anuales y, por tanto, por mucha que sea la discrepancia que dé la fórmula, siempre será de unas pocas horas.

\subsubsection{Zonas norte y noroeste: b) costa gallega}

Si se pone el umbral en $30^{\circ} \mathrm{C}$, en esta zona no se llega a las 100 horas de calor anuales y, por tanto, por mucha que sea la discrepancia que dé la fórmula, siempre será de unas pocas horas.

\subsubsection{Zonas norte y noroeste: c) interior de Galicia y el valle del Bierzo}

Orense. La fórmula de Crossa-Raynaud subestima las horas de calor en un 12\%, en promedio da un $88 \%$ de las horas reales, y por tanto no es una mala aproximación.

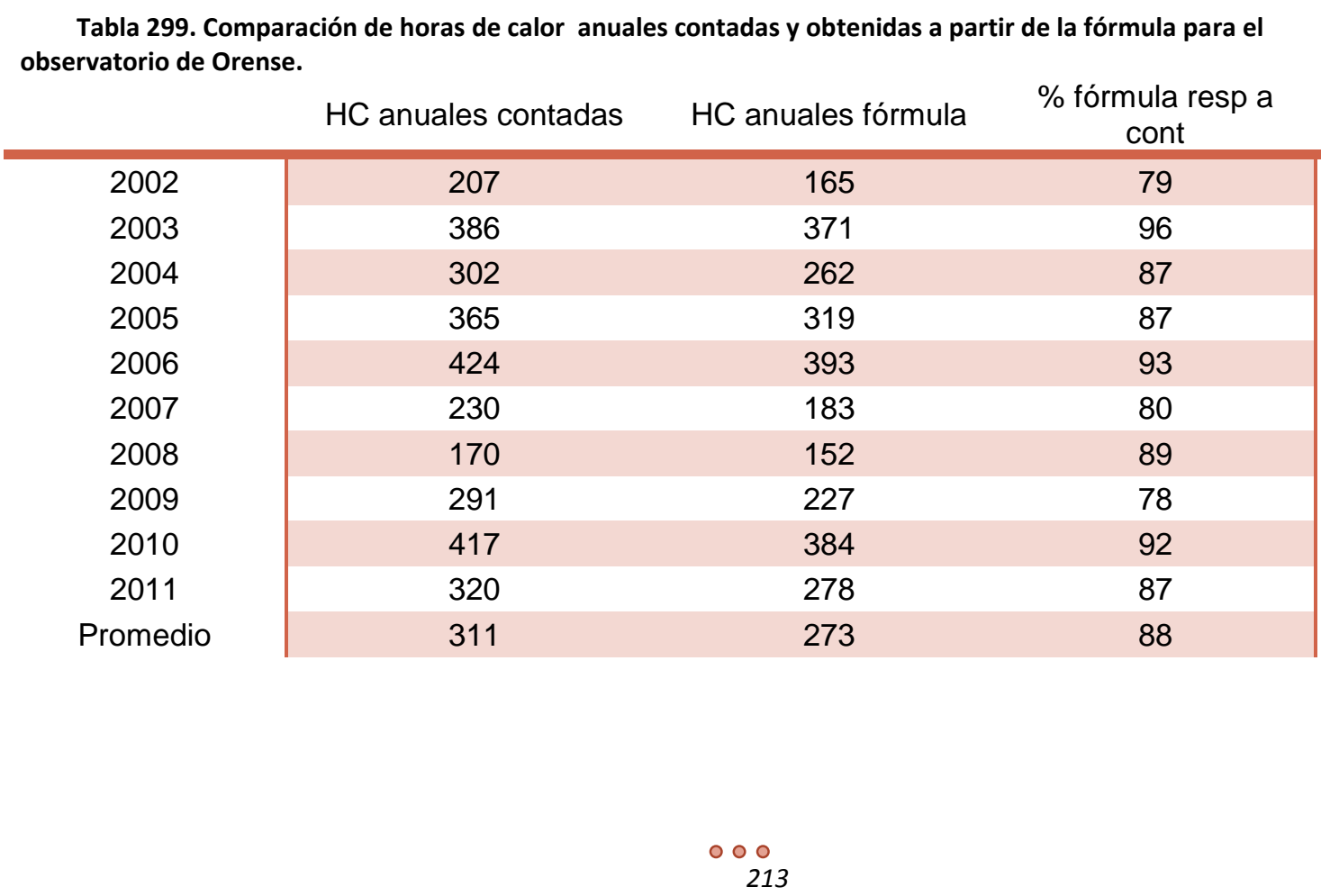


Tabla 300. Comparación de los promedios mensuales de las horas de calor correspondientes al periodo 2002 2011 para el observatorio de Orense.

\begin{tabular}{|c|c|c|c|}
\hline & $\begin{array}{c}\text { HC anuales } \\
\text { contadas }\end{array}$ & $\begin{array}{c}\text { HC anuales } \\
\text { fórmula }\end{array}$ & $\begin{array}{c}\text { \% fórmula resp } \\
\text { a cont }\end{array}$ \\
\hline enero & 0 & 0 & \\
febrero & 0 & 0 & \\
marzo & 0 & 0 & \\
abril & 4 & 2 & 65 \\
mayo & 17 & 11 & 79 \\
junio & 65 & 51 & 92 \\
julio & 80 & 74 & 98 \\
\hline agosto & 92 & 90 & 86 \\
\hline septiembre & 48 & 41 & \\
\hline octubre & 5 & 3 & \\
\hline noviembre & 0 & 0 & 88 \\
\hline diciembre & 0 & 0 & \\
anual & 311 & 273 & \\
\hline
\end{tabular}

La subestima promedio mensual de los meses de julio y agosto, es muy pequeña, lo que indica que la aproximación es buena.

Ponferrada. La fórmula de Crossa-Raynaud subestima las horas de calor, en promedio da un $82 \%$ de las horas reales; no es una buena aproximación.

Tabla 301. Comparación de horas de calor anuales contadas y obtenidas a partir de la fórmula para el observatorio de Ponferrada. $\mathrm{HC}$ anuales contadas $\quad \mathrm{HC}$ anuales fórmula $\quad \%$ fórmula resp a

\begin{tabular}{|c|ccc|}
\hline 2002 & & & cont \\
2003 & 132 & 94 & 71 \\
2004 & 303 & 280 & 93 \\
2005 & 176 & 115 & 66 \\
2006 & 301 & 240 & 80 \\
2007 & 287 & 231 & 80 \\
2008 & 125 & 96 & 76 \\
2009 & 133 & 108 & 81 \\
2010 & 207 & 178 & 86 \\
2011 & 310 & 269 & 87 \\
Promedio & 160 & 132 & 82 \\
\hline
\end{tabular}


Tabla 302. Comparación de los promedios mensuales de las horas de calor correspondientes al periodo 20022011 para el observatorio de Ponferrada.

\begin{tabular}{|c|c|c|c|}
\hline & $\begin{array}{l}\text { HC anuales } \\
\text { contadas }\end{array}$ & $\begin{array}{l}\mathrm{HC} \text { anuales } \\
\text { fórmula }\end{array}$ & $\begin{array}{c}\% \text { fórmula resp } \\
\text { a cont }\end{array}$ \\
\hline enero & 0 & 0 & \\
\hline febrero & 0 & 0 & \\
\hline marzo & 0 & 0 & \\
\hline abril & 0 & 0 & \\
\hline mayo & 7 & 4 & 54 \\
\hline junio & 47 & 34 & 74 \\
\hline julio & 67 & 57 & 84 \\
\hline agosto & 69 & 62 & 89 \\
\hline septiembre & 22 & 17 & 76 \\
\hline octubre & 1 & 0 & \\
\hline noviembre & 0 & 0 & \\
\hline diciembre & 0 & 0 & \\
\hline anual & 213 & 174 & 82 \\
\hline
\end{tabular}

En los meses que hay más horas de calor, julio y agosto, la aproximación es mejor, incluso aceptable.

\section{Resumen para el interior de Galicia y el valle del Bierzo}

En el interior de Galicia y del valle del Bierzo, por debajo de $600 \mathrm{~m}$, no puede considerarse que la aproximación que da la fórmula sea buena; si bien hay que añadir que como el número de horas de calor no es elevado, entre 200 y 300 , el error en horas no es muy grande.

\subsubsection{Meseta Norte}

Soria. La fórmula de Crossa-Raynaud subestima claramente las horas de calor, en promedio da un $75 \%$ de las horas reales, y por tanto es una mala aproximación. 
Tabla 303. Comparación de horas de calor anuales contadas y obtenidas a partir de la fórmula para el observatorio de Soria.

\begin{tabular}{|c|ccc|}
\hline & $H C$ anuales contadas & HC anuales fórmula & \% fórmula resp a cont \\
\hline 2002 & 92 & 79 & 86 \\
2003 & 245 & 196 & 80 \\
2004 & 87 & 70 & 80 \\
2005 & 169 & 137 & 81 \\
2006 & 128 & 95 & 74 \\
2007 & 72 & 59 & 82 \\
2008 & 68 & 50 & 73 \\
2009 & 191 & 129 & 67 \\
2010 & 133 & 94 & 71 \\
2011 & 135 & 78 & 58 \\
promedio & 132 & 99 & 75
\end{tabular}

Tabla 304. Comparación de los promedios mensuales de las horas de calor correspondientes al periodo 20022011 para el observatorio de Soria.

\begin{tabular}{|c|c|c|c|}
\hline & $\begin{array}{c}\text { HC anuales } \\
\text { contadas }\end{array}$ & $\begin{array}{c}\text { HC anuales } \\
\text { fórmula }\end{array}$ & $\begin{array}{c}\text { \% fórmula resp } \\
\text { a cont }\end{array}$ \\
\hline enero & 0 & 0 & \\
\hline febrero & 0 & 0 & \\
\hline marzo & 0 & 0 & \\
\hline abril & 0 & 0 & 81 \\
\hline mayo & 0 & 0 & 71 \\
\hline junio & 22 & 16 & 70 \\
\hline julio & 57 & 40 & 80 \\
\hline agosto & 48 & 39 & 91 \\
\hline septiembre & 5 & 4 & \\
\hline octubre & 0 & 0 & \\
\hline noviembre & 0 & 0 & \\
\hline diciembre & 0 & 0 & 75 \\
\hline anual & 132 & 99 & \\
\hline
\end{tabular}

La subestima promedio mensual de los meses que importan, julio y agosto, es similar a la subestima anual, entre el $70 \%$ y el $80 \%$.

Burgos Villafría. La fórmula de Crossa-Raynaud subestima las horas de calor, en promedio da un $81 \%$ de las horas reales, y por tanto es una mala aproximación. 
Tabla 305. Comparación de horas de calor anuales contadas y obtenidas a partir de la fórmula para el observatorio de Burgos Villafría.

$\mathrm{HC}$ anuales contadas $\quad \mathrm{HC}$ anuales fórmula \% fórmula resp a cont

\begin{tabular}{|c|ccc|}
\hline 2002 & 101 & 87 & 86 \\
2003 & 250 & 231 & 92 \\
2004 & 109 & 88 & 80 \\
2005 & 174 & 134 & 77 \\
2006 & 199 & 154 & 78 \\
2007 & 75 & 58 & 78 \\
2008 & 63 & 51 & 81 \\
2009 & 128 & 94 & 73 \\
2010 & 94 & 66 & 70 \\
2011 & 83 & 65 & 78 \\
promedio & 128 & 103 & 81
\end{tabular}

Tabla 306. Comparación de los promedios mensuales de las horas de calor correspondientes al periodo 20022011 para el observatorio de Burgos Villafría.

\begin{tabular}{|c|c|c|c|}
\hline \multicolumn{1}{|c|}{$\begin{array}{c}\text { HC anuales } \\
\text { contadas }\end{array}$} & $\begin{array}{c}\text { HC anuales } \\
\text { fórmula }\end{array}$ & $\begin{array}{c}\text { \% fórmula resp } \\
\text { a cont }\end{array}$ \\
\hline enero & 0 & 0 & \\
\hline febrero & 0 & 0 & \\
marzo & 0 & 0 & \\
abril & 0 & 0 & 82 \\
mayo & 0 & 0 & 79 \\
junio & 22 & 18 & 81 \\
julio & 50 & 39 & 85 \\
\hline agosto & 49 & 40 & \\
\hline septiembre & 7 & 6 & \\
\hline octubre & 0 & 0 & \\
\hline noviembre & 0 & 0 & 81 \\
\hline diciembre & 0 & 0 & \\
\hline anual & 128 & 103 & \\
\hline
\end{tabular}

La subestima promedio mensual de los meses que importan, julio y agosto, es similar a la subestima anual.

León Virgen del Camino. La fórmula de Crossa-Raynaud subestima mucho las horas de calor, en promedio da un $68 \%$ de las horas reales, y por tanto es una mala aproximación. 
Tabla 307. Comparación de horas de calor anuales contadas y obtenidas a partir de la fórmula para el observatorio de León Virgen del Camino.

\begin{tabular}{|c|c|c|c|}
\hline & HC anuales contadas & HC anuales fórmula & \% fórmula resp a cont \\
\hline 2002 & 53 & 34 & 63 \\
\hline 2003 & 172 & 141 & 82 \\
\hline 2004 & 46 & 31 & 66 \\
\hline 2005 & 100 & 67 & 67 \\
\hline 2006 & 93 & 69 & 74 \\
\hline 2007 & 25 & 18 & 70 \\
\hline 2008 & 36 & 25 & 69 \\
\hline 2009 & 74 & 42 & 57 \\
\hline 2010 & 99 & 55 & 56 \\
\hline 2011 & 56 & 35 & 62 \\
\hline promedio & 75 & 51 & 68 \\
\hline
\end{tabular}

Tabla 308. Comparación de los promedios mensuales de las horas de calor correspondientes al periodo 20022011 para el observatorio de León Virgen del Camino.

$\begin{array}{ccc}\text { HC anuales } & \text { HC anuales } & \% \text { fórmula } \\ \text { contadas } & \text { fórmula } & \text { resp a cont }\end{array}$

\begin{tabular}{|c|c|c|c|}
\hline enero & 0 & 0 & \\
\hline febrero & 0 & 0 & \\
\hline marzo & 0 & 0 & \\
\hline abril & 0 & 0 & \\
\hline mayo & 0 & 0 & 62 \\
\hline junio & 12 & 7 & 65 \\
\hline julio & 27 & 18 & 72 \\
\hline agosto & 32 & 23 & 86 \\
\hline septiembre & 4 & 3 & \\
\hline octubre & 0 & 0 & 68 \\
\hline noviembre & 0 & 0 & 0 \\
\hline diciembre & 0 & 51 & \\
\hline anual & 75 & 0 & \\
\hline
\end{tabular}

La subestima promedio mensual de los meses que importan, julio y agosto, es similar a la subestima anual, el $68 \%$. 
Valladolid Villanubla. La fórmula de Crossa-Raynaud subestima mucho las horas de calor, en promedio da un $74 \%$ de las horas reales, y por tanto es una mala aproximación.

Tabla 309. Comparación de horas de calor anuales contadas y obtenidas a partir de la fórmula para el observatorio de Valladolid Villanubla.

$\mathrm{HC}$ anuales contadas

\begin{tabular}{|c|ccc|}
\hline \multicolumn{1}{|c}{} & HC anuales contadas & HC anuales fórmula & \% fórmula resp a cont \\
\hline 2002 & 141 & 99 & 70 \\
2003 & 249 & 204 & 82 \\
2004 & 128 & 91 & 71 \\
2005 & 208 & 153 & 73 \\
2006 & 198 & 139 & 70 \\
2007 & 88 & 63 & 71 \\
2008 & 89 & 64 & 71 \\
2009 & 162 & 115 & 71 \\
2010 & 165 & 126 & 76 \\
2011 & 125 & 100 & 80 \\
promedio & 155 & 115 & 74
\end{tabular}

Tabla 310.Comparación de los promedios mensuales de las horas de calor correspondientes al periodo 2002-2011 para el observatorio de Valladolid Villanubla.

HC anuales contadas

\section{HC anuales \% fórmula resp fórmula}

\begin{tabular}{|c|c|c|c|}
\hline enero & 0 & 0 & \\
\hline febrero & 0 & 0 & \\
\hline marzo & 0 & 0 & \\
abril & 0 & 0 & 61 \\
mayo & 1 & 1 & 73 \\
junio & 30 & 22 & 70 \\
julio & 57 & 40 & 79 \\
agosto & 58 & 45 & 79 \\
\hline septiembre & 9 & 7 & \\
octubre & 0 & 0 & \\
noviembre & 0 & 0 & 74 \\
\hline diciembre & 0 & 0 & \\
\hline anual & 155 & 115 & \\
\hline
\end{tabular}

La subestima promedio mensual de los meses que importan, julio y agosto, es similar a la subestima anual, entre el $70 \%$ y el $80 \%$. 
Valladolid CMT. La fórmula de Crossa-Raynaud subestima las horas de calor, en promedio da un $84 \%$ de las horas reales.

Tabla 311. Comparación de horas de calor anuales contadas y obtenidas a partir de la fórmula para el observatorio de Valladolid CMT.

$\mathrm{HC}$ anuales contadas

$\mathrm{HC}$ anuales fórmula \% fórmula resp a cont

\begin{tabular}{|c|ccc|}
\hline 2002 & 230 & 187 & 82 \\
2003 & 356 & 321 & 90 \\
2004 & 228 & 186 & 82 \\
2005 & 330 & 270 & 82 \\
2006 & 314 & 257 & 82 \\
2007 & 131 & 107 & 82 \\
2008 & 159 & 124 & 78 \\
2009 & 280 & 225 & 80 \\
2010 & 246 & 223 & 91 \\
2011 & 220 & 183 & 83 \\
promedio & 249 & 208 & 84
\end{tabular}

Tabla 312.Comparación de los promedios mensuales de las horas de calor correspondientes al periodo 2002-2011 para el observatorio de Valladolid CMT.

\begin{tabular}{|c|c|c|c|}
\hline & $\begin{array}{c}\text { HC anuales } \\
\text { contadas }\end{array}$ & $\begin{array}{c}\text { HC anuales } \\
\text { fórmula }\end{array}$ & $\begin{array}{c}\text { \% fórmula resp a } \\
\text { cont }\end{array}$ \\
\hline enero & 0 & 0 & \\
febrero & 0 & 0 & \\
marzo & 0 & 0 & \\
abril & 0 & 0 & 80 \\
\hline mayo & 4 & 3 & 81 \\
\hline junio & 56 & 46 & 80 \\
\hline julio & 92 & 74 & 87 \\
\hline agosto & 83 & 73 & 93 \\
\hline septiembre & 14 & 13 & \\
\hline octubre & 0 & 0 & \\
\hline noviembre & 0 & 0 & 84 \\
\hline diciembre & 0 & 0 & \\
\hline anual & 249 & 208 & \\
\hline
\end{tabular}

La subestima promedio mensual de los meses que importan, julio y agosto, es similar a la subestima anual, entre el $80 \%$ y el $90 \%$. 
Segovia. La fórmula de Crossa-Raynaud subestima las horas de calor, en promedio da un $87 \%$ de las horas reales, y por tanto no es una mala aproximación.

Tabla 313. Comparación de horas de calor anuales contadas y obtenidas a partir de la fórmula para el observatorio de Segovia.

\begin{tabular}{|c|ccc|}
\hline & HC anuales contadas & HC anuales fórmula & $\%$ fórmula resp a cont \\
\hline 2002 & 148 & 106 & 71 \\
2003 & 314 & 288 & 92 \\
2004 & 154 & 131 & 85 \\
2005 & 261 & 217 & 83 \\
2006 & 207 & 189 & 91 \\
2007 & 114 & 94 & 82 \\
2008 & 120 & 105 & 87 \\
2009 & 241 & 199 & 82 \\
2010 & 189 & 184 & 97 \\
2011 & 169 & 153 & 90 \\
promedio & 192 & 166 & 87 \\
\hline
\end{tabular}

Tabla 314. Comparación de los promedios mensuales de las horas de calor correspondientes al periodo 20022011 para el observatorio de Segovia.

\begin{tabular}{|c|c|c|c|}
\hline & $\begin{array}{c}\text { HC anuales } \\
\text { contadas }\end{array}$ & $\begin{array}{c}\text { HC anuales } \\
\text { fórmula }\end{array}$ & $\begin{array}{c}\text { \% fórmula resp } \\
\text { a cont }\end{array}$ \\
\hline enero & 0 & 0 & \\
febrero & 0 & 0 & \\
marzo & 0 & 0 & \\
abril & 0 & 0 & \\
mayo & 1 & 1 & 84 \\
\hline junio & 35 & 29 & 81 \\
julio & 76 & 62 & 91 \\
agosto & 71 & 64 & 113 \\
septiembre & 8 & 10 & \\
\hline octubre & 0 & 0 & \\
noviembre & 0 & 0 & \\
diciembre & 0 & 0 & 87 \\
anual & 192 & 166 & \\
\hline
\end{tabular}

La subestima promedio mensual de los meses que importan, julio y agosto, es similar a la subestima anual, entre el $80 \%$ y el $90 \%$. 
Salamanca Matacán. La fórmula de Crossa-Raynaud subestima mucho las horas de calor, en promedio da un $71 \%$ de las horas reales, y por tanto es una mala aproximación.

Tabla 315. Comparación de horas de calor anuales contadas y obtenidas a partir de la fórmula para el observatorio de Salamanca Matacán.

\begin{tabular}{|c|c|c|c|}
\hline & $\mathrm{HC}$ anuales contadas & $\mathrm{HC}$ anuales fórmula & $\%$ fórmula resp a cont \\
\hline 2002 & 158 & 116 & 73 \\
\hline 2003 & 272 & 231 & 85 \\
\hline 2004 & 173 & 133 & 77 \\
\hline 2005 & 279 & 201 & 72 \\
\hline 2006 & 260 & 208 & 80 \\
\hline 2007 & 169 & 104 & 62 \\
\hline 2008 & 206 & 127 & 62 \\
\hline 2009 & 303 & 194 & 64 \\
\hline 2010 & 300 & 215 & 72 \\
\hline 2011 & 204 & 131 & 64 \\
\hline promedio & 232 & 166 & 71 \\
\hline
\end{tabular}

Tabla 316.Comparación de los promedios mensuales de las horas de calor correspondientes al periodo 2002-2011 para el observatorio de Salamanca Matacán.

$\begin{array}{ccc}\mathrm{HC} \text { anuales } & \mathrm{HC} \text { anuales } & \% \text { fórmula resp } \\ \text { contadas } & \text { fórmula } & \text { a cont }\end{array}$

\begin{tabular}{|c|c|c|c|}
\hline enero & 0 & 0 & \\
\hline febrero & 0 & 0 & \\
\hline marzo & 0 & 0 & \\
abril & 0 & 0 & 63 \\
\hline mayo & 4 & 3 & 70 \\
\hline junio & 52 & 36 & 68 \\
\hline julio & 88 & 59 & 74 \\
\hline agosto & 79 & 59 & 95 \\
\hline septiembre & 9 & 9 & \\
\hline octubre & 0 & 0 & \\
\hline noviembre & 0 & 0 & 71 \\
\hline diciembre & 0 & 0 & \\
\hline anual & 232 & 166 & \\
\hline
\end{tabular}

Los promedios mensuales de los meses que importan, julio y agosto, dan una subestima del $70 \%$, similar a la anual. 
Zamora. La fórmula de Crossa-Raynaud subestima mucho las horas de calor, en promedio da un $77 \%$ de las horas reales, y por tanto es una mala aproximación.

Tabla 317. Comparación de horas de calor anuales contadas y obtenidas a partir de la fórmula para el observatorio de Zamora.

\begin{tabular}{|c|ccc|}
\hline \multicolumn{2}{|c|}{ HC anuales contadas } & HC anuales fórmula & \% fórmula resp a cont \\
\hline 2002 & 207 & 160 & 77 \\
2003 & 350 & 310 & 89 \\
2004 & 255 & 200 & 78 \\
2005 & 336 & 258 & 77 \\
2006 & 368 & 285 & 77 \\
2007 & 146 & 103 & 70 \\
2008 & 207 & 148 & 72 \\
2009 & 341 & 250 & 73 \\
2010 & 348 & 279 & 80 \\
2011 & 270 & 194 & 72 \\
promedio & 283 & 219 & 77
\end{tabular}

Tabla 318. Comparación de los promedios mensuales de las horas de calor correspondientes al periodo 20022011 para el observatorio de Zamora.

\section{$\mathrm{HC}$ anuales $\quad \mathrm{HC}$ anuales $\%$ fórmula resp contadas fórmula a cont}

\begin{tabular}{|c|c|c|c|}
\hline enero & 0 & 0 & \\
\hline febrero & 0 & 0 & \\
\hline marzo & 0 & 0 & \\
\hline Abril & 0 & 0 & 62 \\
\hline mayo & 7 & 4 & 71 \\
\hline Junio & 69 & 49 & 76 \\
\hline Julio & 103 & 78 & 83 \\
\hline agosto & 89 & 74 & 94 \\
\hline septiembre & 15 & 14 & \\
\hline octubre & 0 & 0 & \\
\hline noviembre & 0 & 0 & 77 \\
\hline diciembre & 0 & 0 & \\
\hline anual & 283 & 219 & \\
\hline
\end{tabular}

Los promedios mensuales de los meses que importan, julio y agosto, dan una subestima en torno al $80 \%$, similar a la anual. 


\section{Resumen para la meseta Norte}

Puede concluirse que en la meseta Norte el cálculo de las horas de calor por la fórmula de Crossa-Raynaud subestima en torno al $20 \%$ las horas de calor reales y se da una gran oscilación entre las aproximaciones en los diferentes años. Sin embargo, si se tiene en cuenta el bajo número de horas de calor (con umbral $30^{\circ} \mathrm{C}$ ) que se dan en esta zona, sobre todo en la parte alta de la cuenca, por encima de $800 \mathrm{~m}$, la subestima tiene poca importancia en número de horas.

\subsubsection{Cuenca del Ebro: a) parte baja y relativamente llana del valle del Ebro}

Huesca. La fórmula de Crossa-Raynaud apenas subestima las horas de calor, en promedio da un $95 \%$ de las horas reales, y por tanto es una buena aproximación.

Tabla 319. Comparación de horas de calor anuales contadas y obtenidas a partir de la fórmula para el observatorio de Huesca.

\begin{tabular}{|c|c|c|c|}
\hline & HC anuales contadas & $\mathrm{HC}$ anuales fórmula & $\%$ fórmula resp a cont \\
\hline 2002 & 264 & 235 & 89 \\
\hline 2003 & 547 & 527 & 96 \\
\hline 2004 & 256 & 230 & 90 \\
\hline 2005 & 374 & 354 & 95 \\
\hline 2006 & 307 & 264 & 86 \\
\hline 2007 & 186 & 184 & 99 \\
\hline 2008 & 247 & 239 & 97 \\
\hline 2009 & 359 & 367 & 102 \\
\hline 2010 & 333 & 313 & 94 \\
\hline 2011 & 342 & 337 & 98 \\
\hline Promedio & 322 & 305 & 95 \\
\hline
\end{tabular}


Tabla 320. Comparación de los promedios mensuales de las horas de calor correspondientes al periodo 2002 2011 para el observatorio de Huesca.

\begin{tabular}{|c|c|c|c|}
\hline & $\begin{array}{c}\text { HC anuales } \\
\text { contadas }\end{array}$ & $\begin{array}{c}\text { HC anuales } \\
\text { fórmula }\end{array}$ & $\begin{array}{c}\text { \% fórmula resp } \\
\text { a cont }\end{array}$ \\
\hline enero & 0 & 0 & \\
febrero & 0 & 0 & \\
marzo & 0 & 0 & \\
abril & 0 & 0 & 74 \\
mayo & 5 & 4 & 87 \\
junio & 73 & 64 & 96 \\
julio & 127 & 121 & 99 \\
agosto & 103 & 102 & 100 \\
septiembre & 14 & 14 & \\
octubre & 0 & 0 & \\
noviembre & 0 & 0 & 95 \\
diciembre & 0 & 0 & \\
anual & 322 & 305 & \\
\hline
\end{tabular}

Apenas subestima en el promedio mensual de los meses que importan, julio y agosto, y tampoco lo hace en septiembre y algo más en junio.

Zaragoza aeropuerto. La fórmula de Crossa-Raynaud sobrestima las horas de calor, aunque lo hace por poco. Da en promedio un $105 \%$ de las horas reales, y por tanto es una buena aproximación.

Tabla 321. Comparación de horas de calor anuales contadas y obtenidas a partir de la fórmula para el observatorio de Zaragoza aeropuerto.

$\mathrm{HC}$ anuales contadas $\quad \mathrm{HC}$ anuales fórmula \% fórmula resp a cont

\begin{tabular}{|c|ccc|}
\hline 2002 & 282 & 292 & 104 \\
2003 & 635 & 669 & 105 \\
2004 & 435 & 458 & 105 \\
2005 & 441 & 462 & 105 \\
2006 & 462 & 513 & 111 \\
2007 & 302 & 308 & 102 \\
2008 & 396 & 389 & 98 \\
2009 & 569 & 605 & 106 \\
2010 & 424 & 450 & 106 \\
2011 & 462 & 477 & 103 \\
Promedio & 441 & 462 & 105
\end{tabular}


Tabla 322. Comparación de los promedios mensuales de las horas de calor correspondientes al periodo 2002 2011 para el observatorio de Zaragoza aeropuerto.

\begin{tabular}{|c|c|c|c|}
\hline & $\begin{array}{l}\text { HC anuales } \\
\text { contadas }\end{array}$ & $\begin{array}{l}\text { HC anuales } \\
\text { fórmula }\end{array}$ & $\begin{array}{c}\% \text { fórmula resp } \\
\text { a cont }\end{array}$ \\
\hline enero & 0 & 0 & \\
\hline febrero & 0 & 0 & \\
\hline marzo & 0 & 0 & \\
\hline abril & 2 & 1 & \\
\hline mayo & 14 & 11 & 83 \\
\hline junio & 103 & 107 & 104 \\
\hline julio & 159 & 172 & 108 \\
\hline agosto & 132 & 140 & 106 \\
\hline septiembre & 30 & 31 & 103 \\
\hline octubre & 1 & 1 & \\
\hline noviembre & 0 & 0 & \\
\hline diciembre & 0 & 0 & \\
\hline anual & 441 & 462 & \\
\hline
\end{tabular}

Sobrestima, aunque muy poco en los meses que importan: junio, julio y agosto.

Lérida. La fórmula de Crossa-Raynaud sobrestima las horas de calor, aunque lo hace por poco. Da en promedio un $106 \%$ de las horas reales, y por tanto es una buena aproximación.

Tabla 323. Comparación de horas de calor anuales contadas y obtenidas a partir de la fórmula para el observatorio de Lérida.

$\mathrm{HC}$ anuales contadas $\quad \mathrm{HC}$ anuales fórmula \% fórmula resp a cont

\begin{tabular}{|c|ccc|}
\hline 2002 & 296 & 307 & 104 \\
2003 & 604 & 658 & 109 \\
2004 & 347 & 362 & 104 \\
2005 & 382 & 393 & 103 \\
2006 & 492 & 500 & 102 \\
2007 & 301 & 313 & 104 \\
2008 & 338 & 353 & 104 \\
2009 & 484 & 550 & 114 \\
2010 & 392 & 416 & 106 \\
2011 & 392 & 401 & 102 \\
Promedio & 403 & 425 & 106
\end{tabular}


Tabla 324. Comparación de los promedios mensuales de las horas de calor correspondientes al periodo 2002 2011 para el observatorio de Lérida.

\begin{tabular}{|c|c|c|c|}
\hline & $\begin{array}{c}\text { HC anuales } \\
\text { contadas }\end{array}$ & $\begin{array}{c}\text { HC anuales } \\
\text { fórmula }\end{array}$ & $\begin{array}{c}\text { \% fórmula resp } \\
\text { a cont }\end{array}$ \\
\hline enero & 0 & 0 & \\
\hline febrero & 0 & 0 & \\
marzo & 0 & 0 & \\
abril & 1 & 1 & 90 \\
mayo & 12 & 11 & 100 \\
\hline junio & 91 & 91 & 105 \\
\hline julio & 150 & 158 & 110 \\
\hline agosto & 122 & 135 & 114 \\
\hline septiembre & 25 & 28 & \\
\hline octubre & 1 & 1 & \\
\hline noviembre & 0 & 0 & 106 \\
\hline diciembre & 0 & 0 & \\
\hline anual & 403 & 425 & \\
\hline
\end{tabular}

Sobrestima, aunque muy poco en los meses que importan, los de verano junio, julio, agosto y septiembre.

\subsubsection{Cuenca del Ebro: b) zonas de la parte media de la cuenca: Navarra y La Rioja.}

Logroño Agoncillo. La fórmula de Crossa-Raynaud apenas subestima las horas de calor, da en promedio un $95 \%$ de las horas reales, y por tanto es una buena aproximación.

Tabla 325. Comparación de horas de calor anuales contadas y obtenidas a partir de la fórmula para el observatorio de Logroño Agoncillo.

\begin{tabular}{|c|c|c|c|}
\hline & $\mathrm{HC}$ anuales contadas & $\mathrm{HC}$ anuales fórmula & $\%$ fórmula resp a cont \\
\hline 2002 & 162 & 166 & 103 \\
\hline 2003 & 439 & 435 & 99 \\
\hline 2004 & 217 & 195 & 90 \\
\hline 2005 & 308 & 299 & 97 \\
\hline 2006 & 284 & 269 & 95 \\
\hline 2007 & 168 & 148 & 88 \\
\hline 2008 & 168 & 141 & 84 \\
\hline 2009 & 307 & 295 & 96 \\
\hline 2010 & 224 & 203 & 91 \\
\hline 2011 & 231 & 230 & 100 \\
\hline Promedio & 251 & 238 & 95 \\
\hline
\end{tabular}


Tabla 326. Comparación de los promedios mensuales de las horas de calor correspondientes al periodo 20022011 para el observatorio de Logroño Agoncillo.

$\mathrm{HC}$ anuales contadas
HC anuales fórmula
$\%$ fórmula resp a cont

\begin{tabular}{|c|c|c|c|}
\hline enero & 0 & 0 & \\
\hline febrero & 0 & 0 & \\
\hline marzo & 0 & 0 & \\
abril & 0 & 0 & 77 \\
mayo & 5 & 4 & 89 \\
junio & 57 & 50 & 96 \\
\hline julio & 93 & 89 & 99 \\
\hline agosto & 80 & 79 & 98 \\
\hline septiembre & 15 & 15 & \\
\hline octubre & 1 & 0 & \\
\hline noviembre & 0 & 0 & 95 \\
\hline diciembre & 0 & 0 & \\
anual & 251 & 238 & \\
\hline
\end{tabular}

Apenas subestima en el promedio mensual de los meses que importan: julio y agosto.

Haro. La fórmula de Crossa-Raynaud subestima las horas de calor en un 10\%, da en promedio un $90 \%$ de las horas reales, y por tanto, es una aproximación aceptable.

Tabla 327. Comparación de horas de calor anuales contadas y obtenidas a partir de la fórmula para el observatorio de Haro.

$\mathrm{HC}$ anuales contadas

$\mathrm{HC}$ anuales fórmula \% fórmula resp a cont

\begin{tabular}{|c|ccc|}
\hline 2002 & & & \\
2003 & & & \\
2004 & 138 & 132 & 96 \\
2005 & 215 & 192 & 89 \\
2006 & 188 & 177 & 94 \\
2007 & 113 & 94 & 84 \\
2008 & 100 & 83 & 83 \\
2009 & 218 & 203 & 93 \\
2010 & 157 & 130 & 83 \\
2011 & 141 & 128 & 91 \\
\hline Promedio & 159 & 142 & 90 \\
\hline
\end{tabular}


Tabla 328.Comparación de los promedios mensuales de las horas de calor correspondientes al periodo 2002-2011 para el observatorio de Haro.

\begin{tabular}{|c|c|c|c|}
\hline & $\begin{array}{l}\text { HC anuales } \\
\text { contadas }\end{array}$ & $\begin{array}{l}\mathrm{HC} \text { anuales } \\
\text { fórmula }\end{array}$ & $\begin{array}{c}\% \text { fórmula resp } \\
\text { a cont }\end{array}$ \\
\hline enero & 0 & 0 & \\
\hline febrero & 0 & 0 & \\
\hline marzo & 0 & 0 & \\
\hline abril & 0 & 0 & \\
\hline mayo & 3 & 2 & 61 \\
\hline junio & 32 & 27 & 84 \\
\hline julio & 60 & 57 & 94 \\
\hline agosto & 48 & 43 & 90 \\
\hline septiembre & 15 & 14 & 89 \\
\hline octubre & 0 & 0 & \\
\hline noviembre & 0 & 0 & \\
\hline diciembre & 0 & 0 & \\
\hline anual & 159 & 142 & 90 \\
\hline
\end{tabular}

Pamplona Noáin. La fórmula de Crossa-Raynaud subestima las horas de calor, en promedio da un $81 \%$ de las horas reales, y por tanto no es una buena aproximación.

Tabla 329. Comparación de horas de calor anuales contadas y obtenidas a partir de la fórmula para el observatorio de Pamplona Noáin.

\begin{tabular}{|c|ccc|}
\hline & HC anuales contadas & HC anuales fórmula & $\begin{array}{c}\text { \% fórmula resp a } \\
\text { cont }\end{array}$ \\
\hline 2002 & 138 & 121 & 88 \\
2003 & 366 & 347 & 95 \\
2004 & 159 & 154 & 97 \\
2005 & 193 & 188 & 97 \\
2006 & 189 & 156 & 83 \\
2007 & 140 & 99 & 71 \\
2008 & 138 & 88 & 63 \\
2009 & 262 & 194 & 74 \\
2010 & 177 & 117 & 66 \\
2011 & 210 & 141 & 67 \\
\hline Promedio & 197 & 161 & 81
\end{tabular}


Tabla 330. Comparación de los promedios mensuales de las horas de calor correspondientes al periodo 20022011 para el observatorio de Pamplona Noáin.

\section{$\mathrm{HC}$ anuales $\quad \mathrm{HC}$ anuales $\%$ fórmula resp \\ contadas \\ fórmula \\ a cont}

\begin{tabular}{|c|c|c|c|}
\hline enero & 0 & 0 & \\
\hline febrero & 0 & 0 & \\
marzo & 0 & 0 & \\
abril & 0 & 0 & 46 \\
mayo & 4 & 2 & 75 \\
junio & 46 & 34 & 86 \\
\hline julio & 65 & 56 & 90 \\
\hline agosto & 66 & 59 & 58 \\
\hline septiembre & 16 & 9 & \\
\hline octubre & 1 & 0 & 81 \\
\hline noviembre & 0 & 0 & \\
diciembre & 0 & 0 & \\
anual & 197 & 161 & \\
\hline
\end{tabular}

La subestima promedio mensual de los meses que importan, julio y agosto, es similar a la subestima anual, en torno al $80 \%$.

\section{Resumen para la cuenca del Ebro}

En la parte que podríamos denominar media de la cuenca, en La Rioja y Navarra, la fórmula subestima las horas de calor, pero si se tiene en cuenta que tales horas no llegan en promedio a las 300 horas anuales, la subestima en horas no es alta. Sin embargo, en la parte baja de la cuenca, donde el número de horas de calor es mayor, sobrepasa las 400 anuales en promedio, lo que da la fórmula es una ligera sobrestima de las horas de calor, y la aproximación puede considerarse buena.

\subsubsection{Zona de la franja costera del noreste peninsular: costa catalana}

Barcelona. La fórmula de Crossa-Raynaud subestima las horas de calor en un $5 \%$, en promedio da un $95 \%$ de las horas reales, pero hay una gran variación de unos años a otros, entre una sobrestima del $39 \%$ a una subestima del $26 \%$ por tanto no es buena aproximación. 
Tabla 331. Comparación de horas de calor anuales contadas y obtenidas a partir de la fórmula para el observatorio de Barcelona.

\begin{tabular}{|c|ccc|}
\hline & HC anuales contadas & HC anuales fórmula & $\%$ fórmula resp a cont \\
\hline 2002 & 0 & 1 & \\
2003 & 399 & 385 & 96 \\
2004 & 57 & 76 & 133 \\
2005 & 27 & 37 & 139 \\
2006 & 193 & 143 & 74 \\
2007 & 16 & 22 & 135 \\
2008 & 50 & 43 & 86 \\
2009 & 85 & 86 & 101 \\
2010 & 45 & 47 & 105 \\
2011 & 53 & 41 & 78 \\
Promedio & 93 & 88 & 95 \\
\hline
\end{tabular}

Tabla 332. Comparación de los promedios mensuales de las horas de calor correspondientes al periodo 20022011 para el observatorio de Barcelona.

$\begin{array}{ccc}\mathrm{HC} \text { anuales } & \mathrm{HC} \text { anuales } & \% \text { fórmula resp } \\ \text { contadas } & \text { fórmula } & \text { a cont }\end{array}$

\begin{tabular}{|c|c|c|c|}
\hline enero & 0 & 0 & \\
febrero & 0 & 0 & \\
\hline marzo & 0 & 0 & \\
abril & 0 & 0 & \\
mayo & 0 & 0 & 89 \\
\hline junio & 10 & 12 & 93 \\
julio & 35 & 31 & \\
agosto & 45 & 42 & \\
septiembre & 4 & 4 & \\
\hline octubre & 0 & 0 & 95 \\
\hline noviembre & 0 & 0 & \\
\hline diciembre & 0 & 0 & \\
anual & 93 & 88 & \\
\hline
\end{tabular}

Gerona. La fórmula de Crossa-Raynaud subestima las horas de calor en un 14\%, en promedio da un $86 \%$ de las horas reales, pero lo hace de forma muy pareja unos años y otros; por tanto no es mala aproximación. 
Tabla 333. Comparación de horas de calor anuales contadas y obtenidas a partir de la fórmula para el observatorio de Gerona.

\begin{tabular}{|c|c|c|c|}
\hline & HC anuales contadas & HC anuales fórmula & \% fórmula resp a cont \\
\hline 2002 & 159 & 102 & \\
\hline 2003 & 554 & 454 & 82 \\
\hline 2004 & 212 & 174 & 82 \\
\hline 2005 & 254 & 205 & 81 \\
\hline 2006 & 296 & 283 & 96 \\
\hline 2007 & 210 & 178 & 85 \\
\hline 2008 & 239 & 190 & 80 \\
\hline 2009 & & 306 & \\
\hline 2010 & & & \\
\hline 2011 & & & \\
\hline Promedio & 275 & 236 & 86 \\
\hline
\end{tabular}

Tabla 334. Comparación de los promedios mensuales de las horas de calor correspondientes al periodo 20022011 para el observatorio de Gerona.

\begin{tabular}{|c|c|c|c|}
\hline & $\begin{array}{l}\text { HC anuales } \\
\text { contadas }\end{array}$ & $\begin{array}{l}\text { HC anuales } \\
\text { fórmula }\end{array}$ & $\begin{array}{c}\% \text { fórmula resp } \\
\text { a cont }\end{array}$ \\
\hline enero & 0 & 0 & \\
\hline febrero & 0 & 0 & \\
\hline marzo & 0 & 0 & \\
\hline abril & 0 & 0 & \\
\hline mayo & 4 & 2 & \\
\hline junio & 71 & 53 & 75 \\
\hline julio & 113 & 97 & 86 \\
\hline agosto & 77 & 76 & 98 \\
\hline septiembre & 7 & 8 & \\
\hline octubre & 1 & 0 & \\
\hline noviembre & 0 & 0 & \\
\hline diciembre & 0 & 0 & \\
\hline anual & 275 & 236 & 86 \\
\hline
\end{tabular}

Reus. La fórmula de Crossa-Raynaud subestima las horas de calor en un $11 \%$, en promedio da un $89 \%$ de las horas reales, pero excepto en 2011 lo hace de forma muy pareja unos años y otros por tanto no es mala aproximación. 
Tabla 335. Comparación de horas de calor anuales contadas y obtenidas a partir de la fórmula para el observatorio de Reus.

\begin{tabular}{|c|c|c|c|}
\hline & HC anuales contadas & HC anuales fórmula & \% fórmula resp a cont \\
\hline 2002 & 62 & 64 & \\
\hline 2003 & 348 & 300 & 86 \\
\hline 2004 & 146 & 121 & 83 \\
\hline 2005 & 92 & 96 & 104 \\
\hline 2006 & 283 & 251 & 89 \\
\hline 2007 & 91 & 85 & 93 \\
\hline 2008 & 33 & 31 & 93 \\
\hline 2009 & 64 & 58 & 91 \\
\hline 2010 & 52 & 49 & 93 \\
\hline 2011 & 88 & 70 & 79 \\
\hline Promedio & 126 & 112 & 89 \\
\hline
\end{tabular}

Tabla 336. Comparación de los promedios mensuales de las horas de calor correspondientes al periodo 20022011 para el observatorio de Reus.

\begin{tabular}{|c|c|c|c|}
\hline & $\begin{array}{c}\text { HC anuales } \\
\text { contadas }\end{array}$ & $\begin{array}{c}\text { HC anuales } \\
\text { fórmula }\end{array}$ & $\begin{array}{c}\text { \% fórmula resp } \\
\text { a cont }\end{array}$ \\
\hline enero & 0 & 0 & \\
\hline febrero & 0 & 0 & \\
\hline marzo & 0 & 0 & \\
\hline abril & 0 & 0 & 85 \\
\hline mayo & 1 & 1 & 93 \\
\hline junio & 20 & 17 & 87 \\
\hline julio & 45 & 42 & \\
\hline agosto & 56 & 49 & \\
\hline septiembre & 3 & 3 & \\
\hline octubre & 1 & 1 & \\
\hline noviembre & 0 & 0 & 89 \\
\hline diciembre & 0 & 112 & \\
\hline anual & 126 & & \\
\hline
\end{tabular}

Tarragona. La fórmula de Crossa-Raynaud sobrestima mucho las horas de calor, en un 65\%; en promedio da un $165 \%$ de las horas reales, con grandes variaciones de unos años a otros, y por tanto es una mala aproximación. 
Tabla 337. Comparación de horas de calor anuales contadas y obtenidas a partir de la fórmula para el observatorio de Tarragona.

\begin{tabular}{|c|c|c|c|}
\hline & HC anuales contadas & HC anuales fórmula & \% fórmula resp a cont \\
\hline 2002 & 45 & 82 & 183 \\
\hline 2003 & 221 & 359 & 162 \\
\hline 2004 & & 57 & \\
\hline 2005 & 28 & 73 & 261 \\
\hline 2006 & 71 & 206 & 291 \\
\hline 2007 & 3 & 40 & \\
\hline 2008 & 31 & 37 & 119 \\
\hline 2009 & 89 & 81 & 91 \\
\hline 2010 & 45 & 60 & 133 \\
\hline 2011 & 22 & 25 & 114 \\
\hline promedio & 62 & 102 & 165 \\
\hline
\end{tabular}

Tabla 338. Comparación de los promedios mensuales de las horas de calor correspondientes al periodo 20022011 para el observatorio de Tarragona.

$\begin{array}{ccc}\text { HC anuales } & \text { HC anuales } & \% \text { fórmula resp } \\ \text { contadas } & \text { fórmula } & \text { a cont }\end{array}$

\begin{tabular}{|c|c|c|c|}
\hline enero & 0 & 0 & \\
febrero & 0 & 0 & \\
marzo & 0 & 0 & \\
abril & 0 & 0 & \\
mayo & 0 & 0 & 177 \\
junio & 5 & 9 & 148 \\
julio & 21 & 31 & 139 \\
agosto & 32 & 45 & \\
septiembre & 1 & 1 & \\
octubre & 0 & 0 & \\
noviembre & 0 & 0 & 165 \\
diciembre & 0 & 0 & \\
anual & 62 & 102 & \\
\hline
\end{tabular}

Tortosa. La fórmula de Crossa-Raynaud sobrestima las horas de calor en un 19\%, en promedio da un $119 \%$ de las horas reales, pero con poca variación de unos años a otros y por tanto no es mala aproximación. 
Tabla 339. Comparación de horas de calor anuales contadas y obtenidas a partir de la fórmula para el observatorio de Tortosa.

$\mathrm{HC}$ anuales contadas $\quad \mathrm{HC}$ anuales fórmula \% fórmula resp a cont

\begin{tabular}{|c|ccc|}
\hline 2002 & 285 & 321 & 113 \\
2003 & 582 & 705 & 121 \\
2004 & 344 & 417 & 121 \\
2005 & 449 & 506 & 113 \\
2006 & 540 & 629 & 116 \\
2007 & 319 & 401 & 126 \\
2008 & 344 & 409 & 119 \\
2009 & 546 & 699 & 128 \\
2010 & 518 & 603 & 116 \\
2011 & 500 & 570 & 114 \\
Promedio & 443 & 526 & 119
\end{tabular}

Tabla 340. Comparación de los promedios mensuales de las horas de calor correspondientes al periodo 20022011 para el observatorio de Tortosa.

\begin{tabular}{|c|c|c|c|}
\hline & $\begin{array}{c}\text { HC anuales } \\
\text { contadas }\end{array}$ & $\begin{array}{l}\mathrm{HC} \text { anuales } \\
\text { fórmula }\end{array}$ & $\begin{array}{c}\% \text { fórmula resp } \\
\text { a cont }\end{array}$ \\
\hline enero & 0 & 0 & \\
\hline febrero & 0 & 0 & \\
\hline marzo & 0 & 0 & \\
\hline abril & 1 & 1 & \\
\hline mayo & 10 & 10 & \\
\hline junio & 82 & 93 & 114 \\
\hline Julio & 157 & 185 & 118 \\
\hline agosto & 151 & 188 & 124 \\
\hline septiembre & 38 & 46 & 121 \\
\hline octubre & 4 & 4 & \\
\hline noviembre & 0 & 0 & \\
\hline diciembre & 0 & 0 & \\
\hline anual & 443 & 526 & 119 \\
\hline
\end{tabular}

La subestima promedio mensual de los meses que importan, julio y agosto, es parecida a la anual. 
En la zona costera, cerca del mar, el número de horas de calor (con umbral $30^{\circ} \mathrm{C}$ ) es bajo, y aunque la fórmula puede subestimar las horas reales, tal subestima es baja en número de horas. Hacia el interior, sin embargo, al aumentar el número de horas de calor a valores por encima de las 400, sucede lo mismo que en el bajo valle del Ebro y se da una sobrestima del número de horas; si bien en este caso la discrepancia es notable, y dispar si se comparan unos años con otros, lo que hace que la aproximación no sea buena.

\subsubsection{Cuenca del Tajo}

Madrid Barajas. La fórmula de Crossa-Raynaud subestima las horas de calor, en promedio da un $75 \%$ de las horas reales, y por tanto es una mala aproximación.

Tabla 341. Comparación de horas de calor anuales contadas y obtenidas a partir de la fórmula para el observatorio de Madrid Barajas.

$\mathrm{HC}$ anuales contadas $\quad \mathrm{HC}$ anuales fórmula \% fórmula resp a cont

\begin{tabular}{|c|c|c|c|}
\hline 2002 & 423 & 293 & 69 \\
\hline 2003 & 611 & 467 & 76 \\
\hline 2004 & 485 & 380 & 78 \\
\hline 2005 & 809 & 628 & 78 \\
\hline 2006 & 795 & 641 & 81 \\
\hline 2007 & 443 & 323 & 73 \\
\hline 2008 & 571 & 432 & 76 \\
\hline 2009 & 836 & 631 & 76 \\
\hline 2010 & 623 & 469 & 75 \\
\hline 2011 & 610 & 404 & 66 \\
\hline Promedio & 621 & 467 & 75 \\
\hline
\end{tabular}


Tabla 342. Comparación de los promedios mensuales de las horas de calor correspondientes al periodo 2002 2011 para el observatorio de Madrid Barajas.

\begin{tabular}{|c|c|c|c|}
\hline & $\begin{array}{c}\text { HC anuales } \\
\text { contadas }\end{array}$ & $\begin{array}{l}\text { HC anuales } \\
\text { fórmula }\end{array}$ & $\begin{array}{c}\% \text { fórmula resp } \\
\text { a cont }\end{array}$ \\
\hline enero & 0 & 0 & \\
\hline febrero & 0 & 0 & \\
\hline marzo & 0 & 0 & \\
\hline abril & 0 & 0 & \\
\hline mayo & 15 & 10 & 65 \\
\hline junio & 132 & 95 & 72 \\
\hline julio & 229 & 175 & 76 \\
\hline agosto & 196 & 153 & 78 \\
\hline septiembre & 46 & 33 & 72 \\
\hline octubre & 3 & 1 & \\
\hline noviembre & 0 & 0 & \\
\hline diciembre & 0 & 0 & \\
\hline anual & 621 & 467 & 75 \\
\hline
\end{tabular}

Guadalajara. La fórmula de Crossa-Raynaud apenas subestima las horas de calor, da en promedio un $70 \%$ de las horas reales, y por tanto es una mala aproximación.

Tabla 343. Comparación de horas de calor anuales contadas y obtenidas a partir de la fórmula para el observatorio de Guadalajara.

$\mathrm{HC}$ anuales contadas $\quad \mathrm{HC}$ anuales fórmula \% fórmula resp a cont

\begin{tabular}{|c|ccc|}
\hline 2002 & 447 & 324 & 73 \\
2003 & 705 & 539 & 77 \\
2004 & 517 & 382 & 74 \\
2005 & 648 & 434 & 67 \\
2006 & 579 & 411 & 71 \\
2007 & 323 & 217 & 67 \\
2008 & & & \\
2009 & 624 & 429 & 69 \\
2010 & 457 & 309 & 68 \\
2011 & 286 & 164 & 57 \\
Promedio & 510 & 357 & 70 \\
\hline
\end{tabular}


Tabla 344. Comparación de los promedios mensuales de las horas de calor correspondientes al periodo 20022011 para el observatorio de Guadalajara.

\begin{tabular}{|c|c|c|c|}
\hline 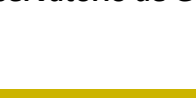 & $\begin{array}{l}\text { HC anuales } \\
\text { contadas }\end{array}$ & $\begin{array}{l}\mathrm{HC} \text { anuales } \\
\text { fórmula }\end{array}$ & $\begin{array}{c}\% \text { fórmula resp } \\
\text { a cont }\end{array}$ \\
\hline enero & 0 & 0 & \\
\hline febrero & 0 & 0 & \\
\hline marzo & 0 & 0 & \\
\hline abril & 0 & 0 & \\
\hline mayo & 13 & 7 & 54 \\
\hline junio & 117 & 76 & 65 \\
\hline julio & 191 & 132 & 69 \\
\hline agosto & 150 & 114 & 76 \\
\hline septiembre & 32 & 21 & 67 \\
\hline octubre & 1 & 1 & \\
\hline noviembre & 0 & 0 & \\
\hline diciembre & 0 & 0 & \\
\hline anual & 510 & 357 & 69 \\
\hline
\end{tabular}

Madrid Getafe. La fórmula de Crossa-Raynaud subestima las horas de calor en un 11\%, da en promedio un $89 \%$ de las horas reales, y por tanto es una aproximación aceptable.

Tabla 345. Comparación de horas de calor anuales contadas y obtenidas a partir de la fórmula para el observatorio de Madrid Getafe.

HC anuales contadas $\quad \mathrm{HC}$ anuales fórmula \% fórmula resp a cont

\begin{tabular}{|c|ccc|}
\hline 2002 & 435 & 380 & 87 \\
2003 & 688 & 632 & 92 \\
2004 & 518 & 470 & 91 \\
2005 & 647 & 584 & 90 \\
2006 & 625 & 576 & 92 \\
2007 & 305 & 290 & 95 \\
2008 & 434 & 373 & 86 \\
2009 & 687 & 602 & 88 \\
2010 & 631 & 544 & 86 \\
2011 & 549 & 467 & 85 \\
Promedio & 552 & 492 & 89
\end{tabular}


Tabla 346. Comparación de los promedios mensuales de las horas de calor correspondientes al periodo 20022011 para el observatorio de Madrid Getafe.

\begin{tabular}{|c|c|c|c|}
\hline \multicolumn{1}{|c|}{$\begin{array}{c}\text { HC anuales } \\
\text { contadas }\end{array}$} & \multicolumn{2}{c|}{$\begin{array}{c}\text { HC anuales } \\
\text { fórmula }\end{array}$} & $\begin{array}{c}\text { \% fórmula resp } \\
\text { a cont }\end{array}$ \\
\hline enero & 0 & 0 & \\
\hline febrero & 0 & 0 & \\
marzo & 0 & 0 & \\
abril & 0 & 0 & 85 \\
mayo & 11 & 9 & 88 \\
junio & 117 & 102 & 88 \\
julio & 210 & 185 & 92 \\
agosto & 178 & 163 & 86 \\
\hline septiembre & 36 & 31 & \\
\hline octubre & 1 & 1 & \\
noviembre & 0 & 0 & 89 \\
\hline diciembre & 0 & 0 & \\
anual & 552 & 492 & \\
\hline
\end{tabular}

Navalmoral de la Mata. La fórmula de Crossa-Raynaud subestima las horas de calor, en promedio da un $84 \%$ de las horas reales, y por tanto no es una mala aproximación.

Tabla 347. Comparación de horas de calor anuales contadas y obtenidas a partir de la fórmula para el observatorio de Navalmoral de la Mata.

\begin{tabular}{|c|c|c|c|}
\hline & HC anuales contadas & $\mathrm{HC}$ anuales fórmula & $\%$ fórmula resp a cont \\
\hline 2002 & 749 & 630 & 84 \\
\hline 2003 & 864 & 761 & 88 \\
\hline 2004 & 801 & 664 & 83 \\
\hline 2005 & 860 & 741 & 86 \\
\hline 2006 & 835 & 725 & 87 \\
\hline 2007 & 566 & 406 & 72 \\
\hline 2008 & 592 & 437 & 74 \\
\hline 2009 & 948 & 814 & 86 \\
\hline 2010 & 842 & 783 & 93 \\
\hline 2011 & 807 & 674 & 84 \\
\hline Promedio & 786 & 664 & 84 \\
\hline
\end{tabular}


Tabla 348. Comparación de los promedios mensuales de las horas de calor correspondientes al periodo 2002 2011 para el observatorio de Navalmoral de la Mata.

HC anuales $\quad H C$ anuales \% fórmula resp

\begin{tabular}{|c|c|c|c|}
\hline enero & 0 & 0 & a cont \\
\hline febrero & 0 & 0 & \\
\hline marzo & 0 & 0 & \\
abril & 1 & 0 & \\
mayo & 27 & 18 & 66 \\
\hline junio & 166 & 133 & 80 \\
\hline julio & 255 & 219 & 86 \\
\hline agosto & 241 & 215 & 89 \\
\hline septiembre & 90 & 71 & 80 \\
\hline octubre & 8 & 7 & \\
\hline noviembre & 0 & 0 & \\
\hline diciembre & 0 & 0 & 84 \\
\hline anual & 786 & 664 & \\
\hline
\end{tabular}

La subestima promedio mensual de los meses que importan, julio y agosto, es mejor que la anual, se acerca al $90 \%$.

Cáceres. La fórmula de Crossa-Raynaud subestima las horas de calor en un 16\% en promedio. Da un $84 \%$ de las horas reales, y por tanto no es una mala aproximación.

Tabla 349. Comparación de horas de calor anuales contadas y obtenidas a partir de la fórmula para el observatorio de Cáceres.

$\mathrm{HC}$ anuales contadas $\quad \mathrm{HC}$ anuales fórmula \% fórmula resp a cont

\begin{tabular}{|c|c|c|c|}
\hline 2002 & 594 & 430 & 72 \\
\hline 2003 & 762 & 630 & 83 \\
\hline 2004 & 773 & 600 & 78 \\
\hline 2005 & 768 & 708 & 92 \\
\hline 2006 & 793 & 735 & 93 \\
\hline 2007 & 443 & 356 & 80 \\
\hline 2008 & 506 & 425 & 84 \\
\hline 2009 & 733 & 630 & 86 \\
\hline 2010 & 822 & 740 & 90 \\
\hline 2011 & 657 & 529 & 81 \\
\hline Promedio & 685 & 578 & 84 \\
\hline
\end{tabular}


Tabla 350. Comparación de los promedios mensuales de las horas de calor correspondientes al periodo 20022011 para el observatorio de Cáceres.

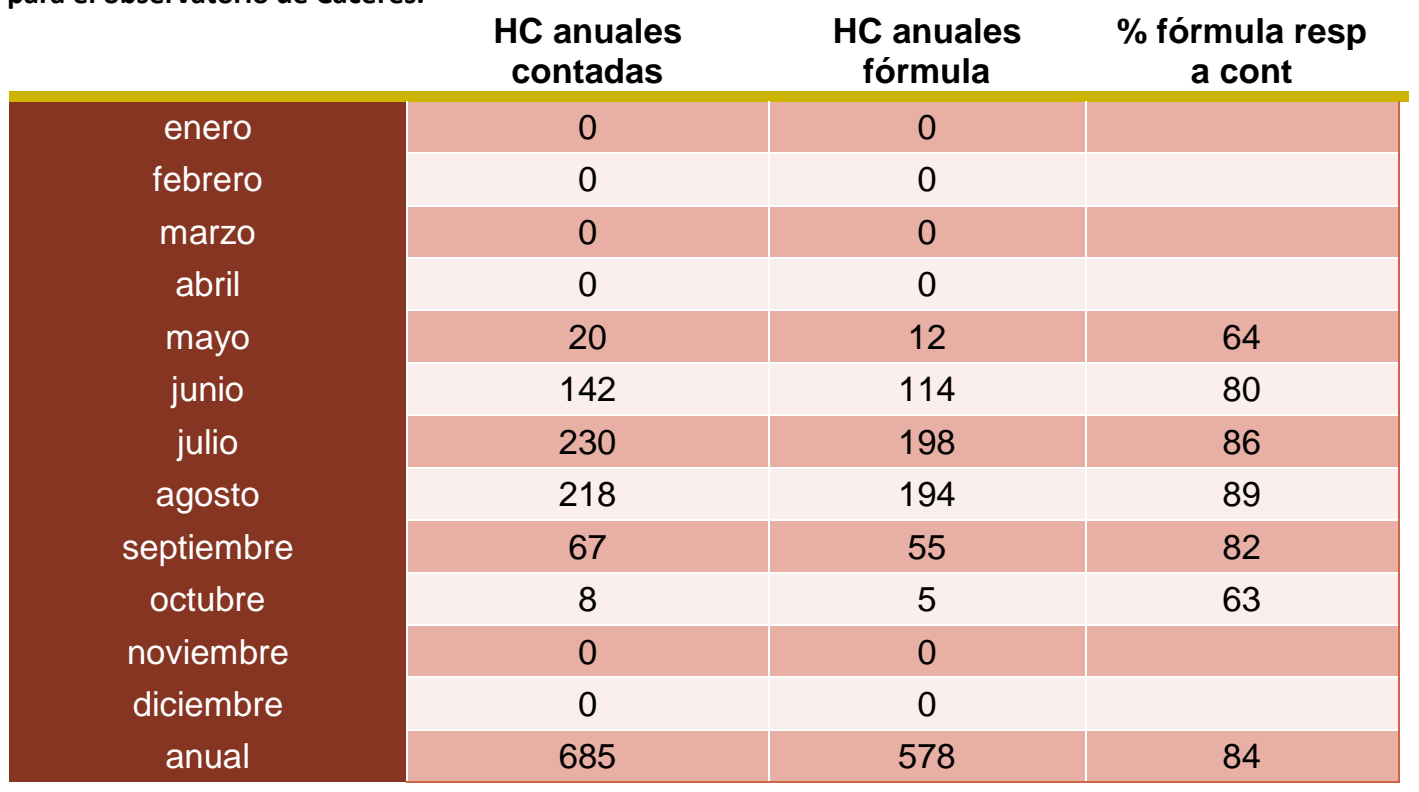

Subestima menos, un $89 \%$, el mes de agosto.

Plasencia. La fórmula de Crossa-Raynaud subestima en un $7 \%$ las horas de calor. Da en promedio un $93 \%$ de las horas reales, y por tanto es una buena aproximación.

Tabla 351. Comparación de horas de calor anuales contadas y obtenidas a partir de la fórmula para el observatorio de Plasencia.
$\mathrm{HC}$ anuales contadas
$\mathrm{HC}$ anuales fórmula
$\%$ fórmula resp a cont

\begin{tabular}{|c|ccc|}
\hline 2002 & 620 & 566 & 91 \\
2003 & & 677 & \\
2004 & 869 & 722 & 83 \\
2005 & 709 & 648 & 91 \\
2006 & 669 & 645 & 96 \\
2007 & 367 & 343 & 94 \\
2008 & 389 & 339 & \\
2009 & 634 & 595 & 94 \\
2010 & 688 & 686 & 100 \\
2011 & 564 & 490 & 87 \\
Promedio & 611 & 571 & 93 \\
& & $0 \circ$ &
\end{tabular}


Tabla 352. Comparación de los promedios mensuales de las horas de calor correspondientes al periodo 20022011 para el observatorio de Plasencia.

\begin{tabular}{|c|c|c|c|}
\hline & $\begin{array}{l}\text { HC anuales } \\
\text { contadas }\end{array}$ & $\begin{array}{c}\mathrm{HC} \text { anuales } \\
\text { fórmula }\end{array}$ & $\begin{array}{c}\% \text { fórmula resp } \\
\text { a cont }\end{array}$ \\
\hline enero & 0 & 0 & \\
\hline febrero & 0 & 0 & \\
\hline marzo & 0 & 0 & \\
\hline abril & 0 & 0 & \\
\hline mayo & 14 & 11 & 78 \\
\hline junio & 127 & 112 & 89 \\
\hline julio & 216 & 194 & 90 \\
\hline agosto & 196 & 194 & 99 \\
\hline septiembre & 55 & 54 & 98 \\
\hline octubre & 8 & 7 & \\
\hline noviembre & 0 & 0 & \\
\hline diciembre & 0 & 0 & \\
\hline anual & 611 & 571 & 93 \\
\hline
\end{tabular}

Es de destacar que en agosto la fórmula da casi exactamente las horas reales.

Toledo. La fórmula de Crossa-Raynaud subestima en un $8 \%$ las horas de calor. Da en promedio un $92 \%$ de las horas reales, y por tanto es una buena aproximación.

Tabla 353.Comparación de horas de calor anuales contadas y obtenidas a partir de la fórmula para el observatorio de Toledo.

\begin{tabular}{|c|ccc|}
\hline & HC anuales contadas & HC anuales fórmula & \% fórmula resp a cont \\
\hline 2002 & 636 & 560 & 88 \\
2003 & 848 & 806 & 95 \\
2004 & 708 & 628 & 89 \\
2005 & 822 & 765 & 93 \\
2006 & 798 & 777 & 97 \\
2007 & 484 & 413 & 85 \\
2008 & 594 & 519 & 87 \\
2009 & 803 & 782 & 97 \\
2010 & 695 & 670 & 96 \\
2011 & 780 & 677 & 87 \\
Promedio & 717 & 660 & 92 \\
& & & \\
& & & \\
\end{tabular}


Tabla 354. Comparación de los promedios mensuales de las horas de calor correspondientes al periodo 20022011 para el observatorio de Toledo.

\begin{tabular}{|c|c|c|c|}
\hline & $\begin{array}{c}\text { HC anuales } \\
\text { contadas }\end{array}$ & $\begin{array}{c}\text { HC anuales } \\
\text { fórmula }\end{array}$ & $\begin{array}{c}\text { \% fórmula resp } \\
\text { a cont }\end{array}$ \\
\hline enero & 0 & 0 & \\
febrero & 0 & 0 & \\
marzo & 0 & 0 & \\
abril & 1 & 0 & 81 \\
\hline mayo & 22 & 17 & 89 \\
junio & 152 & 135 & 94 \\
julio & 247 & 233 & 96 \\
agosto & 220 & 212 & 86 \\
\hline septiembre & 69 & 59 & \\
\hline octubre & 6 & 4 & \\
\hline noviembre & 0 & 0 & 92 \\
diciembre & 0 & 0 & \\
anual & 717 & 660 & \\
\hline
\end{tabular}

En julio y agosto apenas hay subestima de las horas reales.

Trujillo. La fórmula de Crossa-Raynaud subestima las horas de calor, en promedio da un $84 \%$ de las horas reales y, por tanto, no es una mala aproximación.

Tabla 355. Comparación de horas de calor anuales contadas y obtenidas a partir de la fórmula para el observatorio de Trujillo.

$\mathrm{HC}$ anuales contadas $\mathrm{HC}$ anuales fórmula \% fórmula resp a cont

\begin{tabular}{|c|ccc|}
\hline 2002 & & & \\
2003 & 671 & 561 & 82 \\
2004 & 694 & 568 & 86 \\
2005 & 774 & 668 & 91 \\
2006 & 848 & 772 & 83 \\
2007 & 399 & 330 & 80 \\
2008 & 409 & 325 & 83 \\
2009 & 633 & 523 & 83 \\
2010 & 724 & 602 & 76 \\
2011 & 511 & 387 & 84 \\
Promedio & 629 & 526 & 84 \\
& & &
\end{tabular}


Tabla 356. Comparación de los promedios mensuales de las horas de calor correspondientes al periodo 20022011 para el observatorio de Trujillo.

\begin{tabular}{|c|c|c|c|}
\hline & $\begin{array}{l}\text { HC anuales } \\
\text { contadas }\end{array}$ & $\begin{array}{l}\text { HC anuales } \\
\text { fórmula }\end{array}$ & $\begin{array}{c}\% \text { fórmula resp a } \\
\text { cont }\end{array}$ \\
\hline enero & 0 & 0 & \\
\hline febrero & 0 & 0 & \\
\hline marzo & 0 & 0 & \\
\hline abril & 0 & 0 & \\
\hline mayo & 15 & 9 & 65 \\
\hline junio & 125 & 103 & 82 \\
\hline julio & 216 & 183 & 85 \\
\hline agosto & 207 & 179 & 86 \\
\hline septiembre & 60 & 49 & 81 \\
\hline octubre & 6 & 3 & \\
\hline noviembre & 0 & 0 & \\
\hline diciembre & 0 & 0 & \\
\hline anual & 629 & 526 & 84 \\
\hline
\end{tabular}

Puede concluirse que en la parte media de la cuenca, entre 700 y 500 m, la aproximación es mala; la diferencia entre las dos medidas es superior al 20\%, y muy dispar entre los distintos años. En la parte más baja, por debajo de $500 \mathrm{~m}$ de altitud, el cálculo de las horas de calor por la fórmula de Crossa-Raynaud subestima entre el $10 \%$ y el $20 \%$ las horas de calor reales y es menos dispar; puede considerarse una aproximación aceptable siempre que se tenga en cuenta ese dato.

\subsubsection{Cuenca del Guadiana: a) parte alta situada en la meseta Sur, principalmente La Mancha:}

Alcázar de San Juan. Sólo tiene 4 años de datos y en ellos la fórmula subestima en torno al $20 \%$ en los valores reales. 
Tabla 357. Comparación de horas de calor anuales contadas y obtenidas a partir de la fórmula para el observatorio de Alcazar de San Juan.

\begin{tabular}{|c|ccc|}
\hline & HC anuales contadas & HC anuales fórmula & \% fórmula resp a cont \\
\hline 2002 & & & \\
2003 & & & \\
2004 & & & 74 \\
2005 & & & 85 \\
2006 & 589 & 433 & 91 \\
2007 & 793 & 674 & 82 \\
2008 & 666 & 609 & \\
2009 & 730 & 596 & \\
2010 & & & \\
2011 & & & \\
\hline Promedio & & & \\
\hline
\end{tabular}

Almagro. La fórmula subestima las horas de calor en un $14 \%$, da en promedio un $86 \%$ de las horas reales. Por tanto es una aproximación aceptable.

Tabla 358. Comparación de horas de calor anuales contadas y obtenidas a partir de la fórmula para el observatorio de Almagro.

\begin{tabular}{|c|ccc|}
\hline \multicolumn{2}{|c|}{ HC anuales contadas } & HC anuales fórmula & \% fórmula resp a cont \\
\hline 2002 & & & \\
2003 & 767 & 676 & 88 \\
2004 & 727 & 618 & 85 \\
2005 & 817 & 694 & 85 \\
2006 & 810 & 691 & 85 \\
2007 & 504 & 423 & 84 \\
2008 & 571 & 483 & 85 \\
2009 & 851 & 738 & 87 \\
2010 & 728 & 650 & 89 \\
2011 & 722 & 632 & 88 \\
\hline Promedio & 722 & 623 & 86
\end{tabular}


Tabla 359. Comparación de los promedios mensuales de las horas de calor correspondientes al periodo 2002 2011 para el observatorio de Almagro.

\begin{tabular}{|c|c|c|c|}
\hline & $\begin{array}{c}\text { HC anuales } \\
\text { contadas }\end{array}$ & $\begin{array}{c}\text { HC anuales } \\
\text { fórmula }\end{array}$ & $\begin{array}{c}\text { \% fórmula resp } \\
\text { a cont }\end{array}$ \\
\hline enero & 0 & 0 & \\
\hline febrero & 0 & 0 & \\
\hline marzo & 0 & 0 & \\
\hline abril & 0 & 0 & 74 \\
\hline mayo & 21 & 15 & 81 \\
\hline junio & 149 & 121 & 89 \\
\hline julio & 259 & 229 & 90 \\
\hline agosto & 228 & 204 & 81 \\
\hline septiembre & 62 & 50 & 57 \\
\hline octubre & 4 & 2 & \\
\hline noviembre & 0 & 0 & \\
\hline diciembre & 0 & 0 & 86 \\
\hline Anual & 722 & 623 & \\
\hline
\end{tabular}

Sin embargo en los meses en los que hay más horas de calor la aproximación es mejor, del $90 \%$.

Ciudad Real. La fórmula subestima las horas de calor en un $12 \%$, da en promedio un $88 \%$ de las horas reales. Por tanto, es una aproximación aceptable.

Tabla 360. Comparación de horas de calor anuales contadas y obtenidas a partir de la fórmula para el observatorio de Ciudad Real.

$\mathrm{HC}$ anuales contadas

$\mathrm{HC}$ anuales fórmula \% fórmula resp a cont

\begin{tabular}{|c|ccc|}
\hline 2002 & 636 & 551 & 87 \\
2003 & 789 & 688 & 87 \\
2004 & 733 & 635 & 87 \\
2005 & 817 & 716 & 88 \\
2006 & 821 & 754 & 92 \\
2007 & 507 & 435 & 86 \\
2008 & 582 & 490 & 84 \\
2009 & 846 & 760 & 90 \\
2010 & 754 & 686 & 91 \\
2011 & 727 & 635 & 87 \\
promedio & 721 & 635 & 88
\end{tabular}


Tabla 361.Comparación de los promedios mensuales de las horas de calor correspondientes al periodo 2002-2011 para el observatorio de Ciudad Real.

\begin{tabular}{|c|c|c|c|}
\hline & $\begin{array}{c}\text { HC anuales } \\
\text { contadas }\end{array}$ & $\begin{array}{c}\text { HC anuales } \\
\text { fórmula }\end{array}$ & $\begin{array}{c}\text { \% fórmula resp } \\
\text { a cont }\end{array}$ \\
\hline enero & 0 & 0 & \\
febrero & 0 & 0 & \\
marzo & 0 & 0 & \\
abril & 0 & 0 & 71 \\
mayo & 22 & 16 & 85 \\
junio & 154 & 132 & 91 \\
julio & 258 & 235 & 91 \\
agosto & 226 & 206 & 80 \\
\hline septiembre & 56 & 45 & \\
\hline octubre & 4 & 3 & \\
\hline noviembre & 0 & 0 & 88 \\
diciembre & 0 & 0 & \\
\hline anual & 721 & 635 & \\
\hline
\end{tabular}

Sin embargo en los meses en los que hay más horas de calor, julio y agosto, la aproximación es mejor, del $91 \%$.

Hinojosa del Duque. La fórmula subestima las horas de calor en un 18\%, da en promedio un $82 \%$ de las horas reales. Por tanto, no es una buena aproximación.

Tabla 362. Comparación de horas de calor anuales contadas y obtenidas a partir de la fórmula para el observatorio de Hinojosa del Duque.

$\mathrm{HC}$ anuales contadas $\quad \mathrm{HC}$ anuales fórmula \% fórmula resp a cont

\begin{tabular}{|c|c|c|c|}
\hline 2002 & 699 & 514 & 73 \\
\hline 2003 & 880 & 704 & 80 \\
\hline 2004 & & 700 & \\
\hline 2005 & 905 & 715 & 79 \\
\hline 2006 & 878 & 741 & 84 \\
\hline 2007 & 585 & 458 & 78 \\
\hline 2008 & 605 & 485 & 80 \\
\hline 2009 & 867 & 746 & 86 \\
\hline 2010 & 840 & 731 & 87 \\
\hline 2011 & 836 & 658 & 79 \\
\hline promedio & 788 & 645 & 82 \\
\hline
\end{tabular}


Tabla 363. Comparación de los promedios mensuales de las horas de calor correspondientes al periodo 2002 2011 para el observatorio de Hinojosa del Duque.

\begin{tabular}{|c|c|c|c|}
\hline & $\begin{array}{c}\text { HC anuales } \\
\text { contadas }\end{array}$ & $\begin{array}{l}\text { HC anuales } \\
\text { fórmula }\end{array}$ & $\begin{array}{c}\% \text { fórmula resp } \\
\text { a cont }\end{array}$ \\
\hline \multirow{2}{*}{$\begin{array}{c}\text { enero } \\
\text { febrero }\end{array}$} & 0 & 0 & \\
\hline & 0 & 0 & \\
\hline \multirow{2}{*}{$\begin{array}{l}\text { marzo } \\
\text { abril }\end{array}$} & 0 & 0 & \\
\hline & 1 & 0 & \\
\hline mayo & 26 & 16 & 62 \\
\hline junio & 166 & 130 & 78 \\
\hline julio & 272 & 226 & 83 \\
\hline agosto & 257 & 214 & 83 \\
\hline septiembre & 66 & 56 & 84 \\
\hline octubre & 8 & 4 & \\
\hline noviembre & 0 & 0 & \\
\hline diciembre & 0 & 0 & \\
\hline anual & 788 & 645 & 82 \\
\hline
\end{tabular}

La subestima de los meses de más horas de calor es similar a la anual, no es buena aproximación.

\subsubsection{Cuenca del Guadiana: b) parte baja y relativamente llana de la cuenca}

Nota. No se ha hecho la comparación de horas de calor contadas y por fórmula para el observatorio de Badajoz CMT por falta de datos.

Talavera La Real. La fórmula subestima en promedio un 7\% las Tabla de comparación de horas de calor anuales y, por tanto, es una buena aproximación.

Tabla 364. Comparación de horas de calor anuales contadas y obtenidas a partir de la fórmula para el observatorio de Talavera La Real.

\begin{tabular}{|c|c|c|c|}
\hline & HC anuales contadas & $\mathrm{HC}$ anuales fórmula & $\%$ fórmula resp a cont \\
\hline 2002 & 594 & 519 & 87 \\
\hline 2003 & 766 & 718 & 94 \\
\hline 2004 & 736 & 696 & 95 \\
\hline 2005 & 804 & 761 & 95 \\
\hline 2006 & 797 & 734 & 92 \\
\hline 2007 & 567 & 490 & 86 \\
\hline 2008 & 576 & 505 & 88 \\
\hline 2009 & 782 & 757 & 97 \\
\hline 2010 & 823 & 816 & 99 \\
\hline 2011 & 719 & 638 & 89 \\
\hline Promedio & 716 & 664 & 93 \\
\hline
\end{tabular}


Tabla 365. Comparación de los promedios mensuales de las horas de calor correspondientes al periodo 20022011 para el observatorio de Talavera La Real.

\begin{tabular}{|c|c|c|c|}
\hline & $\begin{array}{c}\text { HC anuales } \\
\text { contadas }\end{array}$ & $\begin{array}{c}\text { HC anuales } \\
\text { fórmula }\end{array}$ & $\begin{array}{c}\text { \% fórmula resp } \\
\text { a cont }\end{array}$ \\
\hline enero & 0 & 0 & \\
\hline febrero & 0 & 0 & \\
marzo & 0 & 0 & \\
\hline abril & 4 & 3 & 76 \\
\hline mayo & 36 & 27 & 91 \\
\hline junio & 143 & 131 & 94 \\
\hline julio & 221 & 208 & 96 \\
\hline agosto & 219 & 211 & 91 \\
\hline septiembre & 83 & 75 & \\
\hline octubre & 11 & 8 & \\
\hline noviembre & 0 & 0 & \\
\hline diciembre & 0 & 664 & 93 \\
\hline anual & 716 & 0 & \\
\hline
\end{tabular}

En los meses de más horas de calor, julio y agosto, la aproximación es aún mejor, la subestima es sólo de un $6 \%$ y un $4 \%$ respectivamente.

Mérida. La fórmula subestima en promedio un $8 \%$ las horas de calor anuales y, por tanto, es una buena aproximación.

Tabla 366. Comparación de horas de calor anuales contadas y obtenidas a partir de la fórmula para el observatorio de Mérida.

\begin{tabular}{|c|c|c|c|}
\hline & HC anuales contadas & HC anuales fórmula & $\%$ fórmula resp a cont \\
\hline 2002 & 637 & 515 & 81 \\
\hline 2003 & 900 & 789 & 88 \\
\hline 2004 & 755 & 695 & 92 \\
\hline 2005 & 841 & 774 & 92 \\
\hline 2006 & 817 & 797 & 98 \\
\hline 2007 & & & \\
\hline 2008 & & & \\
\hline 2009 & 767 & 698 & 91 \\
\hline 2010 & 817 & 800 & 98 \\
\hline 2011 & 737 & 623 & 85 \\
\hline Promedio & 774 & 711 & 92 \\
\hline
\end{tabular}


Tabla 367. Comparación de los promedios mensuales de las horas de calor correspondientes al periodo 20022011 para el observatorio de Mérida.

\begin{tabular}{|c|c|c|c|}
\hline & $\begin{array}{l}\text { HC anuales } \\
\text { contadas }\end{array}$ & $\begin{array}{l}\text { HC anuales } \\
\text { fórmula }\end{array}$ & $\begin{array}{c}\% \text { fórmula resp a } \\
\text { cont }\end{array}$ \\
\hline enero & 0 & 0 & \\
\hline febrero & 0 & 0 & \\
\hline marzo & 0 & 0 & \\
\hline abril & 4 & 3 & \\
\hline mayo & 38 & 27 & 72 \\
\hline junio & 148 & 130 & 88 \\
\hline julio & 227 & 206 & 91 \\
\hline agosto & 234 & 221 & 94 \\
\hline septiembre & 87 & 79 & 90 \\
\hline octubre & 14 & 12 & \\
\hline noviembre & 0 & 0 & \\
\hline diciembre & 0 & 0 & \\
\hline anual & 774 & 711 & 92 \\
\hline
\end{tabular}

La aproximación es buena en los meses de más horas de calor, julio y agosto.

\section{Resumen para la cuenca del Guadiana}

En la parte media de la cuenca, la aproximación que da la fórmula subestima los valores reales en algo más del $10 \%$ pero, teniendo en cuenta que en los meses de más calor se aproxima a más del $90 \%$ de los valores tomados de datos horarios, se considera una aproximación aceptable. En la parte baja de la cuenca, la aproximación es buena; lo obtenido por medio de la fórmula es más del $90 \%$ de lo que se obtiene con datos horarios, tanto en valores anuales como en los meses de más calor, y la disparidad entre unos años y otros es baja.

\subsubsection{Cuenca del Guadalquivir: a) parte baja y relativamente llana de la cuenca}

Sevilla San Pablo. No son fiables los resultados por la gran diferencia de lo que sucede en unos años y otros, de no haber subestima en algunos años se pasa a una subestima superior al $40 \%$ en otros. 
Tabla 368. Comparación de horas de calor anuales contadas y obtenidas a partir de la fórmula para el observatorio de Sevilla San Pablo.

$\mathrm{HC}$ anuales contadas $\quad \mathrm{HC}$ anuales fórmula \% fórmula resp a cont

\begin{tabular}{|c|ccc|}
\hline 2002 & 693 & 659 & 95 \\
2003 & 1048 & 1049 & 100 \\
2004 & 1050 & 802 & 76 \\
2005 & 1017 & 1020 & 100 \\
2006 & 1020 & 1066 & 105 \\
2007 & 796 & 490 & 62 \\
2008 & 859 & 505 & 59 \\
2009 & 1072 & 757 & 71 \\
2010 & 1045 & 816 & 78 \\
2011 & 1091 & 638 & 58 \\
\hline Promedio & 969 & 780 & 80
\end{tabular}

Tabla 369.Comparación de los promedios mensuales de las horas de calor correspondientes al periodo 2002-2011 para el observatorio de Sevilla San Pablo.

\begin{tabular}{|c|c|c|c|}
\hline & $\begin{array}{c}\text { HC anuales } \\
\text { contadas }\end{array}$ & $\begin{array}{l}\mathrm{HC} \text { anuales } \\
\text { fórmula }\end{array}$ & $\begin{array}{c}\% \text { fórmula resp } \\
\text { a cont }\end{array}$ \\
\hline enero & 0 & 0 & \\
\hline febrero & 0 & 0 & \\
\hline marzo & 0 & 0 & \\
\hline Abril & 7 & 4 & 54 \\
\hline mayo & 59 & 40 & 69 \\
\hline junio & 185 & 142 & 77 \\
\hline Julio & 297 & 255 & 86 \\
\hline agosto & 279 & 244 & 87 \\
\hline septiembre & 121 & 97 & 80 \\
\hline octubre & 22 & 12 & 55 \\
\hline noviembre & 0 & 0 & \\
\hline diciembre & 0 & 0 & \\
\hline anual & 969 & 780 & 80 \\
\hline
\end{tabular}

Écija. La subestima es un poco superior al $10 \%$ en promedio, pero hay una enormes diferencias entre unos años y otros, de dar un $111 \%$ (sobrestima) del valor sobre datos horarios en el año 2006 se pasa a un $72 \%$ (subestima) en el año 2007. 
Tabla 370. Comparación de horas de calor anuales contadas y obtenidas a partir de la fórmula para el observatorio de Écija.

\begin{tabular}{|c|c|c|c|}
\hline & HC anuales contadas & HC anuales fórmula & \% fórmula resp a cont \\
\hline 2002 & 708 & 548 & 77 \\
\hline 2003 & 1099 & 994 & 90 \\
\hline 2004 & 987 & 867 & 88 \\
\hline 2005 & 830 & 703 & 85 \\
\hline 2006 & 831 & 919 & 111 \\
\hline 2007 & 979 & 706 & 72 \\
\hline 2008 & 841 & 747 & 89 \\
\hline 2009 & 1027 & 931 & 91 \\
\hline 2010 & 912 & 835 & 104 \\
\hline 2011 & 883 & 789 & 89 \\
\hline Promedio & 910 & 804 & 89 \\
\hline
\end{tabular}

Tabla 371. Comparación de los promedios mensuales de las horas de calor correspondientes al periodo 20022011 para el observatorio de Écija.

$\begin{array}{ccc}\text { HC anuales } & \text { HC anuales } & \% \text { fórmula resp } \\ \text { contadas } & \text { fórmula } & \text { a cont }\end{array}$

\begin{tabular}{|c|c|c|c|}
\hline enero & 0 & 0 & \\
\hline febrero & 0 & 0 & \\
\hline marzo & 0 & 0 & \\
\hline abril & 2 & 1 & 63 \\
\hline mayo & 44 & 28 & 84 \\
\hline junio & 178 & 150 & 91 \\
\hline julio & 295 & 269 & 95 \\
\hline agosto & 271 & 257 & 83 \\
\hline septiembre & 106 & 88 & \\
\hline octubre & 17 & 11 & 89 \\
\hline noviembre & 0 & 0 & \\
\hline diciembre & 0 & 804 & \\
\hline anual & 910 & 0 & \\
\hline
\end{tabular}

Los promedios mensuales de los meses de más horas de calor se aproximan a los valores reales, la subestima es menor del $10 \%$. 
Aeropuerto de Córdoba. La subestima en los valores anuales es del $8 \%$ y por tanto es una buena aproximación.

Tabla 372. Comparación de horas de calor anuales contadas y obtenidas a partir de la fórmula para el observatorio del aeropuerto de Córdoba.

$\mathrm{HC}$ anuales contadas

$\mathrm{HC}$ anuales fórmula

\% fórmula resp a cont

\begin{tabular}{|c|ccc|}
2002 & 753 & 671 & 89 \\
2003 & 1103 & 1028 & 93 \\
2004 & 1050 & 975 & 93 \\
2005 & 1102 & 997 & 90 \\
2006 & 1092 & 1044 & 96 \\
2007 & 886 & 792 & 89 \\
2008 & 896 & 802 & 90 \\
2009 & 1107 & 1020 & 92 \\
2010 & 972 & 935 & 96 \\
2011 & 1009 & 891 & 88 \\
Promedio & 997 & 916 & 92
\end{tabular}

Tabla 373. Comparación de los promedios mensuales de las horas de calor correspondientes al periodo 20022011 para el observatorio del aeropuerto de Córdoba.
$\mathrm{HC}$ anuales
contadas
HC anuales \% fórmula resp
fórmula a cont

\begin{tabular}{|c|c|c|c|}
\hline enero & 0 & 0 & \\
\hline febrero & 0 & 0 & \\
\hline marzo & 0 & 0 & 75 \\
\hline abril & 4 & 3 & 69 \\
mayo & 55 & 38 & 87 \\
junio & 192 & 168 & 93 \\
julio & 314 & 293 & 99 \\
agosto & 290 & 289 & 90 \\
septiembre & 121 & 109 & 82 \\
\hline octubre & 19 & 16 & \\
\hline noviembre & 0 & 0 & 92 \\
\hline diciembre & 0 & 0 & \\
anual & 997 & 916 & \\
\hline
\end{tabular}

En los meses en los que hay más horas de calor, julio y agosto, la aproximación que da la fórmula es aún mejor. 
Base aérea de Morón de la Frontera. La subestima en los valores anuales es del 7\% y por tanto es una buena aproximación.

Tabla 374. Comparación de horas de calor anuales contadas y obtenidas a partir de la fórmula para el observatorio de la base aérea de Morón de la Frontera. $\mathrm{HC}$ anuales contadas $\quad \mathrm{HC}$ anuales fórmula \% fórmula resp a cont

\begin{tabular}{|c|ccc|}
\hline 2002 & 575 & 469 & 82 \\
2003 & 896 & 813 & 91 \\
2004 & 883 & 810 & 92 \\
2005 & 852 & 759 & 89 \\
2006 & 853 & 824 & 97 \\
2007 & 645 & 578 & 90 \\
2008 & 733 & 647 & 88 \\
2009 & 890 & 857 & 96 \\
2010 & 862 & 882 & 102 \\
2011 & 906 & 858 & 95 \\
Promedio & 810 & 750 & 93
\end{tabular}

Tabla 375. Comparación de los promedios mensuales de las horas de calor correspondientes al periodo 20022011 para el observatorio de la base aérea de Morón de la Frontera.

\begin{tabular}{|c|c|c|c|}
\hline & $\begin{array}{c}\text { HC anuales } \\
\text { contadas }\end{array}$ & $\begin{array}{c}\text { HC anuales } \\
\text { fórmula }\end{array}$ & $\begin{array}{c}\text { \% fórmula resp } \\
\text { a cont }\end{array}$ \\
\hline enero & 0 & 0 & \\
febrero & 0 & 0 & \\
marzo & 0 & 0 & 49 \\
abril & 4 & 2 & 63 \\
mayo & 41 & 26 & 88 \\
\hline junio & 148 & 129 & 97 \\
julio & 254 & 245 & 101 \\
\hline agosto & 240 & 243 & 86 \\
\hline septiembre & 103 & 89 & 74 \\
\hline octubre & 20 & 15 & \\
\hline noviembre & 0 & 0 & \\
\hline diciembre & 0 & 0 & 93 \\
\hline anual & 810 & 750 & \\
\hline
\end{tabular}

En los meses en los que hay más horas de calor, julio y agosto, la aproximación que da la fórmula es aún mejor. En agosto, en promedio, ni siquiera hay subestima. 
Granada. La aproximación que da la fórmula es muy buena, del $94 \%$.

Tabla 376. Comparación de horas de calor anuales contadas y obtenidas a partir de la fórmula para el observatorio de Granada.

\begin{tabular}{|c|ccc|}
\hline & HC anuales contadas & HC anuales fórmula & $\%$ fórmula resp a cont \\
\hline 2002 & 488 & 445 & 91 \\
2003 & 641 & 624 & 97 \\
2004 & 672 & 628 & 93 \\
2005 & 625 & 612 & 98 \\
2006 & 663 & 625 & 94 \\
2007 & 477 & 446 & 94 \\
2008 & 532 & 500 & 94 \\
2009 & 697 & 648 & 93 \\
2010 & 617 & 580 & 94 \\
2011 & 588 & 528 & 90 \\
promedio & 600 & 564 & 94 \\
\hline
\end{tabular}

Tabla 377. Comparación de los promedios mensuales de las horas de calor correspondientes al periodo 20022011 para el observatorio de Granada.

\begin{tabular}{|c|c|c|c|}
\hline & $\begin{array}{c}\text { HC anuales } \\
\text { contadas }\end{array}$ & $\begin{array}{l}\mathrm{HC} \text { anuales } \\
\text { fórmula }\end{array}$ & $\begin{array}{c}\% \text { fórmula resp } \\
\text { a cont }\end{array}$ \\
\hline enero & 0 & 0 & \\
\hline febrero & 0 & 0 & \\
\hline marzo & 0 & 0 & \\
\hline abril & 0 & 0 & \\
\hline mayo & 14 & 10 & 72 \\
\hline junio & 122 & 108 & 88 \\
\hline julio & 228 & 214 & 94 \\
\hline agosto & 189 & 187 & 99 \\
\hline septiembre & 42 & 40 & 97 \\
\hline octubre & 5 & 4 & \\
\hline noviembre & 0 & 0 & \\
\hline diciembre & 0 & 0 & \\
\hline anual & 600 & 564 & 94 \\
\hline
\end{tabular}

Y en los meses de más calor, julio y agosto, la aproximación es aún mejor, del 94 \% y 99\% respectivamente. 
La aproximación que da la fórmula a las horas de calor es muy buena en toda la cuenca, al menos en valles por debajo de $800 \mathrm{~m}$ de altitud, tanto en los valores anuales como en los meses de más calor, julio y agosto; y se da poca disparidad entre unos años y otros.

\subsubsection{Levante: a) franja costera de Levante: huerta levantina}

Castellón. La fórmula de Crossa-Raynaud subestima las horas de calor, en promedio da un $84 \%$ de las horas reales, y por tanto no es una mala aproximación.

Tabla 378. Comparación de horas de calor anuales contadas y obtenidas a partir de la fórmula para el observatorio de Castellón.

\begin{tabular}{|c|ccc|}
\hline \multicolumn{2}{|c|}{ HC anuales contadas } & HC anuales fórmula & \% fórmula resp a cont \\
\hline 2002 & 104 & 84 & 81 \\
2003 & 560 & 508 & 91 \\
2004 & 255 & 231 & 91 \\
2005 & 271 & 223 & 82 \\
2006 & 270 & 235 & 87 \\
2007 & 144 & 123 & 85 \\
2008 & 171 & 151 & 88 \\
2009 & 258 & 201 & 78 \\
2010 & 229 & 187 & 82 \\
2011 & 198 & 128 & 64 \\
Promedio & 246 & 207 & 84 \\
\hline
\end{tabular}

Tabla 379. Comparación de los promedios mensuales de las horas de calor correspondientes al periodo 20022011 para el observatorio de Castellón.

\begin{tabular}{|c|c|c|c|}
\hline 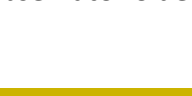 & $\begin{array}{l}\text { HC anuales } \\
\text { contadas }\end{array}$ & $\begin{array}{l}\text { HC anuales } \\
\text { fórmula }\end{array}$ & $\begin{array}{c}\% \text { fórmula resp } \\
\text { a cont }\end{array}$ \\
\hline enero & 0 & 0 & \\
\hline febrero & 0 & 0 & \\
\hline marzo & 0 & 0 & \\
\hline abril & 0 & 0 & \\
\hline mayo & 3 & 2 & 90 \\
\hline junio & 39 & 34 & 87 \\
\hline julio & 91 & 75 & 82 \\
\hline agosto & 98 & 84 & 86 \\
\hline septiembre & 15 & 11 & 76 \\
\hline octubre & 1 & 0 & \\
\hline noviembre & 0 & 0 & \\
\hline diciembre & 0 & 0 & \\
\hline anual & 246 & 207 & 84 \\
\hline
\end{tabular}


Valencia. La fórmula de Crossa-Raynaud sobrestima las horas de calor, da en promedio un $127 \%$ de las horas reales, y por tanto es una mala aproximación.

Tabla 380. Comparación de horas de calor anuales contadas y obtenidas a partir de la fórmula para el observatorio de Valencia.

\begin{tabular}{|c|ccc|}
\hline & HC anuales contadas & HC anuales fórmula & \% fórmula resp a cont \\
\hline 2002 & 83 & 88 & 106 \\
2003 & 497 & 517 & 104 \\
2004 & 218 & 254 & 116 \\
2005 & & & 201 \\
2006 & 62 & 125 & 121 \\
2007 & 73 & 88 & 174 \\
2008 & 58 & 101 & 171 \\
2009 & 89 & 152 & 151 \\
2010 & 87 & 132 & 184 \\
2011 & 53 & 97 & 127 \\
\hline Promedio & 136 & 172 & \\
\hline
\end{tabular}

Tabla 381. Comparación de los promedios mensuales de las horas de calor correspondientes al periodo 20022011 para el observatorio de Valencia.

$\begin{array}{ccc}\text { HC anuales } & \text { HC anuales } & \% \text { fórmula resp } \\ \text { contadas } & \text { fórmula } & \text { a cont }\end{array}$

\begin{tabular}{|c|c|c|c|}
\hline enero & 0 & 0 & \\
\hline febrero & 0 & 0 & \\
\hline marzo & 0 & 0 & \\
\hline abril & 0 & 0 & 101 \\
mayo & 3 & 3 & 113 \\
\hline junio & 21 & 24 & 146 \\
\hline julio & 35 & 51 & 121 \\
\hline agosto & 66 & 80 & 148 \\
\hline septiembre & 9 & 13 & \\
\hline octubre & 2 & 2 & \\
\hline noviembre & 0 & 0 & 127 \\
\hline diciembre & 0 & 0 & \\
anual & 136 & 173 & \\
\hline
\end{tabular}

Valencia Manises. La fórmula de Crossa-Raynaud subestima las horas de calor en un 11\%; da en promedio un $89 \%$ de las horas reales, y por tanto no es una mala aproximación. 
Tabla 382. Comparación de horas de calor anuales contadas y obtenidas a partir de la fórmula para el observatorio de Valencia Manises.

$\mathrm{HC}$ anuales contadas $\quad \mathrm{HC}$ anuales fórmula \% fórmula resp a cont

\begin{tabular}{|c|ccc|}
\hline 2002 & 89 & 98 & 110 \\
2003 & 490 & 467 & 95 \\
2004 & 243 & 250 & 103 \\
2005 & 289 & 214 & 74 \\
2006 & 416 & 356 & 86 \\
2007 & 159 & 146 & 92 \\
2008 & 288 & 229 & 79 \\
2009 & 245 & 222 & 91 \\
2010 & 213 & 179 & 84 \\
2011 & 135 & 118 & 87 \\
\hline Promedio & 257 & 228 & 89
\end{tabular}

Tabla 383. Comparación de los promedios mensuales de las horas de calor correspondientes al periodo 20022011 para el observatorio de Valencia Manises.

\begin{tabular}{|c|c|c|c|}
\hline & $\begin{array}{l}\text { HC anuales } \\
\text { contadas }\end{array}$ & $\begin{array}{l}\text { HC anuales } \\
\text { fórmula }\end{array}$ & $\begin{array}{c}\% \text { fórmula resp a } \\
\text { cont }\end{array}$ \\
\hline enero & 0 & 0 & \\
\hline febrero & 0 & 0 & \\
\hline marzo & 0 & 0 & \\
\hline abril & 0 & 1 & \\
\hline mayo & 5 & 4 & 88 \\
\hline junio & 37 & 33 & 89 \\
\hline julio & 90 & 77 & 86 \\
\hline agosto & 105 & 95 & 90 \\
\hline septiembre & 18 & 16 & 92 \\
\hline octubre & 2 & 2 & \\
\hline noviembre & 0 & 0 & \\
\hline diciembre & 0 & 0 & \\
\hline anual & 257 & 228 & 89 \\
\hline
\end{tabular}

Alicante. La fórmula de Crossa-Raynaud sobrestima las horas de calor, en promedio da un $108 \%$ de las horas reales. Es una buena aproximación. 
Tabla 384. Comparación de horas de calor anuales contadas y obtenidas a partir de la fórmula para el observatorio de Alicante.

\begin{tabular}{|c|ccc|}
\hline & HC anuales contadas & HC anuales fórmula & $\%$ fórmula resp a cont \\
\hline 2002 & 72 & 72 & 100 \\
2003 & 458 & 445 & 97 \\
2004 & 213 & 242 & 114 \\
2005 & 175 & 194 & 111 \\
2006 & 233 & 233 & 100 \\
2007 & 168 & 170 & 101 \\
2008 & 166 & 195 & 118 \\
2009 & 216 & 288 & 133 \\
2010 & 206 & 222 & 108 \\
2011 & 223 & 245 & 110 \\
Promedio & 213 & 231 & 108
\end{tabular}

Tabla 385. Comparación de los promedios mensuales de las horas de calor correspondientes al periodo 20022011 para el observatorio de Alicante.

\begin{tabular}{|c|c|c|c|}
\hline & $\begin{array}{c}\text { HC anuales } \\
\text { contadas }\end{array}$ & $\begin{array}{c}\text { HC anuales } \\
\text { fórmula }\end{array}$ & $\begin{array}{c}\text { \% fórmula resp } \\
\text { a cont }\end{array}$ \\
\hline enero & 0 & 0 & \\
febrero & 0 & 0 & \\
\hline marzo & 0 & 0 & \\
\hline abril & 0 & 0 & 140 \\
\hline mayo & 2 & 3 & 105 \\
\hline junio & 28 & 29 & 112 \\
\hline julio & 70 & 78 & 103 \\
\hline agosto & 92 & 94 & 123 \\
\hline septiembre & 20 & 24 & \\
\hline octubre & 2 & 2 & \\
\hline noviembre & 0 & 0 & 108 \\
\hline diciembre & 0 & 0 & \\
\hline anual & 213 & 231 & \\
\hline
\end{tabular}

Alicante El Altet. La fórmula de Crossa-Raynaud subestima las horas de calor en un $8 \%$ en promedio. Da un $92 \%$ de las horas reales, y por tanto es una buena aproximación. 
Tabla 386. Comparación de horas de calor anuales contadas y obtenidas a partir de la fórmula para el observatorio de Alicante El Altet.

$\mathrm{HC}$ anuales contadas $\quad \mathrm{HC}$ anuales fórmula \% fórmula resp a cont

\begin{tabular}{|c|ccc|}
\hline 2002 & 29 & 57 & 197 \\
2003 & 486 & 401 & 83 \\
2004 & 216 & 203 & 94 \\
2005 & 148 & 140 & 94 \\
2006 & 139 & 121 & 87 \\
2007 & 80 & 79 & 99 \\
2008 & 98 & 95 & 97 \\
2009 & 113 & 105 & 93 \\
2010 & 166 & 160 & 97 \\
2011 & 214 & 199 & 93 \\
Promedio & 169 & 156 & 92
\end{tabular}

Tabla 387. Comparación de los promedios mensuales de las horas de calor correspondientes al periodo 20022011 para el observatorio de El Altet.

\begin{tabular}{|c|c|c|c|}
\hline & $\begin{array}{c}\text { HC anuales } \\
\text { contadas }\end{array}$ & $\begin{array}{l}\mathrm{HC} \text { anuales } \\
\text { fórmula }\end{array}$ & $\begin{array}{l}\text { \% fórmula } \\
\text { resp a cont }\end{array}$ \\
\hline enero & 0 & 0 & \\
\hline febrero & 0 & 0 & \\
\hline marzo & 0 & 0 & \\
\hline abril & 1 & 0 & \\
\hline mayo & 1 & 2 & 133 \\
\hline junio & 22 & 20 & 92 \\
\hline julio & 55 & 50 & 91 \\
\hline agosto & 74 & 66 & 90 \\
\hline septiembre & 15 & 16 & 109 \\
\hline octubre & 2 & 1 & \\
\hline noviembre & 0 & 0 & \\
\hline diciembre & 0 & 0 & \\
\hline anual & 169 & 156 & 92 \\
\hline
\end{tabular}

\subsubsection{Levante: a) huerta murciana}

Base aérea de San Javier. A pesar de las pocas horas de calor, la fórmula en promedio aproxima bien a las horas anuales, sin embargo si se toma año por año, se dan sobrestimas del $137 \%$ y subestimas del $83 \%$. 
Tabla 388. Comparación de horas de calor anuales contadas y obtenidas a partir de la fórmula para el observatorio de la base aérea de San Javier.

\begin{tabular}{|c|c|c|c|}
\hline & HC anuales contadas & HC anuales fórmula & \% fórmula resp a cont \\
\hline 2002 & 32 & 44 & 137 \\
\hline 2003 & 199 & 219 & 110 \\
\hline 2004 & 126 & 121 & 96 \\
\hline 2005 & 75 & 85 & 113 \\
\hline 2006 & 95 & 98 & 103 \\
\hline \multicolumn{4}{|l|}{2007} \\
\hline 2008 & 119 & 121 & 102 \\
\hline 2009 & 137 & 131 & 95 \\
\hline 2010 & 71 & 72 & 102 \\
\hline 2011 & 148 & 122 & 83 \\
\hline promedio & 119 & 111 & 94 \\
\hline
\end{tabular}

Tabla 389. Comparación de los promedios mensuales de las horas de calor correspondientes al periodo 20022011 para el observatorio de la base aérea de San Javier.

\begin{tabular}{|c|c|c|c|}
\hline & $\begin{array}{c}\text { HC anuales } \\
\text { contadas }\end{array}$ & $\begin{array}{c}\text { HC anuales } \\
\text { fórmula }\end{array}$ & $\begin{array}{c}\text { \% fórmula resp a } \\
\text { cont }\end{array}$ \\
\hline enero & 0 & 0 & \\
febrero & 0 & 0 & \\
\hline marzo & 0 & 0 & \\
\hline abril & 0 & 0 & 89 \\
\hline mayo & 3 & 1 & 84 \\
\hline junio & 14 & 12 & 109 \\
\hline julio & 47 & 39 & 81 \\
\hline agosto & 43 & 47 & \\
\hline septiembre & 13 & 10 & \\
\hline octubre & 0 & 1 & \\
\hline noviembre & 0 & 0 & \\
\hline diciembre & 0 & 0 & 94 \\
\hline anual & 119 & 111 & \\
\hline
\end{tabular}

También en los datos mensuales se da una gran disparidad. Un julio hay una subestima notable y en agosto una sobrestima. 
Base aérea de Alcantarilla. La aproximación que da la fórmula es excelente.

Tabla 390. Comparación de horas de calor anuales contadas y obtenidas a partir de la fórmula para el observatorio de la base aérea de Alcantarilla.

HC anuales contadas $\quad \mathrm{HC}$ anuales fórmula \% fórmula resp a cont

\begin{tabular}{|c|ccc|}
\hline 2002 & 459 & 426 & 93 \\
2003 & 871 & 847 & 97 \\
2004 & 675 & 678 & 100 \\
2005 & 636 & 611 & 96 \\
2006 & 705 & 715 & 101 \\
2007 & 569 & 540 & 95 \\
2008 & 646 & 608 & 94 \\
2009 & 771 & 734 & 95 \\
2010 & 593 & 581 & 98 \\
2011 & 734 & 721 & 98 \\
promedio & 663 & 637 & 96
\end{tabular}

Tabla 391. Comparación de los promedios mensuales de las horas de calor correspondientes al periodo 20022011 para el observatorio de la base aérea de Alcantarilla.

$\mathrm{HC}$ anuales contadas

\section{$\mathrm{HC}$ anuales \% fórmula resp fórmula a cont}

\begin{tabular}{|c|c|c|c|}
\hline enero & 0 & 0 & \\
\hline febrero & 0 & 0 & \\
\hline marzo & 0 & 0 & \\
\hline abril & 3 & 2 & 70 \\
\hline mayo & 24 & 17 & 83 \\
\hline junio & 117 & 98 & 98 \\
julio & 236 & 230 & 104 \\
agosto & 217 & 225 & 99 \\
\hline septiembre & 59 & 58 & \\
\hline octubre & 7 & 7 & \\
noviembre & 0 & 0 & \\
\hline diciembre & 0 & 0 & 96 \\
anual & 663 & 637 & \\
\hline
\end{tabular}

Totana. Sólo se pueden comparar tres años, pero en ellos la aproximación es buena, superior al $90 \%$. 
La aproximación que da la fórmula para las horas de calor, tanto anuales como las de los meses con más horas, es buena en las huertas de Murcia y Levante en altitudes por debajo de $250 \mathrm{~m}$ y fuera de la franja pegada a la costa. Al borde del mar, donde hay pocas horas de calor y se producen variaciones muy grandes entre unos años y otros, la aproximación es sólo aceptable.

\subsubsection{Costa Sur}

Málaga aeropuerto. Es el único observatorio donde la fórmula sobrestima con claridad las horas de calor sacadas de datos horarios. La fórmula da un $120 \%$ en promedio de las horas contadas. No puede considerarse una buena aproximación.

Tabla 392. Comparación de horas de calor anuales contadas y obtenidas a partir de la fórmula para el observatorio de Málaga aeropuerto.

\begin{tabular}{|c|c|c|c|}
\hline & HC anuales contadas & HC anuales fórmula & \% fórmula resp a cont \\
\hline 2002 & 197 & 224 & 114 \\
\hline 2003 & 415 & 464 & 112 \\
\hline 2004 & 234 & 278 & 119 \\
\hline 2005 & 286 & 329 & 115 \\
\hline 2006 & 230 & 276 & 120 \\
\hline 2007 & 296 & 321 & 108 \\
\hline 2008 & 266 & 351 & 132 \\
\hline 2009 & 254 & 351 & 138 \\
\hline 2010 & 199 & 263 & 132 \\
\hline 2011 & 281 & 335 & 119 \\
\hline promedio & 266 & 319 & 120 \\
\hline
\end{tabular}

En los meses de más horas de calor, julio y agosto, la aproximación es similar a la anual, se da una sobrestima del $20 \%$. 
Tabla 393. Comparación de los promedios mensuales de las horas de calor correspondientes al periodo 20022011 para el observatorio de Málaga aeropuerto.

\begin{tabular}{|c|c|c|c|}
\hline & $\begin{array}{l}\text { HC anuales } \\
\text { contadas }\end{array}$ & $\begin{array}{l}\text { HC anuales } \\
\text { fórmula }\end{array}$ & $\begin{array}{c}\% \text { fórmula resp } \\
\text { a cont }\end{array}$ \\
\hline enero & 0 & 0 & \\
\hline febrero & 0 & 0 & \\
\hline marzo & 0 & 0 & \\
\hline abril & 1 & 1 & \\
\hline mayo & 6 & 6 & \\
\hline junio & 39 & 43 & 111 \\
\hline julio & 100 & 120 & 120 \\
\hline agosto & 96 & 120 & 125 \\
\hline septiembre & 22 & 27 & 125 \\
\hline octubre & 2 & 2 & \\
\hline noviembre & 0 & 0 & \\
\hline diciembre & 0 & 0 & \\
\hline anual & 266 & 319 & 120 \\
\hline
\end{tabular}

\subsubsection{Zonas altas del interior peninsular}

Soria. La fórmula de Crossa-Raynaud subestima claramente las horas de calor, en promedio da un $75 \%$ de las horas reales, y por tanto es una mala aproximación.

Tabla 394. Comparación de horas de calor anuales contadas y obtenidas a partir de la fórmula para el observatorio de Soria.

$\mathrm{HC}$ anuales contadas $\quad \mathrm{HC}$ anuales fórmula \% fórmula resp a cont

\begin{tabular}{|c|ccc|}
2002 & 92 & 79 & 86 \\
2003 & 245 & 196 & 80 \\
2004 & 87 & 70 & 80 \\
2005 & 169 & 137 & 81 \\
2006 & 128 & 95 & 74 \\
2007 & 72 & 59 & 82 \\
2008 & 68 & 50 & 73 \\
2009 & 191 & 129 & 67 \\
2010 & 133 & 94 & 71 \\
2011 & 135 & 78 & 58 \\
promedio & 132 & 99 & 75
\end{tabular}


Tabla 395. Comparación de los promedios mensuales de las horas de calor correspondientes al periodo 20022011 para el observatorio de Soria.

\begin{tabular}{|c|c|c|c|}
\hline & $\begin{array}{c}\text { HC anuales } \\
\text { contadas }\end{array}$ & $\begin{array}{c}\text { HC anuales } \\
\text { fórmula }\end{array}$ & $\begin{array}{c}\text { \% fórmula } \\
\text { resp a cont }\end{array}$ \\
\hline enero & 0 & 0 & \\
febrero & 0 & 0 & \\
marzo & 0 & 0 & \\
abril & 0 & 0 & 71 \\
mayo & 0 & 0 & 70 \\
\hline junio & 22 & 16 & 80 \\
julio & 57 & 40 & 91 \\
agosto & 48 & 39 & \\
\hline septiembre & 5 & 4 & \\
\hline octubre & 0 & 0 & 75 \\
\hline noviembre & 0 & 0 & \\
\hline diciembre & 0 & 0 & \\
anual & 132 & 99 & \\
\hline
\end{tabular}

La subestima promedio mensual de los meses que importan, julio y agosto, es similar a la subestima anual, entre el $70 \%$ y el $80 \%$.

Molina de Aragón. La fórmula de Crossa-Raynaud subestima las horas de calor, en promedio da un $57 \%$ de las horas reales, y por tanto es una mala aproximación.

Tabla 396. Comparación de horas de calor anuales contadas y obtenidas a partir de la fórmula para el observatorio de Molina de Aragón.

\begin{tabular}{|c|c|c|c|}
\hline & HC anuales contadas & $\mathrm{HC}$ anuales fórmula & $\%$ fórmula resp a cont \\
\hline 2002 & 112 & 65 & 58 \\
\hline 2003 & 287 & 146 & 51 \\
\hline 2004 & 141 & 64 & 46 \\
\hline 2005 & 234 & 131 & 56 \\
\hline 2006 & 173 & 109 & 63 \\
\hline 2007 & 129 & 75 & 58 \\
\hline 2008 & 143 & 71 & 49 \\
\hline 2009 & 293 & 186 & 64 \\
\hline 2010 & 185 & 117 & 63 \\
\hline 2011 & 151 & 95 & 63 \\
\hline Promedio & 185 & 106 & 57 \\
\hline
\end{tabular}


Tabla 397. Comparación de los promedios mensuales de las horas de calor correspondientes al periodo 2002 2011 para el observatorio de Molina de Aragón.

\begin{tabular}{|c|c|c|c|}
\hline & $\begin{array}{l}\text { HC anuales } \\
\text { contadas }\end{array}$ & $\begin{array}{l}\text { HC anuales } \\
\text { fórmula }\end{array}$ & $\begin{array}{c}\% \text { fórmula resp } \\
\text { a cont }\end{array}$ \\
\hline enero & 0 & 0 & \\
\hline febrero & 0 & 0 & \\
\hline marzo & 0 & 0 & \\
\hline abril & 0 & 0 & \\
\hline mayo & 3 & 1 & 49 \\
\hline junio & 34 & 19 & 55 \\
\hline julio & 78 & 44 & 56 \\
\hline agosto & 63 & 38 & 60 \\
\hline septiembre & 7 & 4 & 60 \\
\hline octubre & 0 & 0 & \\
\hline noviembre & 0 & 0 & \\
\hline diciembre & 0 & 0 & \\
\hline anual & 185 & 106 & 57 \\
\hline
\end{tabular}

La subestima promedio mensual de los meses que importan, julio y agosto, es similar a la subestima anual, el $60 \%$.

Daroca. La fórmula de Crossa-Raynaud subestima claramente las horas de calor, en promedio da un $82 \%$ de las horas reales, y por tanto no es una buena aproximación.

Tabla 398. Comparación de horas de calor anuales contadas y obtenidas a partir de la fórmula para el observatorio de Daroca.

\begin{tabular}{c|ccc|}
\hline \multicolumn{1}{|c}{ HC anuales contadas } & HC anuales fórmula & $\%$ fórmula resp a cont \\
\hline 2002 & 255 & 199 & 78 \\
2003 & 499 & 416 & 83 \\
2004 & 272 & 229 & 84 \\
2005 & 362 & 297 & 82 \\
2006 & 348 & 306 & 88 \\
2007 & 239 & 204 & 86 \\
2008 & 308 & 243 & 79 \\
2009 & 486 & 407 & 84 \\
2010 & 338 & 277 & 82 \\
2011 & 405 & 300 & 74 \\
Promedio & 351 & 288 & 82 \\
& & &
\end{tabular}


Tabla 399. Comparación de los promedios mensuales de las horas de calor correspondientes al periodo 20022011 para el observatorio de Daroca.

\begin{tabular}{|c|c|c|c|}
\hline & $\begin{array}{c}\text { HC anuales } \\
\text { contadas }\end{array}$ & $\begin{array}{c}\text { HC anuales } \\
\text { fórmula }\end{array}$ & $\begin{array}{c}\text { \% fórmula resp } \\
\text { a cont }\end{array}$ \\
\hline $\begin{array}{c}\text { enero } \\
\text { febrero }\end{array}$ & 0 & & \\
marzo & 0 & & \\
abril & 0 & & \\
mayo & 0 & 5 & 69 \\
junio & 7 & 54 & 80 \\
julio & 67 & 114 & 78 \\
agosto & 146 & 97 & 89 \\
\hline septiembre & 109 & 18 & 81 \\
octubre & 22 & 1 & \\
\hline noviembre & 1 & & \\
\hline diciembre & 0 & & \\
\hline anual & 0 & 288 & \\
\hline
\end{tabular}

La subestima promedio mensual de los meses que importan, julio y agosto, es similar a la subestima anual, el $80 \%$.

Cuenca. La fórmula de Crossa-Raynaud subestima mucho las horas de calor, en promedio da un $76 \%$ de las horas reales, y por tanto es una mala aproximación.

Tabla 400. Comparación de horas de calor anuales contadas y obtenidas a partir de la fórmula para el observatorio de Cuenca.

\begin{tabular}{|c|c|c|c|}
\hline & $\mathrm{HC}$ anuales contadas & $\mathrm{HC}$ anuales fórmula & $\%$ fórmula resp a cont \\
\hline 2002 & 237 & 178 & 75 \\
\hline 2003 & 432 & 342 & 79 \\
\hline 2004 & 295 & 226 & 76 \\
\hline 2005 & 413 & 298 & 72 \\
\hline 2006 & 396 & 314 & 79 \\
\hline 2007 & 238 & 179 & 75 \\
\hline 2008 & 316 & 224 & 71 \\
\hline 2009 & 553 & 431 & 78 \\
\hline 2010 & 386 & 305 & 79 \\
\hline 2011 & 377 & 274 & 73 \\
\hline promedio & 364 & 277 & 76 \\
\hline
\end{tabular}


Tabla 401. Comparación de los promedios mensuales de las horas de calor correspondientes al periodo 20022011 para el observatorio de Cuenca.

\begin{tabular}{|c|c|c|c|}
\hline & $\begin{array}{c}\text { HC anuales } \\
\text { contadas }\end{array}$ & $\begin{array}{c}\text { HC anuales } \\
\text { fórmula }\end{array}$ & $\begin{array}{c}\text { \% fórmula resp } \\
\text { a cont }\end{array}$ \\
\hline enero & 0 & 0 & \\
febrero & 0 & 0 & \\
marzo & 0 & 0 & \\
abril & 0 & 0 & 67 \\
\hline mayo & 4 & 2 & 76 \\
junio & 68 & 51 & 75 \\
julio & 151 & 113 & 78 \\
agosto & 124 & 97 & 74 \\
septiembre & 17 & 12 & 34 \\
octubre & 1 & 0 & \\
noviembre & 0 & 0 & \\
diciembre & 0 & 0 & 76 \\
anual & 364 & 277 & \\
\hline
\end{tabular}

La subestima promedio mensual de los meses que importan, julio y agosto, es similar a la subestima anual, entre el $70 \%$ y el $80 \%$.

Teruel. La fórmula de Crossa-Raynaud subestima las horas de calor, en promedio da un $78 \%$ de las horas reales.

Tabla 402.Comparación de horas de calor anuales contadas y obtenidas a partir de la fórmula para el observatorio de Teruel.

\begin{tabular}{|c|ccc|}
\hline & HC anuales contadas & HC anuales fórmula & \% fórmula resp a cont \\
\hline 2002 & 161 & 128 & 79 \\
2003 & 326 & 254 & 78 \\
2004 & 205 & 179 & 87 \\
2005 & 307 & 249 & 81 \\
2006 & 251 & 204 & 81 \\
2007 & 184 & 142 & 77 \\
2008 & 230 & 180 & 78 \\
2009 & 410 & 305 & 74 \\
2010 & 252 & 186 & 74 \\
2011 & 334 & 257 & 77 \\
promedio & 266 & 208 & 78 \\
& & &
\end{tabular}


Tabla 403. Comparación de los promedios mensuales de las horas de calor correspondientes al periodo 20022011 para el observatorio de Teruel.

\begin{tabular}{|c|c|c|c|}
\hline & $\begin{array}{c}\text { HC anuales } \\
\text { contadas }\end{array}$ & $\begin{array}{c}\text { HC anuales } \\
\text { fórmula }\end{array}$ & $\begin{array}{c}\text { \% fórmula resp } \\
\text { a cont }\end{array}$ \\
\hline enero & 0 & 0 & \\
febrero & 0 & 0 & \\
\hline marzo & 0 & 0 & \\
\hline abril & 0 & 0 & 68 \\
mayo & 3 & 2 & 75 \\
\hline junio & 42 & 32 & 78 \\
julio & 117 & 92 & 81 \\
\hline agosto & 91 & 73 & 79 \\
\hline septiembre & 13 & 10 & \\
\hline octubre & 1 & 0 & \\
noviembre & 0 & 0 & 78 \\
diciembre & 0 & 0 & \\
anual & 266 & 208 & \\
\hline
\end{tabular}

La subestima promedio mensual de los meses que importan, julio y agosto, es similar a la subestima anual, en torno al $80 \%$.

Albacete Los Llanos. La fórmula de Crossa-Raynaud subestima las horas de calor, en promedio da un $88 \%$ de las horas reales, y por tanto no es una mala aproximación.

Tabla 404. Comparación de horas de calor anuales contadas y obtenidas a partir de la fórmula para el observatorio de Albacete Los Lllanos.

$\mathrm{HC}$ anuales contadas $\mathrm{HC}$ anuales fórmula \% fórmula resp a cont

\begin{tabular}{|c|ccc|}
\hline 2002 & 365 & 308 & 84 \\
2003 & 571 & 520 & 91 \\
2004 & 445 & 400 & 90 \\
2005 & 476 & 426 & 90 \\
2006 & 528 & 460 & 87 \\
2007 & 350 & 309 & 88 \\
2008 & 431 & 366 & 85 \\
2009 & 615 & 537 & 87 \\
2010 & 483 & 435 & 90 \\
2011 & 498 & 433 & 87 \\
promedio & 476 & 420 & 88
\end{tabular}


Tabla 405. Comparación de los promedios mensuales de las horas de calor correspondientes al periodo 20022011 para el observatorio de Albacete Los LLanos.

$\mathrm{HC}$ anuales

contadas

$\mathrm{HC}$ anuales \% fórmula resp a fórmula cont

\begin{tabular}{|c|c|c|c|}
\hline enero & 0 & 0 & \\
febrero & 0 & 0 & \\
marzo & 0 & 0 & \\
abril & 0 & 0 & 85 \\
mayo & 5 & 4 & 82 \\
junio & 91 & 75 & 89 \\
julio & 198 & 176 & 91 \\
agosto & 157 & 143 & 87 \\
septiembre & 24 & 21 & \\
octubre & 1 & 1 & \\
noviembre & 0 & 0 & 88 \\
\hline diciembre & 0 & 0 & \\
anual & 476 & 420 & \\
\hline
\end{tabular}

La subestima promedio mensual de los meses que importan, julio y agosto, es similar a la subestima anual, en torno al $10 \%$.

\section{Resumen para las zonas altas del interior peninsular}

En las zonas entre 700 y 1100 metros de altitud del interior peninsular, el cálculo de las horas de calor por la fórmula de Crossa-Raynaud subestima en torno al $20 \%$ las horas de calor reales en los lugares de más altitud y en torno al 10\% en los lugares más bajos. Puede considerarse una aproximación aceptable, sobre todo si se tiene en cuenta que en las partes más altas hay pocas horas de calor, con lo cual la subestima, aunque sea del $20 \%$, no supone muchas horas. 
Zona: corresponde a zonas climáticas con un cierto grado de homogeneidad en cuanto a la altitud y las condiciones fisiográficas con respecto a los observatorios utilizados como referencia. Debido al bajo número de observatorios utilizados y a la gran variedad de tipos de suelo, cubierta vegetal, orientación, etc., las altitudes son únicamente orientativas y no cubren todo el rango de las que se dan en cada zona . Zonas:

Costa cantábrica ciudades costeras

Costa cantábrica en altitudes menores de $350 \mathrm{~m}$

Costa cantábrica entre 350 y $600 \mathrm{~m}$ de altitud

Costa gallega ciudades costeras

Costa gallega en altitudes menores de $350 \mathrm{~m}$

Interior gallego y El Bierzo en valles por debajo de $600 \mathrm{~m}$

Meseta Norte entre $600 \mathrm{~m}$ y $800 \mathrm{~m}$ de altitud

Meseta Norte entre 800 y $1000 \mathrm{~m}$ de altitud

Cuenca del Ebro en altitudes menores de $300 \mathrm{~m}$

Cuenca del Ebro entre $300 \mathrm{~m}$ y $500 \mathrm{~m}$ de altitud

Costa catalana muy próximo al mar hasta $100 \mathrm{~m}$ de altitud

Costa catalana entre 100 y $300 \mathrm{~m}$ de altitud

Cuenca del Tajo en altitudes menores de $500 \mathrm{~m}$

Cuenca del Tajo entre $500 \mathrm{~m}$ y $700 \mathrm{~m}$ de altitud

Cuenca de Guadiana en altitudes menores de $300 \mathrm{~m}$

Cuenca de Guadiana entre 500 y $700 \mathrm{~m}$ de altitud

Cuenca del Guadalquivir en altitudes menores de $300 \mathrm{~m}$

Cuenca del Guadalquivir en valles entre $500 \mathrm{~m}$ y $700 \mathrm{~m}$

Levante y Murcia ciudades costeras

Levante y Murcia, zona de huerta en altitudes menores de $150 \mathrm{~m}$

Costa Sur en altitudes menores de $100 \mathrm{~m}$ junto al mar

Zonas altas del interior peninsular entre 700 y $900 \mathrm{~m}$

Zonas altas del interior peninsular entre 900 y $1100 \mathrm{~m}$ 
Promedio anual de horas de calor. Se pone una aproximación al número de horas de calor que corresponde al máximo sacado de los observatorios utilizados como referencia en cada zona y, por tanto, en cada una de ellas se refiere en general al de menor altitud en el intervalo correspondiente. A igualdad del resto de las condiciones que influyen en las temperaturas diarias, a menor altitud se darán más horas de calor. La aproximación se redondea al alza debido a que, por la gran variabilidad interanual, se dan años con muchas más horas que las que da el promedio. Sobre este punto es preciso insistir que la variación entre unos años y otros es, en general, muy elevada; en casos del orden de magnitud de ese promedio.

Promedio mensual de horas de calor. Se pone el máximo aproximado del promedio mensual de horas de calor en los meses de julio y agosto de los observatorios utilizados como referencia que dan un mayor número de horas de calor. Igual que en el caso de la acumulación anual, se redondea al alza porque la variación entre unos años y otros para los mismos meses es muy elevada; en muchos casos del orden de magnitud de ese promedio.

Meses completamente libres de horas de calor.

Meses en los que se dan horas de calor todos los años

Variabilidad. Da idea de la variabilidad interanual y entre cada uno de los meses en los distintos años.

Muy marcada. La diferencia entre el año con un mayor número de horas de calor y el año con menor número de horas es superior al $60 \%$ del promedio anual.

Marcada. La diferencia entre el año con un mayor número de horas y el año con menor número de horas está comprendida entre el $40 \%$ y el $60 \%$ del promedio anual, es decir, es del orden de la mitad del promedio anual.

Media. La diferencia entre el año con un mayor número de horas y el año con menor número de horas está comprendida entre el $20 \%$ y el $40 \%$ del promedio anual.

Baja. La diferencia entre el año con un mayor número de horas y el año con menor número de horas está por debajo del $20 \%$ del promedio anual. 
Aproximación de la fórmula. Da idea de la aproximación promedio que proporciona la fórmula respecto al número de horas de calor anuales sacado de los datos horarios.

Buena. La diferencia entre el promedio anual del número de horas de calor que da la fórmula y el que se saca de los datos horarios es menor que el $10 \%$ del valor que se saca de los datos horarios.

Aceptable. La diferencia entre el promedio anual del número de horas de calor que da la fórmula y el que se saca de los datos horarios está comprendida entre el $10 \%$ y el $20 \%$ del valor sacado de los datos horarios.

Mala. La diferencia entre el promedio anual del número de horas de calor que da la fórmula y el que se saca de los datos horarios es superior al $20 \%$ del valor sacado de los datos horarios.

Uniformidad de la aproximación. Da idea de las diferencias en la aproximación en los distintos años, medida según la diferencia entre los años en los que tal aproximación es mejor y peor. Ejemplo: si la aproximación promedio es del $92 \%$, y el año en el que la aproximación es mejor es del $95 \%$, y el año en el que es peor es del $85 \%$, la diferencia

entre ellos es de un 10\%; esta diferencia es superior al $10 \%$ de la aproximación promedio, que sería $9,2 \%$.

Uniforme. La oscilación entre la aproximación más alta y la más baja es igual o menor que el $10 \%$ de la aproximación media.

Poco uniforme. La oscilación entre la aproximación más alta y la más baja está comprendida entre el $10 \%$ y el $20 \%$ de la aproximación media.

Nota. Si se pone el umbral en $30^{\circ} \mathrm{C}$, en las zonas costeras cantábrica y gallega no se llega a las 100 horas de calor anuales y, por tanto, por mucha que sea la discrepancia que dé la fórmula, siempre será de unas pocas horas. Por este motivo no se rellenan las casillas correspondientes en la tabla resumen. 
Tabla 406. Tabla resumen horas de calor.

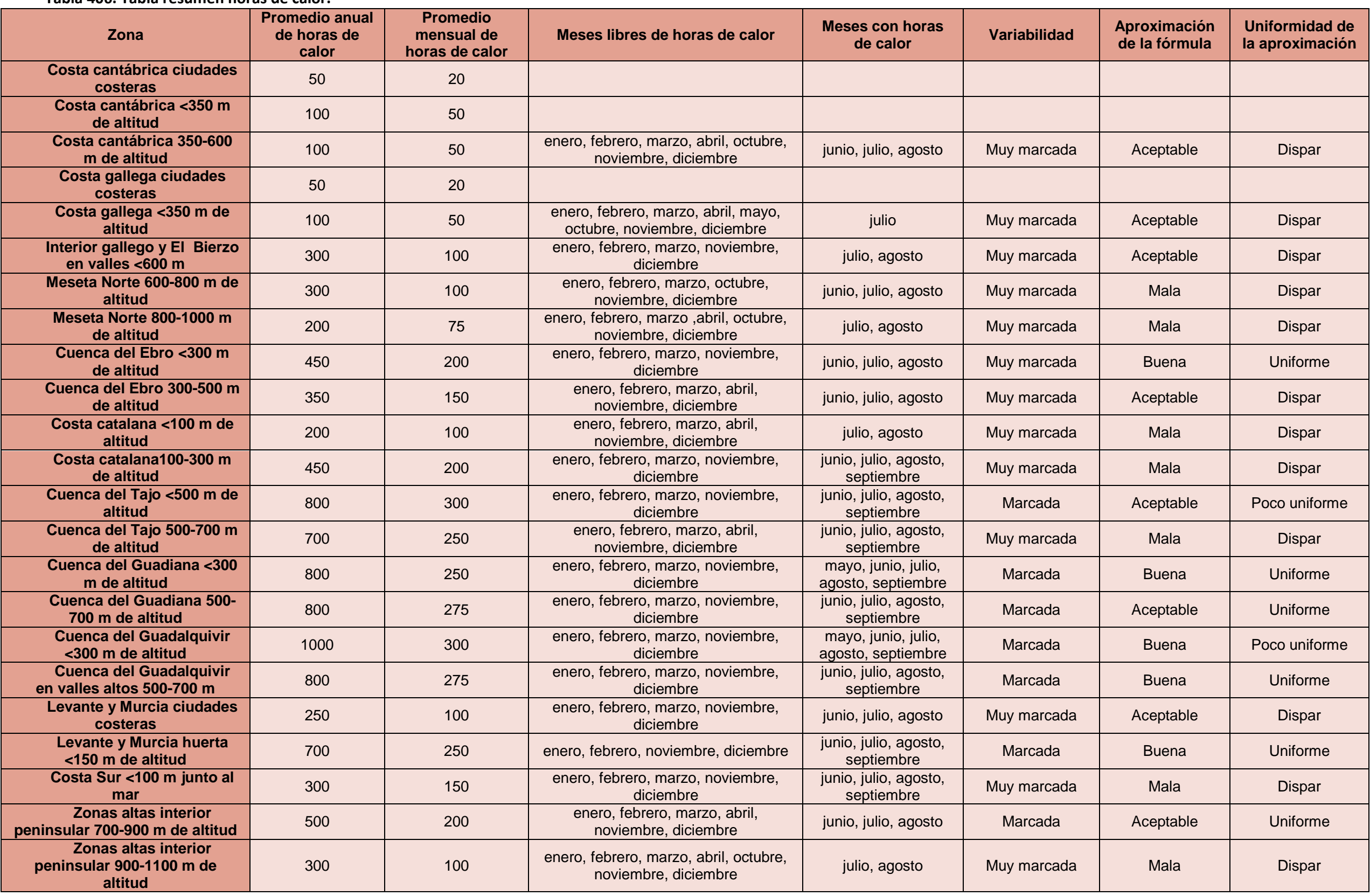




\section{Conclusiones y recomendaciones}

Para responder a una petición concreta de horas frío o de calor deben darse, por supuesto, en cada caso, los datos solicitados; pero sería conveniente proporcionar también como orientación los datos obtenidos en este trabajo correspondientes al observatorio más cercano en la misma zona. Al ser datos elaborados a partir de diez años pueden proporcionar, no sólo una idea del ajuste de la fórmula a lo real en la zona, sino también mostrar la gran variabilidad interanual e intermensual que se da en casi todos los observatorios.

Los promedios a lo largo de varios años de una determinada variable con medidas diarias, mensuales, estacionales 0 anuales da, en general, una buena medida de lo esperable de esa variable en esos intervalos de tiempo. No obstante, en los casos en los que la dispersión de los datos es muy grande, tal dispersión debe ser tenida en cuenta. El dato obtenido en cada una de las realizaciones puede ser muy diferente al promedio. Esto es lo que sucede en la península Ibérica con las horas frío y de calor con los umbrales utilizados en este trabajo $\left(7^{\circ} \mathrm{C}\right.$ para las horas frío y $30^{\circ}$ $C$ para las horas de calor). La variabilidad entre unos años y otros y entre unos meses y otros del número de horas frío y de calor para los distintos años es, en muchos casos, tan alta que debe ser tenida en cuenta. Si se dice que, en un determinado observatorio, un mes tiene un promedio de $\mathrm{N}$ horas frío, debe tenerse en cuenta que la oscilación entre los datos para ese mes en los distintos años puede alcanzar el mismo orden de magnitud que $\mathrm{N}$ en los meses fuera del invierno, $\mathrm{y}$ del orden de N/2 en los de invierno. Lo mismo sucede con la bondad de la aproximación que proporciona la fórmula. Hay zonas en las que, en un mismo observatorio, la fórmula puede incluso sobrestimar el número de horas frío un año y subestimarlo al siguiente en un $85 \%$.

Evidentemente, de contar con medida horaria de la temperatura, lo adecuado es utilizar las medidas horarias para determinar las horas frío o de calor en la zona de ese observatorio. Si no se cuenta con medida horaria pero sí con medida de máximas y mínimas diarias, puede hacerse el cálculo de las horas frío haciendo uso de la fórmula de Crossa-Raynaud, si bien debe advertirse al solicitante de los datos, que el cálculo se ha hecho utilizando una fórmula aproximativa y que esa fórmula subestima el número de horas reales y lo hace en el tanto por ciento aproximado de esa 
zona. También, dependiendo del uso que vaya hacerse de los datos (para fines agrícolas o de calefacción) debe advertirse que en los meses de otoño y primavera la aproximación de la fórmula es más baja, aunque lógicamente de menor importancia por ser menor el número de horas.

Dado que la fórmula supone una linealidad que no se da en la curva diaria de las temperaturas, la aproximación será mayor en los casos en los que tal curva diaria esté un mayor número de horas por encima o por debajo del umbral. Así pues, en el caso de horas frío, la aproximación debería ser tanto mejor cuanto más horas haya con temperatura por debajo de $7^{\circ} \mathrm{C}$; y en el otro extremo cuantas menos haya: caso en los que la curva de variación diaria de temperatura se encuentra la mayor parte del periodo por encima del umbral. Con los datos obtenidos, esto se confirma claramente en las zonas más frías peninsulares. En los meses de invierno con muchas horas frío, la aproximación que da la fórmula es muy buena o excelente, superior al $90 \%$ en todos los observatorios de zonas con suficiente altitud o continentalidad para tener muchas horas frío. Y también en las zonas de temperaturas suaves, zonas costeras en las que es menos frecuente que la temperatura se mantenga por debajo de $7^{\circ} \mathrm{C}$. Por el contrario, la aproximación es mala en los meses de otoño y primavera, cuando el número de horas frío es menor, y también en las zonas del interior de baja altitud, como los valles del Guadiana, Guadalquivir y Ebro, donde el número de horas frío es también bajo. El razonamiento es similar para las horas de calor, cambiando el umbral.

Como es lógico, la aproximación de la fórmula es peor en los casos en los que la curva diaria de las temperaturas se aleja más de la linealidad, lo que depende de las situaciones meteorológicas de cada día; y lo normal es que la fórmula subestime el número de horas reales. También esto se confirma en los datos obtenidos.

La utilidad de horas frío está clara en la agricultura, y es en esta actividad donde es más solicitada, pero es también muy útil en calefacción y refrigeración. Si se diesen a conocer que se pueden calcular, y hacerlo a partir de distintos umbrales, el número de solicitudes para esta aplicación sería mucho mayor. También es un dato útil en el sector de la construcción, claro está que con el umbral conveniente, el umbral por debajo del cual el cemento fragua de forma irregular. Con una difusión adecuada de esta posibilidad, también en este sector habría muchas más peticiones. 
Respecto a los umbrales, es importante señalar que los utilizados en este trabajo son los más solicitados para fines agrícolas, pero no los únicos. Puede haber cultivos en los que sean más útiles otros umbrales. Y, desde luego, para fines de calefacción y refrigeración son más útiles umbrales diferentes. En ese caso deberían hacerse los cálculos para esos umbrales, y darían resultados distintos en cuanto a las aproximaciones y su uniformidad a lo largo del tiempo.

Las comparaciones en este trabajo se dan en porcentajes, por eso es preciso tener en cuenta que, para los porcentajes, se precisa disponer del número suficiente de horas frío o de calor para que tal comparación sea significativa. Por esa razón no se ha hecho la comparación en porcentajes con la fórmula cuando el número de horas frío o de calor es bajo. Si en un determinado mes se dieron 2 horas de calor y la fórmula da 1, la subestima es del $50 \%$ y, sin embargo, es una buena aproximación. Si hubiera 1000 horas y la fórmula diera 500 , la subestima es también el $50 \%$, pero en este caso la aproximación sería muy mala. En los casos (días, meses, estaciones, años) en los que se dan muchas horas frío o de calor la comparación en porcentajes es la adecuada; cuando se dan pocas horas, sin embargo, es preferible dar la diferencia entre lo obtenido a partir de temperaturas horarias y lo obtenido a partir de la fórmula. 


\section{Bibliografía}

Crossa-Raynaud P. 1955 Effects des hivers doux sur le comportement des arbres fruitiers a feuilles caduques. Annals of Service Botanical Agronomy, Tunise n. 28 p. 122. 
